
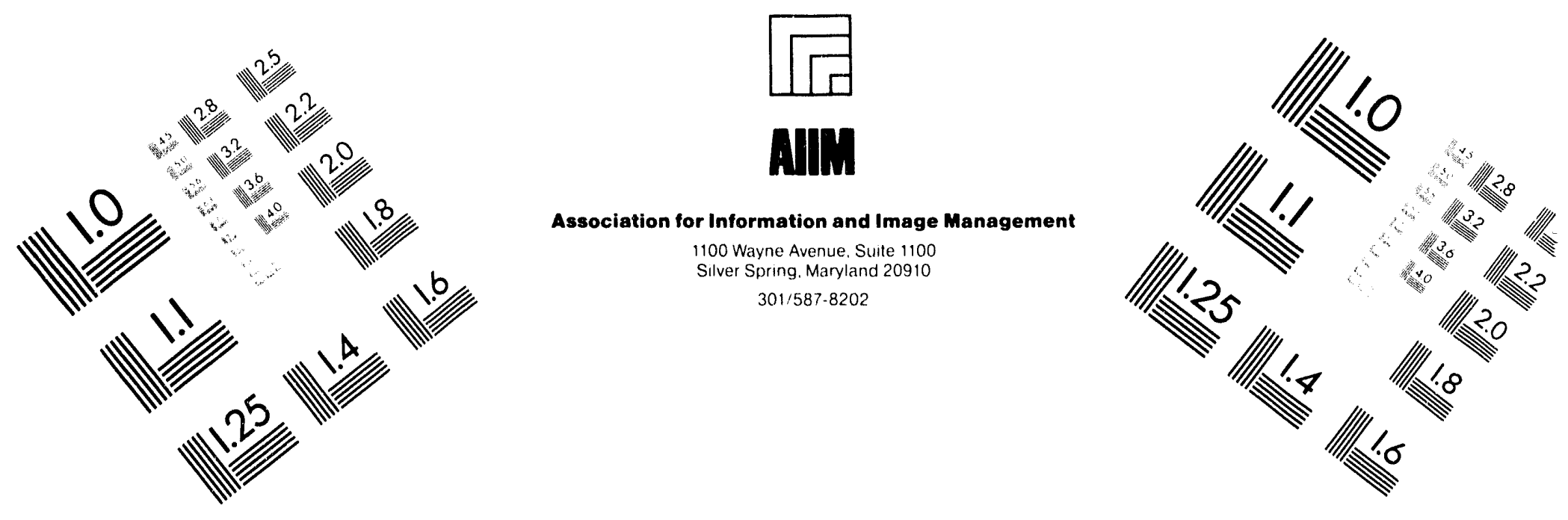

\title{
Centimeter
}

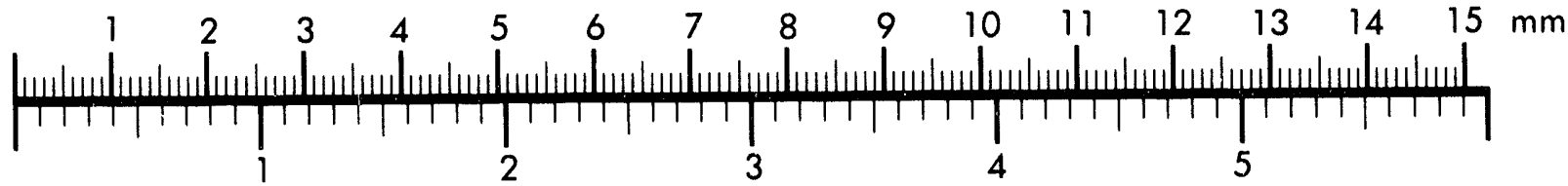
Inches
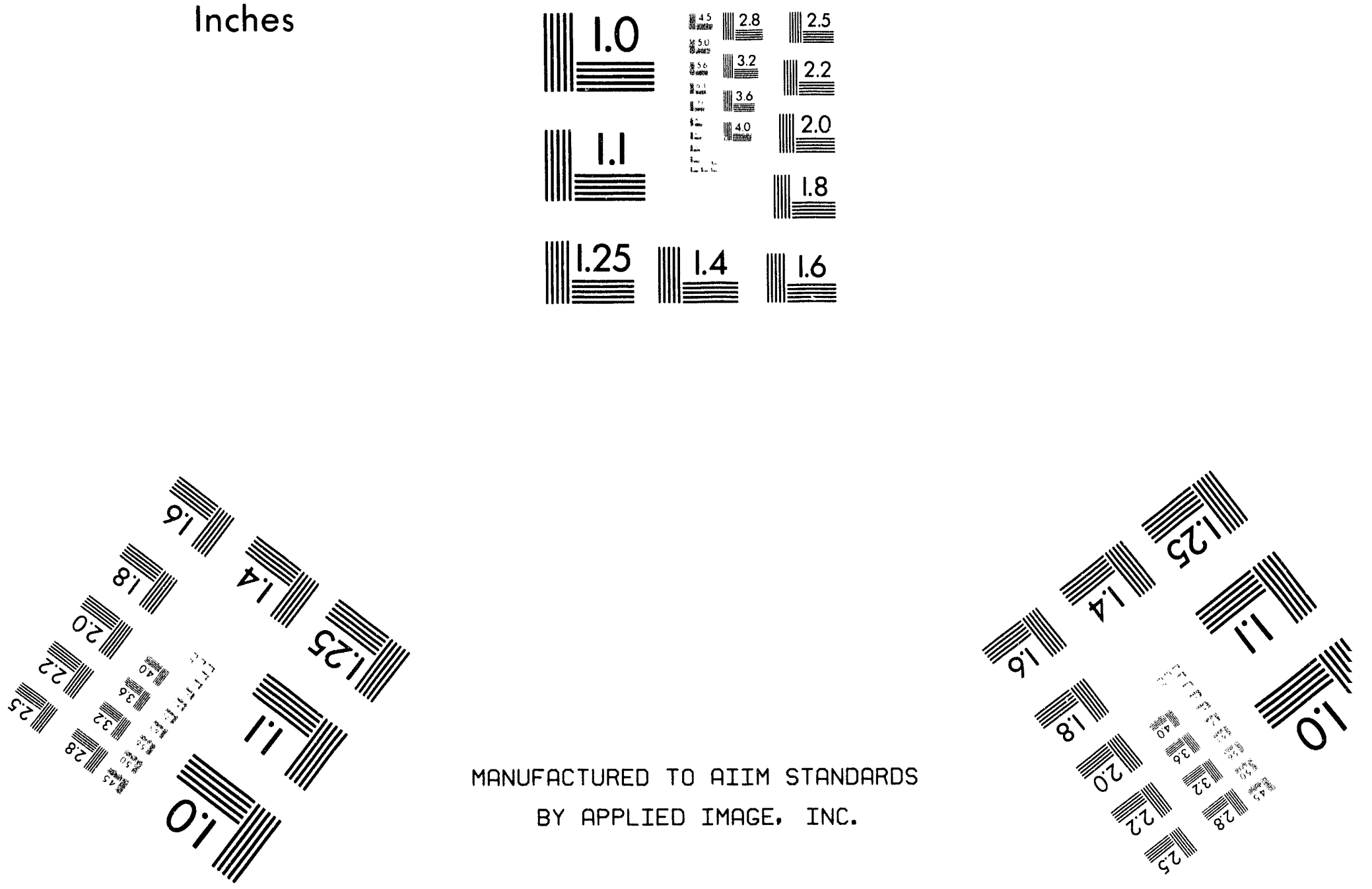

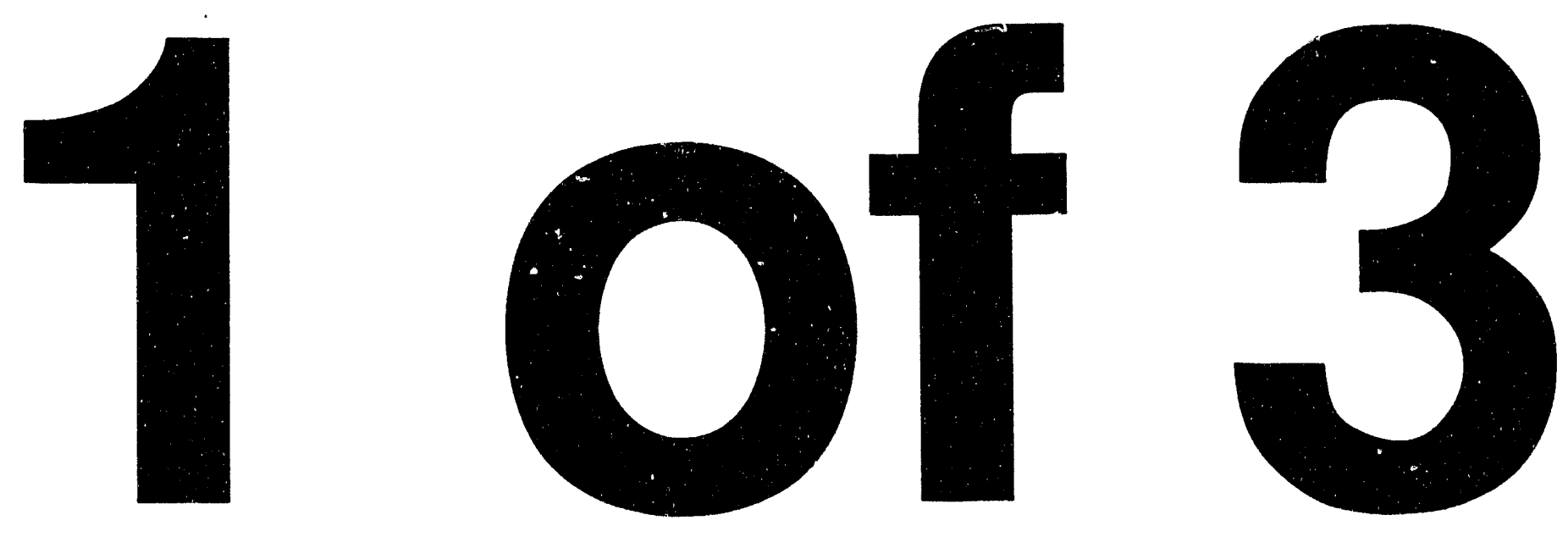
NOTICE

This report was supported in part, or whole, by funds from the Comprehensive Environmental Response, Compensation, and Liability Act trust fund by interagency agreement with the Agency for Toxic Substances and Disease Registry, United States Public Health Service.
FEC: $=0$

MAY 311994

\section{Inhalation Developmental \\ Toxicology Studies: \\ Developmental Toxicity of Chloroprene Vapors in New Zealand White Rabbits}
T. J. Mast
R. L. Rommereim
J. J. Evanoff
R. J. Weigel
R. B. Westerberg

April 1994

Prepared for the National Institute of Environmental Health Sciences, National Toxicology Program under a Related Services Agreement with the U.S. Department of Energy Contract DE-AC06-76RLO 1830

Pacific Northwest Laboratory Operated for the U.S. Department of Energy by Battelle Memorial Institute 


\title{
DISCLAIMER
}

This report was prepared as an account of work sponsored by an agency of the United States Government. Neither the United States Government nor any agency thereof, nor Battelle Memorial Institute, nor any of their employees, makes any warranty, expressed or implied, or assumes any legal liability or responsibility for the accuracy, completeness, or usefulness of any information, apparatus, product, or process disclosed, or represents that its use would not infringe privately owned rights. Reference herein to any specific commercial product, process, or service by trade name, Irademark, manufacturer, or otherwise does not necessarily constitute or imply its endorsement, recommendation, or favoring by the United States Government or any agency thereof, or Battelle Memorial Institute. The views and opinions of authors expressed herein do not necessarily state or reflect those of the United States Government or any agency thereof.

\author{
PACIFIC NORTHWEST LABORATORY \\ operated by \\ BATTELLE MEMORIAL INSTITUTE \\ for the \\ UNITED STATES DEPARTMENT OF ENERGY \\ under Contract DE-ACO6-76RLO 1830
}

Printed in the United States of America

Available to DOE and DOE contractors from the

Office of Scientific and Technical information, P.O. Box 62, Oak Ridge, IN 37831;

prices available from (615) 576-8401. FTS 626-8401.

Available to the public from the National Technical Information Service, U.S. Department of Commerce, 5285 Port Royal Rd., Springfield, VA 22161. 
PNL -7458

UC -408

"This report was supported in part, or whole, by funds from the Comprehensive Environmental Response, Compensation, and Liability Act trust fund by interagency agreement with the Agency for Toxic Substances and Disease Registry, United States Public Health Service."

INHALATION DEVELOPMENTAL TOXICOLOGY STUDIES: DEVELOPMENTAL TOXICITY OF CHLOROPRENE VAPORS IN NEW ZEALAND WHITE RABBITS

Final Report

No. NIH-YO1-ES-70153

T.J. Mast, Principal Investigator

J.J. Evanoff

R.B. Westerberg

R.I. Rommereim

R.J. Weigel

April 1994

Prepared for the National Institute of Environmental Health Sciences, National Toxicology Program under a Related Services Agreement with the U.S. Department of Energy under Contract DE-AC06-76RLO 1830.

Pacific Northwest Laboratory

Richland, WA 99352 


\title{
PEER REVIEW STATEMENT
}

This final technical report has been peer reviewed by two scientists who were members of the Reproductive and Developmental Toxicology Program Review Subcommittee for the National Toxicology Program Board of Scientific Counselors. Reviewers serve as independent scientists, not as representatives of any institution, company, or government agency. In this capacity, these reviews determine if the design and conduct of the NTP studies were appropriate, ensure that the final report presents the experimental results, and that conclusions are consistent with the data.

Reviewers of this developmental toxicity study of chloroprene were:

Dr. George Szczech

Burroughs-Wellcome

Research Triangle Park, NC
Dr. Robert Kavlock U.S. EPA

Research Triangle Park, NC

These reviewers in general agreed that the study was properly designed except one reviewer noted that higher concentrations of inhaled chloroprene would have made this a more rigorous study in rabbit. Both reviewers requested more background information and discussion on the occurrence and significance of variations in the conformation of lung lobes of fetuses. However, no background information on the lobulation of rabbit lungs was found in a search of the literature. This final report takes reviewer's comments into account and incorporates their suggestions on minor points and the format of the report.

\author{
B.A. Schwetz, D.V.M., Ph.D. \\ Project Officer
}


Chloroprene, 2-chloro-1,3-butadiene, is a colorless liquid with a pungent ethereal odor that is primarily used as an intermediate in the manufacture of neoprene rubber, and has been used as such since about 1930 . This study addressed the potential for chloroprene to cause developmental toxicity in New zealand white rabbits following gestational exposure to 0 , 10 , 40, or $175 \mathrm{ppm}$ chloroprene vapors, $6 \mathrm{~h} / \mathrm{dy}, 7 \mathrm{dy} / \mathrm{wk}$. Each treatment group consisted of $\approx 15$ artificially inseminated females exposed on 6 through 28 days of gestation $(\mathrm{dg})$. Body weights were obtained throughout the study period, and uterine and fetal body weights were obtained at sacrifice on $29 \mathrm{dg}$. Implants were enumerated and their status recorded and live fetuses were examined for gross, visceral, skeletal, and soft-tissue craniofacial defects.

There were no overt signs of maternal toxicity and the change in maternal body weight over the course of the study was not affected. Exposure of pregnant rabbits to chloroprene vapors on 6-28 dg had no effect on the number of implantations, the mean percent of live pups per litter, or on the incidence of resorptions per litter. Fetal body, kidney, and liver weights (as means of litter means) were not affected by gestational exposure to chloroprene, nor was the fetal sex ratio affected. The incidence of fetal malformations was not increased by exposure to chloroprene. There were no significant alterations in the incidence of total fetal variations or reduced ossifications among exposed groups. Results of this study indicate that gestational exposure of New Zealand white rabbits to 10,40 , or $175 \mathrm{ppm}$ chloroprene did not result in observable toxicity to either the dam or the offspring. The highest exposure group, $175 \mathrm{ppm}$, was the no observable adverse effect level (NOAEL) for rabbits in the study with respect to both maternal and developmental toxicity. 


\section{ACKNOWLEDGMENTS}

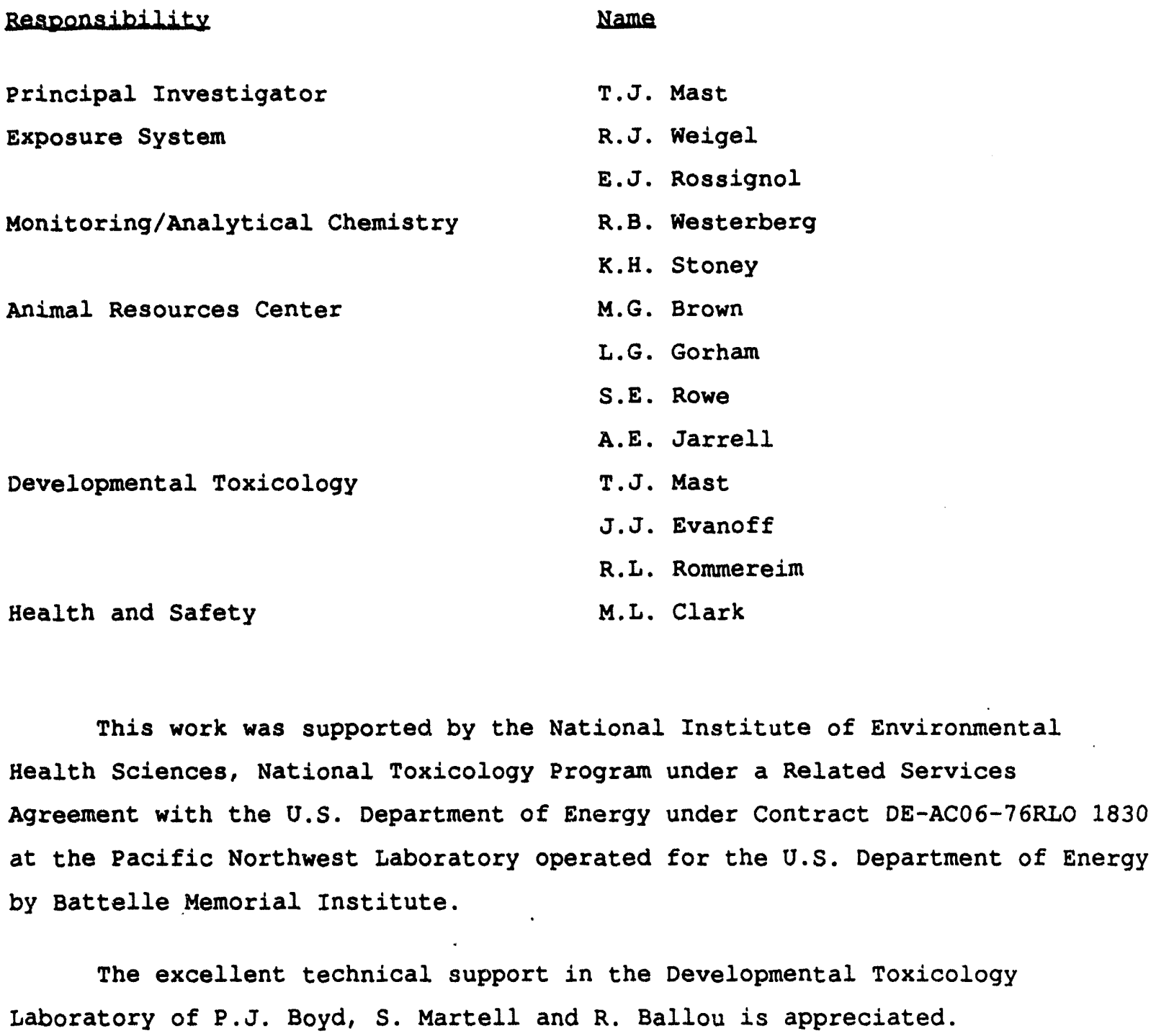




\section{SIGNATURES}

Herreteryates

Terryl-J. Kast, PhD, DABT Principal Investigator and

Developmental Toxicology Task Leader

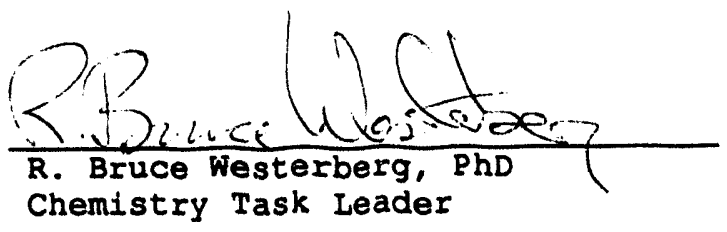

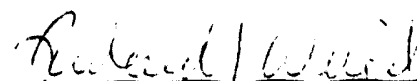

RIchard J. heigel, PhD

Exposure Task Leader

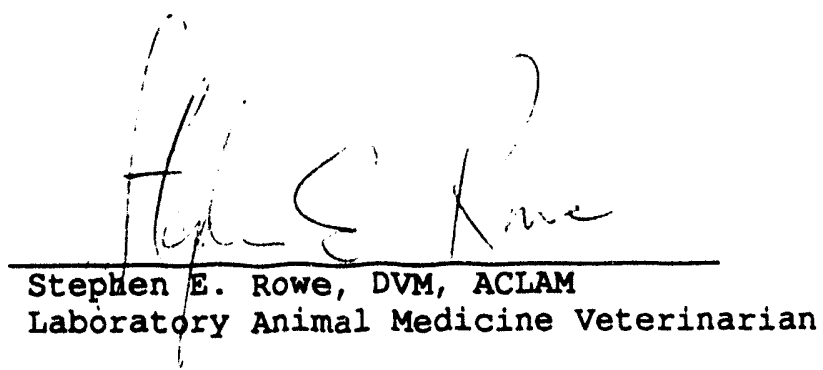

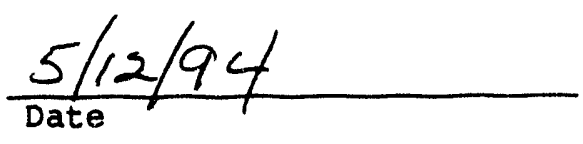
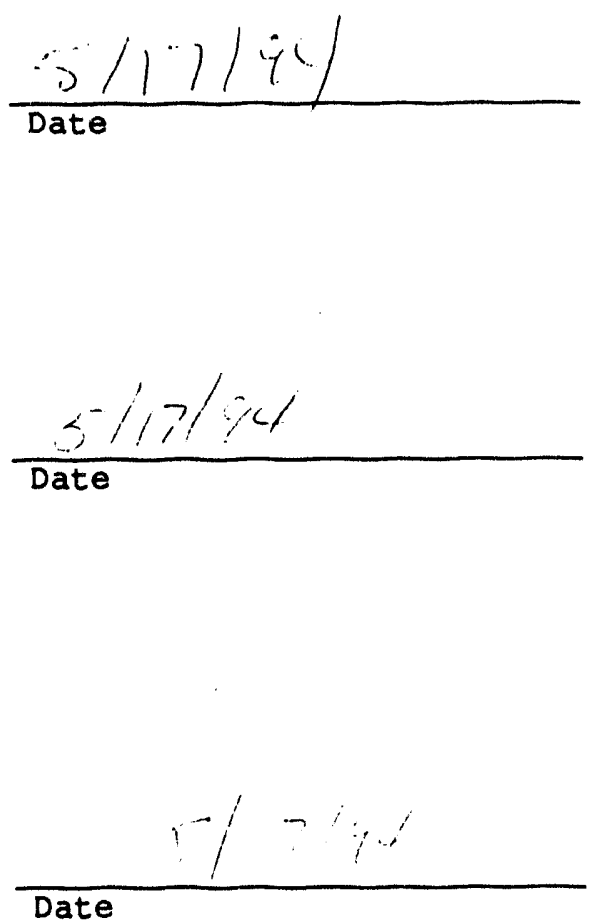


\section{TABLE OF CONTENTS}

INTRODUCTION . . . . . . . . . . . . . . . . . . . . . . 1

hUMAN DATA AND EXPOSURE . . . . . . . . . . . . . . . . . . . 1

DEVELOPMENTAI TOXICITY . . . . . . . . . . . . . . . . . . 3

MATERIALS AND METHOdS . . . . . . . . . . . . . . . . . . . 7

ANALYTICAL CHEMISTRY . . . . . . . . . . . . . . . . . 7

Bulk Chemical Analyais ................. 7

Exposure Chamber Monitoring . . . . . . . . . . . . 7

Degradation and stability studies . . . . . . . . . . 8

GENERATION AND EXPOSURE METHODS . . . . . . . . . . . . . . 9

Exposure Chambers . . . . . . . . . . . . . . . . 9

Exposure Suite System Description.............. 10

Generation and Delivery system . . . . . . . . . . 11

Characterization of Test Article concentration in Chambers . . 12 heALTH AND SAFETY . . . . . . . . . . . . . . . . . . . . . 14 ANIMAL hUSBANDRY . . . . . . . . . . . . . . . . . . . 15

DEVELOPMENTAL TOXICITY STUDY DESIGN . . . . . . . . . . . . . . 18

data analysis . . . . . . . . . . . . . . . . . . . 20

DATA STORAGE . . . . . . . . . . . . . . . . . . . 21

RESULTS

DISCUSSION

REFERENCES 
Figure 1 Inhalation Exposure Chamber Designed at PNL ......... 29

Figure 2 Chloroprene Developmental Toxicity study Exposure suite . . 30

Figure 3 Chloroprene Vapor Generation and Distribution system .... 31

Figure 4 Bulldup and Decay Curves of Concentration in Animal

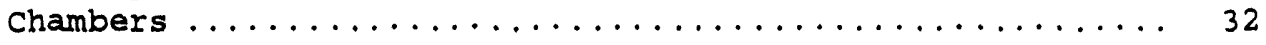

Figure 5 Animal Exposure Chamber Schematic Showing Approximate Sampling

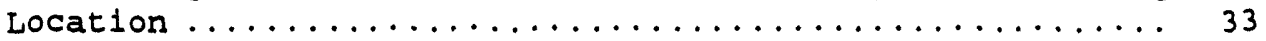

Figure 6 Post-Exposure Monitoring Results of the $175 \mathrm{ppm}$ A Chloroprene

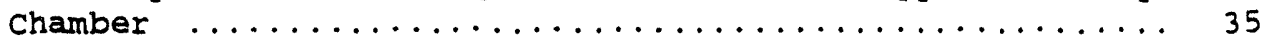

Figure 7 Chamber Relative Humidity Control system ........... 36

\section{LIST OF TABLES}

Table 1

Summary of $\mathrm{T}_{90}$ and $\mathrm{T}_{10}$ Data................. 37

Table 2

Summary of Chamber Uniformity Data ............. 38

Table 3

Summation of Exposure Concentration Data ........... 39

Table 4

Summation of Chamber Environmental Data ........... 40

Table 5

study disposition ...................... 41

Table 6

Summary of Gross observations at Time of Maternal Sacrifice 42

Table 7

Mean Body, Uterine and Extra-gestational Gain and Organ Welghts of Pregnant Developmental Toxicology Rabbits .... 43

Table 8 Reporductive Measures in Rabbits ...............

Table 9 Fetal Organ and Body Weights, Fetal Organ to Body Weight Ratio, and Fetal sex Ratio in Rabbits .............. 45

Table 10 Malformations observed in Live Rabbit Fetuses. 46

Table 11 Variations and Reduced Ossifications Observed in Live Rabbit Fetuses ............................ 47

Table 12 Mean Percent of Live Rabbit Fetuses Affected per Iitter . . 48 


\section{INTRODUCTION}

Chloroprene, 2-chloro-1,3-butadiene, is a colorless liquid with a pungent ethereal odor. It is inherently unstable in the presence of oxygen at room temperature and reacts readily to form peroxides and radicals which lead to rapid polymerization. In order to prevent these reactions from taking place two inhibitors are commonly added to bulk chloroprene, $t$-butylcatechol (TBC) and phenothiazine. Chloroprene is produced by reacting butadiene with chlorine to form a mixture of dichlorobutene isomers (IARC 1979), from which 3,4-dichloro-1-butene is isolated and reacted with caustic soda to form chloroprene.

Chloroprene is used primarily as an intermediate in the manufacture of neoprene rubber, and has been used as such since about 1930. Circa 1976, United states production of chloroprene was approximately $164 \mathrm{million} \mathrm{kg}$, about 100 million $\mathrm{kg}$ in Western Europe, and 80 million $\mathrm{kg}$ in Japan (IARC 1979). Chloroprene is also produced in the USSR and in China; however, no production figures are available for these countries.

The inhalation and dermal routes are relevant to occupational exposure to chloroprene. The current osHA standard for chloroprene in air averaged over an $8-\mathrm{h}$ work day is $25 \mathrm{ppm}\left(80 \mathrm{mg} / \mathrm{m}^{3}\right)$ with an accompanying notation to avoid skin contact, however the ACGIH recommended TLV-TWA is only 10 ppm (35 $\mathrm{mg} / \mathrm{m}^{3}$ ) also with a recommendation to avoid dermal exposure. Infante et al. (1977) estimated that approximately 2500-3000 United States workers are exposed to chloroprene. They reported airborne chloroprene concentrations ranging from 6 to $1420 \mathrm{ppm}$ in various areas of a U.S. chloroprene polymerization plant with the greatest concentrations in the make-up and reactor areas.

HUMAN DATA AND EXPOSURE

Acute exposure to chloroprene vapors results in irritation to the skin, eyes, and mucous membranes of the respiratory tract, and dermal exposure has 
been reported to cause loss of hair (Sittig, 1985). Exposure to higher concentrations causes excessive nervousness and irritability followed by central nervous system effects and respiratory depression (IARC 1979).

Chronic exposure to chloroprene, aside from possible carcinogenicity and reproductive toxicity, may cause CNS depression and damage to the lungs, kidneys, and liver in both humans and experimental animals (Plunkett 1987 and others). Damage to the myocardium in humans has also been reported (Sittig 1985). Evaluation of biochemical and hematological parameters in workers did not indicate or suggest that chloroprene caused alterations of medical significance (Gooch and Hawn 1981).

A large number of studies on the effects of occupational exposure to chloroprene have been performed in Russia and are cited and summarized in an IARC monograph (1979). Reported effects of chronic exposure to chloroprene are numerous and varied and thus, may represent the effect of exposure to a mixture of compounds. Some of the more specific effects include loss of hair, hepatomegaly, abnormal liver function, dystrophy of the myocardium, circulatory changes, anemia, dysfunction of both the central and peripheral nervous system, and peridontal disorders. One Russian study reported low immunological reactivity in more than 200 chloroprene-exposed workers who had been immunized with typhoid vaccine, and several studies reported an increased number of chromosome aberrations in cultured peripheral lymphocytes as well as functional disturbances in male reproductive function.

\section{Metabolism:}

The metabolism of chloroprene has not been studied in depth, but the formation of a reactive intermediate capable of alkylation in vivo was inferred by Bartsch et al (1979) after demonstrating the formation of adducts of 4-(4-nitrobenzyl)pyridine and chloroprene by mouse liver microsomes. These reactive intermediates may be formed by the epoxidation of one or both of the double bonds in chloroprene. Conjugation of chloroprene or a metabolite with glutathione has been shown to occur rapidly in Wistar rats (Summer and Greim 1980). 


\section{DEVITOPMGNTAT TOXICITY}

Several studies have been conducted in order to assess the potential for $\beta$-chloroprene to cause embryonic or developmental toxicity in laboratory animals. Salnikova (1968) investigated the embryotoxic effects of inhalation exposure to chloroprene and ammonia combined; however, since a group exposed to chloroprene alone was not included it is hard to interpret their results. In a later study, Salnikova and Fomenko (1973) exposed pregnant rats to 0.016 , $0.36,0.17,0.83$, and 1.11 ppin chloroprene vapor. The length and duration of the exposures was not specified. An increased incidence of embryonic deaths was reported in the 0.83 and $1.11 \mathrm{ppm}$ groups, and fetuses in the $1.11 \mathrm{ppm}$ group had a significantly lower birth weight than those in the control group. Fetuses in the $1.1 .2 \mathrm{ppm}$ group were also reported to have vascular permeability disturbances as well as decreases in the lengths of the tibia and the fibula. The methodology used for the generation of the chloroprene test atmospheres and the techniques used for monitoring the purity of the atmospheres (if any) were not specified.

$$
\text { Culik et al. (1978) exposed } C D-1 \text { (Sprague-Dawley) rats to } 0,1,10 \text {, or }
$$
$25 \mathrm{ppm}$ chloroprene, $4 \mathrm{~h} /$ day, on 3 through 20 dsye of gestation (dg) to assess developmental toxicity. Another group was exposed to the same concentration on 1 through $12 \mathrm{dg}$ in order to assess the embryotoxic potential of chloroprene. Care was taken during this study to ensure that the animals were exposed to chloroprene which was freshly distilled and relatively free of the toxic dimer. Dans exposed on 3-20 dg were killed on $21 \mathrm{dg}$ and the fetuses examined for signs of developmental toxicity. Dams exposed on 1-12 dg were killed on $17 \mathrm{dg}$ and the uterine contents evaluated for signs of embryotoxicity.

No clinical signs of toxicity were observed in the dams exposed to chloroprene, and there was no affect on weight gain with respect to the control animals. There was no effect on litter size, on the number of implantations, or the number of resorptions in exposed pregnant rats in either the teratology or the embryotoxicity study. Although fetal body weight and crown-rump length were greater for the 10- and 25-ppm groups than for the controls these effects were not thought to be treatment-related. 
The Joint Industry Committee on Chloroprene contracted an inhalation developmental toxicity study on $\beta$-chloroprene in rats (Koeter and Appelman 1980). In this study pregnant rats were exposed to $0,10,25,75$, or 175 ppm chloroprene 6 hours/day, on 4-16 dg. They reported a diminished maternal weight gain during the exposure period for the 25, 75, and $175 \mathrm{ppm}$ group, and during the post-exposure period for the 75 and $175 \mathrm{ppm}$ groups. Postimplantation loss was significantly greater than controls in the 10, 75, and $175 \mathrm{ppm}$ groups, but not in the $25 \mathrm{ppm}$ group. There were fewer live fetuses in the two highest exposure groups than in the controls; however, since there was no apparent dose-response relationship the authors did not attribute this effect to shloroprene exposure.

There was a significant reduction in fetal weight in the 75 and $175 \mathrm{ppm}$ groups, but no abnormalities attributable to treatment were found in the fetuses from any of the exposed groups. There was a statistically significant increase in the incidence of unossified forelimb phalanges and metatarsals in the 25, 75 and $175 \mathrm{ppm}$ groups, and the incidence of unossified cervical vertebral bodies was increased in the 10, 75, and 175 ppm groups. The authors assert there is no clear dose-response relationship and apparently do not view these effects as being toxicologically significant since they are not reported in the study summary.

In contrast to the Russian studies (Salnikova and Fomenko 1973), chloroprene did not appear to cause developmental or reproductive toxicity at exposure concentrations as high as $25 \mathrm{ppm}$ under the conditions of culik et al. (1978). However, since a maternally toxic dose was not achieved, and $25 \mathrm{ppm}$ chloroprene is the OSHA TLV, a margin of safety is not established by this study. Although the data from the Russian studies indicate that chloroprene may be considerably more toxic than implied by Culik et al. (1978), this disparity may be due to the formation of dimers and other toxic reaction products in the exposure atmospheres used by the Russians. Test material generation and monitoring methods were not described by the Russian authors although it is well known that chloroprene rapidly degrades in air to form more toxic products (von oettingen et al. 1936, and others). In the study performed by Koeter and Appelman (1980), higher exposure concentrations were used and care was taken to ensure that the chloroprene used for exposures was 
freshly prepared and properly stored. Test atmospheres were not monitored for dimer concentrations in this study.

The study in rabbits described in this report was conducted in an attempt to clarify the ambiguities regarding the potential for chloroprene to cause embryonic and developmental toxicity in laboratory models. To date only one laboratory specie, the rat, has been well-tested for developmental toxicity. In order to facilitate an interspecies comparison of the data, exposure concentrations similar to those of Koeter and Appelmas (1980) will be used in this study. The lowest concentration, $10 \mathrm{ppm}$, is the current TLV for chloroprene, while the highest concentration, $175 \mathrm{ppm}$, would be exceeded only in accidental situations. This study was designed not so much to evaluate the potential developmental toxicity in the rabbit, but essentially to compare the sensitivity to chloroprene between two different animal models, rabbits and rats, at or above potential occupational exposure levels to humans. 


\section{MATERIALS AND METHODS}

Four groups of New zealand white rabbits were exposed to $0,10,40$ or $175 \mathrm{ppm}$ chloroprene vapors, $6 \mathrm{~h} /$ day, 7 days/week, on 6 through 28 days of gestation (dg). Developmental evaluations were conducted on pregnant rabbits sacrificed on $29 \mathrm{dg}$.

\section{ANALYYTICAI, CHEMISTRY}

Chloroprene (Denka Chemical Corporation, Houston, Texas) was received by Pacific Northwest Laboratory (PNL) on February 14, 1990 (BNW Lot No. 5343620). The test material was inhibited with $\approx 0.18$ each of phenothiazine and t-butylcatechol (4-TBC) at Denka and shipped at ambient temperature. The daily requirement of chloroprene for exposure generation was $\approx 0.6 \mathrm{~kg}$, and $-15 \mathrm{~kg}$ of test material was consumed during the study. Prior to use, test material was maintained at approximately $-20^{\circ} \mathrm{C}$ in the LSL-II storage facility. All transfers of chloroprene were performed under nitrogen to prevent the introduction of air into the bulk chemical.

\section{Bulk Chemical Analysis}

Bulk chemical analyses of the test material were performed using infrared spectroscopy to confirm test material identity. Purity and dimer determinations were conducted by gas chromatography (GC). Test material purity was acceptable throughout the study. Peroxide determinations were made by potentiometric titrations of samples with standardized sodium thiosulfate. Chloroprene was analyzed for peroxide content within 6 weeks prior to use as test material and contained $\leq 1 \mathrm{meq} / \mathrm{kg}$ at each analysis. A specification for a maximum peroxide content of $1 \mathrm{meq} / \mathrm{kg}$ was applied throughout to ensure the safety of the generation process which involved evaporating chloroprene at a temperature of $150^{\circ} \mathrm{C}$. (See Appendix A for details.)

\section{Exposure Chamber Monitoring}

A Hewlett-Packard (HP) 5890 GC system (1/8" 0.d. x 1.0' nickel column packed with 18 SP -1000 on $60 / 80$ mesh Carbopack $B ; 120^{\circ} \mathrm{C}$ ) was used to monitor chambers during animal exposures (Figure 1). This instrument was equipped 
with a 12-port stream select valve and measured chloroprene in the exposure chambers, the control chamber, the exposure room, the on-line standard, and the filtered air blank. An on-line, certified standard, $80 \mathrm{ppm}$ chloroprene in nitrogen (MG Industries Scientific Gases, LOs Angeles, CA), was used to check instrument drift throughout the exposure day. In order to confirm values obtained from the on-line monitor, bubbler samples were collected and analyzed with an HP 5830 or HP 5840 GC equipped with a glass column packed with 108 Carbowax 20 on $80 / 100$ Chromasorb.

The precision of the on-line GC was estimated from measurements of the on-line chloroprene standard; a $0.5 \%$ coefficient of variation was observed. IJinearity of the on-line GC was assured by calibrating it against a gravimetrically calibrated GC. The minimum detectable limit of the GC was determined from precision measurements performed by monitoring a chamber with a low chloroprene concentration and was estimated to be $0.06 \mathrm{ppm}$ chloroprene. (See comments in the "Test Chemical Concentration Monitoring" section in Appendix A).

\section{Degradation and Stability Studies}

The stability of chloroprene and the extent to which less volatile impurities and peroxides concentrated in the generator flask over the 6-hour exposure period were evaluated during prestart testing. A chloroprene sample was removed from the generation flask immediately after filling at the beginning of the day and an additional sample was collected at the end of the exposure period.

Chloroprene was determined to be 98.58 pure by area percent in the generation flask immediately after filling, and 90.68 at the end of generation on the same day. The most concentrated dimer isomer was present at $=28$ while the total dimer content was about 5-6r. The peroxide content in the sample collected immediately after filling was $0.05 \mathrm{meq} / \mathrm{kg}$, while the peroxide content at the end of generation on the same day was $0.14 \mathrm{meg} / \mathrm{kg}$. These analyses indicated that the purity of test material in the generation flask at the end of the day was substantially lower than the purity at the beginning of 
the day due to formation and concentration of dimer isomers and peroxides in the generation flask.

The purity of chloroprene vapor directed to the exposure chambers was monitored every exposure day using a separate HP 5890 GC (on-line purity GC). The on-line purity GC was used to ensure that volatile compounds were vented to waste before initiation of animal exposures. Once exposures were initiated, the GC parameters were changed tC allow both volatile and less volatile impurities (including dimers) to be determined. The on-line purity GC showed an average percent purity of $99.34 \%$ for the study.

Chamber atmospheres and the vapor distribution line were tested for the presence of trace amounts of contaminants or degradation products by gas chromatography. Assignment of dimer and inhibitor peaks was verified by gas chromatography/mass spectrometry. Trace amounts of chlorobutene and 1,3 -chlorobutadiene $(<0.88$ by area) were found in samples collected from the chambers and the distribution line. The inhibitors, 4-TBC and phenothiazine were present in the distribution line at $=3 \mathrm{ppm}$. Dimers were not detected in the distribution or chamber samples by either the analysis of charcoal tube samples or the on-lire purity method. The detection limits for dimer were estimated to be $\approx 0 . j 2 \%$ by the charcoal tube method, and $\approx 0.04 \%$ by the on-line method (as percent of the total peak area of the most abundant dimer isomer). Test chemical stability and purity were considered acceptable for the study.

\section{GENERATION AND EXPOSURE METHODS}

\section{Exposure Chambers}

The animals were exposed and maintained in inhalation exposure chambers developed at PNL (U.S. Patent No. 4,216,741, August 12, 1980; Moss, 1980; Brown and Moss, 1981; Moss et al., 1982) and now commercially produced by the Harford System Division of Lab Products, Inc., Aberdeen, MD. The chamber (Figure 2) facilitates multiple-tier exposures of various laboratory animal species to aerosol- and vapor-laden atmospheres. The total volume of the chamber is $2.3 \mathrm{~m}^{3}$ with an active mixing volume of $1.7 \mathrm{~m}^{3}$, the remainder being the inlet and exhaust volumes where animals are not placed. For rabbits, two 
levels of caging were used, each level was split into two tiers which were offset from each other and from the chamber walls (Figure 2). Drawer-like stainless steel cage units composed of individual animal cages were suspended in the space above each tier. Stainless steel catch pans for the collection of uxine and feces were suspended below each cage unit. The catch pans were left in position during each exposure period. Cageboard was added to these catck pans during non-exposure periods to reduce ammonia concentrations.

The chamber was designed so that uniform aerosol or vapor concentrations can be maintained throughout the chamber when the catch pans are left in position. Incoming air containing a uniform mixture of test material was diverted so that it flowed vertically along the inner surfaces of the chamber. Eddies were formed (Figure 1 ) at each tier as the aerosol or vapor flowed past the catch pans. Stagnant zones that would normally exist above each pair of catch pans were cleared by exhaust flow through the space between the tiers. Aerosol or vapor reaching the lowest level was deflected across the bottom tiers by metal strips in the space between the catch pan and the wall. Tests have shown that aerosol or vapor concentrations uniform to within 3 to 8 \% throughout the chamber can be obtained repeatedly provided the aerosol or vapor is uniformly mixed before passing through the chamber inlet (Moss 1980; Moss, et al. 1982). These tests were performed at PNL on a dynamically similar model of the chamber, as well as in the full scale chamber. Work at the Inhalation Toxicology Research Institute of the Lovelace Foundation, Albuquerque, NM has confirmed these findings (Griffis, et al. 1981).

\section{Exposure Suite System Description}

The chloroprene exposures were conducted using an automated data acquisition and control system in an exposure suite (Figure 3) consisting of three exposure rooms and a suite control center room (only one of the exposure rooms was used for chloroprene exposures). Data and comments from the exposure room were stored on separate magnetic disks and were printed on separate printers. Data were printed and stored immediately upon completion of the measurement to the "Daily Log". At the end of the day (24-hour period), the data were analyzed and a summary was printed. This summary included the mean, standard deviation, percent relative standard deviation, 
maximum, minimum, and number of measurements for each set of data for the 24-hour period. A second printout provided a table of outliers (i.e. all data points which were beyond the critical limits defined in the protocol). A third printout provided a list of all comments generated by the computer and operators.

\section{Generation and Delityery System}

A schematic diagram of the chloroprene generation and delivery system is shown in Figure 4. The generator employed a rotary evaporation system (Büchi Rotavap, Model EL-131S, Brinkman Instruments Co., Westbury, NY) to produce high purity chloroprene vapor. A 1-liter evaporating flask was filled (under a nitrogen blanket) once at the beginning of each day with $=600 \mathrm{~g}$ of chloroprene from one or more of the original 1-gal glass containers, and was immersed in a hot water bath at $=150^{\circ} \mathrm{F}$. A nitrogen stream was metered into the flask and flowed through the generator from the flask to the condenser, carrying chemical vapor to the condenser. The condenser, whose temperature was maintained by an ethylene glycol/water bath, brought the vapor to $\approx-2^{\circ} \mathrm{C}$ and condensed part of the total vapor. The condensation controlled the chloroprene vapor concentration produced by the generator and the refluxing action tended to remove low volatility impurities from the vapor.

From the condenser, the vapor entered a short distribution manifold from which individual delivery lines carried a metered amount of vapor to each exposure chamber. At the chamber end of each delivery line, an AirVac (AirVac Engineering Co., Milford, CN) pump withdrew the appropriate amount of chemical vapor from the manifold to reach the target concentration. Chamber concentrations were adjusted by the metering valves and/or by adjustment of the compressed air pressure to the vacuum pumps. At the end of the delivery line, the vapor entered a pneumatic 3-way valve where it was directed to the. exposure chamber or the chamber exhaust system as appropriate. These valves allowed for a faster buildup of vapor concentration at start-up as well as more rapid diversion of chemical flow from chambers in the event rapid shutdown was necessary. At the start of a generation period, these valves were positioned to route the vapors to the chamber exhaust until the 
concentrations in the distribution system had stabilized and volatile trace contaminants in the evaporation flask were purged. When the system was stable and exposures were ready to proceed, computer-controlled start-up of the exposure was initiated by rotation of the 3-way valves to the exposure position. Dilution of the nitrogen/chloroprene vapor mix with air to the target chamber concentrations occurred immediately before entry to the chambers.

\section{Characterization of Test Article concentration in Chambers}

The buildup of vapor concentration at the beginning of exposure and the decay of concentration at the end of exposure are shown in Figure 5. Buildup and decay rates were measured prior to the start of the study without animals and during the study with animals to determine if the presence of animals would affect the buildup or decay rates. The time following the start of exposure for the concentration to reach 90 of the final stable concentration in the chamber $\left(T_{90}\right)$, and the time following the termination of generation for the vapor concentration to decay to $10 \%$ of the stable concentration $\left(T_{10}\right)$, were determined from the graphs (Table 1). Without animals present, the value of $\mathrm{T}_{90}$ was found to range from approximately 8 to 11 minutes. The value of $\mathrm{T}_{10}$ ranged from 8 to 10 minutes. At a chamber airflow rate of 15 air changes per hour, the theoretical value for $T_{90}$ is approximately 12.5 minutes. With animals present in the chambers, values of $T_{90}$ ranged from 9 to 11 minutes and the values for $T_{10}$ were between 9 and 12 minutes. Contributing to the variations were slightly different flow rates in each chamber and variations in the discrete GC sample times relative to the exposure start and stop times. A $T_{90}$ of 12 minutes was chosen for this study.

Uniformity of vapor concentration in the exposure chambers was measured prior to the start of the study and once during the study. During the prestart tests, uniformity measurements were made before the target concentrations were changed to the final levels. However, the measurements were not retaken as there was no indication of uniformity problems at the initial levels. The sample point was just above and about $10 \mathrm{~cm}$ in from the front or back center of each cage unit (Figure 6). The uniformity data for 
each chamber is summarized in Table 2. Uniformity in all chambers was found acceptable (i.e., WPV 5 \%, BPV $55 \%$, TPVS7\% as defined below).

The possible variation of test chemical concentration measured from one sample port to another during the measurement procedure is termed the total port variability (TPV) and consists of both spatial and temporal variations. Two factors contribute to the TPV. The first, the between port variability (BPV), is the factor of interest as it represents the spatial variation of test chemical distribution within the chamber. The second factor, the within port variability (HPV), represents the temporal fluctuation of the average chemical concentration within the chamber during the time the measurements were taken. This temporal factor includes variations in vapor generation as well as variation of the measurement instrument itself.

The WPV was determined from a minimum of three measurements taken at the on-line monitor port (1F or 2F) before, during and after all other ports were measured. The TPV was determined from measurements from, at the minimum, the front and back ports at each level on which animals were housed as well as one measurement from the on-line monitor port (whether or not animals were housed on that level). The BPV was determined by applying the following equation:

$$
\mathrm{BPV}=\sqrt{(\mathrm{TPV})^{2}-(\mathrm{WPV})^{2}}
$$

Since the WPV is often determined from fewer measurements than the TPV, statistically it is possible for the WPV to be greater than the TPV. In these cases, the BPV is very small, but it cannot be distinguished from the WPV. The BPV can't be determined using the above equation as it yields the square root of a negative number. In this case, it is reported as not resolvable.

Prior to the start of the study, before animals were placed in the chambers and again during the study with animals in the chambers, a Gardner Small Particle Detector (Type CN, Gardner Associates, Schenectady, NY) was used to check the room and all chambers for particles during generation. The minimum resolution of the Gardner counter is approximately 200 particles/ $\mathrm{cm}^{3}$. No counts above the minimum resolvable level were measured in any chamber. 
In order to determine the persistence of the chemical in the chamber following exposure, the concentration of chloroprene in one of the 175-ppm chambers was monitored following shutoff of the chemical flow to the chamber. Monitoring was performed once during the prestart activities without animals, and again during the study when animals were present (Figure 7). The concentration of chloroprene in the chamber without animals was below 18 of the initial concentration approximately 23 minutes following shutdown of the vapor generation system compared with approximately 24 minutes with animals in the chambers. The perturbation in the smooth decay at an elapsed time of approximately 35 minutes was due to opening of the chamber door to perform animal care activities.

Summaries of the concentration data during the study for all exposure chambers and the exposure room are included in Table 3 . Summaries of concentration by exposure day are included in Appendix B along with graphic illustrations of the daily mean and standard deviation for each chamber. The means of concentrations in all chambers for the entire study were between 98 and 100 of the target, with relative standard deviations (zRSD) in the range of 1 to 28. All individual concentration measurements were within $110 \mathrm{z}$ of the target concentrations. The standard gas at the start of the study was produced from a diffusion-type generator with a target output of $4.6 \mathrm{ppm}$. After one day of exposure, the standard gas was switched to a pressurized gas cylinder with a concentration greater than $30 \mathrm{ppm}$.

The only significant excursion occurred on April 6, 1990 when exposure generation was terminated after five hours when a small leak in the generator accelerated the usage of chemical in the reservoir. A complete discussion of all concentration excursions and problems during exposures is included in Appendix B.

\section{HGALTH AND SAEETCY}

This study was conducted under PNL's Health and Safety Plan. Protective clothing, including gloves and respiratory protection in the form of suppliedair respirators, was worn by all personnel working in the exposure room when exposure chamber doors were open. Personnel at risk from contacting liquid 
chloroprene also wore Tyvek (EI duPont deNemours and Co., Wilmington, DE) outer protective clothing and appropriate chemical-resistant gloves.

The ACGIH TLV for chloroprene is $10 \mathrm{ppm}$. The PNL action limit is $1 \mathrm{ppm}$. During exposure periods, room concentration levels were monitored by a gas chromatograph. The highest concentration of chloroprene detected in the room was <MDL (MDL $=0.06 \mathrm{ppm}$ ). The lower $1 \mathrm{imit}$ of detection for the room monitor was <MDL. The results of room monitoring are presented in Appendix $B$. No personnel were exposed above the PNL action limit and no action was taken.

\section{ANIMAL HUSBANDRY}

New Zealand white rabbits (70 fomales; 7 males) were received in good condition on January 29, 1990 from $R$ \& Rabbitry (Stanwood, WA). The females were 5-6 months old and the males were 6-7 months of age. Upon receipt the rabbits were housed in quarantine rooms 530 and 534 of the LSI-II building for -8 weeks prior to the start of exposure. During the quarantine period males and females were housed separately, in individual cages on stainless steel wire racks equipped with automatic waterers. Inseminated females were acclimated in exposure chamber caging for three days prior to the start of exposures. Once exposures started chamber doors remained closed except during animal husbandry procedures. Rabbits were $-7-8$ months of age at the beginning of exposure. Animals which were not selected for this study were discarded after the start of the first exposure.

The rabbits were examined by the vetarinarian upon arxival, and all appeared to be in good condition. The veterinarian also examined the rabbits periodically during quarantine. During this time, two rabbits were treated with penicillin after being diagnosed with an upper respiratory infection. These rabbits were not used on the study. A control rabbit was sacrificed on the second exposure day because of cystitis and upper respiratory infection. Pasteurella multocida was recovered from the nasopharynx of 2 of the 3 rabbits with upper respiratory infections. The cause of the cystitis was not determined. Significant infection or other disease were not seen in any of the other rabbits. Animals were observed twice daily for mortality, morbidity, and clinical signs of toxicity during the study period. 
A measured amount $(\sim 170 \mathrm{~g})$ of pelleted diet (Purina Certified Rabbit Chow \#5322) was available from $J$ type feeders during both the quarantine and exposure periods except durıng the daily chloroprene generation when the feed was removed. Food was discarded each day and new food was added. Contaminant analyses were performed by the manufacturer on each milling of diet. Samples of each milling used during the last 4 weeks of quarantine and during the exposure were collected at PNL and shipped to Lancaster Laboratories, Inc. (Lancaster, PA) for selected nutrlent analyses. Animal drinking water, supplied by the City of Richland municipal system, was softened in PNL facilities and supplied to the animals ad libitum by automatic waterers. A representative sample of water from the LSL II animal facility was analyzed for contaminants during the exposure period. Rooms were illuminated by fluorescent lights with a 12-hour light, 12-hour dark, electrically operated cycle; light started at 0600 .

Airflow in the chambers was maintained by the vacuum in the central chamber exhaust duct. Chamber airflow was measured by a multiplexed orificemeter system consisting of a calibrated orifice located in each chamber exhaust, a Validyne Model DP-45 pressure transducer, a validyne Model CD-18 carrier demodulator, and a validyne Model PM-12 digital voltmeter. Airflow was automatically measured at $\approx 3$-hour intervals throughout each 24 -hour day. Each flow orifice was calibrated prior to the start of the study to within $\pm 0.5 \mathrm{cfm}$.

Temperatures of the exposure chambers and the exposure room were measured by resistance temperature detectors (RTDs). The RTDs were placed in a representative location in each chamber (a top sample port on the back side). Each RTD was connected to an Omega Model 412B digital thermometer (Omega Engineering, Inc., Stamford, CT) by either a manual select switch or by computer controlled scanner relays. Temperatures were automatically recorded at -3 -hour intervals during each 24-hour day. RTDs were calibrated prior to the start of the study to $\pm 0.5^{\circ} \mathrm{F}$.

Relative humidity was measured using an EG\&G Model 910 chilled-mirror dewpoint hygrometer located in the exposure suite control center. Samples of the air from each measurement location were continuously pulled through polytetrafluoroethylene (PTFE) tubing to a central location in the exposure 
suite control center. This assured a fresh sample at the dewpoint hygrometer. Air from the exposure chambers was sampled from a representative location (a top port on the back side). Pexcent RH was automatically recorded at regular intervals during the 24-hour day. Once the dewpoint had been determined by the hygrometer, the $8 R H$ was automatically calculated by the exposure system executive computer using the dewpoint value and the temperature (measured simultaneously at the same location by the RTD system). The following equation was used for this calculation:

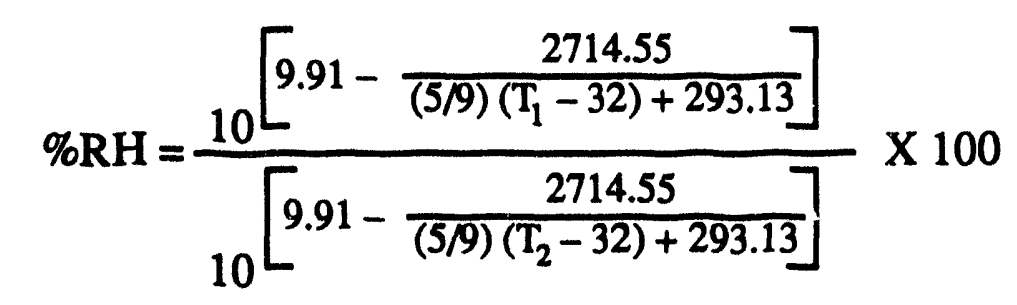

Where: $\quad T_{1}=$ dewpoint temperature $\left({ }^{\circ} \mathrm{F}\right)$

$T_{2}=$ drybulb temperature $\left({ }^{\circ} \mathrm{F}\right)$

Summations of chamber temperature, $8 R H$, and airflow, for the entire study are shown in Table 4. This table includes the mean, the standard deviation (SD), mean expressed as a percentage of the target, the percent relative standard deviation ( $g R S D=100 \times \mathrm{SD} /$ mean), the maximum and minimum values, number of samples, and the percent of samples for which the value was within the specified operating range.

The mean temperature values in all chambers for the entire study were between 66.6 and $68.2^{\circ} \mathrm{F}$, all within the specified limits of 63 to $73^{\circ} \mathrm{F}$. At least 868 of temperature readings for each chamber were within the specified limits. Extremes of the individual measurements ranged from 60.7 to $70.2^{\circ} \mathrm{F}$. Critical low operating limit excursions, i.e. excursion of temperature $563^{\circ} \mathrm{F}$, occurred during the first two days of animals in the chambers when the room temperature was set low to insure that chamber temperatures with the animal load did not exceed the high temperature limit.

The mean values of $8 \mathrm{RH}$ in all chambers for the entire study ranged between 54.1 and $62.1 \% \mathrm{RH}$, all within the specified limits of 40 to $70 \%$. At least $90 \%$ of all relative humidity readings for each chamber were within the 
specified limits throughout the study. Extremes of the individual measurements (considering all chambers) ranged from 38 to $77 \%$.

The mean values of chamber airflow in all chambers for the entire study were between 14.7 and $15.1 \mathrm{cfm}$ ( $1 \mathrm{cfm}=\sim 1$ air change per hour), all within the specified limits of 12 to $18 \mathrm{cfm}$. All (100\%) of the measurerents were within the specified limits.

A summary of the daily chamber environmental data and explanations of excursions of environmental data are provided in the exposure operation discussion sheets included in Appendix $B$.

\section{DEYSTOPMENTAL TOXICITY STUDY DESIGN}

The developmental toxicity study in rabbits was comprised of the following treatment groups:

\begin{tabular}{lcccc} 
& $\begin{array}{c}\text { Number of } \\
\text { Rabbits }\end{array}$ & & $\begin{array}{c}\text { Number of } \\
\text { Exposure } \\
\text { Concentrations }\end{array}$ & Total \\
\hline $0 \mathrm{ppm}$ & 16 & $\mathbf{x}$ & 1 & 16 \\
$10 \mathrm{ppm}$ & 16 & $\mathbf{x}$ & 1 & 16 \\
$40 \mathrm{ppm}$ & 15 & $\mathbf{x}$ & 1 & 15 \\
$175 \mathrm{ppm}$ & 16 & $\mathbf{x}$ & 1 & 16 \\
\hline
\end{tabular}

Female rabbits were weighed 7 weeks after receipt. They were individually eartagged prior to arrival, and the eartag number is referred to as a pretest animal number. A study number was assigned to each rabbit (1-70) to acquire weight data using the XYBION PATH/TOX System (XYBION, Medical Systems Corp., Cedar Knolls, NJ).

Male rabbits were trained to serve an artificial vagina (AV) with the assistance of a teaser doe. The resulting semen sample was evaluated for motility. Acceptable samples from $\geq 3$ bucks were pooled. A sperm count was performed and the semen was extended with oviduct stimulating medium to provide sufficient volume to inseminate $\approx 16$ does. After the female rabbits were artificially inseminated, chorionic gonadotropin was injected in a marginal ear vein to promote ovulation. 
The day female rabbits were artificially inseminated was designated as 0 days of gestation (dg). Bred females were weighed and randomly assigned to one of four exposure groups using body weight as the blocking variable. Insemination was conducted on three consecutive days (gestation groups A, B, and C). Following assignment to treatment groups the animals were individually caged, and on $3 \mathrm{dg}$ were placed in exposure chambers for acclimation until the start of exposure on $6 \mathrm{dg}$. The disposition summary of study animals is shown in Table 5 .

Inseminated female rabbits were exposed to chloroprene in whole-body exposure chambers at target concentrations of $0,10,40$ and 175 ppm for 6 hours + T9o/day, 7 days/week, for 23 consecutive days (6 through $28 \mathrm{dg}$ ). Rabbits in gestation group A began exposure on $3 / 26 / 90$, and groups $B$ and $C$ began on $3 / 27 / 90$ and $3 / 28 / 90$, respectively.

Exposure concentrations were selected on the basis of previous developmental toxicity studies in rats (Koeter and Appelman 1980), and on the lack of apparent maternal toxicity at these concentrations during a test exposure on inseminated New Zealand white rabbits.

Body weights were acquired on $0,6,15,22$, and $29 \mathrm{dg}$. Animals were observed twice each day for signs of chemical toxicity, moribundity, and mortality, 7 days per week.

On the day of scheduled sacrifice $(29 \mathrm{dg})$ rabbits were weighed and killed by a lethal injection of Nembutal via an ear vein in the order of ascending study number. (The sacrifice was conducted blind as to treatment group.) Rabbits in gestation groups $A, B$, and $C$ were killed on $4 / 18,19$, and 20/90, respectively. Animals were examined for gross tissue abnormalities, and the maternal liver and kidneys were removed and weighed. The uterus was removed, weighed, and opened. The number, position, and status (1ive, resorbed [early or late], or dead) of implants were recorded for each gravid uterus. Placentas were examined and discarded unless abnormal in appearance. Apparently non-gravid uteri from bred females were stained with 10\% ammonium sulfide to detect possible implantation sites. Ovarian corpora lutea were counted for gravid females. 
Live fetuses were weighed and examined for gross defects after a lethal injection of Nembutal, their sex was determined by internal examination of the gonads. All live fetuses in the uterus of each litter were examined for visceral defects by dissection of fresh tissue (modified from the method of Staples 1974). Fetal liver and kidney weights were obtained. The heads of fifty percent of the live fetuses were removed and placed in Louin's fixative. The first live fetus in the uterus to be selected for head removal was determined by a coin-toss, fetus $\# 1$ or $\$ 2$, and the remainder were chosen alternately from the first. After fixation in Bouin's fluid, the heads were serially sectioned with a razor blade and examined for soft-tissue craniofacial abnormalities. All fetal carcasses, with and without heads, were prepared for skeletal staining. Cartilage as well as ossified bone was visualized by double-staining with alcian blue and alizarin red $S$. The individual identity of each fetal specimen was maintained throughout the study.

\section{DATA ANALYSIS}

Means and standard deviations for animal data were calculated with SAS statistical software on a VAX $11 / 780$ computer. Mean fetal body weights, as the mean of litter means, were analyzed using the SAS General Linear Models (GLM) Procedure (SAS 1985) with an analysis of variance (ANOVA) model for unbalanced data. Response variables, either body weight or the arc sine transformations of proportional incidence data, were analyzed against the class variable, "treatment", in a nne-way ANOVA model. A Tukey's t-test (twotailed) was used to assess statistically significant differences between control and exposed groups. If appropriate, the dose-response relationship was determined by means of an orthogonal trend test on arc sine transformed variables (Winer 1971). The litter was used as the basis for analysis of fetal variables. 
All residual animal tissues are stored in the LSL-II building, room 1428. All raw data and the study report are stored in the LSL-II building, rooms 1428 and 1229. The duration of storage will be in compliance with 21 CFR 58.195, or until NTP requests transfer of the data, whichever occurs first. 
The chemical stability of chloroprene was evaluated in both the generator reservoir and in the exposure chambers (with and without animals). Chloroprene was found to be stable in the generator reservoir, and there was no evidence of degradation products greater than 0.18 of the target concentration in the exposure chambers (with or without animals). Direct measurements of chamber concentrations of BHT and peroxide confirmed that chamber concentrations of these two less volatile species were insignificant. Temperature-programmed GC failed to show evidence of any other degradation products.

The mean of the chloroprene concentration in each chamber for this study was between 98 and $100 \%$ of the target concentration, with relative standard deviations in the ringe of 1 to 28 (Table 3). The daily mean concentrations for all chambers were within 28 of the target concentrations (the daily protocol required the daily means to be within \pm 10 of of the target concentrations). All individual concentration measurements were within $\pm 10 \%$ of the target levels. The maximum concentrations observed in the control chamber and in the exposure room were less than the minimum detectable limit $(0.06 \mathrm{ppm})$.

Each exposure group consisted of 15-16 artificially inseminated female rabbits which were killed on $29 \mathrm{dg}$. The overall pregnancy rate was 898 and ranged from 80 to $94 \%$ for each exposure group. One dam was found moribund due to an upper respiratory infection and cystitis and was killed on $7 \mathrm{dg}$. There were no maternal signs of toxicity attributable to exposure to the test material, although a few dams in each group exhibited nasal discharge, vaginal bleeding, and loose stools at various times during the study. A few dams in each treatment group were found to have minor lung lesions at the time of maternal sacrifice (Table 6); however, there was no apparent affect on their general health. The incidence of the clinical signs was low and dams appeared to be in excellent health throughout the study and at the time of sacrifice. There were no exposure-related effects on maternal body weight changes (Table 7). The negative adjusted maternal weight change observed in these animals is normal for mature rabbits during pregnancy. 
Exposure of pregnant rabbits to chloroprene vapors on $6-28 \mathrm{dg}$ had no effect on the number of implantations, the mean percent of live pups per litter, or on the percent of resorptions per litter (Table 8). Fetal body, kidney, and liver weights (as means of litter means) were not affected by gestational exposure to chloroprene, nor was the fetal sex ratio affected (Table 9).

The incidence of fetal malformations was not increased by exposure to chloroprene (Tables 10 and 12), in fact the incidence of malformations in the group as a whole was very low. There were no significant alterations in the incidence of total fetal variations or reduced ossifications among exposed groups (Tables 11 and 12). The variation termed "accessory blood vessel" refers to small extra vessels branching from the innominate or right subclavian arteries and would not be expected to affect the offspring. Another variation observed was termed "unusual lung lobes", this term refers to either missing or bifurcated diaphragmatic or cardiac lung lobes and would not be expected to affect the well-being of the offspring. This variation occurred only in exposed groups; however, the incidence was low (Table 12). Since variations in lung structure were noticed (but not recorded) in some of the dams, these variations may have been congenital and thus, not related to treatment. A review of the literature did not reveal any sources addressing the background incidence of variations in the lobulation of lungs in the New zealand white rabbit. 


\section{DISCUSSTON}

Results of this study Indicate that gestational exposure of New zealand white rabbits to 10,40 , or 175 ppm chloroprene did not result in observable toxicity to elther the dam or the offspring. The rabblt appears to be less sensitive to the effects of geatational exposure to chloroprene than the rat. Koeter and Appelman (1980) reported a reduction in fetal weight in Wistar rats at $175 \mathrm{ppm}$ chloroprene, but the mean body weight of the rabbit pups was not affected at that concentration. Furthermore, although there was an increase in the incidence of resorptions at $175 \mathrm{ppm}$ in the rat, this effect was not reproduced in the rabbit.

The highest exposure group, $175 \mathrm{ppm}$, was the no observable adverse effect level (NOAEL) for rabbits in the study with reapect to both maternal and developmental toxicity. 
Bartech H., C. Malavellle, A. Barbin and G. Planche. 1979. Mutagenic and alkylating metabolites of halo-ethylenes, chlorobutadienes and dichlorobutenes produced by rodent or human liver tisaues: Evidence for oxirane formation by P450-1inked microsomal monooxygenases. Arch. Toxicol. $41(4): 249-77$.

Bernatein, D.M. and R.T. Drew. 1980. The major parameters affecting temperature inside inhalation chambers. Am. Ind. Hyg. Assoc. J. 41:420426.

Brown, M.G. and O.R. Moss. 1981. An Inhalation exposure chamber designed for animal handling. Lab. Antm. Scl. 31:717-720.

Culik R., D.P. Kelly and J.J. Clary. 1978. Inhalation studies to evaluate the teratogenic and embryotoxic potential of $\beta$-chloroprene (2chlorobutadiene-1,3). Toxicol. Appl. Pharamcol. 44:81-88.

Gooch, J.J. and W.E. Hawn. 1981. Biochemical and hematological evaluation of chloroprene workers. J. Occup. Med. $23(4): 268-272$.

Griffis, L.C., R.K. Nolff, R.L. Beethe, et al. 1981. Evaluation of a multiTiered inhalation chamber. Fundam. Appl. Toxicol. 1:8-12.

Infante P.F., J.K. Hagoner and R.J. Young. 1977. Chloroprene: Observations of carcinogenesis and mutagenesis. In: Origins of Cancer, Cold Spring Harbor Laboratory.

International Agency for Research on Cancer (IARC). 1979. Working Group on the Evaluation of the Carcinogenic Risk of Chemicals to Man. IARC Monographs on the Svaluation of the Carainogenic Risk of Chemicals to Man. Vol. 19. World Health Organization, Geneva, Switzerland.

Koeter, H.B.W.M. and L.M. Appelman. 1980. Inhalation embryotoxicity/ teratogenicity studies with $\beta$-chloroprene in rats. Report No. R6387. Centraal Instituut voor Voedingstonderzoik, Utrechtseweg 48, zeist. 
Moss, O. R. 1980. A chamber providing uniform concentration of particulates for exposure of animals on tiers separated by catch pans. In Werkshopen Inhalatiton Chamber Technology, BNL 51318, Drew, R.T., editor. Brookhaven National Laboratory, Associated Universities, Inc., Upton, NY.

Hoss, O.R., J.R. Decker and W.C. Cannon. 1982. Aerosol mixing in an animal exposure chamber having three levels of caging with excreta pans. Am. Ind. Hyg. Assoc. J. 43:244-249.

Plunkett, E.R. 1987. Handhook of Induatrial Toxiaology. $3^{\text {rd }}$ Ed. Chemical Publishing Co., New York, NY.

Salnikova, L.S. 1968. Embryotropic effect of volatile substances from nairit latexes. Toksikol. Nov. Prom. Khim. Veshchestv. 11:106-111.

Salnikova, L.S. and V.N. Fomenko. 1973. Effect of chloroprene on embryogeneale. Gig. Tr. Prof. Zabol. 8:23-26.

Sittig, M. 1985. Handbook of Toxic and Haxardous Chomianler $2^{\text {nd }}$ Ed. Noyes Publications, Park Ridge, NJ.

Sumner K.H. and H. Greim. 1980. Detoxiflcation of chloroprene (2-chloro-1,3butadiene) with glutathione in the rat. Blochem. Biophys. Res. Commun. $96(2): 566-573$.

von Oettingen, W.F., W.C. Hueper, G. Deichmann, and F.M. Wiley. 1936. 2-Chlorobutadiene (chloroprene): Its toxicity and pathology and the mechanism of its action. J. Ind. Hyg. Tox. 18:240-270. 


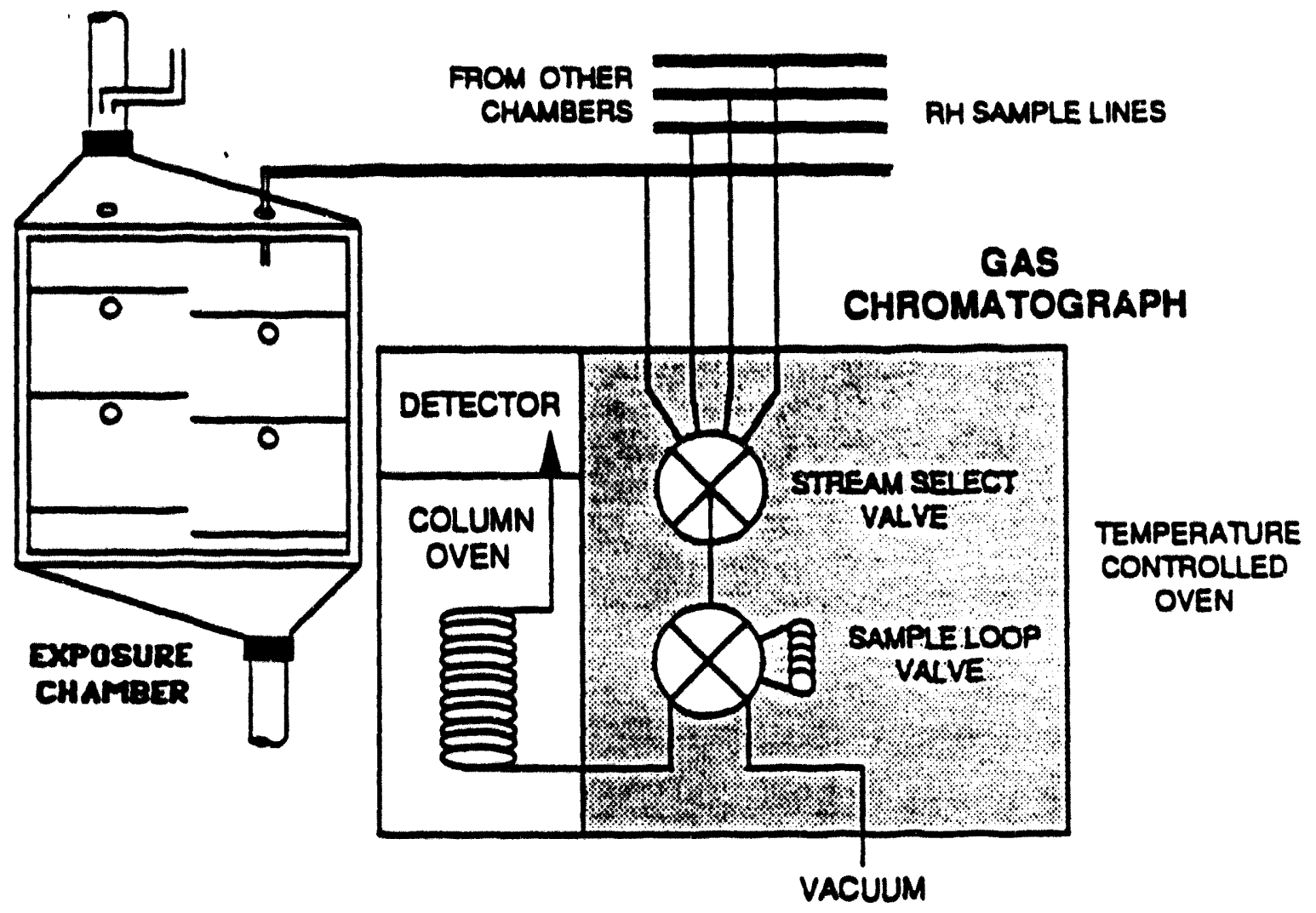

\begin{tabular}{|c|c|}
\hline \multicolumn{2}{|c|}{$\begin{array}{l}\text { STREAM SELECT PORT } \\
\text { ASSIGNMENTS }\end{array}$} \\
\hline $\begin{array}{r}1 \\
2 \\
3 \\
4 \\
5 \\
6 \\
7 \\
8 \\
9 \\
10 \\
11 \\
12\end{array}$ & $\begin{array}{l}\text { Not Used } \\
175 \text { ppm A } \\
175 \text { ppm B } \\
40 \text { ppm A } \\
40 \text { ppm B } \\
10 \text { ppm A } \\
10 \text { ppm B } \\
\text { Filtered Air } \\
\text { Room } \\
\text { O ppm A } \\
\text { Oppm B } \\
\text { Standard Gas }\end{array}$ \\
\hline
\end{tabular}

EIGURE 1. Chloroprene Inhalation Developmental Toxicity Study: Chamber Concentration Monitoring System 


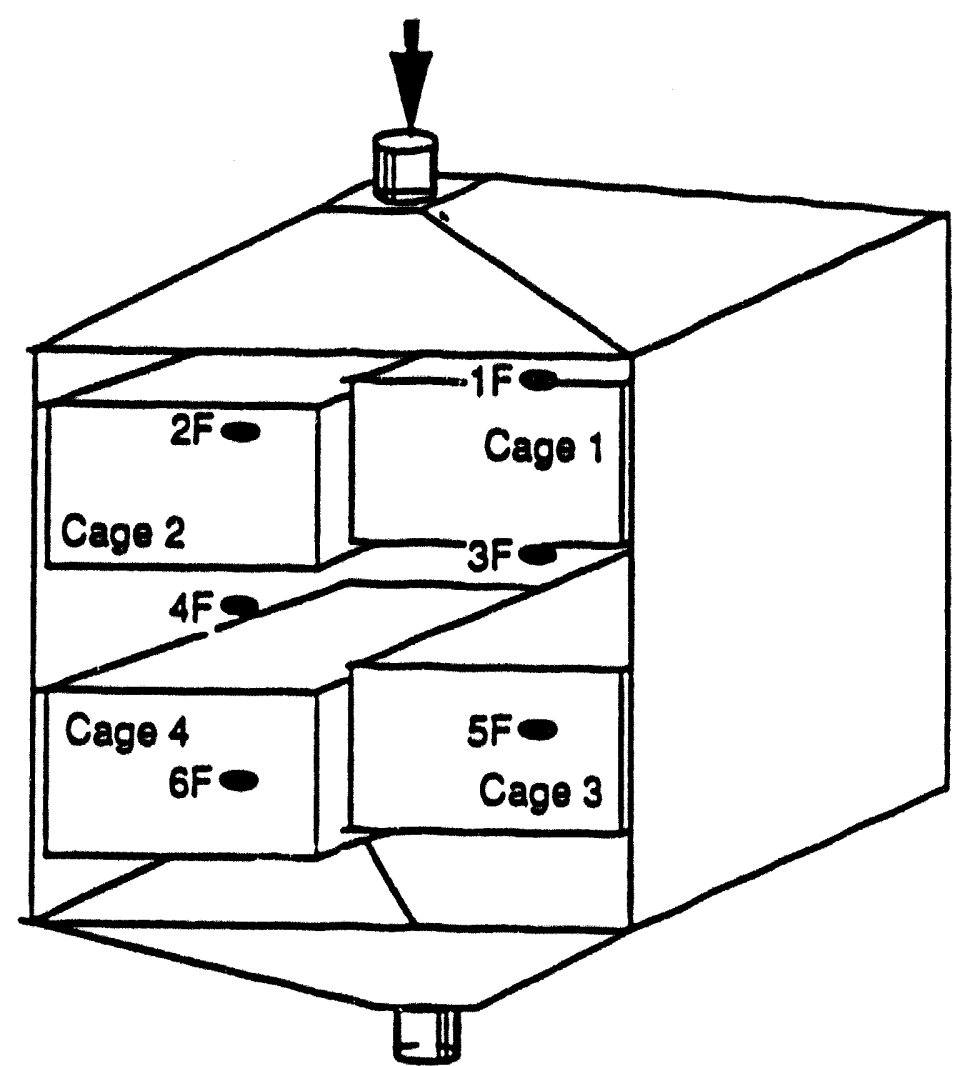

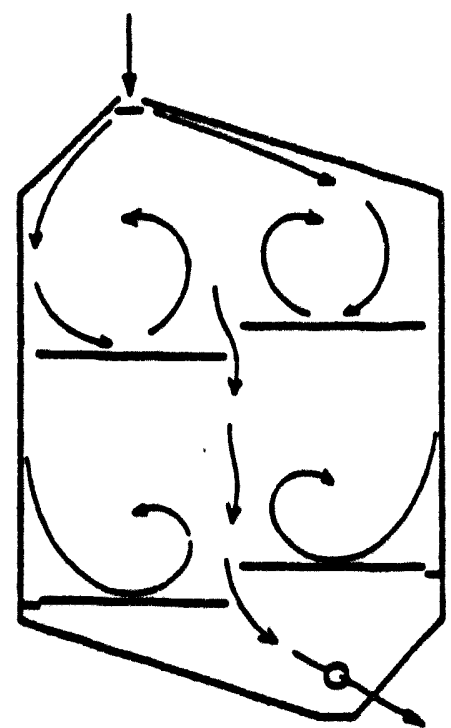

FRONT VIEW

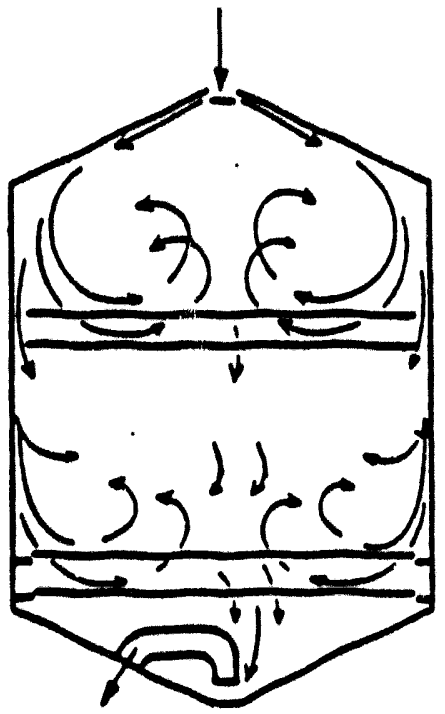

SIOE VIEW

Hose ot a1. 1982. Amex. Ind. Hyg. Assoc. J. 43(4) 244-249

EIGURs 2. Chloroprene Inhalation Developmental Toxicity Study: Inhalation Exposure Chamber U.S. Patent 4,216,741 (Top: Oblique Cutaway View; Bottom: Alrflow Patterns) 


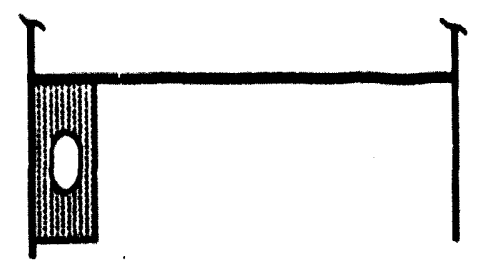

ROOM 327

NOT USED

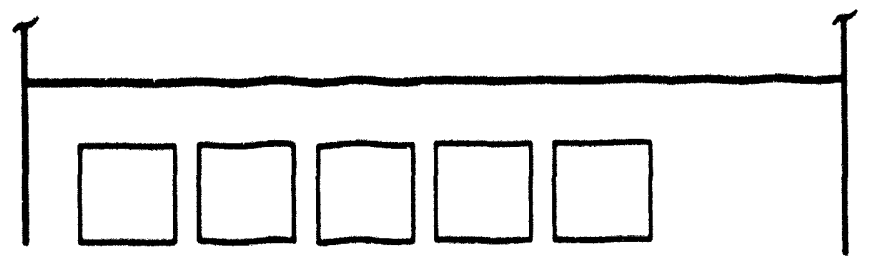

ROOM 428

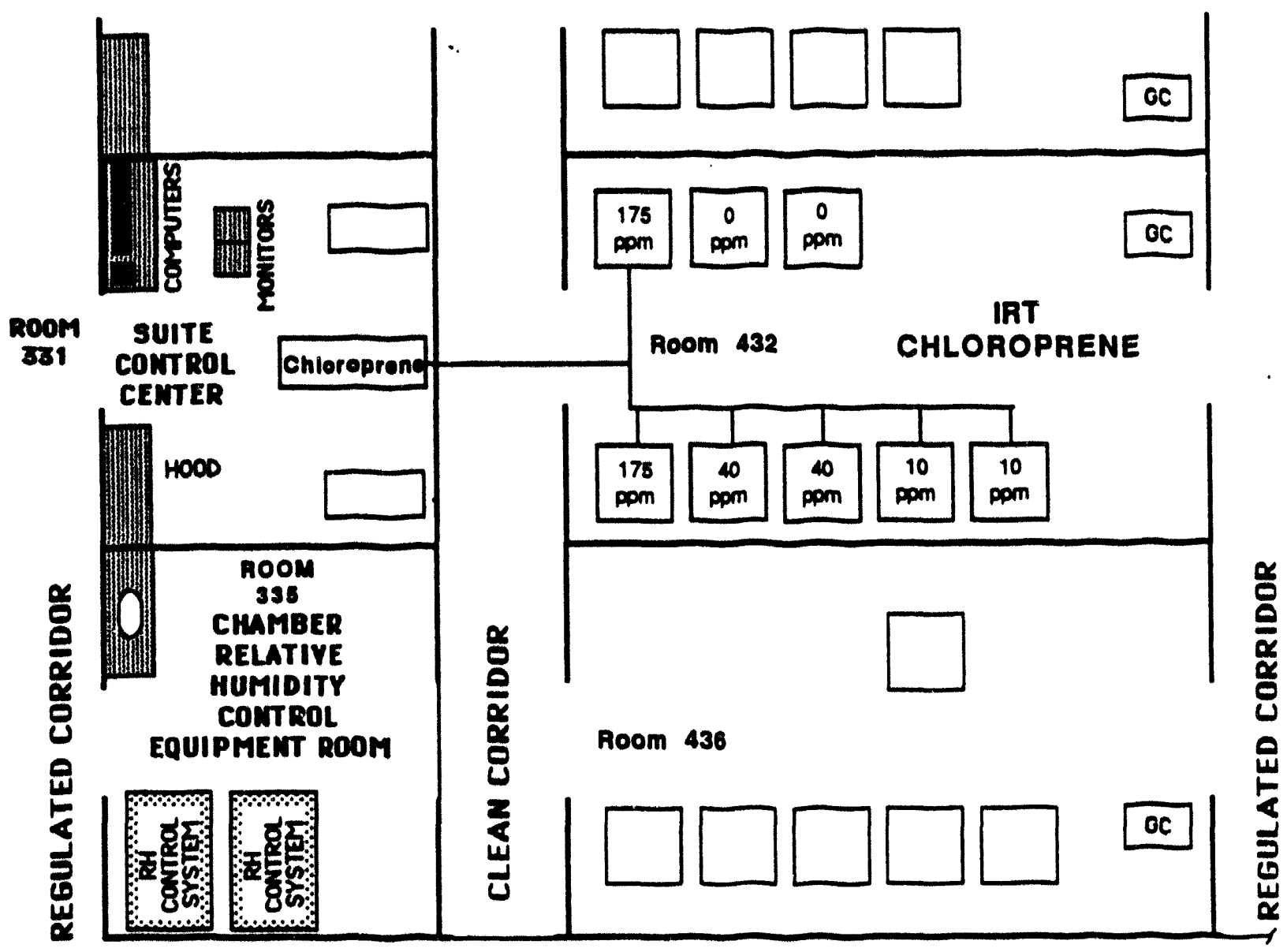

EIGURE 3. Chloroprene Inhalation Developmental Toxiclty Study: Study Exposure Sulte 


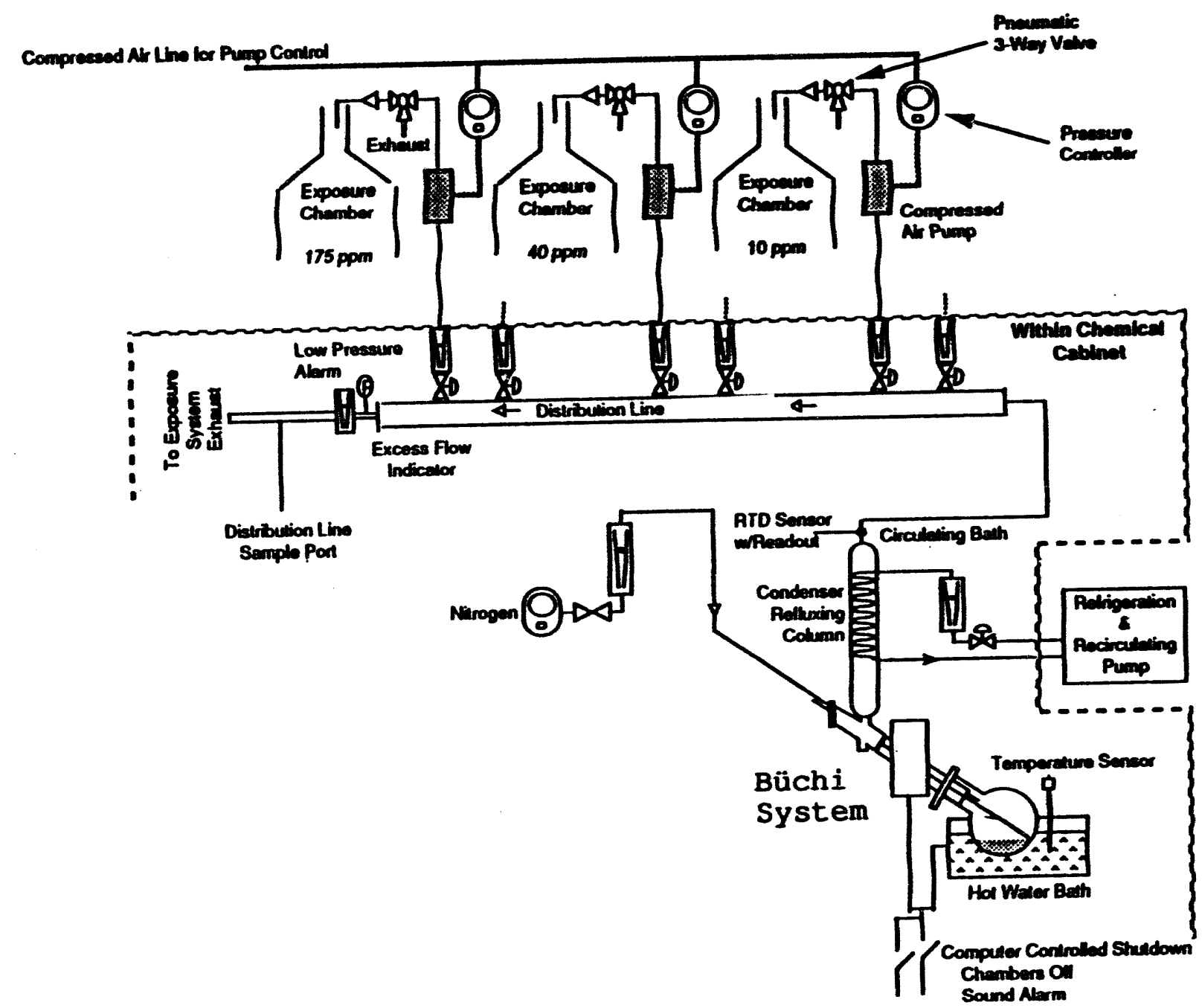



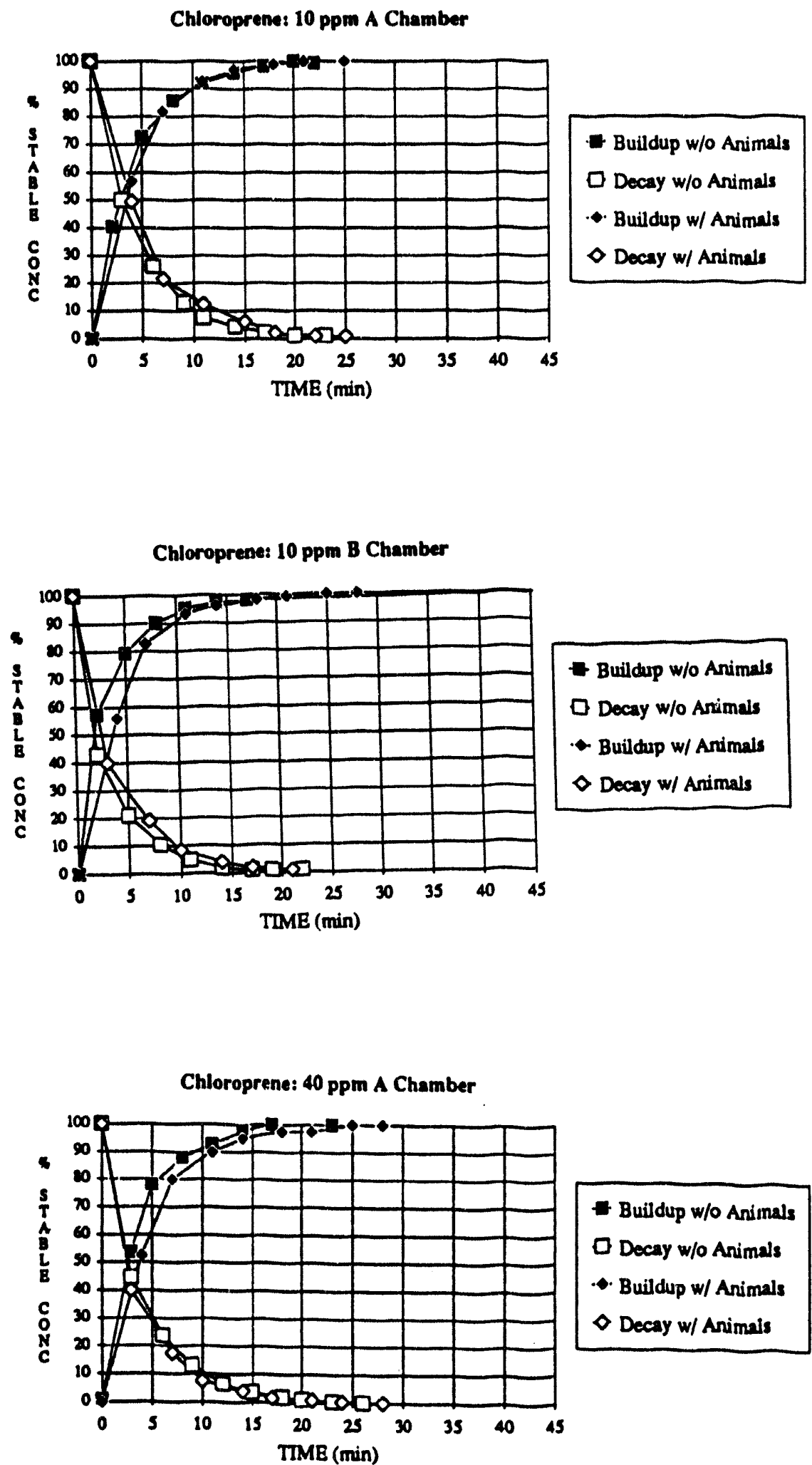

EIGURE 5. Chloroprene Inhalation Developmental Toxicity Study: Buildup and Decay Curves of Concentration in Animal Chambers 

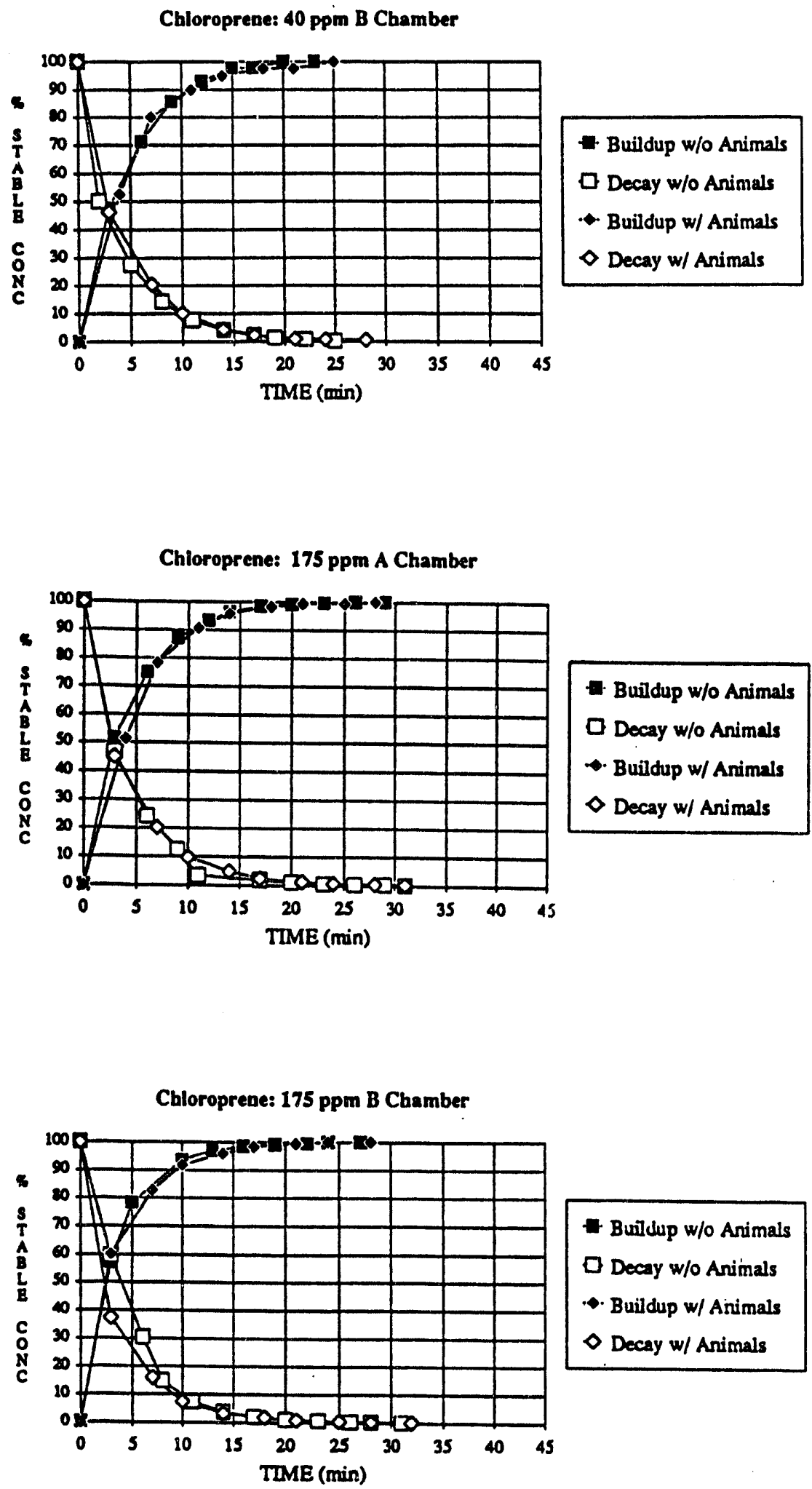

EIGURE 5 (cont). Chloroprene Inhalation Developmental Toxicity Study:

Buildup and Decay Curves of Concentration in Animal Chambers 


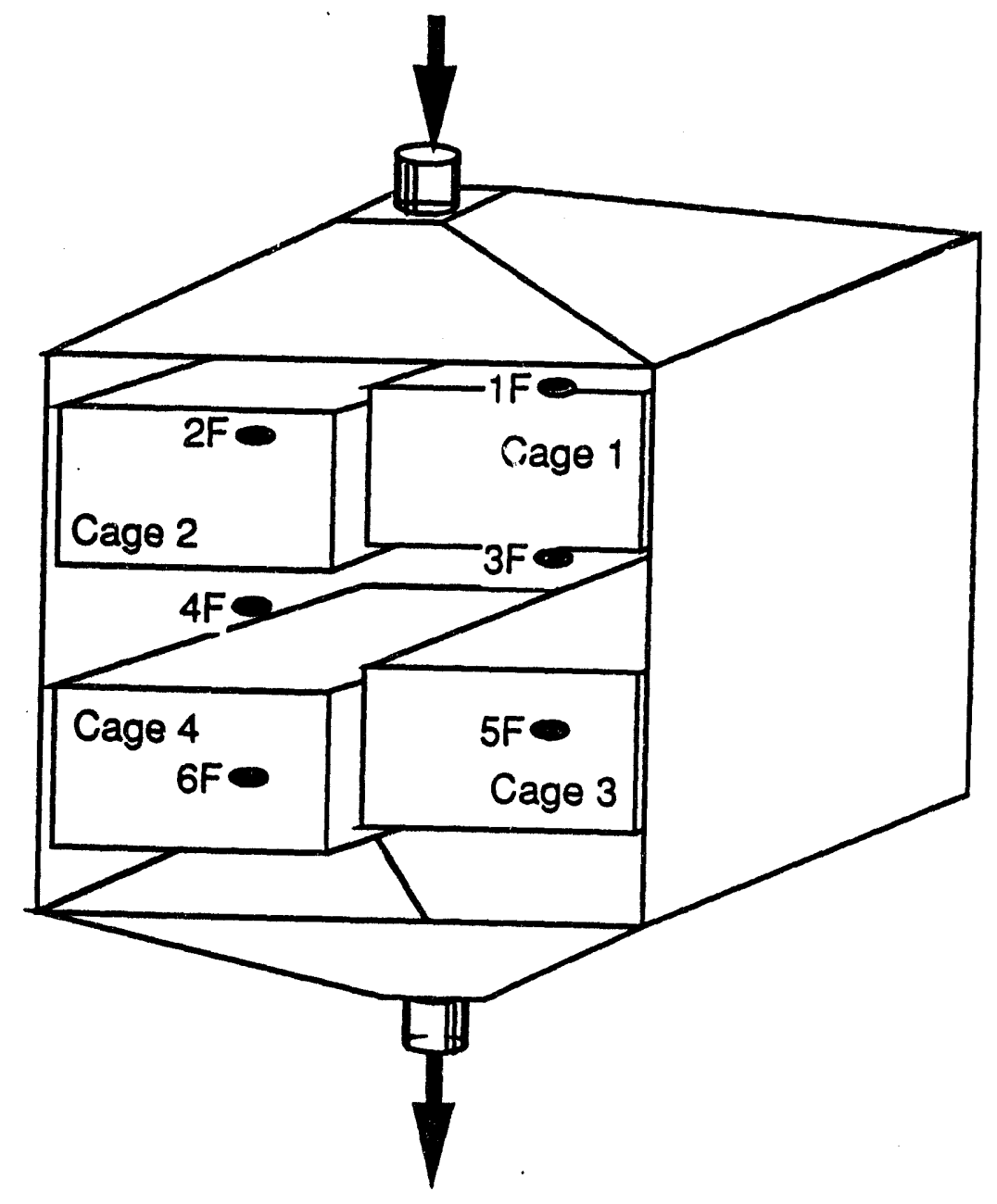

EIGURE 6. Chloroprene Inhalation Developmental Toxicity Study: Animal Exposure Chamber Schematic Showing Approximate Sampling Locations (F - Eront; B = Back) 


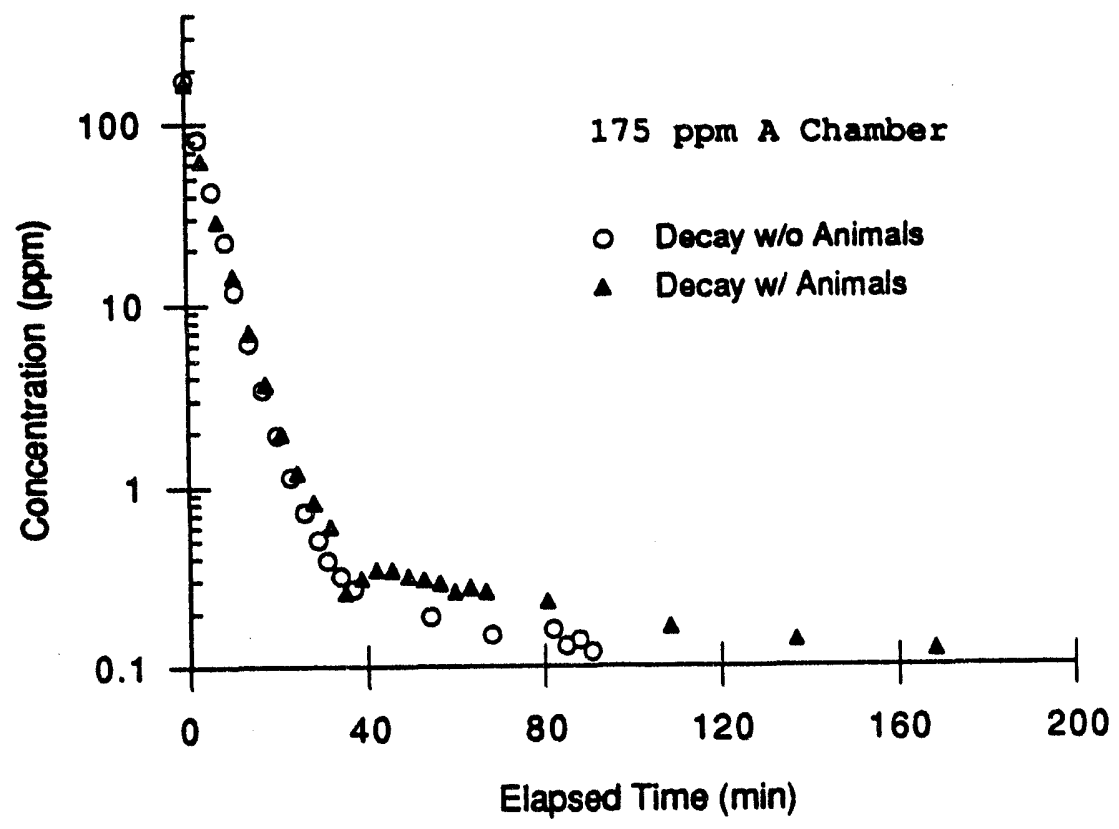

EIGURs 7. Chloroprene Inhalation Developmental Toxicity Study: PostExposure Monitoring Results of the 175 ppm A Chloroprene Chamber. (Persistance of the chemical in the chamber following exposure of animals.) 
TABLE 1. Chloroprene Inhalation Developmental Toxicity Study: Summary of $\mathrm{T}_{90^{\mathrm{a}}}$ and $\mathrm{T}_{10}$ Data.

\begin{tabular}{ccccc}
$\begin{array}{c}\text { Target } \\
\begin{array}{c}\text { Concentration } \\
\text { (ppm) }\end{array}\end{array}$ & $\begin{array}{c}\text { T90 } \\
\text { [min] }\end{array}$ & \multicolumn{2}{c}{ T10 $_{10}$ [min] } \\
Prestart & Poststart & Prestart & Poststart \\
\hline $10 \mathrm{~A}^{\mathrm{b}}$ & 10 & 10 & 10 & 12 \\
$10 \mathrm{~B}$ & 8 & 10 & 8 & 10 \\
$40 \mathrm{~A}$ & 9 & 11 & 10 & 9 \\
$40 \mathrm{~B}$ & 11 & 11 & 10 & 10 \\
$175 \mathrm{~A}$ & 10 & 11 & 9 & 10 \\
$175 \mathrm{~B}$ & 9 & 9 & 10 & 9 \\
\hline
\end{tabular}

a value of 12 minutes was used for T9o for the study.

b Two chambers were used (A and B) for each exposure concentration. 
TABLE2. Chloroprene Inhalation Developmental Toxicity Study: Summary of Chamber Uniformity Data (On-line Measurements only).

\begin{tabular}{|c|c|c|c|c|c|c|c|}
\hline $\begin{array}{l}\text { Targe } \\
\text { (ppm) }\end{array}$ & & $\begin{array}{c}\text { Conc. TP } \\
\text { Prestart }\end{array}$ & $\begin{array}{l}\text { [gRSD] } \\
\text { Poststart }\end{array}$ & $\begin{array}{r}\text { WPV } \\
\text { Prestart }\end{array}$ & $\begin{array}{l}\text { [8RSD] } \\
\text { Poststart }\end{array}$ & $\begin{array}{r}\text { BPV } \\
\text { Prestart }\end{array}$ & $\begin{array}{l}\text { [8RSD] } \\
\text { Poststar }\end{array}$ \\
\hline 10 & A & 0.6 & 1.3 & 0.1 & 0.8 & 0.6 & 1.0 \\
\hline 10 & $B$ & 0.2 & 0.4 & 0.2 & 0.2 & 0.2 & \\
\hline 40 & A & 0.5 & 0.6 & 0.7 & 0.1 & $--a$ & 0.6 \\
\hline 40 & B & 1.6 & 0.7 & 0.3 & 0.4 & 1.6 & 0.6 \\
\hline 175 & A & 0.4 & 0.5 & 0.9 & 0.2 & $--a$ & 0.4 \\
\hline 175 & B & 0.1 & 0.5 & 0.2 & 0.2 & $--a$ & 0.4 \\
\hline
\end{tabular}

TPV = Total Port Variation. Acceptable limit $\leq 78$ RSD.

WPV $=$ Within Port Variation. Acceptable limit $\leq 5 \%$ RSD.

BPV = Between Port Variation. Acceptable limit $\leq 5 \%$ RSD.

a when the WPV is greater than the TPV, the BPV is very small and it cannot be resolved from the WPV.

Note: Concentrations in the chambers during the prestart

measurements were at the originally proposed levels. 
TABLE 3. Chloroprene Inhalation Developmental Toxicity Study: Summation of Exposure Concentration Data.

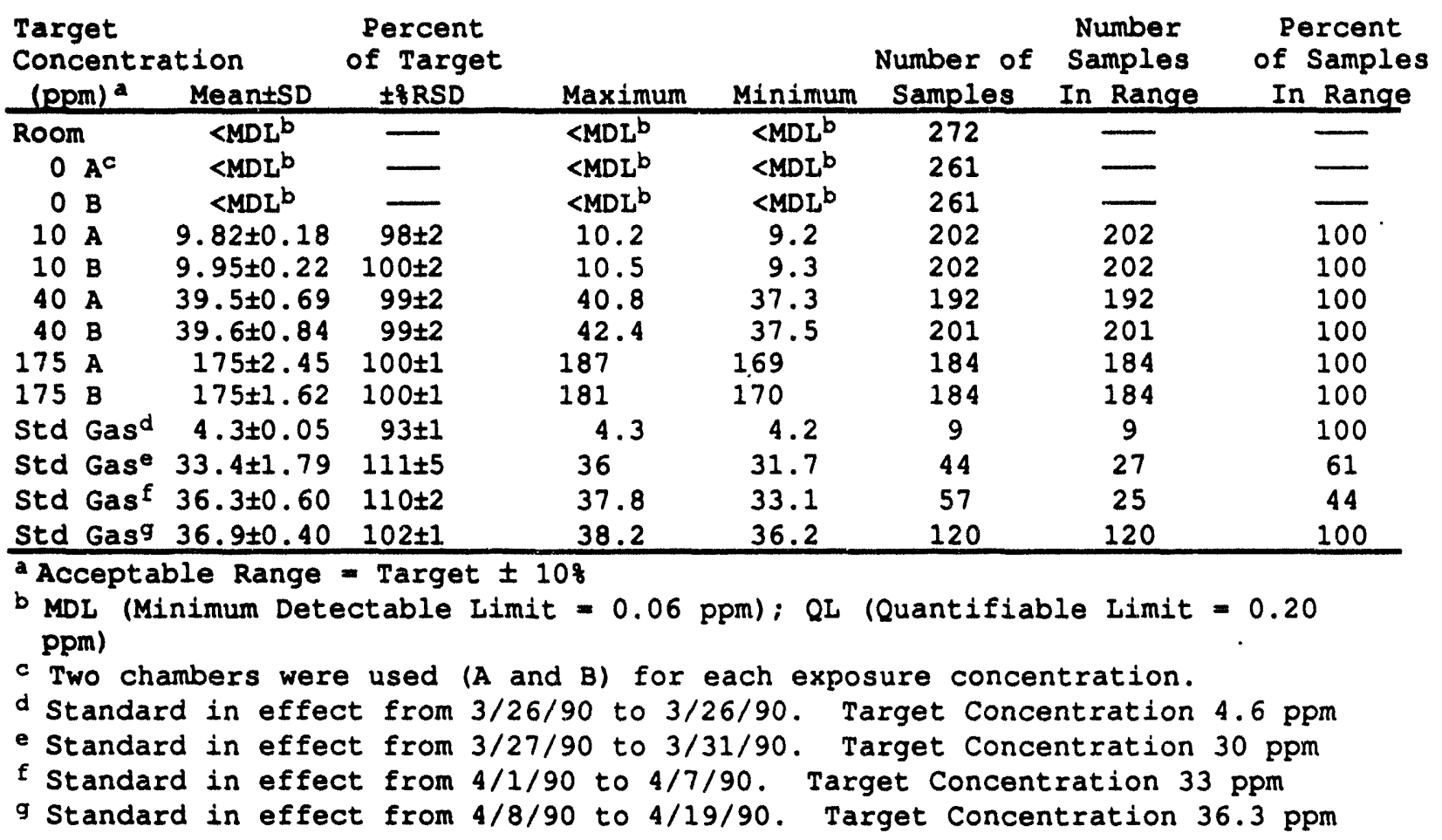


TABLE 4. Chloroprene Inhalation Developmental Toxicity Study: Summation of Chamber Environmental Data.

TEMPERATURE $\left({ }^{\circ} \mathrm{F}\right)^{\mathrm{a}}$

\begin{tabular}{|c|c|c|c|c|c|c|c|}
\hline $\begin{array}{l}\text { Target } \\
\text { Concent }\end{array}$ & ation & Percent of & Maximum & Minimum & $\begin{array}{l}\text { Number of } \\
\text { Samples }\end{array}$ & $\begin{array}{l}\text { Number } \\
\text { Samples } \\
\text { In Range }\end{array}$ & $\begin{array}{l}\text { Percent } \\
\text { of Samples } \\
\text { In Range }\end{array}$ \\
\hline Room & $64.2 \pm 1.8$ & $99 \pm 3$ & 67.9 & 58.5 & 203 & 195 & 96 \\
\hline $\begin{array}{rl}0 & \mathrm{~A}^{\mathrm{b}} \\
0 & \mathrm{~B} \\
10 & \mathrm{~A} \\
10 & \mathrm{~B} \\
40 & \mathrm{~A} \\
40 & \mathrm{~B} \\
175 & \mathrm{~A} \\
175 & \mathrm{~B}\end{array}$ & $\begin{array}{l}67.3 \pm 0.8 \\
67.1 \pm 1.0 \\
66 \cdot 9 \pm 1.8 \\
67.6 \pm 0.8 \\
66.6 \pm 1.9 \\
67.5 \pm 1.1 \\
68 \cdot 0 \pm 1.0 \\
68 \cdot 2 \pm 1.0\end{array}$ & $\begin{array}{l}98 \pm 1 \\
97 \pm 2 \\
97 \pm 3 \\
98 \pm 1 \\
97 \pm 3 \\
98 \pm 2 \\
99 \pm 2 \\
99 \pm 1\end{array}$ & $\begin{array}{l}69.3 \\
69.7 \\
70.0 \\
69.4 \\
70.1 \\
69.3 \\
69.9 \\
70.2\end{array}$ & $\begin{array}{l}65.2 \\
62.9 \\
60.7 \\
65.2 \\
61.3 \\
64.7 \\
64.3 \\
65.7\end{array}$ & $\begin{array}{l}165 \\
192 \\
190 \\
164 \\
187 \\
163 \\
186 \\
161\end{array}$ & $\begin{array}{l}165 \\
190 \\
169 \\
164 \\
161 \\
161 \\
186 \\
161\end{array}$ & $\begin{array}{c}100 \\
99 \\
89 \\
100 \\
86 \\
99 \\
100 \\
100\end{array}$ \\
\hline $\begin{array}{l}\text { accept } \\
\text { the ex }\end{array}$ & ble Range & 65 to $73^{\circ}$ & or the & osure & & 61 to & F for \\
\hline
\end{tabular}

RELATIVE HUMIDITY $(\xi R H)^{c}$

\begin{tabular}{|c|c|c|c|c|c|c|c|}
\hline $\begin{array}{c}\text { Target } \\
\text { Concent } \\
\text { (ppm) }\end{array}$ & $\begin{array}{l}\text { sation } \\
\text { MeantSD }\end{array}$ & $\begin{array}{c}\text { Percent of } \\
\text { TargettrRSD }\end{array}$ & Maximum & Minimum & $\begin{array}{c}\text { Number of } \\
\text { Samples }\end{array}$ & $\begin{array}{c}\text { Number } \\
\text { Samples } \\
\text { In Range }\end{array}$ & $\begin{array}{l}\text { Percent } \\
\text { of Samples } \\
\text { In Range }\end{array}$ \\
\hline $\begin{array}{rl}0 & \mathrm{~A} \\
0 & \mathrm{~B} \\
10 & \mathrm{~A} \\
10 & \mathrm{~B} \\
40 & \mathrm{~A} \\
40 & \mathrm{~B} \\
175 & \mathrm{~A} \\
175 & \mathrm{~B}\end{array}$ & $\begin{array}{l}58.7 \pm 5.6 \\
62.1 \pm 6.8 \\
58.6 \pm 8.1 \\
56.8 \pm 6.2 \\
56.2 \pm 7.9 \\
58.8 \pm 6.4 \\
55.3 \pm 7.2 \\
54.1 \pm 6.5\end{array}$ & $\begin{array}{r}107 \pm 10 \\
113 \pm 11 \\
107 \pm 14 \\
103 \pm 11 \\
102 \pm 1.4 \\
107 \pm 11 \\
101 \pm 13 \\
98 \pm 12\end{array}$ & $\begin{array}{l}69 \\
75 \\
77 \\
71 \\
75 \\
76 \\
71 \\
74\end{array}$ & $\begin{array}{l}46 \\
42 \\
43 \\
44 \\
38 \\
44 \\
40 \\
39\end{array}$ & $\begin{array}{l}183 \\
204 \\
205 \\
182 \\
202 \\
179 \\
198 \\
173 \\
\end{array}$ & $\begin{array}{l}183 \\
184 \\
186 \\
181 \\
192 \\
175 \\
197 \\
171\end{array}$ & $\begin{array}{r}100 \\
90 \\
91 \\
99 \\
95 \\
98 \\
99 \\
99\end{array}$ \\
\hline
\end{tabular}

${ }^{\text {Acceptable Range }}=40$ to $70 \%$.

AIRFLOW (CFM) $^{d}$

\begin{tabular}{|c|c|c|c|c|c|c|c|}
\hline $\begin{array}{r}\text { Target } \\
\text { Concen } \\
\text { (pom) }\end{array}$ & $\begin{array}{l}\text { ation } \\
\text { Mean } \pm S D\end{array}$ & $\begin{array}{l}\text { Percent of } \\
\text { Target } \pm 8 \text { RSD } \\
\end{array}$ & Maximum & Minimum & $\begin{array}{c}\text { Number of } \\
\text { Samples }\end{array}$ & $\begin{array}{c}\text { Number } \\
\text { Samples } \\
\text { In Range }\end{array}$ & $\begin{array}{l}\text { Percent } \\
\text { of Samples } \\
\text { In Range }\end{array}$ \\
\hline $\begin{array}{rl}0 & \mathrm{~A} \\
0 & \mathrm{~B} \\
10 & \mathrm{~A} \\
10 & \mathrm{~B} \\
40 & \mathrm{~A} \\
40 & \mathrm{~B} \\
175 & \mathrm{~A} \\
175 & \mathrm{~B} \\
\end{array}$ & $\begin{array}{l}14.7 \pm 0.4 \\
14.8 \pm 0.4 \\
14.8 \pm 0.2 \\
14.8 \pm 0.3 \\
14.8 \pm 0.2 \\
15.0 \pm 0.3 \\
15.0 \pm 0.3 \\
15.1 \pm 0.3\end{array}$ & $\begin{array}{r}98 \pm 3 \\
99 \pm 3 \\
99 \pm 2 \\
99 \pm 2 \\
99 \pm 1 \\
100 \pm 2 \\
100 \pm 2 \\
100 \pm 2\end{array}$ & $\begin{array}{l}15.5 \\
17.4 \\
15.8 \\
15.3 \\
15.2 \\
15.7 \\
15.7 \\
15.7\end{array}$ & $\begin{array}{l}13.2 \\
13.5 \\
13.2 \\
12.7 \\
13.1 \\
13.1 \\
13.1 \\
13.3\end{array}$ & $\begin{array}{l}175 \\
198 \\
198 \\
174 \\
198 \\
175 \\
198 \\
175\end{array}$ & $\begin{array}{l}175 \\
198 \\
198 \\
174 \\
198 \\
175 \\
198 \\
175\end{array}$ & $\begin{array}{l}100 \\
100 \\
100 \\
100 \\
100 \\
100 \\
100 \\
100\end{array}$ \\
\hline
\end{tabular}

dAcceptable Range $=12$ to 18 CFM. 
TABLE 5. Chloroprene Inhalation Developmental Toxiclty in Rabblts: Study Disposition.

\section{Target}

Chloroprene

Concentration

(pom)

Treatment Group

Inseminated

Pregnant

Removed

\begin{tabular}{lllll}
\hline 0 & 1 & 16 & 12 & $1^{\mathrm{a}}$ \\
10 & 2 & 16 & 15 & 0 \\
40 & 3 & 15 & 13 & 0 \\
175 & 4 & 16 & 15 & 0 \\
\hline
\end{tabular}

ane dam was found moribund on $3 / 27 / 90(7 \mathrm{dg})$ leaving 15 inseminated does In this group. 
TABL5_6. Chloroprene Inhalation Developmental Toxiclty Study. Summary of Gross Observations at Time of Maternal Sacrifice.

\begin{tabular}{|c|c|c|c|c|}
\hline $\begin{array}{l}\text { Target } \\
\text { Chloroprene } \\
\text { Concentration (ppm) }\end{array}$ & 0 & 10 & 40 & 175 \\
\hline $\mathbf{N}$ & 15 & 16 & 15 & 16 \\
\hline $\begin{array}{l}\text { Lungs: } \\
\text { Khak1 colored foc1 } \\
\text { Dark red foc1 } \\
\text { Granular tissue } \\
\text { Cyst }(3-4 \mathrm{~mm})\end{array}$ & $\begin{array}{l}1 \\
0 \\
0 \\
1\end{array}$ & $\begin{array}{l}1 \\
0 \\
1 \\
0\end{array}$ & $\begin{array}{l}0 \\
0 \\
1 \\
0\end{array}$ & $\begin{array}{l}1 \\
1 \\
0 \\
0\end{array}$ \\
\hline $\begin{array}{l}\text { Liver Lesions: } \\
\text { Yellow (1 mm) } \\
\text { Pale (2x4 mm) }\end{array}$ & $\begin{array}{l}0 \\
1\end{array}$ & $\begin{array}{l}0 \\
0\end{array}$ & $\begin{array}{l}1 \\
0\end{array}$ & $\begin{array}{l}0 \\
0\end{array}$ \\
\hline $\begin{array}{l}\text { Bladder: } \\
\text { Thickened wall }\end{array}$ & 0 & 0 & 0 & 1 \\
\hline
\end{tabular}


TaBus I Inhalation Developmental Toxicity Study of Chloroprene in Rabbits: Mean Body, Uterine, Extra-gestational Gaina and Organ Welghts of Pregnant Developmental Toxicology Rabbits (g \pm SD).

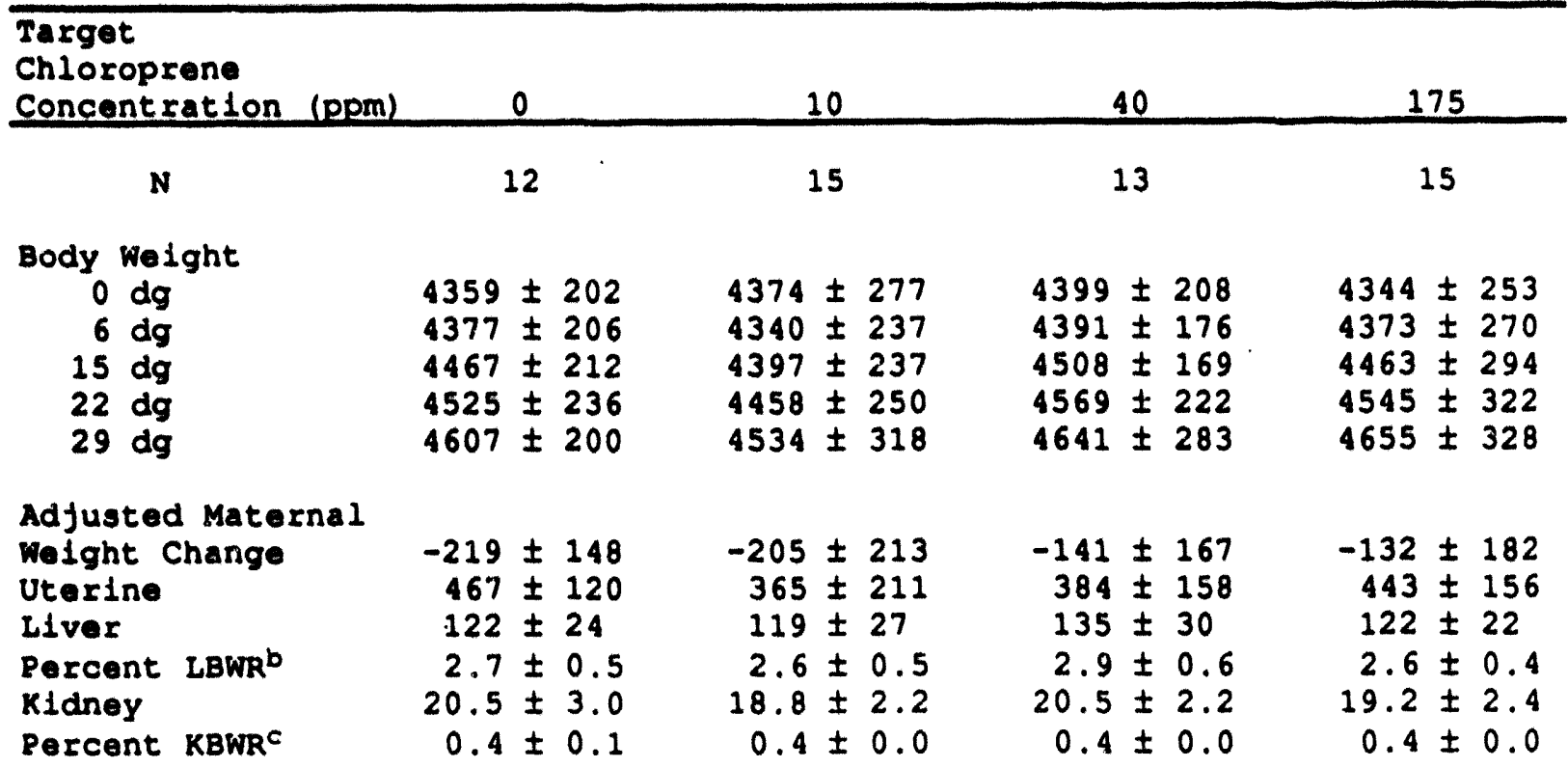

a Adjusted Maternal Body Welght Change = body weight $(20 \mathrm{dg})$ - body weight $(0 \mathrm{dg})$ - uterine weight.

b LBWR = liver to body weight rat $10 \times 100$.

- KBWR - kidney to body weight rat10 $\times 100$. 
TABrs 8. Chloroprene Inhalation Developmental Toxicity Study: Reproductive Measures (Mean \pm SD) in Rabbits.

\section{Target}

Chloroprene

Concentration (pom)

0

10

40

175

NUMBER OF:

Inseminated Females

Number Pregnant

Pregnancies Examined

Corpora Lutea/Dam

Implantations/Dam

Live Fetuses/Litter

Resorptions/Litter:

Early

Late

Dead Fetuses/Litter

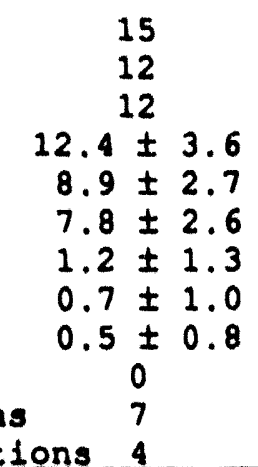

16

15

15

15

13

13

15

$8.9 \pm 4.1$

$10.5 \pm 3.7$

$7.1 \pm 3.4 \quad 7.0 \pm 3.0$

$5.8 \pm 3.6 \quad 6.2 \pm 2.9$

$1.3 \pm 1.9$

$0.8 \pm 1.0$

$1.1 \pm 1.9$

$0.4 \pm 0.8$

$0.1 \pm 0.4$

$0.4 \pm 0.9$

0

Litters with Resorptions

Litters with 22 Resorptions 4

9

9

PERCENTAGE OF:

Pregnant Females

Live Fetuses/Litter

80

94

87

94

Resorptions/Litter:

$87.2 \pm 13.772 .7 \pm 36.282 .9 \pm 28.1$

$84.8 \pm 24.5$

Early

$12.8 \pm 13.727 .3 \pm 36.217 .1 \pm 28.1$

$15.2 \pm 24.5$

Late

$8.2 \pm 12.325 .3 \pm 37.311 .3 \pm 28.1$

$12.0 \pm 25.5$

Dead Fetuses/Litter

$4.6 \pm 7.3$

$2.0 \pm 5.6$

$5.8 \pm 12.0$

$3.3 \pm 5.8$

Litters with Resorptions

58

0

60

0

0

Litters with 22 Resorptions 33

20

23

67

20 
Tagha 9. Chloroprene Inhalation Developmental Toxicity Study: Fetal Organ and Body Welghts (grams), Fetal Organ to Body Woight Rat10, and Fotal Sox Ratio in Rabbits (Mean of Litter Means; \pm SD).

\begin{tabular}{|c|c|c|c|c|}
\hline $\begin{array}{l}\text { Target } \\
\text { Chloroprene } \\
\text { Concentration (ppm) }\end{array}$ & 0 & 10 & 40 & 175 \\
\hline L1tters Examined & 12 & 13 & 12 & 14 \\
\hline $\begin{array}{l}\text { Fetal Welght } \\
\text { Male } \\
\text { Fomale. }\end{array}$ & $\begin{array}{l}43.3 \pm 6.2 \\
42.2 \pm 6.9 \\
44.2 \pm 5.7\end{array}$ & $\begin{array}{l}45.8 \pm 5.5 \\
46.0 \pm 5.2 \\
45.5 \pm 6.1\end{array}$ & $\begin{array}{l}42.0 \pm 4.9 \\
41.8 \pm 5.8 \\
42.0 \pm 5.0\end{array}$ & $\begin{array}{l}43.8 \pm 3.7 \\
44.0 \pm 5.0 \\
43.6 \pm 4.1\end{array}$ \\
\hline $\begin{array}{l}\text { Tetal Liver Weight } \\
\text { Male } \\
\text { Female }\end{array}$ & $\begin{array}{l}3.0 \pm 0.7 \\
2.9 \pm 0.8 \\
3.1 \pm 0.6\end{array}$ & $\begin{array}{l}3.2 \pm 0.5 \\
3.3 \pm 0.5 \\
3.3 \pm 0.6\end{array}$ & $\begin{array}{l}2.9 \pm 0.5 \\
2.9 \pm 0.5 \\
2.9 \pm 0.6\end{array}$ & $\begin{array}{l}3.1 \pm 0.4 \\
3.1 \pm 0.5 \\
3.1 \pm 0.4\end{array}$ \\
\hline $\begin{array}{l}\text { Percent LBWRa } \\
\text { Male } \\
\text { Female }\end{array}$ & $\begin{array}{l}6.9 \pm 0.6 \\
6.8 \pm 0.8 \\
6.9 \pm 0.5\end{array}$ & $\begin{array}{l}7.0 \pm 0.4 \\
7.1 \pm 0.5 \\
7.1 \pm 0.5\end{array}$ & $\begin{array}{l}7.0 \pm 0.6 \\
7.0 \pm 0.5 \\
6.9 \pm 0.7\end{array}$ & $\begin{array}{l}7.0 \pm 0.4 \\
7.1 \pm 0.6 \\
7.0 \pm 0.5\end{array}$ \\
\hline $\begin{array}{l}\text { Fetal Kidney Weight } \\
\text { Male } \\
\text { Female }\end{array}$ & $\begin{array}{l}0.37 \pm 0.05 \\
0.36 \pm 0.07 \\
0.38 \pm 0.05\end{array}$ & $\begin{array}{l}0.41 \pm 0.15 \\
0.43 \pm 0.18 \\
0.37 \pm 0.06\end{array}$ & $\begin{array}{l}0.35 \pm 0.05 \\
0.36 \pm 0.06 \\
0.35 \pm 0.06\end{array}$ & $\begin{array}{l}0.37 \pm 0.03 \\
0.37 \pm 0.05 \\
037 \pm 0.03\end{array}$ \\
\hline $\begin{array}{l}\text { Percent KBWR } \\
\text { Male } \\
\text { Female }\end{array}$ & $\begin{array}{l}0.85 \pm 0.06 \\
0.86 \pm 0.06 \\
0.86 \pm 0.06\end{array}$ & $\begin{array}{l}0.90 \pm 0.28 \\
0.93 \pm 0.34 \\
0.82 \pm 0.06\end{array}$ & $\begin{array}{l}0.84 \pm 0.06 \\
0.86 \pm 0.10 \\
0.83 \pm 0.06\end{array}$ & $\begin{array}{l}0.84 \pm 0.03 \\
0.84 \pm 0.05 \\
0.84 \pm 0.04\end{array}$ \\
\hline
\end{tabular}

Percent Male Eetuses

$52 \pm 24$

$57 \pm 21$

$50 \pm 11$

$49 \pm 16$

a LBWR - liver to body weight ratio $\times 100$.

b KBWR = kidney to body weight rat10 $\times 100$ 
TaBrs 10. Chloroprene Inhalation Developmental Toxicity Study: Malformations Observed in IIve Rabblt Fetuses.

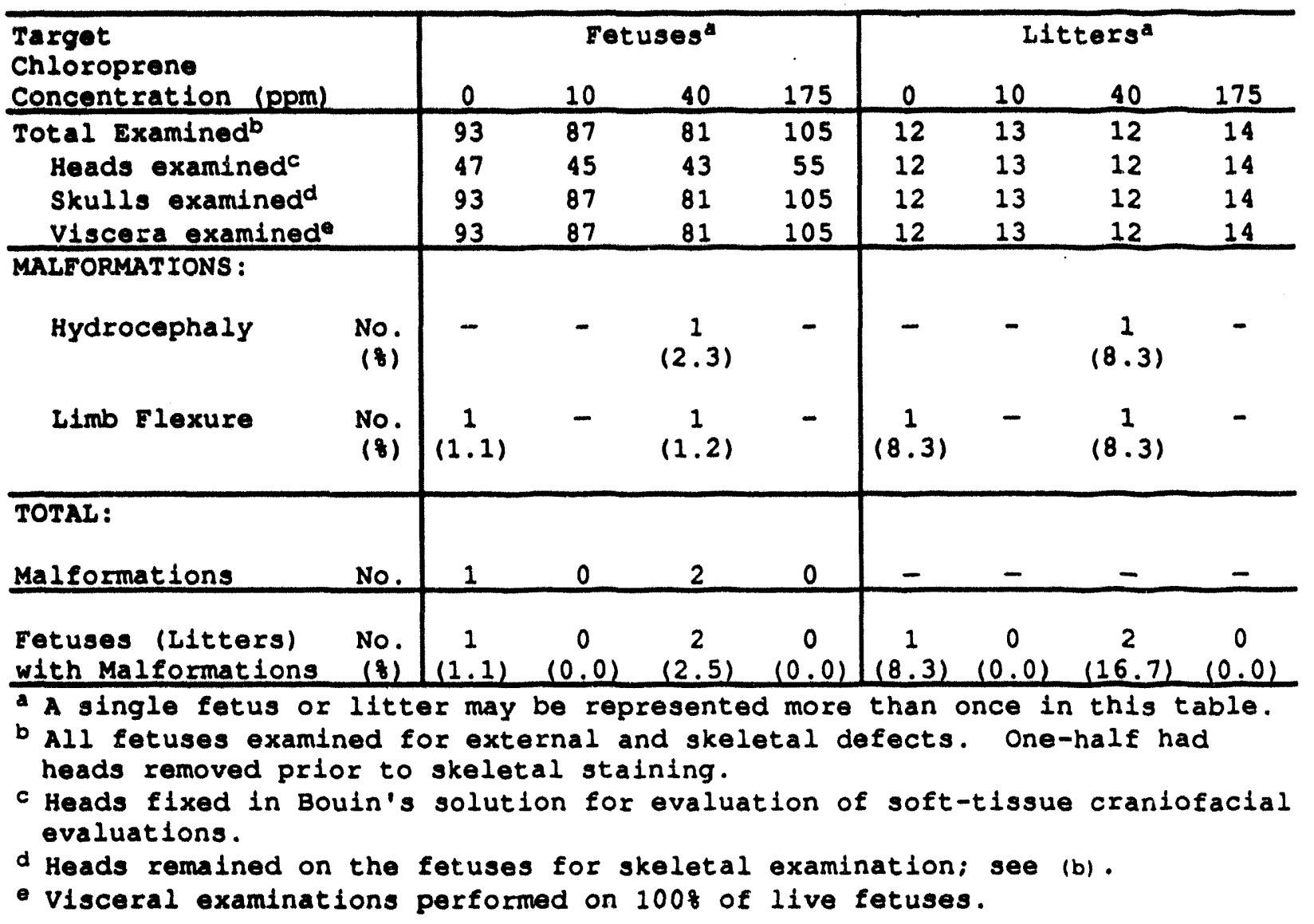


TABIf 11. Chloroprene Inhalation Developmental Toxicity Study: Variations and Reduced Osatilications Observed in Live Rabbit Fetuses.

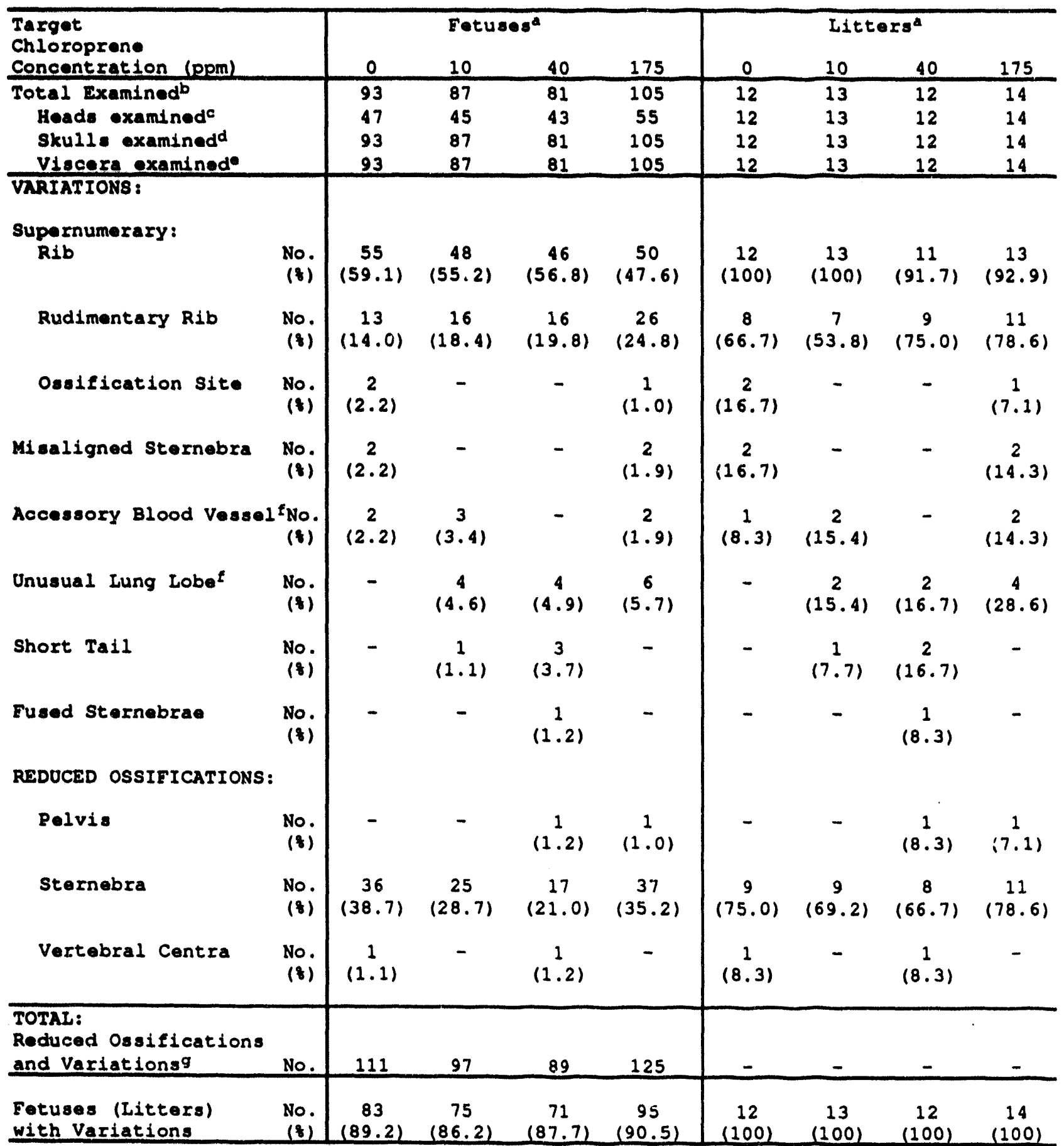

a single fetus or litter may be represented more than once in this table.

b All fetuses examined for external and skeletal defects. One-half had heads removed prior to skeletal staining.

c Heads fixed in Bouin's solution for evaluation of soft-tissue craniofacial evaluations.

d Heads remained on the fetuses for skeletal examination; see (b).

- Visceral examinations performed on 1008 of live fetuses.

f See text for description of accessory blood vessel and unusual lung lobe.

9 There may be $>1$ variation per fetus. 
TABLE 12. Chloroprene Inhalation Developmental Toxicity Study. Mean Percent of Live Rabbit Fetuses Affected per Litter (Mean Percent \pm SD).

\begin{tabular}{|c|c|c|c|c|c|}
\hline $\begin{array}{l}\text { Target } \\
\text { Chloroprene } \\
\text { Concentration (ppm) }\end{array}$ & 0 & & 10 & 40 & 175 \\
\hline Litters Examined & 12 & & 13 & 12 & 14 \\
\hline MALFORMATIONS: & & & & & \\
\hline $\begin{array}{l}\text { Hydroencephaly } \\
\text { Limb Flexure }\end{array}$ & $0.9 \pm 3.2$ & & - & $\begin{array}{l}2.8 \pm 9.6 \\
0.8 \pm 2.9\end{array}$ & - \\
\hline Total Malformations & $0.9 \pm 3.2$ & & - & $2.2 \pm 5.4$ & - \\
\hline \multicolumn{6}{|l|}{ VARIATIONS: } \\
\hline $\begin{array}{l}\text { Supernumerary: } \\
\text { Rib } \\
\text { Rudimentary Rib } \\
\text { Ossification Site: } \\
\text { Misaligned Sternebra } \\
\text { Accessory Blood Vessela } \\
\text { Unusual Lung Lobe } \\
\text { Short Tail } \\
\text { Fused Sternebrae }\end{array}$ & $\begin{aligned} 63.1 & \pm 25.4 \\
13.2 & \pm 13.7 \\
1.7 & \pm 4.0 \\
1.9 & \pm 4.3 \\
1.9 & \pm 6.4 \\
& - \\
& -\end{aligned}$ & $\begin{array}{l}60.8 \\
13.7 \\
\\
4.3 \\
2.9 \\
1.0\end{array}$ & $\begin{array}{l} \pm 25.5 \\
\pm 15.1 \\
- \\
- \\
\pm 10.7 \\
\pm 7.5 \\
\pm 3.5 \\
-\end{array}$ & $\begin{aligned} 56.3 & \pm 33.1 \\
21.1 & \pm 16.9 \\
& = \\
& - \\
& - \\
5.4 & \pm 13.0 \\
4.4 & \pm 11.8 \\
1.7 & \pm 5.8\end{aligned}$ & $\begin{aligned} 46.1 & \pm 27.5 \\
26.2 & \pm 19.0 \\
0.9 & \pm 3.3 \\
2.1 & \pm 5.7 \\
2.3 & \pm 6.1 \\
7.1 & \pm 13.1 \\
& - \\
& -\end{aligned}$ \\
\hline $\begin{array}{l}\text { REDUCED OSSIFICATION : } \\
\text { Pelvis } \\
\text { Sternebra } \\
\text { Vertebral Centra }\end{array}$ & $\begin{array}{c}- \\
33.8 \pm 27.8 \\
0.9 \pm 3.2\end{array}$ & 25.8 & $\begin{array}{l}\overline{-} \\
\pm \\
-\end{array}$ & $\begin{array}{r}1.2 \pm 4.1 \\
19.8 \pm 19.9 \\
1.0 \pm 3.6\end{array}$ & $\begin{array}{c}0.6 \pm 2.4 \\
32.4 \pm 29.0 \\
-\end{array}$ \\
\hline TOTAL VARIATIONS & $89.1 \pm 10.7$ & 85.1 & \pm 18.0 & $87.2 \pm 14.1$ & $89.7 \pm 10.6$ \\
\hline
\end{tabular}


APPENDIX A

CHEMISTRY MONITORING NARRATIVE AND DATA

BNW Bulk Chemical Reanalysis Report Test Chemical Characterization, Storage, Usage and Disposition

Test Chemical Concentration Monitoring Test Chemical Stability in the Exposure system GC/MS Analysis of Chloroprene and Its Dimer Products 
BNW Bulk Chemical Reanalysis Report

A. 3 
COMPOOND :

CAS:

IOT*

VENDOR IOT

APPEARANCE :

RECEIPT DATE:

ANALYSIS PERIOD:

STORAGE TEMPERATURE:

SAYPLE SUBMITTAL DATE:

SAMPIE ANALYSIS DATE:

ANALYSIS PROCEDURE:

NOTEBOOK REFERENCE:

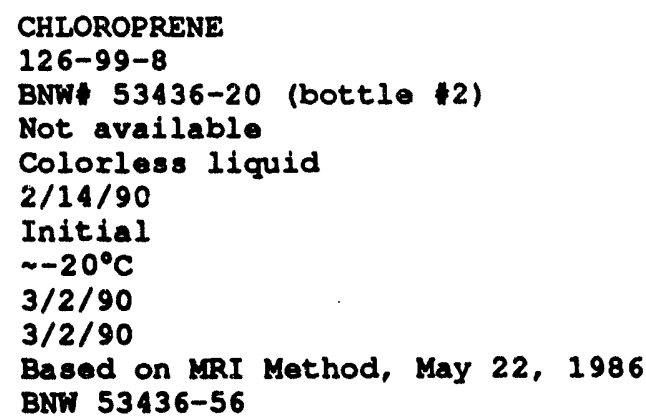

ASSAY:

$3 / 9 / 90$

Gas chromatography used a DB-5 capillary column, $30 \mathrm{~m} \times 0.53 \mathrm{~mm}$

$1.5 \mu$ film thickness for purity by area percent.

Parameters included initial temperature of $35^{\circ} \mathrm{C}$ for 5 minutes with a

program rate of $10^{\circ} \mathrm{C} / \mathrm{minute}$ and a final temperature of $275^{\circ} \mathrm{C}$ for 5 minutes.

Inst rument: HP 5890

RESULTS:

BOTK PURTTY

AVIBAGS

RSD

98.498

98.518

98.528

98.518

0.018

Chloroprene luted at -3.29 minutes.

Sample injections were allowed to run 30 minutes past chloroprene peak to determine if any impurities were present. Chlorobutene and cis/trans-1chlorobutadiene constitute the major impurities (about 0.6 and 0.18 respectively). The major dimer eluded at 217.06 minutes with 0.248 of total chloroprene sample area.

IDENTITY: Infrared spectroscopy used silver chloride plates scanned from $3 / 2 / 90$ $4000 \mathrm{~cm}-1$ to $600 \mathrm{~cm}-1$. Instrument: Beckman Aculab 8

RESUITS: The spectrum was similar to copy of MRI spectrum.

PEROXIDES: A Fisher Computer Aided Titrimeter was utilized for peroxide analysis. $3 / 7 / 90$

\begin{tabular}{lll}
$\begin{array}{l}\text { Peroxide } \\
\text { Meg/Ka }\end{array}$ & $\begin{array}{l}\text { Average } \\
\text { Yea/Kg }\end{array}$ & BSD \\
\hline 0.08 & & \\
0.0 .5 & 0.06 & 34.88
\end{tabular}

Conclusion: Infrared spectroscopy confirms the identity of lot BNW\# 53436-20 (bottle 2). Gas chromatography shows this lot to be 98.518 pure by area percent with the major dimer constituting 0.24 of the total chloroprene sample area. The peroxide is within the limit of $1.0 \mathrm{Meg} / \mathrm{Kg}$. Chloroprene lot BNW533436-20 is acceptable for use.

Signature of
Technician:
Reviewed by: Date: $3-10-90$


Test Chemical Characterization, Storage, Usage and Disposition 


\section{2IST CHEAICAL CHARACTERIZATION, STORAGE, OSAGE AND DISPOSITION}

\section{A. Test Material Recelpt, storage and Veage}

1. Recuipt

Chloroprene test material was recelved from Denka Chemical Corporation, Houston, Texas 77017. Twelve, four-liter bottles containing a total of $\sim 46 \mathrm{~kg}$ of chloroprene [BNW Lot No. 53436-20, bottles 1 through 12] were received $2 / 14 / 90$. The test material was inhibited with $\sim 0.18$ each of phenothiazine and t-butylcatechol at Denka. The material was shipped at ambient temperature.

\section{Storage Conditioas}

The bulk chemical was stored in its original container at $\sim-20^{\circ} \mathrm{C}$ under a nitrogen headspace in the Chemical Storage and Transfer Facility adjacent to the LSL-II laboratory.

\section{Vaage}

An average of $0.6 \mathrm{~kg}$ chloroprene was consumed per exposure day. The study required about $15 \mathrm{~kg}$ for animal exposure.

\section{Transfer Procedures}

A one liter evaporation flask was filled (under a nitrogen blanket) once at the beginning of each day with $\sim 600$ grams of chloroprene from one of the original four-liter glass containers. The flask was kept at a positive nitrogen atmosphere to prevent the introduction of air to the system during the generation period.

\section{Waste Disposal}

Excess used test material was transferred to a labelled glass bottle containing $\sim 2 \mathrm{~g}$ each of phenothiazine and tert-butylcatechol in $\sim 1$ liter of xylene. Full bottles were stored at LSL-II until disposed of by the BNW Waste Management and Environmental Compliance Group.

\section{Surplus Disposal}

Surplus test material (e.g., unused bulk material) will be disposed of by the BNW Waste Management and Environmental Compliance Group at the end of all studies currently planned unless otherwise instructed.

\section{B. Chomical Malysis}

\section{Inalyo1s at Mldwest Rasarch Institute}

Chemical characterization of chloroprene test material (supplied by Denka) was presented in the May 22, 1986 MRI Report and provides an indication of test material purity to be expected. Bulk chemical (BNW Lot No. 12103-4-1, MRI Batch No. 01) was identified as chloroprene. Cumulative analytical data indicated a purity of approximately 968 as received by MRI. 
The observed spectra by infrared, ultraviolet/visible and nuclear magnetic resonance analyses were also consistent with literature references.

Elemental analysis results for carbon and hydrogen were in agreement with theoretical values. Karl Fischer titrimetry indicated less than 0.018 water. Analysis for peroxide by titration indicated $1.96 \pm 0.06 \mathrm{meg} / \mathrm{kg}$ of test materlal. Inhibitor (t-butylcatechol) was approximated to be present at 40 to $50 \mathrm{ppm}$. It is important to note that the present material is inhibited to $0.18(1000 \mathrm{ppm})$ with t-butylcatechol and phenothiazine.

Thin-layer chromatographic analysis indicated a mafor spot only. Gas chromatographic analyses by two systems each indicated impuritles with total peak areas of 0.96 and 3.308 relat 1 ve to the major peak area. Five impurities were tentatively Identified as three chloroprene dimers, a chlorobutene, and a chloroprene isomer by gas chromatography/mass spect rometry.

An accelerated stability study $\left(55^{\circ} \mathrm{C}\right.$ for up to 6 hours) indicated that in addition to dimerization ( 628 increase in dimer content), significant polymerization also occurs.

An unopened bottle of the bulk chemical was shipped to Research Triangle Institute on 2/20/90 for chemical characterization. The results of this assay were not available at the time of report preparation.

\section{Ranalyeis at Battelle Paciele Horthwest Laboratorlea}

The MRI recommended procedure, based on the May 22, MRI Special Report "Chemical Characterization of Chloroprene" was implemented as BNW SOP* ØB-AC3A14. Bulk chemical purity was monitored upon receipt and at $16 \pm 2$ week intervals during storage and use at BNW. The bulk chemical reanalysis included an analysis within thirty days prior to the start of the study. Subsequent reanalysis of bulk material were performed using gas chromatography to determine purity ( 8 ) of chloroprene and dimer content. Analysis to determine peroxide content of each bottle was performed within 6 weeks prior to use as generation material.

Identity of bulk chemical was confirmed during initial bulk analysis by infrared spectroscopy. Bulk purity analysis was performed by gas chromatography using a DB-5 capillary column, $30 \mathrm{~m} \times 0.53 \mathrm{~mm} 1 . d$. fused silica, $1.5 \mu \mathrm{film}$ thickness. Concentrations of phenothiazine and t-butylcatechol (inhibitors) were verified upon receipt by gas chromatography. Test material BNW Lot No. 53436-20 bottle $\# 2$ was $98.51 \%$ pure upon receipt and was found to contain $-0.06 \mathrm{meq} / \mathrm{kg}$ of peroxides at the time of the analysis. The predominate dimer isomer was present at $\sim 0.24 \%$. Chlorobutene and 1chlorobutadiene were present at $\sim 0.6$ and 0.18 , respectively. Thus, bulk purity was similar to that observed by BNW from past experience with chloroprene test material. However, the concentration of dimer was about 2 to 3 times greater than seen in the earlier repeated dose and subchronic studies performed at BNW. The greater dimer content may have resulted from shipment at amblent temperature. The earlier shipments were via refrigerated freight. 
Test Chemical Concentration Monitoring 


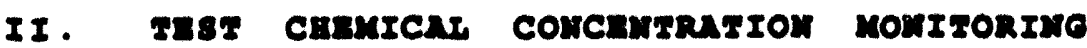

\section{A. Monitoring syaten Desoription}

Chamber and room concentrations of chloroprene were determined using an onIIne Hewlett-Packard Model 5890 gas chromatograph equipped with a tam Ionization detector operated at $250^{\circ} \mathrm{C}$. A $1 / 8$ inch $0 . D$. $x \sim 1$ ft. nickel column packed with 18981000 on $60 / 80$ Carbopack B was used to separate chloroprene from other components. The carrier gas was nitrogen at a flow rate of $\sim 30$ $\mathrm{ml} / \mathrm{min}$. The column was malntained lsothermally at $120^{\circ} \mathrm{C}$. Under these conditions, chloroprene exhiblted a retention time of 0.66 minutes.

An oven-mounted, 12-port stream select valve constructed of Hastelloy-C provided the interiace between the on-line gas chromatograph and the exposure chambers, the control chambers, the exposure room, the on-line standard and a flitered air blank. This valve directed a continuous stream of sampled atmosphere to a $1.0 \mathrm{ml}$ nickel sample loop outfitted with an oven-mounted sampling valve (Hastelloy-C). Automatic switching of the stream select valve allowed access to all test chambers, the room, a blank and the on-ilne standard. A schematic diagram of the chamber concentration monitoring system is shown in Figure A.1. Individual 1/4-inch Tefion sample lines (also used for monitoring relative humidity) lead from each chamber to a position close to the on-line monitor. These sample 11 nes had a flow of 2 to $2.51 / \mathrm{min}$. reed from each of these lines were 1/16-inch Teflon IInes, 4 feet in length, which lead to each port of the stream select valve. These ilnes were purged at $-30 \mathrm{ml} / \mathrm{min}$ for $\sim 2.6 \mathrm{~min}$ prior to sample injection.

Data were transferred from the HP5890 chromatographic Integrator to an HP85B computer. The HP85B computer remotely controlled the selection of the correct sample stream and the operation of the monitor. Each analysis required about 3 minutes. Thus, all chamber positions, the room, the blank, and the on-line standard were monitored approximately every 36 minutes. The equation of the calibration curve was contained in the HP85B and was applied to the data transmitted by the on-line GC monitor. The HP85B also accumulated and printed the sample values until all 12 ports of the stream select valve had been measured. These values were then sent to the executive computer for printing and storage. Each value accumulated by the HP85B was compared with limit values for that particular location. If the value was beyond the control limits, the HP85B immediately sent the information to the executive computer which took the appropriate action.

As described in the section that follows, the monitor was calibrated against gravimetrically prepared standards. The gravimetric standards were related to the on-line monitor through quantitative analysis of grab samples taken from exposure chambers simultaneously sampled by the on-line GC while the on-line GC was kept in normal rotation.

Additionally, the operation of the chamber monitor was checked throughout the day against an on-line standard. This check provided a measure of day-to-day instrument drift. Additional calibration checks by grab sampling were performed to check the monitor calibration when drift of the on-iine standard response factor was detected. 
Dally operating procedures for the concentration monitoring system are contalned in SOP $0 \mathrm{~B}-\mathrm{AC}-3 \mathrm{~B} 1 \mathrm{~N}$ and $\mathrm{BB}-\mathrm{BE}-3 \mathrm{~B} 2 \mathrm{~V}$.

\section{Caldbration or the on-rine Mondtor}

The relationshlp between the on-line GC response and the concentration of chlorop:rene in the chamber was established from independent analysis of chamber grab samples taken directly from the exposure chambers during a routine exposure period. The calibration of the on-ilne monitor was established by correlation of the on-ilne monitor peak area lat the time of grab sampling) againgt indopendont moasurement of chamber concentration (analysis of chamber grab samples). The normal dynamic operation of the monitor was not disrupted during collection of these grab samples.

Grab samples were obtalned by collecting chloroprene in bubblers contalning 20 ml of dimethylformamide (DNF). Known volumes of chamber atmosphere from each chamber were collected using a calibrated critlcal oriflce controlled sampler at a constant flow rate of approximately $1.0 \mathrm{l} / \mathrm{min}$. Internal standard solution was added to each bubbler after sample collection to correct for any volume change in the DMF, variations in infection volume, and instrument drift. Breakthrough of chloroprene was determined with a back-up bubbler linked in serles to the primary bubbler used to sample one of the $175 \mathrm{ppm}$ exposure chambers. Typlcal breakthrough for a 2 liter sample was approximately 5t. Total mass of chloroprene collected in the primary bubblers was corrected for breakthrough.

Grab samples and standards were analyzed on an off-line Hewlett-packard gas chromatograph equipped with a flame lonization detector operated at $250^{\circ} \mathrm{C}$ and a glass column packed with 10 Carbowax $20 \mathrm{M}$ on 80/100 Chromasorb. One microliter sample volumes were injected using an on-column configuration and an automatic liquid sampler. The initial oven temperature $\left(70^{\circ} \mathrm{C}\right)$ was held lsothermally for 3 minutes. The temperature was then ramped at $10^{\circ} \mathrm{C} / \mathrm{minute}$ to $150^{\circ} \mathrm{C}$ and held tor 20 minutes. Chloroprene luted at -1.9 minutes and the dodecane internal standard at $\sim 8.0$ minutes using these parameters.

Gravimetrically prepared standard solutions of chloroprene in DMF were used to calibrate the off-line GC used to quantitate chloroprene collected by grab sampling. A set of four standards was run for each analysis session. The concentration range of the standards bracketed the expected concentration range of the chamber grab samples. Two independently weighed stock solutions were used each $t$ im the standard series was prepared. The preparation of dual stock solutions helped "flag" any weighing errors. A linear callbration curve with a zero (Figure A.2) intercept was used for the on-line monitor determination of chloroprene concentrations in the exposure chambers, room, air blank and on-line standard.

\section{On-Iine standard}

An on-1ine atandard of chloroprene was used to check instrument drift throughout each exposuxe day. The on-line standard of chloroprene in nitrogen gave reproducible day-to-day results and within day results having relative standard deviations of $<18$ as shown in the table in section $E$. The data used to determine the reproducibility of the on-line standard was taken from three days each having 6 hours of continuous generation.

The chloroprene standard was monitored every 12 th sample throughout the exposure period. It was also checked before the start of each exposure day. The measured concentration for the standard was required to be within $\pm 10 \mathrm{r}$ of 


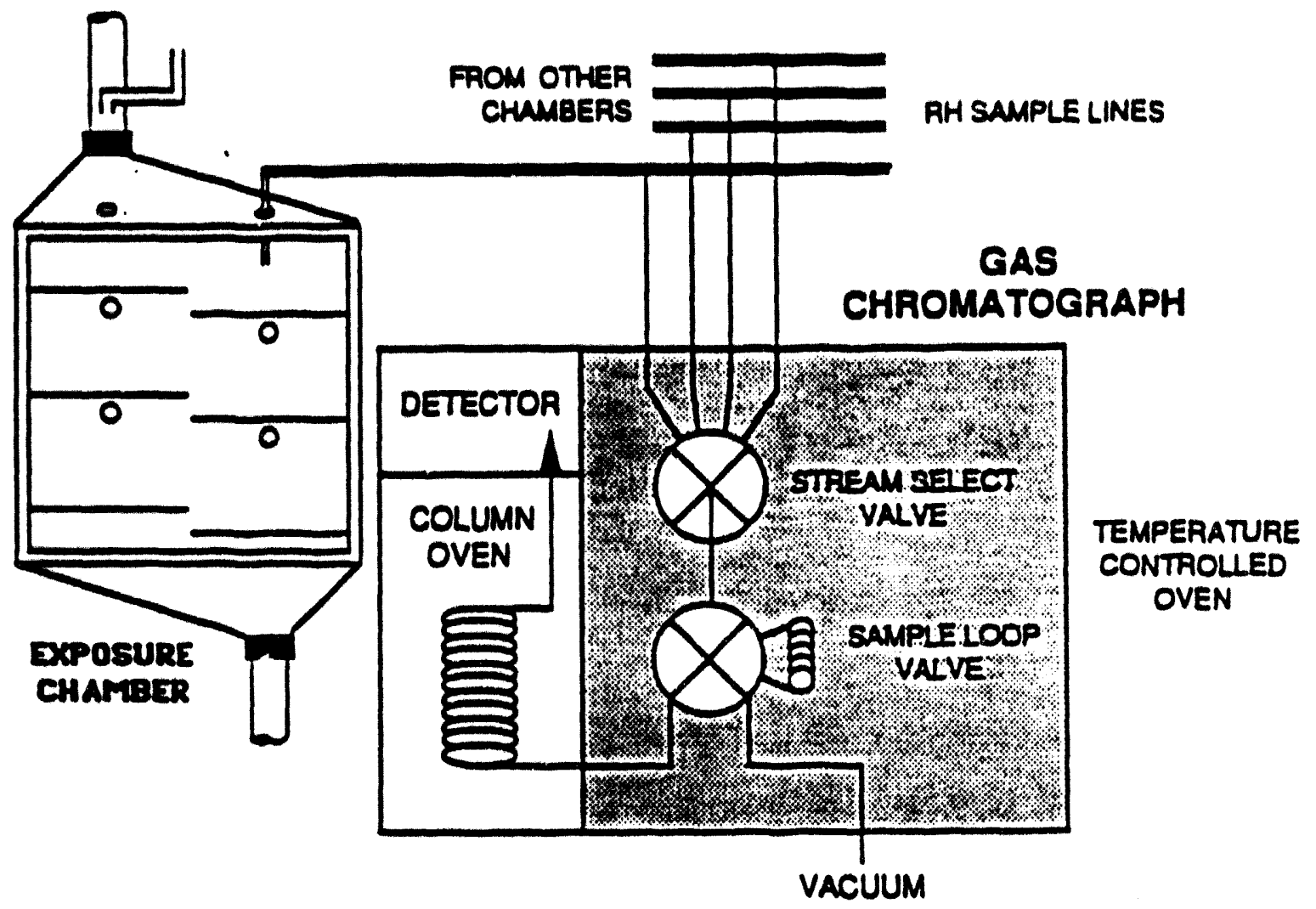

\begin{tabular}{|cl|}
\hline $\begin{array}{c}\text { STREAM SELECT PORT } \\
\text { ASSIGNMENTS }\end{array}$ \\
1 & Filtered Air \\
2 & $175 \mathrm{ppm} \mathrm{A}$ \\
3 & $175 \mathrm{ppm} \mathrm{B}$ \\
4 & $40 \mathrm{ppm} \mathrm{A}$ \\
5 & $40 \mathrm{ppm} \mathrm{B}$ \\
6 & $10 \mathrm{ppm} \mathrm{A}$ \\
7 & $10 \mathrm{ppm} \mathrm{B}$ \\
8 & Filtered Air \\
9 & Room \\
10 & 0 ppm A \\
11 & 0 ppm B \\
12 & Standard Gas \\
\end{tabular}

EIGURE_A. Chloroprene Trhalation Developmental Toxicity study: Diagram of the Exposure Chamber Concentration Monitoring System. 


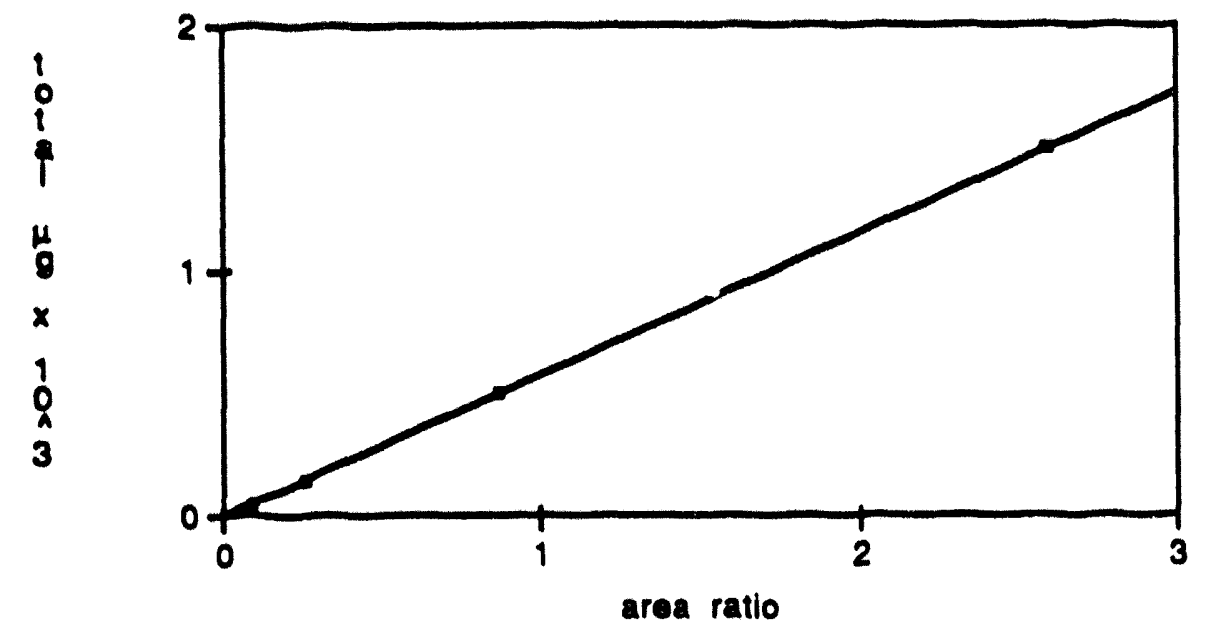

\begin{tabular}{ccccc}
$\begin{array}{c}\text { Variable } \\
\text { Name }\end{array}$ & Coefficient & $\begin{array}{c}\text { Std. Err. } \\
\text { Estimate }\end{array}$ & Statistic & Prob $>1$ \\
\hline area ratio & $5.7480+2$ & 3.4140 .1 & $1.6840+3$ & 2.930 .18
\end{tabular}

Data File: Chloroprene Standards 3/5/90

\begin{tabular}{lrcccc} 
Source & $\begin{array}{c}\text { Sum of } \\
\text { Squares }\end{array}$ & $\begin{array}{c}\text { Deg. of } \\
\text { Froedom }\end{array}$ & $\begin{array}{c}\text { Moan } \\
\text { Squares }\end{array}$ & F.Ratio & Prob>F \\
\hline Model & $2.6080+6$ & 1 & $2.608 \theta+6$ & $1.480 \theta+62.080-17$ \\
Error & $1.057 \theta+1$ & 6 & $1.762 \theta+0$ & \\
\hline Total & $2.608 \theta+6$ & 7 & & &
\end{tabular}

$\begin{array}{ll}\text { Coefficient of Determination (R^2) } & 1.000 \theta+0 \\ \text { Adjusted Coefficient (R^2) } & 1.000 \theta+0 \\ \text { Coefficient of Correlation (R) } & 1.000 \theta+0 \\ \text { Standard Error of Estimate } & 1.327 \theta+0 \\ \text { Durbin-Watson Statistic } & 1.728 \theta+0\end{array}$

EIGURE A.2. Chloroprene Inhalation Developmental Toxicity Study: Calibration Curve for Gravimetrically Prepared standards. 
the assigned target value before any exposure could begin without consultation with the exposure control task leader. During the course of the exposure, if the on-Iine standard was within \pm 5 t of the target value, no change in calibration was required. If the on-line standard was beyond \pm 5 of its assigned target, the chemist was informed immediately by an exposure opocialist. Additional grab sampling was initlated by the chemist on a case by case basis when drift in the on-line standard was between $\pm 5-108$. A drift of 108 or more required high priority recalibration of the on-line monitor by grab sampling.

\section{Detection IIItse}

\section{Daslattion of mi, mar, ma and ar}

The Minimum Detectable IImit (MDL) is defined as the lowest concentration of analyte that can be reliably detected. Minimum Quantifiable IImit (MQL) is defined as that concentration of analyte sufficiently in excess of MDL such that a numerical value can be assigned to the analyte. MDL and MQL are theoretical values which we normally have based on a blank value exhibited by the on-line monitor. When a blank value is observed, MDL and MQL are established as 3 and 10 times the standard deviation of the blank value. However, for the IRT chloroprene prestart study a zero value was obtained for blank masurements. In the absence of a finite blank value the lowest concentration of chloroprene that could be practlcally maintained in an exposure chamber was used to determine MDL and MQL. This was accomplished as described in the section on determination of MLQ.

The Minimum Iimit of Quantitation (MLQ) is defined as the lowest concentration of analyte that can rellably be assigned a numerical value with an RSD of $\leq 10$ z and a relative error of S108. Therefore, to determine MLQ, grab sampling must be performed to allow a comparison between the on-line monitor determination and a reference method assumed to yield the true value for chloroprene concentration.

The Quantitation Iimit (QL) is defined as the concentration below which acceptable quantitation cannot be achieved. The quantitation limit is usually defined the same as the MLQ. However, in some cases where MLQ is near the lowest exposure concentration, the QL may be assigned the same value as MQL. Measured values below the QL are not normally reported in dally summaries.

\section{Determination of uDL and MRI}

Analysis of the charcoal filtered air blank by the on line monitor while the stream select valve was in normal rotation falled to detect chloroprene. To determine YDL and MQL, the precision measurements were performed by monitoring a chamber with a low chloroprene concentration. A standard deviation of 188 area counts was found for a chloroprene concentration measured at 0.88 ppm by the on-line monitor $(0.73 \mathrm{ppm}$ by grab sampling). MDL and MQL are set at three and ten times the standard deviation expressed in concentration units. On this basis MDL and MQL were 0.06 and $0.20 \mathrm{ppm}$ respectively.

\section{Detexnination of urg}

\section{a . Experimental}

Sampling to determine MLQ was done by taking grab samples with DMF filled bubblers. The bubbler samples were analyzed on an off-line GC calibrated using gravimetrically prepared chloroprene standards. Each standard and 
bubbler had a constart amount of internal standard added. The purpose of the Internal standard was to compensate for any fluctuations in sample volume and Infection volume. Grab samples were taken from the low concentration chamber. The vapor delivery rate into the exposure chamber was reduced so that concentrations of about $10,5,2$ and $1 \mathrm{ppm}$ could be achleved.

Gravimetric standards were prepared so that the standards bracketed the expected concentration of chloroprene to be sampled at each level. The standards and samples were analyzed by GC using procedure similar to that used to analyze grab samples acquired from the chamber for purposes of on-Iine monitor callbration.

\section{b. Resulte}

The off-line GC showed good sensitivity and precision for the low gravimetric standard. The relative response factor for the standards was used to determine the amount of chloroprene collected in the bubblers. Based upon the criteria that MIQ is the concentration of analyte for which the relative standard deviation $18 \leq 108$ and the relative error is also $\leq 108$, MLQ was set to $5 \mathrm{ppm}$ using the data shown in rable A.1. The established MLQ was 508 of the low exposure chambex concentration.

\section{Deterandation or Qr}

Since the established MLQ of $5 \mathrm{ppm}$ was 508 of the low exposure chamber concentration, the QI was set to $0.2 \mathrm{ppm}$ which was the MQL.

\section{E. Preolelon, Ilnearity and Nbsolute Racovery of the On-IIne} Mondtor

Precision of the on-line monitor was estimated from measurements of the on-line standard sampled from each of the 12 sample valve ports. These measurements had a relative standard deviation of 0.58 (N-12). In addition, in order to estimate precision for the on-line monitor at each concentration level, repeated measurements were made from each exposure chamber (at the original target concentrations). The following values were obtalned:

$\begin{array}{rcccc}\text { Lecation } & \begin{array}{c}\text { Number of } \\ \text { Measurements }\end{array} & \text { N N Mean (pom) } & \begin{array}{c}\text { Standard } \\ \text { Deviation (SD) }\end{array} & \begin{array}{c}\text { Relative Standa } \\ \text { Deviation (R }\end{array} \\ 125 \text { ppm chamber } & 5 & 117.19 & 0.14 & 0.128 \\ 125 \text { ppm chamber } & 5 & 122.73 & 0.11 & 0.098 \\ 25 \text { ppm chamber } & 5 & 23.03 & 0.09 & 0.408 \\ 25 \text { ppm chamber } & 5 & 24.61 & 0.09 & 0.388 \\ 5 \text { ppm chamber } & 5 & 4.81 & 0.01 & 0.278 \\ 5 \text { ppm chamber } & 5 & 5.00 & 0.01 & 0.168\end{array}$


TaBreaf. Chloroprene Inhalation Developmental Toxicity Study: Chloroprene MLQ Determination Results.

$\begin{array}{lccccc}\begin{array}{l}\text { Grab Conc. } \\ \text { Dpm }\end{array} & \begin{array}{c}\text { On-Line Monitor } \\ \text { Conc (pom) }\end{array} & \begin{array}{c}\text { Error } \\ \text { (pom) }\end{array} & \begin{array}{c}\text { Relative } \\ \text { Error }\end{array} & \begin{array}{c}\text { Monitor } \\ \text { Response }\end{array} & \begin{array}{c}\text { Monitor } \\ \text { (BRSD) }\end{array} \\ 10.33 & 10.08 & 0.25 & 2.48 & 96,411 & 1.1 \\ 5.61 & 5.19 & 0.42 & 7.58 & 49,598 & 0.5 \\ 2.43 & 1.88 & 0.55 & 22.68 & 18,075 & 0.4 \\ 1.21 & 0.86 & 0.35 & 28.98 & 8,390 & 2.2\end{array}$


The precision results reported above for the measurements made on the chamber concentrations were affected by both variations in test material concentration in the chamber and instrument imprecision of the on-line monitor. However, the overall precision was adequate to demonstrate adequate instrument precision at each sampling point. The excellent precision seen for the onine standard also indicated good reproducibility for the on-line monitor. Performance of these tests at the initial target concentrations does not compromise this validation of instrument precision. That is, instrumental precision should not change due to the difference in concentration between the initial and revised dose levels.

Linearity of the on-line monitor was determined by calibrating the on-line monitor against a gravimetrically calibrated GC (see "Calibration of the on-Line Monitor" section). The on-line monitor calibration was linear through the range of interest.

Absolute recovery of the bubbler grab sampling method was confirmed by obtaining grab samples with backup bubblers from each of the exposure chambers. An average breakthrough of less than 58 was detected. The determination of chamber concentration by analysis of grab samples was corrected to account for breakthrough.

\section{Monitoring Lor Chloroprene in Bullding Erhaust}

Effluent from the exposure chambers and the exposure generation system was diluted with the exhaust air of the entire ISI-II building prior to exhausting from the building stack. The expected concentration of chloroprene in the bullding exhaust was less than $0.11 \mathrm{ppm}$. The chloroprene concentration in the exhaust of the building was determined using grab sampling employing standard charcoal gas sampling tubes and desorbed with DMF. Good recovery and trapping of chloroprene using charcoal tubes was shown during the chemical stability studies. Three samples were collected. from different locations within the exhaust stream. The average building exhaust concentration of chloroprene was shown to be $0.09 \mathrm{ppm}$ with a SD of $0.01 \mathrm{ppm}$ for the three samples. 
Test Chemical Stability in the Exposure System 


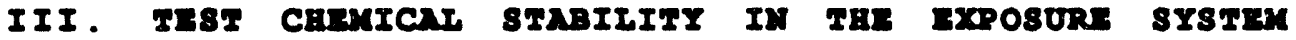

\section{A. Int roduction}

In exposure systems designed to generate organic test chemical vapors, BNW frequently employs a common approach to the identification and analysis of potential impurities in the exposure atmosphere. First, the generation system can cause degradation of the test chemical when high temperatures must be employed to vaporize the required amount of test chemical into the exposure system. This can result in thermal decomposition or polymerization of the test chemical. Moreover, the products of such thermal decomposition or polymerization may also be subject to further thermal degradation forming other volatile components. Secondly, volatile impurities in the test chemical are evaluated as possible contaminants of the generated test atmosphere. This source of contamination can be especially significant when a test chemical impurity exhibits a vapor pressure which is substantially higher than that of the test chemical. Relative to the test material, concentrations of highly volatile impurities can become enriched in the exposure atmosphere, even when present in the original test chemical at low concentrations.

Chloroprene is quite reactive and known to polymerize in the vapor generator. The test material was fortified with inhibitors to limit polymerization and reduce peroxide formation. However, the generator design provided for removal of less volatile inhibitors and degradation products. Thus, the details of the generator design and operation are a critical ingredient to the discussion of test material stability and the composition of the atmosphere which was presented to the animals. Generator design is discussed elsewhere, however in brief: achievement of exposure levels was obtained by passing a nitrogen stream over a pool of heated chloroprene. The nitrogen stream exited the generator through a refluxing condenser and was directed down a distribution ine. This refluxing action removed impurities and degradation products less volatile than chloroprene from the generator effluent. A portion of the distribution line flow was directed to each chamber to provide the required concentration.

Chloroprene undergoes both dimerization and rapid reaction with oxygen to form peroxides. Chloroprene peroxides serve as a free radical source and can initiate runaway exothermic polymerization. Peroxide formation is reduced by the use of tert-butylcatechol (TBC), which acts as an oxygen scavenger. Polymerization, once initiated, is limited by inhibition with phenothiazine, a free radical scavenger. The chloroprene used in this study was inhibited at the 0.18 level with both TBC and phenothiazine. Maintenance of a nitrogen blanket and the use of inhibitors keep the formation of peroxides and polymer to a minimum. These measures were effective in preventing polymer formation during the repeated dose and subchronic studies performed earlier at BNW.

However, despite the ability of the measures outlined above to reduce peroxide and polymer formation, it is important to recognize that the rate of dimer formation is cependent upon temperature and is not influenced by the presence of inhibitors. It is reported that the rate of dimer formation is about $0.35 \%$ per day at room temperature and about 18 per day at the boiling point of chloroprene (Kirk-Othmer, 1979, Encyclopedia of Chemical Technology, 3rd Edition, vol 5). Thus, substantial amounts of dimer were formed in the vapor generator evaporation flask.

The literature (Stewart, CA, 1971, I.Amer. Chem.Soc. 93: 4815-4821) reports the elution pattern for a total of six dimer lsomers on a SE-30 
column, two of the dimer isomers co-eluted (11-chloro-4-(1chlorovinyl)cyclohexene and 2-chloro-4-(1-chlorovinyl)cyclohexene). The SE-30 column employed by stewart is a dimethyl silicon stationary phase of relatively low polarity (2 ft SE-30, 20 on Dlaport $S$ support). An infection port temperature of $150^{\circ} \mathrm{C}$ and a FID temperature of $175^{\circ} \mathrm{C}$ were used to "minimize thermal destruction of sensitive compounds." At both $\sim 20^{\circ} \mathrm{C}$ and at $60^{\circ} \mathrm{C}$ more trans-1,2-dichloro-1,2-divinylcyclobutane was formed than any other dimer isomers (from 30 to 428 of the total dimer content, depending upon temperature and extent of conversion with lower amounts formed at $60^{\circ} \mathrm{C}$ ). The dimer isomer formed in the greatest quantity demonstrated the shortest chromatographic retention time. Stewart also concluded that the six isomers reported represent the predominate products formed at room temperature dimerization, "it is believed that no other products are present in room temperature dimerization in an amount greater than 18 of the mixture." Three of the dimer isomers are present in about equal amounts. The remaining divinylcyclobutane adduct (cis-1,2-dichloro-4-vinylcyclobutane) readily undergoes rearrangement to form 1,6-dichloro-1,5-cyclooctadiene; none of this rearrangement product is formed directly by initial monomer dimerization. At higher temperatures the rearrangement and dechlorination of other dimers becomes significant with formation of dehydrochlorination products.

In the repeated dose and subchronic studies BNW found that dimer concentration In the chambers was about 0.018 of the chloroprene concentration, even though the concentration of dimer rose to about $6 \%$ in the evaporation flask by the end of the day. This is a result of the refluxing nature of the vapc:generator and the wide differences in boiling point between chloroprene and the various dimer 1somers, 1.e. fractionation in the generator purifies the chloroprene vapor.

A significant increase in the dimer concentration in the distribution line was not expected to occur unless the condenser malfunctioned (resulting in loss of separating capability), or if the contents of the generator flask became quite depleted in chloroprene and significantly enriched in dimer. Taken to the extreme, once all of the monomer is "distilled over" then the less volatile dimer isomers will exhibit greater partial pressures. Thus, it was important to run the generator so that an adequate "heel" of chloroprene remained at the end of each generation day. BNW's daily operation procedure for the generator was designed to ensure that dimer concentration was not excessively enriched at the end of a particular exposure day.

Two measures were implemented to minimize chamber dimer concentrations. First the generator was charged with enough chloroprene to ensure that about 150 grams remained at the end of the exposure day. If the start of the exposure was excessively delayed, the generator was shut down and additional

chloroprene added to the flask. The other measure which ensured that a low animal exposure to dimer was maintained was the use of the dedicated on-line monitor to determine test material purity throughout each exposure day. BNW implemented a second on-line gas chromatographic monitor to repeatedly sample the distribution line throughout the exposure day. A longer GC run time was required than used on the on-line chamber monitoring GC in order that both very volatile (1,3-butadiene and 3-buten-1-yne) and less volatile isomers (such as dimer) could both be resolved. In the event that some inadvertent change in the operation of the generator increased the dimer content of the generator output, then the on-line purity determination allowed the exposure personnel to shut down the vapor generator.

In surmary, the majority of the impurities expected in the test chemical exhibit boiling points greater than ehloroprene, and were thus not expected to 
occur in measurable quantities in the exposure atmospheres. Of the known impurities in chloroprene, only 1,3-butadiene and 3-buten-1-yne were subject to enrichment from selective vaporization in the generated exposure

atmospheres. These impurities were reduced to less than $0.5 \%$ of the generated vapor before animal exposure was allowed to proceed. Most of the volatile products of thermal decomposition are also less volatile than chloroprene and were expected to remain in the generator reservoir. Impurities present in the bulk test material that are similar in volatility to chloroprene and could not be removed by this method of generation include chlorobutene and cis/trans 1 chlorobutadiene.

Studies of the chemical stability of chloroprene in the generator reservoir, distribution line and exposure chambers were conducted in both empty and occupied chambers. The chamber samples were collected within the first and last hour of the generation day. The characterization of chemical stability included use of gas chromatography mass spectrometry (GC/MS) to identify dimer and other organic impurities in an aged sample of test material and gas chromatography to measure the amounts of impurities present in the chambers, distribution Iine and generator flask samples obtained at the beginning and end of the day. During the prestart, peroxide content was determined in test material from the generation flask at the beginning and end of the exposure day and measurement of inhibitors in samples acquired from the distribution line was accomplished by gas chromatography. In addition, an on-line GC method was implemented to measure the purity of the chloroprene vapor in the distribution line.

\section{B. Ixperimetal Methodology and Reaults}

\section{Determination of Chloroprene Purity in the Generation Pagk.}

For exposure generation, a one liter evaporation flask was filled (under a nitrogen blanket) once at the beginning of each exposure day with $\sim 530 \mathrm{grams}$ of chloroprene from one of the original 4-liter glass containers. Stability of chloroprene in the generator generation flask was demonstrated by determining the purity of chloroprene in the generation flask over the time period that the material was contained in the generation flask during normal study operation.

Purity analysis and peroxide content of the generation flask samples was accomplished using the same methods used for the routine bulk chemical reanalysis of chloroprene. A chloroprene sample was removed from the generation flask immediately after filling at the beginning of the day. An additional chloroprene sample was collected at the end of the exposure period.

The purity assay of samples from the generation flask was performed on a HP 5890 GC equipped with a FID and a DB-5 capillary column, $30 \mathrm{~m} \times 0.53 \mathrm{~mm} 1 . \mathrm{d}$. fused silica, $1.5 \mu$ film thickness. The peroxide content of the generation flask samples was determined by potentiometric titration of samples with standardized sodium thiosulfate. Complete instrument parameters can be found in SOP DB-AC-3A14 "Bulk Analysis of Chloroprene".

The chloroprene in the generation flask immediately after filling was determined to be $98.5 \%$ pure by area percent. The area percent purity of the material at the end of generation on the same day was determined to be $90.6 \%$, the most concentrated dimer isomer was present at about 28 while the total dimer content was about 5-6\%. The peroxide content in the sample collected 
immediately after filling was $0.05 \mathrm{meq} / \mathrm{kg}$. The peroxide content in the sample collected at the end of generation on the same day was $0.14 \mathrm{meq} / \mathrm{kg}$.

\section{Determination of 4-TBC and Phonothiazine in the Diatribution Iina}

The chloroprene exposure material contained $\sim 1,000$ ppm 4-tertbutylcatechol (4TBC) as an anti-oxidant and $\sim 1,000 \mathrm{ppm}$ phenothiazine as an inhibitor to polymer formation. The design of the generation system and the fact that 4TBC and phenothiazine are much less volatile than chloroprene ensured that 4TBC and phenothiazine were not present at significant levels in the exposure atmosphere. Efficient removal of 4-TBC and phenothiazine from the vapor generator output was confirmed by GC analysis of samples from the distribution ine. Ten liter samples (containing about $3.3 \mathrm{~g}$ of chloroprene) were collected from the exposure distribution line in DMF filled bubblers within the first hour and the last hour of generation on a normal six hour generation day (samples acquired $3 / 15 / 90$; BNW NB $53436 \mathrm{pg} 92$ ).

Recovery of 4-TBC and phenothiazine was confirmed by spiking a bubbler with a known amount of 4-TBC and phenothiazine and pulling 10 liters of room air through the bubbler. The recovery study indicated no loss of 4-TBC or phenothiazine for a 10 liter air sample. The relative amount of inhibitor and detection limits were calculated relative to the sample size of chloroprene. The amount of chloroprene collected was calculated from the sample volume and the concentration of chloroprene present in the distribution line.

The samples were analyzed relative to gravimetrically prepared 4-TBC and phenothiazine standard solutions using a HP 5890 gas chromatograph with a FID and a 30 meter $\times 0.53$ umeter, 1.0 umeter film, DB-5 capillary column (J\&W). Azobenzene was used as an internal standard. The detector was operated at $275^{\circ} \mathrm{C}$. One microliter cool on-column infections were made with an initial oven temperature of $130^{\circ} \mathrm{C}$. The oven temperature was ramped to $250^{\circ} \mathrm{C}$ at $15^{\circ} \mathrm{C} / \mathrm{minute}$. See Table A.2 for complete GC conditions. A linear calibration curve was observed for both sets of standards.

No 4-TBC or phenothiazine were detected in these samples, the amounts were below that of the lowest concentration standard which produced a detectable response. Using the concentration of this standard lequivalent to $200 \mathrm{\mu g}$ in a bubbler sample) as a detection limit, the amount of 4-TBC and phenothiazine in the distribution line was shown to be less than 0.0068 (w/w) with respect to chloroprene. This equates to a distribution line concentration of $\sim 3 \mathrm{ppm}$ 4-TBC and phenothiazine. Allowing for the dilution of the distribution line to the exposure chambers, the concentration of 4-TBC and phenothiazine in the $175 \mathrm{ppm}$ chamber, $40 \mathrm{ppm}$ chamber and the $10 \mathrm{ppm}$ chamber would be less than 120 $\mathrm{ppb}, 30 \mathrm{ppb}$ and $6 \mathrm{ppb}$, respectively.

\section{Determination of Trace Contaminants or Degradation Products in the Ixposure Atmosphere and the Generation Reservo1x}

The possible presence of trace amounts of contaminants or degradation products was investigated in samples collected from various points in the exposure generation system. Analysis was by gas chromatography. Samples were collected with standard charcoal gas sampling tubes from the 10 and $175 \mathrm{ppm}$ exposure chambers and the distribution line during the first and last hours of generation on a normal six hour generation day during the study. The charcoal tubes were desorbed with dimethylformamide. Standards of suspected degradation product and impurities were not available. 
TABIE A.2. Chloroprene Inhalation Developmental Toxicity study: Gas Chromatographic Conditions Used for the Analysis of Chloroprene Distribution Iine Samples on $3 / 29 / 90$.

Gas Chromatograph:

Column:

Inttial Temperature:

Initial Time:

Rate:

Elnal Temperature:

Einal Time:

Detector Type:

Detector Temperature:

Injector:

Injection volume:
Hewlett Packard 5890A

30 meter $x 0.53 \mathrm{~mm}$ I.D. Megabore DB-5

1.0 Hmeter film (J W Scientific)

$130^{\circ} \mathrm{C}$

5.00 minutes

$15^{\circ} \mathrm{C} / \mathrm{minute}$

$250^{\circ} \mathrm{C}$

5:00 minutes

Elame Ionization

$275^{\circ} \mathrm{C}$

On-Column

$1 \mu 1$ 
Sample size was approximately 0.25 liters for the distribution line, 7 liters for $175 \mathrm{ppm}$ chamber and 10 liters for the $10 \mathrm{ppm}$ chamber. Breakthrough was found to be less than 18 for all charcoal samples by analysis of the secondary charcoal bed within the tubes. We assume that good trapping efficlency for lsomers such as dimex will be achieved when good trapping efficiency is observed for chloroprene. Comparison of a chloroprene standard with a chloroprene standard desorbed from charcoal shows a greatex than 90 average recovery ratio from the charcoal.

The samples were analyzed using a HP 5890 gas chromatograph with a FID and a 30 meter $x 0.53$ umeter, 1.5 umeter $111 \mathrm{~m}, \mathrm{DB}-5$ caplllary column (JCW). The detector was operated at $300^{\circ} \mathrm{C}$ and the infector was operated at $250^{\circ} \mathrm{C}$. Duplicate injections were made using a HP 7673A autosampler.

Assignment of dimer and Inhibitor peaks was verifled by $\mathrm{GC} / \mathrm{MS}$. The complete GC/MS report is located in this appendix. Compounds identifled as chlorobutene and 1-chlorobutadiene were detected in all samples at approximately 0.1 to 0.88 by area. No dimers or inhibitors were present in the distribution or chamber samples at greater than 0.018 of the total sample area. An unidentifled compound was noted in the samples collected during the first hour of generation from the distribution line and chamber samples on $3 / 29 / 90$ that was not observed in samples collected the last hour of the generation period from the chambers or distribution line. This compound exhibited a retention time of $\sim 15.6$ minutes compared to a retention time of $\sim 4.6$ minutes for chloroprene. In the samples acquired at the start of the generation day this compound was found to be present at between 0.002 and 0.138 by area relative to chloroprene. No additional compounds were noted with area response amounts of greater than 0.118 relative to chloroprene (percent of total peak area). Results of the analysis of distribution line and chamber samples are summarized in Table A.3.

\section{On-Iine Determination of Chloroprene Purity}

The purity of chloroprene vapor directed to the exposure chambers was monitored every exposure day using a separate HP5890 gas chromatograph (online purity GC). The on-line purity GC sampled an $\sim 10,000 \mathrm{ppm}$ st ream of chloroprene produced by an air dilution of the $\sim 90,000 \mathrm{ppm}$ generated chloroprene vapor. By sampling this high concentration stream of chloroprene relatively small amounts of impurities were easily detected.

The on-line purity GC was used to insure that volatile compounds were vented to waste before initiation of animal exposures. Once exposures were initiated the GC parameters were changed to allow both volatile and less volatile impurities (including dimers) to be determined. This allowed daily confirmation that the study animals were not subject to significant concentration of chloroprene dimer or the more volatile impurities found in chloroprene.

The dally operation of the purity GC was controlled by a BASIC program running in the background. At the start of the exposure day the program loaded and executed a short/low temperature analysis of volatile compounds in the generated chloroprene. When the area percentage of the major volatile peak was less than 0.58 and the area percent of the chloroprene was greater than 98.5\% the BASIC program ramped the GC oven temperature to clear trapped compounds and began temperature programmed analyses of the chloroprene vapor to allow monitoring of both volatile compounds and less volatile compounds including the dimers of chloroprene. Finally, after the termination of generation the BASIC program directed the purity GC to monitor a sample 


\section{TABLsan. Chloroprene Inhalation Developmental Toxiclty Study: Composition}

of Degradation Samples by GC Area

\section{Sample}

Distribution Ine $(3 / 29 / 90)$

175 ppm Chamber $(3 / 29 / 90)$

10 ppa Chambor $(3 / 29 / 90)$

Distribution Ine $(3 / 29 / 90)$

p.m.

p.m.

p.m.

10 ppm Chamber $(3 / 29 / 90)$

a.m.

99.28

99.2 ?

99.18

99.18

99.18

Note: No dimers or inhibitors were present in the distribution or chamber samples at greater than 0.028 of the total sample area.
Chlorobutene 1-Chlorobutadiene

$\begin{array}{ll}0.58 & 0.048 \\ 0.68 & 0.058 \\ 0.58 & 0.038\end{array}$

0.78

0.08

0.88

0.18

0.88

$0.04 \%$

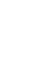


containing a low anount of dimers and a room sample for a blank. The instrument parameters for the on-line purity GC are shown in Table A.4.

A diffusion generator, used to produce a chloroprene dimer vapor, was set up using materlal from the chloroprene generator at the end of a test generation day (BNW 12377-45). Removal of the majority of the chloroprene from the dimers was achleved using nitrogen spaxging. The diffusion generator was loaded with a single cell containing the high dimar materlal and operated at a diffusion cell temperature of $50^{\circ} \mathrm{C}$ and a total flow of $183 \mathrm{ml} / \mathrm{mln}$ of nitrogen (BNW 53436-96). Thls source of dimer vapor allowed confirmation of the retention time of the predominate dimor lsomers and an estimation of the detection limit for dimer by the on-ilne purity method.

A chromatogram from the start of the test exposure day (short/low temperature analysis) is given in Figure A.3 (top chromatogram). Chloroprene was found to - lute at about 2 minutes on this system. The on-line purity GC allowed the separation and area percent quantification of 5 compounds more volatile than chloroprene. The total area percent of these compounds was found to be less than 0.658 at the start of the day and less than 0.047 at the end of the day. A large percentage $(\sim 608)$ of the volat1le compounds was due to a single peak eluting at 0.9 minutes belleved to be 1,3-butadiene or 3-buten-1-yne or a mixture of the two compounds. Two compounds less volatile than chloroprene were detected. These compounds (belleved to be 1-chlorobutadiene and 1somers of chlorobutene) were present at about 0.78 at the start of exposure and 0.58 (by area percent) at the end of exposure.

A chromatogram from the end of the test exposure day using temperature programmed analysis is shown in the middle chromatogram in Figure A.3. No chloroprene dimer peaks were observed. The small peaks seen at the end of the run. were background peaks and were seen in the analysis of blank samples.

A chromatogram obtalned from the on-line purity GC by sampling the dimer diffusion generator output is shown in the bottom chromatogram of Figure A.3. The peak at 1.429 minutes is methylene chloride which was used to transfer the dimers to the diffusion generator. Three dimer peaks eluted at about 9.9, 11.3 and 12.3 minutes. These retention times agree with retention times of the three most abundant chloroprene dimers. Retention time mapping of the dimers was achieved by the comparison of the direct infection of a very small amount of neat chloroprene into the on-line purity GC (3/13/90 run $\$ 298)$ with GC/MS analysis on a similar column (the complete GC/MS report is contained in the Appendix). The large to small graded peak area of the dimers on the on-line purity GC was due to the enhancement of more volatile compounds by the diffusion generator.

During the prestart, the average area percent purity determined by the on-line GC for chloroprene vapor generated on $3 / 15 / 90$ (a typical test exposure day) was $99.18 \pm 0.348$. The on-1ine purity GC showed an average purity of 99.348 for the study. An area percent purity determination is valid when the eluted compounds show the same flame lonization detector (EID) response as chloroprene. The FID response of the compounds found in chloroprene is similar to chloroprene since they are structurally similar chloroprene in the amount of oxidation, unsaturation, and halogenation. Dimer was detected at the end of only three exposure days during the study and was present at less than $0.1 \%$. The purity GC was estimated to have a detection level for dimers of $\sim 0.048$ of the chloroprene peak area. This indicated that the chloroprene vapor used for animal exposures had an average purity greater than 998 and generally contained less than 0.048 (w/w) dimer, thus the $175 \mathrm{ppm}$ chamber contained less than $0.035 \mathrm{ppm}(\mathrm{v} / \mathrm{v})$ of the predominate dimer isomer. 
TABLs A4. Chloroprene Inhalation Developmental Toxiclty Study: Instrument Parameters for on-ilne Determination of Chloroprene Vapor Purlty.

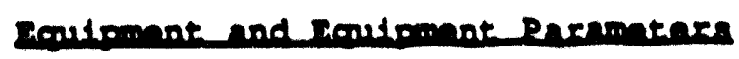

Gas Chromeograph

Detector

Integrator

Detector Temperature

Sample valve

Stream select

Valve Box Temperature

Column

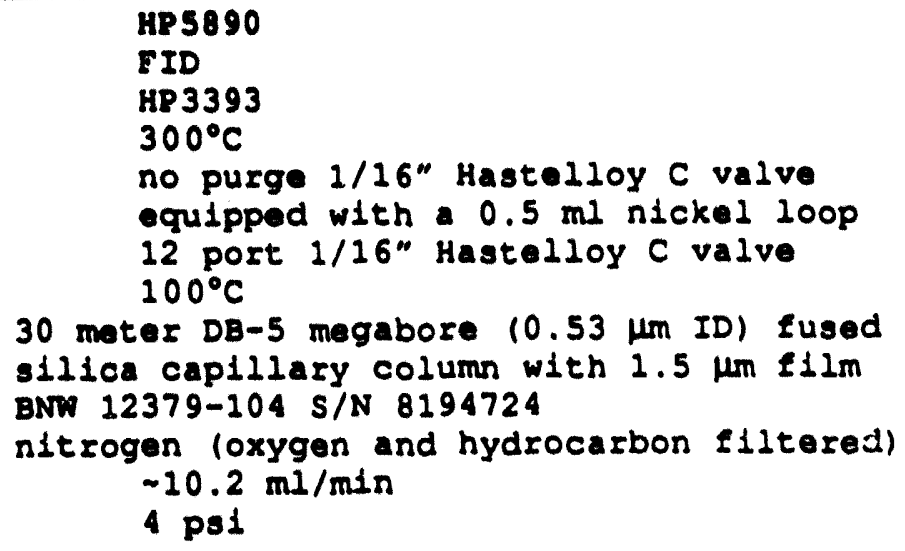

Short Buntim Analyses Paramaters Initial Oven Temperature Initial Time

Run Length

$30^{\circ} \mathrm{C}$
$3 \mathrm{~min}$
$3 \mathrm{~min}$

Iong Bunt tme Analyses Paramelers. Initial Oven Temperature $\quad 30^{\circ} \mathrm{C}$

Initial Time

$3 \mathrm{~min}$

$15^{\circ} \mathrm{C} / \mathrm{min}$

$275^{\circ} \mathrm{C}$

5 min

Final Temperature

Final Time

Run Length

$24.33 \mathrm{~min}$ ( $w / 0$ cooling time required to return to the initial oven

temperature - the total cycle time is $-40 \mathrm{~min}$ 

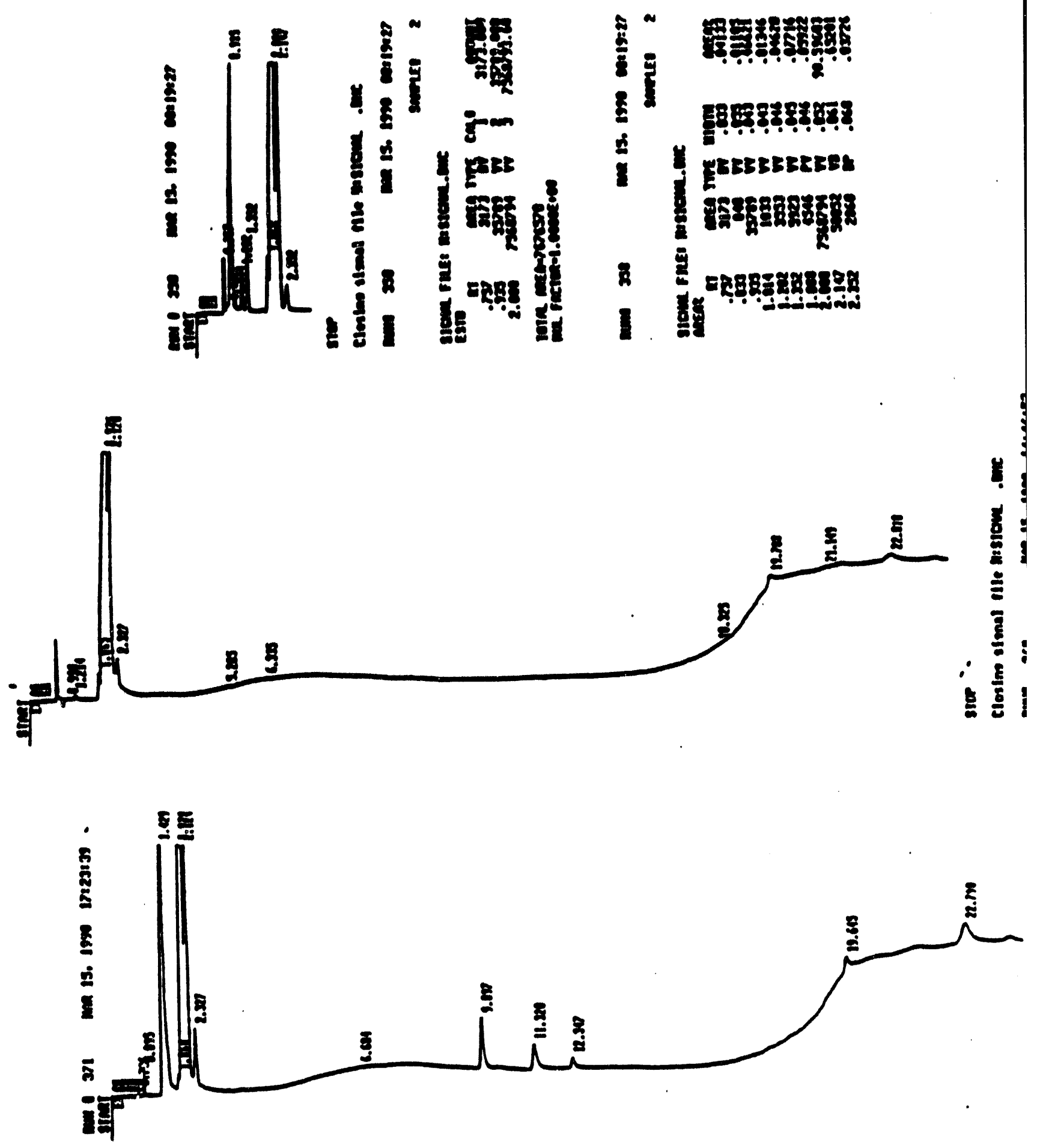

EIGURE_A.3. Chloroprene Inhalation Developmental Toxicity Study: Chromatograms for On-line Purity Determination. Top: Isothermal analysis of distributilon line; Middle: Oven-tempered program analysis of distribution line; Bottom: oven-tempered program analysis of dimer standard. Dimers elut. at $9.9,11.3$, and 12.3 minutes. 


\section{Discuse10a}

Gas chromatography showed that the purity of the test material in the generation flask at the end of the generation day was substantially lower than the purity at the beginning of the day. This was dus to formation and concentration of dimer lsomars in the generation flask.

One Impurity poak at less than 0.138 (as percent of total peak area) was observed in charcoal tube samples acquired from the chambers and distribution line during the first hour of the exposure day. The unknown eluted after chloroprene and before the dimer peaks. This unknown was not observed with the on-line purity mothod. We do not belleve this 1solatad observation Indicated signiflcant exposure of the test animals to this unknown product.

Trace amounts of chlorobutene and 1-chlorobutadiene were found in samples collected from the chambers and the distribution line. The amounts of these impurities were found to be less than 0.8 by area. The Inhibitors, 4-TBC and phenothiazine were present in the distribution line at approximately $3 \mathrm{ppm}$. Dimers were not detected in the distribution or chamber samples by either the analysis of charcoal tube samples or the on-line purity method. The detection limits of dimer were estimated to be $\sim 0.02$ by the charcoal tube method and $\sim 0.041$ by the on-line method (as percent of the total peak area of the most abundant dimer lsomer). Test chemical stability and purity were considered acceptable for the study. 
GC/MS Analysis of Chloroprene and Its Dimer Products 
DATE March 13, 1990

TO Barry Hayden

FROM RB Lucke $\Omega \mathcal{L} \mathcal{L}$ whe

SUBJECT GCMS analysis of chloroprene and its dimer products..

One samples, BNW 53436-72-2 was analyzed by GCMS. All pertinent information was recorded in BNW\# 12410 pages 39-42. Hardcopy data is stored in the GC/MS file in room 2 of 329 building while the electronic-data is archived on magnetic tape in Lab 15a of the 329 building.

\section{Instrumentation:}

* Hewiet Packard 5988 GC/MS.

* Hewlett Packard 5890 GC.

* Hewlet Packard RTE-6 data station.

* GC conditions: The column used was a DB-1 capillary GC column, 30 meter by $0.25 \mathrm{~mm}$ i.d.by $1.0 \mu \mathrm{m}$ film thickness (J\&W serial \# 81665). Injection was in the splittless mode at $200^{\circ} \mathrm{C}, 0.6 \mathrm{~min}$ purge. The oven profile started at $35^{\circ} \mathrm{C}$ for 5 minutes followed by a $10^{\circ} \mathrm{C}$ per minure ramp to $275^{\circ} \mathrm{C}$ with a final hold ime of $5 \mathrm{~min}$.

* Mass Spectrometer Conditions: Operated in the Electron Impact mode (EI) at 70eV. The mass range was scanned from $40-400$ amu with the electron multipier set at 2643 volts (300 volts above autorune) and a $300 \mu \mathrm{A}$ emission current. The source temperature was set at $200^{\circ} \mathrm{C}$ and the inrerface was at $200^{\circ} \mathrm{C}$. The GCMS was autotuned with PFIBA prior to analysis for instrument calibration. In addition, $1.2 \mathrm{ng}$ of methyl stearate was injected into the GCMS to verify instrument performance. Mass spectra identification was made by comparison of spectra from individual standards, the EPANNIH library and/or from conventional mass spectral interpretation.

\section{DATA and RESULTS:}

This includes 17 figures attached to this letter report.

[Referred to as FIGURES A.4.1 through A.4.17]

The GCIMS total ion chromatogram compares very well with the GC/FID chromatogram (Figures 1 and 2). Figures 5 through 12 show the mass spectra and the library hits. Mass specral comparison with that from the EPANNIH library indicates that all the peaks are chloropropene dimers with the exception of terburylcatechol and phenothiazine. The most abundant ion in most all of the mass spectrum is the 88 atomic mass unit (amu) ion. Figure 16 shows the extracted ion chromatogram for 88 amu and compares very well with the TIC in figure 15. This indicates that the peaks are of a similar molecule that fragment in a similar way.

Analysis Cost:

Work order number M38969 was charged 7 units of GC/MS usage (\$214 / unit). This included instrument and operator time spent directly on the project. 


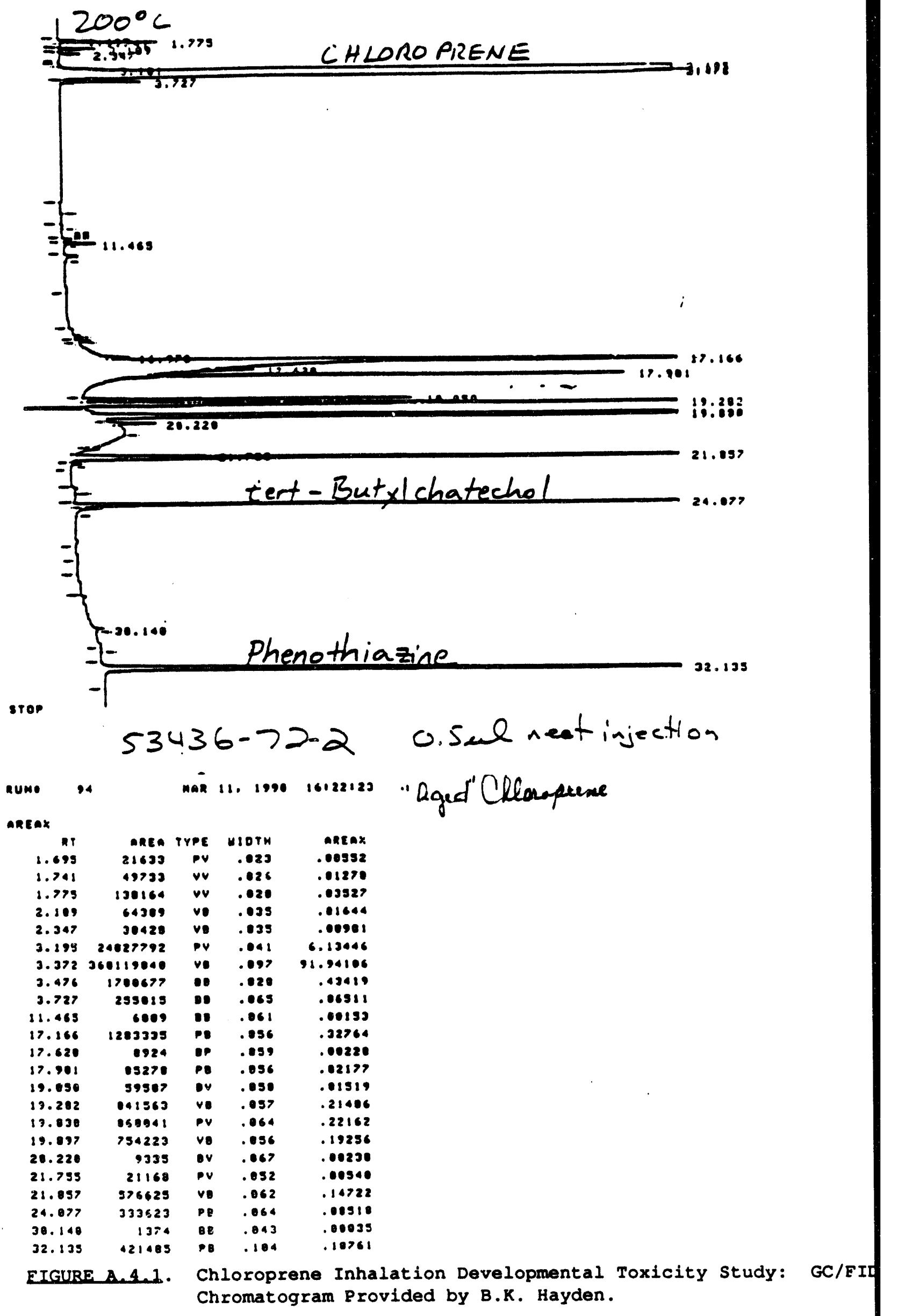




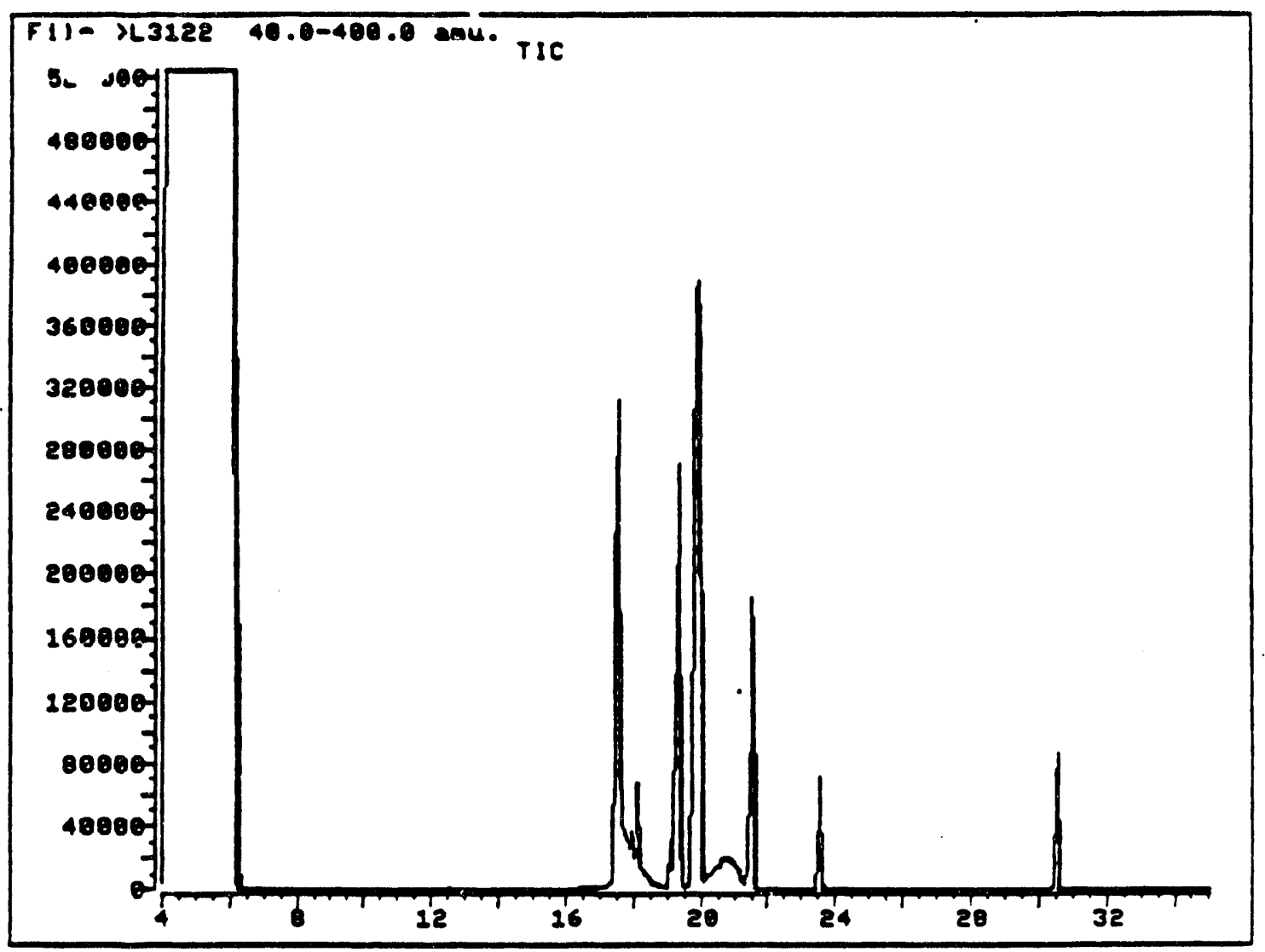

EIGURE A.4.2. Chloroprene Inhalation Developmental Toxicity Study: GC/MS Total Ion Chromatogram of Sample 53436-72-2. 


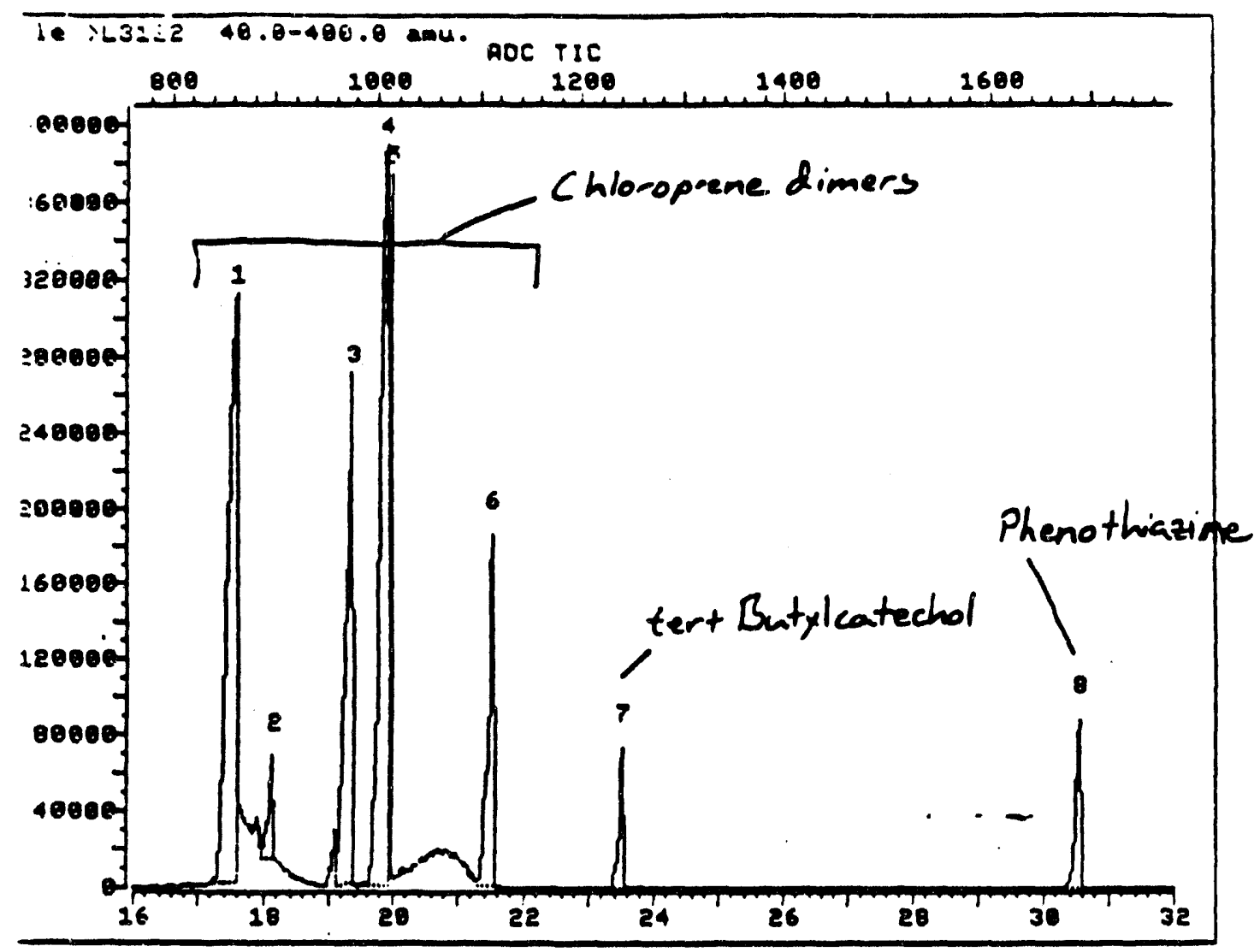

EIGURE A.4.3. Chloroprene Inhalation Developmental Toxicity Study: GC/MS TIC of Sample 53436-72-2 with Peak Numbers. 
MS dote file heoder from: IL3122

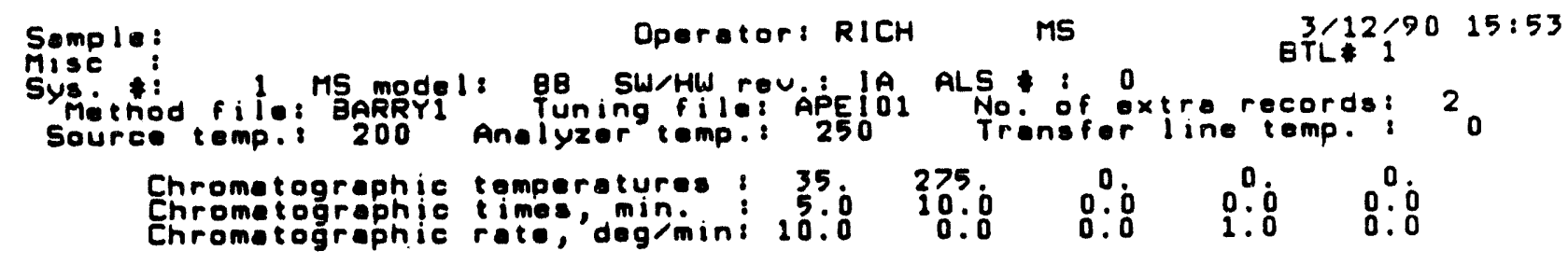
$>$ L 3122 IOTI 400.0 ADC TIC Upslope: $0: 20$ Aree Rejecti $5.00 \%$ Max Peoksi B Bunching: 1

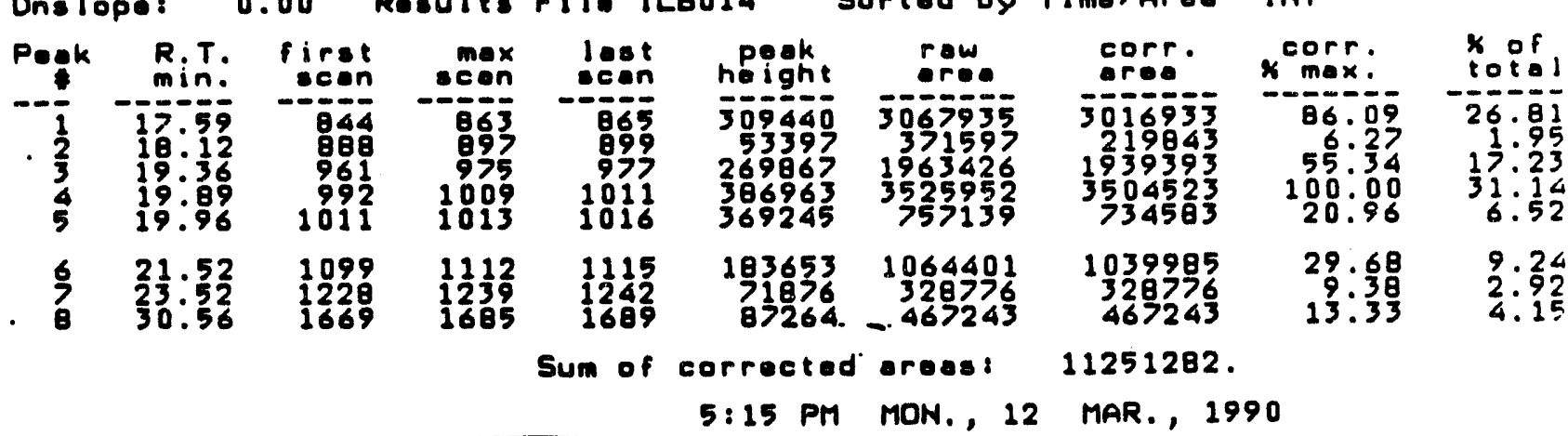

EIGURE A.4.4. Chloroprene Inhalation Developmental Toxicity study: Integration Report Table of Figure A.4.3. 


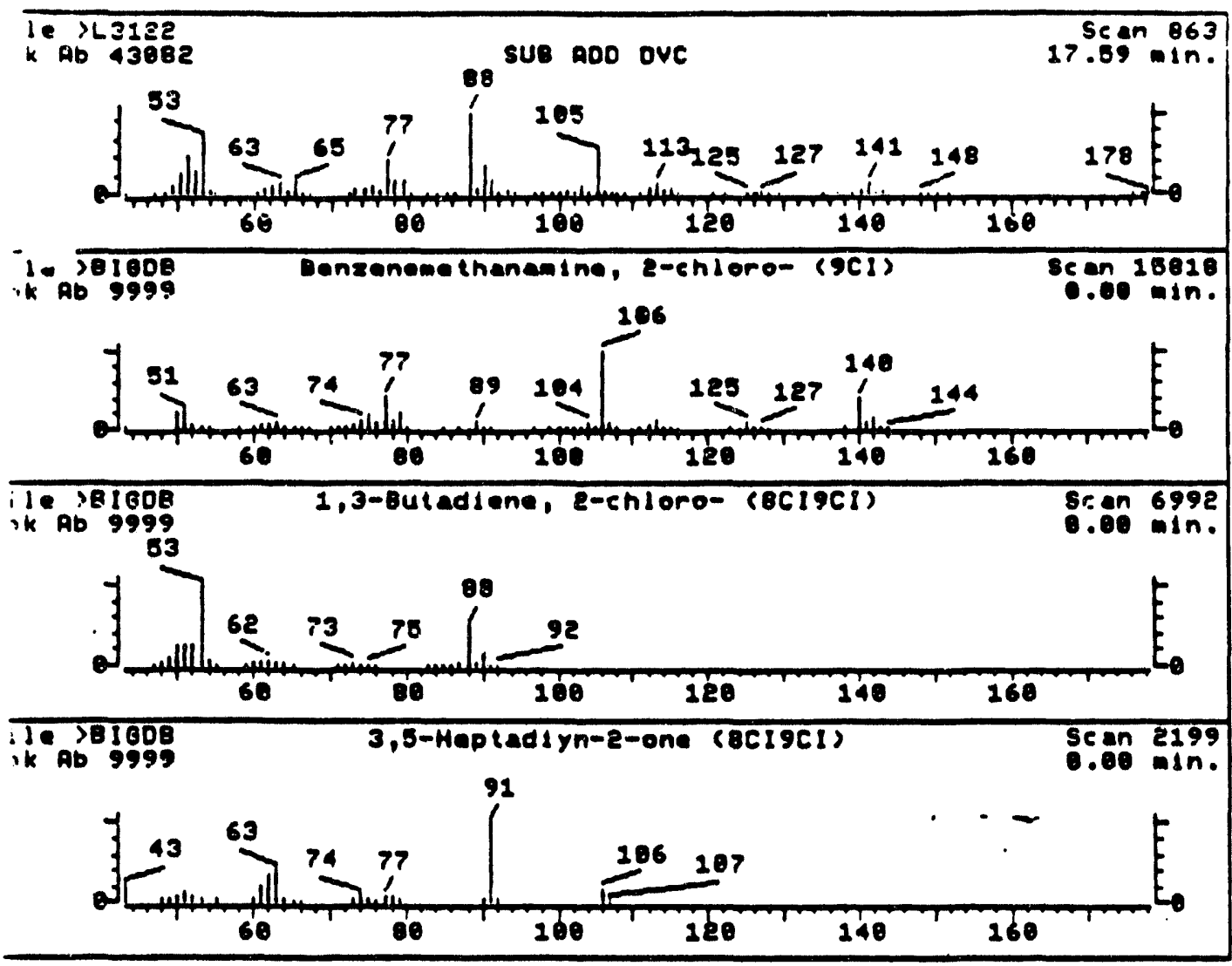

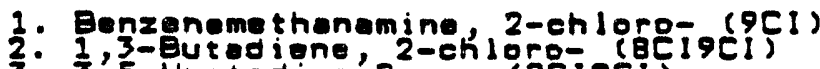

3: 3,5-Heptadiyn-2-one (8Cigci)

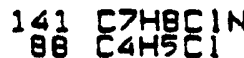

106 है। 140

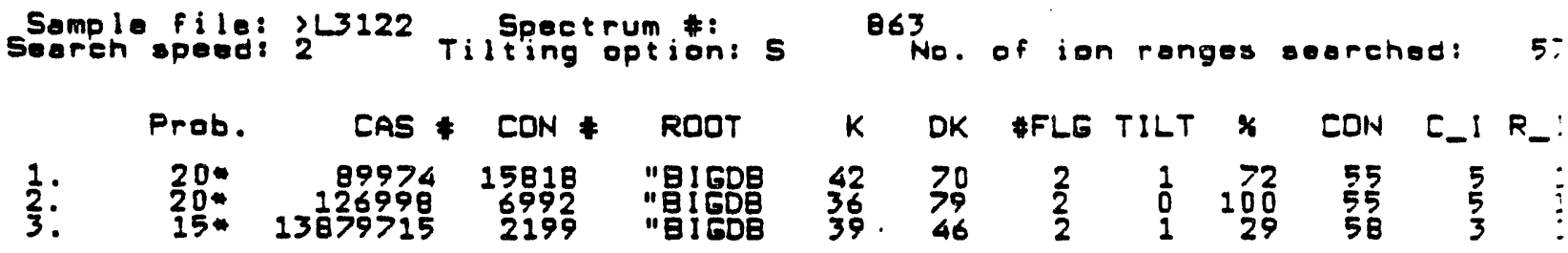

EIGURE A.4.5. Chloroprene Inhalation Developmental Toxicity study: Mass Spectra and Library Hit Spectra of Peak 1 . 


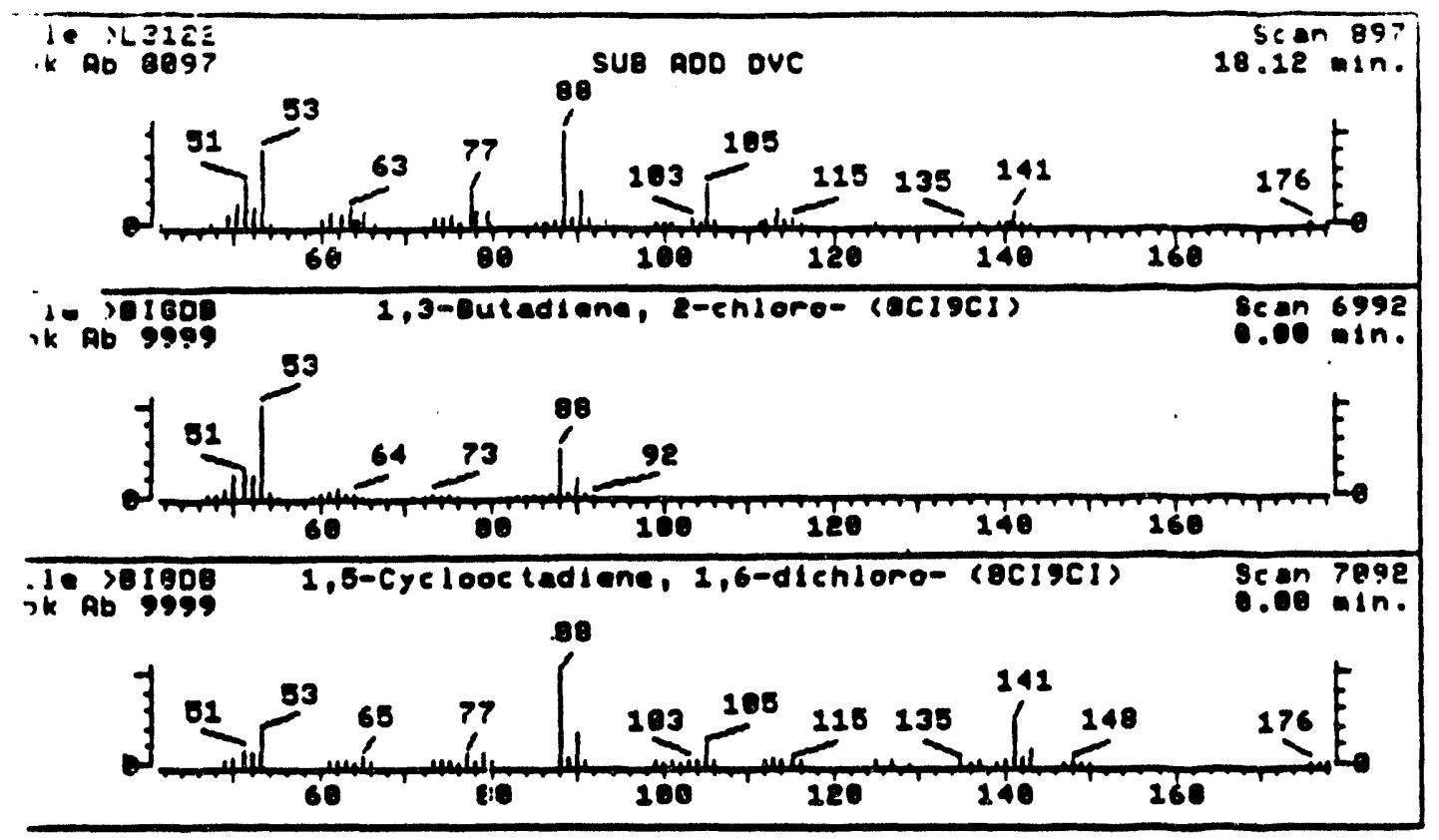

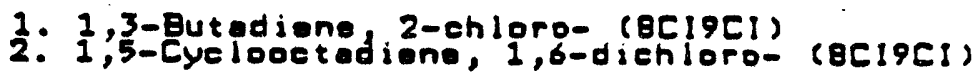

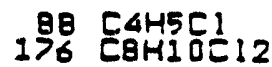

Sample file: >L3122 Spectrum \#: B97

Search speed: 2 Tilting option: 5 No. of ion ranges searehed: 5j Prob. CAS * CON * ROOT $K$ OK \&FLGTILT $x$ CON C_l R_l

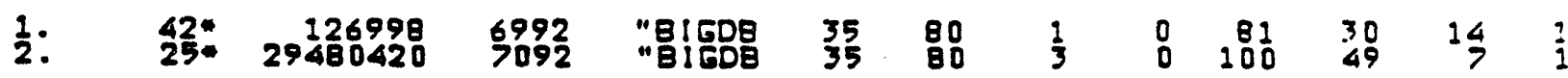

EIGURE A.4.6. Chloroprene Inhalation Developmental Toxicity study: Mass Spectra and Library Hit Spectra of Peak $\$ 2$. 


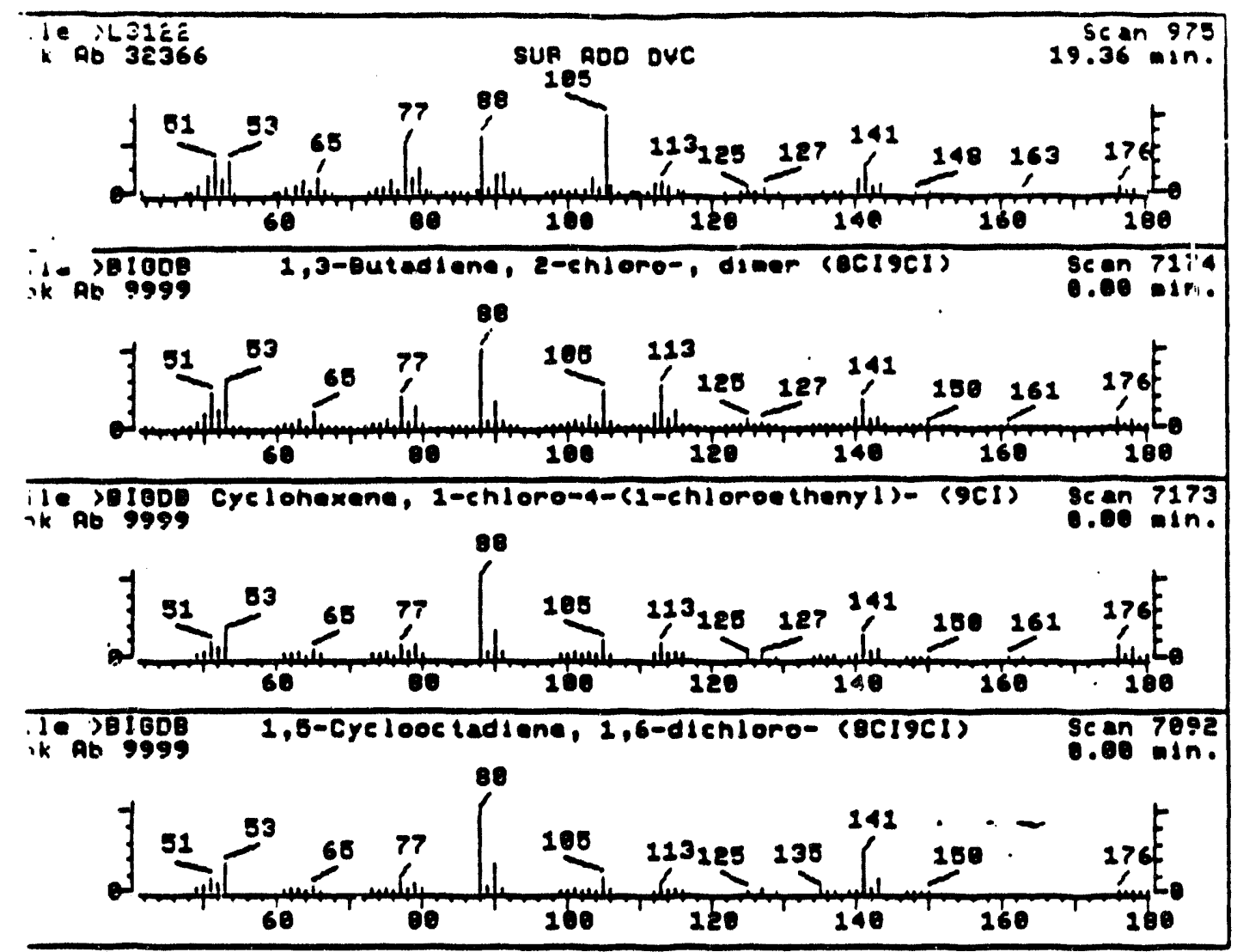

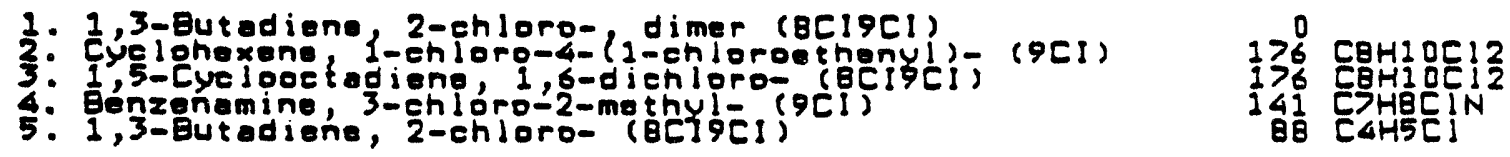

Sample file: IL3122 Speetrum *: 975

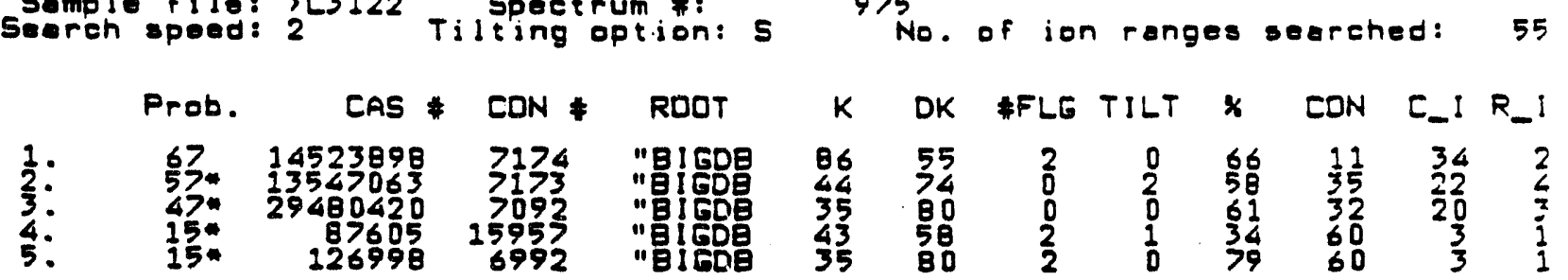

EIGURE A.4.2. Chloroprene Inhalation Developmental Toxicity Study: Mass Spectra and Library Hit spectra of Peak 3 . 


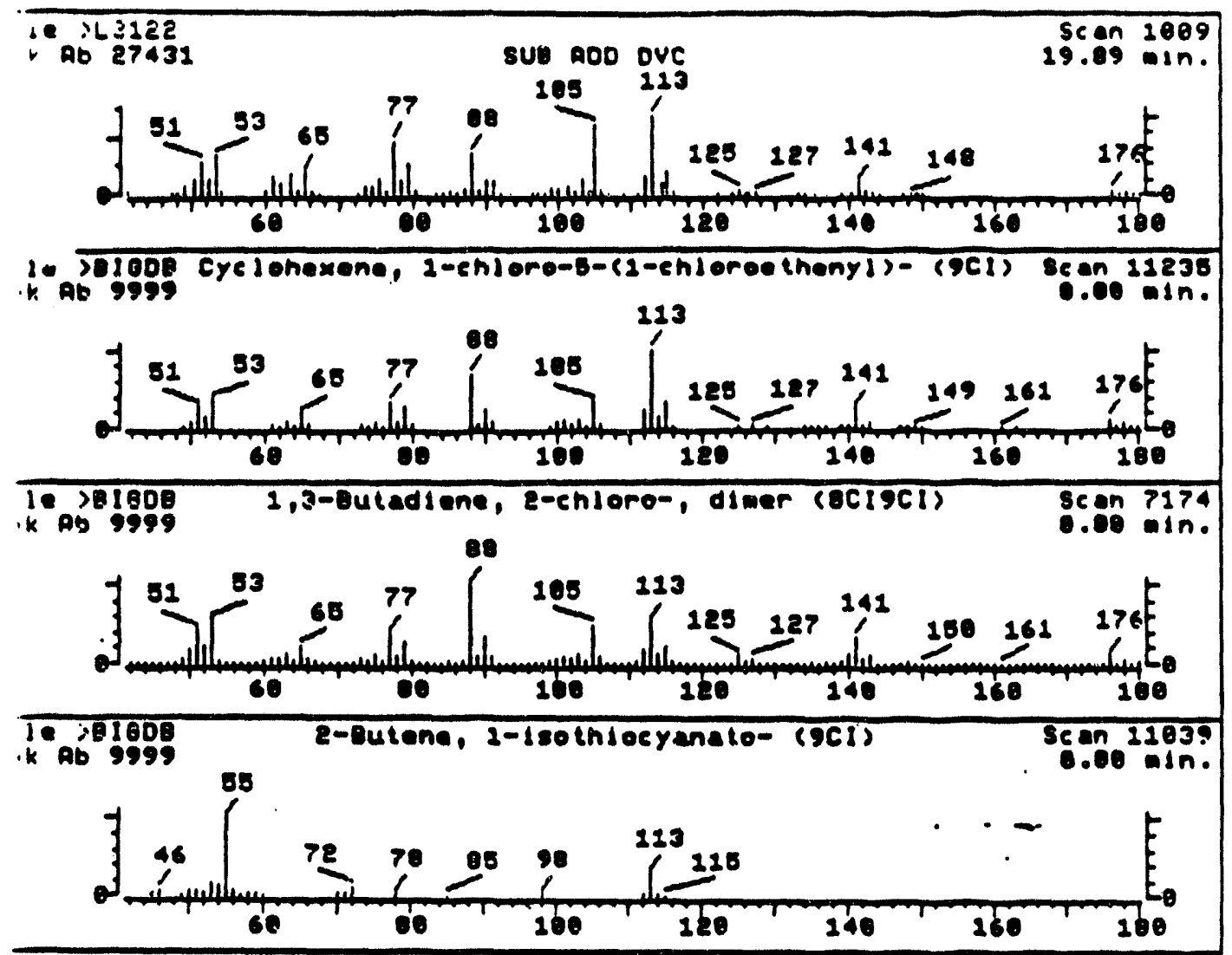

1. Cyelohexene, 1-chloro-5-(1-chloroethenyl)- (9Cl)

3. $\frac{1}{2}, 3-$ - Et adiene, 2-enloro-, dimer (BCIgCY)

3. 2-Eutane, 1-isothioeyanoto- (9CJ)

5. Eyclohexéne 1-ehloro-4-(I-ehloroethenyl)- (9CI) (9C1) 1133 C5HDNS

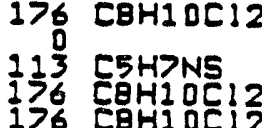

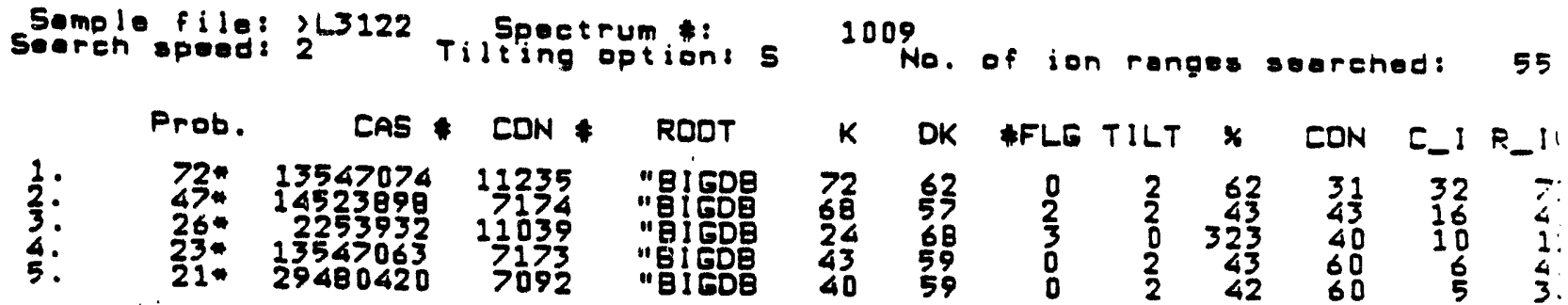

EIGURE A.4.8. Chloroprene Inhalation Developmental Toxicity Study: Mass Spectra and Library Hit Spectra of Peak $\$ 4$. 

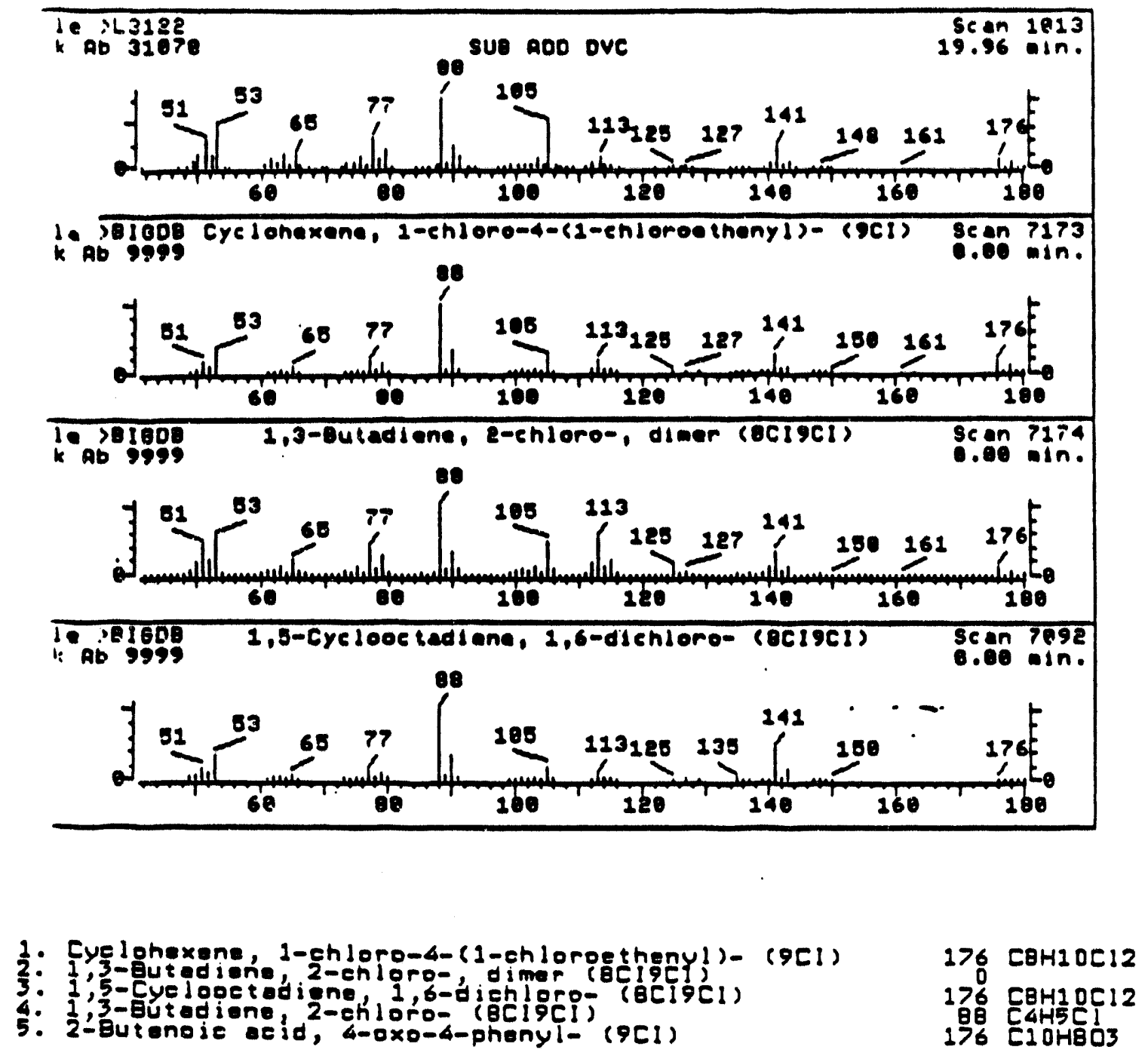

Semple file: ?L3122 Tpeetrum : St: 1013

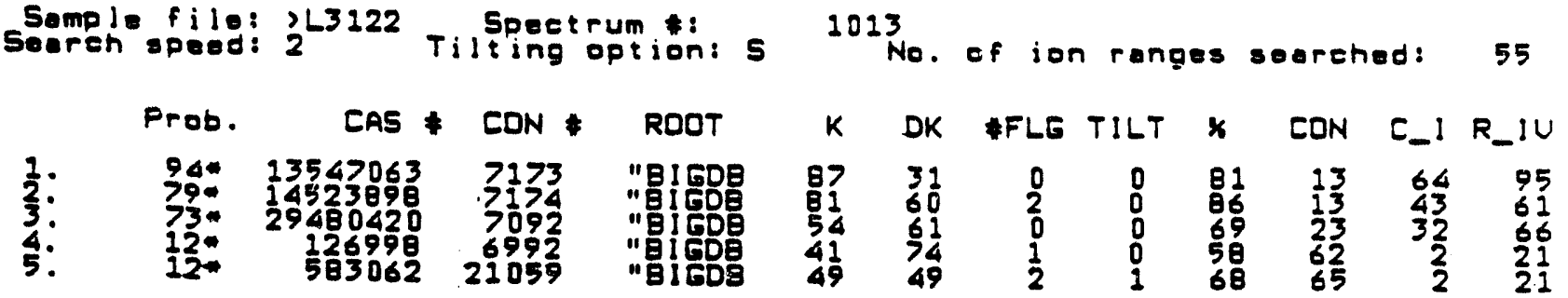

EIGUR5 A.4.9. Chloroprene Inhalation Developmental Toxicity Study: Mass Spectra and Library Hit Spectra of Peak $\$ 5$. 


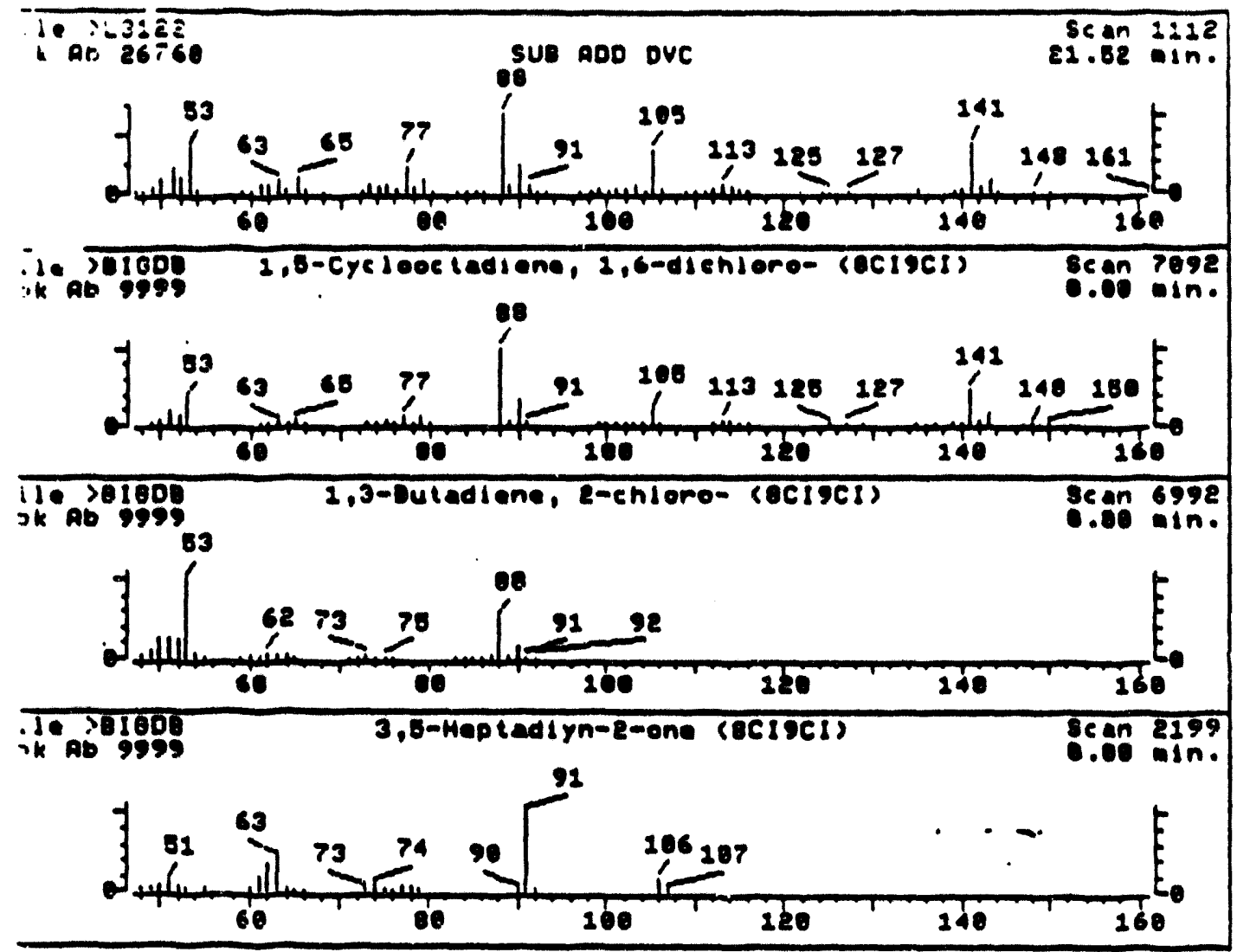

1. 1, 5-Cyelooetedigne, 1,6-dichloro- (BClgCl)

3. $\frac{1}{3}, 5-$ Heptadiyn-2-one (BCigci)

176 C8H10C12

106 ESHGO

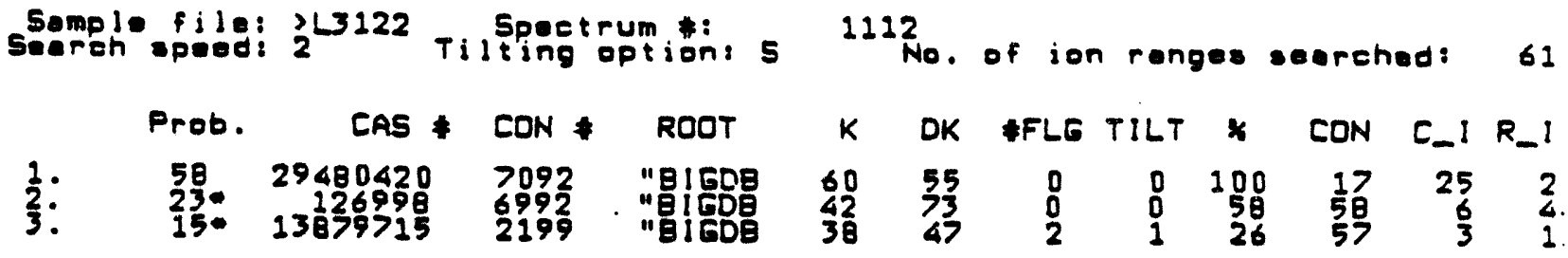

EIGURS A.4.10. Chloroprene Inhalation Developmental Toxiclty study: Mass Spectra and Library Hit Spectra of Peak $\$ 6$. 


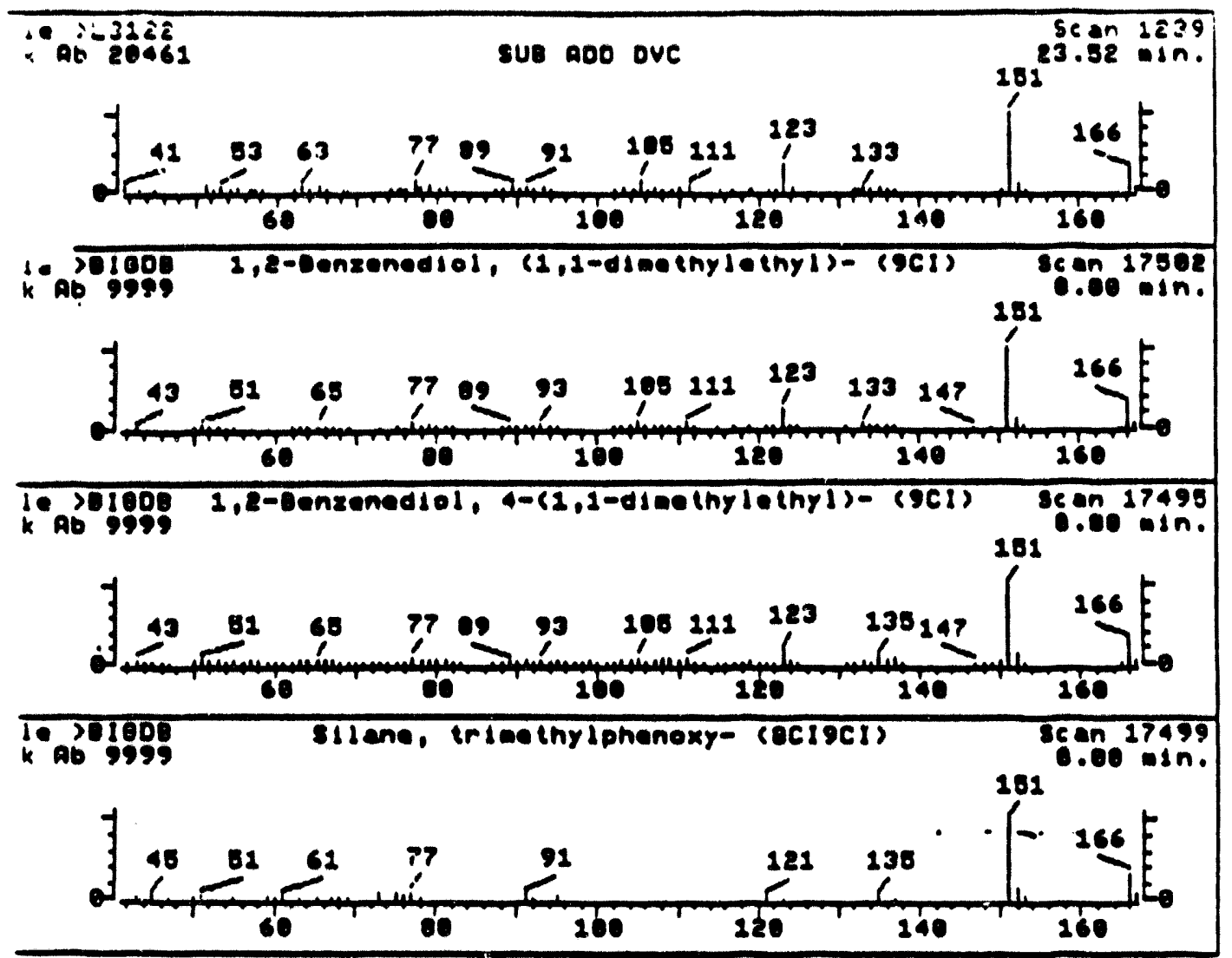

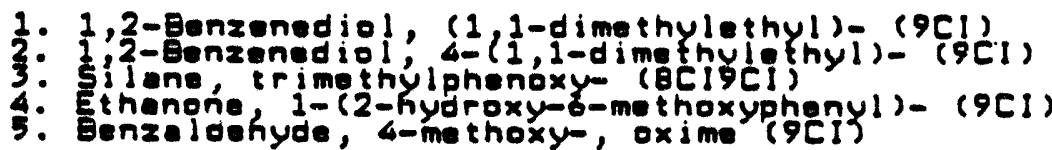

166 CIOHI 402

166 CIOHI 1402

166 CoH1 $405 i$

151 CBH9ND2

Somple file: ?L3122 Tiliting option: 5 1239

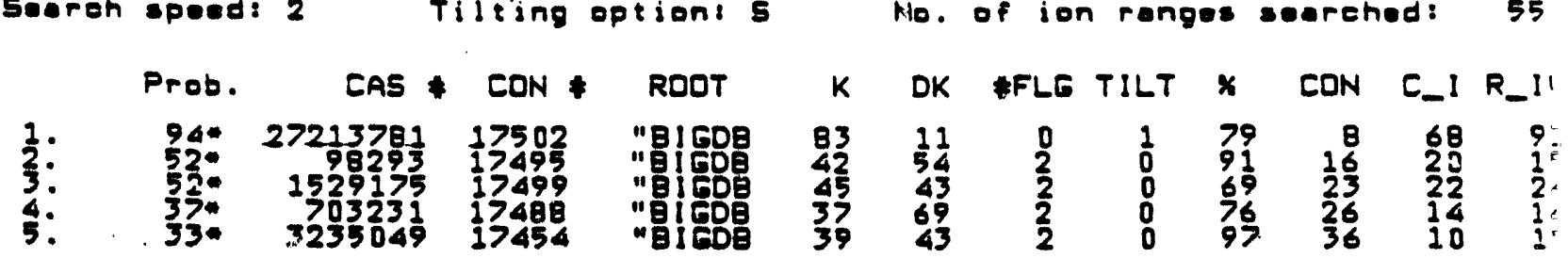

EIGURS A.4.11. Chloroprene Inhalation Developmental Toxicity study: Mass Spectra and Library Hit Spectra of Peak 7 . 


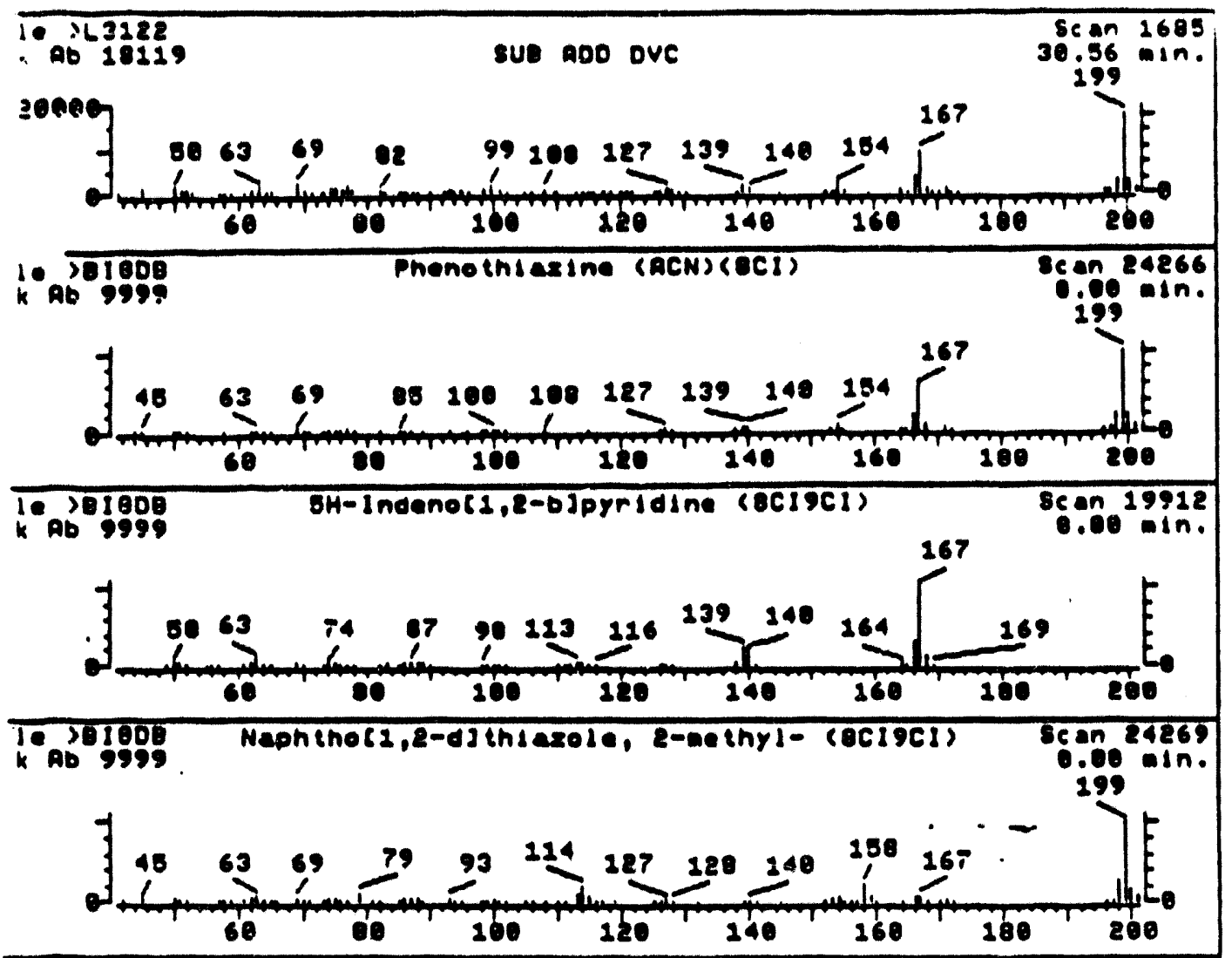

1. Phenethiezing (ACN) (BCI)

2. SH-Indenoti,2-b jpyridine (BClgCl)

3. Naphtho( $1,2-d)$ thiazole, 2-methyl- (BCI9CI)

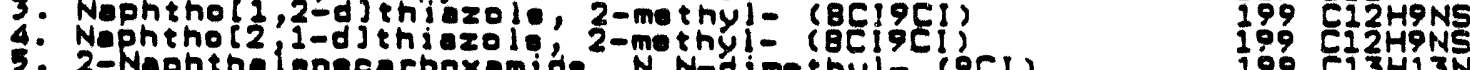
2-Nephthalenecarboxamide, N,N-dimethyl- (9CI)

Sample file: ?L3122 Tpeetrum : 1685

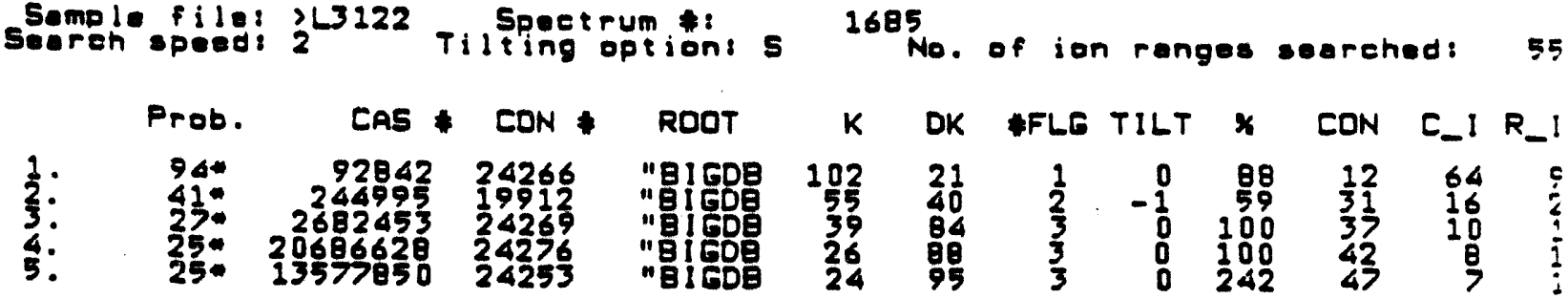

EIGURE A.42. Chloroprene Inhalation Developmental Toxicity Study: Mass Spectra and Library Hit Spectra of Peak $\$ 8$. 

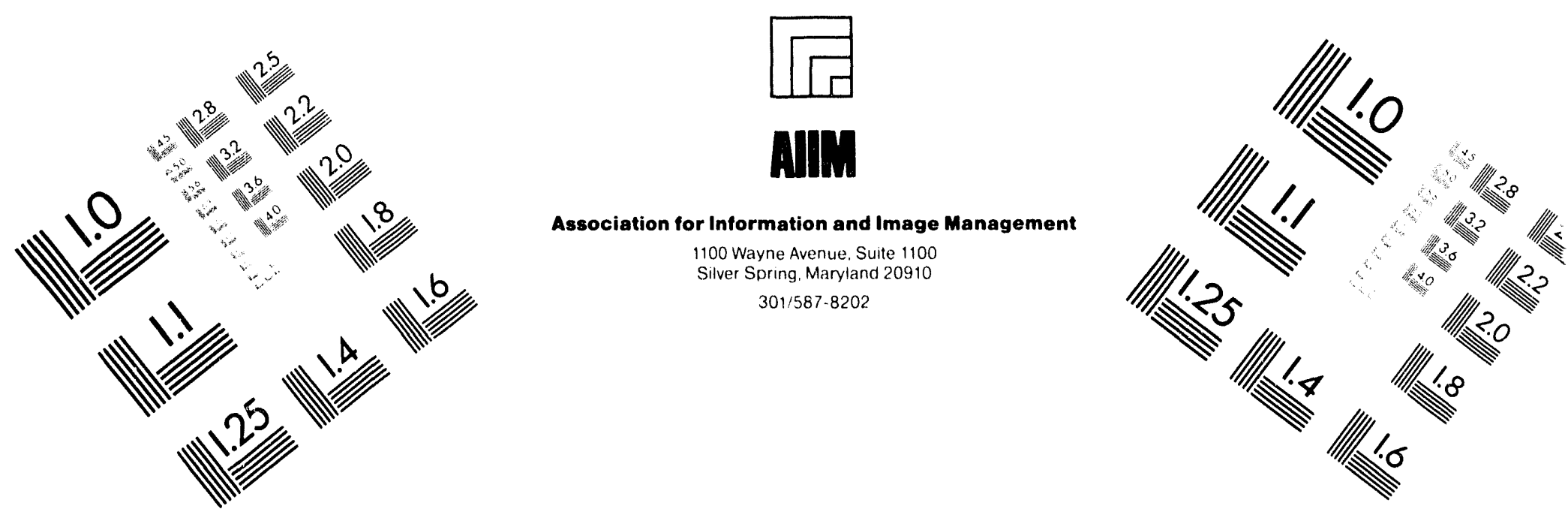

Centimeter

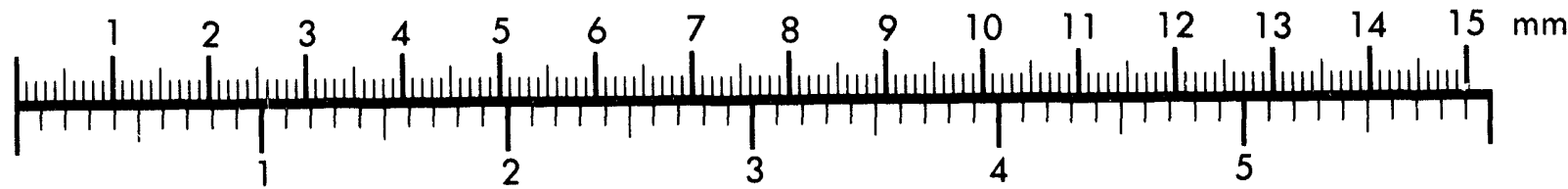

Inches
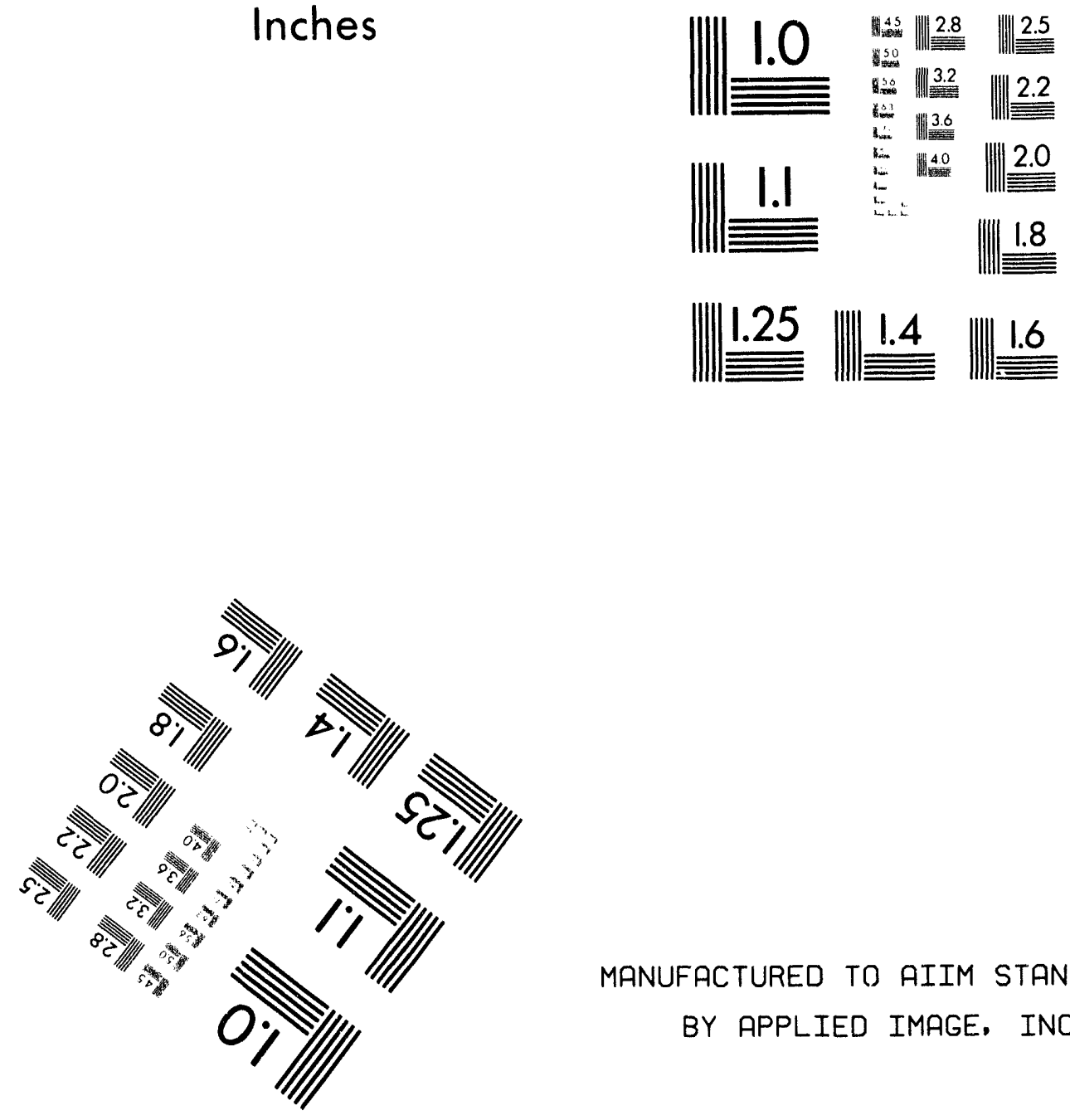

MANUFACTURED TO AIIM STANDARDS

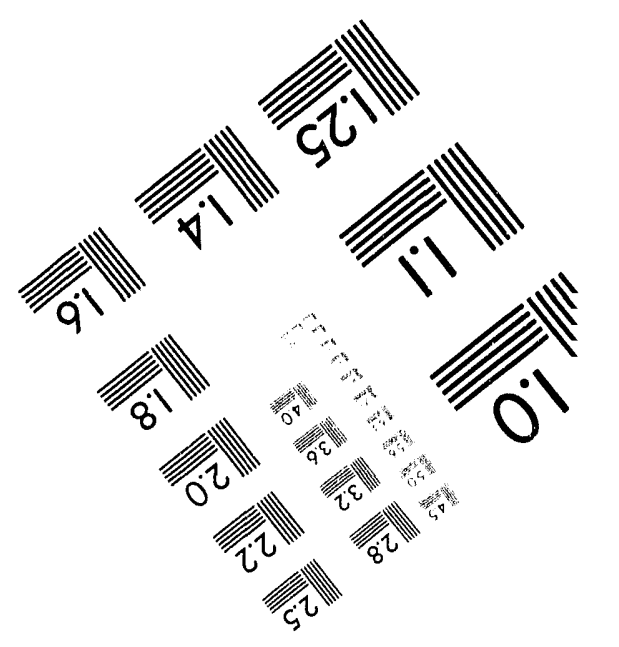



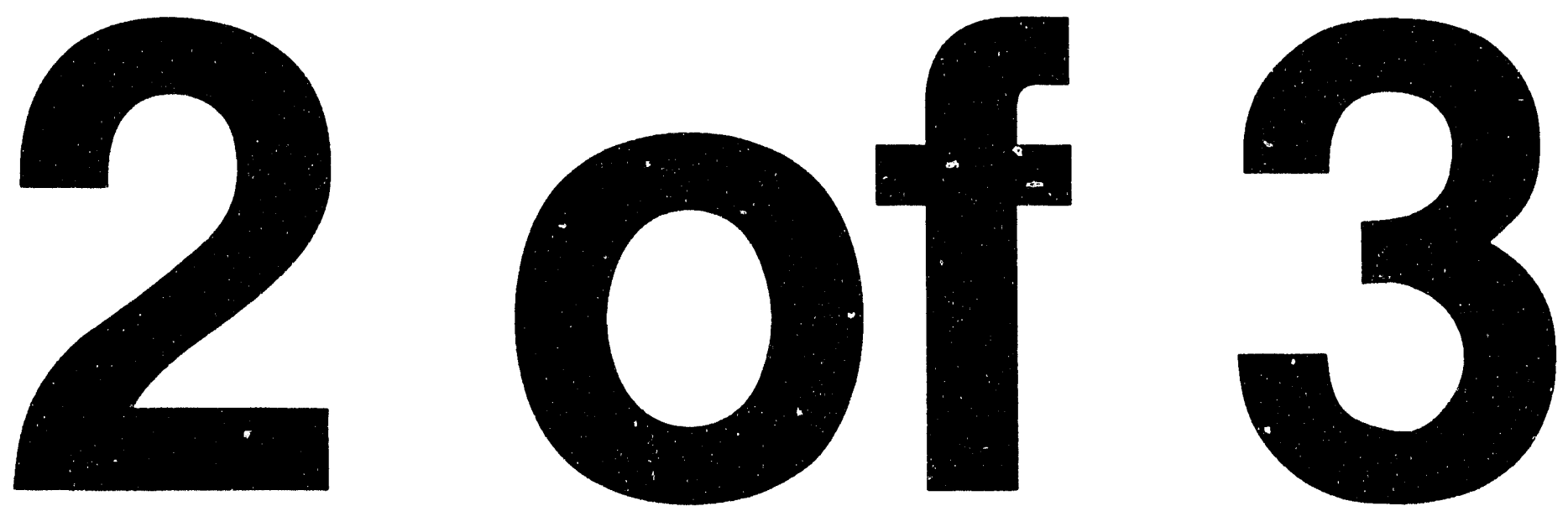


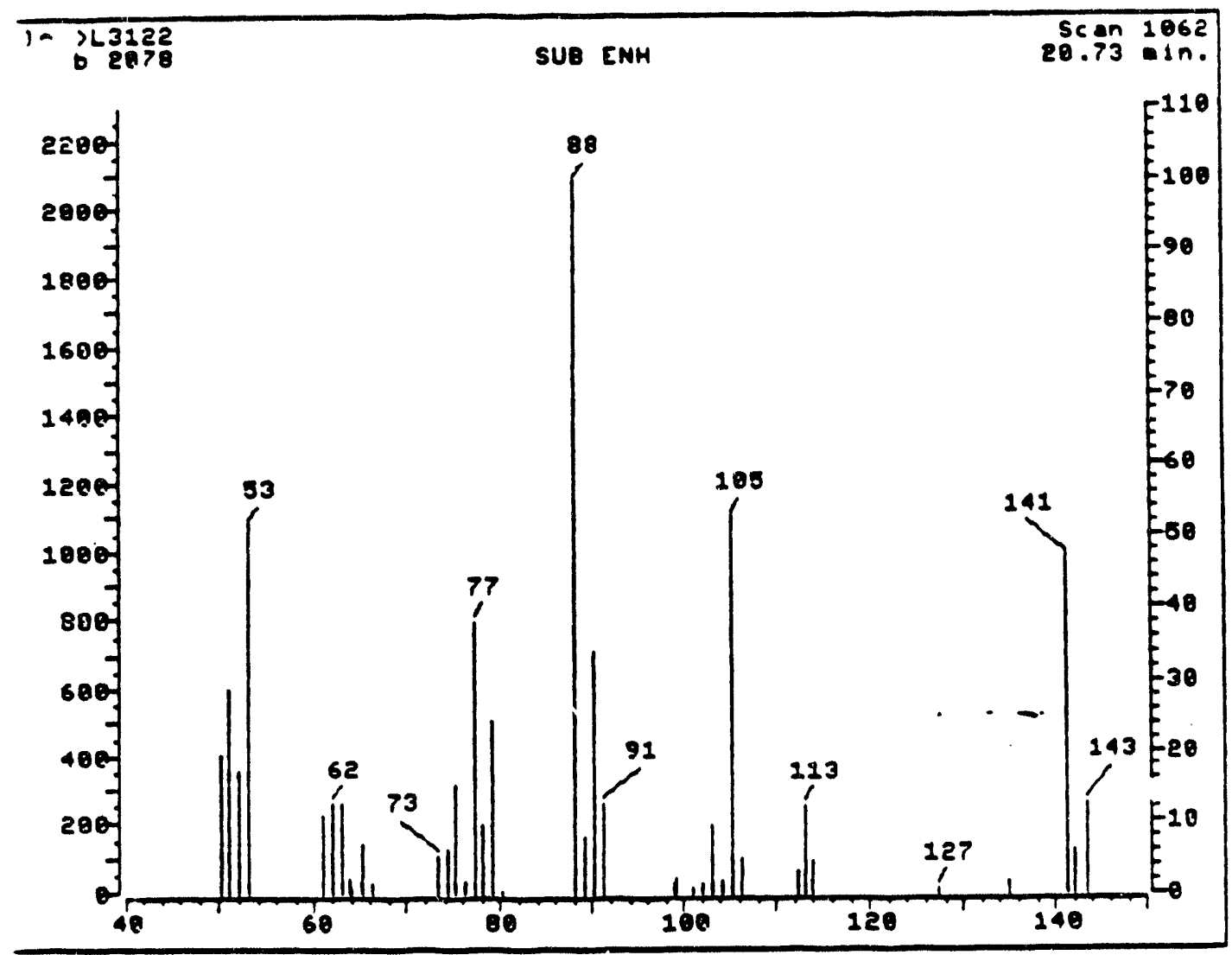

EIGURE A.4.13. Chloroprene Inhalation Developmental Toxicity Study: Mass Spectra of Broad Peak Between Peak $\$ 5$ and Peak $\# 6$. 

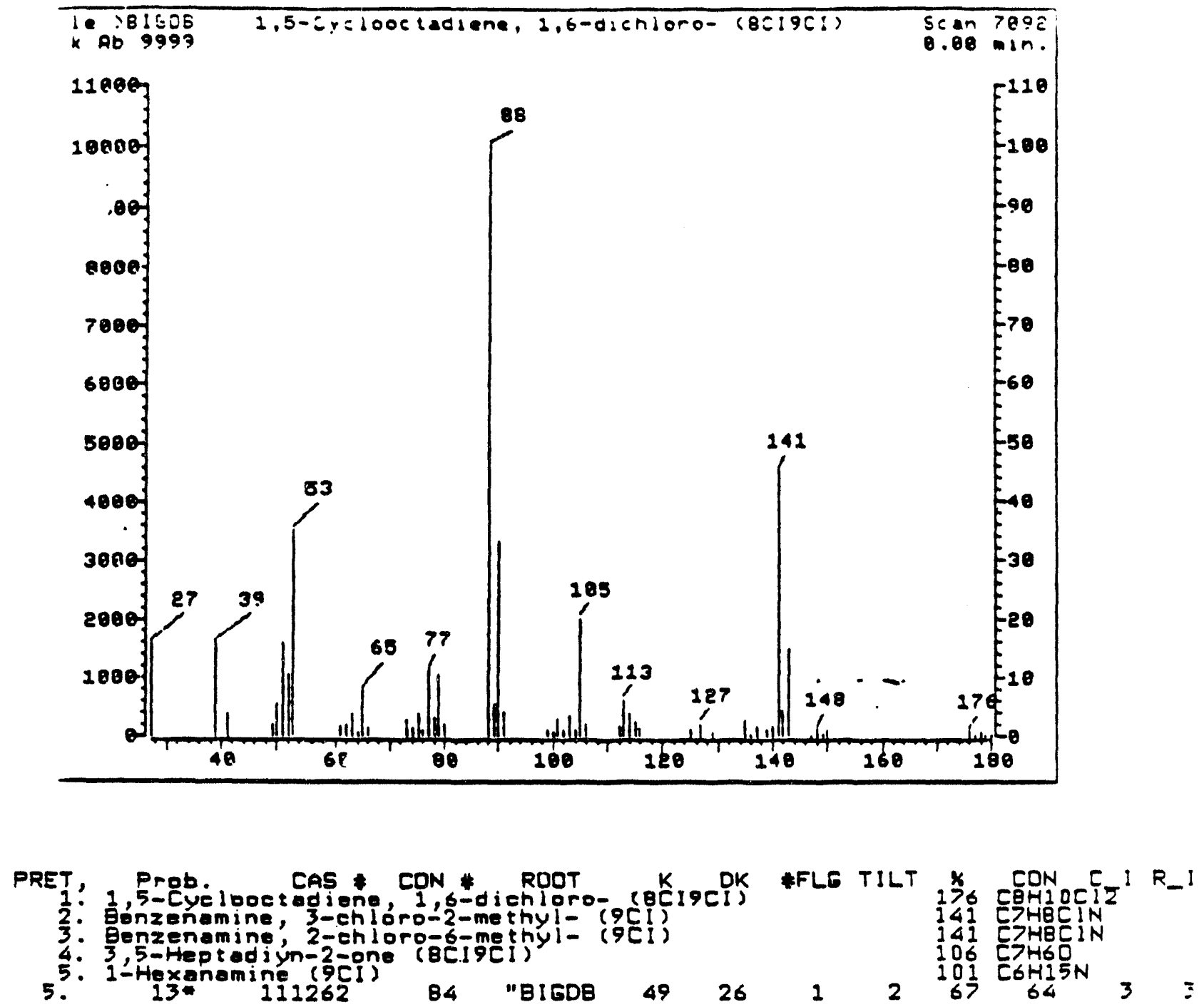

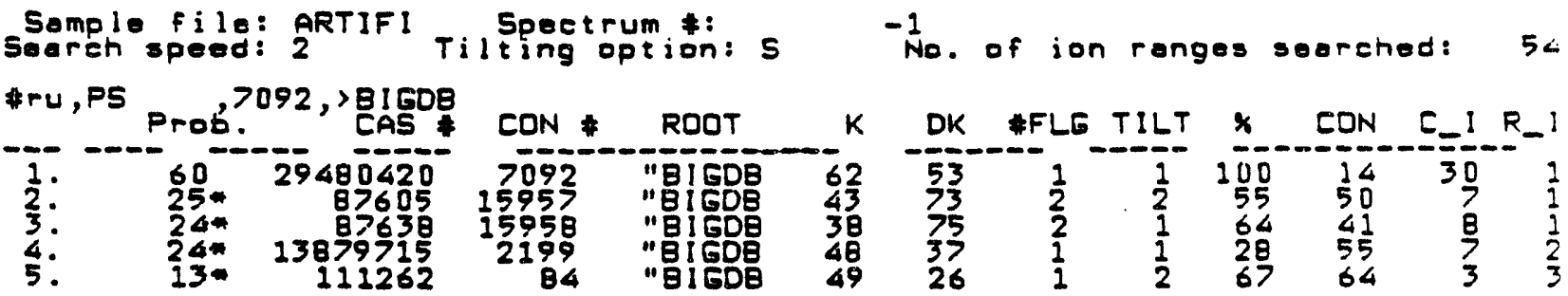

EIGURE A.4.14. Chloroprene Inhalation Developmental Toxicity Study: Library Hit Spectra and Results For Peak at $20.73 \mathrm{~min}$. (See Figure A.4.131. 


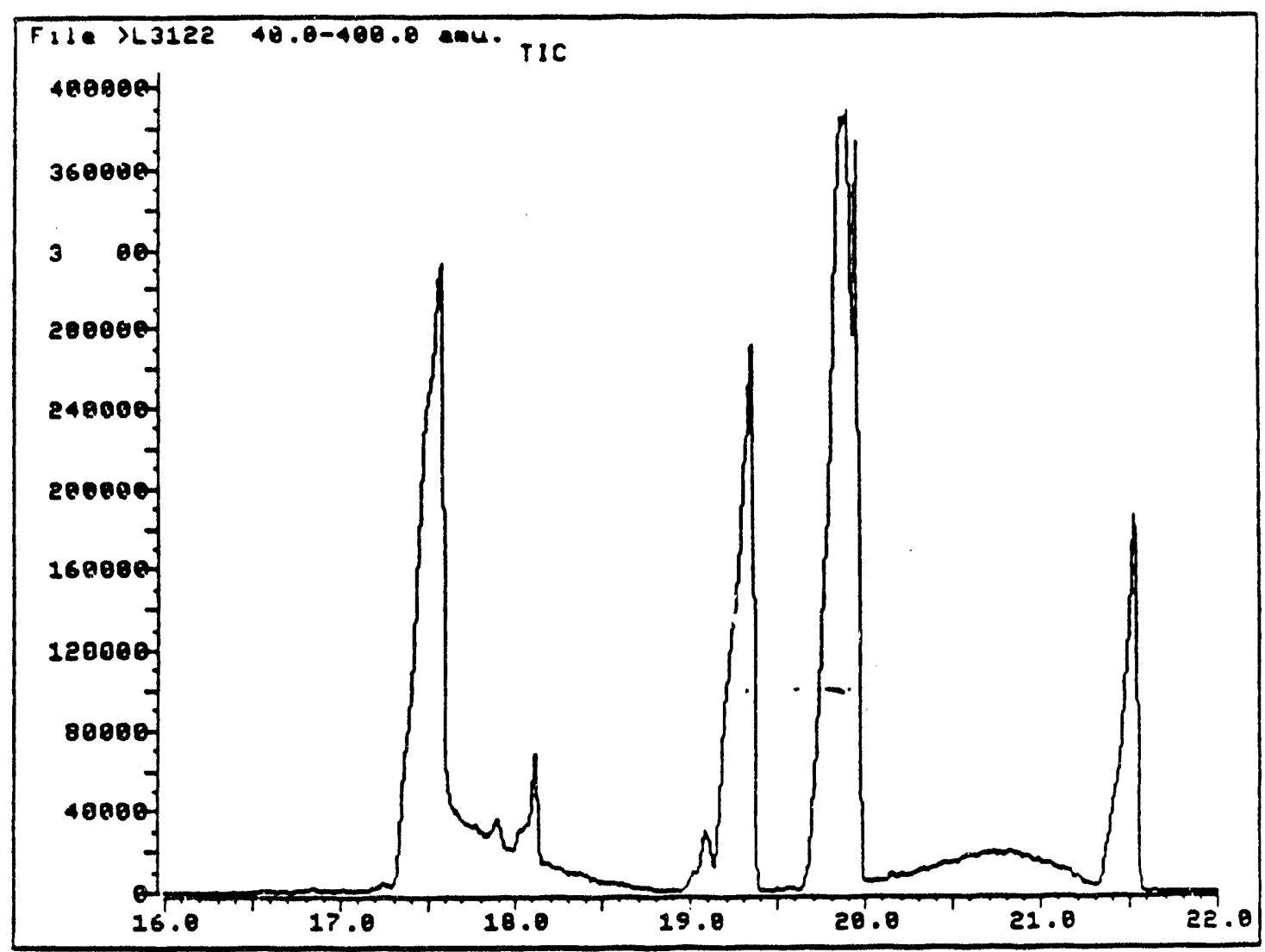

EIGURE A.4.15. Chloroprene Inhalation Developmental Toxicity Study: GC/MS Total Ion Chromatogram of Sample 53436-72-2. 


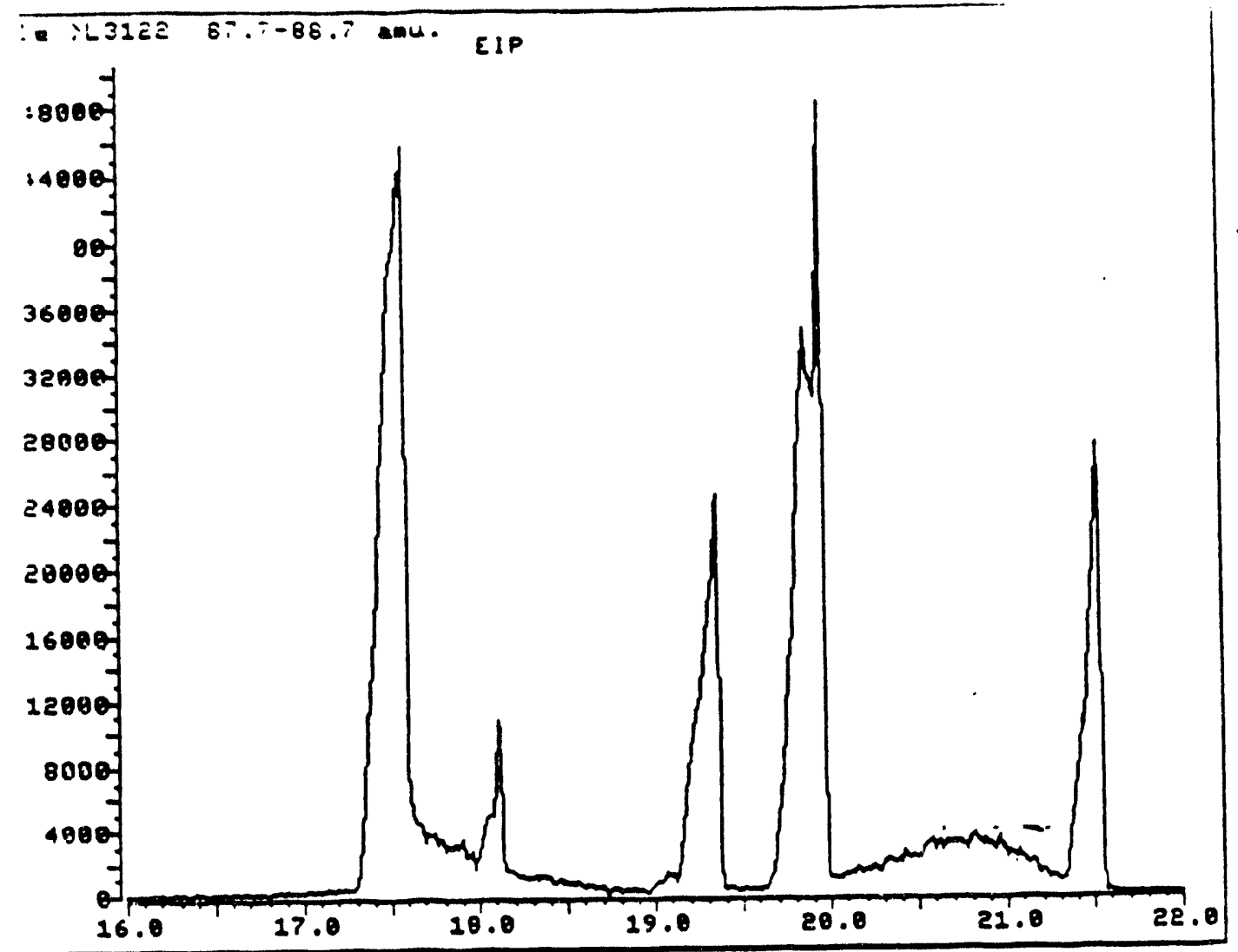

EIGURE A.4.16. Chloroprene Inhalation Developmental Toxicity Study: Extracted Ion Chromatogram of Mass 88. 


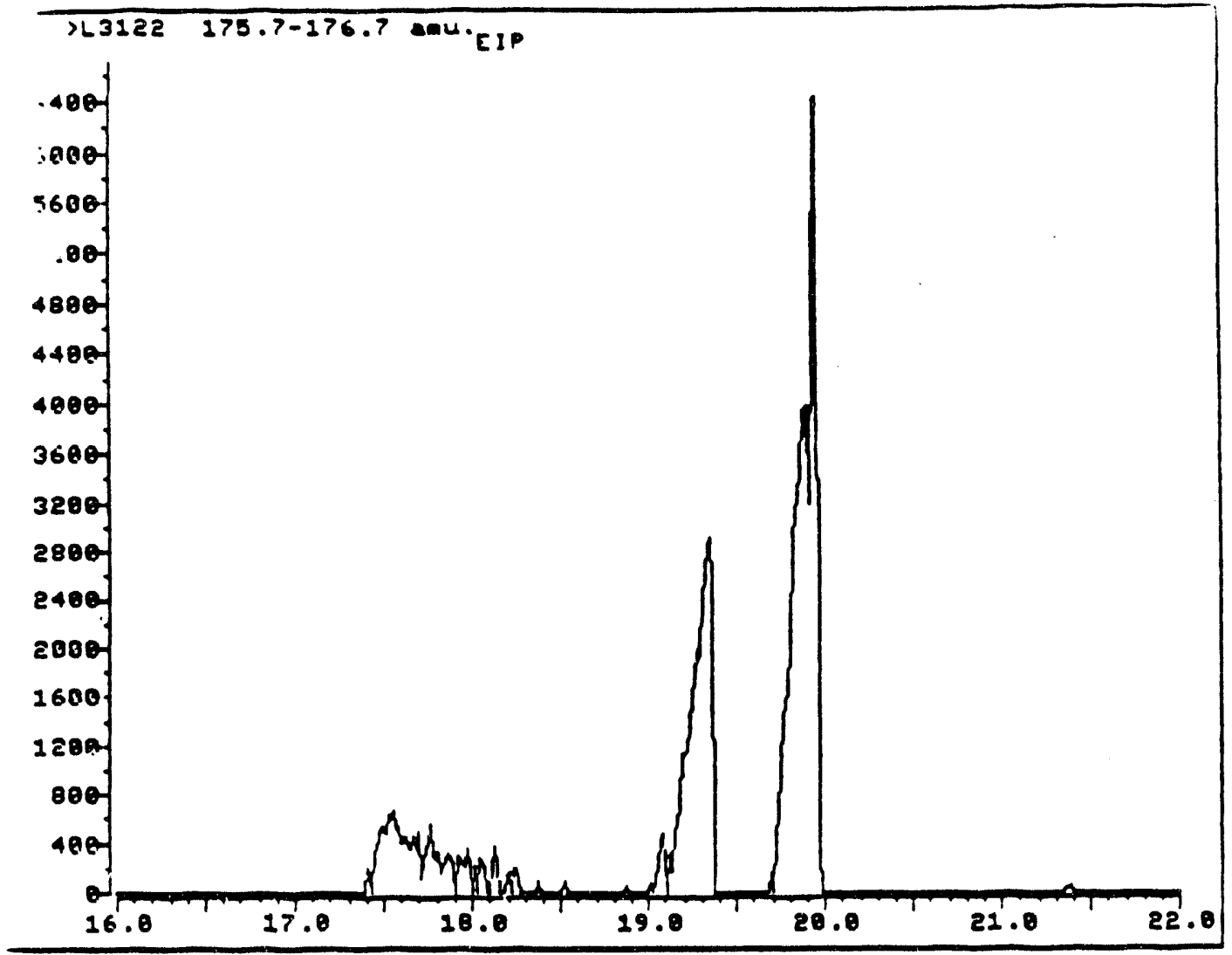

EIGURE A.4.17. Chloroprene Inhalation Developmental Toxicity Study: Extracted Ion Chromatogram of Mass 176. 


\author{
APPENDIX B \\ EXPOSURE DATA \\ Summation Equations \\ Concentration Data \\ Temperature Data \\ Relative Humidity Data \\ Exhaust Airflow Data \\ Exposure Operation Discussion Sheets \\ Chamber Uniformity Data
}


Summation Equations

$$
\text { B - } 3
$$




\section{SUMMATIONEOUATRONS}

Mean: $\bar{x}=\frac{1}{n} \sum_{i=1}^{n} x_{i}$

Standard Deviation:

$$
s=\sqrt{\sum_{i=1}^{n} x_{i}^{2} \cdot\left(\sum_{i=1}^{n} x_{i}\right)^{2} / n}
$$

where:

$$
\begin{aligned}
& \mathbf{X}_{\mathbf{i}}=\text { individual reading of concentration, temperaure or } \\
& \text { relauive humidity } \\
& \mathrm{n} \text { = number of individual readings }
\end{aligned}
$$

The weekly and study means and standard deviations for concentration were derived from the daily means and standard deviacions using the following equation.

$$
\text { Mean: } \bar{x}=\frac{\sum_{j=1}^{K}\left(n_{j}\right)\left(\bar{x}_{j}\right)}{\sum_{j=1}^{K} n_{j}}
$$

Standard Deviation:

$$
s=\sqrt{\frac{\sum_{j=1}^{K}\left(n_{j}-1\right)\left(S_{j}^{2}\right)}{\sum_{j=1}^{K} n_{j}-1}}
$$

where:

$$
\begin{aligned}
& n_{j}=\text { number of daily readings } \\
& \bar{x}_{j}=\text { daily mean } \\
& S_{j}=\text { daily standard deviarion } \\
& K=\text { number of days included in summations } \\
& \mathrm{K} \cdot 5
\end{aligned}
$$


Concentration Data

B. 7 
Daily Summation For Chloroprene Develoo. Toxicity (Rabbits)

From 26 Mar 1990 through 19 Apr 1990

\begin{tabular}{|c|c|c|c|c|c|c|c|c|}
\hline Summ & mary Data & for: Room & /Concentra & & & $O O E+$ & $5.00 \mathrm{E}$ & \\
\hline Date & & Mean & Std Der & Maximum & Minimum & N & $N$ in & $\% \mathrm{~N}$ in \\
\hline $26 r$ & Mar 1990 & $0.00 E+00$ & $0.000 E+00$ & $0.00 E+00$ & $0.00 E+00$ & 13 & 13 & $100.0 \%$ \\
\hline $27 N$ & Mar 1990 & $0.00 E+00$ & $0.000 E+00$ & $0.00 E+00$ & $0.00 E+00$ & 12 & 12 & $100.0 \%$ \\
\hline 281 & Mar 1990 & $0.00 E+00$ & $0.000 E+00$ & $0.00 E+00$ & $0.00 E+00$ & 26 & 26 & $100.0 \%$ \\
\hline 291 & Mar 1990 & $0.00 E+00$ & $0.000 E+00$ & $0.00 E+00$ & $0.00 E+00$ & 8 & 8 & $100.0 \%$ \\
\hline 301 & Mar 1990 & $0.00 E+00$ & $0.000 E+00$ & $0.00 E+00$ & $0.00 E+00$ & 8 & 8 & $100.0 \%$ \\
\hline 311 & Mar 1990 & $0.00 E+00$ & $0.000 E+00$ & $0.00 E+00$ & $0.00 E+00$ & 9 & 9 & $100.0 \%$ \\
\hline & Apr 1990 & $0.00 E+00$ & $0.000 E+00$ & $0.00 E+00$ & $0.00 E+00$ & 9 & 9 & $100.0 \%$ \\
\hline 2 & Apr 1990 & $0.00 E+00$ & $0.000 \mathrm{E}+00$ & $0.00 E+00$ & $0.00 E+00$ & 8 & 8 & $100.0 \%$ \\
\hline $3 A$ & Apr 1990 & $0.00 E+00$ & $0.000 E+00$ & $0.00 E+00$ & $0.00 E+00$ & 6 & 6 & $100.0 \%$ \\
\hline & Apr 1990 & $0.00 E+00$ & $0.000 E+00$ & $0.00 E+00$ & $0.00 E+00$ & 8 & 8 & $100.0 x$ \\
\hline & Apr 1990 & $0.00 E+00$ & $0.000 E+00$ & $0.00 E+00$ & $0.00 E+00$ & 8 & 8 & $100.0 \%$ \\
\hline & Apr 1990 & $0.00 E+00$ & $0.000 E+00$ & $0.00 E+00$ & $0.00 E+00$ & 9 & 9 & $100.0 \%$ \\
\hline 7 & Apr 1990 & $0.00 E+00$ & $0.000 E+00$ & $0.00 E+00$ & $0.00 E+00$ & 10 & 10 & $100.0 \%$ \\
\hline & Apr 1990 & $0.00 E+00$ & $0.000 E+00$ & $0.00 E+00$ & $0.00 E+00$ & 11 & 11 & $100.0 \%$ \\
\hline 9 & Apr 1990 & $0.00 E+00$ & $0.000 E+00$ & $0.00 E+00$ & $0.00 E+00$ & 9 & 9 & $100.0 \%$ \\
\hline 10 & Apr 1990 & $0.00 \mathrm{E}+00$ & $0.000 E+00$ & $0.00 E+00$ & $0.00 \varepsilon+00$ & 10 & 10 & $100.0 \%$ \\
\hline 11 & Apr 1990 & $0.00 E+00$ & $0.000 E+00$ & $0.00 E+00$ & $0.00 E+00$ & 11 & 11 & $100.0 \%$ \\
\hline 12 & Apr 1990 & $0.00 E+00$ & $0.000 E+00$ & $0.00 E+00$ & $0.00 E+00$ & 11 & 11 & $100.0 \%$ \\
\hline 13 & Apr 1990 & $0.00 E+00$ & $0.000 E+00$ & $0.00 E+00$ & $0.00 E+00$ & 11 & 11 & $100.0 \%$ \\
\hline 14 & Apr 1990 & $0.00 E+00$ & $0.000 E+00$ & $0.00 E+00$ & $0.00 E+00$ & 14 & 14 & $100.0 \%$ \\
\hline 15 & Apr 1990 & $0.00 E+00$ & $0.000 E+00$ & $0.00 E+00$ & $0.00 E+00$ & 10 & 10 & $100.0 \%$ \\
\hline 16 & Apr 1990 & $0.00 E+00$ & $0.000 E+00$ & $0.00 E+00$ & $0.00 E+00$ & 13 & 13 & $100.0 \%$ \\
\hline & Apr 1990 & $0.00 E+00$ & $0.000 E+00$ & $0.00 E+00$ & $0.00 E+00$ & 13 & 13 & $100.0 \%$ \\
\hline 18 & Apr 1990 & $0.00 E+00$ & $0.000 E+00$ & $0.00 E+00$ & $0.00 E+00$ & 13 & 13 & $100.0 \%$ \\
\hline 19 & Apr 1990 & $0.00 E+00$ & $0.000 E+00$ & $0.00 E+00$ & $0.00 \mathrm{E}+00$ & 12 & 12 & $100.0 \%$ \\
\hline Sum & mary & $0.00 E+00$ & $0.000 E+00$ & $0.00 E+00$ & $0.00 E+00$ & 272 & 272 & $100.0 \%$ \\
\hline
\end{tabular}

\section{Chloroprene Develop. Toxicity (Rabbits) \\ Room}

Mean \& Standard Deviation

From 26 Mar 1990 through 19 Apr 1990

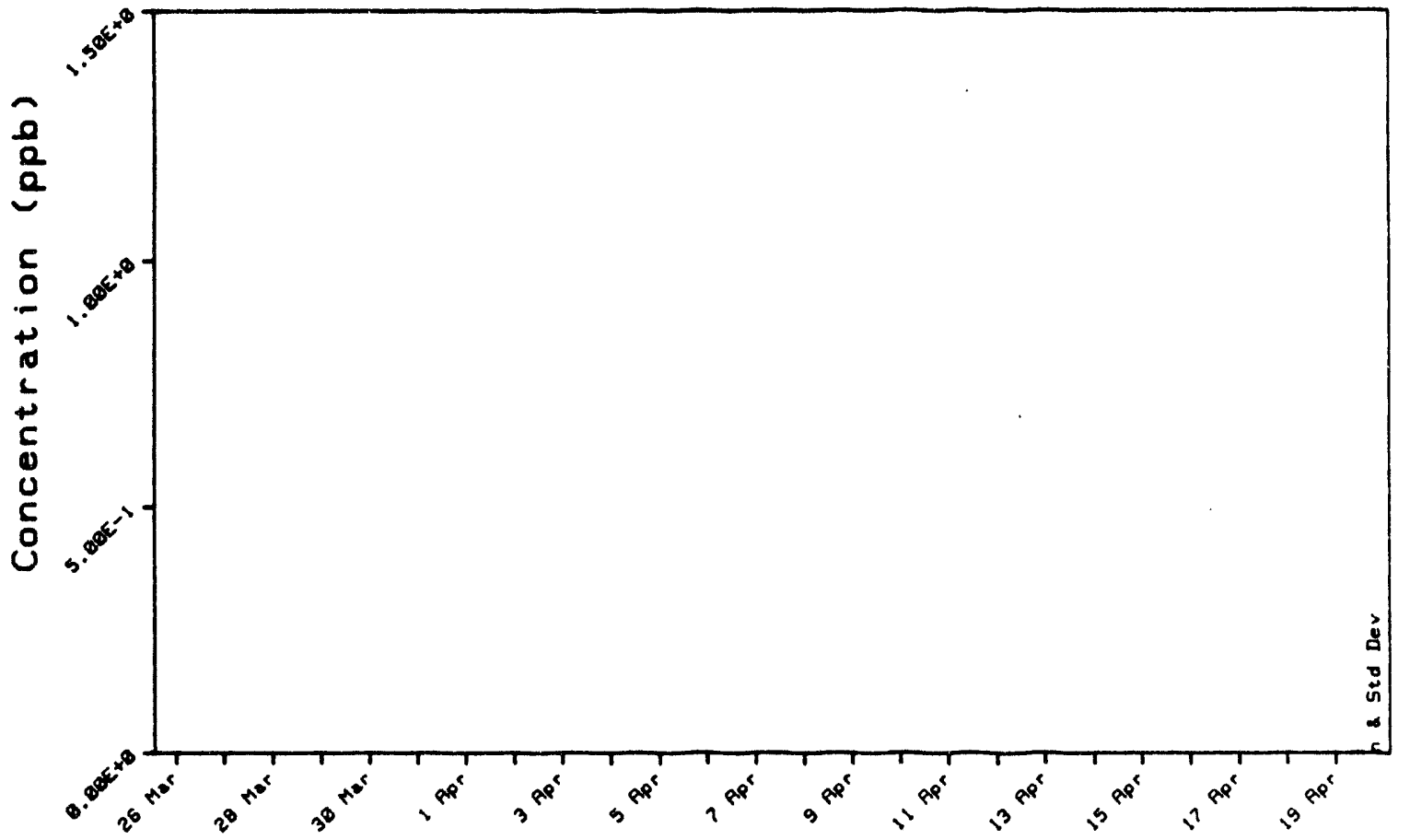


Daily Summation For Chloroprene Develop. Toxicity (Rabbits)

From 27 Mar 1990 through 19 Apr 1990

\begin{tabular}{|c|c|c|c|c|c|c|c|}
\hline Summary Data & for: $0 \mathrm{ppm}(\mathrm{A})$ & /Concentration & & & OOE+O & $5.00 \mathrm{E}-$ & \\
\hline Date & Mean & Std Dev & Maximum & Minimum & $N$ & $N$ in & $\% \mathrm{~N}$ in \\
\hline 27 Mar 1990 & $0.00 E+00$ & $0.000 E+00$ & $0.00 E+00$ & $0.00 E+00$ & 12 & 12 & $100.0 \%$ \\
\hline $28 \operatorname{Mar} 1990$ & $0.00 E+00$ & $0.000 E+00$ & $0.00 E+00$ & $0.00 E+00$ & 27 & 27 & $100.0 \%$ \\
\hline $29 \operatorname{Mar} 1990$ & $0.00 E+00$ & $0.000 E+00$ & $0.00 E+00$ & $0.00 E+00$ & 9 & 9 & $100.0 \%$ \\
\hline 30 Mar 1990 & $0.00 E+00$ & $0.000 E+00$ & $0.00 E+00$ & $0.00 E+00$ & 10 & 10 & $100.0 \%$ \\
\hline 31 Mar 1990 & $0.00 E+00$ & $0.000 E+00$ & $0.00 E+00$ & $0.00 E+00$ & 11 & 11 & $100.0 \%$ \\
\hline 1 Apr 1990 & $0.00 E+00$ & $0.000 E+00$ & $0.00 E+00$ & $0.00 E+00$ & 11 & 11 & $100.0 \%$ \\
\hline 2 Apr 1990 & $0.00 E+00$ & $0.000 E+00$ & $0.00 E+00$ & $0.00 E+00$ & 6 & 6 & $100.0 \%$ \\
\hline 3 Apr 1990 & $0.00 E+00$ & $0.000 E+00$ & $0.00 E+00$ & $0.00 E+00$ & 6 & 6 & $100.0 \%$ \\
\hline 4 Apr 1990 & $0.00 E+00$ & $0.000 E+00$ & $0.00 E+00$ & $0.00 E+00$ & 9 & 9 & $100.0 \%$ \\
\hline 5 Apr 1990 & $0.00 E+00$ & $0.000 E+00$ & $0.00 E+00$ & $0.00 E+00$ & 8 & 8 & $100.0 \%$ \\
\hline 6 Apr 1990 & $0.00 E+00$ & $0.000 E+0 n$ & $0.00 E+00$ & $0.00 E+00$ & 9 & 9 & $100.0 \%$ \\
\hline 7 Apr 1990 & $0.00 E+00$ & $0.000 E+00$ & $0.00 E+00$ & $0.00 E+00$ & 11 & 11 & $100.0 \%$ \\
\hline 8 Apr 1990 & $0.00 E+00$ & $0.000 E+00$ & $0.00 E+00$ & $0.00 E+00$ & 11 & 11 & $100.0 \%$ \\
\hline 9 Apr 1990 & $0.00 E+00$ & $0.000 E+00$ & $0.00 E+00$ & $0.00 \varepsilon+00$ & 9 & 9 & $100.0 \%$ \\
\hline 10 Apr 1990 & C. $005+00$ & $0.000 E+00$ & $0.00 E+00$ & $0.00 E+00$ & 10 & 10 & $100.0 \%$ \\
\hline 11 Apr 1990 & $0.00 E+00$ & $0.000 E+00$ & $0.00 E+00$ & $0.00 E+00$ & 11 & 11 & $100.0 \%$ \\
\hline 12 Apr 1990 & $0.00 E+00$ & $0.000 E+00$ & $0.00 E+00$ & $0.00 E+00$ & 10 & 10 & $100.0 \%$ \\
\hline 13 Apr 1990 & $0.00 E+00$ & $0.000 E+00$ & $0.00 E+00$ & $0.00 E+00$ & 9 & 9 & $100.0 \%$ \\
\hline 14 Apr 1990 & $0.00 E+00$ & $0.000 E+00$ & $0.00 E+00$ & $0.00 E+00$ & 14 & 14 & $100.0 \%$ \\
\hline 15 Apr 1990 & $0.00 E+00$ & $0.000 E+00$ & $0.00 E+00$ & $0.00 E+00$ & 10 & 10 & $100.0 \%$ \\
\hline $16 \mathrm{Apr} 1990$ & $0.00 E+00$ & $0.000 E+00$ & $0.00 E+00$ & $0.00 E+00$ & 12 & 12 & $100.0 \%$ \\
\hline 17 Apr 1990 & $0.00 E+00$ & $0.000 E+00$ & $0.00 E+00$ & $0.00 E+00$ & 12 & 12 & $100.0 \%$ \\
\hline 18 Apr 1990 & $0.00 E+00$ & $0.000 E+00$ & $0.00 E+00$ & $0.00 E+00$ & 12 & 12 & $100.0 \%$ \\
\hline 19 Apr 1990 & $0.00 E+00$ & $0.000 E+00$ & $0.00 \mathrm{E}+00$ & $0.00 \mathrm{E}+00$ & 12 & 12 & $100.0 \%$ \\
\hline Sunmary & $0.00 E+00$ & $0.000 E+00$ & $0.00 E+00$ & $0.00 E+00$ & 261 & 261 & $100.0 \%$ \\
\hline
\end{tabular}

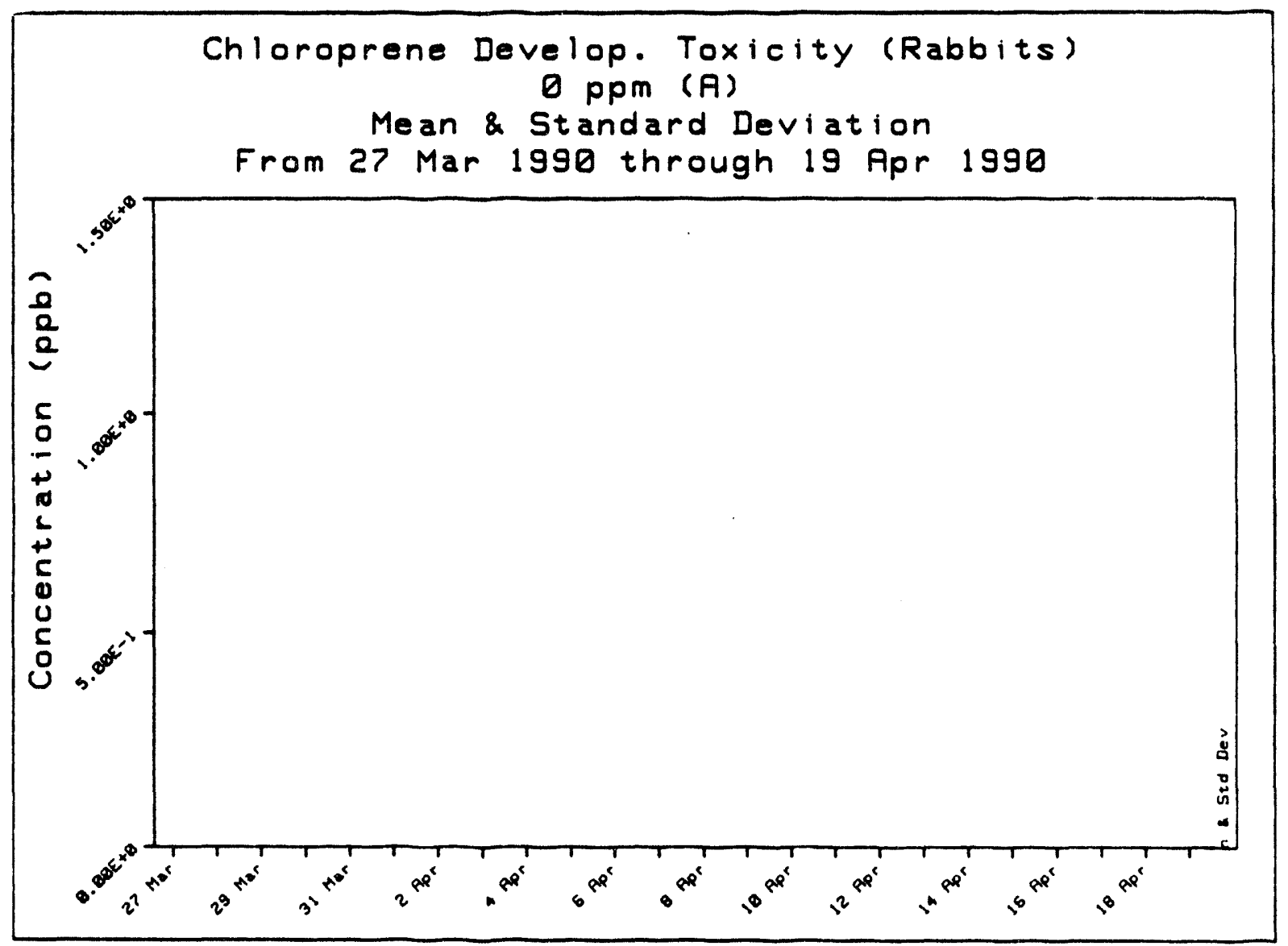


Daily Sumation For Chloroprene Develoo. Toxicity (Rabbits)

\begin{tabular}{|c|c|c|c|c|c|c|c|}
\hline \multirow{2}{*}{\multicolumn{2}{|c|}{$\begin{array}{l}\text { Sumary Data for: } 0 \text { ppen (8) } \\
\text { Date }\end{array}$}} & \multirow{2}{*}{$\begin{array}{l}\text { /Concentration } \\
\text { Std Dev }\end{array}$} & \multirow[b]{2}{*}{ Maximum } & \multicolumn{4}{|c|}{ Range $=0.00 E+0$ to $5.00 E-1$} \\
\hline & & & & Minimum & $\mathrm{N}$ & $N$ in & $X N$ in \\
\hline $26 \operatorname{Mar} 1990$ & $0.00 E+00$ & $0.000 E+00$ & $0.00 E+00$ & $0.00 E+00$ & 13 & 13 & $100.0 \%$ \\
\hline 27 Mar 1990 & $0.00 E+00$ & $0.000 E+00$ & $0.00 E+00$ & $0.00 E+00$ & 14 & 14 & $100.0 \%$ \\
\hline $28 \operatorname{Mar} 1990$ & $0.00 E+00$ & $0.000 E+\infty 00$ & $0.00 E+00$ & $0.00 E+00$ & 24 & 24 & $100.0 \%$ \\
\hline $29 \operatorname{Mar} 1990$ & $0.00 E+00$ & $0.000 E+00$ & $0.00 E+00$ & $0.00 E+00$ & 7 & 7 & $100.0 \%$ \\
\hline 30 Mar 1990 & $0.00 E+00$ & $0.000 E+00$ & $0.00 E+00$ & $0.00 E+00$ & 7 & 7 & $100.0 \%$ \\
\hline 31 Mar 1990 & $0.00 E+00$ & $0.000 E+\infty 0$ & $0.00 E+00$ & $0.00 \varepsilon+00$ & 12 & 12 & $100.0 \%$ \\
\hline 1 Apr 1990 & $0.00 E+00$ & $0.000 E+00$ & $0.00 E+00$ & $0.00 E+00$ & 11 & 11 & $100.0 \%$ \\
\hline 2 Apr 1990 & $0.00 E+00$ & $0.000 E+00$ & $0.00 E+00$ & $0.00 E+00$ & 7 & 7 & $100.0 \%$ \\
\hline 3 Apr 1990 & $0.00 E+00$ & $0.000 E+00$ & $0.00 E+00$ & $0.00 E+00$ & 5 & 5 & $100.0 \%$ \\
\hline 4 Apr 1990 & $0.00 E+00$ & $0.000 E+00$ & $0.00 E+00$ & $0.00 E+00$ & 9 & 9 & $100.0 \%$ \\
\hline 5 Apr 1990 & $0.00 E+00$ & $0.000 E+00$ & $0.00 E+00$ & $0.0 C E+00$ & 8 & 8 & $100.0 \%$ \\
\hline 6 Apr 1990 & $0.00 E+00$ & $0.000 E+00$ & $0.00 E+00$ & $0.00 E+00$ & 9 & 9 & $100.0 \%$ \\
\hline 7 Apr 1990 & $0.00 E+00$ & $0.000 E+00$ & $0.00 E+00$ & $0.00 E+00$ & 11 & 11 & $100.0 \%$ \\
\hline 8 Apr 1990 & $0.00 E+00$ & $0.000 E+00$ & $0.00 E+00$ & $0.00 E+00$ & 11. & 11 & $100.0 \%$ \\
\hline 9 Apr 1990 & $0.00 E+00$ & $0.000 E+00$ & $0.00 E+00$ & $0.00 E+00$ & 8 & 8 & $100.0 \%$ \\
\hline 10 Apr 1990 & $0.00 E+00$ & $0.000 E+00$ & $0.00 E+00$ & $0.00 E+00$ & 10 & 10 & $100.0 \%$ \\
\hline 11 Apr 1990 & $0.00 E+00$ & $0.000 E+00$ & $0.00 E+00$ & $0.00 E+00$ & 11 & 11 & $100.0 \%$ \\
\hline 12 Apr 1990 & $2.00 E+00$ & $0.000 \mathrm{E}+00$ & $0.00 E+00$ & $0.00 E+00$ & 11 & 11 & $100.0 \%$ \\
\hline 13 Apr 1990 & $0.00 E+00$ & $0.000 E+00$ & $0.00 E+00$ & $0.00 E+00$ & 11 & 11 & $100.0 \%$ \\
\hline 14 Apr 1990 & $0.00 E+00$ & $0.000 E+00$ & $0.00 E+00$ & $0.00 E+00$ & 13 & 13 & $100.0 \%$ \\
\hline 15 Apr 1990 & $0.00 E+00$ & $0.000 E+00$ & $0.00 E+30$ & $0.00 E+00$ & 11 & 11 & $100.0 \%$ \\
\hline 16 Apr 1990 & $0.00 E+00$ & $0.000 E+00$ & $0.00 E+\infty 0$ & $0.00 E+00$ & 13 & 13 & $100.0 \%$ \\
\hline 17 Apr 1990 & $0.00 E+00$ & $0.000 E+00$ & $0.00 E+00$ & $0.00 E+00$ & 12 & 12 & $100.0 \%$ \\
\hline 18 Apr 1990 & $0.00 \mathrm{E}+00$ & $0.000 E+00$ & $0.00 E+00$ & $0.00 \mathrm{E}+00$ & 13 & 13 & $100.0 \%$ \\
\hline Sumary & $0.00 E+00$ & $0.000 E+00$ & $0.00 E+00$ & $0.00 E+00$ & 261 & 261 & $100.0 \%$ \\
\hline
\end{tabular}

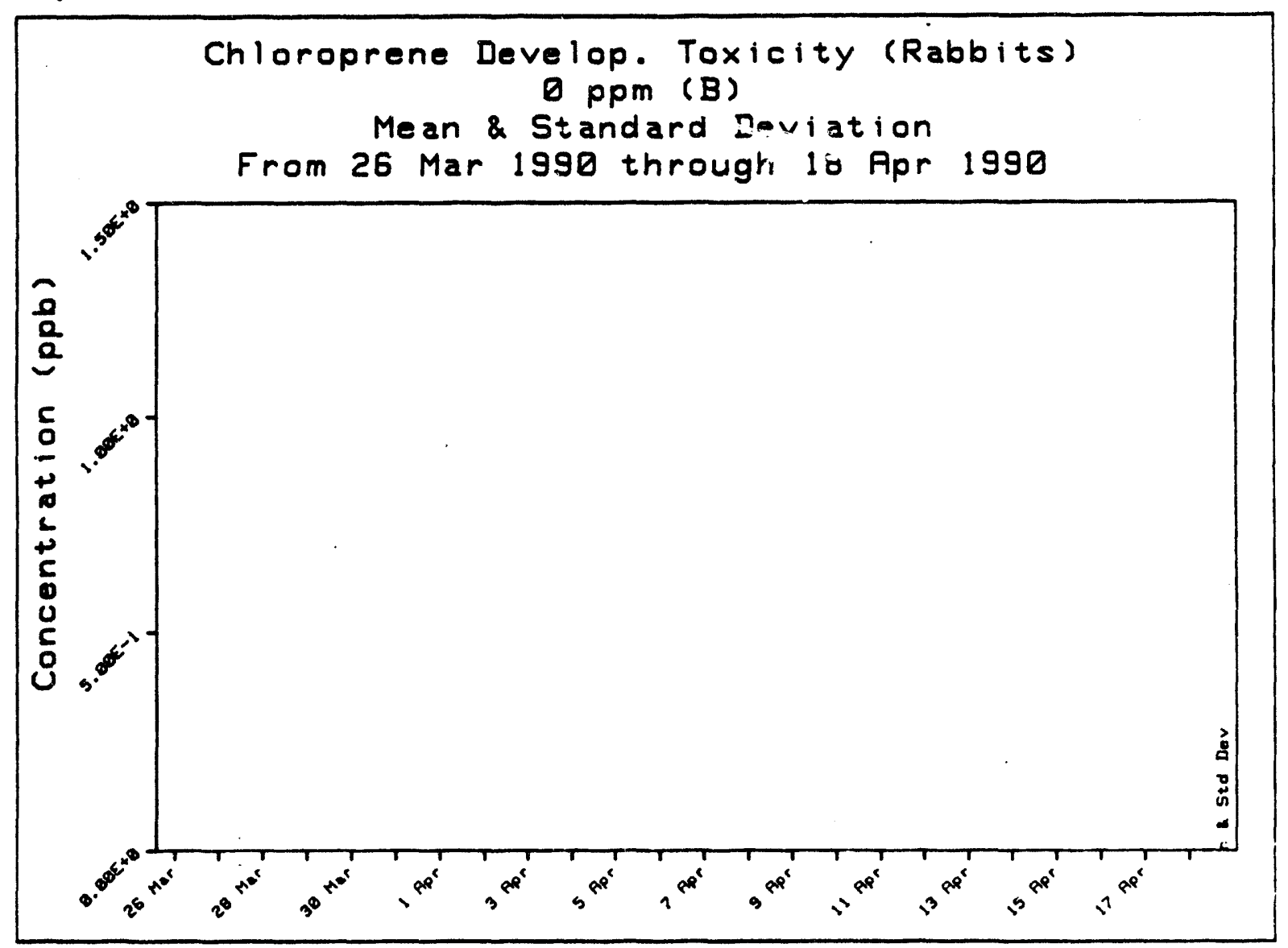


Daily Summation For Chloroprene Develon. Toxicity (Rabbits)

From 26 Mar 1990 through 18 Apr 1990

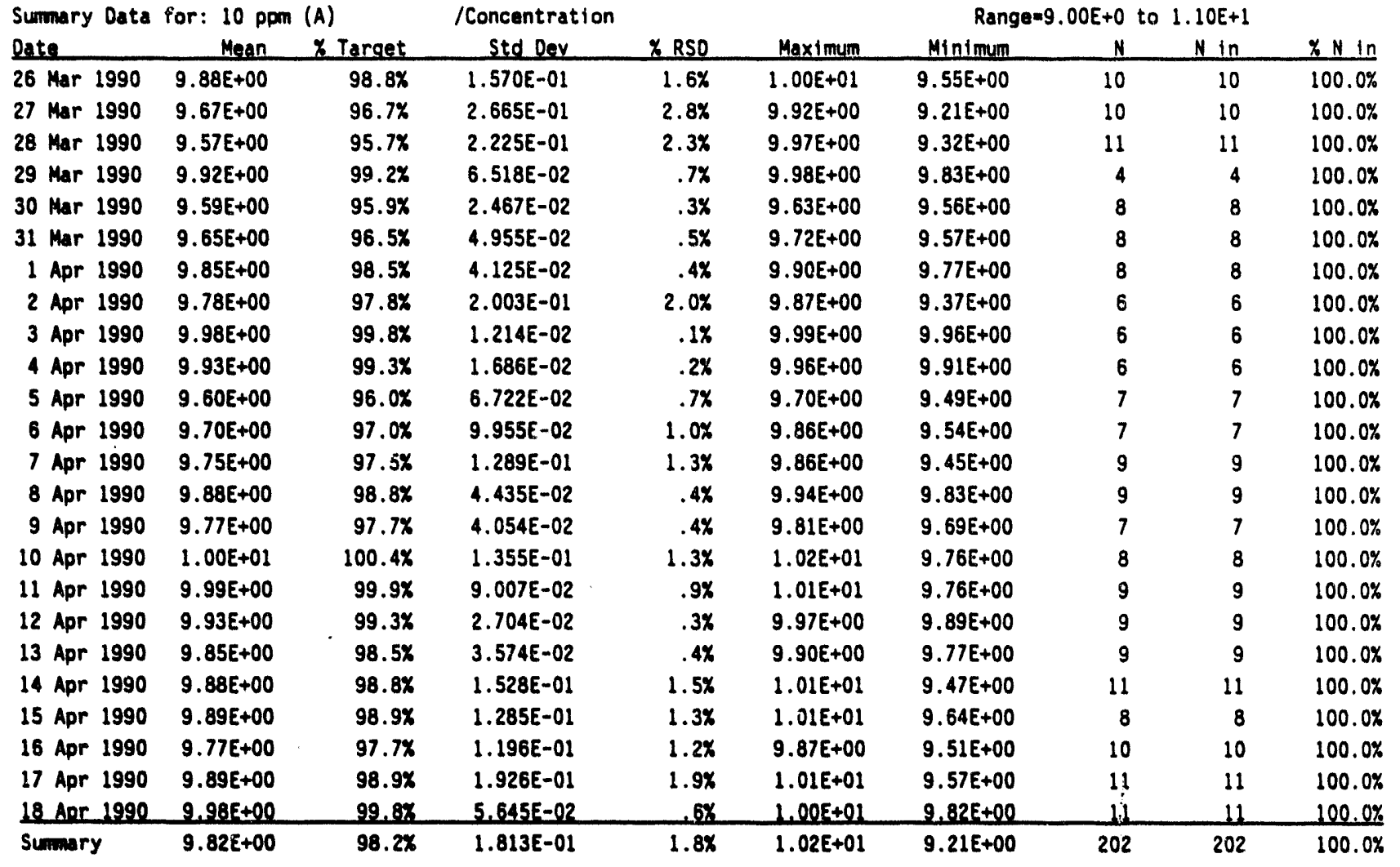

Chloroprene Develop. Toxicity (Rabbits) 10 ppm (A)

Mean \& Standard Deviation

From 26 Mar 1990 through 18 Apr 1990

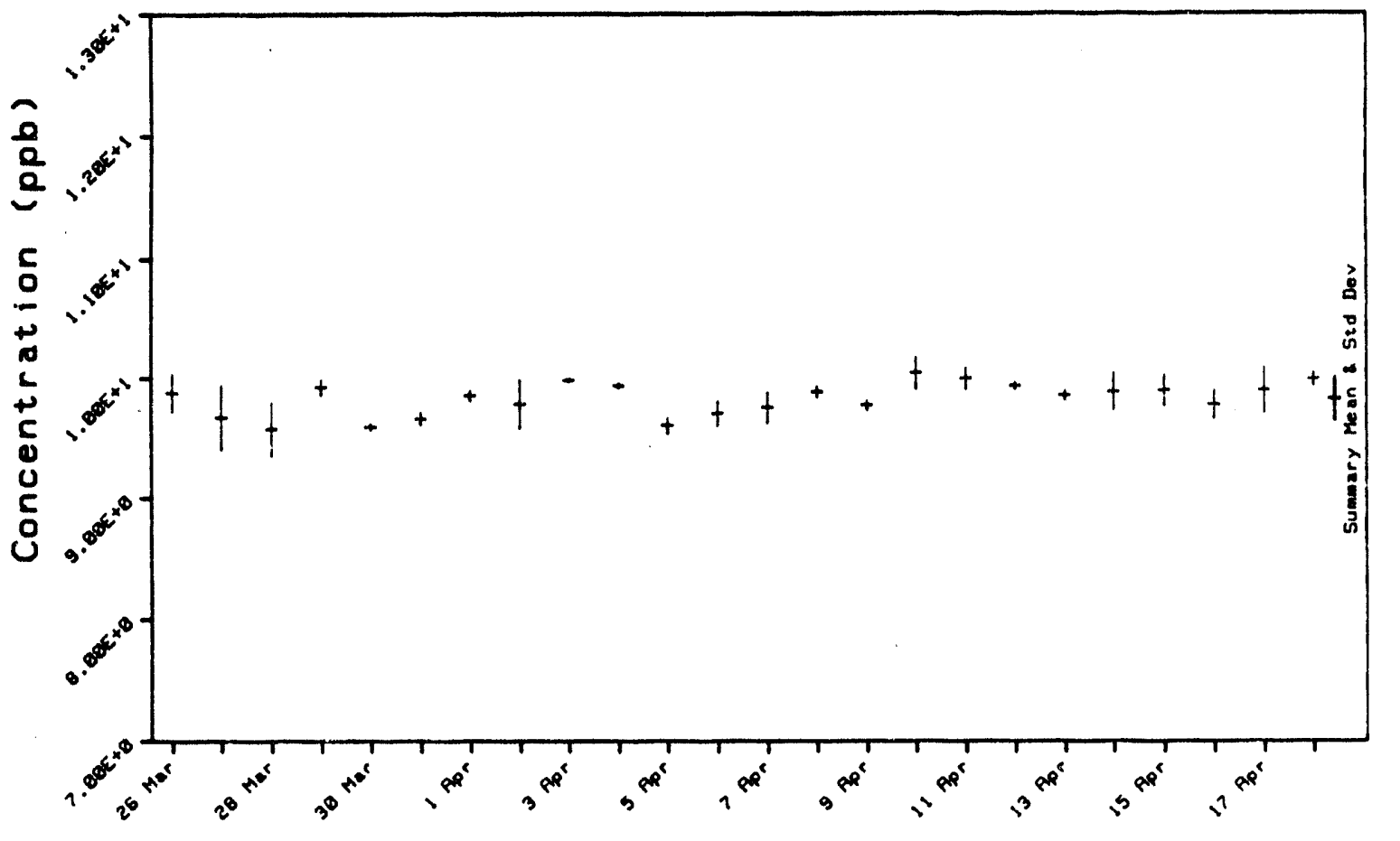


Daily Sumation for Chloroprene Develop. Toxicity (Rabbits)

From 27 Mar 1990 through 19 Apr 1990

\begin{tabular}{|c|c|c|c|c|c|c|c|c|c|}
\hline Summary Data & for: $10 \mathrm{ppr}$ & (B) & /Concentrat & & & Rang & $E+0$ & $.10 E+1$ & \\
\hline Date & Mean & $x$ Tarqet & Std Dev & $\times$ RSO & Maximum & Minimum & $N$ & $N$ in & $x \mathrm{~N}$ in \\
\hline 27 Mar 1990 & $1.01 E+01$ & $101.3 \%$ & $1.565 E-01$ & $1.5 \%$ & $1.04 E+01$ & $9.92 E+00$ & 10 & 10 & $100.0 \%$ \\
\hline $28 \operatorname{Mar} 1990$ & $1.00 E+01$ & $100.2 \%$ & $3.309 E-01$ & $3.3 \%$ & $1.05 E+01$ & $9.28 E+00$ & 11 & 11 & $100.0 \%$ \\
\hline $29 \operatorname{Mar} 1990$ & $1.02 E+01$ & $102.1 \%$ & $2.575 E-01$ & $2.5 \%$ & $1.05 E+01$ & $9.87 E+00$ & 4 & 4 & $100.0 \%$ \\
\hline 30 Mar 1990 & $9.42 E+00$ & $94.2 \%$ & $6.754 E-02$ & $.7 \%$ & $9.49 E+00$ & $9.27 E+00$ & 8 & 8 & $100.0 \%$ \\
\hline 31 Mar 1990 & $9.58 E+00$ & $95.8 \%$ & $1.123 \mathrm{E}-01$ & $1.2 \%$ & $9.75 E+00$ & $9.38 \varepsilon+00$ & 8 & 8 & $100.0 \%$ \\
\hline 1 Apr 1990 & $9.93 E+00$ & $99.3 x$ & $1.791 E-01$ & $1.8 \%$ & $1.02 E+01$ & $9.66 E+00$ & 8 & 8 & $100.0 \%$ \\
\hline 2 Apr 1990 & $9.88 E+00$ & $98.8 \%$ & $2.335 E-01$ & $2.4 x$ & $1.02 E+01$ & $9.60 E+00$ & 5 & 5 & $100.0 \%$ \\
\hline 3 Apr 1990 & $1.01 E+01$ & $100.8 \%$ & $2.221 E-01$ & $2.2 \%$ & $1.03 E+01$ & $9.80 E+00$ & 7 & 7 & $100.0 \%$ \\
\hline 4 Apr 1990 & $9.95 E+00$ & $99.5 \%$ & $1.567 E-01$ & $1.6 x$ & $1.02 E+01$ & $9.76 E+00$ & 7 & 7 & $100.0 \%$ \\
\hline 5 Apr 1990 & $9.76 E+00$ & $97.6 \%$ & $1.674 E-02$ & $.2 \%$ & $9.79 E+00$ & $9.75 E+00$ & 6 & 6 & $100.0 \%$ \\
\hline 6 Apr 1990 & $9.72 E+00$ & $97.2 \%$ & $1.548 E-01$ & $1.6 \%$ & $9.83 E+00$ & $9.39 E+00$ & 7 & 7 & $100.0 \%$ \\
\hline 7 Apr 1990 & $9.90 E+00$ & $99.0 \%$ & $1.784 E-01$ & $1.8 \%$ & $1.01 E+01$ & $9.58 E+00$ & 9 & 9 & $100.0 \%$ \\
\hline 8 Apr 1990 & $9.95 E+00$ & $99.5 \%$ & $2.936 E-02$ & $.3 \%$ & $1.00 E+01$ & $9.91 E+00$ & 9 & 9 & $100.0 \%$ \\
\hline 9 Apr 1990 & $1.02 E+01$ & $101.8 \%$ & $3.716 E-02$ & $.4 \%$ & $1.02 E+01$ & $1.01 E+01$ & 7 & 7 & $100.0 \%$ \\
\hline 10 Apr 1990 & $9.85 E+00$ & $98.5 \%$ & $5.126 E-02$ & $.5 \%$ & $9.91 E+00$ & $9.77 E+00$ & 8 & 8 & $100.0 \%$ \\
\hline 11 Apr 1990 & $9.94 E+00$ & $99.4 x$ & $3.611 E-02$ & $.4 \%$ & $1.00 E+01$ & $9.89 E+00$ & 9 & 9 & $100.0 \%$ \\
\hline 12 Apr 1990 & $9.92 E+00$ & $99.2 x$ & $1.976 E-02$ & $.2 x$ & $9.95 E+00$ & $9.89 E+00$ & 9 & 9 & $100.0 \%$ \\
\hline 13 Apr 1990 & $9.90 \mathrm{E}+00$ & $99.0 \%$ & $2.469 E-02$ & $.2 x$ & $9.94 E+00$ & $9.86 E+00$ & 9 & 9 & $100.0 \%$ \\
\hline 14 Apr 1990 & $9.99 E+00$ & $99.9 \%$ & $1.361 E-01$ & $1.4 \%$ & $1.02 E+01$ & $9.79 E+00$ & 11 & 11 & $100.0 \%$ \\
\hline 15 Apr 1990 & $9.90 E+00$ & $99.1 \%$ & $6.538 E-02$ & $.7 \%$ & $9.95 E+00$ & $9.76 E+00$ & 8 & 8 & $100.0 \%$ \\
\hline 16 Apr 1990 & $1.00 E+01$ & $100.4 x$ & $7.638 \mathrm{E}-02$ & $.8 \%$ & $1.01 E+01$ & $9.83 E+00$ & 10 & 10 & $100.0 \%$ \\
\hline 17 Apr 1990 & $1.01 E+01$ & $101.0 \%$ & $4.315 E-02$ & $.4 \%$ & $1.02 E+01$ & $1.01 E+01$ & 11 & 11 & $100.0 \%$ \\
\hline 18 Apr 1990 & $1.01 E+01$ & $100.6 \%$ & $4.765 E-02$ & $.5 \%$ & $1.01 E+01$ & $9.95 E+00$ & 11 & 11 & $100.0 \%$ \\
\hline 19 Apr 1990 & $1.02 E+01$ & $101.9 \%$ & $4.296 \mathrm{E}-02$ & $.4 \%$ & $1.02 E+01$ & $1.01 E+01$ & 10 & 10 & $100.0 \%$ \\
\hline Summary & $9.95 E+00$ & $99.5 \%$ & $2.181 E-01$ & $2.2 \%$ & $1.05 E+01$ & $9.27 E+00$ & 202 & 202 & $100.0 \%$ \\
\hline
\end{tabular}

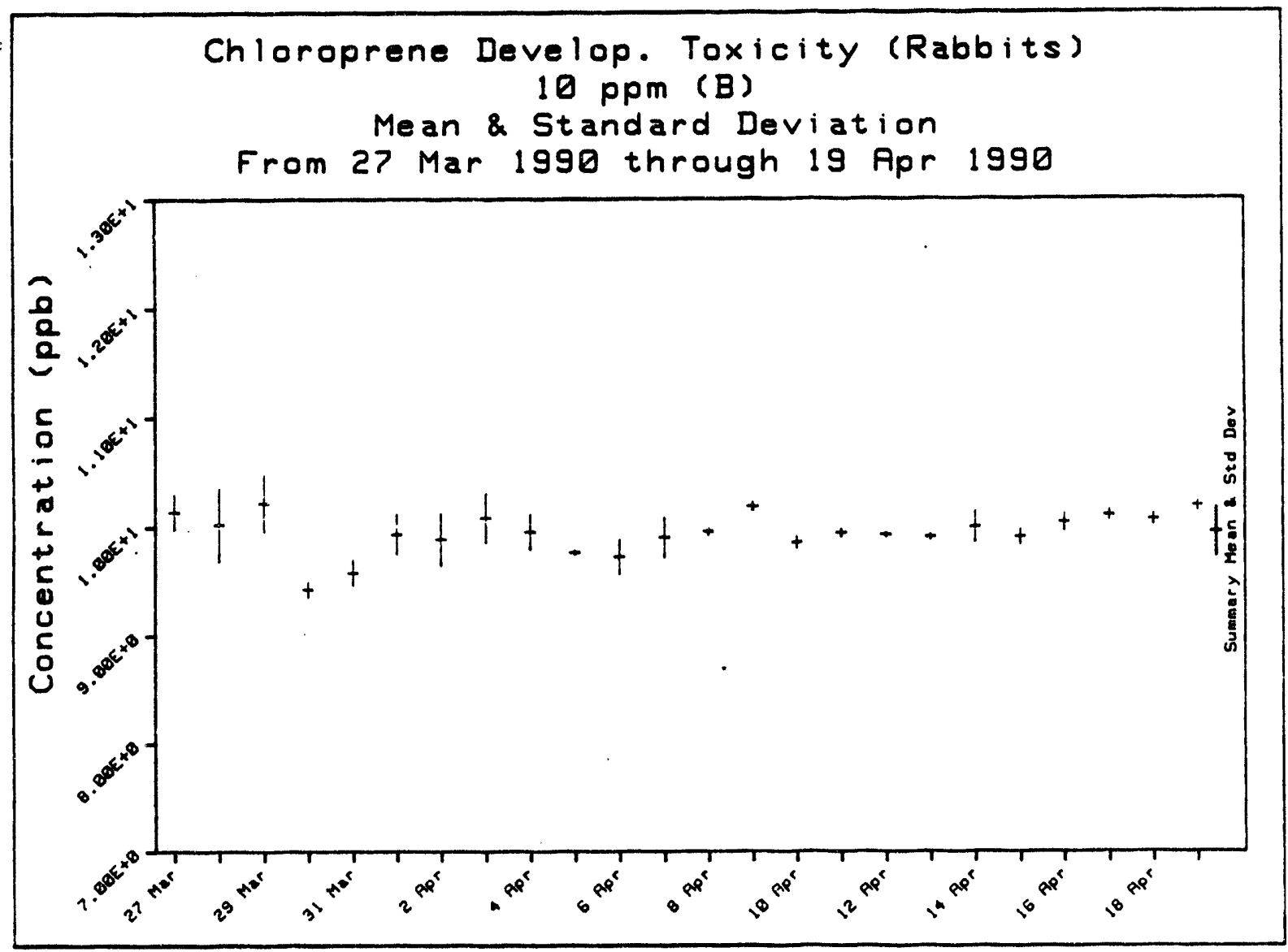


Daily Summation For Chloroprene Develoo. Toxicity (Rabbits) From 26 Mar 1990 through 18 Apr 1990

\begin{tabular}{|c|c|c|c|c|c|c|c|c|c|}
\hline Sumnary Data & for: $40 \mathrm{ppr}$ & (A) & /Concentrat & & & Rang & $E+1$ & $40 E+1$ & \\
\hline Date & Mean & * Target & Std Dev & $x$ RSO & Maximuin & Minimum & $\mathrm{N}$ & $N$ in & $\mathrm{XN}$ in \\
\hline 26 Mar 1990 & $3.92 E+01$ & $98.1 \%$ & $8.761 E-01$ & $2.2 \%$ & $3.98 \mathrm{E}+01$ & $3.73 E+01$ & 8 & 8 & $100.0 \%$ \\
\hline 27 Mar 1990 & $3.91 E+01$ & $97.9 \%$ & $3.749 E-01$ & $1.0 \%$ & $3.94 E+01$ & $3.83 E+01$ & 9 & 9 & $100.0 \%$ \\
\hline $28 \operatorname{Mar} 1990$ & $3.99 \mathrm{E}+01$. & $99.8 x$ & $2.705 E-01$ & $.7 \%$ & $4.03 E+01$ & $3.94 E+01$ & 10 & 10 & $100.0 \%$ \\
\hline $29 \operatorname{Mar} 1990$ & $4.06 E+01$ & $101.6 \%$ & $1.305 E-01$ & $.3 \%$ & $4.08 E+01$ & $4.05 E+01$ & 4 & 4 & $100.0 \%$ \\
\hline 30 Mar 1990 & $3.82 E+01$ & $95.5 x$ & $1.718 \mathrm{E}-01$ & $.4 \%$ & $3.84 E+01$ & $3.79 E+01$ & 8 & 8 & $100.0 \%$ \\
\hline $31 \operatorname{Mar} 1990$ & $3.85 E+01$ & $96.3 \%$ & $5.420 E-01$ & $1.4 \%$ & $3.92 E+01$ & $3.75 E+01$ & 8 & 8 & $100.0 \%$ \\
\hline 1 Apr 1990 & $4.01 E+01$ & $100.3 \%$ & $4.018 E-01$ & $1.0 \%$ & $4.05 E+01$ & $3.92 E+01$ & 8 & 8 & $100.0 \%$ \\
\hline 2 Apr 1990 & $4.00 E+01$ & $99.9 \%$ & $1.494 E-01$ & $.4 x$ & $4.01 E+01$ & $3.98 E+01$ & 5 & 5 & $100.0 \%$ \\
\hline 3 Apr 1990 & $3.99 \varepsilon+01$ & $99.8 \%$ & $1.782 E-01$ & $.4 \%$ & $4.01 E+01$ & $3.97 E+01$ & 5 & 5 & $100.0 \%$ \\
\hline 4 Apr 1990 & $3.98 E+01$ & $99.5 \%$ & $2.481 E-01$ & $.6 \%$ & $4.01 E+01$ & $3.95 E+01$ & 6 & 6 & $100.0 \%$ \\
\hline 5 Apr 1990 & $3.95 E+01$ & $98.8 \%$ & $6.071 E-01$ & $1.5 \%$ & $4.02 E+01$ & $3.85 E+01$ & 7 & 7 & $100.0 \%$ \\
\hline 6 Apr 1990 & $3.97 E+01$ & $99.2 \%$ & $4.724 E-01$ & $1.2 \%$ & $4.00 E+01$ & $3.87 E+01$ & 7 & 7 & $100.0 \%$ \\
\hline 7 Apr 1990 & $3.97 E+01$ & $99.3 \%$ & $2.579 E-01$ & $.6 \%$ & $4.01 E+01$ & $3.94 E+01$ & 9 & 9 & $100.0 \%$ \\
\hline 8 Apr 1990 & $3.95 E+01$ & $98.8 \%$ & $6.145 E-01$ & $1.6 \%$ & $4.00 E+01$ & $3.80 E+01$ & 9 & 9 & $100.0 \%$ \\
\hline 9 Apr 1990 & $3.99 E+01$ & $99.8 \%$ & $3.035 E-01$ & $.8 \%$ & $4.02 E+01$ & $3.92 E+01$ & 8 & 8 & $100.0 \%$ \\
\hline $10 \mathrm{Apr} 1990$ & $3.96 E+01$ & $99.1 \%$ & $4.904 E-01$ & $1.2 \%$ & $4.01 E+01$ & $3.88 E+01$ & 8 & 8 & $100.0 \%$ \\
\hline 11 Apr 1990 & $3.99 E+01$ & $99.6 \%$ & $3.861 E-01$ & $1.0 \%$ & $4.01 E+01$ & $3.89 E+01$ & 9 & 9 & $100.0 \%$ \\
\hline 12 Apr 1990 & $3.95 E+01$ & $98.8 \%$ & $5.608 E-01$ & $1.4 x$ & $3.99 E+01$ & $3.81 E+01$ & 9 & 9 & $100.0 \%$ \\
\hline 13 Apr 1990 & $3.91 E+01$ & $97.8 \%$ & $5.883 E-01$ & $1.5 \%$ & $3.94 E+01$ & $3.76 E+01$ & 9 & 9 & $100.0 \%$ \\
\hline 14 Apr 1990 & $3.93 E+01$ & $98.3 \%$ & 5.797E-01 & $1.5 \%$ & $4.01 E+01$ & $3.85 E+01$ & 10 & 10 & $100.0 \%$ \\
\hline 15 Apr 1990 & $3.97 E+01$ & $99.3 x$ & $6.144 E-01$ & $1.5 \%$ & $4.02 E+01$ & $3.87 E+01$ & 7 & 7 & $100.0 \%$ \\
\hline 16 Apr 1990 & $4.04 E+01$ & $100.9 \%$ & $8.352 E-01$ & $2.1 \%$ & $4.07 E+01$ & $3.81 E+01$ & 9 & 9 & $100.0 \%$ \\
\hline 17 Apr 1990 & $3.91 E+01$ & $97.8 x$ & $6.014 E-01$ & $1.5 x$ & $4.04 E+01$ & $3.83 E+01$ & 10 & 10 & $100.0 \%$ \\
\hline 18 Aor 1990 & $3.93 E+01$ & $98.3 \%$ & $6.687 E-02$ & $.2 \%$ & $3.94 E+01$ & $3.93 E+01$ & 10 & 10 & $100.0 \%$ \\
\hline Summary & $3.95 E+01$ & $98.8 \%$ & $6.860 E-01$ & $1.7 x$ & $4.08 E+01$ & $3.73 E+01$ & 192 & 192 & $100.0 \%$ \\
\hline
\end{tabular}

Chloroprene Develop. Toxicity (Rablits) $40 \mathrm{ppm}$ ( $A$ )

Mean \& Standard Deviation From 26 Mar 1990 through 18 Apr 1990

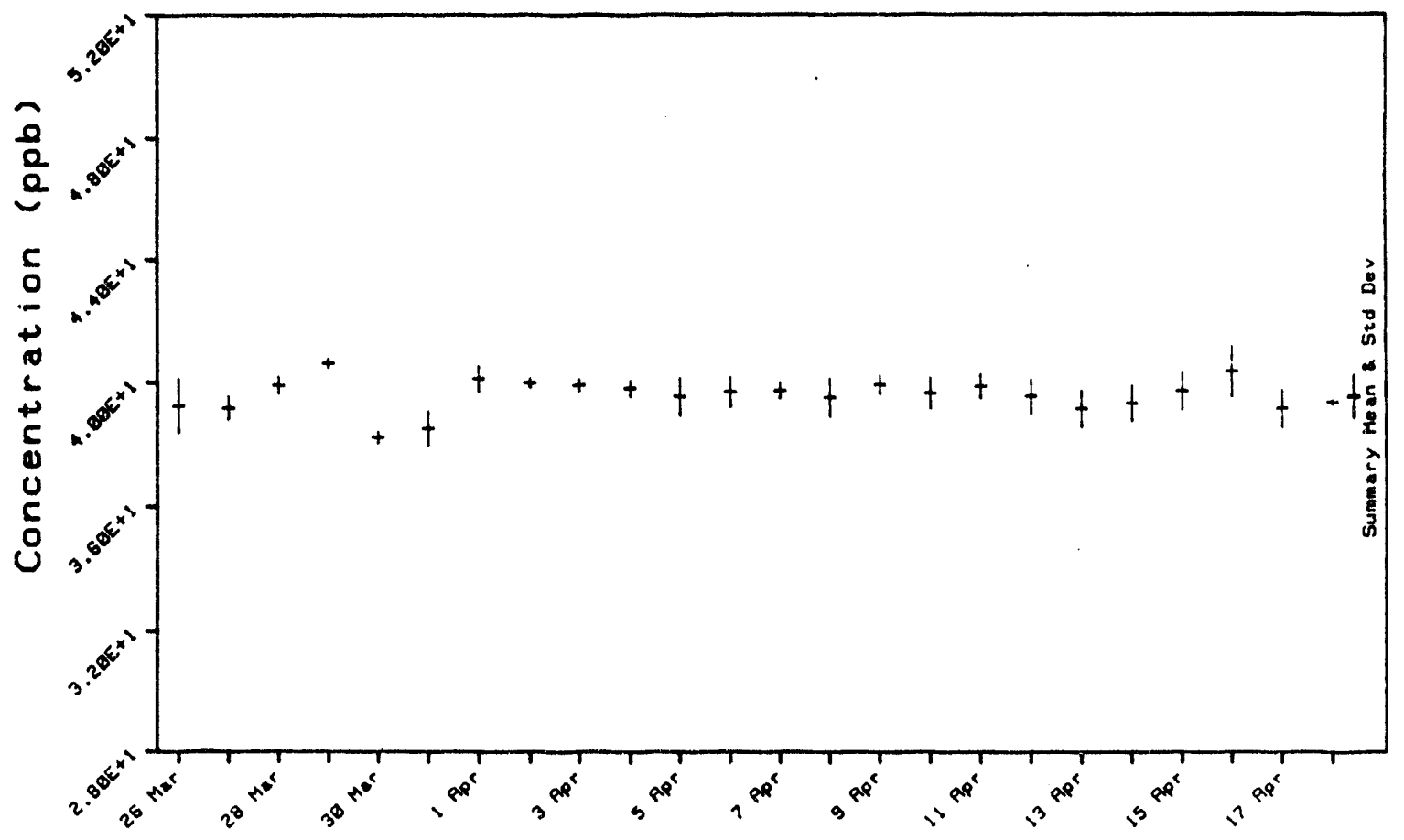


Daily Sumation For Chloroprene Develon. Toxicity (Rabbits)

\begin{tabular}{|c|c|c|c|c|c|c|c|c|c|}
\hline Summary Data & for: $40 \mathrm{ppm}$ & (B) & /Concentrat & & & Rang & $E+1$ & $.40 E+1$ & \\
\hline Date & Mean & $x$ Taraet & Std Dev & $\times$ RSD & Maximum & Minimum & $N$ & $\mathrm{~N}$ in & $X N$ in \\
\hline $27 \operatorname{Mar} 1990$ & $3.92 E+01$ & $97.9 \%$ & $4.901 E-01$ & $1.3 \%$ & $3.94 E+01$ & $3.78 E+01$ & 10 & 10 & $100.0 \%$ \\
\hline $28 \operatorname{Mar} 1990$ & $4.04 E+01$ & $101.1 \%$ & $1.560 E+00$ & $3.9 \%$ & $4.24 E+01$ & $3.75 E+01$ & 11 & 11 & $100.0 \%$ \\
\hline $29 \operatorname{Mar} 1990$ & $4.06 E+01$ & $101.6 \%$ & $3.092 E-01$ & $.8 \%$ & $4.11 E+01$ & $4.04 E+01$ & 4 & 4 & $100.0 \%$ \\
\hline 30 Mar 1990 & $3.83 E+01$ & $95.8 \%$ & $7.906 \mathrm{E}-02$ & $.2 \%$ & $3.84 E+01$ & $3.82 E+01$ & 8 & 8 & $100.0 \%$ \\
\hline 31 Mar 1990 & $3.87 E+01$ & $96.6 \%$ & $2.483 E-01$ & $.6 \%$ & 3. $92 E+01$ & $3.83 E+01$ & 8 & 8 & $100.0 \%$ \\
\hline 1 Apr 1990 & $3.97 E+01$ & $99.3 \%$ & $1.800 E-01$ & $.5 \%$ & $3.99 \mathrm{E}+01$ & $3.94 E+01$ & 8 & 8 & $100.0 \%$ \\
\hline 2 Apr 1990 & $3.98 E+01$ & $99.5 \%$ & $1.837 \mathrm{E}-01$ & $.5 \%$ & $4.01 E+01$ & $3.96 E+01$ & 6 & 6 & $100.0 \%$ \\
\hline 3 Apr 1990 & $3.96 E+01$ & $98.9 \%$ & $2.009 E-01$ & $.5 \%$ & $3.98 E+01$ & $3.93 E+01$ & 5 & 5 & $100.0 \%$ \\
\hline 4 Apr 1990 & $3.94 E+01$ & $98.5 \%$ & 4.170E-01 & $1.1 \mathrm{x}$ & $3.97 E+01$ & $3.88 E+01$ & 6 & 6 & $100.0 \%$ \\
\hline 5 Apr 1990 & $3.86 E+01$ & $96.6 \%$ & 2.299E-01 & $.6 \%$ & $3.89 E+01$ & $3.83 E+01$ & 7 & 7 & $100.0 \%$ \\
\hline 6 Apr 1990 & $3.88 E+01$ & $97.0 \%$ & $5.284 E-01$ & $1.4 \%$ & $3.94 E+01$ & $3.78 E+01$ & 7 & 7 & $100.0 \%$ \\
\hline 7 Apr 1990 & $3.99 E+01$ & $99.8 \%$ & $1.231 E+00$ & $3.1 \%$ & $4.14 E+01$ & $3.82 E+01$ & 9 & 9 & $100.0 \%$ \\
\hline $8 \mathrm{Apr} 1990$ & $4.05 E+01$ & $101.3 x$ & $4.004 E-01$ & $1.0 \%$ & 4. $10 E+01$ & $3.97 E+01$ & 9 & 9 & $100.0 \%$ \\
\hline 9 Apr 1990 & $4.00 E+01$ & $100.0 \%$ & $8.831 E-01$ & $2.2 \%$ & $4.16 E+01$ & $3.94 E+01$ & 7 & 7 & $100.0 \%$ \\
\hline 10 Apr 1990 & $3.96 \mathrm{E}+01$ & $98.9 \%$ & $2.974 E-01$ & $.8 \%$ & $3.99 E+01$ & $3.91 E+01$ & 8 & 8 & $100.0 \%$ \\
\hline 11 Apr 1990 & $3.93 E+01$ & $98.2 \%$ & $2.561 E-01$ & $.7 \%$ & $3.96 E+01$ & $3.88 E+01$ & 9 & 9 & $100.0 \%$ \\
\hline 12 Apr 1990 & $3.90 E+01$ & $97.5 x$ & $4.879 E-01$ & $1.3 \%$ & $4.02 E+01$ & $3.86 E+01$ & 9 & 9 & $100.0 \%$ \\
\hline 13 Apr 1990 & $4.03 E+01$ & $100.9 \%$ & $2.426 \mathrm{E}-01$ & $.6 x$ & $4.08 E+01$ & $3.99 E+01$ & 9 & 9 & $100.0 \%$ \\
\hline $14 \mathrm{Apr} 1990$ & $4.02 E+01$ & $100.4 x$ & $8.268 E-01$ & $2.1 \%$ & $4.16 E+01$ & $3.89 E+01$ & 11 & 11 & $100.0 \%$ \\
\hline 15 Apr 1990 & $4.01 E+01$ & $100.2 \%$ & 5.503E-01 & $1.4 x$ & $4.11 E+01$ & $3.95 E+01$ & 8 & 8 & $100.0 \%$ \\
\hline 16 Apr 1990 & $3.96 E+01$ & $99.0 \%$ & $3.798 E-01$ & $1.0 x$ & $4.00 E+01$ & $3.88 E+01$ & 10 & 10 & $100.0 \%$ \\
\hline 17 Apr 1990 & $3.98 E+01$ & $99.5 \%$ & $3.604 E-01$ & $.9 x$ & $4.01 E+01$ & $3.88 E+01$ & 11 & 11 & $100.0 \%$ \\
\hline $18 \mathrm{Apr} 1990$ & $3.95 E+01$ & $98.8 \%$ & $4.956 E-01$ & $1.3 x$ & $3.99 E+01$ & $3.82 E+11$ & 11 & 11 & $100.0 \%$ \\
\hline 19 Apr 1990 & $4.00 E+01$ & $100.0 \%$ & $6.393 E-01$ & $1.6 \%$ & $4.03 E+01$ & $3.82 E+01$ & 10 & 10 & $100.0 \%$ \\
\hline Sumiary & $3.96 E+01$ & $99.1 \%$ & $8.406 E-01$ & $2.1 \%$ & $4.24 E+01$ & $3.75 E+01$ & 201 & 201 & $100.0 \%$ \\
\hline
\end{tabular}

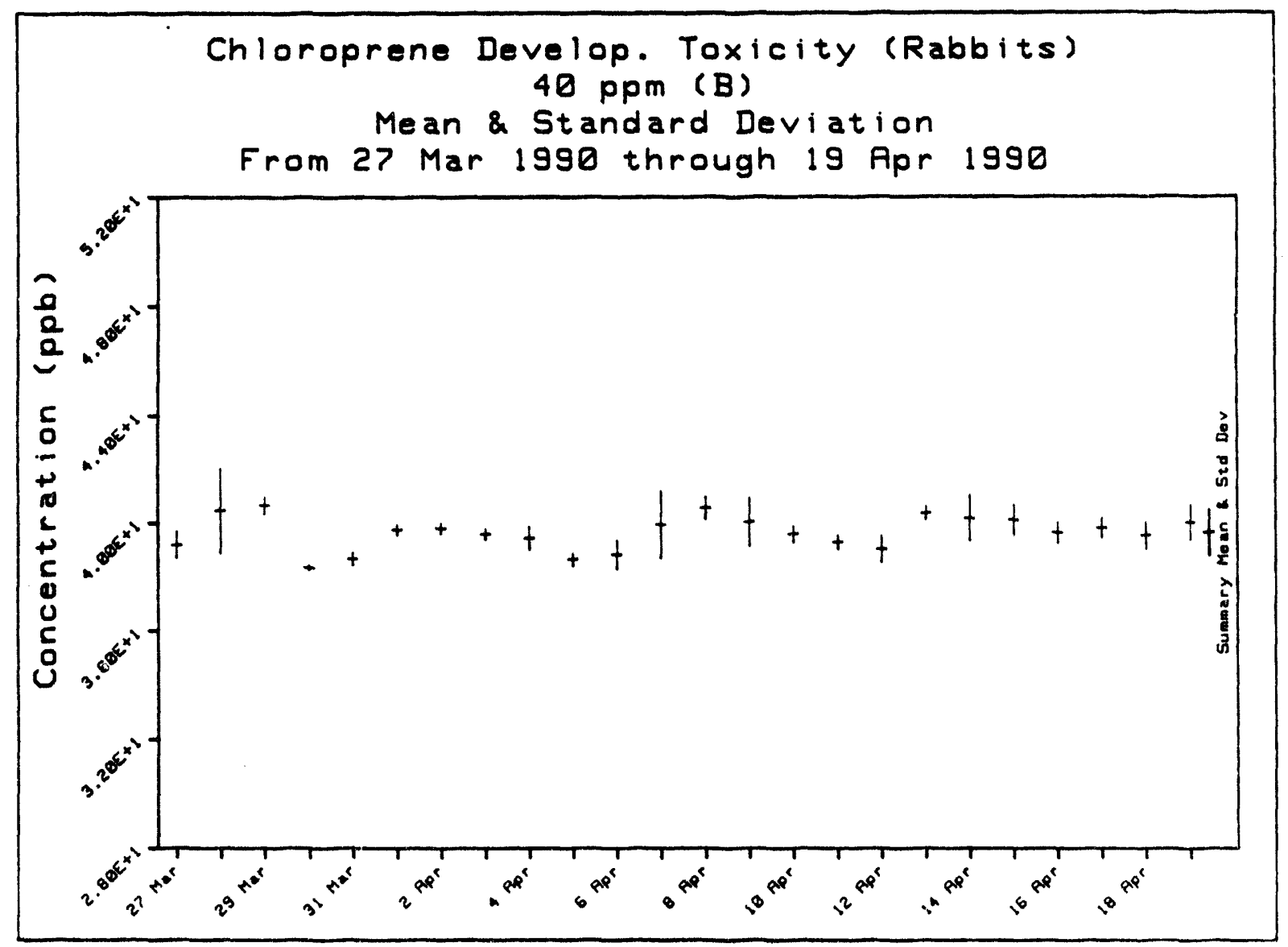


Daily Sumation For Chloroorene Develoo. Toxicity (Rabbits)

From 26 Mar 1990 through 18 Apr 1990

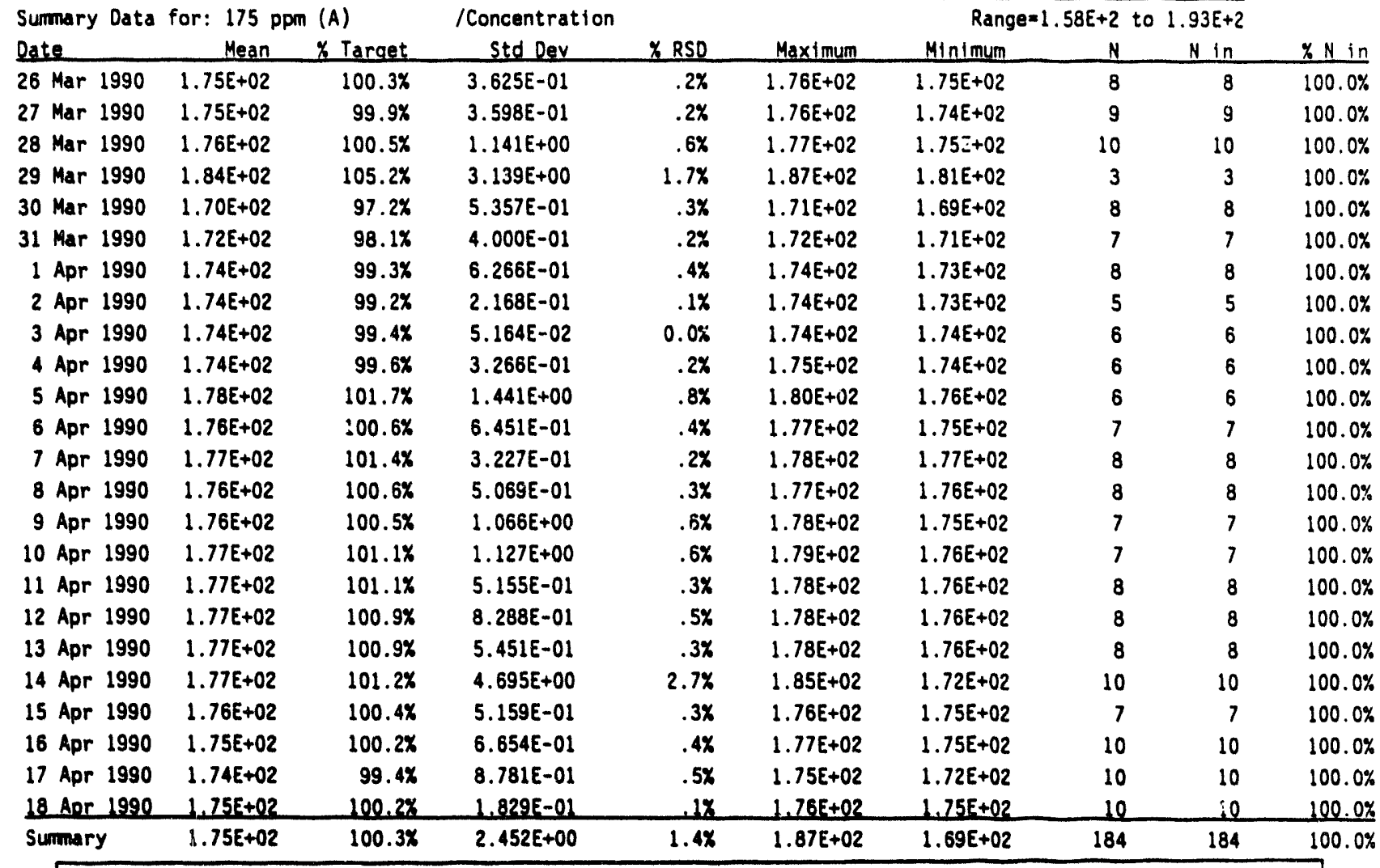

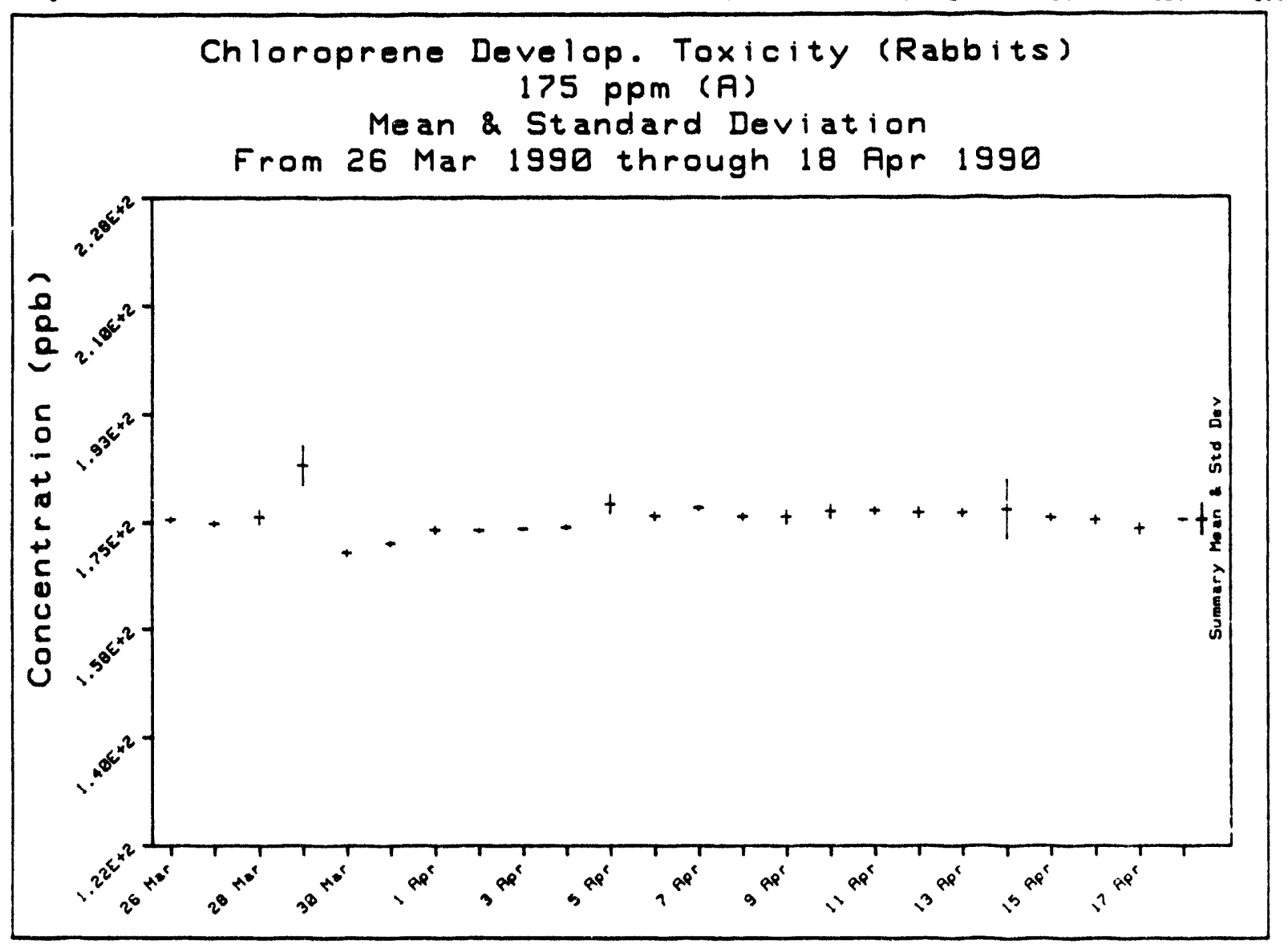


Datly Sumation for Chloroprene Develop. Toxicity (Rabbits)

\begin{tabular}{|c|c|c|c|c|c|c|c|c|c|}
\hline \multicolumn{3}{|c|}{ Summary Data for: 175 ppm (B) } & \multicolumn{3}{|c|}{ /Concentration } & \multicolumn{4}{|c|}{ Range $=1.58 \mathrm{E}+2$ to $1.93 \mathrm{E}+2$} \\
\hline Date & Mean & $x$ Target & Std Der & X RSD & Maximum & Minimum & $\mathrm{N}$ & $N$ in & $X N$ in \\
\hline $27 \operatorname{Mar} 1990$ & $1.74 E+02$ & $99.6 \%$ & $2.991 E-01$ & $.2 \%$ & $1.75 E+02$ & $1.74 E+02$ & 9 & 9 & $100.0 \%$ \\
\hline 28 Mar 1990 & $1.75 E+02$ & $100.1 \%$ & $8.720 E-01$ & $.5 \%$ & $1.78 E+02$ & $1.75 E+02$ & 10 & 10 & $100.0 \%$ \\
\hline 29 Mar 1990 & $1.76 E+02$ & $100.4 x$ & $2.061 E+00$ & $1.2 \%$ & $1.77 E+02$ & $1.73 E+02$ & 4 & 4 & $100.0 \%$ \\
\hline $30 \operatorname{Mar} 1990$ & $1.73 E+02$ & $98.8 \%$ & $1.332 E+00$ & $.8 \%$ & $1.75 E+02$ & $1.72 E+02$ & 8 & 8 & $100.0 \%$ \\
\hline 31 Mar 1990 & $1.74 E+02$ & $99.4 \%$ & $2.416 E-01$ & $.1 \%$ & $1.74 E+02$ & $1.74 E+02$ & 8 & 8 & $100.0 \%$ \\
\hline 1 Apr 1990 & $1.75 E+02$ & $99.9 \%$ & $3.055 E-01$ & $.2 x$ & $1.75 E+02$ & $1.75 E+02$ & 7 & 7 & $100.0 \%$ \\
\hline 2 Apr 1990 & $1.77 E+02$ & $100.9 x$ & $8.367 E-02$ & $0.0 x$ & $1.77 E+02$ & $1.76 E+02$ & 5 & 5 & $100.0 \%$ \\
\hline 3 Apr 1990 & $1.75 E+02$ & $100.2 x$ & $3.114 E-01$ & $.2 \%$ & $1.76 E+02$ & $1.75 E+02$ & 5 & 5 & $100.0 \%$ \\
\hline 4 Apr 1990 & $1.75 E+02$ & $99.9 x$ & $3.189 \mathrm{E}-01$ & $.2 \%$ & $1.76 E+02$ & $1.75 E+02$ & 6 & 6 & $100.0 \%$ \\
\hline 5 Apr 1990 & $1.74 E+02$ & $99.7 \%$ & $1.271 E+00$ & $.7 x$ & $1.76 E+02$ & $1.73 \varepsilon+02$ & 6 & 6 & $100.0 \%$ \\
\hline 6 Apr 1990 & $1.72 E+02$ & $98.0 \%$ & $7.139 \mathrm{E}-01$ & $.4 \%$ & $1.73 E+02$ & $1.71 E+02$ & 6 & 6 & $100.0 \%$ \\
\hline 7 Apr 1990 & $1.75 E+02$ & $100.0 \%$ & $1.263 E+00$ & .74 & $1.76 E+02$ & $1.72 E+02$ & 8 & 8 & $100.0 \%$ \\
\hline 8 Apr 1990 & $1.75 E+02$ & $100.0 \%$ & 5.339E-01 & $.3 \%$ & $1.76 E+02$ & $1.74 E+02$ & 8 & 8 & $100.0 \%$ \\
\hline 9 Apr 1990 & $1.75 E+02$ & $99.8 \%$ & $1.545 E+00$ & $.9 x$ & $1.78 E+02$ & $1.74 E+02$ & 7 & 7 & $100.0 \%$ \\
\hline 10 Apr 1990 & $1.75 E+02$ & $99.8 \%$ & $2.029 E+00$ & $1.2 \%$ & $1.79 E+02$ & $1.74 E+02$ & 7 & 7 & $100.0 \%$ \\
\hline 11 Apr 1990 & $1.76 E+02$ & $100.6 \%$ & $2.020 E+00$ & $1.1 \%$ & $1.81 E+02$ & $1.75 E+02$ & 8 & 8 & $100.0 \%$ \\
\hline 12 Apr 1990 & $1.74 E+02$ & $99.3 \%$ & $2.073 E+00$ & $1.2 \%$ & $1.79 E+02$ & $1.72 E+02$ & 8 & 8 & $100.0 \%$ \\
\hline 13 Apr 1990 & $1.75 E+02$ & $100.0 \%$ & $5.097 E-01$. & $.3 \%$ & $1.76 E+02$ & $1.74 E+02$ & 8 & 8 & $100.0 \%$ \\
\hline 14 Apr 1990 & $1.75 \varepsilon+02$ & $100.2 \%$ & $2.358 E+00$ & $1.3 \%$ & $1.80 E+02$ & $1.73 E+02$ & 10 & 10 & $100.0 \%$ \\
\hline 15 Apr 1990 & $1.77 \varepsilon+02$ & $101.1 x$ & $7.319 E-01$ & $.4 \%$ & $1.78 E+02$ & $1.76 E+02$ & 7 & 7 & $100.0 \%$ \\
\hline 16 Apr 1990 & $1.74 E+02$ & $99.2 x$ & $1.270 E+00$ & $.7 \%$ & $1.75 E+02$ & $1.70 E+02$ & 10 & 10 & $100.0 \%$ \\
\hline 17 Apr 1990 & $1.74 E+02$ & $99.2 x$ & $1.541 E+00$ & $.9 \%$ & $1.76 E+02$ & $1.70 E+02$ & 10 & 10 & $100.0 \%$ \\
\hline 18 Apr 1990 & $1.75 E+02$ & $100.2 x$ & $8.486 E-01$ & $.5 \%$ & $1.76 E+02$ & $1.74 E+02$ & 10 & 10 & $100.0 \%$ \\
\hline 19 Aor 1990 & $1.76 E+02$ & $100.7 x$ & $4.206 E-01$ & $.2 \%$ & $1.77 \mathrm{E}+02$ & $1.76 \mathrm{E}+02$ & -9 & 9 & $100,0 \%$ \\
\hline Sumnary & $1.75 E+02$ & $99.9 x$ & $1.622 E+00$ & $.9 \%$ & $1.81 E+02$ & $1.70 E+02$ & 184 & 184 & $100.0 \%$ \\
\hline
\end{tabular}

Chloroprene Develop. Toxicity (Rabbits) 175 ppm (B)

Mean \& Standard Deviation From 27 Mar 1990 through 19 Apr 1990

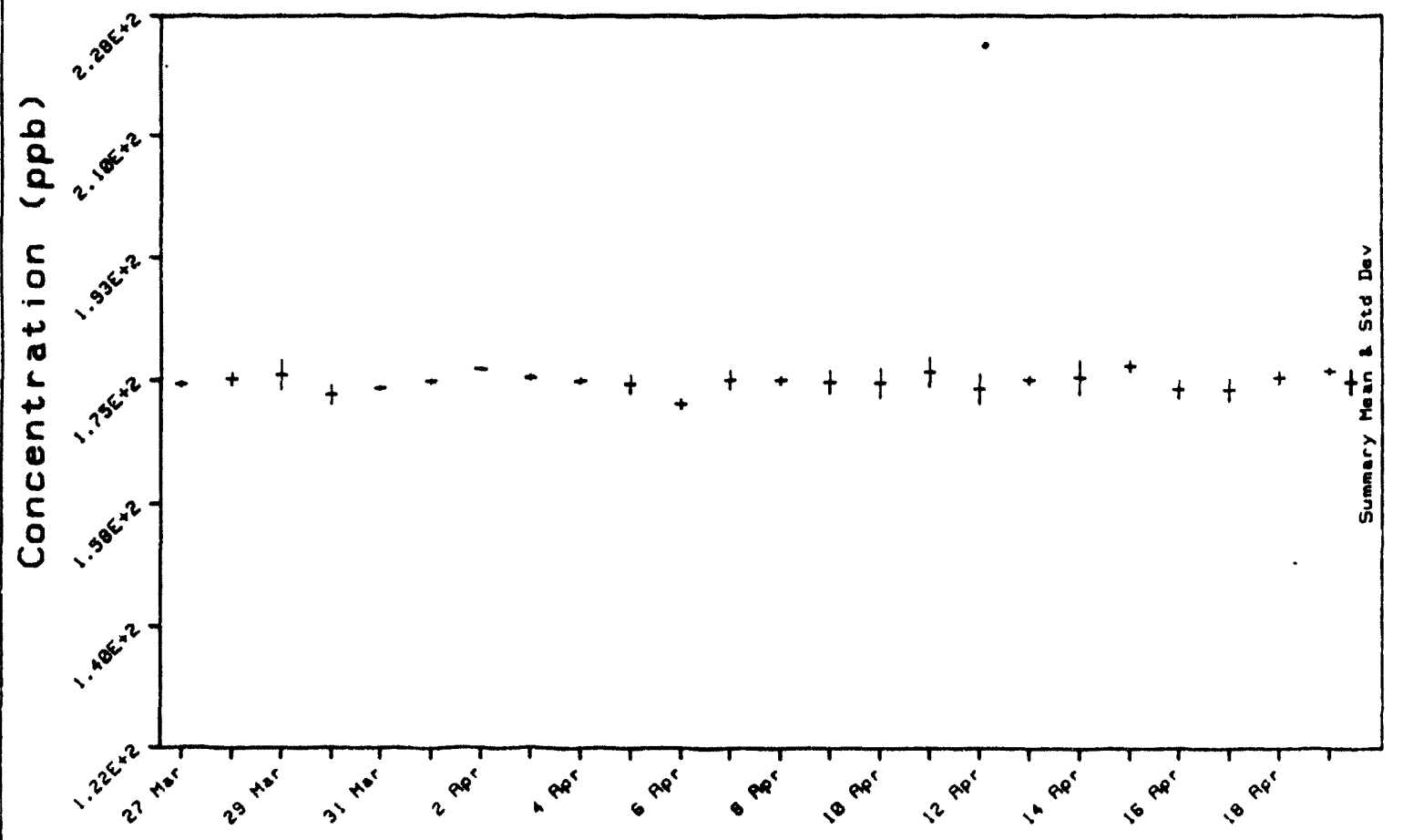


Qaily Symation for Chioroprene Develoo. Toxtcity (Rabbits) Summary Data for: Standard Gas /Concentration

From 26 Mar 1990 through 26 Mar 1990

\begin{tabular}{|c|c|c|c|c|c|c|c|c|c|}
\hline & & & t & & & Naing y & 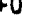 & .0067 & \\
\hline Date & Mean & * Taraet & Std Dev & \& RSO & Maximum & Minimum & $N$ & $\mathrm{~N}$ in & $\% N$ in \\
\hline $26 \operatorname{Mar} 1990$ & $4.265+00$ & $92.7 x$ & $5.173 E-02$ & $1.2 \%$ & $4.34 E+00$ & 4.21E+00 & 9 & 8 & $100.0 \%$ \\
\hline Summary & $4.26 E+00$ & $92.7 x$ & $5.173 E-02$ & $1.2 x$ & $4.34 E+00$ & $4.21 E+00$ & 9 & 9 & $100.0 \%$ \\
\hline
\end{tabular}

Daily Sumation For Chloroprene Develop. Toxicity (Rabbits)

From 27 Mar 1990 through 31 Mar 1990

\begin{tabular}{|c|c|c|c|c|c|c|c|c|c|}
\hline Summary Data & for: Stand & Gas & /Concentrat & & & Rang & +1 & $30 E+1$ & \\
\hline Date & Mean & x Tarqet & Std Dev & $x$ RSD & Maximum & Minimum & $N$ & $N$ in & $\mathrm{XN}$ in \\
\hline 27 Mar 1990 & $3.19 E+01$ & $106.2 \%$ & $6.651 E-02$ & $.2 \%$ & $3.19 E+01$ & $3.17 E+01$ & 12 & 12 & $100.0 \%$ \\
\hline $28 \operatorname{Mar} 1990$ & $3.20 E+01$ & $106.6 x$ & $9.477 E-02$ & $.3 x$ & $3.21 E+01$ & 3. $19 E+01$ & 11 & 11 & $100.0 \%$ \\
\hline $29 \operatorname{Mar} 1990$ & $3.30 E+01$ & $109.8 \%$ & $1.415 E+00$ & $4.3 \%$ & $3.55 E+01$ & $3.22 E+01$ & 5 & 4 & $80.0 \%$ \\
\hline 30 Mar 1990 & $3.54 E+01$ & $117.9 x$ & $7.770 E-01$ & $2.2 x$ & $3.60 E+01$ & $3.35 E+01$ & 8 & 0 & $0.0 \%$ \\
\hline 31 Mar 1990 & $3.57 E+01$ & $119.1 x$ & $1.502 E-01$ & $.4 x$ & $3.59 E+01$ & $3.54 E+01$ & 8 & 0 & $0.0 \%$ \\
\hline Summary & $3.34 E+01$ & $111.2 \%$ & $1.791 E+00$ & $5.4 x$ & 3. $60 E+01$ & $3.17 E+01$ & 44 & 27 & $61.4 \%$ \\
\hline
\end{tabular}

Daily Sumation for Chloroprene Develog. Toxicity (Rabbits)

\begin{tabular}{|c|c|c|c|c|c|c|c|c|c|}
\hline Summary Data & for: Stand & d Gas & /Concentrat & & & Rang & +1 & $63 E+1$ & \\
\hline Date & Maan & $x$ Tarqet & Std Dev & X RSO & Maximum & Minimum & $N$ & $x$ in & $X N$ in \\
\hline 1 Apr 1990 & $3.59 E+01$ & $108.7 \%$ & $9.996 E-02$ & $.3 x$ & $3.60 E+01$ & $3.57 E+01$ & 8 & 8 & $100.0 \%$ \\
\hline 2 Apr 1990 & $3.59 E+01$ & $108.9 \%$ & $7.189 E-01$ & $2.0 \%$ & $3.64 E+01$ & $3.45 E+01$ & 6 & 4 & $66.7 \%$ \\
\hline 3 Apr 1990 & $3.64 E+01$ & $110.2 x$ & 1. $103 E+00$ & $3.0 x$ & $3.68 E \div 01$ & $3.31 E+01$ & 11 & 1 & $9.1 \%$ \\
\hline 4 Apr 1990 & $3.65 E+01$ & $110.5 \%$ & $8.361 E-02$ & $.2 x$ & $3.66 E+01$ & $3.63 E+01$ & 7 & 0 & $0.0 \%$ \\
\hline 5 Apr 1990 & $3.63 E+01$ & $110.1 x$ & $1.217 \mathrm{E}-01$ & $.3 \%$ & $3.65 E+01$ & $3.61 E+01$ & 7 & 3 & $42.9 \%$ \\
\hline 6 Apr 1990 & $3.67 E+01$ & $111.1 \%$ & $4.488 E-01$ & $1.2 x$ & $3.78 E+01$ & $3.62 E+01$ & 9 & 1 & $11.1 \%$ \\
\hline I Apr 1990 & $3.62 E+01$ & $109.7 x$ & $1.034 E-01$ & $.3 \%$ & $3.64 E+01$ & $3.60 E+01$ & 9 & 8 & $88.9 \%$ \\
\hline Summary & $3.63 E+01$ & $109.9 x$ & $6.025 E-01$ & $1.7 x$ & $3.78 E+01$ & $3.31 E+01$ & 57 & 25 & $43.9 \%$ \\
\hline
\end{tabular}

Datily Summation For Chloroprene Develop. Toxictty (Rabbits)

\begin{tabular}{|c|c|c|c|c|c|c|c|c|c|}
\hline Summary Data & for: Stand & d Gas & /Concentrat & & & Rang & $E+1$ & $99 E+1$ & \\
\hline Date & Mean & $x$ Target & Std Dev & $x$ RSD & Maximum & Minimum & $N$ & $N$ in & $\% \mathrm{Ni}$ \\
\hline 8 Apr 1990 & $3.65 E+01$ & $100.5 \%$ & $1.556 \mathrm{E}-01$ & $.4 \%$ & $3.68 E+01$ & $3.62 E+01$ & 8 & 8 & 100.0 \\
\hline 9 Apr 1990 & $3.74 E+01$ & $102.9 \%$ & $8.887 \varepsilon-02$ & $.2 \%$ & $3.75 E+01$ & $3.72 E+01$ & 8 & 8 & 100.0 \\
\hline $10 \mathrm{Apr} 1990$ & $3.76 E+01$ & $103.6 \%$ & $1.586 \mathrm{E}-01$ & $.4 \%$ & $3.82 E+01$ & $3.74 E+01$ & 15 & 15 & 100.0. \\
\hline 11 Apr 1990 & $3.72 E+01$ & $102.4 x$ & $1.385 E-01$ & $.4 x$ & $3.73 E+01$ & $3.69 E+01$ & 9 & 9 & 100.0 \\
\hline 12 Apr 1990 & $3.71 E+01$ & $102.1 \%$ & $1.413 \mathrm{E}-01$ & $.4 x$ & $3.72 E+01$ & $3.68 E+01$ & 9 & 9 & $100.0^{\circ}$ \\
\hline 13 Apr 1990 & $3.69 E+01$ & $101.8 \%$ & $1.328 \mathrm{E}-01$ & $.4 \%$ & $3.71 E+01$ & $3.68 E+01$ & 9 & 9 & 100.0 \\
\hline 14 Apr 1990 & $3.69 E+01$ & $101.8 \%$ & $8.256 E-02$ & $.2 \%$ & $3.70 E+01$ & $3.68 E+01$ & 11 & 11 & 100.0: \\
\hline 15 Apr 1990 & $3.65 E+01$ & $100.7 \%$ & $1.245 E-01$ & $.3 \%$ & $3.67 E+01$ & $3.63 E+01$ & 10 & 10 & 100.0: \\
\hline 16 Apr 1990 & $3.64 E+01$ & $100.3 \%$ & $5.254 E-02$ & $.1 \%$ & $3.65 E+01$ & 3. $63 E+01$ & 10 & 10 & 100.0 \\
\hline 17 Apr 1990 & $3.65 E+01$ & $100.5 x$ & $1.251 \mathrm{E}-01$ & $.3 \%$ & $3.67 E+01$ & $3.62 E+01$ & 10 & 10 & 100.0 \\
\hline 18 Apr 1990 & $3.68 E+01$ & $101.4 x$ & $1.663 \mathrm{E}-01$ & $.5 \%$ & $3.71 E+01$ & $3.65 E+01$ & 11 & 11 & $100.0^{\circ}$ \\
\hline 19 Apr 1990 & $3,69 E+01$ & $101.6 x$ & $2.238 E-01$ & $.6 \%$ & $3,73 E+01$ & $3.65 E+01$ & 10 & 10 & 100.0 \\
\hline Surmary & $3.69 E+01$ & $101.7 x$ & $4.025 E-01$ & $1.1 \%$ & $3.82 E+01$ & $3.62 E+01$ & 120 & 120 & $100.0:$ \\
\hline
\end{tabular}




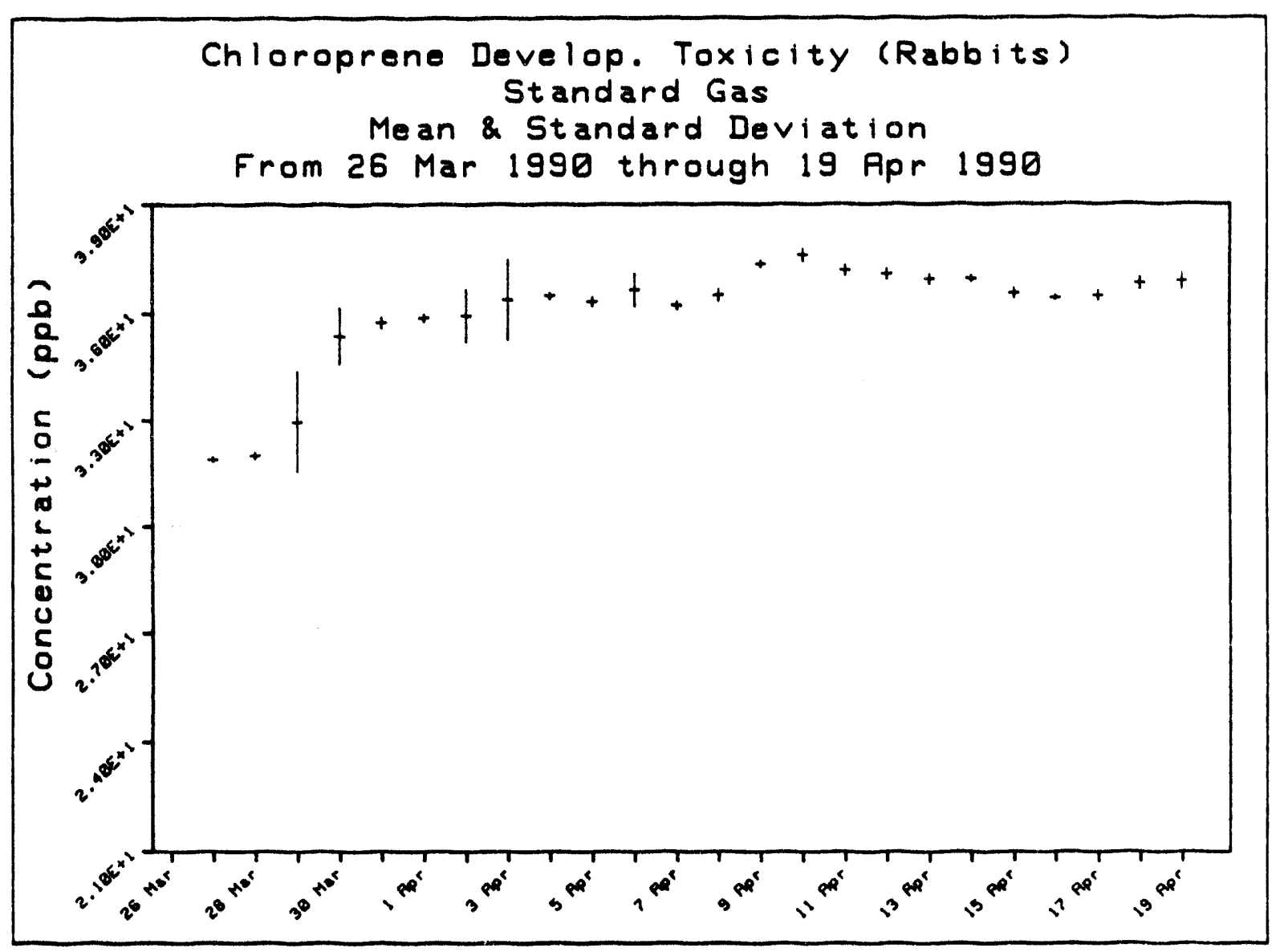


Temperature Data

B -21 
Datly Sumation for Chloroprane Develoo. Toxicity (Rabbits) From 23 Mar 1990 throuah 18 Apr 1990

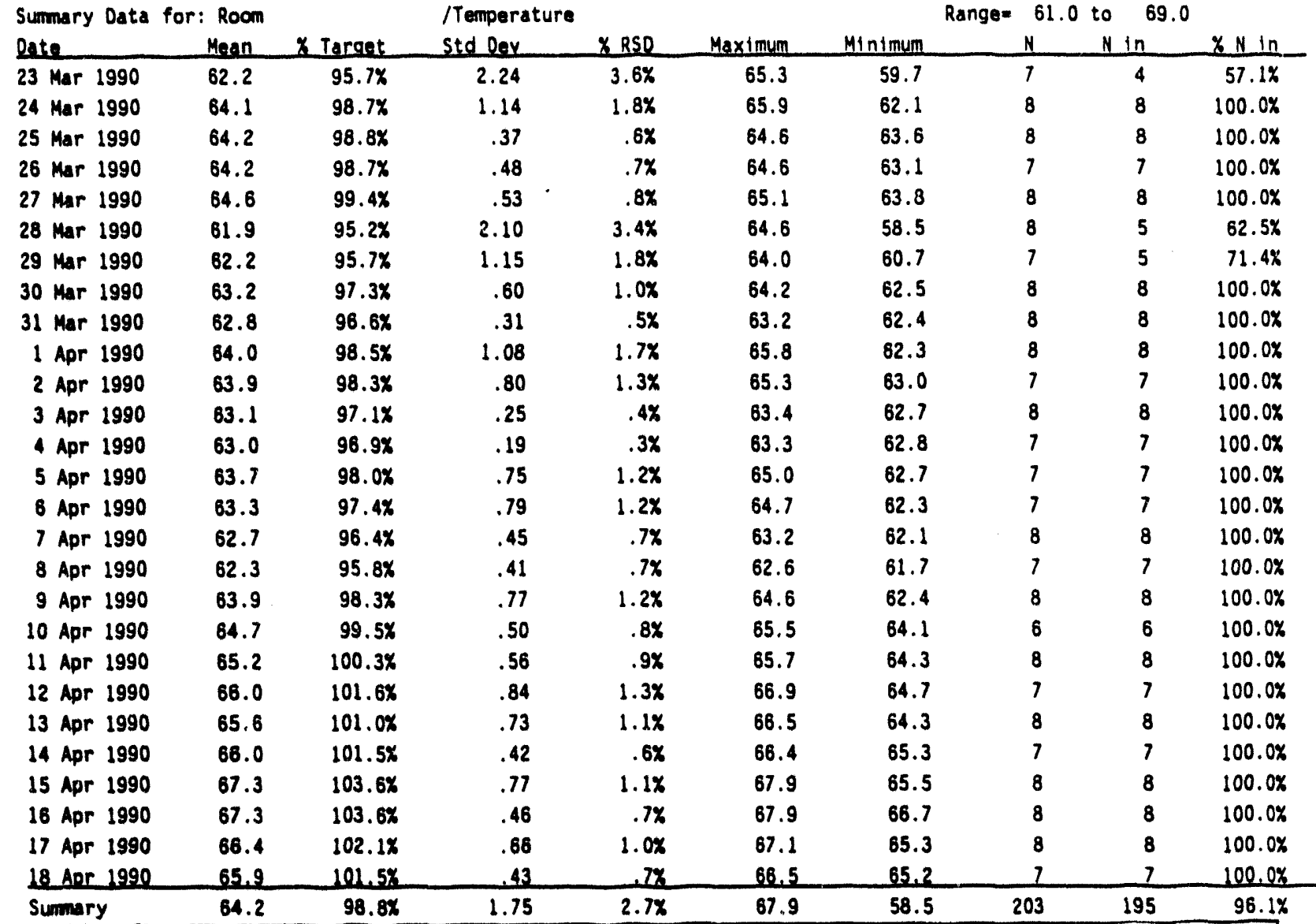

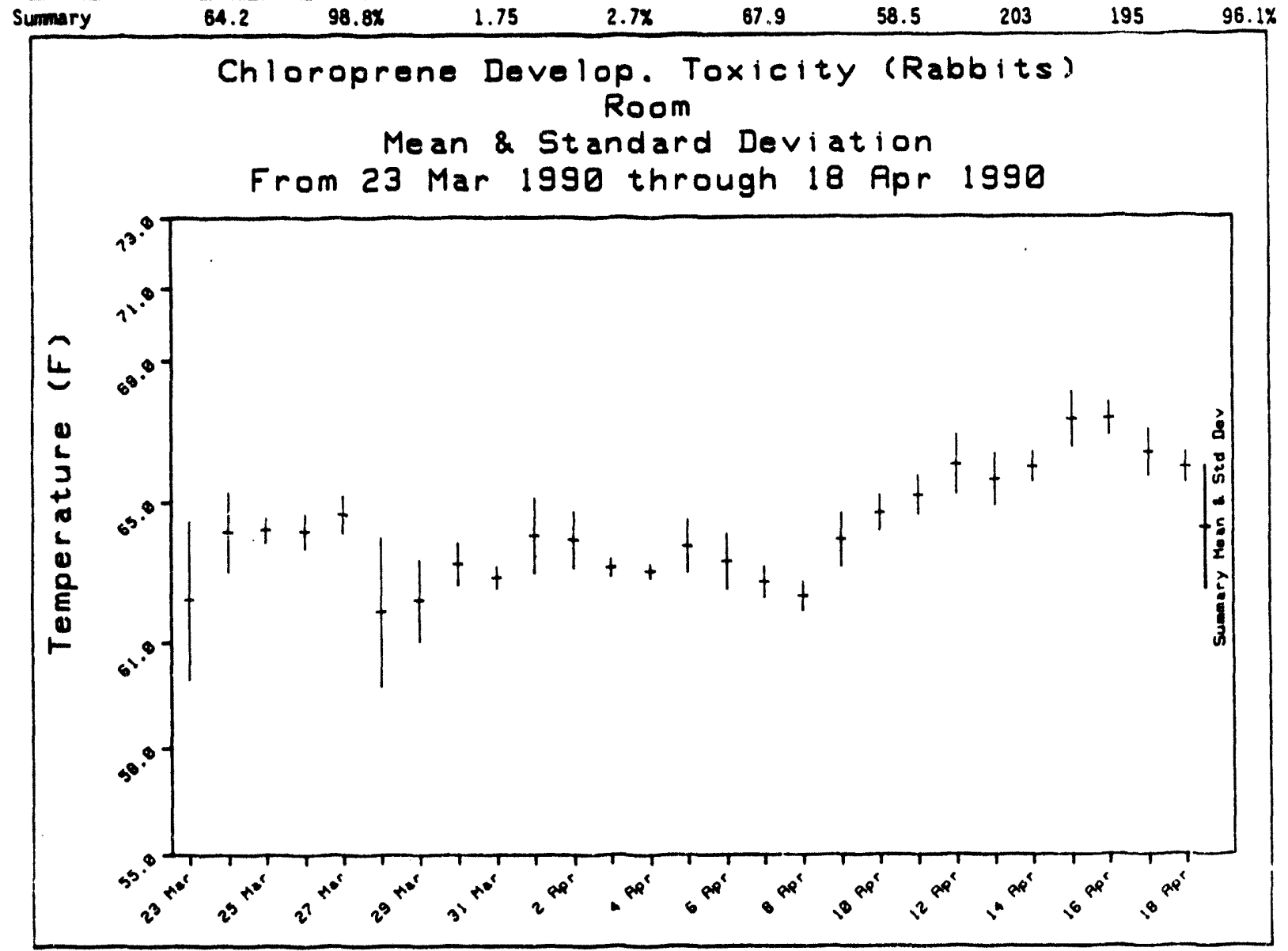


Dajly Summation For Chloroprene Develog. Toxicity (Rabbits)

\begin{tabular}{|c|c|c|c|c|c|c|c|c|c|}
\hline Sumary Data & $: 0 \mathrm{pp}$ & & /Tempera & & & & 6 & to 7 & \\
\hline Date & Mean & $x$ Target & Std Dev & $X$ RSD & Maximum & Minimum & $\mathrm{N}$ & $N$ in & $X N$ in \\
\hline 27 Mar 1990 & 66.8 & $96.8 x$ & .49 & $.7 x$ & 67.4 & 66.1 & 5 & 5 & $100.0 \%$ \\
\hline $28 \operatorname{Mar} 1990$ & 67.2 & $97.3 \%$ & 1.32 & $2.0 \%$ & 69.3 & 65.4 & 7 & 7 & $100.0 \%$ \\
\hline $29 \operatorname{Mar} 1990$ & 66.6 & $96.5 \%$ & .67 & $1.0 \%$ & 67.3 & 65.2 & 7 & 7 & $100.0 \%$ \\
\hline 30 Mar 1990 & 67.4 & $97.6 \%$ & .89 & $1.3 \%$ & 68.9 & 66.3 & 8 & 8 & $100.0 x$ \\
\hline $31 \operatorname{Mar} 1990$ & 67.6 & $97.9 \%$ & .67 & $1.0 \%$ & 68.8 & 66.6 & 7 & 7 & $100.0 \%$ \\
\hline 1 Apr 1990 & 68.1 & $98.6 x$ & .80 & $1.2 x$ & 69.1 & 67.3 & 6 & 6 & $100.0 \%$ \\
\hline 2 Apr 1990 & 67.1 & $97.2 \%$ & .37 & $.6 x$ & 67.6 & 66.6 & 6 & 6 & $100.0 \%$ \\
\hline 3 Apr 1990 & 66.9 & $96.9 \%$ & .56 & $.8 x$ & 67.6 & 66.0 & 8 & 8 & $100.0 \%$ \\
\hline+ Apr 1990 & 66.6 & $96.6 \%$ & .63 & $.9 \%$ & 67.3 & 65.3 & 7 & 7 & $100.0 \%$ \\
\hline 5 Apr 1990 & 67.5 & $97.8 x$ & .24 & $.4 x$ & 67.9 & 67.2 & 6 & 6 & $100.0 \%$ \\
\hline 6 Apr 1990 & 66.9 & $97.0 \%$ & .56 & $.8 \%$ & 67.4 & 65.8 & 7 & 7 & $100.0 \%$ \\
\hline 7 Apr 1990 & 66.7 & $96.6 \%$ & .18 & $.3 x$ & 66.9 & 66.4 & 7 & 7 & $100.0 \%$ \\
\hline 8 Apr 1990 & 66.7 & $96.7 x$ & .29 & $.4 \%$ & 67.0 & 66.4 & 6 & 6 & $100.0 \%$ \\
\hline 9 Apr 1990 & 66.5 & $96.3 \%$ & .49 & $.7 x$ & 67.4 & 66.0 & 8 & 8 & $100.0 \%$ \\
\hline $10 \mathrm{Apr} 1990$ & 66.5 & $96.3 x$ & .53 & $.8 \%$ & 67.0 & 65.7 & 6 & 6 & $100.0 \%$ \\
\hline 11 Apr 1990 & 67.4 & $97.6 x$ & .55 & $.8 \%$ & 68.2 & 66.6 & 7 & 7 & $100.0 x$ \\
\hline 12 Apr 1990 & 67.7 & $98.0 \%$ & .36 & $.5 x$ & 68.2 & 67.2 & 6 & 6 & $100.0 x$ \\
\hline 13 Apr 1990 & 67.8 & $98.2 x$ & .39 & $.6 x$ & 68.3 & 67.3 & 7 & 7 & $100.0 \%$ \\
\hline 14 Apr 1990 & 67.7 & $98.1 x$ & .30 & $.4 x$ & 68.0 & 67.2 & 7 & 7 & $100.0 x$ \\
\hline 15 Apr 1990 & 67.6 & $98.0 \%$ & .19 & $.3 \%$ & 68.0 & 67.4 & 8 & 8 & $100.0 \%$ \\
\hline 16 Apr 1990 & 68.3 & $98.9 \%$ & .36 & $.5 x$ & 88.6 & 67.7 & 7 & 7 & $100.0 x$ \\
\hline 17 Apr 1990 & 88.0 & $98.6 x$ & .30 & $.4 x$ & 68.3 & 67.4 & 8 & 8 & $100.0 x$ \\
\hline 18 Apr 1990 & 68.0 & $98.6 \%$ & .37 & $.5 \%$ & 68.6 & 67.4 & 7 & 7 & $100.0 \%$ \\
\hline 19 Aor 1990 & 66.9 & $97.0 \%$ & .49 & $.7 x$ & 67.3 & 66.2 & 7 & 1 & $100.0 x$ \\
\hline Summary & 67.3 & $97.5 x$ & .76 & $1.1 \%$ & 69.3 & 65.2 & 165 & 165 & $100.0 \%$ \\
\hline
\end{tabular}

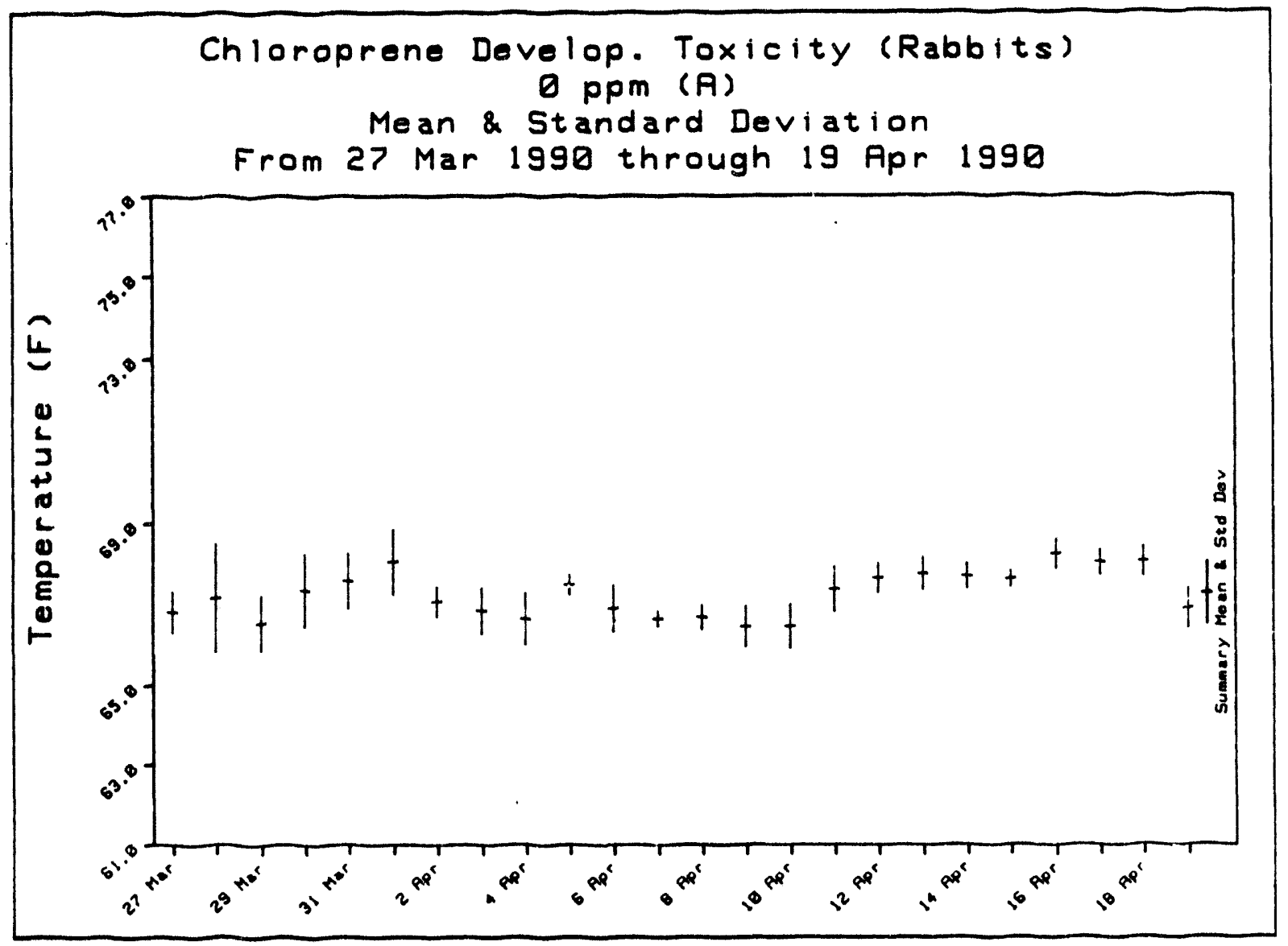


Dafly Sumation For Chloroprane Daveloo. Toxtatty (Rabbits) From 23 Mar 1990 through 18 Apr 1990

\begin{tabular}{|c|c|c|c|c|c|c|c|c|c|}
\hline Summary Data & $: 0 \mathrm{ppr}$ & (B) & /Tempara & & & & Range= & to & \\
\hline Date & Mean & $x$ Target & Std Der & $\times$ RSD & Maximum & Minimum & N & $N$ in & $x N$ in \\
\hline 23 Mar 1990 & 65.1 & $94.4 \%$ & 1.93 & $3.0 \%$ & 68.6 & 62.9 & 7 & 6 & $85.7 \%$ \\
\hline $24 \operatorname{Mar} 1990$ & 66.9 & $96.9 x$ & 1.19 & $1.8 \%$ & 68.4 & 64.4 & 8 & 8 & $100.0 \%$ \\
\hline $25 \operatorname{Mar} 1990$ & 67.4 & $97.7 x$ & .97 & $1.4 \%$ & 68.9 & 66.3 & 8 & 8 & $100.0 \%$ \\
\hline $26 \operatorname{Mar} 1990$ & 67.8 & $98.3 x$ & .65 & $1.0 \%$ & 68.3 & 66.5 & 7 & 7 & $100.0 \%$ \\
\hline 27 Mar 1990 & 68.8 & $99.7 \%$ & .81 & $1.2 \%$ & 69.7 & 67.2 & 7 & 7 & $100.0 \%$ \\
\hline 28 Mar 1990 & 67.3 & $97.5 \%$ & 1.46 & $2.2 \%$ & 69.1 & 64.9 & 7 & 6 & $85.7 \%$ \\
\hline $29 \operatorname{Mar} 1990$ & 66.2 & $95.9 \%$ & .66 & $1.0 \%$ & 67.2 & 65.2 & 7 & 7 & $100.0 \%$ \\
\hline 30 Mar 1990 & 66.7 & $96.7 x$ & .98 & $1.5 \%$ & 68.6 & 65.5 & 8 & 8 & $100.0 \%$ \\
\hline 31 Mar 1990 & 66.8 & $96.8 \%$ & .68 & $1.0 \%$ & 67.9 & 65.7 & 8 & 8 & $100.0 \%$ \\
\hline 1 Apr 1990 & 67.5 & $97.9 \%$ & .91 & $1.3 x$ & 68.9 & 66.8 & 6 & 6 & $100.0 \%$ \\
\hline 2 Apr 1990 & 67.0 & $97.1 \%$ & .38 & $.6 \%$ & 67.4 & 66.4 & 6 & 6 & $100.0 \%$ \\
\hline 3 Apr 1990 & 66.6 & $96.5 \%$ & .41 & $.6 \%$ & 67.0 & 65.8 & 8 & 8 & $100.0 \%$ \\
\hline 4 Apr 1990 & 66.4 & $96.3 x$ & .69 & $1.0 \%$ & 67.3 & 65.4 & 7 & 7 & $100.0 \%$ \\
\hline 5 Apr 1990 & 67.2 & $97.4 \%$ & .28 & $.4 x$ & 67.4 & 66.7 & 6 & 6 & $100.0 \%$ \\
\hline 8 Apr 1990 & 66.7 & $96.7 x$ & .58 & $.9 \%$ & 67.8 & 65.8 & 7 & 7 & $100.0 x$ \\
\hline 7 Apr 1990 & 66.7 & $96.7 \%$ & .44 & $.7 \%$ & 67.5 & 66.3 & 7 & 7 & $100.0 \%$ \\
\hline 8 Apr 1990 & 66.4 & $96.2 x$ & .39 & $.6 \%$ & 67.0 & 65.8 & 6 & 6 & $100.0 \%$ \\
\hline 9 Apr 1990 & 66.6 & $96.5 \%$ & .40 & $.6 \%$ & 67.0 & 65.8 & 8 & 8 & $100.0 \%$ \\
\hline $10 \mathrm{Apr} 1990$ & 66.6 & $96.5 \%$ & .40 & $.6 \%$ & 67.0 & 66.0 & 6 & 6 & $100.0 \%$ \\
\hline 11 Apr 1990 & 67.6 & $98.0 \%$ & .42 & $.6 \%$ & 68.2 & 67.1 & 7 & 7 & $100.0 \%$ \\
\hline 12 Apr 1990 & 67.9 & $98.4 \%$ & .24 & $.4 x$ & 68.3 & 67.7 & 6 & 6 & $100.0 \%$ \\
\hline 13 Apr 1990 & 67.8 & $98.3 \%$ & .24 & $.4 \%$ & 68.2 & 67.4 & 8 & 8 & $100.0 \%$ \\
\hline 14 Apr 1990 & 67.9 & $98.4 \%$ & .29 & $.4 \%$ & 68.1 & 67.3 & 7 & 7 & $100.0 \%$ \\
\hline 15 Apr 1990 & 67.8 & $98.3 x$ & .29 & $.4 \%$ & 68.2 & 67.4 & 8 & 8 & $100.0 \%$ \\
\hline 16 Apr 1990 & 68.1 & $98.7 x$ & .16 & $.2 \%$ & 68.4 & 67.9 & 7 & 7 & $100.0 \%$ \\
\hline 17 Apr 1990 & 68.1 & $98.6 x$ & .27 & $.4 x$ & 68.5 & 67.7 & 8 & 8 & $100.0 \%$ \\
\hline 18. Apr 1990 & 66,1 & $95.7 \%$ & .53 & $.8 \%$ & 67.2 & 85.6 & 1 & 1 & $100.0 \%$ \\
\hline Summary & 67.1 & $97.3 \%$ & 1.04 & $1.6 \%$ & 69.7 & 62.9 & 192 & 190 & $99.0 \%$ \\
\hline
\end{tabular}

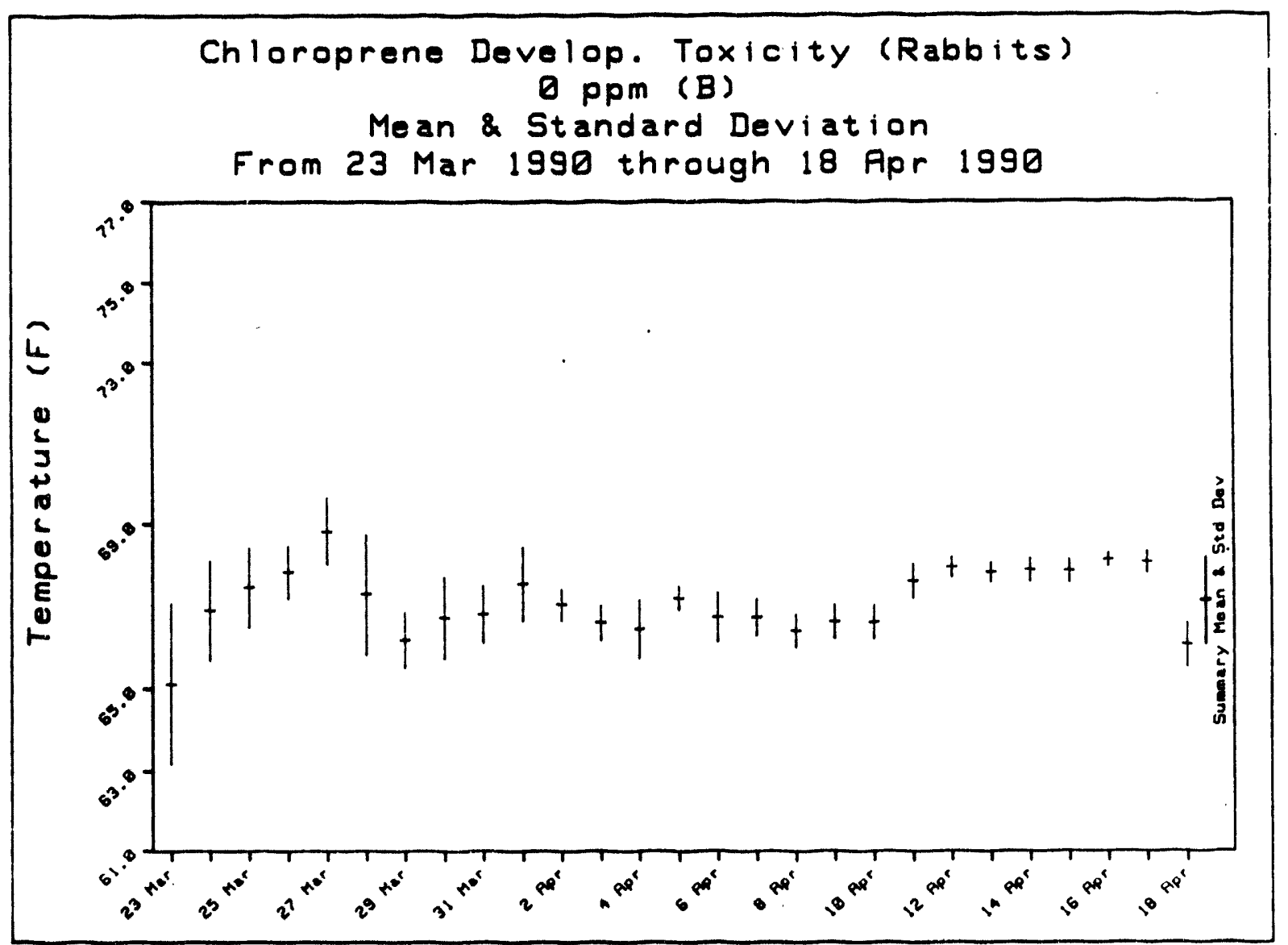


Daily Sumation for Chloroprene Develoo. Toxicity (Rabbits)

From 23 Mar 1990 through 18 Aor 1990

\begin{tabular}{|c|c|c|c|c|c|c|c|c|c|}
\hline Summary Data & $: 10 \mathrm{pF}$ & $(A)$ & /Temperat & & & & Range: 65 & to 7 & \\
\hline Date & Mean & $x$ Taraet & Std Dev & $\times$ RSD & Maximum & Minimum & $N$ & $\mathrm{~N}$ in & $x \times$ in \\
\hline $23 \operatorname{Mar} 1990$ & 63.4 & $91.9 \%$ & 2.33 & $3.7 x$ & 67.7 & 60.7 & 7 & 4 & $57.1 x$ \\
\hline $24 \operatorname{Mar} 1990$ & 85.5 & $94.9 \%$ & 1.44 & $2.2 \%$ & 67.2 & 62.7 & 8 & 7 & $87.5 \%$ \\
\hline $25 \operatorname{Mar} 1990$ & 65.8 & $95.4 x$ & .77 & $1.2 \%$ & 66.8 & 64.5 & 8 & 8 & $100.0 \%$ \\
\hline $26 \operatorname{Mar} 1990$ & 67.0 & $97.1 \%$ & 1.04 & $1.5 x$ & 68.0 & 65.2 & 7 & 7 & $100.0 \%$ \\
\hline 27 Mar 1990 & 68.1 & $98.7 \%$ & .83 & $1.2 \%$ & 68.9 & 66.5 & 7 & 7 & $100.0 x$ \\
\hline 28 Mar 1990 & 66.2 & $96.0 \%$ & 1.93 & $2.9 \%$ & 68.6 & 63.3 & 7 & 5 & $71.4 x$ \\
\hline 29 Mar 1990 & 65.0 & $94.2 \%$ & 1.05 & $1.6 \%$ & 66.3 & 63.1 & 6 & 3 & $50.0 \%$ \\
\hline $30 \operatorname{Mar} 1990$ & 66.1 & $95.7 x$ & 1.33 & $2.0 \%$ & 68.2 & 63.8 & 8 & 7 & $87.5 x$ \\
\hline 31 Mar 1990 & 66.9 & $97.0 \%$ & .98 & $1.5 \%$ & 68.6 & 65.7 & 8 & 8 & $100.0 x$ \\
\hline $1 \mathrm{Apr} 1990$ & 67.1 & $97.3 x$ & 1.21 & $1.8 \%$ & 68.8 & 66.1 & 6 & 6 & $100.0 x$ \\
\hline 2 Apr 1990 & 66.6 & $96.5 x$ & .64 & $1.0 \%$ & 67.3 & 65.7 & 6 & 6 & $100.0 x$ \\
\hline 3 Apr 1990 & 66.1 & $95.8 x$ & .90 & $1.4 \%$ & 67.2 & 64.8 & 8 & 7 & $87.5 x$ \\
\hline 4 Apr 1990 & 65.7 & $95.2 \%$ & .60 & $.9 x$ & 66.6 & 64.8 & 7 & 6 & $85.7 x$ \\
\hline 5 Apr 1990 & 66.5 & $96.4 x$ & .54 & $.8 x$ & 67.5 & 66.0 & 6 & 6 & $100.0 x$ \\
\hline 6 Apr 1990 & 66.2 & $96.0 \%$ & 1.07 & $1.6 \%$ & 67.4 & 64.7 & 7 & 5 & $71.4 x$ \\
\hline 7 Apr 1990 & 66.5 & $96.4 x$ & .57 & $.9 x$ & 67.0 & 65.5 & 7 & 7 & $100.0 x$ \\
\hline 8 Apr 1990 & 65.3 & $94.7 \%$ & .58 & $.9 x$ & 66.2 & 64.8 & 6 & 3 & $50.0 x$ \\
\hline 9 Apr 1990 & 65.1 & $94.3 x$ & .55 & $.8 \%$ & 66.1 & 64.2 & 8 & 5 & $62.5 x$ \\
\hline 10 Apr 1990 & 67.0 & $97.1 \%$ & 1.21 & $1.8 \%$ & 68.2 & 64.9 & 6 & 5 & $83.3 x$ \\
\hline 11 Apr 1990 & 68.3 & $99.0 \%$ & .63 & $.9 x$ & 69.0 & 67.2 & 7 & 7 & $100.0 x$ \\
\hline 12 Apr 1990 & 68.9 & $99.9 x$ & .52 & $.7 \%$ & 69.6 & 68.1 & 6 & 6 & $100.0 x$ \\
\hline 13 Apr 1990 & 68.9 & $99.8 \%$ & .60 & $.9 \%$ & 69.6 & 68.0 & 8 & 8 & $100.0 x$ \\
\hline 14 Apr 1990 & 69.0 & $100.0 \%$ & .48 & $.7 x$ & 69.6 & 68.3 & 7 & 7 & $100.0 x$ \\
\hline 15 Apr 1990 & 69.2 & $100.3 x$ & .45 & $.6 \%$ & 70.0 & 68.7 . & 8 & 8 & $100.0 \%$ \\
\hline $16 \mathrm{Apr} 1990$ & 69.0 & $100.0 \%$ & .39 & $.6 \%$ & 69.5 & 68.4 & 7 & 7 & $100.0 \%$ \\
\hline 17 Apr 1990 & 68.9 & $99.9 \%$ & 1.00 & $1.5 x$ & 69.9 & 66.9 & 7 & 7 & $100.0 x$ \\
\hline 18 Aor 1990 & 67.2 & $97.4 x$ & .48 & $.7 x$ & 68.1 & 66.6 & 7 & 1 & $100.0 \%$ \\
\hline Sumary & 66.9 & $96.9 x$ & 1.76 & $2.6 \%$ & 70.0 & 60.7 & 190 & 169 & 88.97 \\
\hline
\end{tabular}

Chloroprene Develop. Toxicity (Rabbits)

$10 \mathrm{ppm}(A)$

Mean \& Standard Deviation

From 23 Mar 1990 through 18 Apr 1990

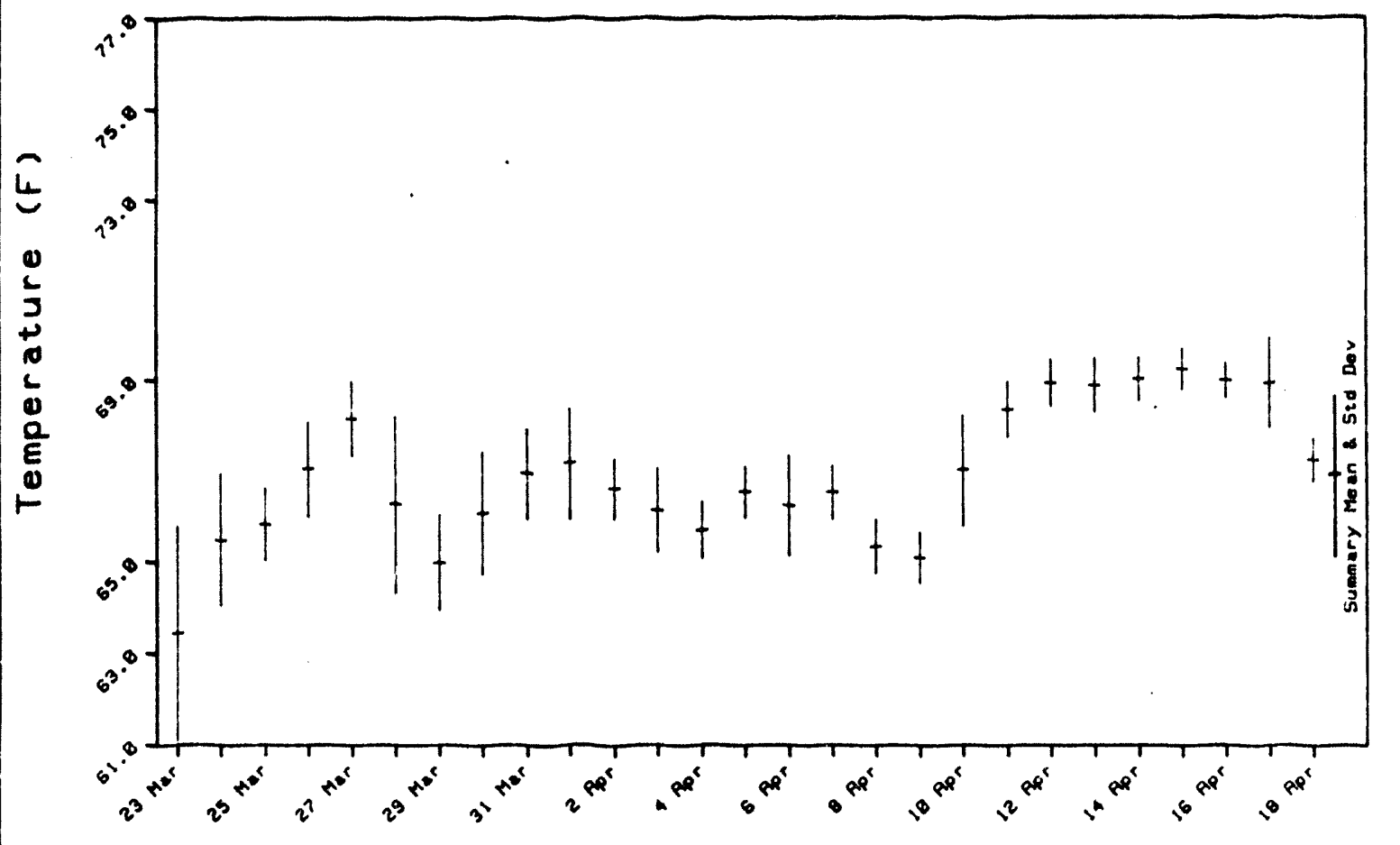


Qaily Sumation For Chloroprene Develoo. Toxicity (Rabbits)

From 27 Mar 1990 through 19 Apr 1990

\begin{tabular}{|c|c|c|c|c|c|c|c|c|c|}
\hline Sumary Data & : $10 \mathrm{pp}$ & (B) & /Temperat & & & & $\theta=6$ & to 73 & \\
\hline Date & Mean & $\%$ Target & Std Dev & X RSD & Maximum & Minimum & $\mathrm{N}$ & $N$ in & $\% \mathrm{~N}$ in \\
\hline 27 Mar 1990 & 67.0 & $97.1 \%$ & .30 & $.5 \%$ & 67.3 & 66.5 & 6 & 6 & $100.0 \%$ \\
\hline $28 \operatorname{Mar} 1990$ & 67.3 & $97.5 \%$ & 1.46 & $2.2 \%$ & 69.3 & 65.2 & 7 & 7 & $100.0 \%$ \\
\hline $29 \operatorname{Mar} 1990$ & 66.3 & $96.2 \%$ & .49 & $.7 x$ & 66.9 & 65.4 & 6 & 6 & $100.0 \%$ \\
\hline 30 Mar 1990 & 67.4 & $97.7 \%$ & .96 & $1.4 x$ & 68.9 & 65.9 & 8 & 8 & $100.0 \%$ \\
\hline 31 Mar 1990 & 67.9 & $98.4 \%$ & .89 & $1.3 x$ & 69.3 & 66.8 & 8 & 8 & $100.0 \%$ \\
\hline 1 Apr 1990 & 68.1 & $98.8 \%$ & .77 & $1.1 \%$ & 69.2 & 67.4 & 6 & 6 & $100.0 \%$ \\
\hline 2 Apr 1990 & 67.4 & $97.7 \%$ & .43 & $.6 \%$ & 68.1 & 66.8 & 6 & 6 & $100.0 \%$ \\
\hline 3 Apr 1990 & 66.9 & $97.0 \%$ & .24 & $.4 \%$ & 67.3 & 66.6 & 8 & 8 & $100.0 \%$ \\
\hline 4 Apr 1990 & 67.0 & $97.0 \%$ & .36 & $.5 x$ & 67.3 & 66.5 & 6 & 6 & $100.0 \%$ \\
\hline 5 Apr 1990 & 67.5 & $97.8 \%$ & .28 & $.4 x$ & 67.8 & 67.0 & 6 & 6 & $100.0 x$ \\
\hline 6 Apr 1990 & 67.1 & $97.3 x$ & .57 & $.9 \%$ & 67.8 & 66.2 & 7 & 7 & $100.0 \%$ \\
\hline 7 Apr 1990 & 67.0 & $97.1 \%$ & .44 & $.7 \%$ & 67.5 & 66.4 & 7 & 7 & $100.0 \%$ \\
\hline 8 Apr 1990 & 66.8 & $96.8 \%$ & .26 & $.4 \%$ & 67.1 & 66.5 & 6 & 6 & $100.0 \%$ \\
\hline 9 Apr 1990 & 66.8 & $96.8 \%$ & .39 & $.6 \%$ & 67.4 & 66.3 & 8 & 8 & $100.0 \%$ \\
\hline 10 Apr 1990 & 67.2 & $97.4 \%$ & .33 & $.5 \%$ & 67.6 & 66.7 & 5 & 5 & $100.0 \%$ \\
\hline 11 Apr 1990 & 67.8 & $98.3 \%$ & .48 &. $.7 \%$ & 68.3 & 67.1 & 7 & 7 & $100.0 \%$ \\
\hline 12 Apr 1990 & 68.2 & $98.9 \%$ & .34 & $.5 \%$ & 68.8 & 67.8 & 6 & 6 & $100.0 \%$ \\
\hline 13 Apr 1990 & 68.4 & $99.2 \%$ & .61 & $.9 \%$ & 69.4 & 67.3 & 8 & 8 & $100.0 \%$ \\
\hline 14 Apr 1990 & 68.1 & $98.7 \%$ & .24 & $.4 \%$ & 68.5 & 67.7 & 7 & 7 & $100.0 \%$ \\
\hline $15 \mathrm{Apr} 1990$ & 68.2 & $98.9 \%$ & .37 & $.5 x$ & 69.0 & 67.7 & 8 & 8 & $100.0 \%$ \\
\hline 16 Apr 1990 & 68.1 & $98.7 \%$ & .26 & $.4 x$ & 68.4 & 67.7 & 7 & 7 & $100.0 \%$ \\
\hline 17 Apr 1990 & 68.5 & $99.3 \%$ & .52 & $.8 \%$ & 69.3 & 67.9 & 7 & 7 & $100.0 \%$ \\
\hline 18 Apr 1990 & 68.7 & $99.6 \%$ & .41 & $.6 x$ & 69.0 & 67.8 & 7 & 7 & $100.0 \%$ \\
\hline 19 Apr 1990 & 67.0 & $97.1 \%$ & .43 & $.6 \%$ & 67.5 & 66.3 & 7 & 7 & $100.0 \%$ \\
\hline Sumary & 67.6 & 97.98 & .84 & $1.2 x$ & 69.4 & 65.2 & 164 & 164 & $100.0 \%$ \\
\hline
\end{tabular}

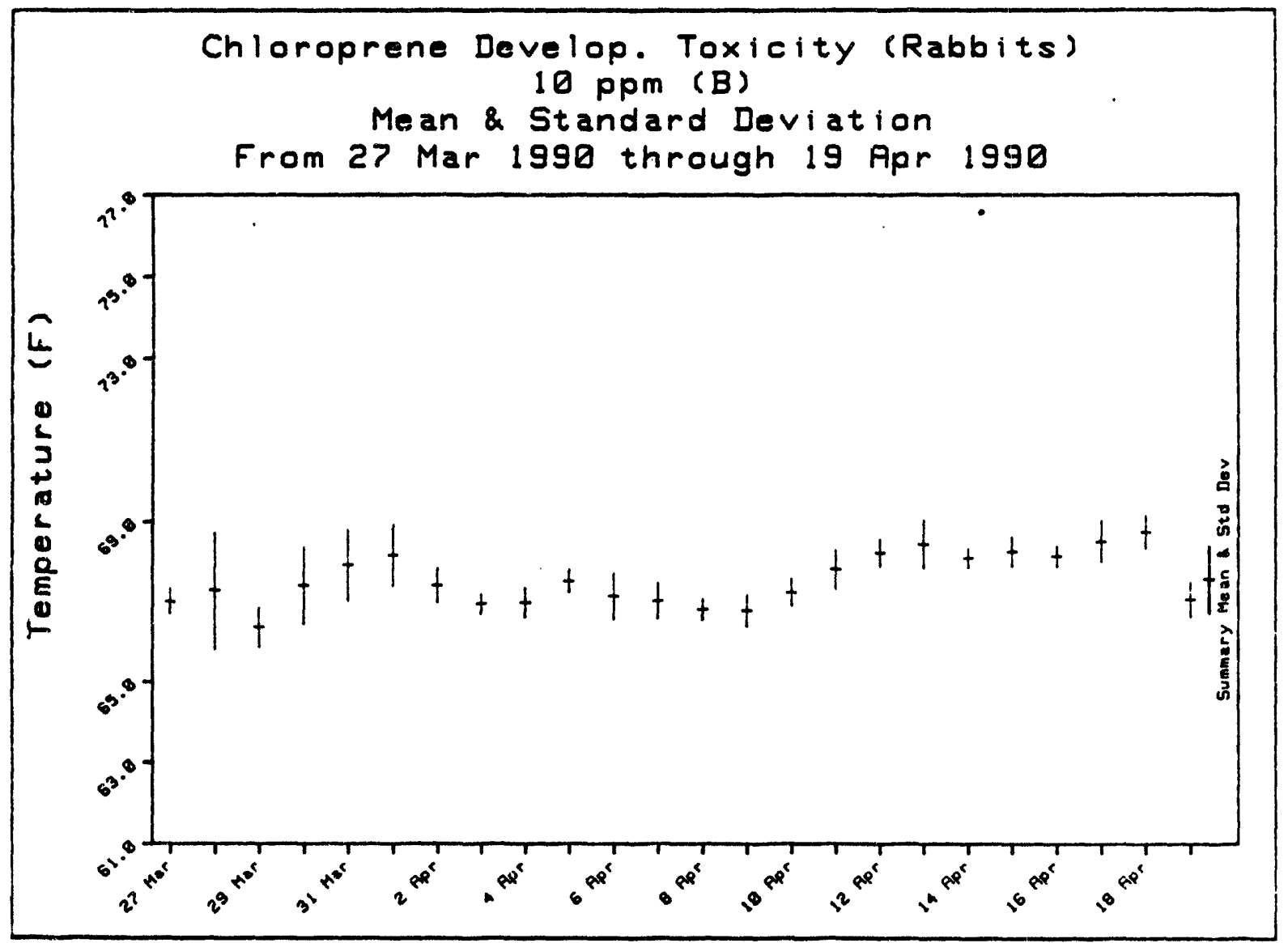


Daily Sumation For Chloroprene Develoo. Toxicity (Rabbits) From 23 Mar 1990 through 18 Apr 1990

\begin{tabular}{|c|c|c|c|c|c|c|c|c|c|}
\hline Sumary Data & $: 40 \mathrm{pp}$ & (A) & / Temperat & & & & Range $=65$ & & \\
\hline Date & Mean & $x$ Tarqet & Std Dev & X RSD & Maximum & Minimum & $\mathrm{N}$ & $\mathrm{N}$ in & $x N$ in \\
\hline 23 Mar 1990 & 63.5 & $92.0 \%$ & 1.70 & $2.7 \%$ & 66.5 & 61.3 & 7 & 4 & $57.1 \%$ \\
\hline $24 \operatorname{Mar} 1990$ & 64.8 & $93.9 \%$ & 1.39 & $2.1 \%$ & 66.5 & 62.5 & 8 & 7 & $87.5 \%$ \\
\hline $25 \operatorname{Mar} 1990$ & 65.2 & $94.4 \%$ & 1.21 & $1.9 \%$ & 66.5 & 63.8 & 8 & 8 & $100.0 x$ \\
\hline 26 Mar 1990 & 65.8 & $95.4 \%$ & .98 & $1.5 \%$ & 66.8 & 63.9 & 7 & 6 & $85.7 \%$ \\
\hline 27 Mar 1990 & 67.4 & $97.6 \%$ & 1.02 & $1.5 x$ & 68.2 & 65.2 & 7 & 7 & $100.0 x$ \\
\hline $28 \operatorname{Mar} 1990$ & 65.5 & $95.0 \%$ & 1.22 & $1.9 \%$ & 66.9 & 63.5 & 7 & 5 & $71.4 \%$ \\
\hline $29 \operatorname{Mar} 1990$ & 64.5 & $93.5 \%$ & .63 & $1.0 \%$ & 65.4 & 63.7 & 6 & 1 & $16.7 x$ \\
\hline 30 Mar 1990 & 65.5 & $95.0 \%$ & 1.10 & $1.7 \%$ & 67.0 & 63.9 & 8 & 6 & $75.0 \%$ \\
\hline 31 Mar 1990 & 66.0 & $95.7 \%$ & .93 & $1.4 x$ & 67.6 & 64.8 & 8 & 7 & $87.5 \%$ \\
\hline 1 Apr 1990 & 66.9 & $96.9 \%$ & .94 & $1.4 \%$ & 68.1 & 65.6 & 6 & 6 & $100.0 \%$ \\
\hline 2 Apr 1990 & 65.8 & $95.3 \%$ & .41 & $.6 x$ & 66.3 & 65.2 & 6 & 6 & $100.0 \%$ \\
\hline 3 Apr 1990 & 65.5 & $94.9 \%$ & .54 & $.8 x$ & 66.5 & 64.8 & 8 & 6 & $75.0 \%$ \\
\hline 4 Apr 1990 & 65.3 & $94.6 \%$ & .47 & $.7 x$ & 65.7 & 64.4 & 6 & 5 & $83.3 \%$ \\
\hline 5 Apr 1990 & 65.9 & $95.5 \%$ & .30 & $.5 \%$ & 66.3 & 65.6 & 6 & 6 & $100.0 \%$ \\
\hline 6 Apr 1990 & 65.5 & $94.9 \%$ & .65 & $1.0 \%$ & 66.4 & 64.5 & 7 & 6 & $85.7 \%$ \\
\hline 7 Apr 1990 & 65.4 & $94.8 \%$ & .64 & $1.0 \%$ & 66.3 & 64.5 & 7 & 5 & $71.4 \%$ \\
\hline 8 Apr 1990 & 65.2 & $94.5 \%$ & .51 & $.8 \%$ & 65.9 & 64.5 & 6 & 4 & $66.7 \%$ \\
\hline 9 Apr 1990 & 65.1 & $94.3 \%$ & .55 & $.8 x$ & 65.7 & 64.1 & 8 & 5 & $62.5 \%$ \\
\hline 10 Apr 1990 & 67.7 & $98.1 \%$ & .19 & $.3 x$ & 67.9 & 67.5 & 5 & 5 & $100.0 \%$ \\
\hline 11 Apr 1990 & 68.4 & $99.2 x$ & .90 & $1.3 \%$ & 69.6 & 66.9 & 7 & 7 & $100.0 \%$ \\
\hline 12 Apr 1990 & 69.3 & $100.4 x$ & .50 & $.7 x$ & 70.1 & 68.7 & 6 & 6 & $100.0 \%$ \\
\hline 13 Apr 1990 & 69.4 & $100.6 \%$ & .54 & $.8 x$ & 70.1 & 68.4 & 8 & 8 & $100.0 \%$ \\
\hline 14 Apr 1990 & 69.3 & $100.4 x$ & .31 & $.4 x$ & 69.7 & 68.8 & 7 & 7 & $100.0 \%$ \\
\hline 15 Apr 1990 & 69.3 & $100.5 \%$ & .27 & $.4 x$ & 69.9 & 69.1 & 8 & 8 & $100.0 \%$ \\
\hline 16 Apr 1990 & 69.2 & $100.2 x$ & .16 & $.2 \%$ & 69.4 & 69.0 & 7 & 7 & $100.0 x$ \\
\hline 17 Apr 1990 & 69.2 & $100.3 x$ & .38 & $.5 x$ & 69.9 & 68.9 & 7 & 7 & $100.0 \%$ \\
\hline 18 Apr 1990 & 67.0 & $97.1 \%$ & .52 & $.8 x$ & 67.3 & 66.0 & 6 & 6 & $100.0 \%$ \\
\hline Sumary & 66.6 & $96.5 x$ & 1.92 & $2.9 \%$ & 70.1 & 61.3 & 187 & 161 & $86.1 \%$ \\
\hline
\end{tabular}

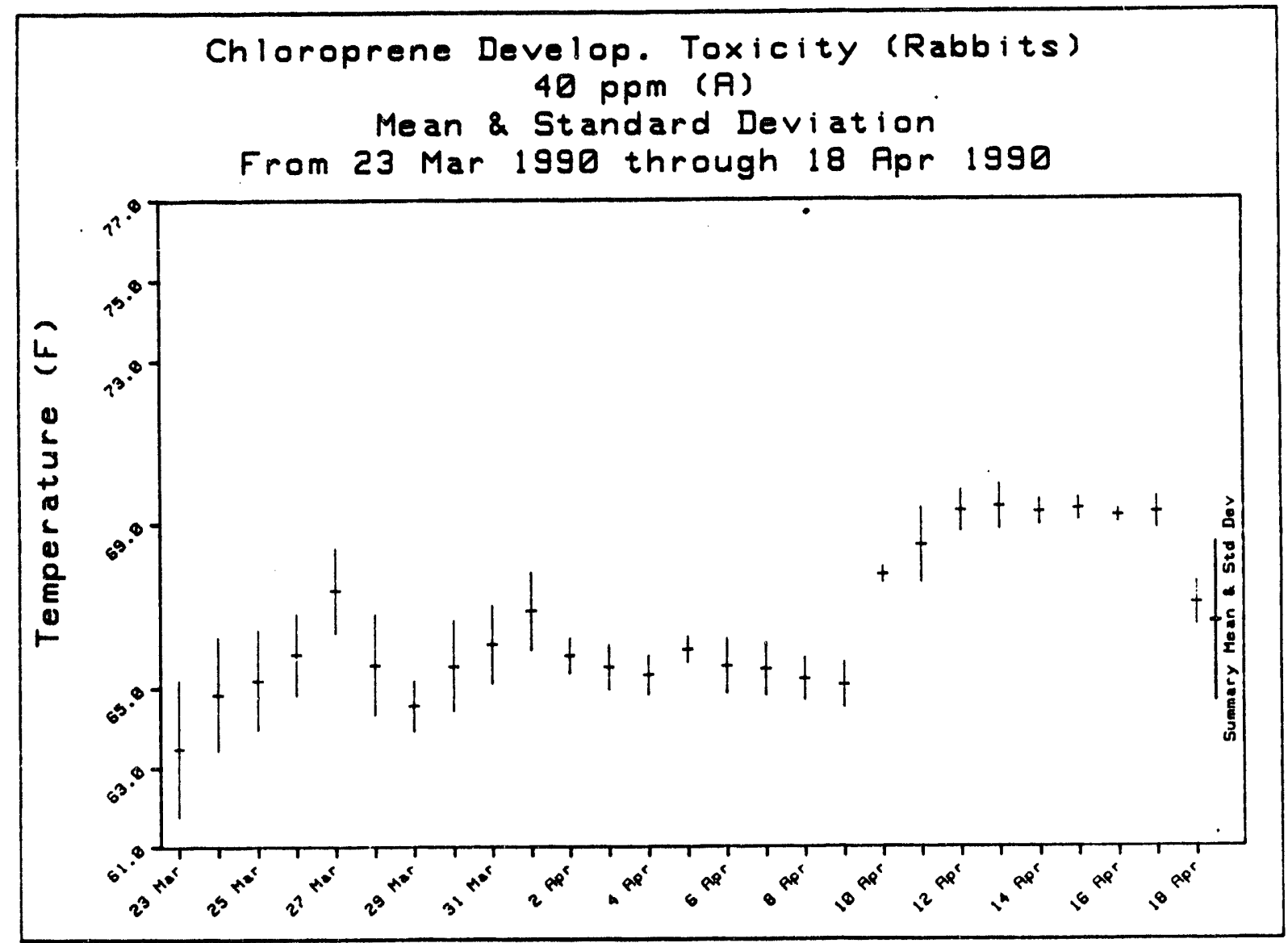


Daily Sumation For Chloroprene Develoo. Toxicity (Rabbits) From 27 Mar 1990 through 19 Apr 1990

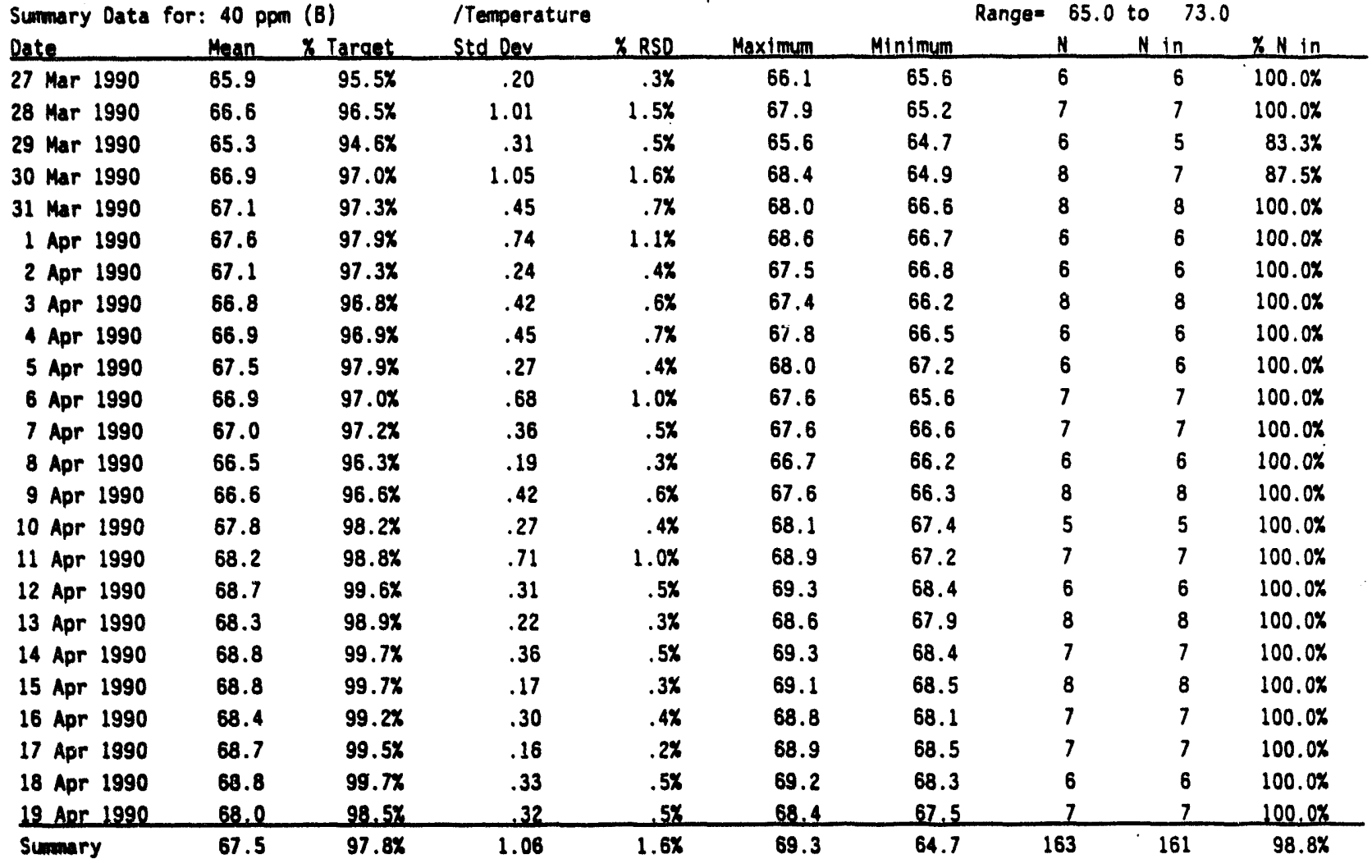

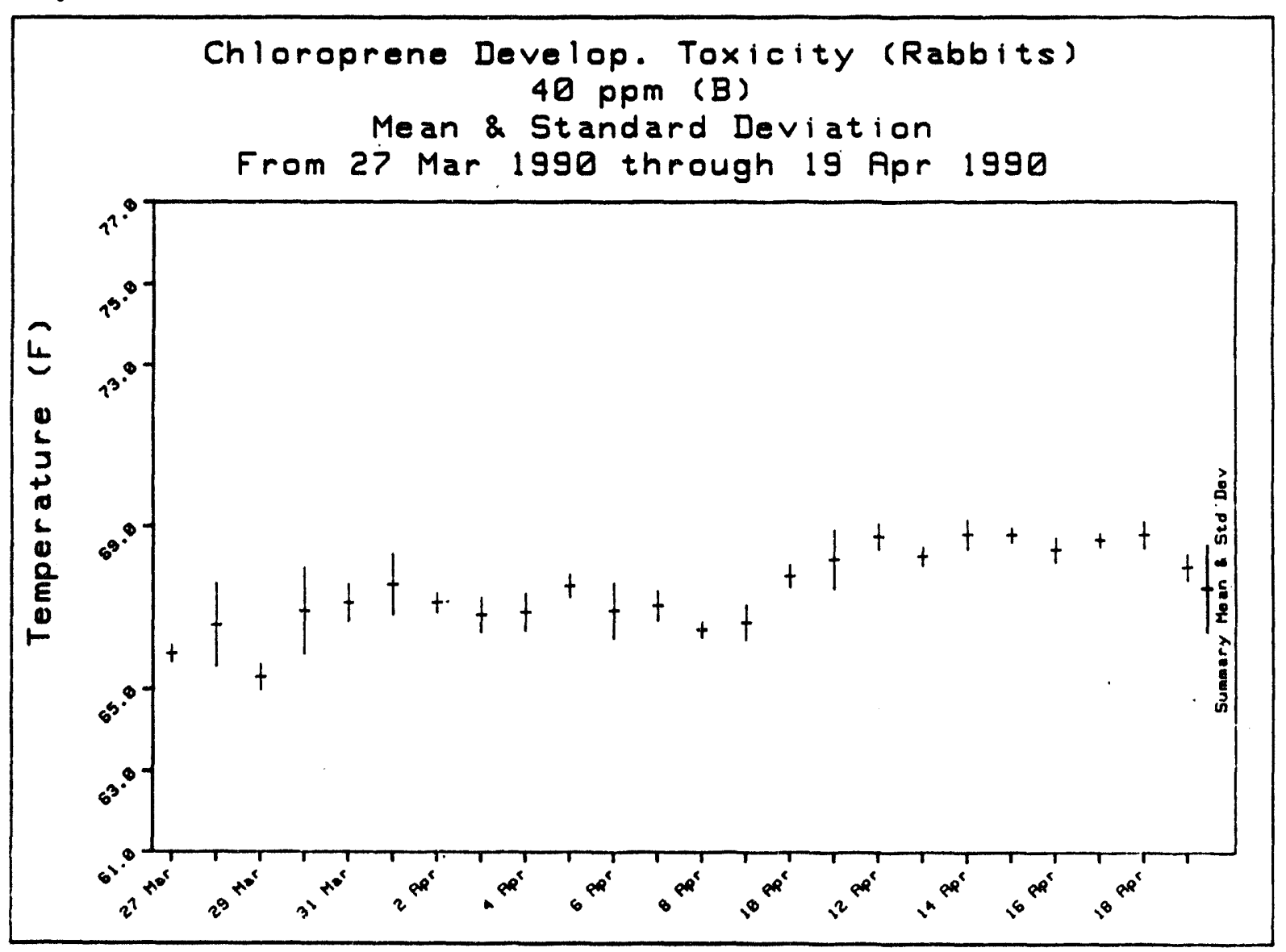


Daily Summation For Chloroprene Develoo. Toxtcity (Rabbits) From 23 Mar 1990 through 18 Apr 1990

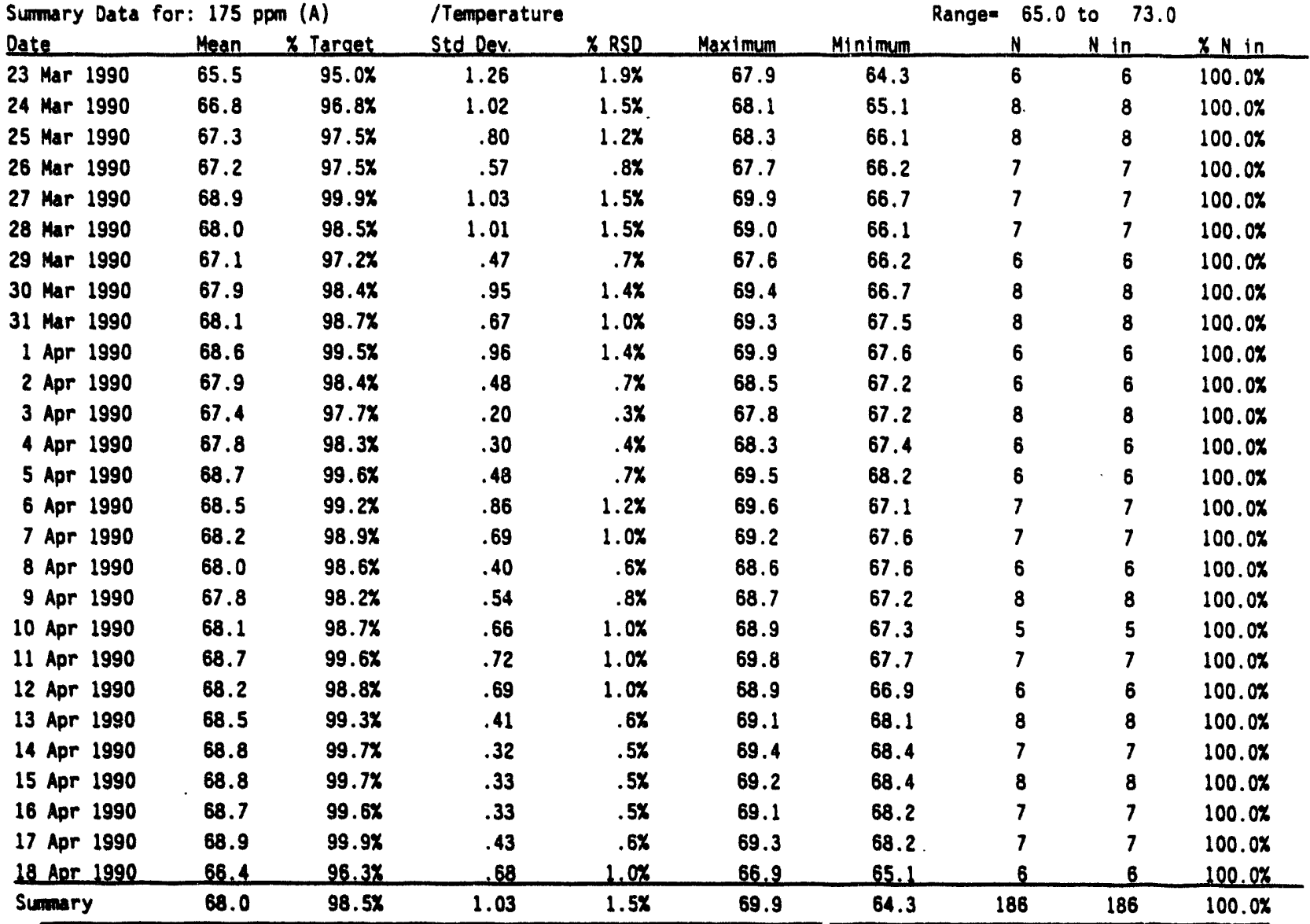

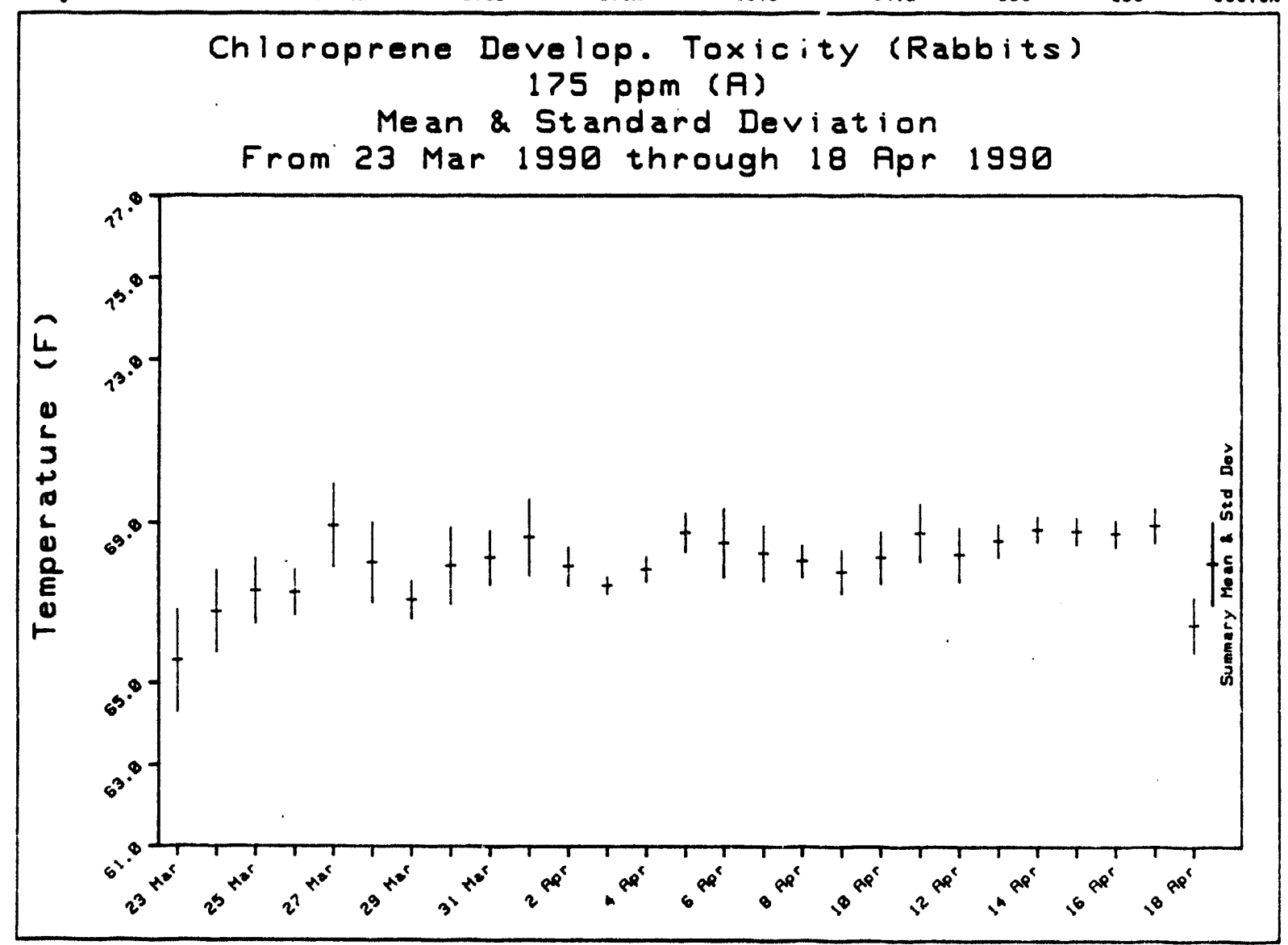


Qaily Sumation For Chloroprene Develoo. Toxicity (Rabbits)

From 27 Mar 1990 through 19 Apr 1990

\begin{tabular}{|c|c|c|c|c|c|c|c|c|c|}
\hline Sumary Data & : 175 & (B) & /Temperat & & & & Range: 65 & & \\
\hline Date & Man & $x$ Tarant & Std Dey & XRSD & Maxtmum & Minimum & $\mathrm{N}$ & $\mathrm{N}$ in & $X N$ in \\
\hline $27 \operatorname{Mar} 1990$ & 67.4 & $97.6 \%$ & .45 & $.7 \%$ & 67.8 & 66.7 & 6 & 6 & $100.0 \%$ \\
\hline $28 \operatorname{Mar} 1990$ & 68.0 & $98.5 \%$ & 1.43 & $2.1 x$ & 69.6 & 65.9 & 6 & 6 & $100.0 x$ \\
\hline 29 Mar 1990 & 67.0 & $97.1 x$ & .68 & $1.0 x$ & 67.6 & 65.7 & 6 & 6 & $100.0 \%$ \\
\hline 30 Mar 1990 & 67.7 & $98.2 x$ & 1.24 & $1.8 \%$ & 69.6 & 65.8 & 8 & 8 & $100.0 \%$ \\
\hline 31 Mar 1990 & 68.0 & $98.5 \%$ & .78 & $1.2 x$ & 69.1 & 66.7 & 8 & 8 & $100.0 x$ \\
\hline 1 Apr 1990 & 68.8 & $99.7 \%$ & .84 & $1.2 x$ & 69.7 & 67.7 & 6 & 6 & $100.0 \%$ \\
\hline 2 Apr 1990 & 68.1 & $98.7 x$ & .62 & $.9 x$ & 69.2 & 67.4 & 6 & 6 & $100.0 \%$ \\
\hline 3 Apr 1990 & 67.6 & $98.0 \%$ & .62 & $.9 x$ & 68.7 & 68.9 & 8 & 8 & $100.0 \%$ \\
\hline 4 Apr 1990 & 67.8 & $98.2 x$ & .68 & $1.0 \%$ & 68.7 & 66.7 & 6 & 6 & $100.0 \%$ \\
\hline 5 Apr 1990 & 68.3 & $99.1 \%$ & .49 & $.7 x$ & 69.2 & 67.8 & 6 & 6 & $100.0 \%$ \\
\hline 6 Apr 1990 & 68.1 & $98.7 x$ & 1.02 & $1.5 x$ & 69.5 & 66.7 & 7 & 7 & $100.0 \%$ \\
\hline 7 Apr 1990 & 67.8 & $98.3 x$ & .71 & $1.1 x$ & 68.9 & 67.2 & 7 & 7 & $100.0 \%$ \\
\hline 8 Apr 1990 & 67.8 & $98.2 x$ & .68 & $1.0 x$ & 69.0 & 67.2 & 6 & 6 & $100.0 \%$ \\
\hline 9 Apr 1990 & 67.6 & $97.9 \%$ & .60 & $.9 x$ & 68.6 & 66.9 & 8 & 8 & $100.0 x$ \\
\hline $10 \mathrm{Apr} 1990$ & 67.9 & $98.4 x$ & .42 & $.6 \%$ & 68.3 & 67.4 & 5 & 5 & $100.0 \%$ \\
\hline $11 \mathrm{Apr} 1990$ & 68.9 & $99.8 \%$ & .71 & $1.0 \%$ & 69.9 & 68.1 & 7 & 7 & $100.0 \%$ \\
\hline 12 Apr 1990 & 69.0 & $100.0 \%$ & .64 & $.9 x$ & 69.9 & 68.2 & 6 & 6 & $100.0 \%$ \\
\hline 13 Apr 1990 & 68.8 & $99.7 \%$ & .54 & $.8 \%$ & 69.3 & 68.1 & 8 & 8 & $100.0 x$ \\
\hline 14 Apr 1990 & 68.9 & $99.9 \%$ & .30 & $.4 x$ & 69.5 & 68.6 & 7 & 7 & $100.0 \%$ \\
\hline 15 Apr 1990 & 68.9 & $99.9 \%$ & .37 & $.5 x$ & 69.4 & 68.6 & 7 & 7 & $100.0 \%$ \\
\hline 16 Apr 1990 & 69.1 & $100.2 x$ & .44 & $.6 \%$ & 69.7 & 68.5 & 7 & 7 & $100.0 \%$ \\
\hline 17 Apr 1990 & 69.5 & $100.7 x$ & .43 & $.6 \%$ & 70.1 & 68.9 & 7 & 7 & $100.0 \%$ \\
\hline 18 Apr 1990 & 69.5 & $100.7 \%$ & .59 & $.8 \%$ & 70.2 & 68.7 & 6 & 6 & $100.0 \%$ \\
\hline 19 Apr 1990 & 67.5 & $97.9 \%$ & 56 & $.8 \%$ & 68.3 & 66.7 & 1 & 2 & $100.0 x$ \\
\hline Sumary & 88.2 & $98.9 x$ & .95 & $1.4 x$ & 70.2 & 65.7 & 161 & 161 & $100.0 \%$ \\
\hline
\end{tabular}

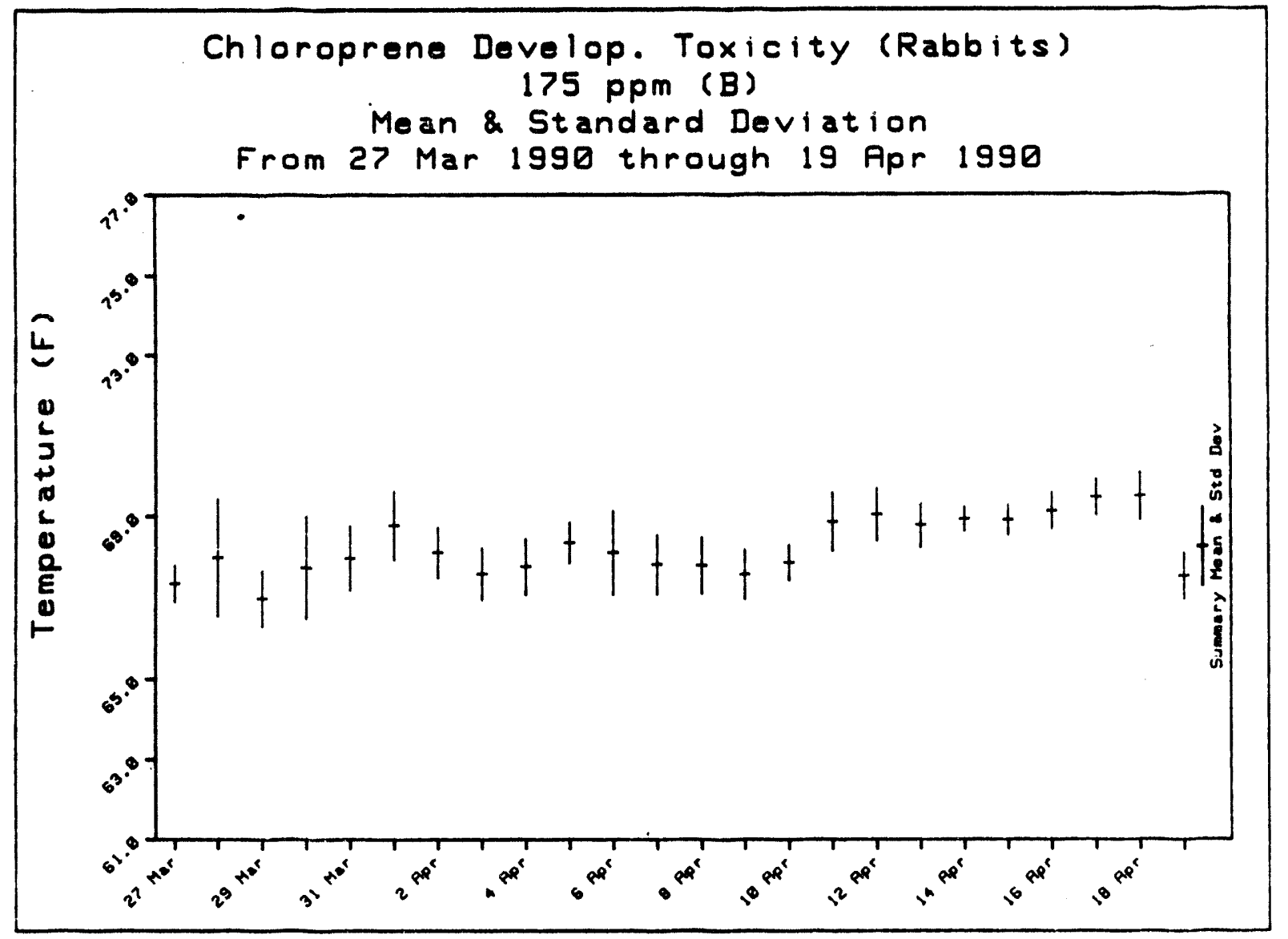


$$
\text { Relative Humidity Data }
$$

B -33 
Deily Sumation For Chlorogrene Develoo. Toxicity (Rabbite)

From 22 Mar 1990 through 19 Apr 1990

\begin{tabular}{|c|c|c|c|c|c|c|c|c|c|}
\hline Suminary Data & 0 PD & & /Relative & idity & & & e. 4 & to 70 & \\
\hline Date & Manan & $x$ laraet & Std Der & $\times \mathrm{RSD}$ & Maximum & Minimum & $N$ & $N$ in & $x \times$ in \\
\hline 27 Mar 1990 & 52.0 & $94.5 x$ & 3.10 & $6.0 x$ & 56.0 & 47.0 & 8 & 6 & $100.0 x$ \\
\hline $28 \operatorname{Mar} 1990$ & 58.9 & $107.0 x$ & 5.84 & $9.9 x$ & 67.0 & 52.0 & 8 & 8 & $100.0 x$ \\
\hline $29 \operatorname{Mar} 1990$ & 58.8 & $106.8 \%$ & 4.83 & $8.2 x$ & 84.0 & 52.0 & 8 & 8 & $100.0 x$ \\
\hline 30 Mar 1990 & 61.1 & $111.1 x$ & 5.51 & $9.0 x$ & 67.0 & 52.0 & 8 & 8 & $100.0 x$ \\
\hline 31 Mar 1990 & 62.3 & $113.2 x$ & 5.41 & $8.7 \%$ & 68.0 & 55.0 & 7 & 7 & $100.0 x$ \\
\hline 1 Apr 1990 & 59.8 & $108.6 x$ & 5.83 & $9.4 x$ & 68.0 & 52.0 & 8 & 8 & $100.0 x$ \\
\hline 2 Apr 1990 & 63.1 & $114.8 x$ & 4.10 & $6.5 \%$ & 68.0 & 58.0 & 7 & 7 & $100.0 x$ \\
\hline 3 Apr 1990 & 61.5 & $111.8 x$ & 5.13 & $8.3 x$ & 68.0 & 55.0 & 8 & 8 & $100.0 x$ \\
\hline 4 Apr 1990 & 59.5 & $108.2 x$ & 5.71 & $9.6 x$ & 88.0 & 52.0 & 8 & 8 & $100.0 \%$ \\
\hline 5 Apr 1990 & 59.6 & $108.4 x$ & 5.97 & $10.0 x$ & 68.0 & 53.0 & 8 & 8 & $100.0 x$ \\
\hline 6 Apr 1990 & 62.5 & $113.6 x$ & 4.84 & $7.7 x$ & 68.0 & 56.0 & 8 & 8 & $100.0 x$ \\
\hline 7 Apr 1990 & 60.4 & $109.8 \%$ & 4.87 & $8.1 x$ & 68.0 & 55.0 & 8 & 8 & $100.0 x$ \\
\hline 8 Apr 1990 & 58.3 & $102.3 x$ & 8.91 & $15.8 x$ & 69.0 & 47.0 & 8 & 8 & $100.0 x$ \\
\hline 9 Apr 1990 & 60.0 & $109.1 x$ & 4.78 & $7.9 x$ & 66.0 & 52.0 & 7 & 7 & $100.0 \%$ \\
\hline 10 Apr 1990 & 57.6 & $104.7 \%$ & 5.47 & $9.5 x$ & 64.0 & 51.0 & 7 & 7 & $100.0 x$ \\
\hline 11 Apr 1990 & 58.9 & $107.0 \%$ & 4.12 & $7.0 x$ & 64.0 & 54.0 & 8 & 8 & $100.0 \%$ \\
\hline 12 Apr 1990 & 55.6 & $101.1 x$ & 4.63 & $8.3 x$ & 61.0 & 48.0 & 8 & 8 & $100.0 \%$ \\
\hline 13 Apr 1990 & 60.9 & $110.6 x$ & 4.60 & $7.6 x$ & 66.0 & 52.0 & 7 & 7 & $100.0 x$ \\
\hline 14 Apr 1990 & 61.3 & $111.4 x$ & 2.98 & $4.9 x$ & 67.0 & 58.0 & 7 & 1 & $100.0 x$ \\
\hline 15 Apr 1990 & 57.4 & $104.4 \%$ & 1.51 & $2.6 x$ & 60.0 & 56.0 & 7 & 7 & $100.0 x$ \\
\hline 16 Apr 1990 & 59.5 & $108.2 x$ & 3.85 & $6.5 x$ & 84.0 & 54.0 & 8 & 8 & $100.0 \%$ \\
\hline 17 Apr 1990 & 55.6 & $101.1 x$ & 5.10 & $9.2 x$ & 63.0 & 49.0 & 8 & 8 & $100.0 x$ \\
\hline 18 Apr 1990 & 52.1 & $94.8 x$ & 2.30 & $4.4 x$ & 55.0 & 49.0 & 8 & 8 & $100.0 x$ \\
\hline 12 Aor 1990 & 53.2 & $92.7 \%$ & 5.09 & $2.5 x$ & 61.0 & 46.0 & 8 & 8 & $100.0 x$ \\
\hline Summary & 58.7 & $108.7 x$ & 5.55 & $9.5 x$ & 69.0 & 46.0 & 183 & 183 & $100.0 x$ \\
\hline
\end{tabular}

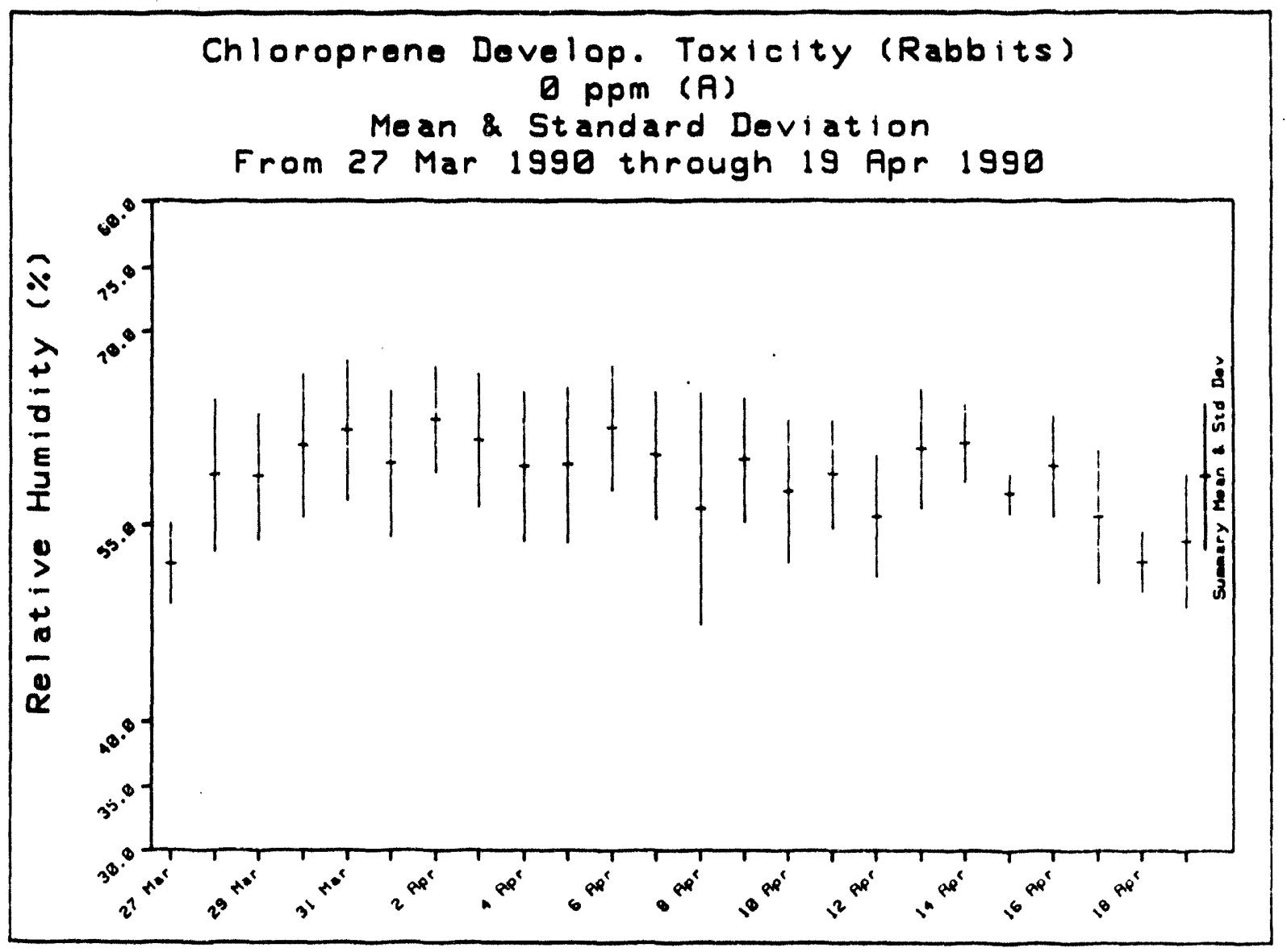


Dally Sumation for Chloroprene Develog, Ioxicity (Rabbits) From 23 Mar 1990 through 18 Aor 1990 Sumary Data for: 0 ppm (B) /Relative Humidity Range= 40.0 to 70.0

\begin{tabular}{|c|c|c|c|c|c|c|c|c|c|}
\hline Date & Man. & $x$ Iargat & Stad Dey & $X \mathrm{RSO}$ & Maximum & Minimum & $N$ & $N$ in & $x \|$ in \\
\hline 23 Mar 1990 & 65.8 & $119.7 x$ & 6.62 & $10.0 x$ & 75.0 & 60.0 & 6 & 4 & $66.7 x$ \\
\hline $24 \operatorname{Mar} 1990$ & 51.6 & $93.9 x$ & 4.69 & $9.1 x$ & 63.0 & 49.0 & 8 & 8 & $100.0 x$ \\
\hline 25 Mar 1990 & 48.6 & $88.4 x$ & 2.97 & $6.1 \%$ & 51.0 & 42.0 & 8 & 8 & $100.0 x$ \\
\hline 26 Mar 1990 & 53.0 & $96.4 x$ & 6.99 & $13.2 x$ & 62.0 & 45.0 & 8 & 8 & $100.0 x$ \\
\hline 27 Mar 1990 & 61.9 & $112.5 x$ & 6.20 & $10.0 x$ & 69.0 & 52.0 & 7 & 7 & $100.0 x$ \\
\hline 28 Mar 1990 & 64.2 & $118.8 x$ & 7.11 & $11.1 x$ & 73.0 & 55.0 & 8 & 6 & $75.0 x$ \\
\hline $29 \operatorname{Mar} 1990$ & 63.8 & $115.9 x$ & 4.71 & $7.4 x$ & 70.0 & 56.0 & 8 & 8 & $100.0 x$ \\
\hline $30 \operatorname{Mar} 1990$ & 64.7 & $117.7 x$ & 5.85 & $9.0 x$ & 72.0 & 58.0 & 8 & 7 & $87.5 x$ \\
\hline $31 \operatorname{Mar} 1990$ & 67.3 & $122.3 x$ & 4.19 & $6.2 x$ & 71.0 & 61.0 & 7 & 4 & $57.1 x$ \\
\hline 1 Apr 1990 & 68.7 & $121.4 x$ & 4.74 & $7.1 x$ & 73.0 & 60.0 & 8 & 6 & $75.0 x$ \\
\hline 2 Apr 1990 & 65.2 & $118.5 x$ & 4.45 & 6.8x & 71.0 & 60.0 & 6 & 5 & $83.3 x$ \\
\hline 3 Apr 1990 & 65.9 & $119.8 x$ & 3.23 & $4.9 x$ & 69.0 & 80.0 & 8 & 8 & $100.0 \%$ \\
\hline 4 Apr 1990 & 62.0 & $112.7 x$ & 5.35 & $8.6 x$ & 70.0 & 54.0 & 8 & 8 & $100.0 x$ \\
\hline 5 Apr 1990 & 63.4 & $115.2 x$ & 4.03 & $6.4 x$ & 69.0 & 58.0 & 8 & 8 & $100.0 x$ \\
\hline 6 Apr 1990 & 62.9 & $114.3 \%$ & 5.46 & $8.7 \%$ & 69.0 & 56.0 & 1 & 7 & $100.0 x$ \\
\hline 7 Apr 1990 & 64.4 & $117.0 x$ & 3.85 & $6.0 x$ & 69.0 & 59.0 & 8 & 8 & $100.0 x$ \\
\hline 8 Apr 1990 & 58.8 & $106.8 x$ & 7.80 & $13.3 x$ & 68.0 & 51.0 & 8 & 8 & $100.0 x$ \\
\hline 9 Apr 1990 & 64.7 & $117.7 x$ & 5.79 & $9.0 x$ & 70.0 & 55.0 & 7 & 7 & $100.0 x$ \\
\hline 10 Apr 1990 & 64.9 & $117.9 x$ & 6.09 & $9.4 x$ & 71.0 & 56.0 & 7 & 5 & $71.4 x$ \\
\hline 11 Apr 1990 & 65.6 & $119.3 x$ & 6.50 & $9.9 x$ & 72.0 & 56.0 & 8 & 5 & $62.5 x$ \\
\hline 12 Apr 1990 & 62.3 & $113.2 x$ & 5.99 & $9.6 x$ & 70.0 & 53.0 & 8 & 8 & $100.0 x$ \\
\hline 13 Apr 1990 & 66.7 & $121.3 x$ & 5.15 & $7.7 x$ & 12.0 & 59.0 & 7 & 4 & $57.1 x$ \\
\hline 14 Apr 1990 & 64.4 & $117.1 x$ & 4.04 & $6.3 x$ & 73.0 & 61.0 & 7 & 6 & $85.7 x$ \\
\hline 15 Apr 1990 & 61.6 & $111.9 x$ & 2.23 & 3.6x & 64.0 & 58.0 & 7 & 7 & $100.0 x$ \\
\hline 16 Apr 1990 & 64.2 & $116.8 \%$ & 4.95 & $7.7 x$ & 70.0 & 56.0 & 8 & 8 & $100.0 x$ \\
\hline 17 Apr 1990 & 59.6 & $108.4 x$ & 4.50 & $1.6 x$ & 67.0 & 54.0 & 8 & 8 & $100.0 \%$ \\
\hline 18 Aor 1990 & 56.3 & $102,3 \%$ & 2.66 & $4.7 x$ & 59.2 & 51.0 & 8 & 8 & $100.0 \%$ \\
\hline Sumary & 62.1 & $112.9 x$ & 6.82 & $11.0 \%$ & 75.0 & 42.0 & 204 & 184 & $90.2 x$ \\
\hline
\end{tabular}

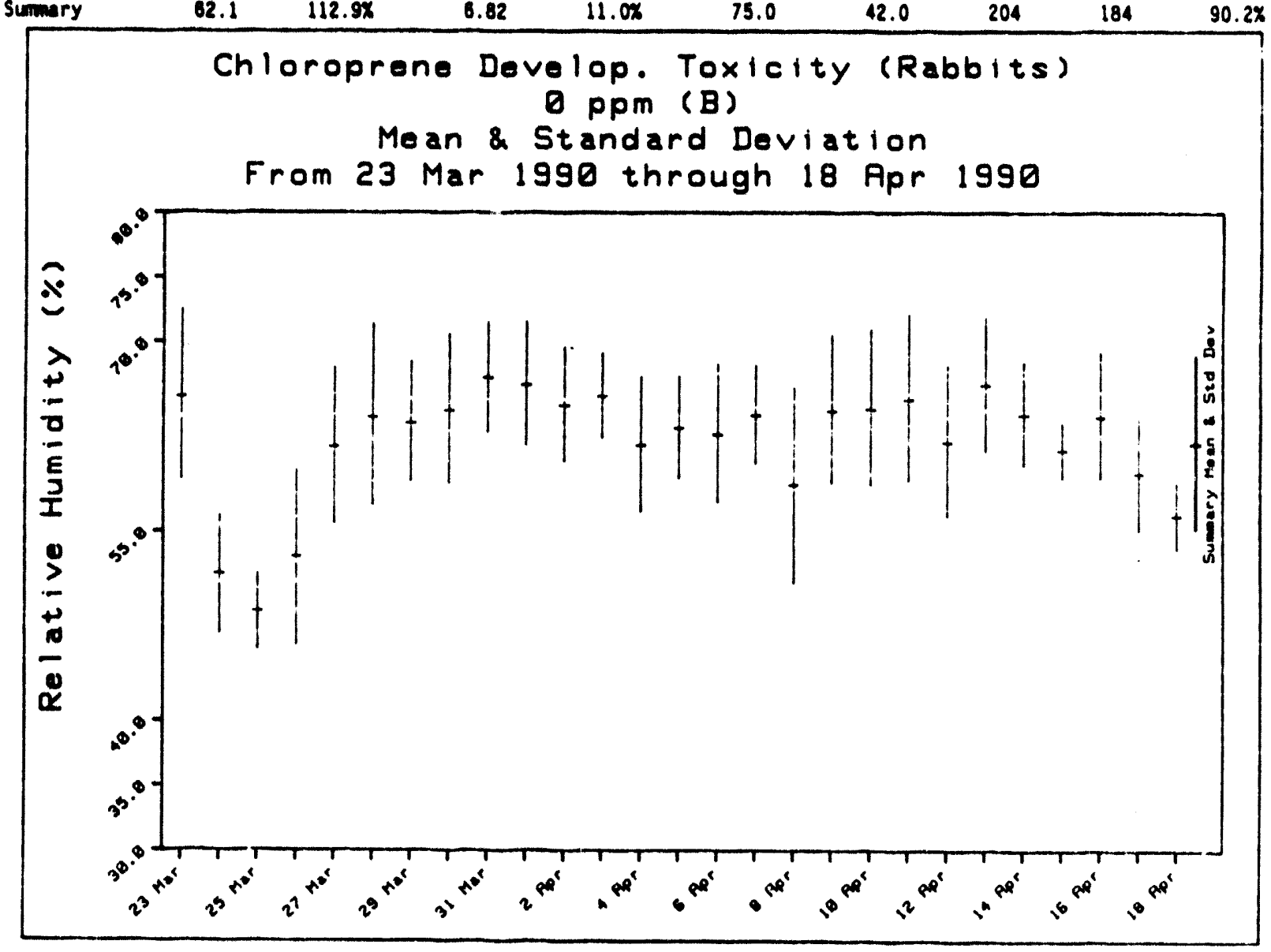


Dulle Sumution For Chloroprene Develog. Toxicity (Rabbite) From 23 Mar 1990 throuah 18 Aor 1990

\begin{tabular}{|c|c|c|c|c|c|c|c|c|c|}
\hline Suminary Data & $: 10 \mathrm{pp}$ & (A) & /Relative & Idity & & & Range: 40 & to 70 & \\
\hline Quth & Mun & $x$ rarent & Std Dery & $\times$ RSD & Maximum & Minimum & $\mathrm{N}$ & $N$ in & $x \times$ in \\
\hline 23 Mar 1990 & 66.0 & $120.0 x$ & 7.18 & $10.8 x$ & 75.0 & 56.0 & 6 & 5 & $83.3 x$ \\
\hline 24 Mar 1990 & 58.0 & $105.5 x$ & 5.48 & $9.4 x$ & 70.0 & 53.0 & 8 & 8 & $100.0 x$ \\
\hline 25 Mar 1990 & 57.1 & $103.9 x$ & 2.95 & $5.2 x$ & 60.0 & 52.0 & 8 & 8 & $100.0 \%$ \\
\hline $26 \operatorname{Mar} 1990$ & 59.0 & $107.3 x$ & 8.90 & $15.1 x$ & 69.0 & 45.0 & 8 & 8 & $100.0 \%$ \\
\hline 27 Mar 1990 & 64.7 & $117.7 x$ & 7.20 & $11.1 x$ & 72.0 & 55.0 & 7 & 5 & $71.4 x$ \\
\hline 28 Mur 1990 & 65.1 & $118.4 x$ & 9.37 & $14.4 x$ & 77.0 & 54.0 & 8 & 4 & $50.0 x$ \\
\hline 29 Mar 1990 & 55.2 & $100.5 x$ & 9.45 & $17.1 x$ & 68.0 & 43.0 & 8 & 8 & $100.0 \%$ \\
\hline 30 Mar 1990 & 57.3 & $104.1 \%$ & 8.28 & $14.5 \%$ & 84.0 & 43.0 & 8 & 8 & $100.0 \%$ \\
\hline 31 Mar 1990 & 57.6 & $104.7 x$ & 7.78 & $13.5 x$ & 65.0 & 47.0 & 7 & 7 & $100.0 \%$ \\
\hline 1 Apr 1990 & 58.4 & $108.1 x$ & 7.61 & $13.0 \%$ & 67.0 & 46.0 & 8 & 8 & $100.0 x$ \\
\hline 2 Apr 1990 & 56.6 & $102.9 x$ & 6.24 & $11.0 x$ & 84.0 & 50.0 & 7 & 7 & $100.0 \%$ \\
\hline 3 Apr 1990 & 60.1 & $109.3 x$ & 6.51 & $10.8 x$ & 70.0 & 49.0 & 8 & 8 & $100.0 \%$ \\
\hline 4 Apr 1990 & 60.1 & $109.3 \%$ & 9.28 & $15.4 x$ & 72.0 & 48.0 & 8 & 7 & $87.5 \%$ \\
\hline 5 Apr 1990 & 58.5 & $108.4 x$ & 9.13 & $15.6 \%$ & 70.0 & 48.0 & 8 & 8 & $100.0 \%$ \\
\hline 6 Apr 1990 & 61.3 & $111.4 x$ & 11.13 & $18.2 \%$ & 74.0 & 48.0 & 7 & 4 & $57.1 x$ \\
\hline 7 Apr 1990 & 61.6 & $112.0 x$ & 9.35 & $15.2 \%$ & 72.0 & 48.0 & 8 & 7 & $87.5 \%$ \\
\hline 8 Apr 1990 & 58.1 & $105.7 x$ & 11.81 & $20.0 x$ & 74.0 & 46.0 & 8 & 6 & $75.0 \%$ \\
\hline 9 Apr 1990 & 67.1 & $122.1 x$ & 8.86 & $13.2 x$ & 75.0 & 54.0 & 7 & 3 & $42.9 \%$ \\
\hline 10 Apr 1990 & 59.4 & $108.1 x$ & 9.95 & $16.7 x$ & 76.0 & 48.0 & 7 & 6 & $85.7 \%$ \\
\hline 11 Apr 1990 & 57.5 & $104.5 x$ & 5.78 & $10.1 x$ & 63.0 & 50.0 & 8 & 8 & $100.0 \%$ \\
\hline 12 Apr 1990 & 54.5 & 99.18 & 6.80 & $12.5 x$ & 62.0 & 43.0 & 8 & 8 & $100.0 x$ \\
\hline 13 Apr 1990 & 58.0 & $105.5 \%$ & 6.08 & $10.5 x$ & 65.0 & 47.0 & 7 & 7 & $100.0 \%$ \\
\hline 14 Apr 1990 & 59.0 & $107.3 x$ & 4.20 & $7.1 \%$ & 68.0 & 55.0 & 7 & 7 & $100.0 \%$ \\
\hline 15 Apr 1990 & 53.6 & $97.4 x$ & 2.94 & $5.5 x$ & 58.0 & 49.0 & 7 & 7 & $100.0 \%$ \\
\hline 16 Apr 1990 & 55.9 & $101.6 x$ & 6.10 & $10.9 x$ & 84.0 & 46.0 & 8 & 8 & $100.0 \%$ \\
\hline 17 Apr 1990 & 54.0 & $98.2 x$ & 4.44 & $8.2 x$ & 62.0 & 48.0 & 8 & 8 & $100.0 \%$ \\
\hline 18Aor 1990 & 50.8 & $92,3 x$ & 5.18 & 10.27 & Bo.e & 43.0 & 8 & 8 & $100.0 \%$ \\
\hline Sumary & 58.6 & $108.5 x$ & 8.00 & $13.8 x$ & 71.0 & 43.0 & 205 & 186 & $90.7 \%$ \\
\hline
\end{tabular}

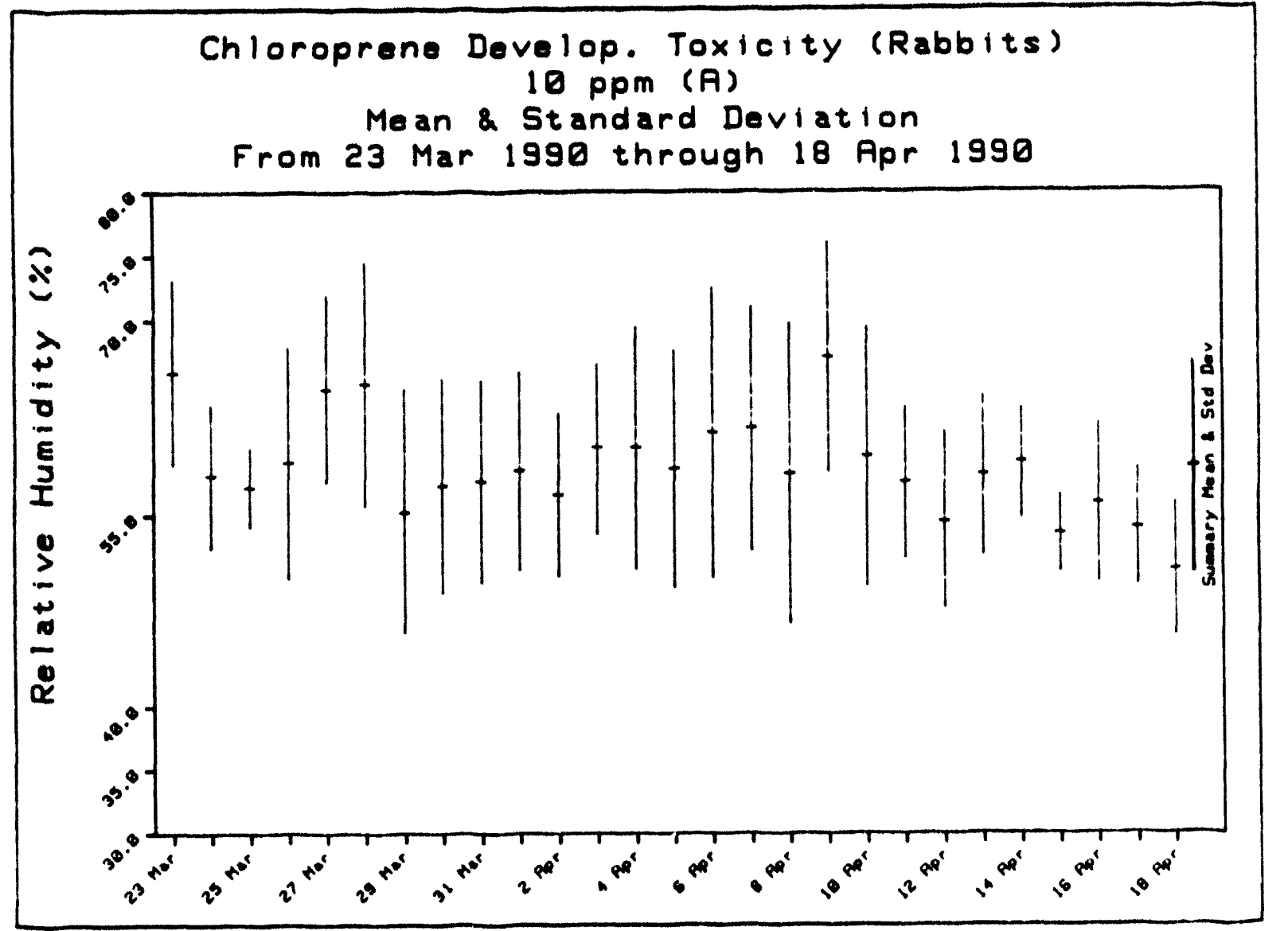


Qully Sumation for Chloroprene Develoo. Ioxtaity (Rabblts) From 22 Mar 1990 through 19 Aor 1990

\begin{tabular}{|c|c|c|c|c|c|c|c|c|c|}
\hline \multicolumn{3}{|c|}{ Summary Data for: $10 \mathrm{ppm}$ (B) } & \multicolumn{3}{|c|}{ /Rolative Humidity } & \multicolumn{4}{|c|}{ Range= 40.0 to 10.0} \\
\hline Qute & Man & $x$ Taront & Std Der & $\times$ RSD & Maximm & Minimin. & 1 & Nin & $x y \ln$ \\
\hline 27 Mar 1990 & 59.0 & $107.3 \%$ & 3.85 & $6.5 \%$ & 64.0 & 54.0 & 6 & 6 & $100.0 x$ \\
\hline 28 Mar 1990 & 62.0 & $112.7 x$ & 6.46 & $10.4 x$ & 71.0 & 52.0 & 8 & 7 & $87.5 x$ \\
\hline $29 \operatorname{Mar} 1990$ & 53.6 & $97.5 x$ & 6.28 & $11.7 x$ & 65.0 & 46.0 & 8 & 8 & $100.0 x$ \\
\hline 30 Mar 1990 & 55.7 & $101.4 x$ & 6.50 & $11.7 x$ & 63.0 & 45.0 & 8 & 8 & $100.0 x$ \\
\hline 31 Mar 1990 & 53.4 & $100.8 x$ & 5.83 & $10.5 x$ & 62.0 & 46.0 & 7 & 7 & $100.0 x$ \\
\hline 1 Apr 1990 & 59.1 & $107.5 \%$ & 7.04 & $11.9 x$ & 68.0 & 49.0 & 8 & 8 & $100.0 x$ \\
\hline 2 Apr 1990 & 57.9 & $105.2 x$ & 4.74 & $8.2 x$ & 63.0 & 52.0 & 7 & 7 & $100.0 x$ \\
\hline 3 Apr 1990 & 59.3 & $107.7 x$ & 3.23 & $8.8 x$ & 65.0 & 51.0 & 8 & 8 & $100.0 x$ \\
\hline 4 Apr 1990 & 54.7 & $99.5 x$ & 7.81 & $14.3 \%$ & 63.0 & 44.0 & 8 & 8 & $100.0 x$ \\
\hline 5 Apr 1990 & 55.6 & $101.1 x$ & 8.03 & $14.4 x$ & 65.0 & 46.0 & 8 & 8 & $100.0 x$ \\
\hline 6 Apr 1990 & 56.6 & $102.9 x$ & 6.24 & $11.0 x$ & 65.0 & 49.0 & 7 & 7 & $100.0 x$ \\
\hline 1 Apr 1990 & 56.0 & $101.8 x$ & 6.97 & $12.4 x$ & 84.0 & 46.0 & 8 & 8 & $100.0 \%$ \\
\hline 8 Apr 1990 & 53.5 & $97.3 x$ & 1.73 & $14.4 \%$ & 65.0 & 48.0 & 8 & 8 & $100.0 x$ \\
\hline 9 Apr 1990 & 57.0 & $103.6 x$ & 5.86 & $10.3 x$ & B2. 0 & 48.0 & 7 & 7 & $100.0 x$ \\
\hline 10 Apr 1990 & 57.6 & $104.7 x$ & 5.22 & $9.1 x$ & 64.0 & 50.0 & 7 & 7 & $100.0 x$ \\
\hline 11 Apr 1990 & 60.0 & $109.1 \%$ & 6.74 & $11.2 x$ & 69.0 & 52.0 & 8 & 8 & $100.0 x$ \\
\hline 12 Apr 1990 & 57.0 & $103.6 \%$ & 7.15 & $12.5 x$ & 68.0 & 45.0 & 8 & 8 & $100.0 x$ \\
\hline 13 Apr 1990 & 56.0 & $101.8 x$ & 4.86 & $8.7 x$ & 68.0 & 50.0 & 1 & 7 & $100.0 x$ \\
\hline 14 Apr 1990 & 80.1 & $109.4 x$ & 2.27 & $3.8 \%$ & 62.0 & 58.0 & 7 & 7 & $100.0 x$ \\
\hline 15 Apr 1990 & 57.6 & $104.7 x$ & 1.27 & $2.2 \%$ & 59.0 & 56.0 & 7 & 7 & $100.0 x$ \\
\hline 16 Apr 1990 & 60.5 & 110.08 & 6.12 & $10.1 x$ & 66.0 & 50.0 & 8 & 6 & $100.0 x$ \\
\hline 17 Apr 1990 & 54.0 & $98.2 x$ & 5.90 & $10.9 x$ & 65.0 & 45.0 & 8 & 8 & $100.0 x$ \\
\hline 18 Apr 1990 & 49.1 & $89.3 x$ & 2.75 & $5.6 x$ & 33.0 & 45.0 & 8 & 8 & $100.0 x$ \\
\hline 19 Apr 1990 & 56.2 & $102.0 \%$ & s.5! & $8.2 \%$ & 83.0 & 50.0 & 8 & 8 & $100.0 \%$ \\
\hline Sumary & 56.8 & $103.2 x$ & 8.23 & $11.0 x$ & 71.0 & 44.0 & 182 & 181 & $99.5 x$ \\
\hline
\end{tabular}

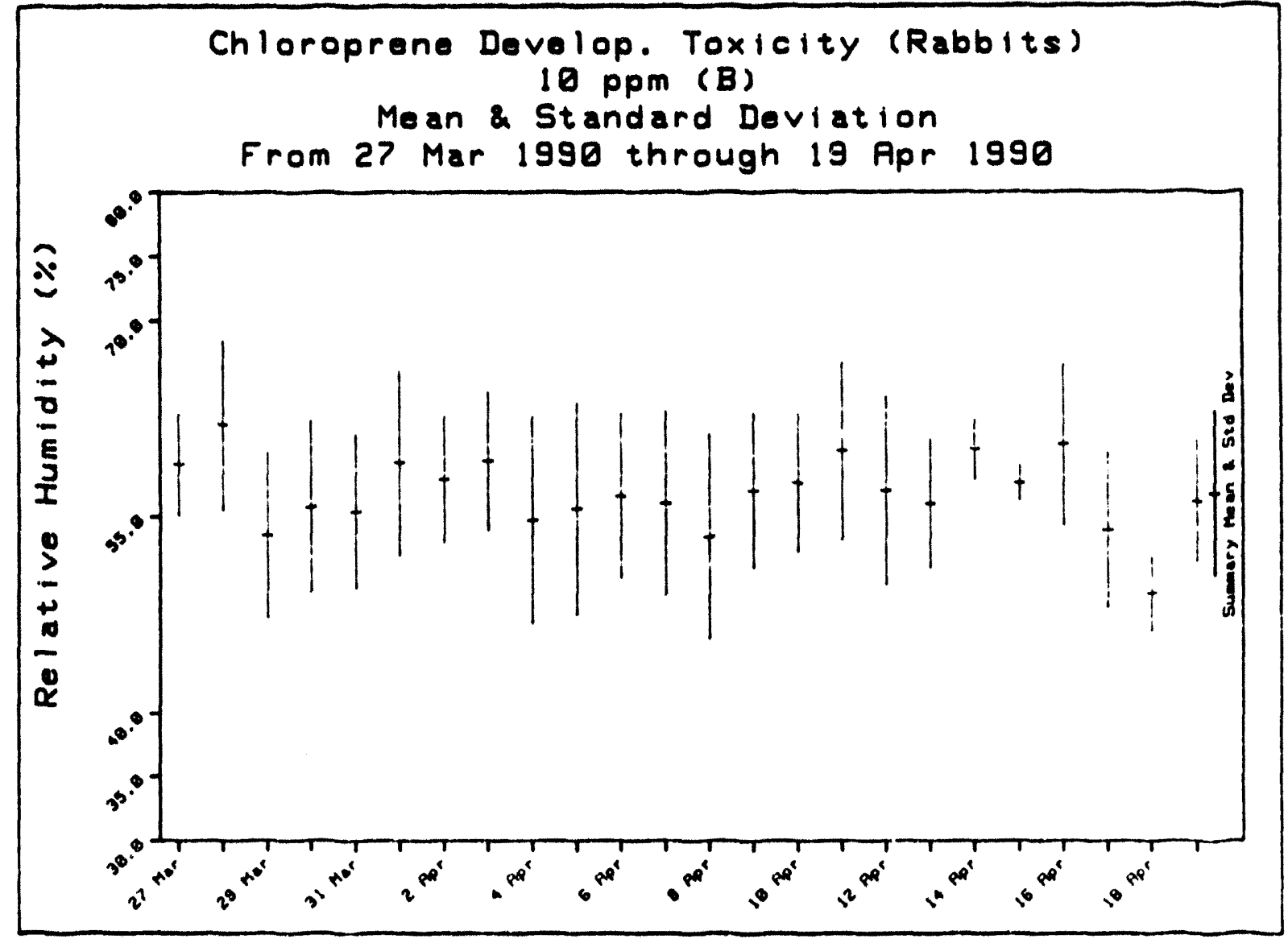




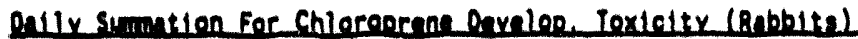

From 23 Mar 1990 through 18 Aor 1990

\begin{tabular}{|c|c|c|c|c|c|c|c|c|c|}
\hline \multicolumn{3}{|c|}{ Sumary Data for: $10 \mathrm{ppm}(\mathrm{A})$} & \multirow{2}{*}{\multicolumn{3}{|c|}{$\begin{array}{l}\text { /Rolative Humidity } \\
\text { std Oay }\end{array}$}} & \multicolumn{4}{|c|}{ Ranga: 10.0 to 70.0} \\
\hline Dith & man & $x$ Inrent & & & Meximm & Minimin & -1 & N $\ln$ & $x \times \ln$ \\
\hline 23 Mar 1990 & 53.7 & $97.6 x$ & 6.06 & $11.3 x$ & 60.0 & 46.0 & 6 & 6 & $100.0 x$ \\
\hline 24 Mar 1990 & 47.1 & $85.7 x$ & 6.13 & $13.0 x$ & 60.0 & 40.0 & 8 & 8 & $100.0 \%$ \\
\hline 25 Mar 1990 & 47.1 & $85.7 x$ & 4.49 & $9.5 x$ & 51.0 & 39.0 & 8 & 7 & $87.5 x$ \\
\hline 26 Mar 1890 & 60.8 & $110.5 \%$ & 11.65 & $19.2 x$ & 73.0 & 38.0 & 8 & 5 & $62.5 x$ \\
\hline 27 Mar 1990 & 68.4 & $124.4 x$ & 7.00 & $10.2 x$ & 75.0 & 58.0 & 7 & 3 & $42.8 x$ \\
\hline 20 Mar 1990 & 64.9 & $118.0 x$ & 7.90 & $12.2 x$ & 74.0 & 54.0 & 8 & 6 & $75.0 x$ \\
\hline 29 Mar 1990 & 54.2 & $98.6 x$ & 8.03 & $14.8 x$ & 68.0 & 45.0 & 8 & 8 & $100.0 x$ \\
\hline 30 Mar 1990 & 56.9 & $103.4 x$ & 7.85 & $13.8 x$ & 65.0 & 44.0 & 8 & 8 & $100.0 x$ \\
\hline 31 Mar 1990 & 58.6 & $106.5 x$ & 7.63 & $13.0 x$ & 86.0 & 48.0 & 7 & 7 & 100.08 \\
\hline 1 Apr 1980 & 59.3 & $107.7 x$ & 7.17 & $12.1 x$ & 67.0 & 50.0 & 8 & 8 & $100.0 x$ \\
\hline 2 Apr 1990 & 58.3 & $108.1 x$ & 6.47 & $11.1 \%$ & 64.0 & 50.0 & 6 & 6 & $100.0 \%$ \\
\hline 3 Apr 1990 & 39.5 & $108.2 x$ & 6.57 & $11.0 \%$ & 66.0 & 49.0 & 8 & 8 & $100.0 x$ \\
\hline 4 Apr 1990 & 54.1 & $98.4 x$ & 6.89 & $12.7 x$ & 63.0 & 46.0 & 7 & 7 & $100.0 \%$ \\
\hline 5 Apr 1990 & 58.1 & $102.0 x$ & 7.90 & $14.2 x$ & 65.0 & 46.0 & 8 & 8 & $100.0 \%$ \\
\hline 6 Apr 1990 & 60.7 & $110.4 x$ & 7.43 & $12.2 x$ & 68.0 & 50.0 & 7 & 7 & $100.0 x$ \\
\hline 7 Apr 1990 & 59.8 & $108.6 x$ & 6.48 & $10.8 \%$ & 68.0 & 50.0 & 8 & 8 & $100.0 x$ \\
\hline A Apr 1990 & 54.7 & $99.5 \%$ & 6.92 & $12.6 \%$ & 83.0 & 47.0 & 8 & 8 & $100.0 \%$ \\
\hline - Apr 1990 & 58.4 & $106.2 x$ & 6.50 & $11.1 \%$ & 63.0 & 49.0 & 7 & 7 & $100.0 x$ \\
\hline 10 Apr 1990 & 55.6 & $101.0 x$ & 5.32 & $9.6 x$ & 64.0 & 49.0 & 7 & 7 & $100.0 \%$ \\
\hline 11 Apr 1990 & 57.5 & $104.5 x$ & 6.35 & $11.0 \%$ & 68.0 & 50.0 & 8 & 8 & $100.0 x$ \\
\hline 12 Apr 1990 & 52.7 & $95.9 x$ & 1.38 & $14.0 x$ & 81.0 & 40.0 & 8 & 8 & $100.0 x$ \\
\hline 13 Apr 1990 & 51.1 & $93.0 \%$ & 4.88 & $9.5 \%$ & 80.0 & 45.0 & 7 & 7 & $100.0 x$ \\
\hline 14 Apr 1990 & 56.1 & $102.1 x$ & 3.58 & $6.4 x$ & 59.0 & 49.0 & 7 & 7 & $100.0 x$ \\
\hline 15 Apr 1990 & 54.0 & $98.2 x$ & 2.71 & $5.1 x$ & 56.0 & 50.0 & 7 & 7 & $100.0 \%$ \\
\hline 16 Apr 1990 & 56.3 & $102.3 x$ & 5.15 & $9.2 x$ & 81.0 & 48.0 & 7 & 7 & $100.0 x$ \\
\hline 17 Apr 1990 & 53.6 & $97.5 x$ & 4.75 & $8.9 x$ & 82.0 & 46.0 & 8 & 8 & $100.0 \%$ \\
\hline 1. Aor 1990 & 48.5 & $89.8 x$ & 111 & $8.5 \%$ & sten & 43.0 & 8 & -8 & $100.0 \%$ \\
\hline Sumary & 56.2 & 102.18 & 7.87 & 14.08 & 75.0 & 38.0 & 202 & 192 & $95.0 \%$ \\
\hline
\end{tabular}

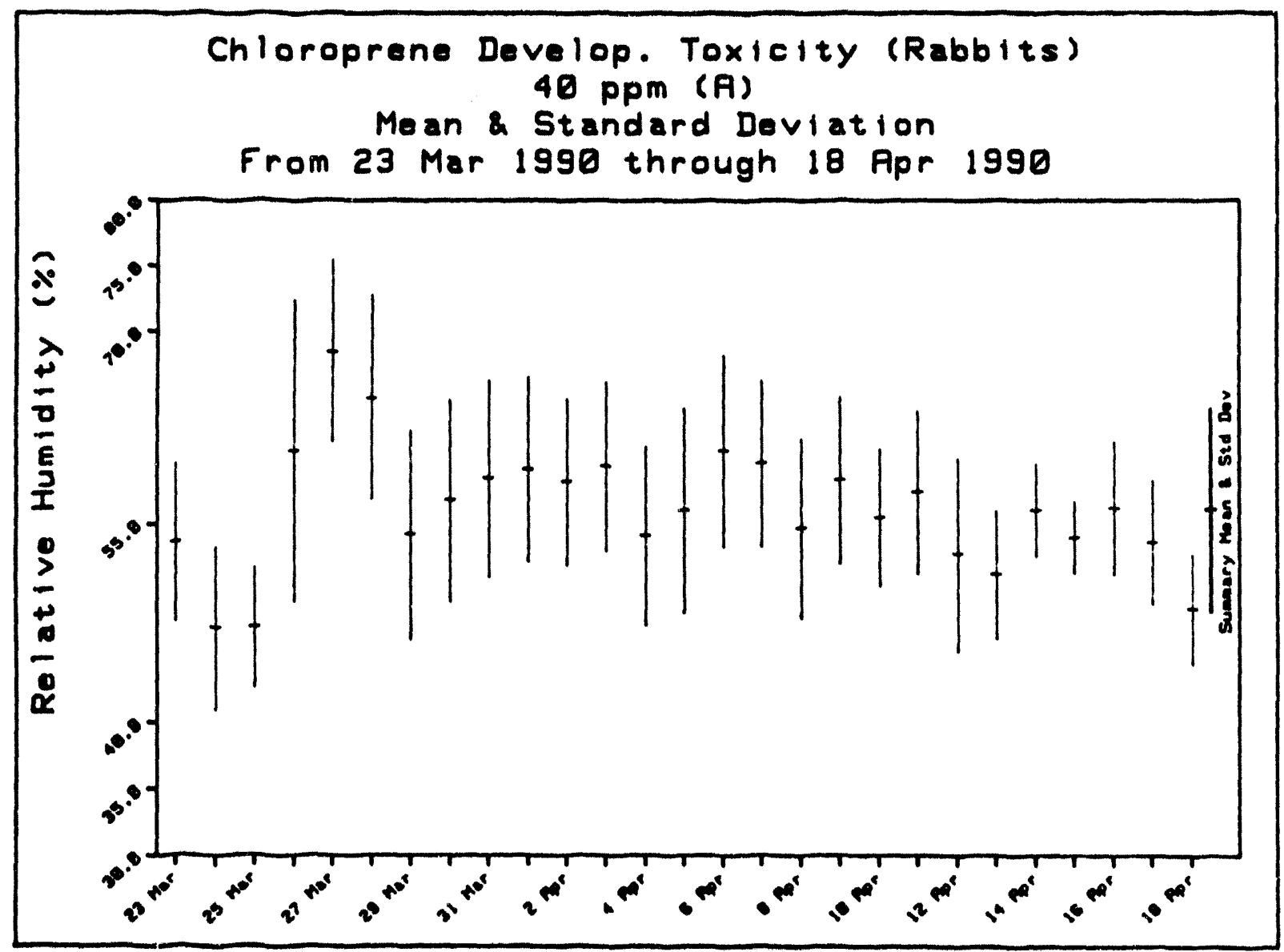


Dally Sumation for Chloroprene Develop. Ioxicity (Rabbits)

From 27 Mar 1990 through 19 Apr 1990

\begin{tabular}{|c|c|c|c|c|c|c|c|c|c|}
\hline Summary Data & $: 40 \mathrm{pl}$ & (8) & /Relative & idity & & & Range: 4 & & \\
\hline Deth & men & $x$ Inront & Std Der & $X$ RSO & Maximin & Minimim & $N$ & $N$ in & $x N$ in \\
\hline $27 \operatorname{Mar} 1990$ & 64.3 & $117.0 x$ & 3.27 & $5.1 x$ & 68.0 & 59.0 & 6 & 6 & $100.0 \%$ \\
\hline 28 Mar 1990 & 68.8 & $125.0 \%$ & 5.63 & $8.2 x$ & 76.0 & 61.0 & 8 & 4 & $50.0 \%$ \\
\hline 29 Mar 1990 & 56.8 & $103.4 x$ & 4.94 & $8.7 x$ & 62.0 & 48.0 & 8 & 8 & $100.0 x$ \\
\hline 30 Mar 1990 & 59.6 & $108.4 x$ & 8.31 & $13.9 \%$ & 69.0 & 47.0 & 8 & 8 & $100.0 x$ \\
\hline 31 Mar 1990 & 63.0 & $114.5 x$ & 6.48 & $10.3 x$ & 70.0 & 53.0 & 7 & 7 & $100.0 x$ \\
\hline 1 Apr 1990 & 62.0 & $112.7 x$ & 7.52 & $12.1 \%$ & 69.0 & 50.0 & 8 & 8 & $100.0 x$ \\
\hline 2 Apr 1990 & 60.7 & $110.3 x$ & 5.82 & $9.6 x$ & 67.0 & 53.0 & 6 & 6 & $100.0 x$ \\
\hline 3 Apr 1990 & 60.5 & $110.0 x$ & 6.39 & $10.6 x$ & 66.0 & 51.0 & 8 & 8 & $100.0 x$ \\
\hline 4 Apr 1990 & 34.4 & $99.0 x$ & 7.14 & $13.1 \%$ & 65.0 & 44.0 & 7 & 7 & $100.0 x$ \\
\hline 5 Apr 1990 & 56.1 & $102.0 x$ & 6.24 & $11.1 x$ & 63.0 & 48.0 & 8 & 8 & $100.0 \%$ \\
\hline 6 Apr 1990 & 59.1 & $107.5 \%$ & 6.62 & $11.2 \%$ & 64.0 & 50.0 & 7 & 7 & $100.0 \%$ \\
\hline 7 Apr 1990 & 57.8 & $105.0 \%$ & 5.87 & $10.2 x$ & 63.0 & 48.0 & 8 & 8 & $100.0 x$ \\
\hline - Apr 1990 & 54.0 & 98.2X & 1.67 & $14.2 \%$ & 65.0 & 47.0 & 8 & 8 & $100.0 x$ \\
\hline - Apr 1990 & 60.4 & $109.9 x$ & 5.88 & $9.7 x$ & 65.0 & 51.0 & 7 & 7 & $100.0 x$ \\
\hline 10 Apr 1990 & 57.3 & $104.2 x$ & 5.44 & $9.5 x$ & 63.0 & 49.0 & 7 & 7 & $100.0 x$ \\
\hline 11 Apr 1990 & 58.3 & $105.9 x$ & 5.70 & $9.8 \%$ & 67.0 & 52.0 & 8 & 8 & $100.0 x$ \\
\hline 12 Apr 1990 & 57.9 & $105.2 x$ & 7.14 & $12.3 \%$ & 66.0 & 47.0 & 8 & 8 & $100.0 x$ \\
\hline 13 Apr 1990 & 61.9 & $112.5 \%$ & 4.85 & $7.8 \%$ & 66.0 & 52.0 & 7 & 7 & $100.0 x$ \\
\hline 14 Apr 1890 & 59.6 & $108.3 x$ & 2.82 & $4.7 x$ & 65.0 & 56.0 & 7 & 7 & $100.0 \%$ \\
\hline 15 Apr 1990 & 56.9 & $103.4 x$ & 1.68 & 2.98 & 59.0 & 55.0 & 7 & 7 & $100.0 x$ \\
\hline 16 Apr 1980 & 60.1 & $109.4 x$ & 4.22 & $7.0 \%$ & 65.0 & 54.0 & 7 & 7 & $100.0 x$ \\
\hline 17 Apr 1990 & 55.6 & $101.1 \%$ & 3.78 & $6.8 \%$ & 62.0 & 52.0 & 8 & 8 & $100.0 x$ \\
\hline 18 Apr 1990 & 52.6 & $95.7 x$ & 3.11 & $5.9 \%$ & 59.0 & 48.0 & 8 & 8 & $100.0 x$ \\
\hline 12. Apr 1990 & 56.0 & $101.8 x$ & 2.98 & $5.3 x$ & BLe & 53.0 & 8 & 8 & $100.0 \%$ \\
\hline Sumary & 58.8 & $106.9 x$ & 8.40 & $10.9 x$ & 76.0 & 44.0 & 179 & 175 & $97.8 \%$ \\
\hline
\end{tabular}

Chloroprene Develop. Toxicity (Rabbits)

$40 \mathrm{ppm}$ (B)

Mean \& Standard Deviation

From 27 Mar 1990 through 19 Apr 1990

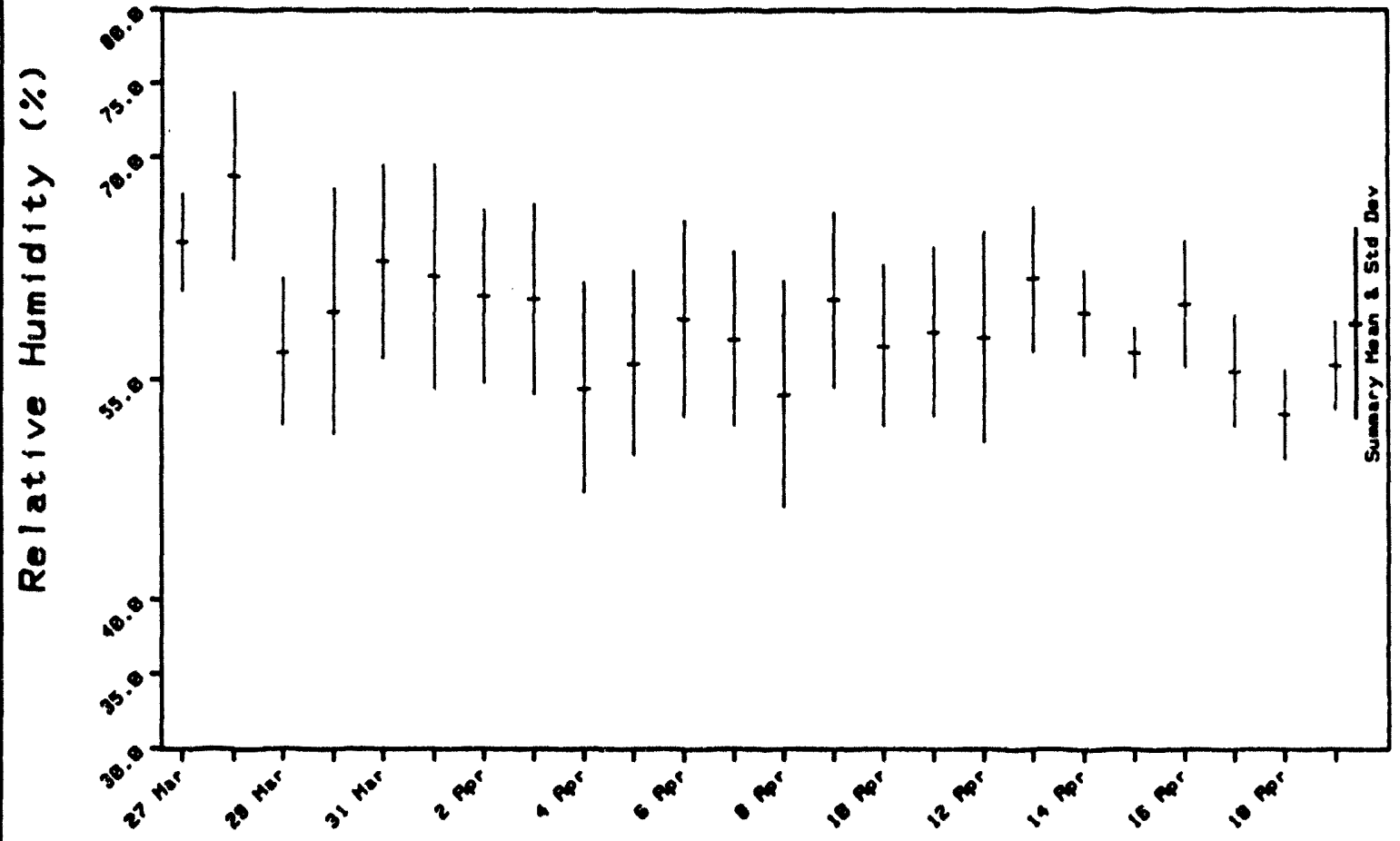


Dally Sumition for chloroprene Develoo. Toxictity (Rabbitg) From 23 Mar 1990 through 18 Apr 1990

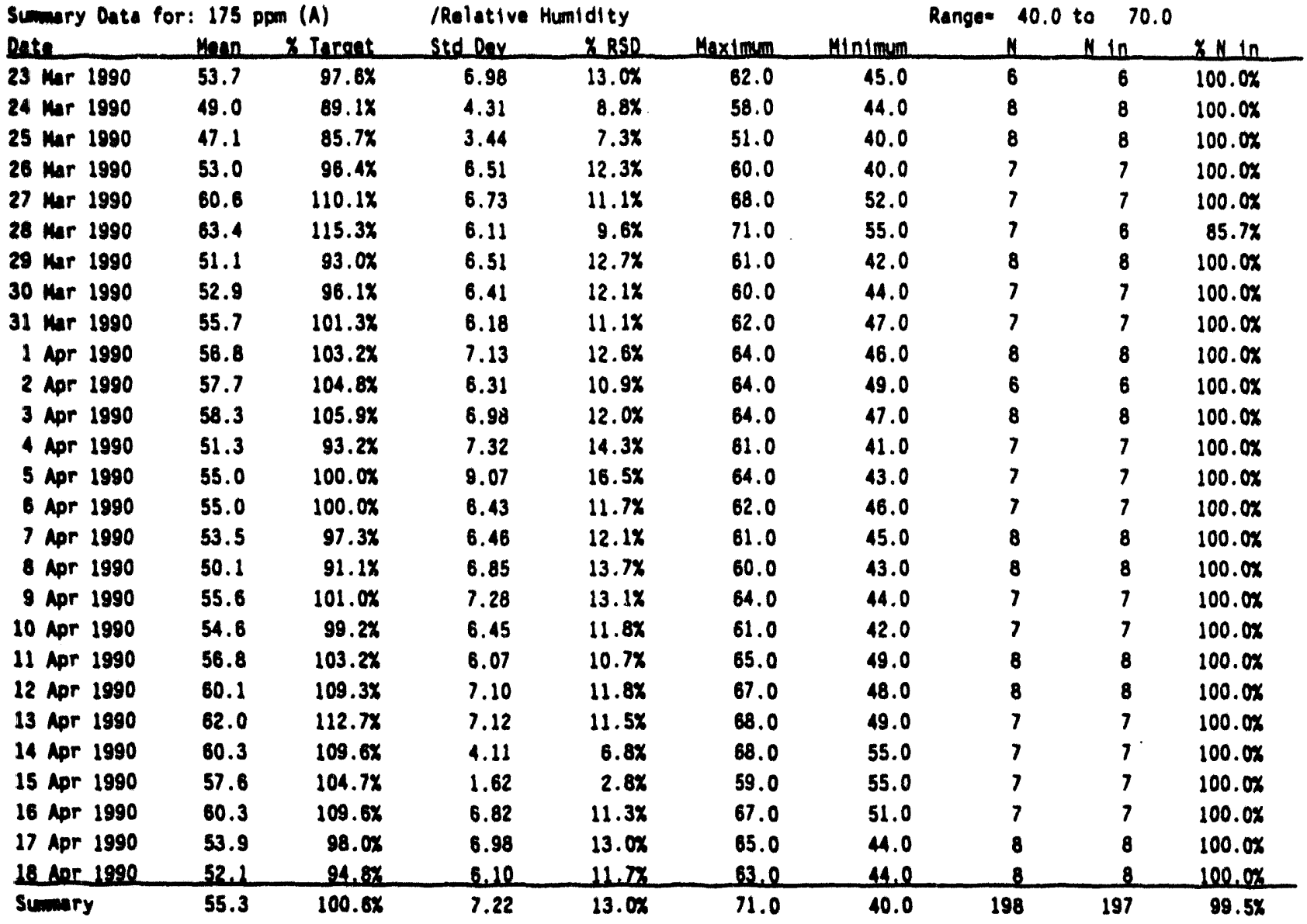

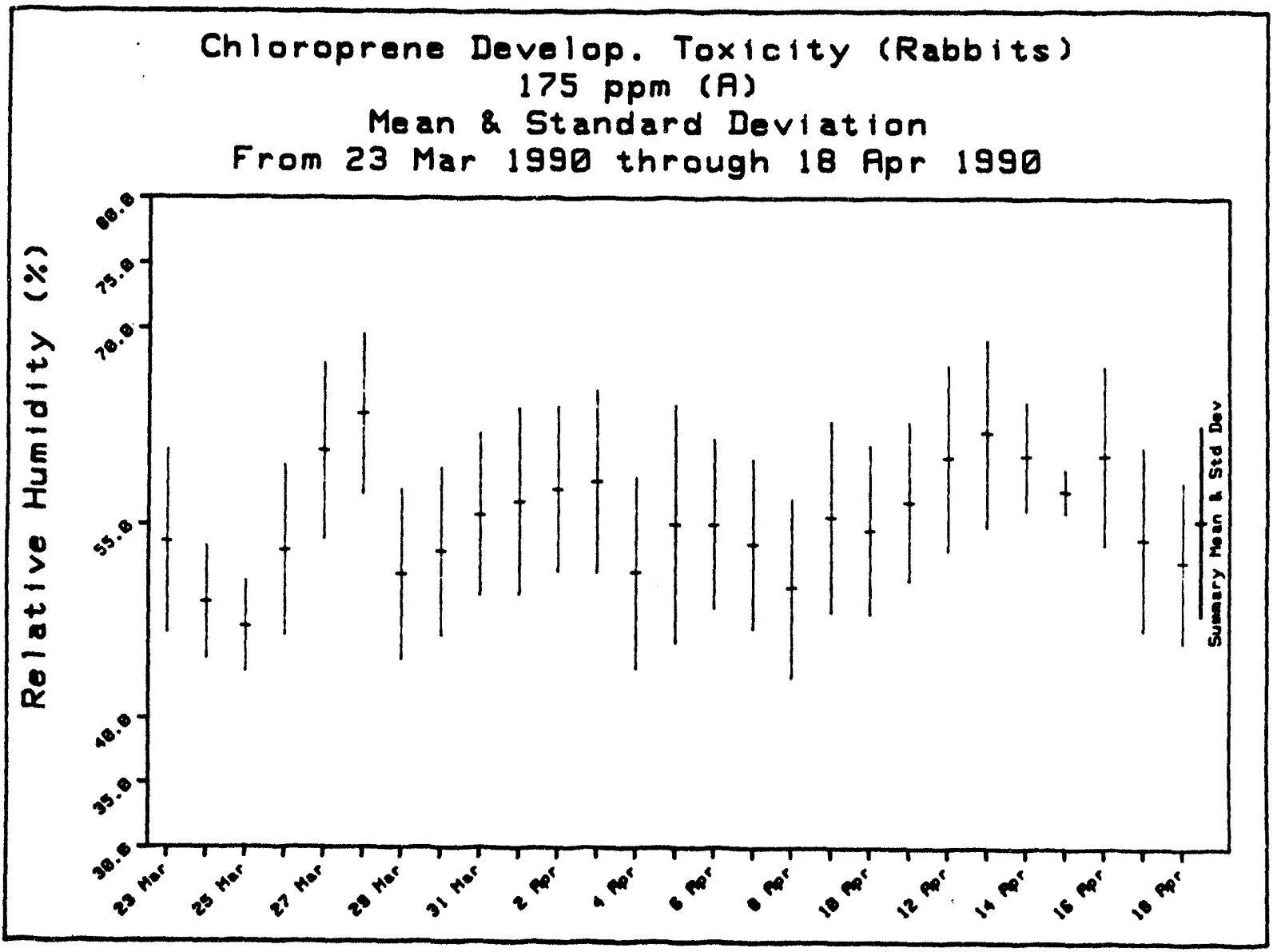


Dally Sumation for Chloroprene Davelop. Ioxicity (Rabbits)

From 27 Mar 1990 through 19 Apr 1990

\begin{tabular}{|c|c|c|c|c|c|c|c|c|c|}
\hline Sumary Data & $: 175$ & $n(8)$ & /Relative & idity & & & Range: $\quad 40$ & to & \\
\hline Date & Mean & $x$ Taraet & Std Dey & X RSD & Maximum & Mininum & I & $N$ in & $x \times$ in \\
\hline 27 Mar 1990 & 56.3 & $102.4 \%$ & 6.31 & $11.2 x$ & 62.0 & 45.0 & 6 & 6 & $100.0 \%$ \\
\hline 28 Mar 1990 & 62.7 & $114.0 \%$ & 6.45 & $10.3 x$ & 74.0 & 57.0 & 7 & 6 & $85.7 \%$ \\
\hline $29 \operatorname{Mar} 1990$ & 48.1 & $87.5 \%$ & 5.08 & $10.6 \%$ & 56.0 & 41.0 & 8 & 8 & $100.0 \%$ \\
\hline 30 Mar 1990 & 52.1 & $94.8 \%$ & 8.65 & $16.6 \%$ & 61.0 & 39.0 & 7 & 6 & $85.7 x$ \\
\hline 31 Mar 1990 & 56.3 & $102.4 x$ & 6.22 & $11.0 \%$ & 63.0 & 48.0 & 6 & 6 & $100.0 \%$ \\
\hline 1 Apr 1990 & 58.5 & $106.4 \%$ & 6.80 & $11.6 x$ & 65.0 & 48.0 & 8 & 8 & $100.0 \%$ \\
\hline 2 Apr 1990 & 58.5 & $106.4 \%$ & 5.72 & $9.8 \%$ & 65.0 & 51.0 & 6 & 6 & $100.0 \%$ \\
\hline 3 Apr 1990 & 58.1 & $105.7 x$ & 6.27 & $10.8 \%$ & 63.0 & 49.0 & 8 & 8 & $100.0 \%$ \\
\hline 4 Apr 1990 & 53.9 & $97.9 x$ & 8.25 & $15.1 \%$ & 64.0 & 42.0 & 7 & 7 & $100.0 \%$ \\
\hline 5 Apr 1990 & 56.7 & $103.1 \%$ & 5.99 & $10.6 \%$ & 63.0 & 48.0 & 7 & 7 & $100.0 \%$ \\
\hline 6 Apr 1990 & 56.5 & $102.7 x$ & 6.53 & $11.6 \%$ & 64.0 & 49.0 & 6 & 6 & $100.0 x$ \\
\hline 7 Apr 1990 & 53.7 & $97.7 x$ & 7.03 & $13.1 \%$ & 60.0 & 42.0 & 8 & 8 & $100.0 x$ \\
\hline 8 Apr 1990 & 49.2 & $89.5 \%$ & 6.94 & $14.1 \%$ & 60.0 & 43.0 & 8 & 8 & $100.0 \%$ \\
\hline 9 Apr 1990 & 52.4 & $95.3 \%$ & 6.24 & $11.9 \%$ & 60.0 & 43.0 & 7 & 7 & $100.0 \%$ \\
\hline 10 Apr 1990 & 52.6 & $95.6 x$ & 5.80 & $11.0 \%$ & 58.0 & 41.0 & 7 & 7 & $100.0 \%$ \\
\hline 11 Apr 1990 & 54.0 & $98.2 \%$ & 5.32 & $9.8 \%$ & 62.0 & 47.0 & 8 & 8 & $100.0 \%$ \\
\hline 12 Apr 1990 & 50.3 & $91.4 \%$ & 5.50 & $10.9 x$ & 56.0 & 40.0 & 7 & 7 & $100.0 x$ \\
\hline 13 Apr 1990 & 55.3 & $100.5 x$ & 6.63 & $12.0 \%$ & 63.0 & 44.0 & 7 & 7 & $100.0 x$ \\
\hline 14 Apr 1990 & 56.7 & $103.1 \%$ & 2.29 & $4.0 \%$ & 61.0 & 54.0 & 7 & 7 & $100.0 x$ \\
\hline 15 Apr 1990 & 54.9 & $99.7 x$ & 2.12 & $3.9 \%$ & 57.0 & 51.0 & 7 & 7 & $100.0 \%$ \\
\hline 16 Apr 1990 & 52.9 & $96.1 \%$ & 4.30 & $8.1 \%$ & 56.0 & 45.0 & 7 & 7 & $100.0 x$ \\
\hline 17 Apr 1990 & 50.4 & $91.6 \%$ & 4.72 & $9.4 \%$ & 56.0 & 43.0 & 8 & 8 & $100.0 x$ \\
\hline 18 Apr 1990 & 48.7 & $88.6 \%$ & 3.96 & 8.18 & 53.0 & 43.0 & 8 & 8 & $100.0 \%$ \\
\hline 19 Apr 1990 & 53.4 & $97.0 \%$ & 4.90 & $9.2 \%$ & 60.0 & 41.0 & 8 & 8 & $100.0 x$ \\
\hline Sumary & 54.1 & $98.4 \%$ & 6.53 & 12.18 & 74.0 & 39.0 & 173 & 171 & $98.8 \%$ \\
\hline
\end{tabular}

Chloroprene Develop. Toxicity (Rabbits) $175 \mathrm{ppm}$ (B)

Mean \& Standard Deviation

From 27 Mar 1990 through 19 Apr 1990

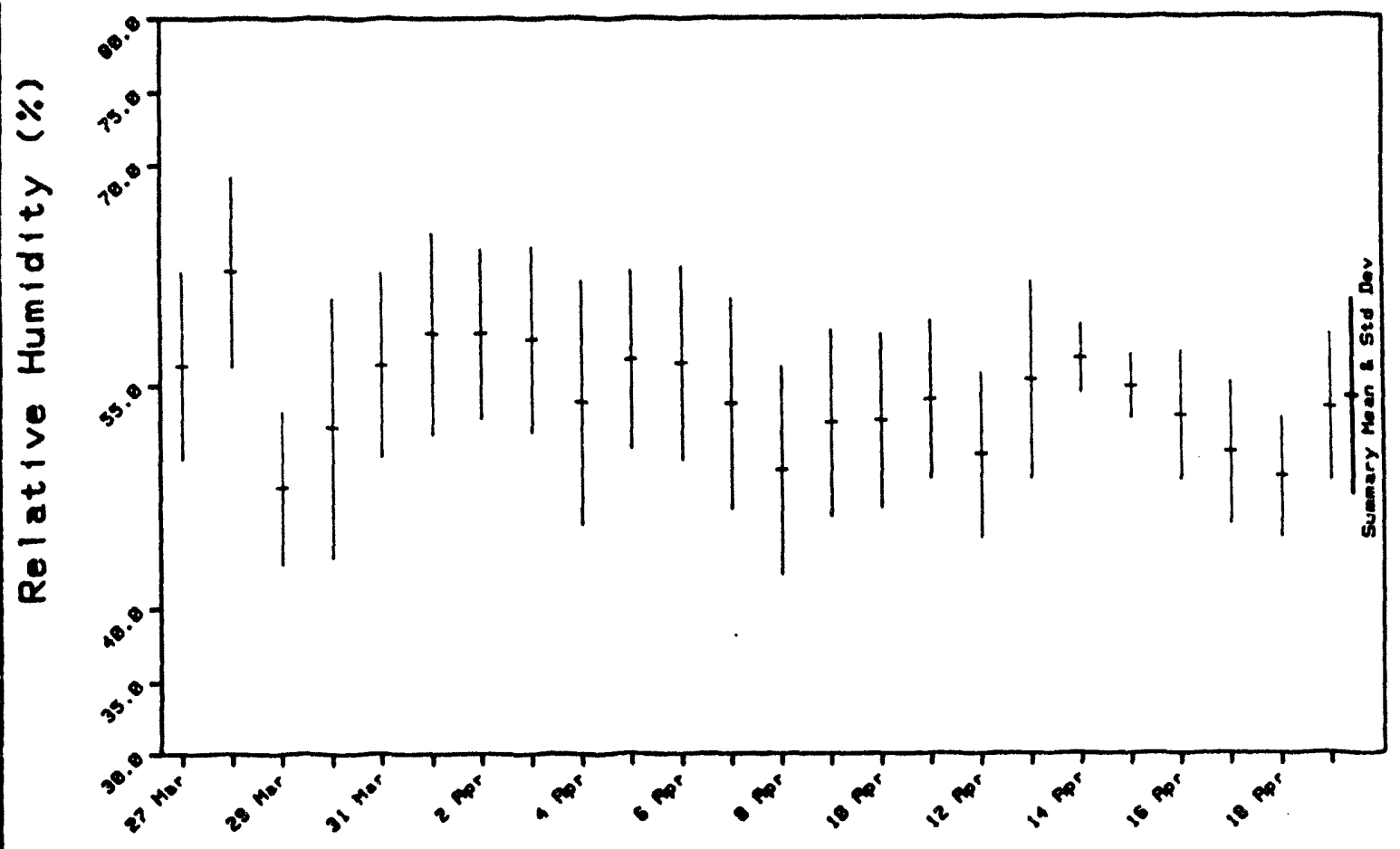


Exhaust Airflow Data

B -43 
Daily Sumation for Chloroprene Develoo. Toxicity (Rabbits)

From 27 Mar 1990 through 19 Apr 1990

\begin{tabular}{|c|c|c|c|c|c|c|c|c|c|}
\hline Sumary Data & : $0 \mathrm{ppm}$ & (A) & /Exhaust & flow & & & $=12$ & to 18 & \\
\hline Date & Mean & \% Tarqet & Std Dev. & \& RSD & Maximum & Minimum & $\mathrm{N}$ & $N$ in & $\mathrm{XN}$ in \\
\hline 27 Mar 1990 & 14.5 & $96.8 \%$ & .10 & $.7 \%$ & 14.7 & 14.3 & 7 & 7 & $100.0 \%$ \\
\hline 28 Mar 1990 & 15.0 & $100.0 \%$ & .28 & $1.9 \%$ & 15.2 & 14.5 & 8 & 8 & $100.0 \%$ \\
\hline 29 Mar 1990 & 15.0 & $100.0 \%$ & .10 & $.6 \%$ & 15.2 & 14.9 & 7 & 7 & $100.0 \%$ \\
\hline 30 Mar 1990 & 14.9 & $99.0 \%$ & .06 & $.4 \%$ & 15.0 & 14.8 & 8 & 8 & $100.0 \%$ \\
\hline $31 \operatorname{Mar} 1990$ & 14.8 & $98.4 \%$ & .07 & $.4 x$ & 14.8 & 14.7 & 8 & 8 & $100.0 \%$ \\
\hline 1 Apr 1990 & 14.7 & $98.2 \%$ & .05 & $.4 x$ & 14.8 & 14.7 & 8 & 8 & $100.0 \%$ \\
\hline 2 Apr 1990 & 14.6 & $97.2 \%$ & .03 & $.2 x$ & 14.6 & 14.5 & 7 & 7 & $100.0 \%$ \\
\hline 3 Apr 1990 & 14.5 & $96.7 \%$ & .03 & $.2 \%$ & 14.6 & 14.5 & 7 & 7 & $100.0 \%$ \\
\hline 4 Apr 1990 & 14.3 & $95.6 \%$ & .05 & $.4 \%$ & 14.4 . & 14.3 & 7 & 7 & $100.0 \%$ \\
\hline 5 Apr 1990 & 14.1 & $94.2 x$ & .08 & $.5 x$ & 14.3 & 14.1 & 7 & 7 & $100.0 \%$ \\
\hline 6 Apr 1990 & 14.5 & $97.0 \%$ & .42 & $2.9 x$ & 14.9 & 14.1 & 7 & 7 & $100.0 \%$ \\
\hline 7 Apr 1990 & 14.8 & $98.8 \%$ & .07 & $.5 \%$ & 15.0 & 14.7 & 8 & 8 & $100.0 \%$ \\
\hline 8 Apr 1990 & 14.7 & $98.1 x$ & .12 & $.8 \%$ & 14.9 & 14.6 & 7 & 7 & $100.0 \%$ \\
\hline 9 Apr 1990 & 14.4 & $96.2 \%$ & .13 & $.9 \%$ & 14.6 & 14.2 & 8 & 8 & $100.0 \%$ \\
\hline $10 \mathrm{Apr} 1990$ & 14.0 & $93.5 \%$ & .14 & $1.0 x$ & 14.3 & 13.9 & $\varepsilon$ & 6 & $100.0 \%$ \\
\hline 11 Apr 1990 & 14.6 & $97.1 \%$ & .52 & $3.6 \%$ & 15.0 & 13.9 & 8 & 8 & $100.0 \%$ \\
\hline 12 Apr 1990 & 14.7 & $98.2 \%$ & .11 & $.8 \%$ & 14.9 & 14.6 & 7 & 7 & $100.0 \%$ \\
\hline 13 Apr 1990 & 14.4 & $96.2 x$ & .16 & i.1. & 14.6 & 14.2 & 7 & 7 & $100.0 \%$ \\
\hline 14 Apr 1990 & 15.1 & $100.7 \%$ & .37 & $2.5 x$ & 15.4 & 14.3 & 7 & 7 & $100.0 \%$ \\
\hline 15 Apr 1990 & 15.2 & $101.5 \%$ & .10 & $.6 \%$ & 15.4 & 15.2 & 7 & 7 & $100.0 \%$ \\
\hline 16 Apr 1990 & 14.8 & $98.7 x$ & .18 & $1.2 x$ & 15.1 & 14.7 & 7 & 7 & $100.0 \%$ \\
\hline 17 Apr 1990 & 14.6 & $97.6 \%$ & .13 & $.9 \%$ & 14.8 & 14.5 & 7 & 7 & $100.0 \%$ \\
\hline 18 Apr 1990 & 14.6 & $97.2 x$ & .76 & $5.2 \%$ & 15.4 & 13.2 & 7 & 7 & 100.06 \\
\hline 19 Anr 1990 & 15.4 & $103.0 \%$ & .07 & 4x & 15.5 & 15.3 & 8 & 8 & $100.0 \%$ \\
\hline Susmary & 14.7 & $98.0 x$ & .39 & $2.6 x$ & 15.5 & 13.2 & 175 & 175 & $100.0 \%$ \\
\hline
\end{tabular}

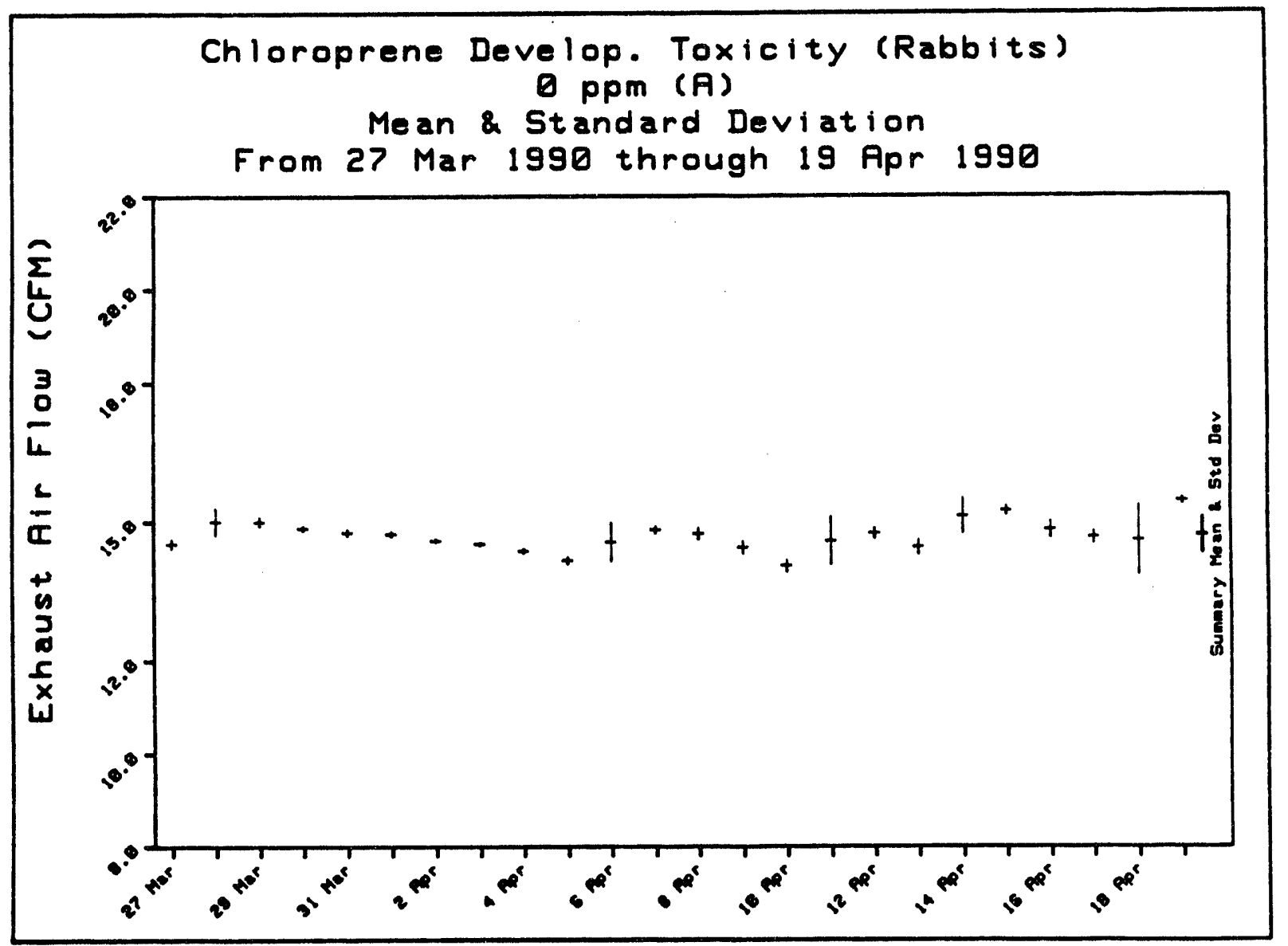


Daily Sumation for Chloroprene Develoo. Toxicity (Rabbits)

From 23 Mar 1990 throuah 18 Aor 1990

\begin{tabular}{|c|c|c|c|c|c|c|c|c|c|}
\hline Summary Data & $: 0 \mathrm{ppr}$ & (B) & /Exhaust & Flow & & & $\theta=1$ & to 1 & \\
\hline Date & Mean & $x$ Target & Sto Der & X RSD & Maximum & Minimum & $N$ & $N$ in & $X N$ in \\
\hline 23 Mar 1990 & 15.2 & $101.2 \%$ & .06 & $.4 \%$ & 15.2 & 15.1 & 7 & 7 & $100.0 \%$ \\
\hline 24 Mar 1990 & 15.1 & $100.9 \%$ & .07 & $.5 \%$ & 15.2 & 15.0 & 8 & 8 & $100.0 \%$ \\
\hline 25 Mar 1990 & 15.1 & $100.4 \%$ & .08 & $.5 \%$ & 15.2 & 15.0 & 8 & 8 & $100.0 \%$ \\
\hline $26 \mathrm{Mar} 1990$ & 15.0 & $100.1 \%$ & .08 & $.5 x$ & 15.1 & 14.9 & 7 & 7 & $100.0 \%$ \\
\hline 27 Mar 1990 & 15.2 & $101.4 \%$ & .87 & $5.7 \%$ & 17.4 & 14.8 & 8 & 8 & $100.0 \%$ \\
\hline 28 Mar 1990 & 14.8 & $98.8 \%$ & .06 & $.4 \%$ & 14.9 & 14.7 & 8 & 8 & $100.0 \%$ \\
\hline $29 \operatorname{Mar} 1990$ & 14.7 & $98.3 \%$ & .07 & $.4 x$ & 14.9 & 14.7 & 7 & 7 & $100.0 \%$ \\
\hline 30 Mar 1990 & 14.7 & $97.7 \%$ & .03 & $.2 \%$ & 14.7 & 14.6 & 8 & 8 & $100.0 \%$ \\
\hline 31 Mur 1990 & 14.7 & $97.7 x$ & .02 & $.1 \%$ & 14.7 & 14.6 & 8 & 8 & $100.0 \%$ \\
\hline 2 Apr 1990 & 14.6 & $97.5 \%$ & .01 & $.1 \%$ & 14.6 & 14.6 & 8 & 8 & $100.0 \%$ \\
\hline 2 Apr 1990 & 14.6 & $97.2 x$ & .04 & $.3 \%$ & 14.7 & 14.5 & 7 & 7 & $100.0 \%$ \\
\hline 3 Apr 1990 & 14.5 & $96.9 \%$ & .02 & $.2 \%$ & 14.6 & 14.5 & 7 & 7 & $100.0 \%$ \\
\hline 4 Apr 1990 & 14.5 & $96.6 \%$ & .03 & $.2 x$ & 14.5 & 14.5 & 7 & 7 & $100.0 \%$ \\
\hline 5 Apr 1990 & 14.5 & $96.4 x$ & .04 & $.3 \%$ & 14.5 & 14.4 & 7 & 7 & $100.0 \%$ \\
\hline 6 Apr 1990 & 14.5 & $96.4 x$ & .03 & $.2 \%$ & 14.5 & 14.4 & 7 & 7 & $100.0 \%$ \\
\hline 7 Apr 1990 & 14.5 & $96.4 \%$ & .03 & $.2 \%$ & 14.5 & 14.4 & 8 & 8 & $100.0 \%$ \\
\hline 8 Apr 1990 & 14.4 & $96.2 \%$ & .04 & $.3 x$ & 14.5 & 14.4 & 7 & 7 & $100.0 \%$ \\
\hline 9 Apr 1990 & 14.4 & $95.8 \%$ & .05 & $.4 \%$ & 14.5 & 14.3 & 8 & 8 & $100.0 x$ \\
\hline 10 Apr 1990 & 14.3 & $95.5 \%$ & .03 & $.2 \%$ & 14.4 & 14.3 & 6 & 6 & $100.0 \%$ \\
\hline 11 Apr 1990 & 14.8 & $98.8 \%$ & .43 & $2.9 \%$ & 15.1 & 14.3 & 8 & 8 & $100.0 \%$ \\
\hline 12 Apr 1990 & 15.1 & $100.7 x$ & .04 & $.3 x$ & 15.2 & 15.1 & 7 & 7 & $100.0 \%$ \\
\hline 13 Apr 1990 & 15.0 & $100.2 \%$ & .06 & $.4 x$ & 15.1 & 14.9 & 7 & 7 & $100.0 \%$ \\
\hline 14 Apr 1990 & 15.3 & $102.1 \%$ & .16 & $1.0 \%$ & 15.4 & 15.0 & 7 & 7 & $100.0 \%$ \\
\hline 15 Apr 1990 & 15.4 & $102.5 \%$ & .04 & $.2 x$ & 15.4 & 15.3 & 7 & 7 & $100.0 x$ \\
\hline 16 Apr 1990 & 15.4 & $102.3 \%$ & .05 & $.3 \%$ & 15.4 & 15.3 & 7 & 7 & $100.0 \%$ \\
\hline 17 Apr 1990 & 15.3 & $101.7 \%$ & .05 & $.3 \%$ & 15.3 & 15.2 & 7 & 7 & $100.0 x$ \\
\hline 18 Apr 1990 & 15.2 & $101.2 x$ & .29 & $5.2 x$ & 15.9 & 13.5 & 1 & 7 & $100.0 \%$ \\
\hline Sumary & 14.8 & $98.9 \%$ & .41 & $2.7 \%$ & 17.4 & 13.5 & 198 & 198 & $100.0 \%$ \\
\hline
\end{tabular}

Chloroprene Develop. Toxicity (Rabbits) Q ppm (B)

Mean \& Standard Deviation

From 23 Mar 1990 through 18 Apr 1990

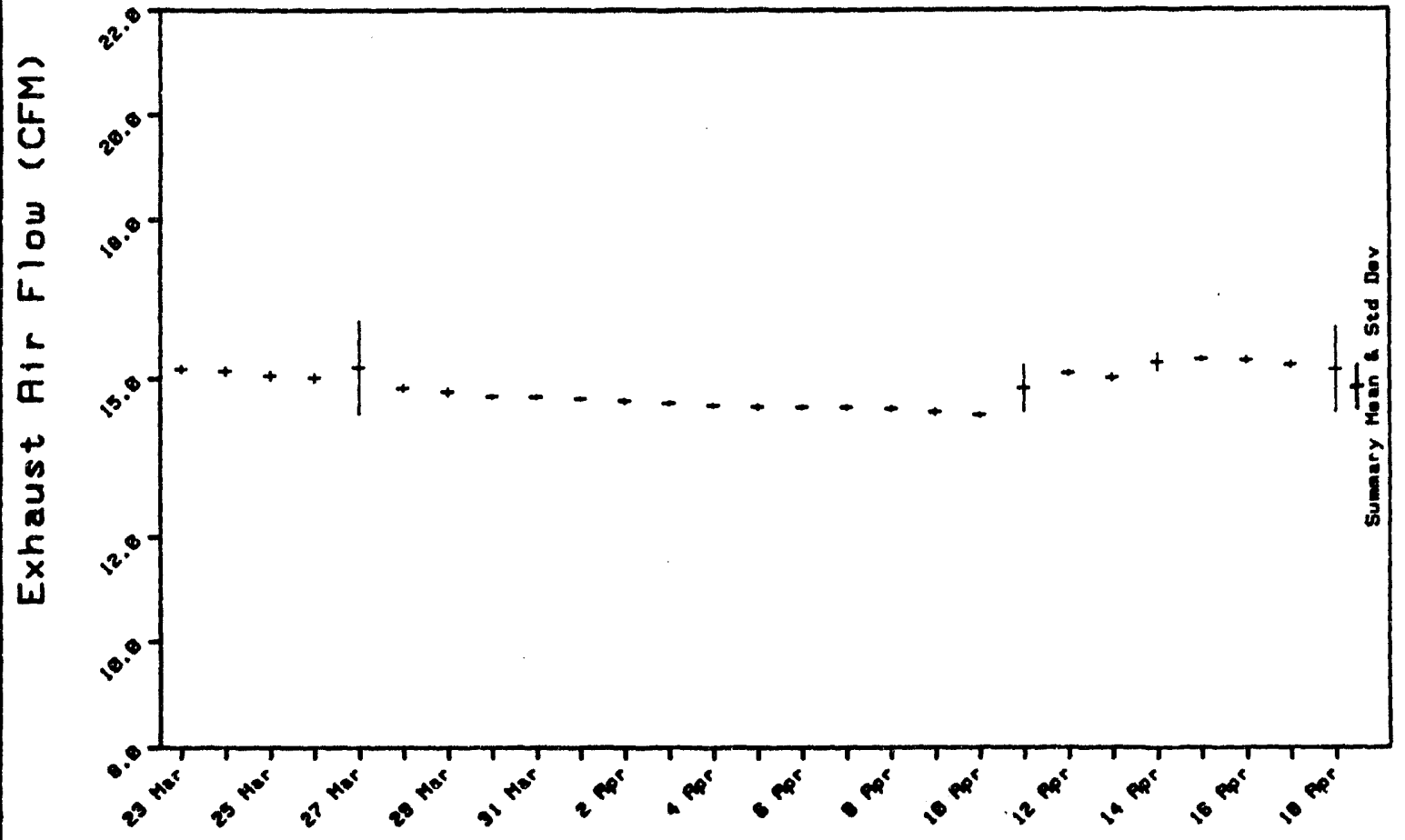


Dafly Sumation for Chloroprene Develop. Toxicity (Rabbits)

From 23 Mar 1990 through 18 Apr 1990

Sumary Data for: $10 \mathrm{ppm}$ (A) /Exhaust Air Flow

\begin{tabular}{|c|c|c|c|c|c|c|c|c|c|}
\hline Date & Mean & \& Taroet & Std Dev & $y$ RSD & Maximum & Minimum & $N$ & Nin & $X N$ in \\
\hline 23 Mar 1990 & 14.8 & $98.8 \%$ & .08 & $.5 \%$ & 15.0 & 14.7 & 7 & 7 & $100.0 \%$ \\
\hline $24 \operatorname{Mar} 1990$ & 14.7 & $98.1 \%$ & .09 & $.6 \%$ & 14.8 & 14.6 & 8 & 8 & $100.0 \%$ \\
\hline 25 Mar 1990 & 14.6 & $97.6 \%$ & .06 & $.4 \%$ & 14.7 & 14.6 & 8 & 8 & $100.0 \%$ \\
\hline $26 \operatorname{Mar} 1990$ & 14.7 & $97.8 \%$ & .10 & $.7 \%$ & 14.9 & 14.6 & 7 & 7 & $100.0 \%$ \\
\hline 27 Mar 1990 & 14.6 & $97.4 x$ & .15 & $2.0 \%$ & 14.8 & 14.4 & 8 & 8 & $100.0 \%$ \\
\hline 28 Mar 1990 & 14.4 & $95.8 \%$ & .15 & $1.0 \%$ & 14.5 & 14.1 & 8 & 8 & $100.0 \%$ \\
\hline $29 \operatorname{Mar} 1990$ & 14.5 & $96.7 \%$ & .12 & $.9 \%$ & 14.7 & 14.4 & 7 & 7 & $100.0 \%$ \\
\hline 30 Mar 1990 & 14.9 & $99.3 \%$ & .22 & $1.5 \%$ & 15.1 & 14.4 & 8 & 8 & $100.0 \%$ \\
\hline 31 Mar 1990 & 14.9 & $99.6 \%$ & .11 & $.8 \%$ & 15.1 & 14.8 & 8 & 8 & $100.0 \%$ \\
\hline 1 Apr 1990 & 14.9 & $99.5 \%$ & .11 & $.7 \%$ & 15.1 & 14.8 & 8 & 8 & $100.0 \%$ \\
\hline 2 Apr 1990 & 14.9 & $99.3 x$ & .11 & $.7 x$ & 15.1 & 14.8 & 7 & 7 & $100.0 \%$ \\
\hline 3 Apr 1990 & 15.0 & $100.0 \%$ & .15 & $1.0 \%$ & 15.2 & 14.9 & 7 & 7 & $100.0 \%$ \\
\hline 4 Apr 1990 & 15.0 & $100.1 x$ & .14 & $.9 \%$ & 15.2 & 14.9 & 7 & 7 & $100.0 \%$ \\
\hline 5 Apr 1990 & 14.9 & $99.2 \%$ & .11 & $.7 x$ & 15.1 & 14.8 & 7 & 7 & $100.0 \%$ \\
\hline 6 Apr 1990 & 14.8 & $98.9 \%$ & .12 & $.8 \%$ & 15.1 & 14.8 & 7 & 7 & $100.0 \%$ \\
\hline 7 Apr 1990 & 14.8 & $98.5 \%$ & .12 & $.8 \%$ & 15.0 & 14.7 & 8 & 8 & $100.0 \%$ \\
\hline 8 Apr 1990 & 14.8 & $98.6 \%$ & .12 & $.8 \%$ & 15.0 & 14.6 & 7 & 7 & $100.0 \%$ \\
\hline 9 Apr 1990 & 14.8 & $99.0 \%$ & .13 & $.9 x$ & 15.1 & 14.7 & 8 & 8 & $100.0 \%$ \\
\hline 10 Apr 1990 & 14.8 & $98.5 \%$ & .11 & $.7 x$ & 15.0 & 14.7 & 6 & 6 & $100.0 \%$ \\
\hline 11 Apr 1990 & 14.8 & $98.6 \%$ & .15 & $1.0 x$ & 15.0 & 14.5 & 8 & 8 & $100.0 \%$ \\
\hline 12 Apr 1990 & 14.8 & $98.7 \%$ & .12 & $.8 \%$ & 15.0 & 14.7 & 7 & 7 & $100.0 \%$ \\
\hline 13 Apr 1990 & 14.8 & $98.5 \%$ & .17 & $1.2 \%$ & 15.0 & 14.5 & 7 & 7 & $100.0 \%$ \\
\hline 14 Apr 1990 & 14.8 & $99.0 \%$ & .13 & $.9 x$ & 15.1 & 14.7 & 7 & 7 & $100.0 \%$ \\
\hline 15 Apr 1990 & 14.8 & $98.5 \%$ & .13 & $.9 \%$ & 15.0 & 14.7 & 7 & 7 & $100.0 \%$ \\
\hline 16 Apr 1990 & 15.2 & $101.1 \%$ & .17 & $1.1 \%$ & 15.4 & 15.0 & 7 & 7 & $100.0 \%$ \\
\hline 17 Apr 1990 & 15.0 & $100.3 \%$ & .35 & $2.3 \%$ & 15.8 & 14.8 & 7 & 7 & $100.0 \%$ \\
\hline 18 Aor 1990 & 14.8 & $98.6 \%$ & .72 & $4.8 \%$ & 15.2 & 13.2 & 7 & 7 & $100.0 \%$ \\
\hline Sumbary & 14.8 & $98.7 \%$ & .24 & $1.6 \%$ & 15.8 & 13.2 & 198 & 198 & $100.0 \%$ \\
\hline
\end{tabular}

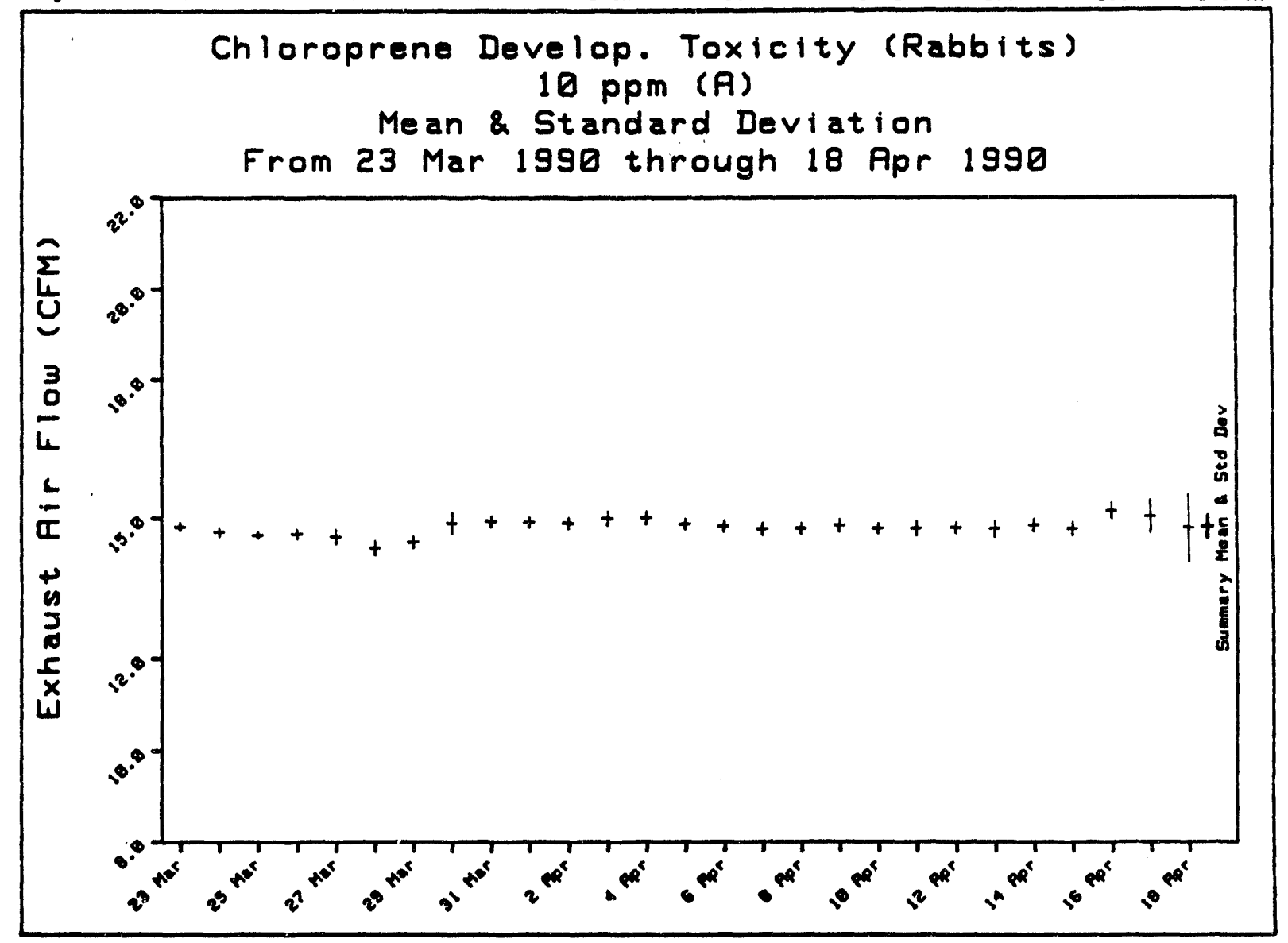


Daily Sumation for Chloroprene Develog. Toxicity (Rabbits)

From 27 Mar 1990 through 19 Apr 1990

Sume

27 Mar 1990

28 Mar 1990

29 Mar 1990

30 Mar 1990

31 Mar 1990

1 Apr 1990

2 Apr 1990

3 Apr 1990

4 Apr 1990

5 Apr 1990

6 Apr 1990

7 Apr 1990

8 Apr 1990

9 Apr 1990

10 Apr 1990

11 Apr 1990

12 Apr 1990

13 Apr 1990

14 Apr 1990

15 Apr 1990

16 Apr 1990

17 Apr 1990

18 Apr 1990

19 Apr 1990

Summary
IExhaust Air Flow

Mean $\%$ Tarqet Std Dev

$14.9 \quad 99.3 \%$

$14.7 \quad 97.7 \%$

$14.7 \quad 97.9 \%$

$15.0 \quad 100.1 \%$

$14.9 \quad 99.5 \%$

14.8

14.8

15.0

15.0

14.9

14.8

14.8

14.8

14.8

14.9

14.9

14.9

14.9

14.8

14.7

$14.697 .5 \%$

$14.6 \quad 97.2 \%$

$14.4 \quad 96.2 \%$

14.9

14.8

.15

.09

.22

.19

.12

.24

.53

.15

.15

.11

.11

.11

.10

.12

.12

.15

.11

.12

.11

.12

.17

.10

.79

.79

.26 $\frac{x \text { RSO }}{1.0 \%}$

$.6 \%$

$.8 \%$

$1.3 \%$

$.8 \%$

1. $6 \%$

$3.6 \%$

$1.0 \%$

$1.0 \%$

$.7 \%$

$.7 \%$

$.8 \%$

$.7 \%$

$.8 \%$

$.8 \%$

$1.0 \%$

$.7 x$

$.8 \%$

$.7 \%$

$.8 \%$

$1.1 \%$

$.7 \%$

$5.5 \%$
Maximum

15.1

14.7

14.9

15.2

15.1

15.0

15.2

15.3

15.3

15.1

15.1

15.0

14.9

15.0

15.2

15.1

15.1

15.0

15.0

14.9

14.9

14.7

14.9

15.0

$1.7 \%$

15.3
Range= 12.0 to 18.0

Minimum

14.7

14.5

14.6

14.6

14.8

14.3

13.6

14.9

14.9

14.8

14.7

14.7

14.7

14.7

14.9

14.7

14.8

14.8

14.7

14.6

14.4

14.5

12.7

14.7

12.7

$\frac{N}{7} \quad \mathrm{~N}$ in

$\frac{x \times \text { in }}{100.0 \%}$

$100.0 \%$
$100.0 \%$

$100.0 \%$

$100.0 \%$

$100.0 \%$

$100.0 \%$

$100.0 \%$

$100.0 \%$

$100.0 \%$

$100.0 \%$

$100.0 \%$

$100.0 \%$

$100.0 \%$

$100.0 \%$

$100.0 \%$

$100.0 \%$

$100.0 \%$

$100.0 \%$

$100.6 \%$

$100.0 \%$

$100.0 \%$

$100.0 \%$

$100.0 \%$ $100.0 \%$ $100.0 \%$

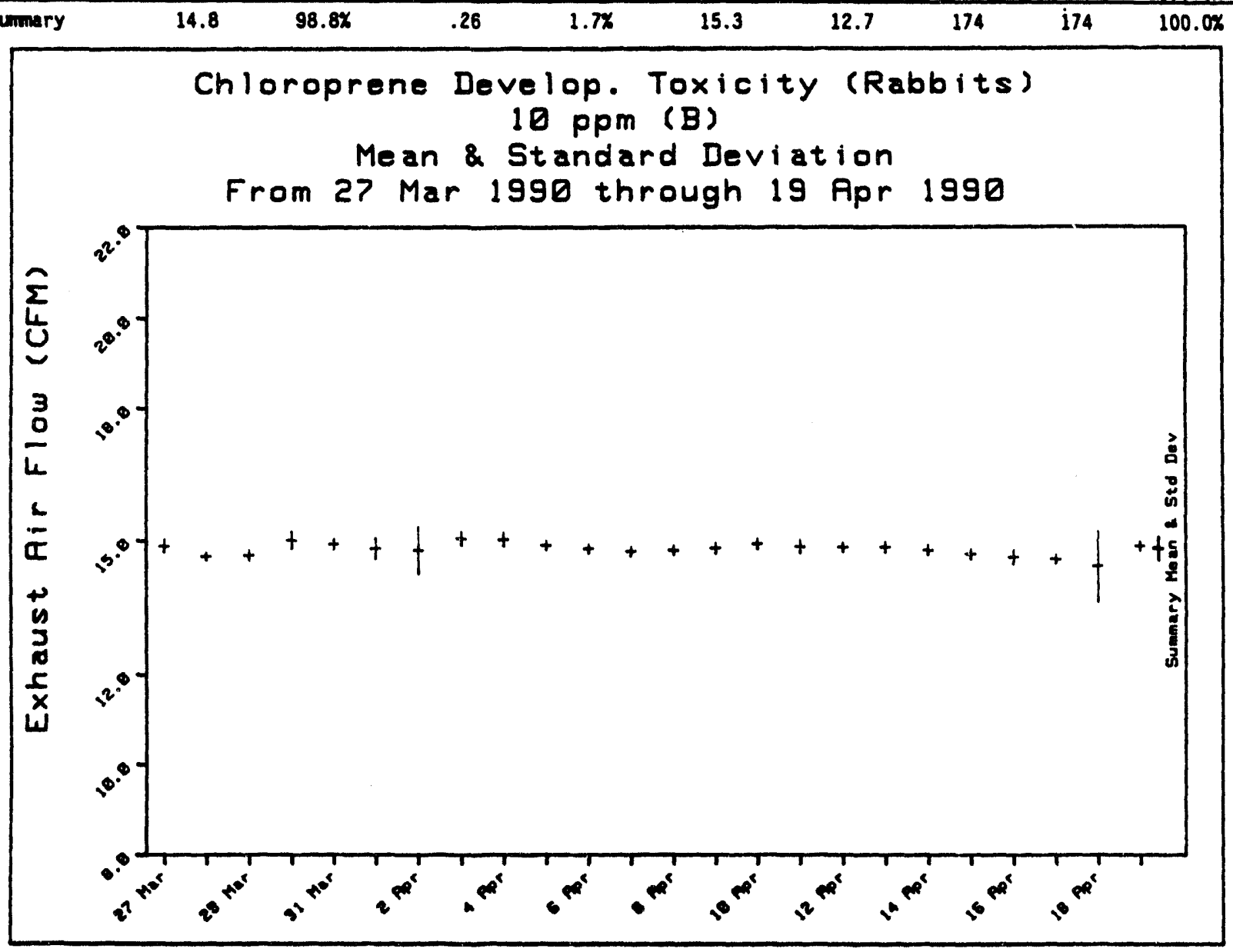


Dally Surmation for Chloroprene Develoo. Toxiclty (Rabblts)

From 23 Mar 1990 through 18 Apr 1990

\begin{tabular}{|c|c|c|c|c|c|c|c|c|c|}
\hline Sumary Data & $: 40 \mathrm{pl}$ & $(A)$ & /Exhaust & Flow & & & $=1$ & to 1 & \\
\hline Date & Menn & $x$ Tarat & Std Dey & $\times$ RSD & Moximum & Minimum & 1 & $N$ in & $x \mathrm{~N}$ in \\
\hline 23 Mar 1990 & 15.1 & $100.8 \%$ & .07 & $.5 \%$ & 15.2 & 15.0 & 7 & 7 & $100.0 \%$ \\
\hline $24 \operatorname{Mar} 1990$ & 15.0 & $100.0 \%$ & .08 & $.5 \%$ & 15.1 & 14.8 & 8 & 8 & $100.0 \%$ \\
\hline $25 \operatorname{Mar} 1990$ & 14.9 & $99.6 \%$ & .06 & $.4 x$ & 15.0 & $14: 9$ & 8 & 8 & $100.0 \%$ \\
\hline $26 \operatorname{Mar} 1990$ & 14.9 & $99.4 x$ & .08 & $.5 \%$ & 15.1 & 14.8 & 7 & 7 & $100.0 x$ \\
\hline 27 Mar 1990 & 14.7 & $97.7 x$ & .14 & $1.0 x$ & 14.9 & 14.4 & 8 & 8 & $100.0 \%$ \\
\hline 28 Mar 1990 & 14.5 & $96.4 x$ & .07 & $.5 x$ & 14.5 & 14.3 & 8 & 8 & $100.0 \%$ \\
\hline $29 \operatorname{Mar} 1990$ & 14.6 & $97.0 \%$ & .06 & $.4 x$ & 14.7 & 14.5 & 7 & 7 & $100.0 \%$ \\
\hline 30 Mar 1990 & 14.8 & $98.9 \%$ & .15 & $1.0 \%$ & 15.0 & 14.5 & 8 & 8 & $100.0 \%$ \\
\hline 31 Mar 1990 & 14.8 & $98.9 \%$ & .05 & $.4 x$ & 14.9 & 14.8 & 8 & 8 & $100.0 \%$ \\
\hline 1 Apr 1990 & 14.9 & $99.0 \%$ & .04 & $.2 x$ & 14.9 & 14.8 & 8 & 8 & $100.0 \%$ \\
\hline 2 Apr 1990 & 14.8 & $98.9 \%$ & .05 & $.4 x$ & 14.9 & 14.8 & 7 & 7 & $100.0 \%$ \\
\hline 3 Apr 1990 & 14.9 & $99.1 \%$ & .10 & $.7 x$ & 15.0 & 14.8 & 7 & 7 & $100.0 \%$ \\
\hline 4 Apr 1990 & 14.9 & $99.5 \%$ & .09 & $.6 \%$ & 15.1 & 14.8 & 7 & 7 & 100.08 \\
\hline 5 Apr 1990 & 14.8 & $39.0 x$ & .09 & $.6 \%$ & 15.0 & 14.7 & 7 & 7 & $100.0 \%$ \\
\hline 6 Apr 1990 & 14.9 & $99.2 \%$ & .08 & $.5 x$ & 15.1 & 14.8 & 7 & 7 & $100.0 \%$ \\
\hline 7 Apr 1990 & 14.8 & $98.6 \%$ & .09 & $.6 \%$ & 14.9 & 14.7 & 8 & 8 & $100.0 \%$ \\
\hline 8 Apr 1990 & 14.8 & $98.4 x$ & .09 & $.6 \%$ & 14.9 & 14.6 & 7 & 7 & $100.0 x$ \\
\hline 9 Apr 1990 & 14.8 & $98.9 \%$ & .06 & $.4 \%$ & 14.9 & 14.7 & 8 & 8 & $100.0 x$ \\
\hline 10 Apr 1990 & 14.7 & $98.1 x$ & .08 & $.5 \%$ & 14.9 & 14.7 & 6 & 6 & $100.0 \%$ \\
\hline 11 Apr 1990 & 14.8 & $98.7 \%$ & .13 & $.9 x$ & 15.0 & 14.6 & 8 & 8 & $100.0 \%$ \\
\hline 12 Apr 1990 & 14.8 & $98.7 \%$ & .06 & $.4 \%$ & 14.9 & 14.8 & 7 & 7 & $100.0 \%$ \\
\hline 13 Apr 1990 & 14.8 & $98.4 \%$ & .11 & $.8 \%$ & 14.9 & 14.6 & 7 & 7 & $100.0 \%$ \\
\hline 14 Apr 1990 & 14.8 & $98.6 \%$ & .09 & $.6 \%$ & 15.0 & 14.7 & 7 & 7 & $100.0 x$ \\
\hline 15 Apr 1990 & 14.7 & $97.9 \%$ & .07 & $.5 \%$ & 14.8 & 14.6 & 7 & 7 & $100.0 x$ \\
\hline 16 Apr 1990 & 14.6 & $97.4 x$ & .10 & $.7 x$ & 14.8 & 14.5 & 7 & 7 & $100.0 \%$ \\
\hline 17 Apr 1990 & 14.6 & $97.4 \%$ & .08 & $.5 \%$ & 14.7 & 14.6 & 7 & 7 & $100.0 x$ \\
\hline 18 Apr 1990 & 14.5 & $97.0 \%$ & .66 & 4.6\% & 14.9 & 13.1 & 1 & 7 & $100.0 \%$ \\
\hline Summary & 14.8 & $98.6 \%$ & .20 & $1.4 x$ & 15.2 & 13.1 & 198 & 198 & $100.0 \%$ \\
\hline
\end{tabular}

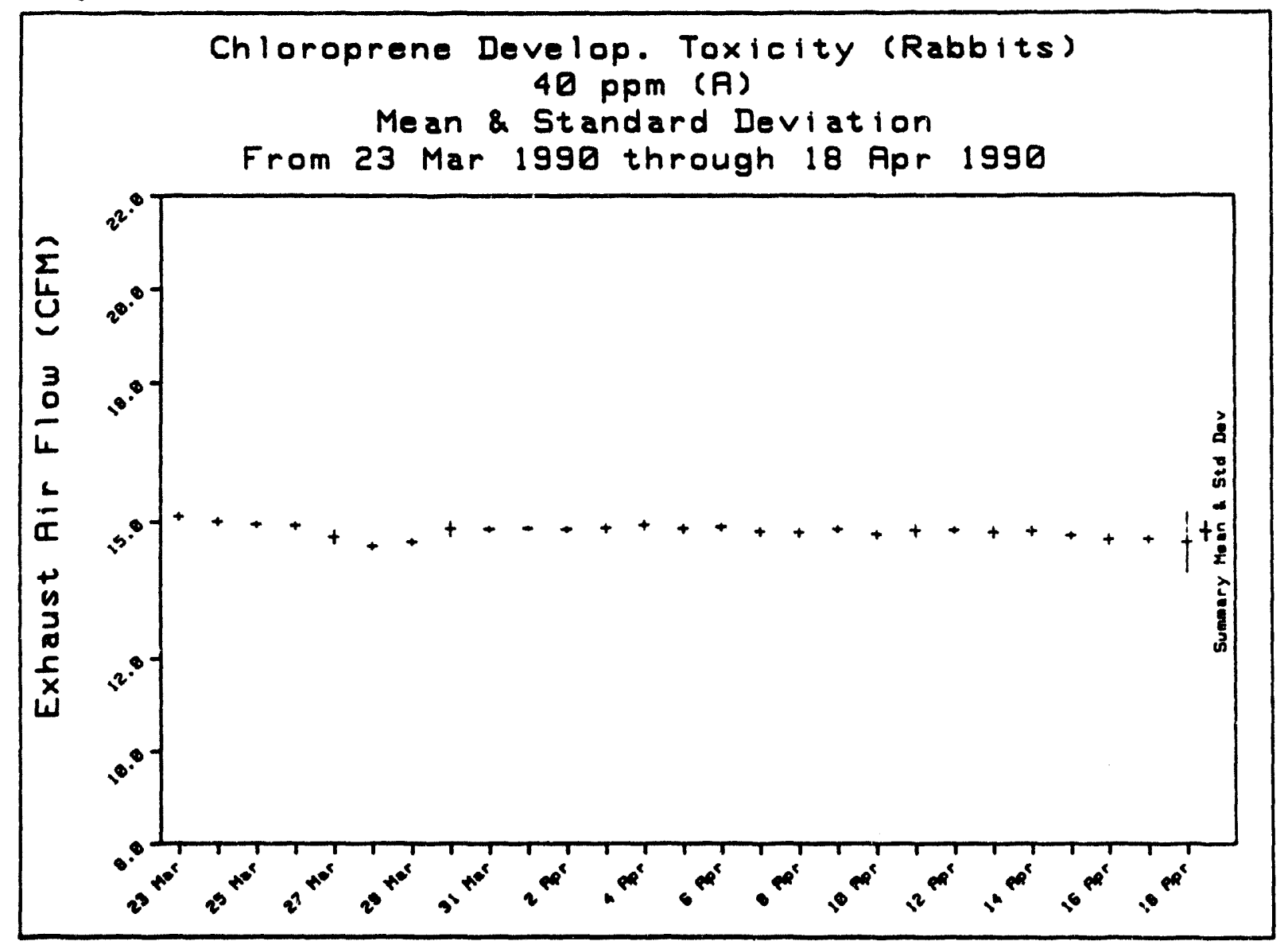


Dajly Summation For Chloroprene Develon. Ioxlalty (Rabbits) From 27 Mar 1990 throuah 19 Apr 1990

\begin{tabular}{|c|c|c|c|c|c|c|c|c|c|}
\hline Summary Data & : $40 \mathrm{pr}$ & (8) & /Exhaust & Flow & & & Rangea 1 & & \\
\hline Date & Mean & $x$ Taront & Std Dey & $\times$ RSD & Maximim & Minimum & $\mathrm{N}$ & $N$ in & $x \times$ in \\
\hline 27 Mar 1990 & 15.0 & $100.0 x$ & .13 & $.8 x$ & 15.2 & 14.8 & 7 & 7 & $100.0 x$ \\
\hline 28 Mar 1990 & 14.8 & $98.6 x$ & .11 & $.7 x$ & 14.9 & 14.6 & 8 & 8 & $100.0 x$ \\
\hline 29 Mar 1990 & 14.8 & $98.6 \%$ & .13 & $.9 x$ & 15.0 & 14.7 & 7 & 7 & $100.0 x$ \\
\hline 30 Mar 1990 & 15.1 & $100.9 x$ & .21 & $1.4 \%$ & 15.4 & 14.7 & 8 & 8 & $100.0 x$ \\
\hline 31 Mar 1990 & 15.1 & $100.9 x$ & .08 & $.6 \%$ & 15.3 & 15.0 & 8 & 8 & $100.0 x$ \\
\hline 1 Apr 1990 & 15.2 & $101.0 \%$ & .08 & $.5 x$ & 15.3 & 15.0 & 8 & 8 & $100.0 x$ \\
\hline 2 Apr 1990 & 15.2 & $101.1 x$ & .08 & $.5 \%$ & 15.3 & 15.1 & 7 & 7 & $100.0 x$ \\
\hline 3 Apr 1990 & 15.2 & $101.4 x$ & .12 & $.8 \%$ & 15.3 & 15.1 & 7 & 7 & $100.0 x$ \\
\hline 4 Apr 1990 & 15.4 & $102.7 x$ & .12 & $.8 \%$ & 15.6 & 15.3 & 7 & 7 & $100.0 x$ \\
\hline 5 Apr 1990 & 15.3 & $101.8 x$ & .11 & $.7 \%$ & 15.5 & 15.2 & 7 & 7 & $100.0 x$ \\
\hline 6 Apr 1990 & 15.2 & $101.4 \%$ & .10 & $.6 x$ & 15.4 & 15.1 & 7 & 7 & $100.0 x$ \\
\hline 7 Apr 1990 & 15.1 & $100.9 x$ & .10 & $.7 x$ & 15.3 & 15.1 & 8 & 8 & $100.0 x$ \\
\hline 8 Apr 1990 & 15.1 & $100.9 x$ & .10 & $.7 x$ & 15.3 & 15.0 & 7 & 7 & $100.0 x$ \\
\hline 9 Apr 1990 & 15.2 & $101.4 x$ & .13 & $.8 \%$ & 15.4 & 15.0 & 8 & 8 & $100.0 x$ \\
\hline 10 Apr 1990 & 15.2 & $101.2 x$ & .09 & $.6 \%$ & 15.3 & 15.1 & 6 & 6 & $100.0 x$ \\
\hline 11 Apr 1990 & 15.5 & $103.1 \%$ & .19 & $1.2 \%$ & 15.7 & 15.2 & 8 & 8 & $100.0 x$ \\
\hline 12 Apr 1990 & 15.1 & $100.9 x$ & .36 & $2.4 \%$ & 15.7 & 14.9 & 7 & 7 & $100.0 \%$ \\
\hline 13 Apr 1990 & 14.9 & $99.3 x$ & .14 & $.9 \%$ & 15.1 & 14.7 & 7 & 7 & $100.0 \%$ \\
\hline 14 Apr 1990 & 14.9 & $99.2 x$ & .09 & $.6 x$ & 15.0 & 14.8 & 7 & 7 & $100.0 \%$ \\
\hline 15 Apr 1990 & 14.8 & $98.7 x$ & .11 & $.7 x$ & 15.0 & 14.7 & 7 & 7 & $100.0 x$ \\
\hline 16 Apr 1990 & 14.7 & $98.1 x$ & .13 & $.9 \%$ & 14.9 & 14.6 & 7 & 7 & $100.0 \%$ \\
\hline 17 Apr 1990 & 14.7 & $97.9 x$ & .09 & $.6 \%$ & 14.8 & 14.6 & 7 & 7 & $100.0 x$ \\
\hline 18 Apr 1990 & 14.6 & $97.3 \%$ & .66 & $4.5 \%$ & 15.0 & 13.1 & 7 & 7 & $100.0 \%$ \\
\hline 19 Apr 1990 & 14.9 & $99.6 x$ & .09 & $.6 \%$ & 15.1 & 14.8 & 8 & 8 & $100.0 \%$ \\
\hline Sumary & 15.0 & $100.3 x$ & .28 & $1.9 \%$ & 15.7 & 13.1 & 175 & 175 & $100.0 \%$ \\
\hline
\end{tabular}

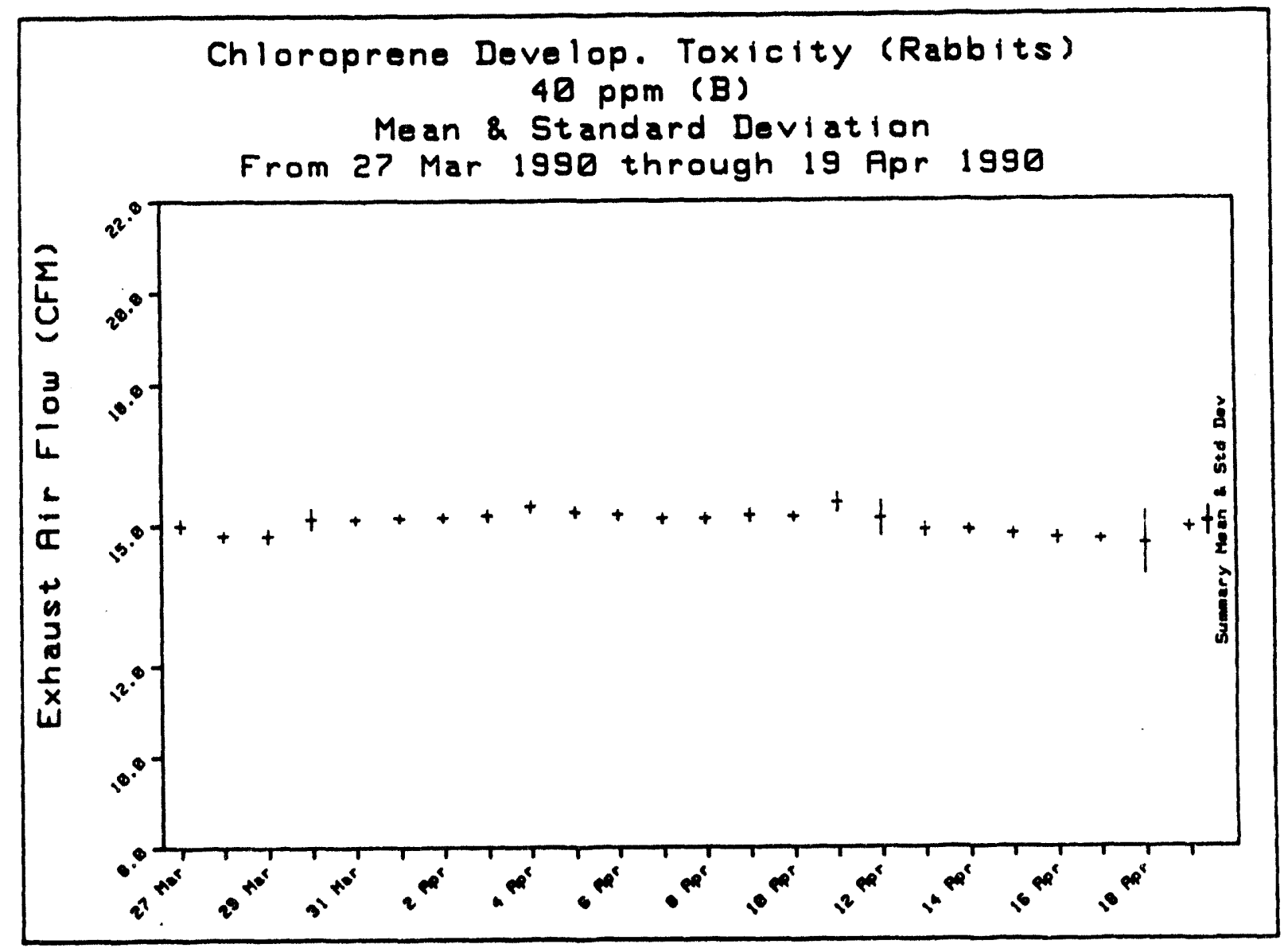


Dally Svamition for Chlorogrene Daveloo Ioxtaity (Babbite) Sumary Date for: 175 pom (A)

Erom 23 Mur 1990 throuth 18 Aor 1990

\begin{tabular}{|c|c|c|c|c|c|c|c|c|c|}
\hline Anth & Ann & XInent & sed ony & XRSD & Mxtmm & Minima & 1 & in & $x y$ in \\
\hline 23 Mar 1990 & 14.9 & $99.0 x$ & .08 & $.5 x$ & 15.0 & 14.7 & 7 & 7 & $100.0 x$ \\
\hline $24 \operatorname{Mar} 1990$ & 14.8 & $98.4 x$ & .08 & $.6 x$ & 14.9 & 14.6 & 8 & 8 & $100.0 \%$ \\
\hline $25 \operatorname{Mar} 1980$ & 14.7 & $98.0 \%$ & .07 & $.5 x$ & 14.8 & 14.6 & 8 & 8 & $100.0 x$ \\
\hline 28 Mar 1990 & 14.7 & $98.1 \%$ & .08 & $.6 x$ & 14.9 & 14.6 & 7 & 7 & $100.0 \%$ \\
\hline 27 Mar 1980 & 14.7 & $98.2 x$ & .14 & $1.0 x$ & 15.0 & 14.6 & 8 & 8 & $100.0 \%$ \\
\hline 28 Mar 1980 & 14.6 & $97.2 \%$ & .13 & $.9 x$ & 14.7 & 14.3 & 8 & 8 & $100.0 x$ \\
\hline 28 Mar 1990 & 14.7 & $98.1 x$ & .10 & $.7 x$ & 14.9 & 14.6 & 7 & 7 & $100.0 \%$ \\
\hline 30 Mar 1990 & 15.1 & $100.9 x$ & .23 & $1.5 x$ & 15.4 & 14.6 & 8 & 8 & $100.0 \%$ \\
\hline 31 Mar 1990 & 15.2 & $101.0 \%$ & .10 & $.7 x$ & 15.3 & 15.1 & 8 & 8 & $100.0 \%$ \\
\hline 1 Apr 1990 & 15.2 & $101.2 x$ & .11 & $.7 x$ & 15.3 & 15.1 & 8 & 8 & $100.0 x$ \\
\hline 2 Apr 1990 & 15.1 & $100.8 x$ & .10 & $.7 x$ & 15.3 & 15.1 & 7 & 7 & $100.0 x$ \\
\hline 3 Apr 1990 & 15.2 & $101.0 x$ & .15 & $1.0 x$ & 15.3 & 15.0 & 7 & 7 & 100.00 \\
\hline A Apr 1990 & 15.1 & $100.7 x$ & .14 & $.9 x$ & 15.3 & 15.0 & 7 & 7 & $100.0 x$ \\
\hline 5 Apr 1990 & 15.2 & $101.2 x$ & .11 & $.7 x$ & 15.3 & 15.1 & 7 & 7 & $100.0 x$ \\
\hline - Apr 1980 & 15.3 & $101.9 \%$ & .12 & $.8 x$ & 15.5 & 15.2 & 7 & 7 & $100.0 x$ \\
\hline 7 Apr 1990 & 15.3 & $101.7 x$ & .12 & $.8 x$ & 15.5 & 15.1 & 8 & 8 & $100.0 x$ \\
\hline - Apr 1990 & 15.3 & $101.9 x$ & .11 & $.7 \%$ & 15.5 & 15.1 & 7 & 7 & $100.0 x$ \\
\hline 9 Apr 1990 & 15.3 & $102.3 x$ & .12 & $.8 x$ & 15.6 & 15.2 & 8 & 8 & $100.0 \%$ \\
\hline 10 Apr 1990 & 15.3 & $101.7 x$ & .11 & $.7 x$ & 15.5 & 15.2 & 6 & 6 & $100.0 \%$ \\
\hline 11 Apr 1990 & 15.2 & $101.4 x$ & .15 & $1.0 x$ & 15.4 & 15.0 & 8 & 8 & $100.0 \%$ \\
\hline 12 Apr 1990 & 15.5 & $103.1 x$ & .15 & $1.0 \%$ & 15.7 & 15.4 & 7 & 7 & $100.0 \%$ \\
\hline 13 Apr 1990 & 15.4 & $102.9 x$ & .15 & $1.0 x$ & 15.6 & 15.1 & 7 & 7 & $100.0 \%$ \\
\hline 14 Apr 1990 & 15.0 & $100.0 x$ & .18 & $1.2 x$ & 15.4 & 14.9 & 7 & 7 & $100.0 x$ \\
\hline 15 Apr 1890 & 14.8 & 98.7x & .11 & $.8 \%$ & 15.0 & 14.7 & 7 & 7 & $100.0 x$ \\
\hline 16 Apr 1990 & 14.7 & $98.0 x$ & .19 & $1.3 x$ & 15.0 & 14.8 & 7 & 7 & $100.0 x$ \\
\hline 17 Apr 1990 & 14.8 & $98.7 x$ & .00 & $.6 x$ & 14.9 & 14.7 & 7 & 7 & $100.0 \%$ \\
\hline 18 Anr 1990 & 14.7 & $97.9 x$ & .70 & $4.0 x$ & 15.0 & 13.1 & 1 & 1 & $100.0 \%$ \\
\hline Sumary & 15.0 & $100.1 x$ & .31 & $2.1 x$ & 15.7 & 13.1 & 198 & 198 & $100.0 \%$ \\
\hline
\end{tabular}

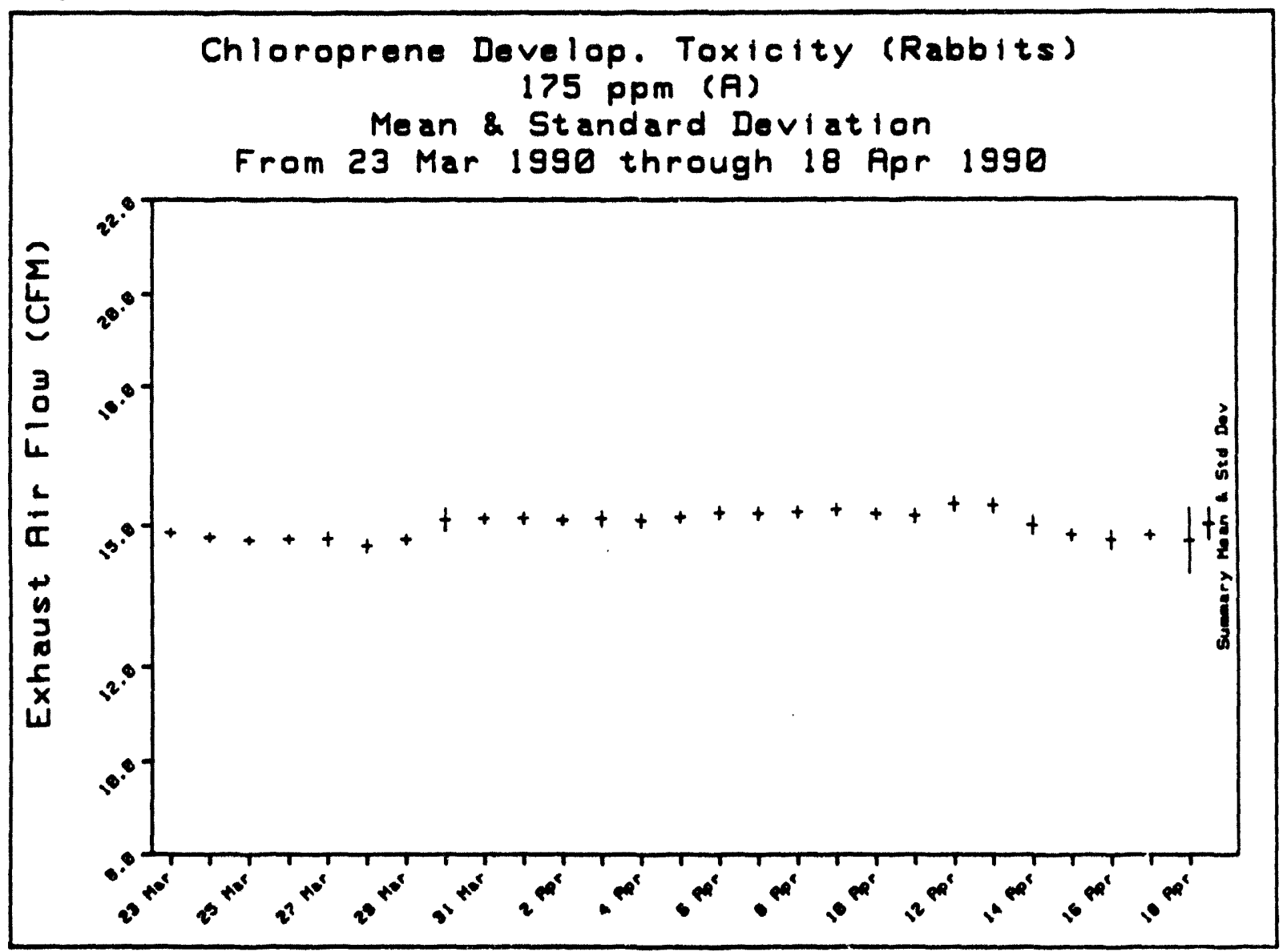


Qully Sinntion for chloroprene Davelon Ioxialty (Babbite)

From 22 Mar 1990 through 19 Aor 1990

\begin{tabular}{|c|c|c|c|c|c|c|c|c|c|}
\hline Summary Oata & 175 & $m(8)$ & /Exhaust & Flow & & & $=1$ & to 1 & \\
\hline Qhen & Men & $x$ raront & sted Dey & $x$ BSO & Maximm & Mintmin & 1 & N In & xyin \\
\hline $27 \mathrm{Mar} 1980$ & 15.3 & $102.3 x$ & .21 & $1.3 x$ & 15.7 & 15.1 & 7 & 7 & $100.0 x$ \\
\hline 28 Mar 1980 & 15.2 & $101.2 x$ & .15 & $1.0 \%$ & 15.3 & 15.0 & 8 & 8 & $100.0 x$ \\
\hline 29 Mar 1990 & 15.2 & $101.7 x$ & .17 & 1.18 & 15.5 & 15.1 & 7 & 7 & $100.0 x$ \\
\hline 30 Mar 1990 & 15.2 & 101.28 & .15 & $1.0 \%$ & 15.4 & 15.1 & 8 & 8 & $100.0 x$ \\
\hline 31 Mar 1990 & 15.1 & $100.9 x$ & .11 & $.7 x$ & 15.3 & 15.0 & 8 & 8 & $100.0 x$ \\
\hline 1 Apr 1990 & 15.2 & 101.28 & .13 & $.8 x$ & 15.3 & 15.1 & 8 & 8 & $100.0 \%$ \\
\hline 2 Apr 1990 & 15.0 & $100.0 \%$ & .13 & $.9 \%$ & 15.2 & 14.9 & 7 & 7 & $100.0 \%$ \\
\hline 3 Apr 1980 & 15.0 & $100.3 x$ & .17 & $1.1 x$ & 15.3 & 14.9 & 7 & 7 & $100.0 \%$ \\
\hline 4 Apr 1990 & 15.1 & $100.5 x$ & .18 & $1.2 \%$ & 15.3 & 15.0 & 7 & 7 & $100.0 \%$ \\
\hline 5 Apr 1990 & 15.4 & $102.4 x$ & .09 & $.6 x$ & 15.5 & 15.3 & 1 & 7 & $100.0 \%$ \\
\hline 6 Apr 1990 & 15.3 & 102.08 & .14 & $.9 x$ & 15.6 & 15.2 & 7 & 7 & $100.0 \%$ \\
\hline 7 Apr 1990 & 15.2 & $101.2 x$ & .11 & $1.1 \mathrm{x}$ & 15.5 & 15.1 & 8 & 8 & $100.0 x$ \\
\hline - Apr 1990 & 15.2 & $101.1 \%$ & .15 & $1.0 \%$ & 15.4 & 15.0 & 7 & 7 & $100.0 \%$ \\
\hline O Apr 1990 & 15.0 & $99.9 x$ & .16 & $1.1 \mathrm{x}$ & 15.2 & 14.8 & 8 & 8 & $100.0 \%$ \\
\hline 10 Apr 1990 & 14.9 & $99.4 x$ & .12 & $.8 x$ & 15.1 & 14.8 & 6 & 6 & $100.0 \%$ \\
\hline 11 Apr 1990 & 14.7 & $98.0 \%$ & .19 & $1.3 \%$ & 14.9 & 14.4 & 8 & 8 & $100.0 \%$ \\
\hline 12 Apr 1890 & 15.0 & $100.0 \%$ & .15 & $1.0 x$ & 15.3 & 14.9 & 7 & 7 & $100.0 x$ \\
\hline 13 Apr 1990 & 14.9 & $99.5 x$ & .19 & $1.3 x$ & 15.2 & 14.7 & 7 & 7 & $100.0 x$ \\
\hline 14 Apr 1990 & 14.8 & $97.6 \%$ & .15 & $1.0 \%$ & 14.8 & 14.5 & 7 & 7 & $100.0 x$ \\
\hline 15 Apr 1990 & 14.6 & $97.0 \%$ & .16 & $1.1 \%$ & 14.8 & 14.4 & 7 & 7 & $100.0 x$ \\
\hline 16 Apr 1990 & 14.9 & $99.7 x$ & .19 & $1.2 x$ & 15.2 & 14.8 & 7 & 7 & $100.0 x$ \\
\hline 17 Apr 1990 & 15.0 & $89.8 x$ & .15 & $1.0 x$ & 15.2 & 14.9 & 7 & 7 & $100.0 x$ \\
\hline 18 Apr 1990 & 14.9 & $99.5 x$ & .74 & $4.9 x$ & 15.4 & 13.3 & 7 & 7 & $100.0 x$ \\
\hline 12 Anr 1990 & 15.3 & $102.1 \%$ & .14 & $9 x$ & 15.5 & 15.1 & 8 & 8 & $100.0 \%$ \\
\hline Sumary & 15.1 & $100.4 x$ & .29 & $1.9 x$ & 15.7 & 13.3 & 175 & 175 & $100.0 x$ \\
\hline
\end{tabular}

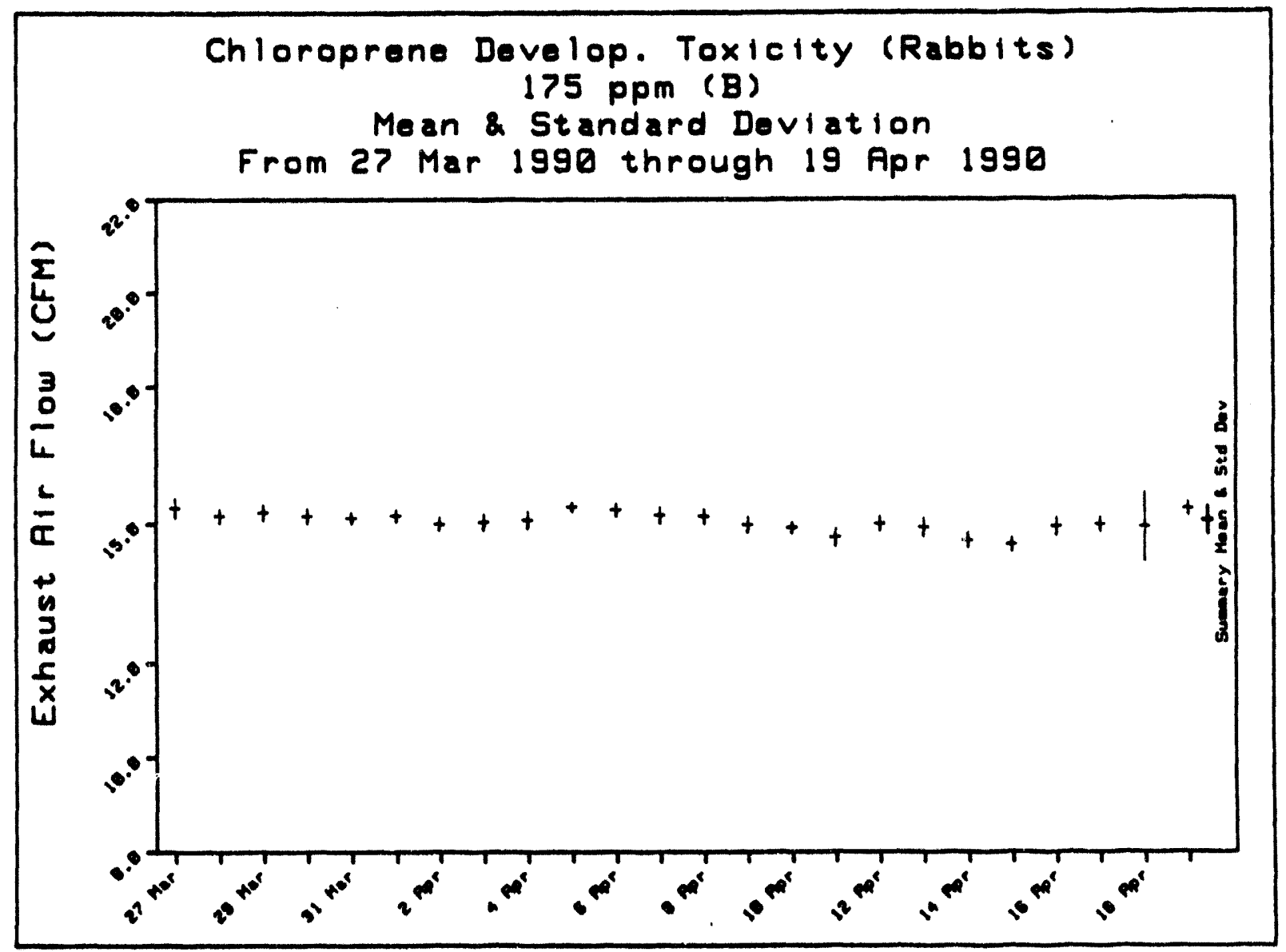


Exposure Operation Discussion Sheets

B $\cdot 53$ 


\title{
EXPOSURE OPERATION DISCUSSION SHEET
}

\begin{abstract}
INCLUDES DISCUSSIONS AND/OR EXPLANATIONS OF PROBLEMS AFFECTING ANIMAL ENVIRONMENT AND EXPOSURES. EXPLANATIONS ARE INCLUDED FOR DATA IN WHICH THERE WERE EXCURSIONS OF DAII Y MEAN OR STANDARD DEVIATION BEYOND ALLOWABLE OPERATINO LIMITS OR EXCURSIONS OF INDIVIDUAL DATUM BEYOND CRITICAL LIMITS.
\end{abstract}

STUDY: IRT Chloroprene Inhalation Teratology Study

REPORTING PERIOD: March 23 - April 19, 1990

NOTE: 24 Hour Collection Period extends from $5: 00 \mathrm{a} . \mathrm{m}$. $10 \sim 5: 00 \mathrm{a.m}$.

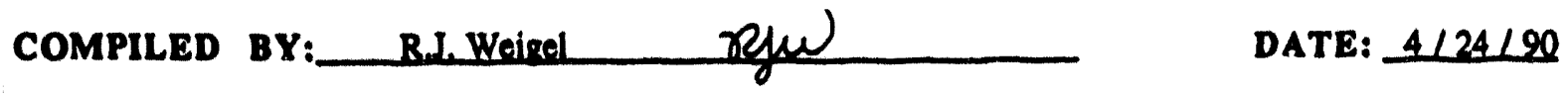

CHAMBER CONCENTRATION

DATE DISCUSSIONOR EXPLANATION

$3 / 29 / 90$

The stream-select valve on the on-line GC failed before the stan of the exposure. Exposures were started at the usual time using the purity GC as a monitor. This GC was checked against the standard and agreed. During the day, the exposure operating parameters were kept at the previous day's settings. Four hours into the exposure, the main GC was brought back on-line and subsequent readings agreed with those of the purity GC. Only 4 concentration readings per chamber were obtained during the exposure; no purity data was obtained.

4/6/90 Exposures were terminated after $5 \mathrm{hr} 1 \mathrm{~min}$. Chemical consumption in the generator was much higher than normal and it was unlikely that sufficient chemical remained to complete a normal exposure. In addition, small amounts of dimer were picked up by the purity GC. The high consumption was due to a leak in the generator. New seals were put into the generator. A small amount of polymer may also have been on the neck of the flask, preventing a good seal.

\section{TEMPERATURE \& RELATIVE HUMIDITY}

DATE DISCUSSIONOR EXPLANATION

$3 / 23 / 90 \quad$ First day in chambers. Temperatures were set low $t 0$ insure that the animals did not get overheated. However, chamber temperatures did not rise with animal loading as expected. Therefore, the following readings were below the critical low alarm limit $\left(63^{\circ} \mathrm{F}\right)$ and the following chamber mean temperatures were below the protocol-defined operating limit of $65^{\circ} \mathrm{F}$.

$\begin{array}{lcccc}\text { Time } & \text { Chamber } & \text { Beading } & \text { Alarm Limis } & \text { Mean } \\ \text { 00:56 } & 0 \text { ppm-B } & 62.9 & 63 & 65.1 \\ 21: 48 & 10 \mathrm{ppm}-\mathrm{A} & 61.5 & 63 & 63.4 \\ 00: 49 & & 60.7 & & \\ 04: 13 & & 62.2 & & \\ 21: 51 & 40 \mathrm{ppm}-\mathrm{A} & 62.3 & 63 & 63.5 \\ 00: 53 & & 61.3 & & \\ 04: 16 & & 62.3 & & \end{array}$

The specialist increased the room temperature early the following morning

Two chambers had temperatures below the critical low alarm limit in the moming before the changes in room temperature were reflected in the chamber temperatures. They were in the 10 $\mathrm{ppm}-\mathrm{A}\left(62.7^{\circ} \mathrm{F}\right)$ and in the $40 \mathrm{ppm}-\mathrm{A}\left(62.5^{\circ} \mathrm{F}\right)$. Mean temperature in the $40 \mathrm{ppm}-\mathrm{A}$ chamber was $64.8^{\circ} \mathrm{F}$, below the protocol-defined lower limit of $65^{\circ} \mathrm{F}$.

$3 / 28 / 90$ Relative humidity in the $10 \mathrm{ppm} \mathrm{A} \mathrm{chamber} \mathrm{(77 \%} \mathrm{at} \mathrm{00:06)} \mathrm{and} \mathrm{in} \mathrm{the} 40 \mathrm{pm} \mathrm{B}$ chamber ( $76 \%$ at 03:21) exceeded the critical high alarm limit (75\%). Adjustments were made to the wet/dry air mixture. 
Bautelle

Pacific Northwest Laboratories

Monthly Progress Report

for March - April, 1990

$3 / 29 / 90$ Temperature in the $40 \mathrm{ppm}$ A chamber ranged from 63.7 to $65.4^{\circ} \mathrm{F}$. While no temperatures exceeded the critical low alarm limit $\left(63^{\circ} \mathrm{F}\right)$, the mean temperature in this chamber was $64.5^{\circ} \mathrm{F}$, below the protocol-defined lower operating limit of $65^{\circ} \mathrm{F}$.

$4 / 10 / 90$ Relative humidity in the $10 \mathrm{ppm} A$ chamber (76\% at 05:36) exceeded the critical high alarm limit (75\%). Adjustments were made to the weV/dry air mixture.

CHAMBER FLOW \& VACUUM

DATE DISCUSSION OR EXPLANATION

No problems or excursions to report this month. 
Chamber Uniformity Data

B - 57 


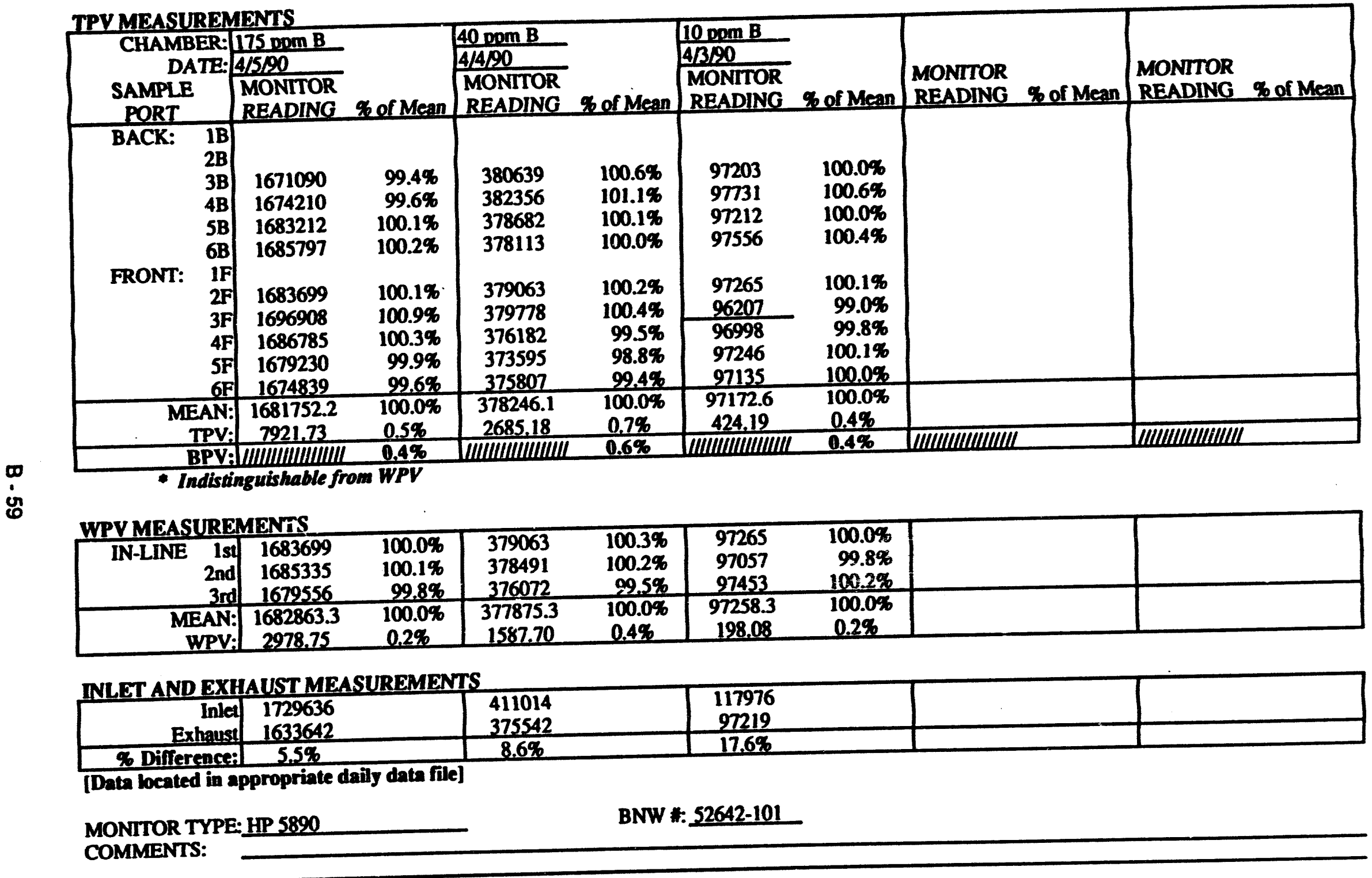

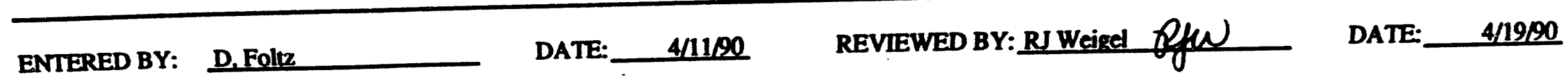


CHAMBER UNIFORMITY DATA SHEET

COMPOUND: Chloroprene

EXPOSURE ROOM NUMBER: 432

\begin{tabular}{|c|c|c|c|c|c|c|c|c|}
\hline $\begin{array}{c}\text { CHAMBER: } \\
\text { DATE: } \\
\text { SAMPLE } \\
\text { PORT } \\
\end{array}$ & $\begin{array}{l}\frac{175 \mathrm{ppm} \mathrm{A}}{4 / 490} \\
\text { MONITOR } \\
\text { READING }\end{array}$ & gof Mean & \begin{tabular}{|l}
$40 \mathrm{ppm} \mathrm{A}$ \\
$4 / 3 / 90$ \\
MONITOR \\
READING \\
\end{tabular} & \%o of Mean & \begin{tabular}{|l}
$10 \mathrm{ppm} \mathrm{A}$ \\
42190 \\
MONITOR \\
READING \\
\end{tabular} & \% of Mean & $\begin{array}{l}\text { MONITOR } \\
\text { READING go of Mean }\end{array}$ & $\begin{array}{l}\text { MONITOR } \\
\text { READING } q_{0} \text { of Mean }\end{array}$ \\
\hline $\begin{array}{ll}\text { BACK: } & 1 \mathrm{~B} \\
& 2 \mathrm{~B} \\
3 \mathrm{~B} \\
4 \mathrm{~B} \\
\mathrm{5B} \\
6 \mathrm{~B} \\
\text { FRONT: } & 1 \mathrm{~F} \\
& \mathrm{~F} \\
3 \mathrm{~F} \\
\mathrm{4F} \\
\mathrm{5F} \\
\\
6 \mathrm{~F} \\
\end{array}$ & $\begin{array}{l}1673970 \\
1689357 \\
1685631 \\
1690149 \\
\\
1698376 \\
1699081 \\
1685464 \\
1686928 \\
1695778 \\
\end{array}$ & $\begin{array}{r}99.1 \% \\
100.0 \% \\
99.8 \% \\
100.0 \% \\
\\
100.5 \% \\
100.6 \% \\
99.8 \% \\
99.9 \% \\
100.4 \% \\
\end{array}$ & $\begin{array}{l}380494 \\
385380 \\
380447 \\
383069 \\
\\
383173 \\
380047 \\
384416 \\
378849 \\
384183 \\
\end{array}$ & $\begin{array}{r}99.5 \% \\
100.8 \% \\
99.5 \% \\
100.2 \% \\
\\
100.2 \% \\
99.4 \% \\
100.6 \% \\
99.1 \% \\
100.5 \% \\
\end{array}$ & $\begin{array}{l}94804 \\
95801 \\
94147 \\
94099 \\
\\
94866 \\
93699 \\
93931 \\
91297 \\
93368 \\
\end{array}$ & $\begin{array}{r}100.9 \% \\
101.9 \% \\
100.2 \% \\
100.1 \% \\
100.9 \% \\
99.7 \% \\
99.9 \% \\
97.1 \% \\
99.3 \% \\
\end{array}$ & & \\
\hline $\begin{array}{r}\text { MEAN: } \\
\text { TPV: }\end{array}$ & $\begin{array}{c}1689414.9 \\
7821.63\end{array}$ & $\begin{array}{l}100.0 \% \\
0.5 \%\end{array}$ & $\begin{array}{c}382228.7 \\
2304.83\end{array}$ & $\begin{array}{l}100.0 \% \\
0.6 \%\end{array}$ & \begin{tabular}{|c|}
94001.3 \\
1248.62 \\
\end{tabular} & $\begin{array}{l}100.0 \% \\
1.3 \%\end{array}$ & & \\
\hline BPV: & IIIIIIIIIIIIIIIII & $0.4 \%$ & |ІІІІІІІІІІІІІІІІІ & $0.6 \%$ & 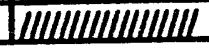 & $1.0 \%$ & ІІІІІІІІІІІІІІІІ & 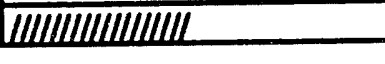 \\
\hline $\begin{array}{|rr|}\text { IN-LINE } & 1 \text { st } \\
2 \text { nd } \\
3 \text { rd } \\
\end{array}$ & \begin{tabular}{|l|}
1698376 \\
1695190 \\
1691592 \\
\end{tabular} & $\begin{array}{l}100.2 \% \\
100.0 \% \\
99.8 \% \\
\end{array}$ & $\begin{array}{l}383173 \\
382156 \\
383021 . \\
\end{array}$ & $\begin{aligned} 100.1 \% \\
99.8 \% \\
100.1 \% \\
\end{aligned}$ & $\begin{array}{l}94866 \\
94930 \\
93525 \\
\end{array}$ & $\begin{array}{r}100.5 \% \\
100.5 \% \\
99.0 \% \\
\end{array}$ & & \\
\hline $\begin{array}{l}\text { MEAN: } \\
\text { WPV: }\end{array}$ & $\begin{array}{c}1695052.7 \\
3394.08 \\
\end{array}$ & $\begin{array}{l}100.0 \% \\
0.2 \%\end{array}$ & $\begin{array}{c}382783.3 \\
548.58 \\
\end{array}$ & $\begin{array}{l}100.0 \% \\
0.1 \%\end{array}$ & $\begin{array}{c}94440.3 \\
793.35 \\
\end{array}$ & $\begin{array}{l}100.0 \% \\
0.8 \%\end{array}$ & & \\
\hline $\begin{array}{r}\text { INLET AND EXX } \\
\text { Inlet } \\
\text { Exhaust }\end{array}$ & $\begin{array}{l}1856075 \\
1677431\end{array}$ & & $\begin{array}{r}519393 \\
378804 \\
\end{array}$ & & $\begin{array}{l}102240 \\
93916 \\
\end{array}$ & & & \\
\hline \% Difference: & $9.6 \%$ & & $27.1 \%$ & & $8.1 \%$ & & & \\
\hline
\end{tabular}

[Data located in appropriate daily data file]

MONITOR TYPE: HP 5890

BNW \#: 52642-101

COMMENTS: Measurements with animals in chambers,

ENTERED BY: D, Follz

DATE:

$4 / 11190$

REVIEWED BY: RJ Weigel tefW

DATE:

$4 / 19 / 90$ 


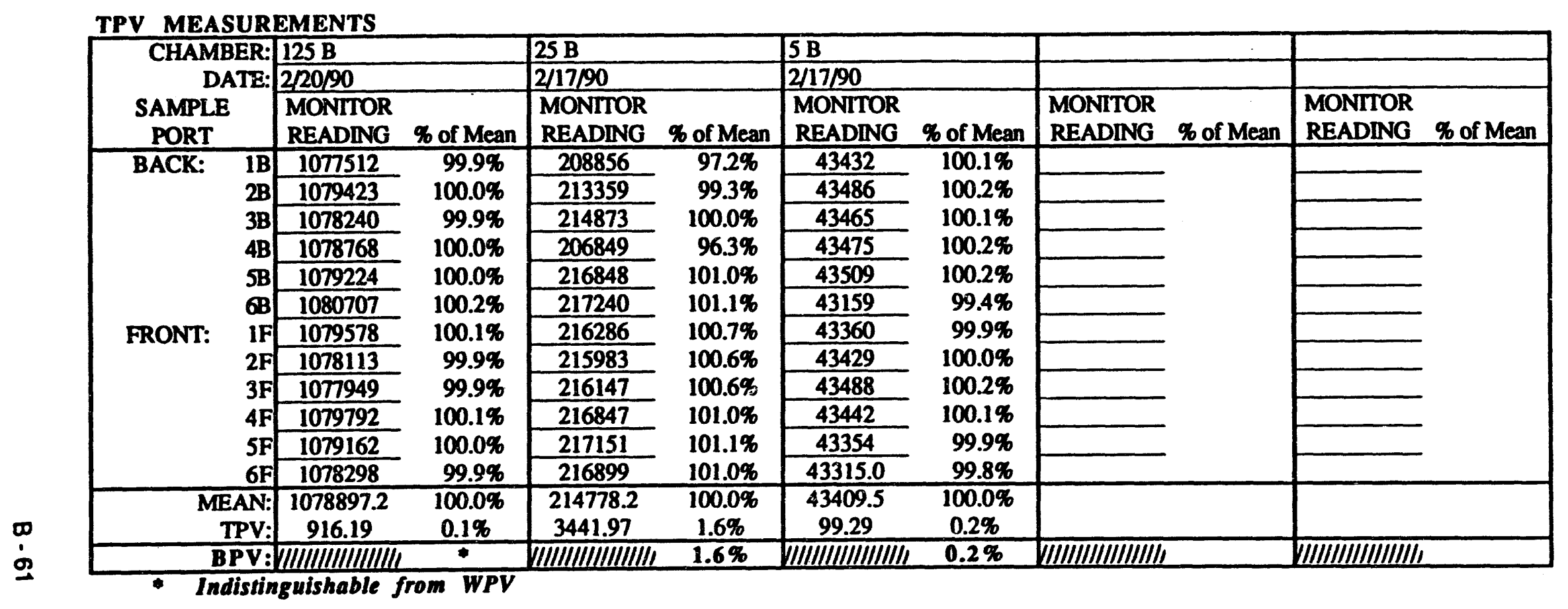

\section{WPV MEASUREMENTS}

\begin{tabular}{|c|c|c|c|c|c|c|c|c|}
\hline $\begin{array}{lr}\text { IN-LINE } & \text { 1st } \\
& \text { 2nd } \\
& 3 \mathrm{rd}\end{array}$ & $\begin{array}{l}1081218 \\
1078113 \\
1078835\end{array}$ & $\begin{array}{r}100.2 \% \\
99.9 \% \\
99.9 \%\end{array}$ & $\begin{array}{l}216147 \\
216021 \\
217371\end{array}$ & $\begin{array}{r}99.8 \% \\
99.8 \% \\
100.4 \%\end{array}$ & $\begin{array}{l}43360 \\
43473 \\
43481 \\
\end{array}$ & $\begin{array}{l}99.8 \% \\
100.1 \% \\
100.1 \%\end{array}$ & & \\
\hline $\begin{array}{l}\text { MEAN: } \\
\text { WPV: }\end{array}$ & $\begin{array}{c}1079388.7 \\
1624.86 \\
\end{array}$ & $\begin{array}{c}100.0 \% \\
0.2 \%\end{array}$ & $\begin{array}{c}216513.0 \\
745.72\end{array}$ & $\begin{array}{l}100.0 \% \\
0.3 \%\end{array}$ & $\begin{array}{c}43438.0 \\
67.67 \\
\end{array}$ & $\begin{array}{l}100.0 \% \\
0.2 \%\end{array}$ & & \\
\hline
\end{tabular}

\section{INLET AND EXHAUST MEASUREMENTS}

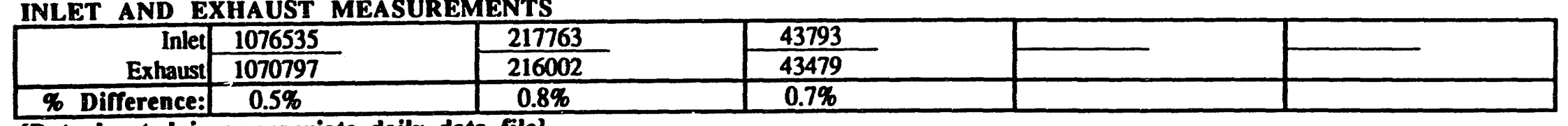

[Data located in appropriate daily data file]

MONITOR TYPE: GC 5890

BNW \#: $32-813342$

COMMENTS: Prestart lests without animals. Tests performed at original target levels before changes were made. Data located in BNW Notebook 53435 pg 42

ENTERED BY: D. Foltz

DATE: 2/21/90 
CHAMBER UNIFORMITY DATA SHEET

COMPOUND: Chloroprene-IRT

EXPOSURE ROOM NUMBER: 432

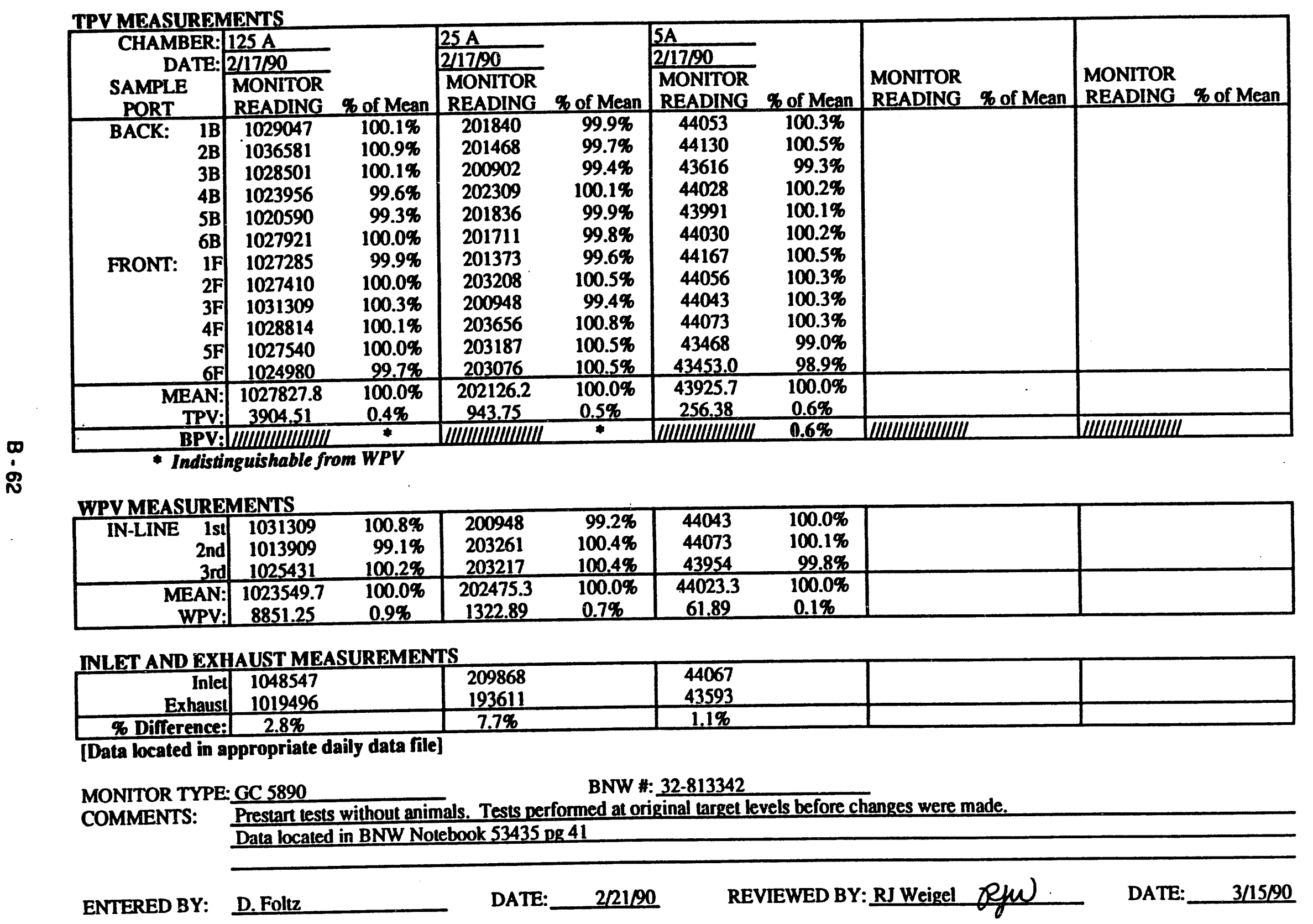


APPENDIX C

DEVELOPMENTAL TOXICITY DATA

Calendar of Events

Maternal Body and Organ Weights

Reproductive Measures and Fetal Data

C. 1 
$$
\text { Calendar of Events }
$$$$
\text { C - } 3
$$ 
Inbalation Developmental Toxiclty study of Chloroprene in Rabblts: CALENDAR OF EVENTS

Expoaure levela; treatments $1-4$

Ordered rabbits

Recelved rabbit: (ARs\$900029)

Assigned ID numbers to female rabbits

We1ghed female rabb1ts (pre-study wt)

Anlmalo released for atudy

Artiflelally Inseminated $D$ dg (f in Ges GIP) welghed, randomized

Exposure (6 hours/day: 7 days/wook; $6-28 \mathrm{dg}$ )

Weighed (6dg) started exposure

Weighed (15dg)

Weighed (22dg)

Weighed (29dg)

Teratology sacrifice $(29 \mathrm{dg})$

Fetal apecimen exams completed
$0,10,40,175 \mathrm{ppm}$

$11 / 22 / 89$

$1 / 31 / 90$

$2 / 26 / 90$

$3 / 16 / 90$

$3 / 19 / 90$

(A) $3 / 20 / 90$ (17)

(B) $3 / 21 / 90 \quad$ (23)

(C) $3 / 22 / 90$ (23)

(A) $3 / 26$ to $4 / 17 / 90$

(B) $3 / 27$ to $4 / 18 / 90$

(C) $3 / 28$ to $4 / 19 / 90$

(A-C) $3 / 26$ to $3 / 28 / 90$

(A-C) $4 / 4$ to $4 / 6 / 90$

(A-C) $4 / 11$ to $4 / 13 / 90$

(A-C) $4 / 18$ to $4 / 20 / 90$
(A) $4 / 18 / 90$
(B) $4 / 19 / 90$
(C) $4 / 20 / 90$

$6 / 13 / 90$ 
Maternal Body and Organ Weights

C - 7 
TNT $=0$ ppm Chloroprone

\begin{tabular}{|c|c|c|c|c|c|c|c|c|c|c|}
\hline DAMID & $\begin{array}{l}\text { Pro-study } \\
\text { Wt (g) }\end{array}$ & $w_{t} d g$ & ${ }_{w t}^{6} d g$ & $\begin{array}{l}15 \mathrm{dg} \\
w_{t}(g)\end{array}$ & $\begin{array}{l}22 \\
\text { wt (g) }\end{array}$ & $\begin{array}{l}28 \text { dg } \\
\text { itt (g) }\end{array}$ & $\begin{array}{l}\text { Uter } \\
\text { wt (g) }\end{array}$ & $\begin{array}{l}\text { Liver } \\
\text { wt (g) }\end{array}$ & $\begin{array}{l}\text { Kidney } \\
\text { wit (o) }\end{array}$ & Pregnent \\
\hline $\begin{array}{r}6 \\
9 \\
14 \\
15 \\
17 \\
29 \\
35 \\
36 \\
39 \\
44 \\
46 \\
52 \\
53 \\
54 \\
67\end{array}$ & $\begin{array}{l}4568 \\
4410 \\
4334 \\
4456 \\
4687 \\
4780 \\
4624 \\
4579 \\
4685 \\
4394 \\
4386 \\
4640 \\
4186 \\
4279 \\
3893\end{array}$ & $\begin{array}{l}4655 \\
4460 \\
4336 \\
4463 \\
4163 \\
4828 \\
4644 \\
4819 \\
4533 \\
4463 \\
4463 \\
4671 \\
4184 \\
4281 \\
3944\end{array}$ & $\begin{array}{l}4420 \\
4439 \\
4391 \\
4360 \\
4137 \\
4712 \\
4555 \\
4698 \\
4568 \\
4459 \\
4374 \\
4168 \\
4283 \\
4288 \\
3918\end{array}$ & $\begin{array}{l}4683 \\
4628 \\
4465 \\
4329 \\
4238 \\
4742 \\
4664 \\
4853 \\
4826 \\
4462 \\
4685 \\
3968 \\
4291 \\
4418 \\
4657\end{array}$ & $\begin{array}{l}4691 \\
4637 \\
4481 \\
4462 \\
4246 \\
4874 \\
4668 \\
4969 \\
4732 \\
4436 \\
4612 \\
4697 \\
4366 \\
4617 \\
4063\end{array}$ & $\begin{array}{l}4727 \\
4684 \\
4616 \\
4659 \\
4468 \\
4829 \\
4832 \\
6816 \\
4720 \\
4682 \\
4624 \\
4191 \\
4471 \\
4446 \\
4282\end{array}$ & $\begin{array}{r}437.30 \\
613.28 \\
527.90 \\
9.69 \\
336.42 \\
6.59 \\
667.44 \\
651.95 \\
391.30 \\
497.76 \\
619.63 \\
9.52 \\
258.16 \\
474.90 \\
423.94\end{array}$ & $\begin{array}{r}152.65 \\
116.87 \\
97.11 \\
145.16 \\
107.18 \\
168.12 \\
138.78 \\
136.81 \\
113.20 \\
119.92 \\
91.10 \\
139.61 \\
171.46 \\
97.61 \\
125.86\end{array}$ & $\begin{array}{l}18.38 \\
21.86 \\
18.22 \\
24.48 \\
16.47 \\
20.97 \\
21.64 \\
24.17 \\
17.71 \\
24.93 \\
18.73 \\
19.59 \\
25.85 \\
19.21 \\
19.88\end{array}$ & $\begin{array}{l}1 \\
1 \\
1 \\
0 \\
1 \\
0 \\
1 \\
1 \\
1 \\
1 \\
1 \\
0 \\
1 \\
1 \\
1\end{array}$ \\
\hline
\end{tabular}


Inhelation Developmental Toxicity Study of Chloroprene in Rabbits: Body and Organ wolghts (g) for Faneles

TMT=10 ppm Chloroprene

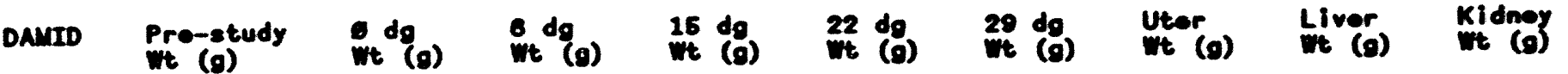

\begin{tabular}{|c|c|c|c|c|c|c|c|c|c|c|}
\hline $\begin{array}{l}4 \\
5 \\
13 \\
19 \\
25 \\
28 \\
32 \\
33 \\
38 \\
56 \\
58 \\
69 \\
62 \\
63 \\
65\end{array}$ & $\begin{array}{l}4387 \\
4746 \\
4276 \\
4285 \\
4802 \\
4737 \\
4607 \\
4427 \\
4520 \\
4248 \\
4260 \\
4208 \\
4028 \\
4121 \\
1273 \\
3819\end{array}$ & $\begin{array}{l}4436 \\
4737 \\
4361 \\
4381 \\
4876 \\
4663 \\
4659 \\
4511 \\
4433 \\
4315 \\
4275 \\
4176 \\
4977 \\
4657 \\
4381 \\
3824\end{array}$ & $\begin{array}{l}4403 \\
4631 \\
4296 \\
4278 \\
4685 \\
4742 \\
4608 \\
4493 \\
4492 \\
4322 \\
4237 \\
4225 \\
4047 \\
4670 \\
4282 \\
3859\end{array}$ & $\begin{array}{l}4431 \\
4698 \\
4434 \\
4257 \\
4869 \\
4851 \\
4603 \\
4461 \\
4462 \\
4363 \\
4262 \\
4317 \\
4165 \\
4224 \\
4371 \\
3884\end{array}$ & $\begin{array}{l}4395 \\
4698 \\
4328 \\
4333 \\
4873 \\
4987 \\
4677 \\
4443 \\
4691 \\
4448 \\
4191 \\
4467 \\
4188 \\
4344 \\
4629 \\
3972\end{array}$ & $\begin{array}{l}4448 \\
4861 \\
4057 \\
4488 \\
4695 \\
5224 \\
4799 \\
4637 \\
4837 \\
4614 \\
4176 \\
4378 \\
4188 \\
4471 \\
4657 \\
4184\end{array}$ & $\begin{array}{r}16.16 \\
174.49 \\
444.96 \\
9.87 \\
272.61 \\
717.40 \\
509.76 \\
10.46 \\
518.28 \\
643.72 \\
216.60 \\
567.64 \\
326.19 \\
464.74 \\
503.69 \\
202.22\end{array}$ & $\begin{array}{r}199.47 \\
180.96 \\
92.64 \\
114.02 \\
130.41 \\
137.44 \\
116.05 \\
121.38 \\
160.83 \\
119.70 \\
103.41 \\
80.51 \\
91.65 \\
120.13 \\
98.55 \\
130.35\end{array}$ & $\begin{array}{l}19.93 \\
22.93 \\
18.18 \\
15.33 \\
18.63 \\
19.81 \\
22.06 \\
16.64 \\
19.68 \\
19.91 \\
18.09 \\
16.43 \\
14.48 \\
18.73 \\
18.96 \\
17.77\end{array}$ & $\begin{array}{l}1 \\
1 \\
1 \\
1\end{array}$ \\
\hline
\end{tabular}

$\stackrel{?}{\dot{0}}$ 


\begin{tabular}{|c|c|c|c|c|c|c|c|c|c|c|}
\hline DAMID & $\begin{array}{l}\text { Pre-study } \\
\text { wt (g) }\end{array}$ & $e^{2} d g$ & 8 dg $(g)$ & 16 dg & $22 d g$ & $29 \mathrm{dg}$ & $\begin{array}{l}\text { Uteor } \\
\text { we }(a)\end{array}$ & Liver & $\begin{array}{l}\text { Kidapy } \\
\text { wt (o) }\end{array}$ & Pregnent \\
\hline $\begin{array}{l}2 \\
7 \\
18 \\
12 \\
27 \\
81 \\
37 \\
41 \\
42 \\
43 \\
48 \\
68 \\
68 \\
64 \\
68\end{array}$ & $\begin{array}{l}4894 \\
4242 \\
4397 \\
4462 \\
4779 \\
4682 \\
4654 \\
4361 \\
4290 \\
4419 \\
4689 \\
4383 \\
3832 \\
4222 \\
4609\end{array}$ & $\begin{array}{l}4657 \\
4252 \\
4377 \\
4511 \\
4713 \\
4772 \\
4619 \\
4299 \\
4255 \\
4466 \\
4649 \\
4276 \\
3836 \\
4196 \\
4056\end{array}$ & $\begin{array}{l}4491 \\
4286 \\
4468 \\
4442 \\
4698 \\
4686 \\
4468 \\
4348 \\
4230 \\
4421 \\
4536 \\
4338 \\
3872 \\
4249 \\
4644\end{array}$ & $\begin{array}{l}4644 \\
4417 \\
4684 \\
4682 \\
4818 \\
4749 \\
4575 \\
4465 \\
4324 \\
4468 \\
4612 \\
4440 \\
3938 \\
4351 \\
4220\end{array}$ & $\begin{array}{l}4763 \\
4641 \\
4685 \\
4642 \\
4919 \\
4861 \\
4681 \\
4670 \\
4378 \\
449 \\
4021 \\
4400 \\
3873 \\
4491 \\
4082\end{array}$ & $\begin{array}{l}4915 \\
4746 \\
4594 \\
4090 \\
5185 \\
4917 \\
4736 \\
4702 \\
4486 \\
4322 \\
4854 \\
4271 \\
3907 \\
4691 \\
4171\end{array}$ & $\begin{array}{r}463.70 \\
498.45 \\
511.58 \\
415.92 \\
468.72 \\
351.12 \\
345.21 \\
684.43 \\
6.90 \\
282.50 \\
8.75 \\
168.97 \\
7.51 \\
436.14 \\
488.66\end{array}$ & $\begin{array}{r}127.08 \\
141.80 \\
135.77 \\
116.83 \\
191.19 \\
140.34 \\
116.05 \\
138.89 \\
161.44 \\
118.24 \\
187.35 \\
199.73 \\
122.79 \\
181.94 \\
77.87\end{array}$ & $\begin{array}{l}18.99 \\
19.75 \\
20.32 \\
21.94 \\
23.71 \\
22.94 \\
18.94 \\
20.40 \\
22.91 \\
20.72 \\
17.37 \\
17.63 \\
18.81 \\
22.49 \\
16.37\end{array}$ & $\begin{array}{l}1 \\
1 \\
1 \\
1 \\
1 \\
1 \\
1 \\
1 \\
1 \\
1 \\
8 \\
1 \\
0 \\
1 \\
1\end{array}$ \\
\hline
\end{tabular}

$\stackrel{?}{\vdots}$ 
Inholetion Dovelopmental Toxicity Study of Chloroprene In Rabbite: Body end Organ Woighte (a) for Famelea TMT=175 ppon Chloroprene

\begin{tabular}{|c|c|c|c|c|c|c|c|c|c|c|}
\hline DAMID & $\begin{array}{l}\text { Pro-study } \\
\text { wit (g) }\end{array}$ & edt $d g$ & $d g(g)$ & $15 \stackrel{d g}{d g}$ & $22 \mathrm{dg}$ & 29 do & $\begin{array}{l}\text { Utor } \\
\text { wt (o) }\end{array}$ & Liver & $\begin{array}{l}\text { Kidnoy } \\
\text { it }(\sigma)\end{array}$ & Pregnant \\
\hline $\begin{array}{l}1 \\
8 \\
8 \\
18 \\
24 \\
28 \\
80 \\
34 \\
46 \\
46 \\
47 \\
49 \\
51 \\
69 \\
61 \\
69\end{array}$ & $\begin{array}{l}4627 \\
4716 \\
4486 \\
4162 \\
4716 \\
4714 \\
4689 \\
4640 \\
4381 \\
4286 \\
4136 \\
4331 \\
4348 \\
4684 \\
4841 \\
3812\end{array}$ & $\begin{array}{l}4631 \\
4639 \\
4398 \\
4169 \\
4608 \\
4678 \\
4642 \\
4609 \\
4368 \\
4271 \\
4190 \\
4308 \\
4329 \\
4111 \\
4069 \\
3793\end{array}$ & $\begin{array}{l}4673 \\
4678 \\
4283 \\
4142 \\
4610 \\
4690 \\
4626 \\
4683 \\
4463 \\
4342 \\
4143 \\
4312 \\
4269 \\
4696 \\
1168 \\
3813\end{array}$ & $\begin{array}{l}4873 \\
4805 \\
4242 \\
4203 \\
4883 \\
4810 \\
4048 \\
4703 \\
4184 \\
4469 \\
4235 \\
4475 \\
4432 \\
4189 \\
4225 \\
3938\end{array}$ & $\begin{array}{l}4879 \\
4868 \\
4272 \\
4305 \\
4883 \\
4877 \\
4768 \\
4034 \\
4162 \\
4627 \\
4274 \\
4682 \\
4619 \\
4178 \\
4284 \\
4048\end{array}$ & $\begin{array}{l}5197 \\
4834 \\
4361 \\
4460 \\
6021 \\
4989 \\
4976 \\
6026 \\
4218 \\
4660 \\
4365 \\
4798 \\
4426 \\
4370 \\
4496 \\
4149\end{array}$ & $\begin{array}{r}648.61 \\
586.35 \\
11.30 \\
633.10 \\
505.21 \\
395.61 \\
365.27 \\
804.53 \\
394.25 \\
656.43 \\
16.37 \\
585.04 \\
467.03 \\
390.06 \\
312.41 \\
471.74\end{array}$ & $\begin{array}{r}144.38 \\
95.74 \\
112.17 \\
93.74 \\
147.02 \\
138.75 \\
164.05 \\
135.15 \\
102.89 \\
108.68 \\
132.94 \\
127.69 \\
135.87 \\
117.86 \\
121.36 \\
80.36\end{array}$ & $\begin{array}{l}29.29 \\
17.64 \\
18.38 \\
18.33 \\
17.96 \\
23.27 \\
18.42 \\
22.22 \\
16.97 \\
17.31 \\
21.18 \\
23.84 \\
18.88 \\
17.81 \\
19.14 \\
17.16\end{array}$ & $\begin{array}{l}1 \\
1 \\
0 \\
1 \\
1 \\
1 \\
1 \\
1 \\
1 \\
1 \\
1 \\
1 \\
1 \\
1 \\
1 \\
1\end{array}$ \\
\hline
\end{tabular}


Reproductive Measures and Fetal Data

$$
\text { C }-13
$$


Iaholetion Dovelopmental Toxicity Study of Chloroprene In Rabblts: Raw Rabblt Fotol Dote

code Sheot for Identification of Fotsl Abnormalitlos

\begin{tabular}{|c|c|}
\hline 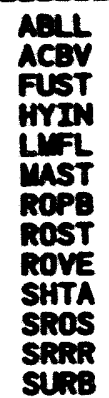 & 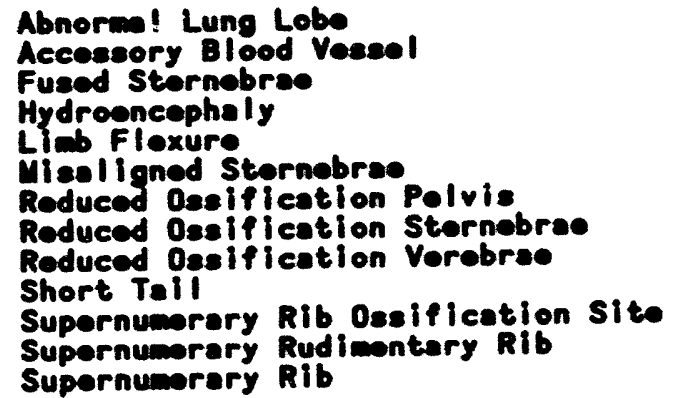 \\
\hline
\end{tabular}

$?$

$\vec{G}$ 
sas

Inhalation Dovelopmental Toxicity Study of Chloroprene in Rabbite: Row Rabbit Fotal Date

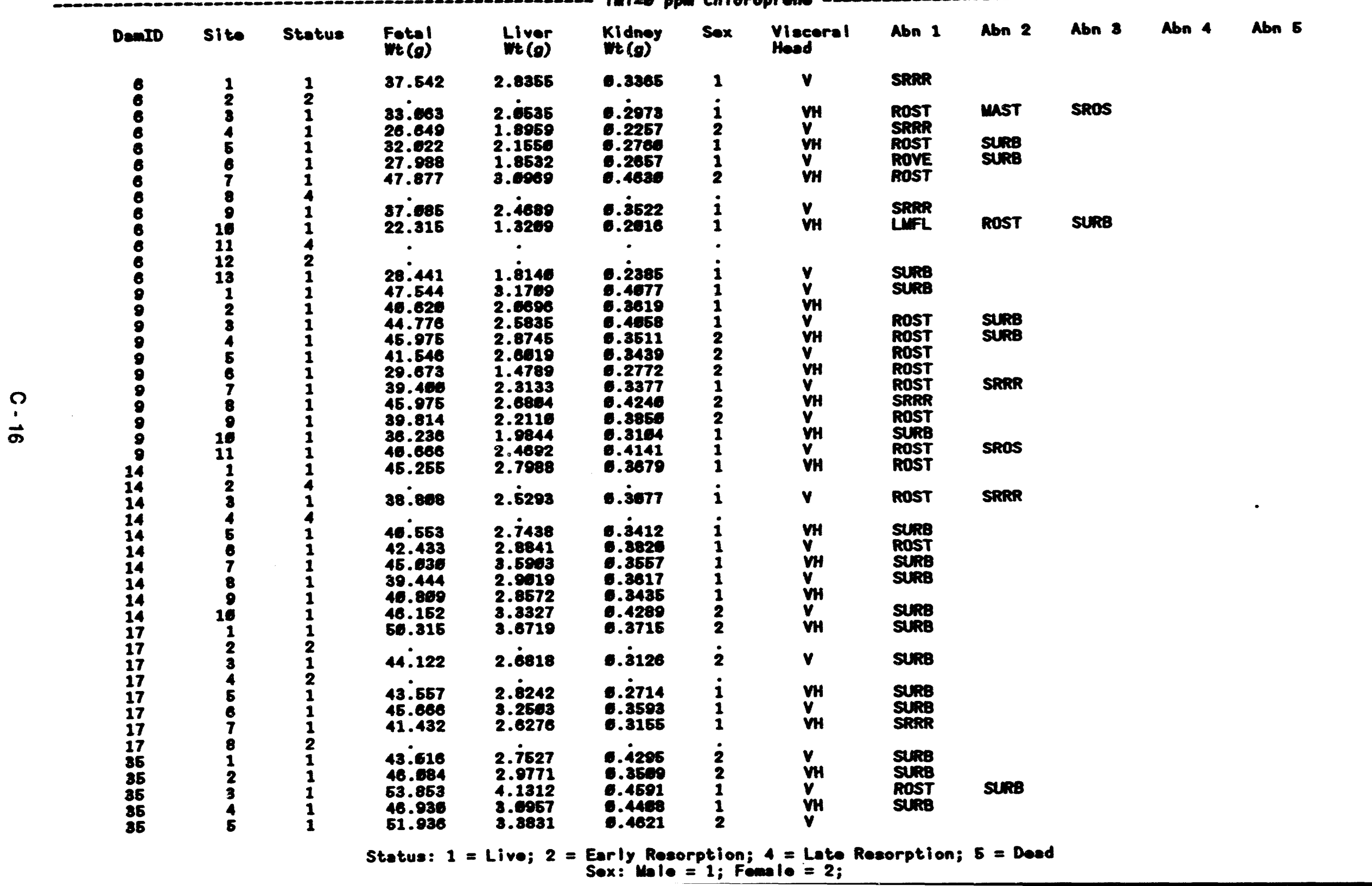


Inhelation Developmental Toxicity Study of Chloroprene in Rabbita: Raw Rabbit Fotal Data

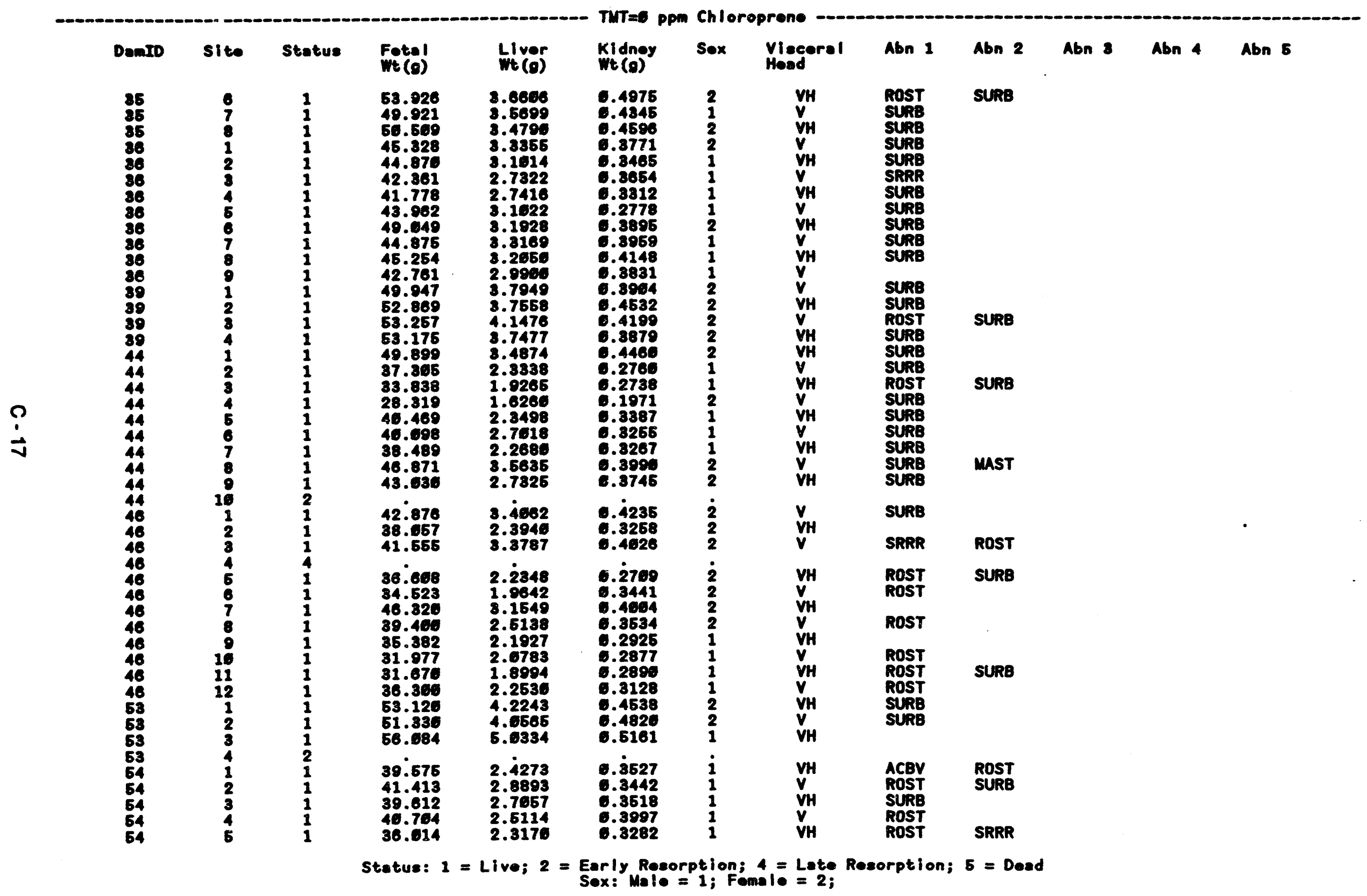


Inhaletion Developmental Toxicity Study of Chloroprene in Rabbits: Raw Rabbit Fotal Date

\begin{tabular}{|c|c|c|c|c|c|c|c|c|c|c|c|c|}
\hline DamID & site & Stetus & $\begin{array}{l}\text { Fotol } \\
W t(g)\end{array}$ & $\begin{array}{l}\text { Liver } \\
\text { wt (g) }\end{array}$ & $\begin{array}{l}\text { Kidnoy } \\
W \in(g)\end{array}$ & $\operatorname{Sex}$ & $\begin{array}{l}\text { Viecersel } \\
\text { Head }\end{array}$ & Abn 1 & Abn 2 & Abn 8 & Abn 4 & Abn 5 \\
\hline $\begin{array}{l}54 \\
54 \\
54 \\
54 \\
67 \\
67 \\
67 \\
67 \\
67 \\
67 \\
67 \\
67 \\
67\end{array}$ & $\begin{array}{l}6 \\
7 \\
8 \\
9 \\
1 \\
2 \\
3 \\
4 \\
5 \\
6 \\
7 \\
8 \\
8\end{array}$ & $\begin{array}{l}1 \\
1 \\
1 \\
1 \\
2 \\
1 \\
4 \\
1 \\
1 \\
1 \\
1 \\
1 \\
1\end{array}$ & $\begin{array}{c}42.582 \\
33.679 \\
36.521 \\
39.321 \\
46.216 \\
46.014 \\
45.892 \\
46.820 \\
39.877 \\
35.497 \\
46.471\end{array}$ & $\begin{array}{c}2.9875 \\
2.6977 \\
2.0436 \\
2.8243 \\
3.8444 \\
3.4616 \\
3.1617 \\
2.8716 \\
2.7691 \\
2.6374 \\
3.4983\end{array}$ & $\begin{array}{r}0.2994 \\
6.2718 \\
0.2651 \\
6.3286 \\
0.4624 \\
0.3984 \\
6.4243 \\
0.3886 \\
6.3356 \\
0.3214 \\
6.3769\end{array}$ & $\begin{array}{l}1 \\
2 \\
2 \\
2 \\
i \\
\dot{2} \\
2 \\
1 \\
2 \\
2 \\
1 \\
1\end{array}$ & $\begin{array}{l}\mathbf{v} \\
V H \\
v \\
V H \\
V H \\
V H \\
V \\
V_{H} \\
V_{V H} \\
V_{H} \\
V_{H}\end{array}$ & $\begin{array}{l}\text { ROST } \\
\text { ACBV } \\
\text { ROST } \\
\text { SRRR } \\
\text { ROST } \\
\text { ROST } \\
\text { SURB } \\
\text { ROST } \\
\text { ROST }\end{array}$ & $\begin{array}{l}\text { SURB } \\
\text { SURB } \\
\text { SRRR } \\
\text { SRRR }\end{array}$ & SURB & & \\
\hline
\end{tabular}


Inhalation Developmentel Toxicity Study of Chloroprene In Rabbita: Raw Rabbit Fotal Date

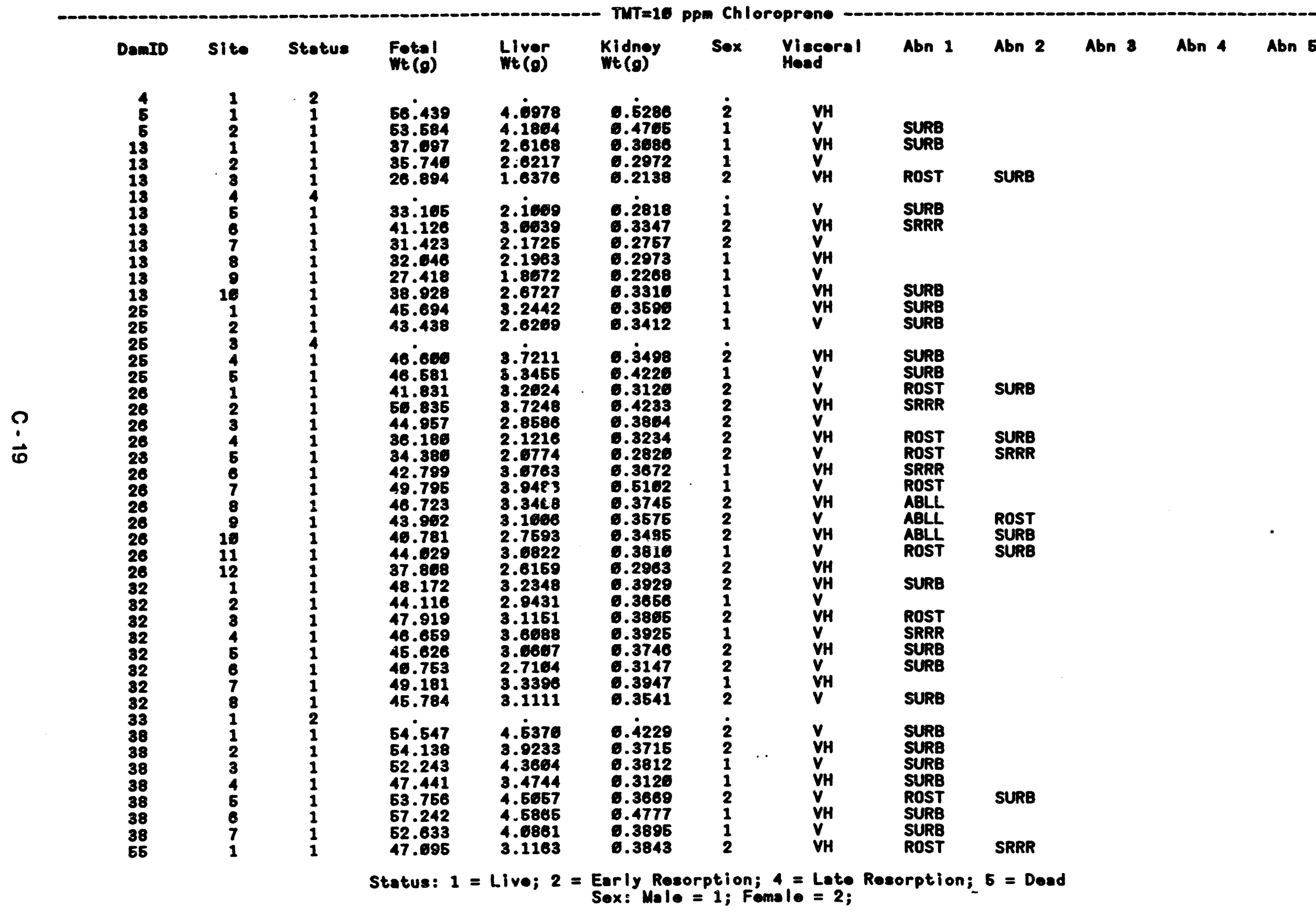


Inhelation Dovelopmental Toxicity Study of Chloroprene in Rabbita: Raw Rabbit Fatal Date

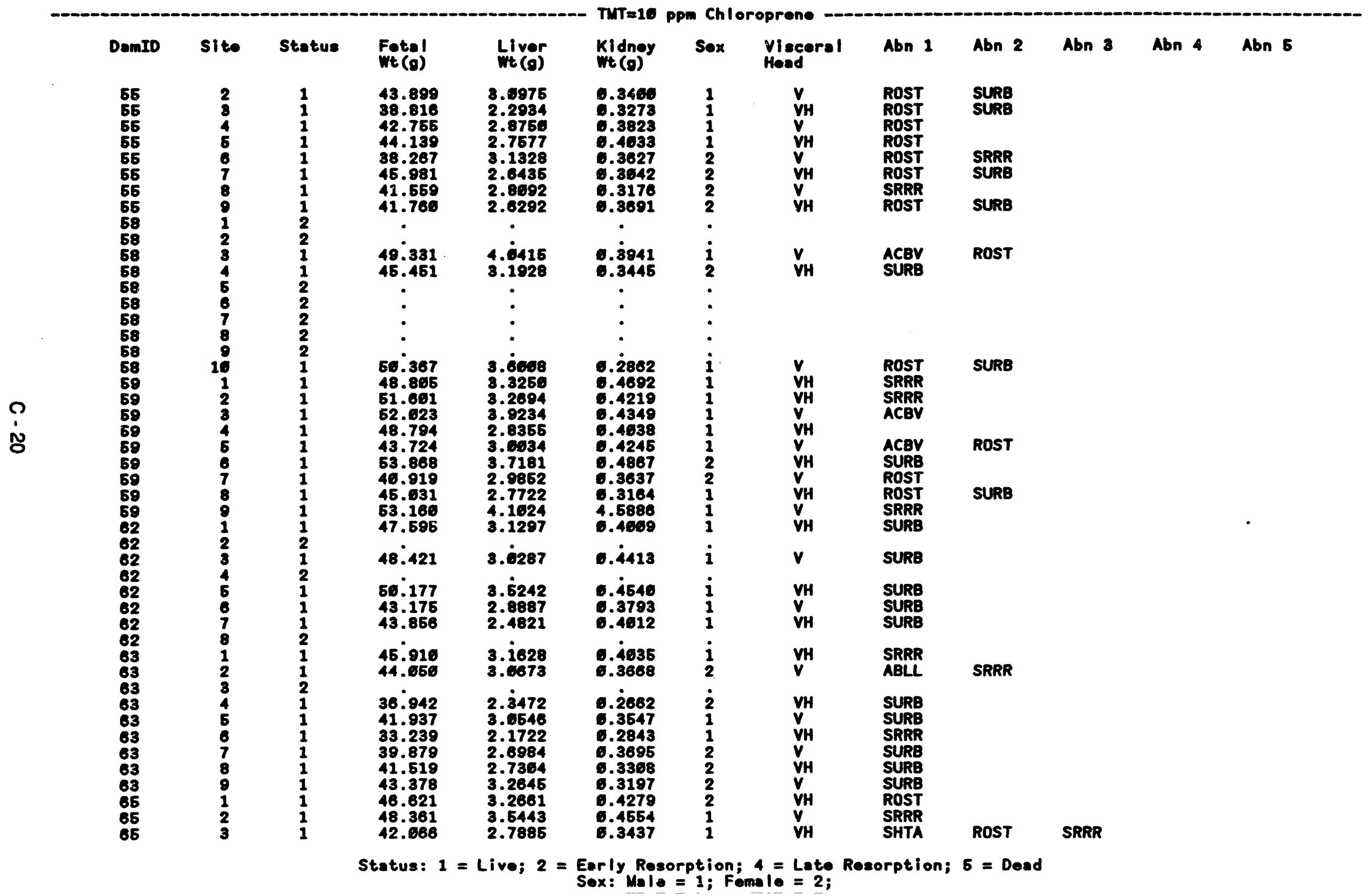


Inhalation Developmentel Toxicity Study of Chloroprone in Rabblts: Raw Rabbit Fotel Date

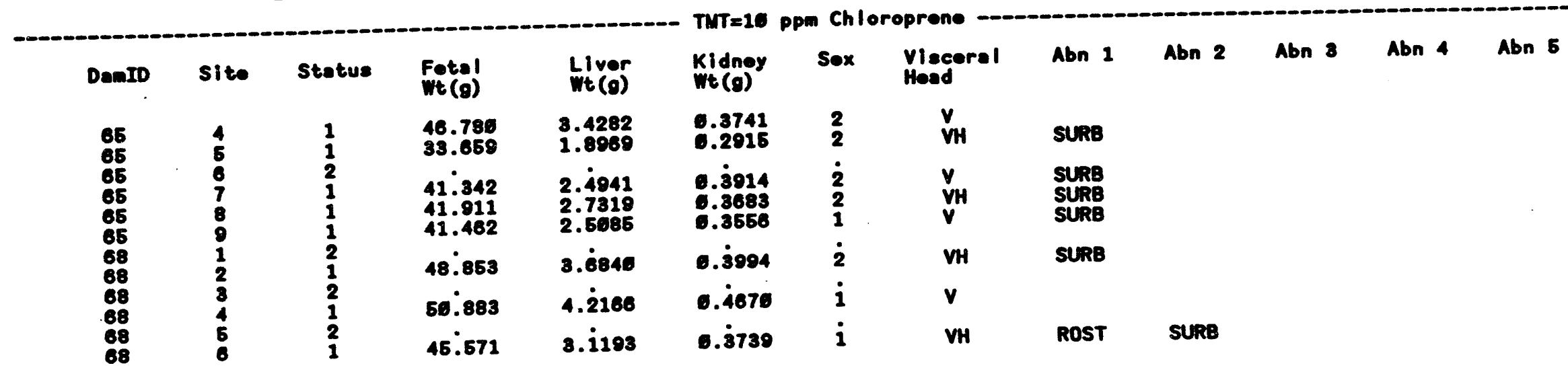


SAS

Inhalation Developmental Toxicity Study of Chloroprone in Rabbits: Raw Rabbit Fotal Data

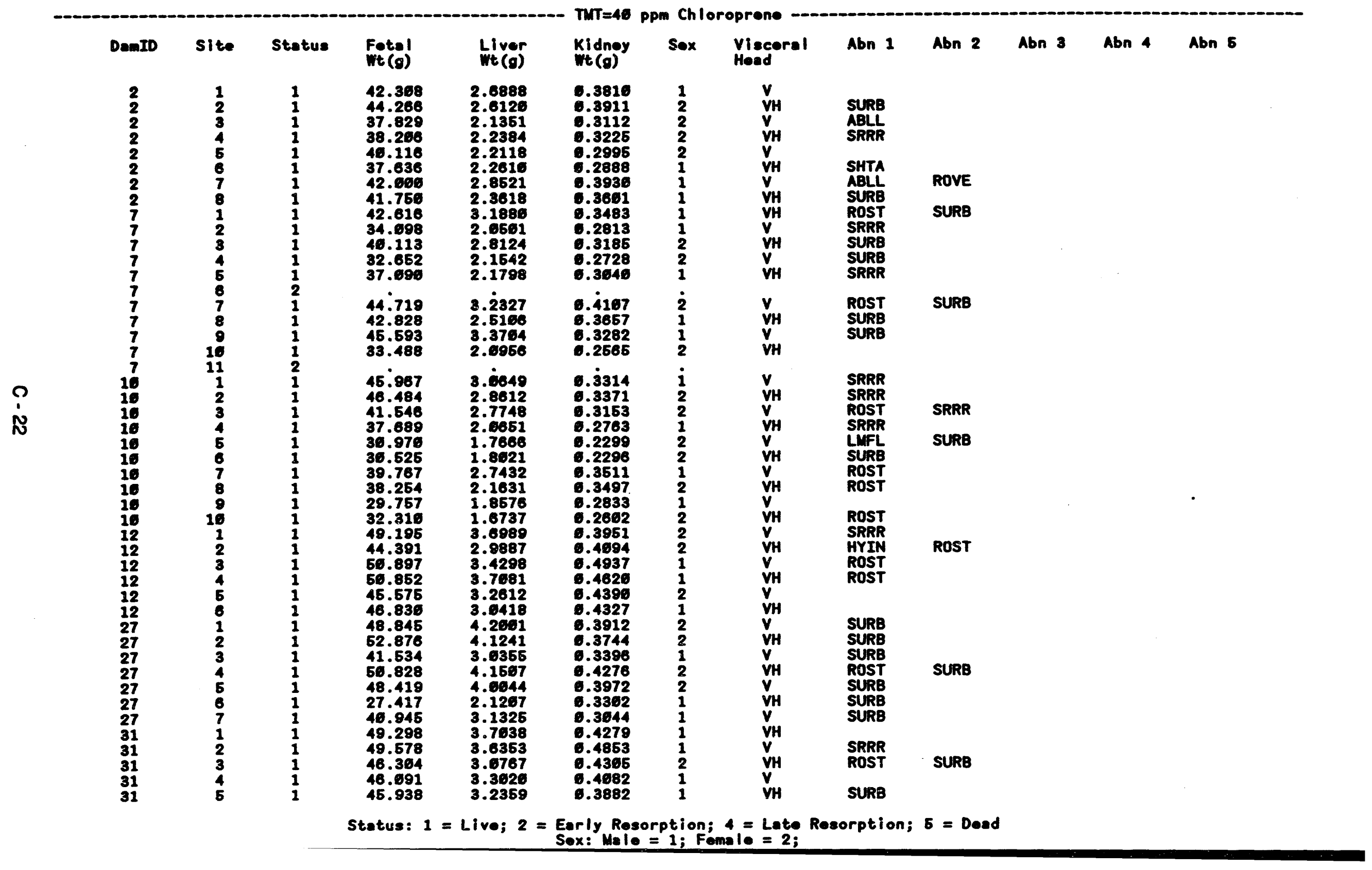


Inhalation Dovelopmental Toxicity Study of Chloropreno in Rabbits: Raw Rabbit Fotal Data

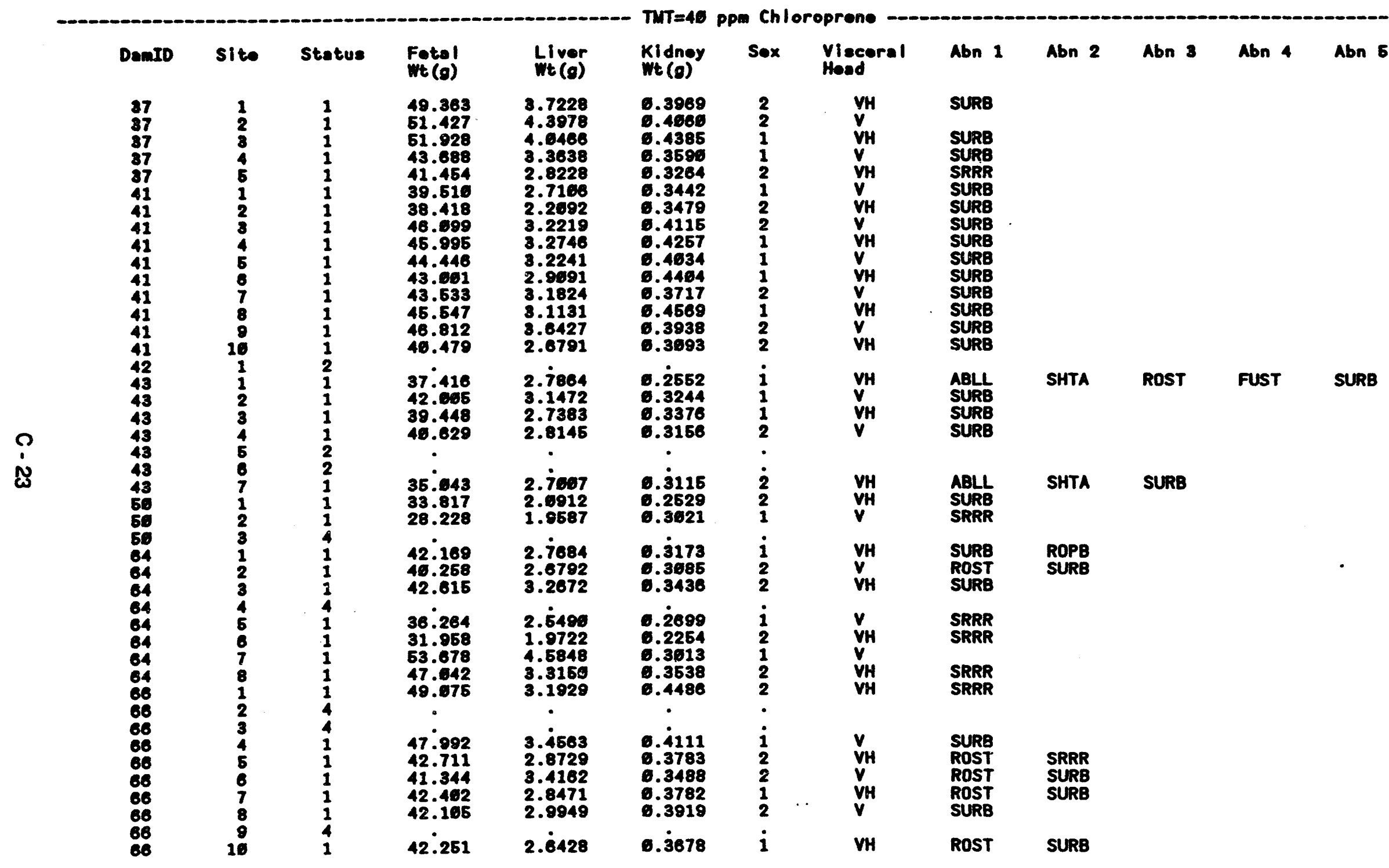

Status: 1 = Live; 2 = Early Resorption; 4 = Late Resorption; 5 = Dead Sox: Male = 1; Fomale = 2; 
Inhaletion Developmental Toxicity Study of Chloroprene in Rabbits: Raw Rabbit Fotal Data

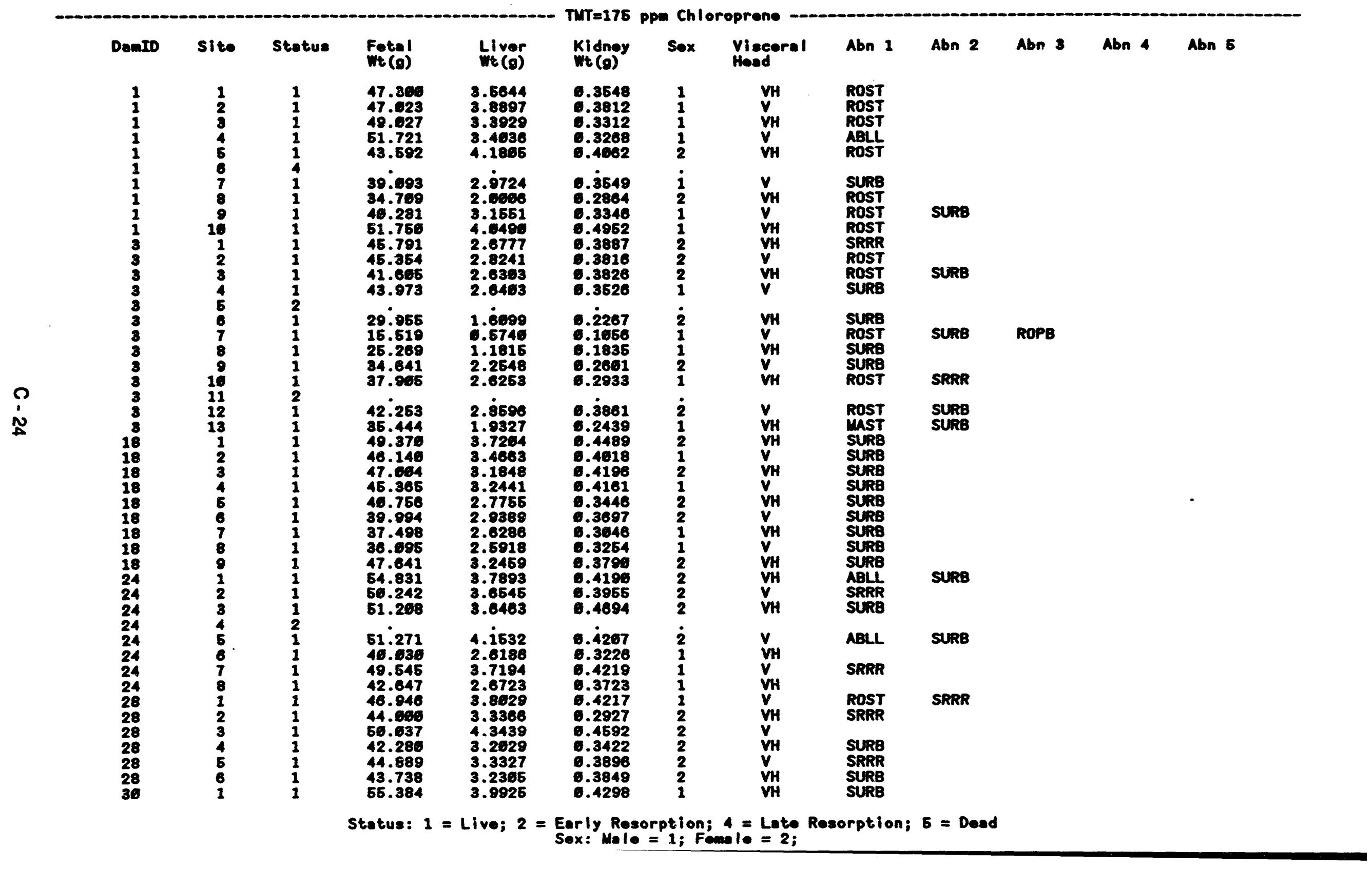


Inhalation Dovelopmental Toxicity Study of Chloroprone in Rabbits: Row Rabbit Fatal Date

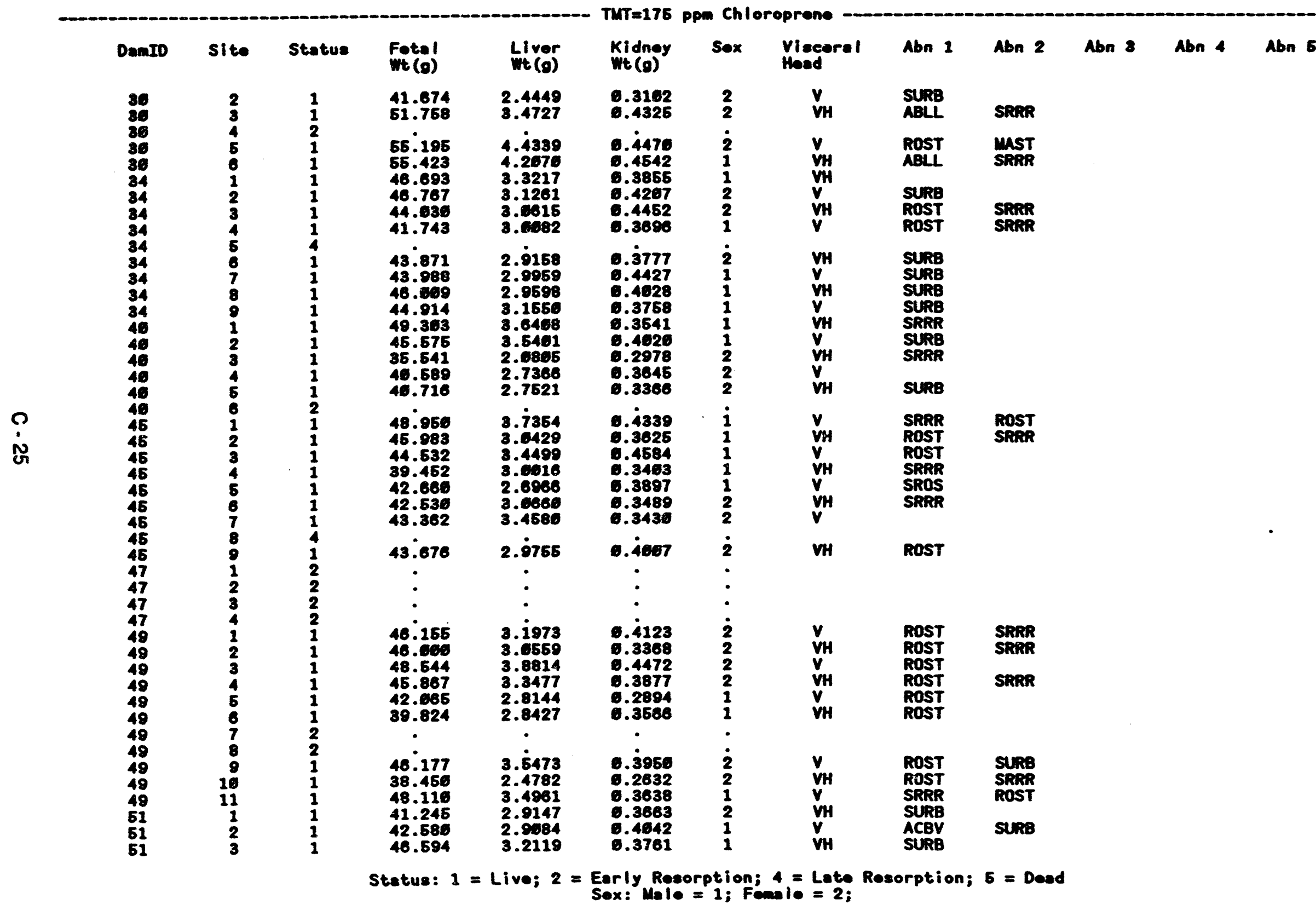


Inhalation Dovelopmental Toxicity Study of Chloropreno in Rabbits: Raw Rabbit Fotel Date

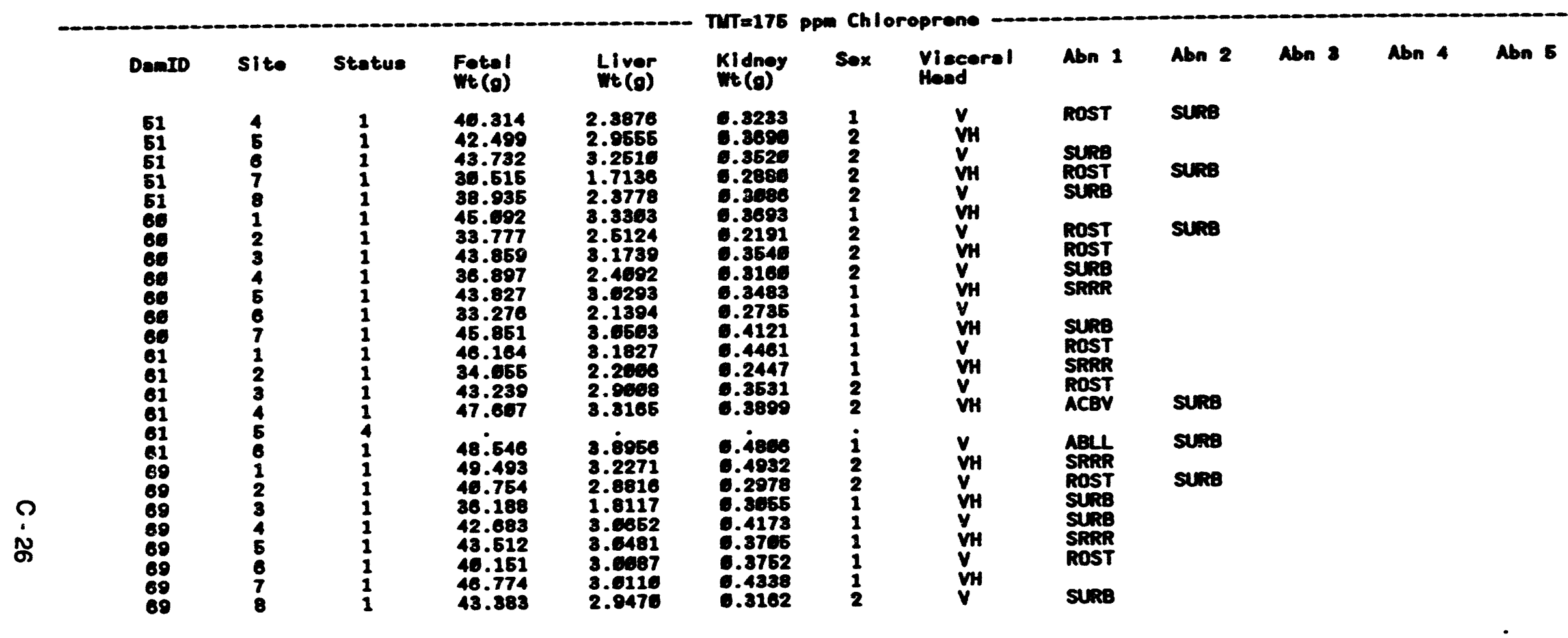


APPENDIX D

PROTOCOL AND CAGE MAPS

Study Protocol

Cage Maps

D. 1 
Study Protocol

D. 3 


\section{STUDY PROTOCOL}

Inhalation Developmental Toxicity Study of

Chloroprene in Rabbits

Submitted to:

Dr. Bernard Schwetz

National Toxicology Program

National Institute Environmental Health Sciences

Research Triangle Park, NC

Submitted by:

Dr. Terryl J. Mast

Battelle - Pacific Northwest Laboratory

Richland, WA 99352

March 12, 1990 


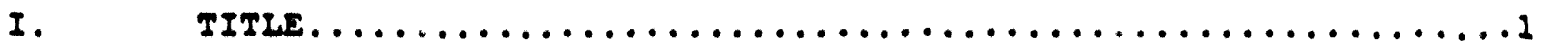

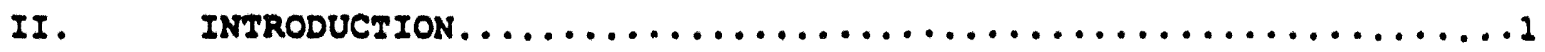

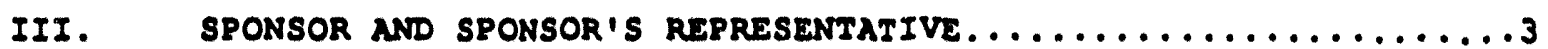

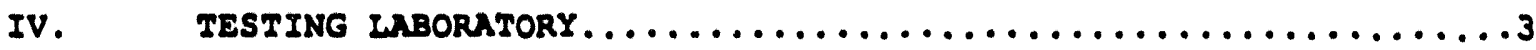

v. PROROSED SCHEDULE OF EVENTS......................

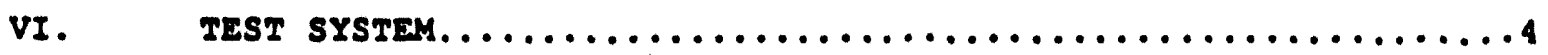

vII. EXPERIMENTAL DESIGN AND DOSE LEVELS................

VIII. TEST SYSTEM HOUSING, HANDLING AND ENVIRONMENTAL CONDITIONS....

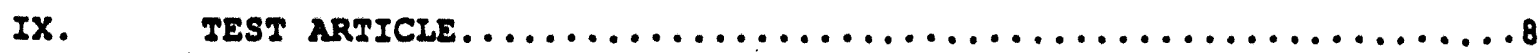

X. DESCRIPTION OF INHALATION EXPOSURE SYSTEM.............10

XI. EXPERIMENTAI OBSERVATIONS.......................

XII. PROPOSED STATISTICAI METHODS....................

XIII. RECORDS RETENTION $(\varnothing B-9 A-3 E \emptyset 6) \ldots \ldots \ldots \ldots \ldots \ldots \ldots \ldots \ldots$

XIV. OTHER SPECIFICATIONS .........................

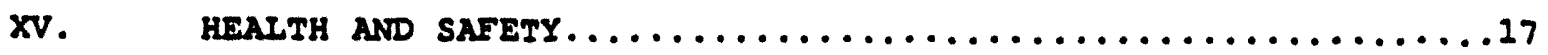

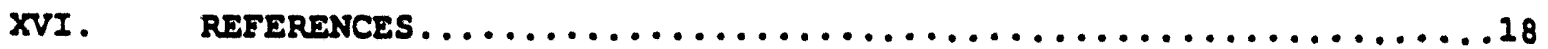

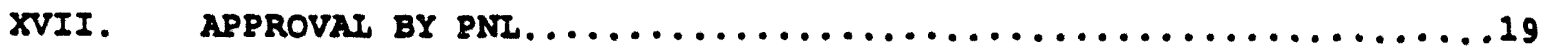

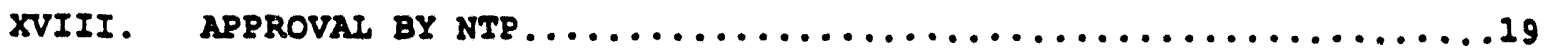

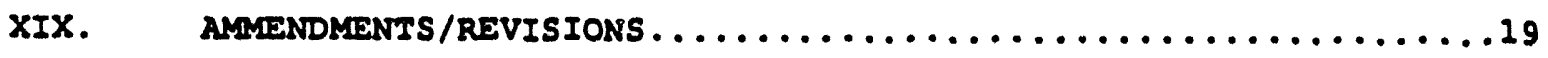




\title{
INEALATION DEVELOPMENTAI TOXICOLOGY STUDY PROTOCOL CELOROPRENE
}

\author{
I. 2xore \\ INHAIATION DEVELOPMENTAL TOXICOLOGY STUDY OE CHLOROPRENE IN \\ RABBITS.
}

I.

\section{INersontertos}

Chloroprene is a clear, colorless liquid with a pungent ethereal odor and is primarily used as a chemical intermediate in the manufacture of neoprene rubber (Table 1 ).

This study will determine the potential for inhaled chloroprene to cause developmental toxicity in the New zealand white rabbit.

Table 1. Summary of Physical and Chemical Properties of Chloroprenea

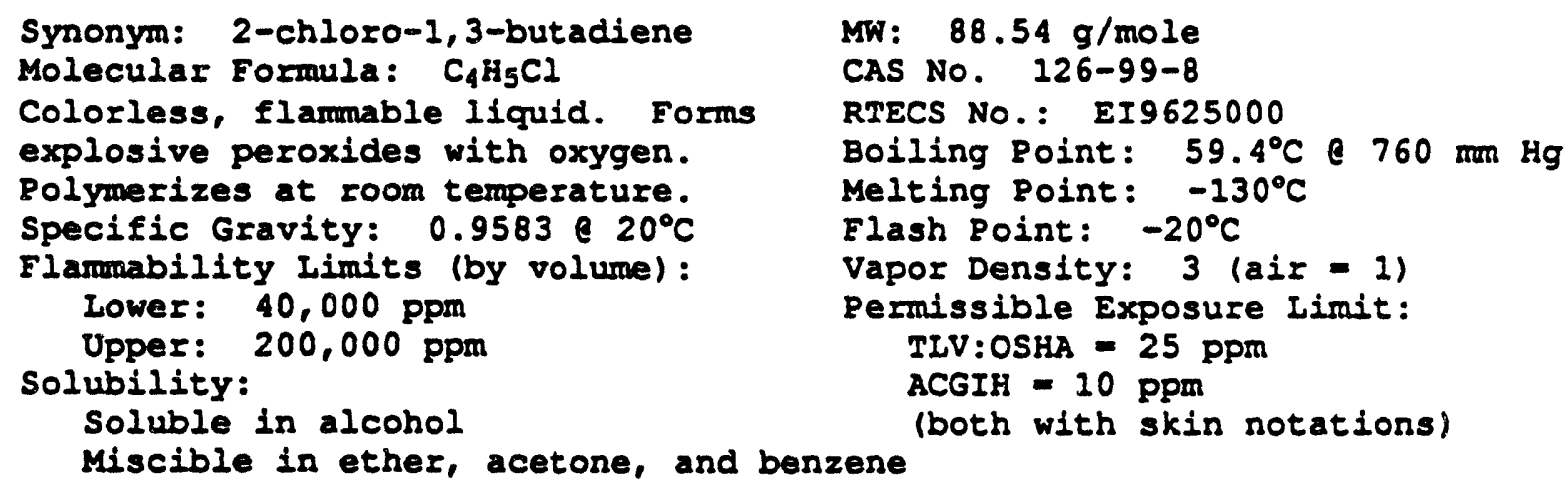

Condensed from Little (1987) and references therein.

Several studies have been conducted in order to assess the potential for B-chloroprene to cause embryonic or cevelopmental toxicity in laboratory animals. Salnikova (1968) investigated the embryotoxic effects of inhalation exposure to chloroprene and ammonia combined; however, since a group exposed to chloroprene alone was not included it is hard to interpret their results. In a later study, Salnikova and Fomenko (1973) exposed pregnant rats to $0.016,0.36,0.17,0.83$, and 1.11 ppm chloroprene vapor. The length and duration of the exposures was not specified. An increased incidence of embryonic deaths was reported in the 0.83 and 1.11 ppm groups, and fetuses in the 1.11 ppm group had a significantly lower birth weight than those in the control group. Fetuses in the $1.11 \mathrm{ppm}$ group were also reported to have vascular permeability disturbances aj well as decreases in the lengths of the tibia and the fibula. The methodology used for the generation of the chloroprene test atmospheres and the techniques used for monitoring the purity of the atmospheres (if any) were not specified.

Culik et al. (1978) exposed CD-1 (Sprague-Dawley) rats to 0, 1, 10, or 25 ppra chloroprene, $4 \mathrm{~h} /$ day, on 3 through 20 days of gestation (dg) to assess developmental toxicity. Another group was exposed to the same 
concentration on 1 through $12 \mathrm{dg}$ in order to assess the embryotoxic potential of chloroprene. Care was taken during this study to ensure that the animals were exposed to chloroprene which was freshly distilled and relatively free of the toxic dimer. Dams exposed on $3-20$ dg were killed on $21 \mathrm{dg}$ and the fetuses examined for signs of developmental toxicity. Dams exposed on 1-12 dg were killed on $17 \mathrm{dg}$ and the uterine contents evaluated for signs of embryotoxicity.

No clinical signs of toxicity were observed in the dams exposed to chloroprene, and there was no affect on weight gain with respect to the control animals. There was no effect on litter size, on the number of implantations, or the number of resorptions in exposed pregnant rats in either the teratology or the embryotoxicity study. Although fetal body weight was significantly greater for the controls than for the 25-ppm group, and fetal crown-rump length was significantly greater than controls for both the 10- and the 25-ppm groups, these effects were not thought to be treatment-related.

The Joint Industry Comittee on Chloroprene contracted an inhalation developmental toxicity study on B-chloroprene in rats (Koeter and Appelman 1980). In this study pregnant rats were exposed to $0,10,25,75$, or 175 ppm chloroprene 6 hours/day, on 4-16 dg. They reported a diminished maternal weight gain during the exposure period for the 25, 75 , and 175 ppm group, and during the post-exposure period for the 75 and 175 ppm groups. Post-implantation loss was significantly greater than controls in the 10 , 75. and 175 ppm groups, but not in the $25 \mathrm{ppm}$ group. There were fewer live fetuses in the two highest exposure groups than in the controls: however, since there was no apparent dose-response relationship the authors did not attribute this effect as related to chloroprene exposure.

There was a significant reduction in fetal weight in the 75 and 175 ppm groups, but no abnormalities attributable to treatment were found in the fetuses from any of the exposed groups. There was a statistically significant increase in the incidence of unossified forelimb phalanges and metatarsals in the 25, 75 and 175 ppm groups, and the incidence of unossified cervical vertebral bodies was increased in the 10,75, and 175 ppm groups. The authors assert there is no clear dose-response relationship and apparently do not view these effects as being toxicologically significant since they are not reported in the study sumarya

In contrast to the Russian studies (Salnikova and Fomenko 1973), chloroprene did not appear to cause developmental or reproductive toxicity at exposure concentrations as high as 25 ppm under the conditions of culik et al. (1978). However, since a maternally toxic dose was not achieved, and 25 ppm chloroprene is the OSHA TIV, a margin of safety is not established by this study. Although the data from the Russian studies indicate that chloroprene may be considerably more toxic than implied by Culik et al. (1978), this disparity may be due to the formation of dimers and other toxic reaction products in the exposure atmospheres used by the Russians. Test material generation and monitoring methods were not described by the Russian authors although it is well known that chloroprene rapidly degrades in air to form more toxic products (von oettingen et al. 1936, and others). In the study performed by Koeter and Appelman (1980), higher exposure concentrations were used and care was taken to ensure that the chloroprene used for exposures was freshly prepared and properly stored. Test atmospheres were not monitored for dimer concentrations in this study. Although the authors assert that the results of this study do 
not indicate the presence of embryo or developmental toxicity, alternative interpretations of this data are possible.

The study in rabbits delineated in this protocol is being conducted in an attempt to clarify the ambiguities regarding the potential for $\beta$-chloroprene to cause embryonic and developmental toxicity. To date only one laboratory specie, the rat, has been well-tested for developmental toxicity. In order to facilitate an interspecies comparison of the data, exposure concentrations similar to those of Koeter and Appelman $(1980)$ will be used in this study. The composition of the test material and the exposure atmospheres will be closely monitored for formation of the toxic dimer and permissible peroxide levels in the test material will be limited to $1 \mathrm{meq} / \mathrm{kg}$.

\section{SPONSOR AND SPONSORIS REPRESENTATIES}

A. Sponsor:

National Institute of Environmental Health Sciences

National Toxicology Program (NTP)

P.O. Box 12233

Research Iriangle Park, N.C. 27709

B. Seonser's Representatives:

Dr. Bernard Schwetz

IV.

$$
\text { TESTIKG raBogATORY }
$$

A. Eacility

Battelle - Pacific Northwest Laboratory (PNI) P.O.Box 999; Richland, Washington 99352

B. Reinciple Inrestigater:

Dr. Terryl J. Mast

v.

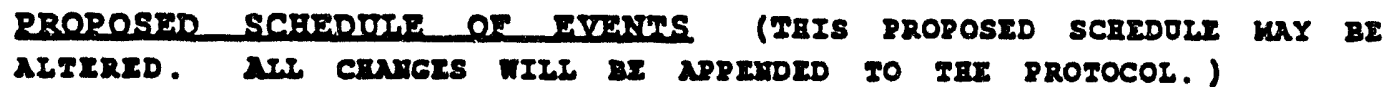
A. Order animals:
B. Animals arrive week of:
$11 / 22 / 89$
C. Prestart audit for GLP compliance:
$1 / 29 / 90$
D. Initiate breeding procedures ${ }^{2}$ :
$3 / 19 / 90$
E. Initiate exposure; dg $6^{\mathrm{a}}$ :
$3 / 20 / 90$
F. Complete exposure:
$3 / 26 / 90$
G. Initiate necropsy; dg $29^{\mathrm{a}}$ :
$4 / 19 / 90$
H. Complete fetal specimen evaluation:
$4 / 18 / 90$
I. Submit draft report week of:
$6 / 25 / 90$
$8 / 3 / 90$

Babbits

J. Submit final report: 45 days after receipt of reviewers coments

These dates are for the first gestational group (gestational group A), there will be three gestational groups (designated A, $B$, and $C)$. 
vI. gesm sysure

A. Species: Rabbits

B. Strain: New zealand white

C. Number of Animals and Supplier:

Rabbits from $R$ \& Rabbitry, Stanwood, WA

Rabbits: 7 males

70 females

D. Age of Antmals Upon Acrival:

$$
\begin{array}{ll}
\text { Males: } & 6-7 \text { months } \\
\text { Females: } & 5-6 \text { months }
\end{array}
$$

VII. EXPGRTMENTST DESTGN AND DOSE TEVETS

A. Developmental Toxicolocy study: Four groups of mated female rabbits will be exposed to the test chemical for 23 consecutive days $(6-28 \mathrm{dg})$ and killed on $29 \mathrm{dg}$ for maternal and fetal evaluations.

B. Exposure Recimen: Exposure concentrations of chloroprene will be $0,10,40$, and 175 ppm, 6 hours per day, 7 days per week.

C. Experimental Animals: Approximately one-third of the females will be artificially inseminated each day during a 3-day period. Details of the artificial insemination procedure can be found in Attachment III which contains the SOR (DB-DT-3BøE) for that procedure. On the day of insemination, females will be randomly assigned to four dose groups for a total of $16 /$ group over 3 days (6B-DT-3BDB). Females will be inseminated using freshly collected semen pooled from at least three breeder males. The day of insemination will be denoted as day of gestation 0 (dg 0 ).

E. Number of Aaimals in the Developmental roxicity study:

\begin{tabular}{llllllll} 
& Species & $\begin{array}{c}\text { Mated } \\
\text { Females }\end{array}$ & $\begin{array}{c}\text { Treatment } \\
\text { Groups }\end{array}$ & Total \\
\hline Teratology & 1 & $\mathrm{x}$ & 16 & $\mathrm{x}$ & 4 &
\end{tabular}

E. Selection of Atmospheric concentrations: Exposure concentrations were selected on the basis of previous developmental toxicity studies in rats (Koeter and Appelman 1980), and on the lack of apparent maternal toxicity during a test exposure in pregnant New zealand white rabbits. 


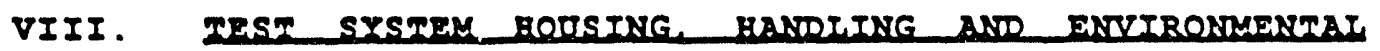
conprugens

A. Quarantine (BB-AR-3BEA)

1. The uncrating will be conducted at the door of the animal facility (ISL-II). While being removed from the crates the animals will be examined by the staff veterinarian for evidence of shipping stress. Rabbits will be transported to the quarantine room in exposure chambers.

2. The animals will be quarantined and acclimatized in the ISIII building for 6-7 weeks prior to the start of the study. A minimum of 4 weeks is required to assure that there are no pseudo-pregnancies.

3. During the quarantine/acclimatization period the animals will be housed individually in wire cages on flush racks. The cage space will meet the requirements stated in the $1985 \mathrm{NIH}$ "Guide for Care and Use of Laboratory Animals".

4. Room temperature during the quarantine period will be maintained at $69 \pm 4^{\circ} \mathrm{F}$ and relative humidity at $55 \pm 15 \%$. These measurements will be recorded at least twice daily.

5. Twelve hours light and twelve hours dark will be maintained with light starting at 0600 .

6. The clinical veterinarian will make a visual inspection of the animals to be used in the study just prior to their release for the study (documented on the quarantine/acclimatization record).

7. Females not selected for the study will be discarded. The disposition of these females will be recorded on the Animal Disposition Record and retained in the study files.

B. Exposure Chamber Housing and Environmental Conditions

The exposure chamber doors will be closed throughout the exposure and non-exposure periods, except during animal care procedures.

There will be 8 rabbits per exposure chamber ( 2 rabbits per level) in 8 chambers. Techsorbo cageboard (Shepard Specialty Papers, Kalamazoo, MI) will be used during non-exposure periods to absorb urine.

Exposure chamber temperatures will be maintained at $69 \pm 40^{\circ}$ and relative humidities at $55 \pm 158$.

Airflow will be maintained at $15 \pm 3$ CFM and the chamber pressure at

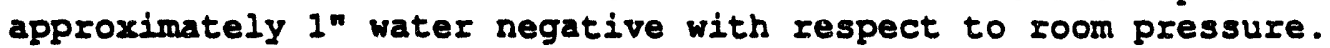

C. Feed (OB-AR-3Fø5)

1. Purina Certified Rabbit Chow $\$ 5322$ (pellets) from A \& Brazell Distributing, Kennewick, WA, will be used during the

\section{BATTELLE - PACIFIC NORTHWEST LABORATORY}

$$
\text { D. } 11
$$


quarantine/acclimatization periods and throughout the duration of the study.

2. Feed will be provided, $-170 \mathrm{~g}$ per day, in J-type feeders during the study, except during exposure hours.

\section{Water}

1. Fresh softened water (ion exchange softener, Illinois Water Treatment Company, Model 2R-2240, Rockford, II) will be supplied ad libitum at all times. The hardness of the water will be checked approximately once every week. Records will be retained in the ISI-II building engineer's office.

2. The automatic watering system used during quarantine will be from Systems Engineering, Napa, CA. The automatic watering system used while the rabbits are housed in the exposure chambers will be from Edstrom Industries, Waterford, WI.

3. A representative sample of animal drinking water from one of the NTP study rooms will be analyzed for contaminants at least once each calendar year (DB-AR-3B1S).

E. Identification:

1. All animals, male and female, will be individually identified with metal eartags by the supplier prior to receipt at PNI. Prior to breeding animals will be assigned a laboratory study number. A list correlating the eartag number to the study ID number will be kept in the animal and exposure rooms at all times, and a copy will be kept with study records at all times.

2. Cage maps (øB-DT-3Bø3) showing placement of individual animals in each cage unit of the exposure chamber will be prepared and updated as needed. Each exposure chamber will be identified by chamber number and exposure level. The proposed arrangement of the exposure chambers in the room is. included in Figure 1.

F. Bandemization: Females will be inseminated and assigned to exposure groups by means of a computer-assisted randomization program (ØB-DT-3BØB) which is based on a single blocking factor, 0 dg body weight.

G. Chamber, Cage, Feeder and Automatic Water Line Sanitation Rrocedures

\section{Daily Sanitation Procedures (GB-AR-3FøA)}

The excreta pans will be changed every day. The soiled pans will be hosed and washed in the exposure room.

Automatic watering systems will be checked daily during animal care procedures to ensure they are functioning properly. 


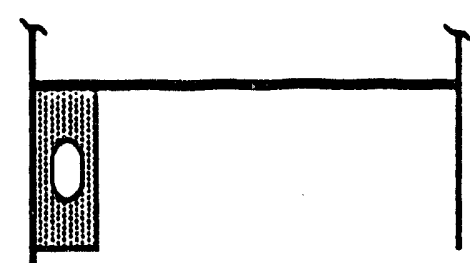

ROOM 327

NOT USED

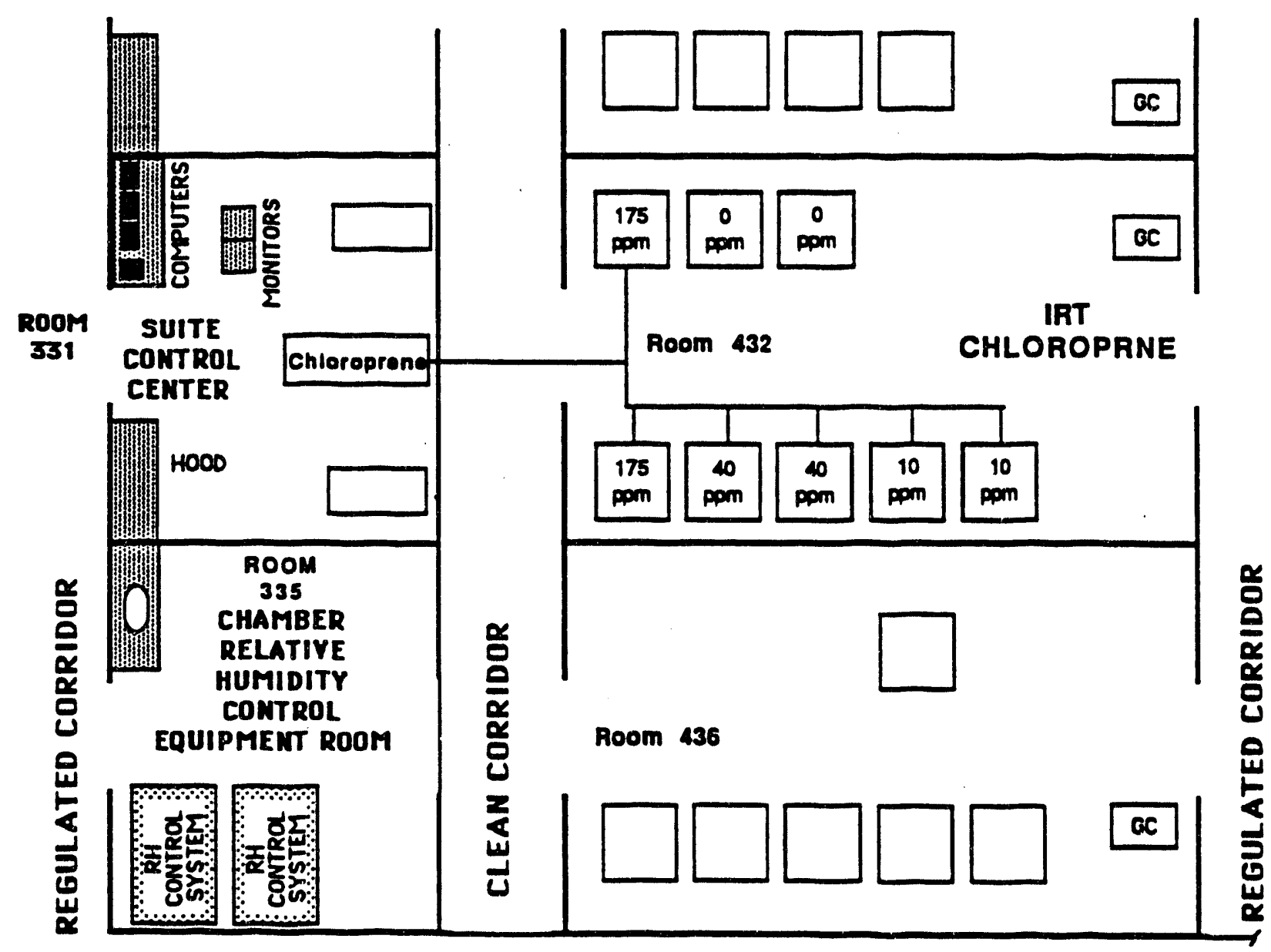


2. Weekly Sanitation Procedures (DB-AR-3BD3, DB-AR-3GDI)

Chamber and cage units in use will be changed and washed every 7 days.

Exposure chambers, with animal housing components (cage units, feeders, automatic watering Iines, and excreta pans), will be moved as a unit, with the chamber doors closed through the regulated (dirty) corridor, to the wash area.

The automatic water lines in the cage units and chambers will be flushed with $180-190^{\circ} \mathrm{F}$ water for a minimum of 1 minute prior to being washed in the cage washer.

The entire chamber will be washed in the cage washer.

The clean chamber will be stored in a clean holding area. the individual cage waterers will be checked before the chamber is moved back through the clean corridor to the exposure room.

The individual cage waterers will be checked before the chamber is used.

$\mathbf{I X}$. TEST ARTICTE

A. Test Antiale

1. Chemical:

2. Formula:

3. CAS NO:

4. PNL Assigned Lot No.:

5. Manufacturer:

6. Vehicle control:

7. Storage conditions:

\section{Chloroprene}

$\mathrm{C}_{4} \mathrm{H}_{5} \mathrm{Cl}$

$126-99-8$

BNW53436-20 (Bottles 1-12)

Denka Chemical Company 8701 Park Place Blvd. Houston, TX 77017

Filtered air

The bulk test material will be stored in the chemical transfer and storage facility immediately adjacent to the Iife Sciences Laboratory-II building. The bulk test material will be maintained at approximately $-20^{\circ} \mathrm{C}$ in amber glass bottles. A nitrogen headspace will be maintained in each bottle.

B. BuIk Assay Procedure (BB-AC-3A14)

1. Research Triangle Institute (RTI) Assay Conclusions: Not available at this time. 
PNI will confirm the identity by using infrared spectroscopy and determine the purity by using gas chromatography.

2. PNL Assay Conclusions: Infrared spectroscopy confirmed the 1dentity of BNW 53436-20 (bottle 2 ) as chloroprene. Gas chromatography showed this lot to be 98.518 pure by area percent with the major dimer constituting 0.248 of the total chloroprene sample area. Chlorobutene and cis/trans-1-chlorobutadiene constituted impurities $0: 5$ approximately 0.6 and 0.18 , respnctively. The peroxide concentration is within the limit of $1 \mathrm{meq} / \mathrm{kg}$.

C. Analusis schedule

1. The identity and purity of the test material will be determined upon receipt. The purity will be performed within one month of the start of animal exposures and at $16 \pm 2$ week intervals thereafter.

2. The stability of the test material in the generator will be characterized prior to the start of the study.

3. The stability of the test material in the highest and the lowest concentration exposure chambers will be characterized prior to the start of the study. This characterization will be repeated with occupied chambers following the initiation of animal exposures.

4. Peroxide concentrations in the test material will be determined within six weeks prior to the use of any particular bottle of test material. Peroxide content must be less than $1 \mathrm{meg} / \mathrm{kg}$.

D. On-Iitoe Gas Chromatoaraphic (Hewlett-Packard) Chamber Monttors $(8 B-A C-3 B 1 N, 6 B-A C-3 C D V)$

Detector:

Column:

Packing:

Column Temperature:

Valve Oven Temperature:

Carrier:

Carrier Elow:

Sample Valve:

Sample Loop:
Flame Icnization

$1^{\prime} \times 1 / 8^{\prime}$ OD Nickel

$1 \%$ sp-1000 on $60 / 80$ Chromosorb

$120^{\circ} \mathrm{C}$

$140^{\circ} \mathrm{C}$

Nitrogen

$20-30 \mathrm{ml} / \mathrm{min}$

Hastelloy-C mounted in valve oven (Valco)

1-ml Nickel 
Stream select Valve:

Chromatographic Run Time:

On-Iine Standard:

Calibration Frequency:

Control Range:

Critical Iimits:

Monitoring Frequency: 12-port, Hastelloy-C mounted in valve oven (valco).

Approximately $1.5 \mathrm{~min}$ exclusive of report generation.

Chloroprene in nitrogen will be used to detect drift of the online monitor.

Da1ly check against on-1ine standard, additlonal checks against grab samples as Indicated by the on-1ine standard.

Target concentration \pm 108 .

Target concentration \pm 208 , alarmed (will) be automatically shut off if upper limit: is reached).

Each chamber and the room will be monitored approximately once every 30 minutes. The concentration of the major chloroprene dimer in the distribution line will be monitored daily.

\section{$x$. DESCRTPUTON OF TNRATATION EXPOSURE SYSTEM}

The Inhalation chambers will be located in room 432 of the ISI-II building. A detailed description of the inhalation exposure system to be usad in this study is included in Attachment 2 of this protocol. The location of the exposure room and chamber layout are shown in Eigure 1 .

A. Environmental Monitoring

1. Alr filtration: HEPA and charcoal filters will be used for intake air, and a HEPA filter will be used for exhaust air. New exhaust and intake filters will be installed prior to the start of the study.

2. Temperatures will be monitored by resistance temperature devices (RTDs) multiplexed to a digital thermometer with computer data acquisition at approximately 4-hour cycles for 24 hours per day (minimum of 3 measurements per day). The control range is $69 \pm 4^{\circ} \mathrm{F}$ with critical limits, <63 or $>75^{\circ} \mathrm{F}$. Any shamber temperature excursion beyond the critical limits will be recorded and alarmed automatically. 
3. Relative humidity will be monitored by a single dew point hygrometer in conjunction with a multiplexed sampling system with computer data acquisition at approximately 4-hour cycles, 24 hours per day (minimum of 3 measurements per day). The control range is $55 \pm 15$ with critical limits of <35t or >75t. Any relative humidity excursion beyond the critical linits will be recorded and alarmed automatically.

4. Chamber airflow will be monitored at an exhaust orifice using a multiplexed validyne pressure transducer system with computer data acquisition at approximately 4-hour cycles, 24 hours per day (minimum of 3 measurements per day). The control range is $15 \pm 3$ air changes/hour (15士3 CrM) with critical limits of <10 CFM or $>20 \mathrm{CFM}$. Any chamber flow excursion beyond critical limits will be recorded and alarmed automatically. A critically low flow will result in automatic termination of the exposure. Chloroprene concentrations in the chambers may be controlled in part by the adjustment of chamber airflow.

5. Chamber vacuum will be monitored using a multiplexed Validyne pressure transducer system with computer data acquisition at approximately 4-hour cycles, 24 hours per day (minimum of one measurement per day). The control range is -0.2 to -2.0 inches of water pressure with critical limits set at the same values. Any chamber vacuum excursion beyond the critical limits will be recorded and alarmed automatically. : If chamber vacuum exceeds the limits of -0.2 inch of water, the exposure will be automatically terminated.

6. Uniformity of the concentration of the test chemical in each of the chambers will be made at the beginning of the study with the animals in the chambers. A between port and within port variability of $S 5$ relative standard deviation (RSD) is considered acceptable.

7. Build up and decay times will be determined during the prestart testing period. Buildup and decay measurements will also be made at the beginning of this study with the animals in the chamber.

8. Samples will be taken from all chambers to check for the presence of aerosols before the start of exposures and at the beginning of the study when animals are present.

B. Effluent Treatment ( $1 B-A C-3 A 37)$ Chamber exhaust will be HEPA filtered to remove all aerosol. The building exhaust stack will be monitored once during the study to prove efficiency of the effluent treatment.

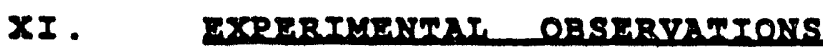

A. Clinical obserrations (øB-DT-3Bø3): Study females will be observed twice daily for mortality, morbidity, and signs of toxicity. The date and time of death or euthanasia of moribund animals will be recorded and the animals will be necropsied (פB-DT-3BøE) . 
B. Body Weights (BB-AR-3GøH): All females will be weighed within one week prior to mating. Mated females will be weighed on $0,6,15$, 22 and $29 \mathrm{dg}$.

C. Scheduled Necrepsy (8B-DT-3BgG): Animals will be welghed in the exposure room the morning of sacrifice. They will then be transported to room 1428 and killed by a lethal injection of sodium pentabarbital (Nembuta10).

At necropsy maternal animals will be examined for gross tissue abnormalities. In order to document the presence of lesions which may be due to chemical exposure, any organs or tisaues with lesions $w 111$ be preserved in 10 neutral buffered formalin (NBE). In this case, comparable organs or tissues from approximately 208 of the control animals will be preserved in 108 NBE. Iiver and $k i d n e y s w 111$ be weighed and tissues discarded unless abnormal.

The gravid uterl will be removed immediately upon death of the animals. The gravid uteri will be weighed, opened, and the number, position and status of implants wi1l be recorded. Any apparently non-gravid uteri will be weighed and stained with 10 \& ammonium sulfide to detect possible implantation sites. The placentas will be examined and preserved in 108 neutral buffered formalin (NBF) if abnormal. Uvarian corpora lutea counts will be obtained for both gravid anis non-gravid females.

D. Eetal Examination (8B-DT-3BgG):

1. The 1dentity of live fetuses (by study, dam number, and Implant number) will be retained throughout all examinations. Iive fetuses will be examined for gross defects and weighed (DS-SI-5ED2, DS-SI-5ED3). Following euthanasia, a complete visceral examination will be performed on 1008 of all ilve fetuses. Sex will be determined on all live fetuses by internal examination of gonads. Ifver and kidneys will be weighed and tissues discarded unless abnormal.

2. Approximately 50 of the fetal heads will be removed and examined by razor-blade sectioning of the fixed preparations (פB-DT-3BgI). All carcasses, with and without heads, will be stained with Alizaris red $S$ and aleian blue and examined for cartilage and centers of ossification (OB-DT-3BOH). Records of morphologic lesions observed during examinations will include photographs of unusual representative lesions. All fetal specimens will be double bagged and sent to NIP Archives . (DB-HI-3Gø9, DB-DT-3Eפ2) 
F. Indiaes of stencts: The following parameters will be expressed as mean \pm SD, when appropriate.

- Number of animals on study, number of dead animals, animals removed from the study and reason for removal

- Surmary of observed toxicity, including incldence of changes detected during clinical observations

- Number and percent pregnant at sacrifice

- Maternal body weights taken on 0, 6, 15, 22 and $29 \mathrm{dg}$ (sacrifice)

- Welght of gravid uterus

- Maternal liver and kidney weights

- Extragestational weight and weight gain

- Number of corpura lutea/dam

- Number of implantation sites/litter

- Number of litters with live fetuses

- Number and percent of live fetuses/litter

- Body weight of male and female fetuses/litter

- Fetal liver and kidney weights

- Sex ratio of fetuses/litter

- Number and percent of early and late resorptions/litter

- Number and percent of dead fetuses/11tter

- Number and percent of non-live/litter (early and late resorptions and dead fetuses/

- Ilsting of malformations and variations observed in fetuses/litters

- Number and percent fetuses/litter with malformations (variations)

- Number and percent of litters with malformations (variations)

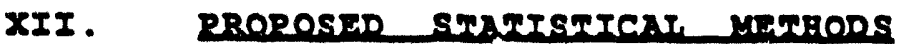

The methods proposed for the statistical analyses of representative maternal, reproductive and fetal indices of effects are: sumary statistics, N, mean, standard deviation, with accompanying ANovA based on multiple comparisons where appropriate. Arc sine transformations will be performed on proportional incidence data. Further statistical analyses will be performed as necessary. 
XIII. RECORDS RECENOTON $(68-9 A-3286)$

Records that accumulate during the study will be retained at PNL unt11 requested and shipped to NTP archives. Sore of these records may be presented as part of the protocol or reports. These will include but not be limited to the following records:

\section{A. Rersonnel Records}

1. List of PNL personnel participating in the study

2. Name, address, and function of any outside consultant (s)

3. Record of removal of any Individual from direct contact of the test system due to 11 lness

B. Health and Safety Recerds loriginal records and five copies of microfiche will be submitted to NTP within approximately two months after the end of each fiscal year). Chemical specific records will be submitted with the study. Eacility specific records will be submitted annually.

1. Medlcal records of all personnel participating in the study. These records will be retalned by Hanford Environmentbl Health Foundation (HEHF), P.O. BOX 100, Richland, WA 99352 for a minimum of 40 years. A letter verifying this arrangement will be retained for each test material file.

2. Records and results of any biological monitoring on laboratory personnel (if applicable)

3. NTP Health and Safety package for chloroprene

4. PNL biohazard protocols and PNL Health and Safety Plan

5. Chemical specific health and safety training records

6. Waste disposal records

7. Respiratory protection program with documentation of user training (specific fit testing if needed) for each type of respirator

B. Building ventilation system, hoods and exhausting system monitoring records (pertinent to NTP studies)

9. Health and safety section of the monthly progress reports

10. Accident/injury reports for personnel involved in this study

11. NTP site visit reports, attention items and related correspondence on health and safety

C. Rrotocols

1. Approved and dated PNI study protocol 

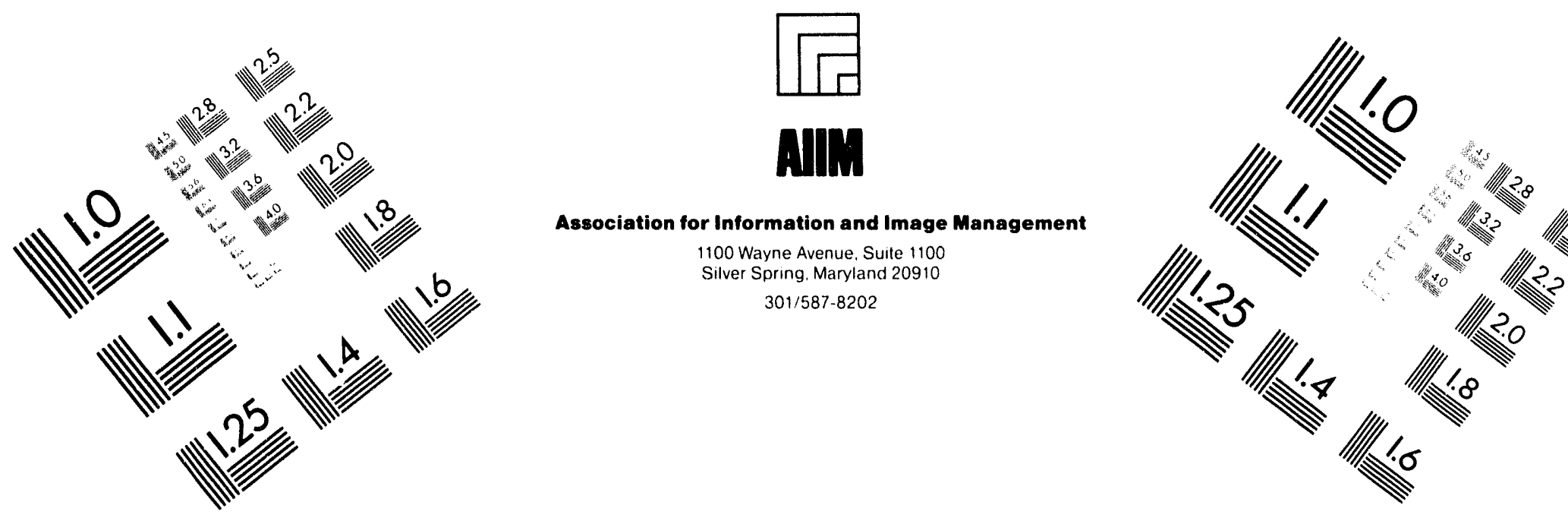

\section{Centimeter}

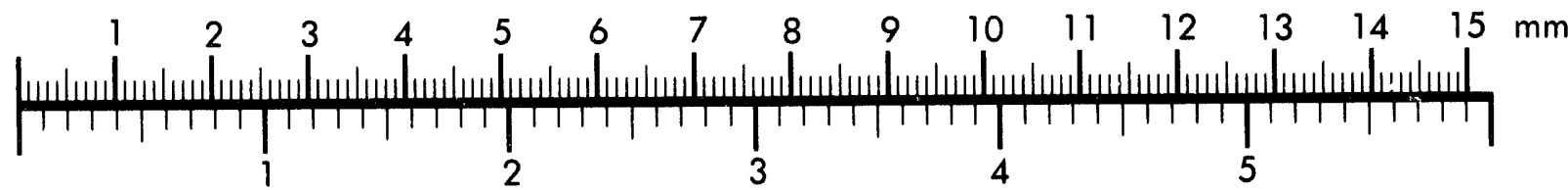

Inches
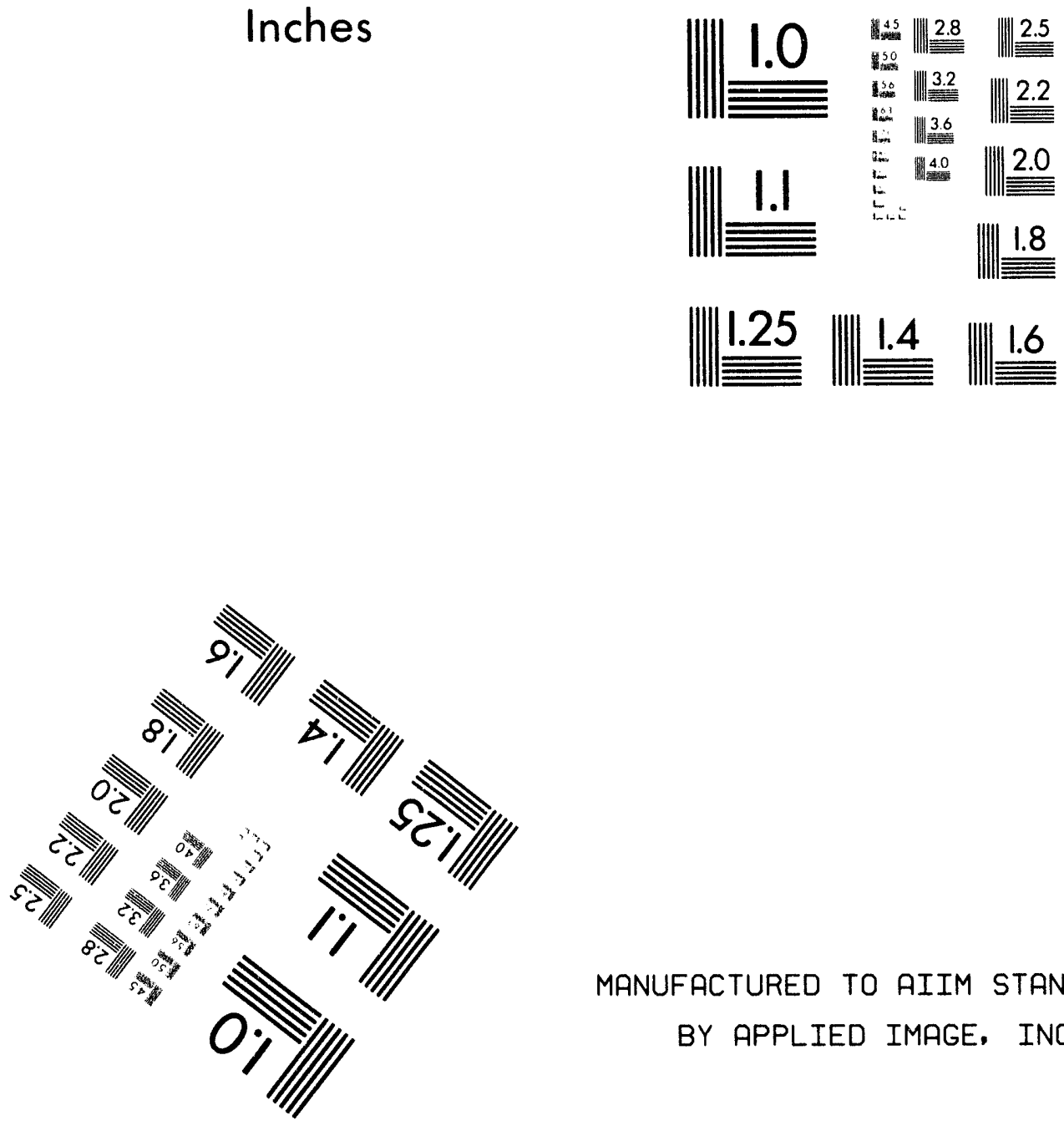

MANUFACTURED TO AIIM STANDARDS

BY APPLIED IMAGE, INC.

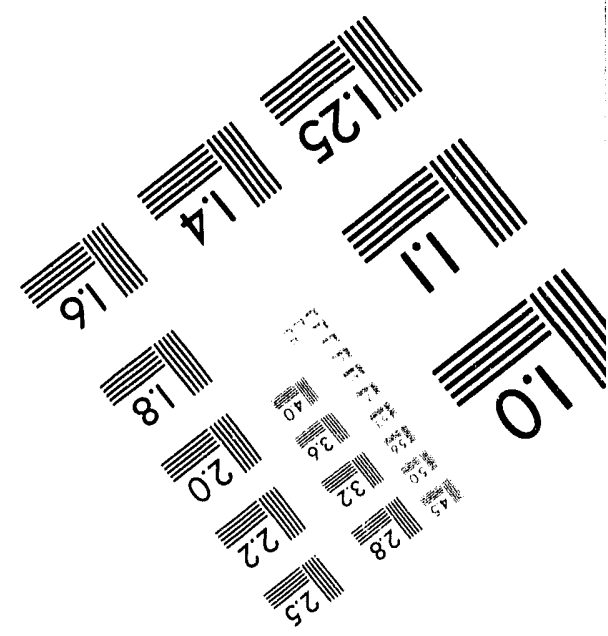



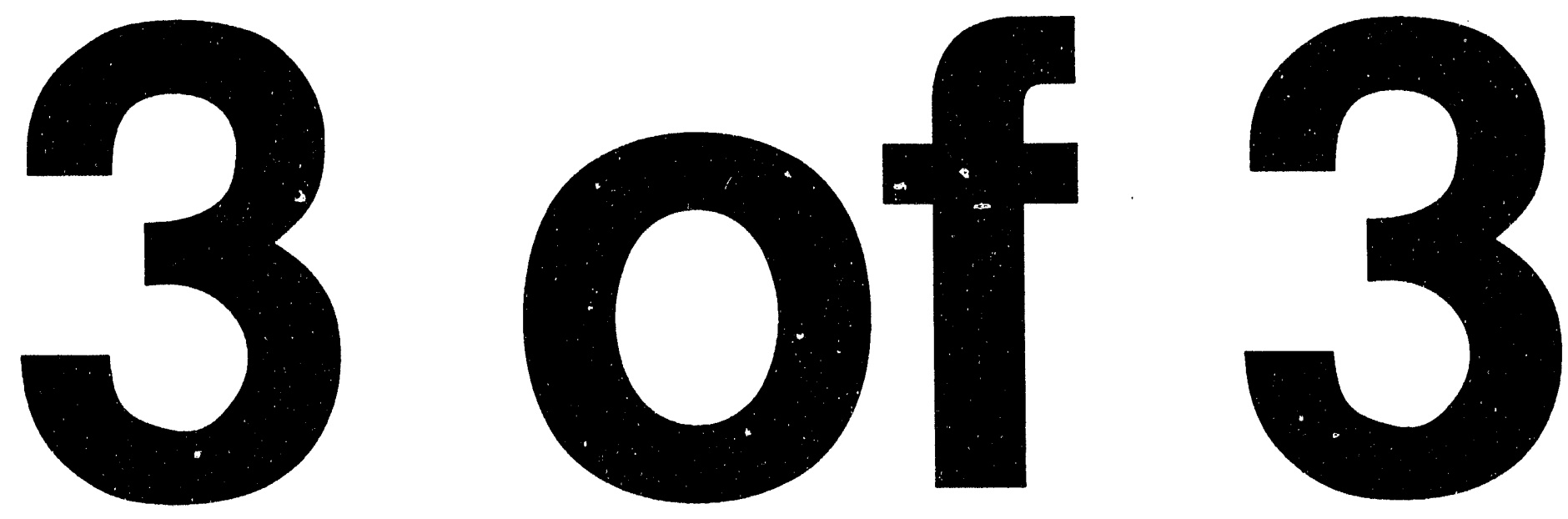
2. Protocol amendments including NTP technical contract modifications which affect the study

3. Documentation of any deviation from the protocol

4. Documentation of any unforeseen circumstances that may affect the integrity of the study and corrective actions taken.

D. Test Material Records

1. Test material identity records including manufacturer, quantity, lot number(s), purity grade and date(s), etc.

2. NTP analytical contractor characterization reports

3. NTP analytical contractor bulk stability reports

4. NTP analytical contractor shipment records (if available)

5. PNI test chemical receipt records

6. PNI storage records including storage conditions

7. PNI bulk analysis and degradation records

8. PNL method development records

9. Chemical exposure generation system description and procedures

10. Chamber concentration monitoring records

11. Uniformity (chamber balance) records

12. Generation and chamber degradation study records

13. PNI test material inventory and usage records

14. Records of shipment to NTP repository of any unused test material

15. Aerosol determination records

16. Chamber concentration buildup, decay, and overnight monitoring records

17. Exposure generation operating parameter records

E. Animad Records - Pretest

1. Animal receiving records including supplier, species, strain, birth week, sex, number of animals for each sex, receiving date and receiving conditions.

2. Quarantine records

3. Pretest health records and animal health notebook

4. Randomization records 
5. Arimal identification records

6. Written release records from clinical veterinarian

7. Disposal of excess animals

F. Animal Becords - On Test

1. Exposure room location and chamber layout records

2. Chamber cage map

3. Cage type, rack type during study

4. Cageboard type

5. Type of watering system

6. Body weight records

7. Daily observation records

8. Clinical signs of toxicity records

9. Study animal disposition records

10. Inventory list of archived specimens

G. Eeed

1. Feed tags with manufacturer, lot numbers and milling dates

2. Feed analysis records as provided by NTP analytical contract laboratory

H. Water

1. Annual water analysis

2. Weekly water hardness check (records will be maintained in building engineer and/or building manager's office).

I. Quarantine Room Exposure Room, and Inbalation Exposure Chamber Records

1. Exposure chamber description

2. Exposure suite control center description

3. Temperature raw data and daily and monthly summation report

4. Relative humidity raw data and daily and monthly sumation reports

5. Airflow raw data and daily and monthly summation reports

6. Chamber vacuum raw data and daily and monthly sumation reports 
7. Exposure system monitors calibration and maintenance records.

8. Description of the lighting system and light/dark regimen.

9. Sanitation procedures and pest control program.

J. LLL Relevant cerrespondence

K. Reports

1. Monthly Progress Report

2. Special study reports (if any)

3. Incident reports (if applicable)

4. Draft study report

5. Final study report

I. Internal computer Generated Foms and Tables

1. Developmental toxicology results and statistical analyses

2. Analytical chemistry results

3. Exposure suite control center computer printouts

4. XYBION printouts (if any)

XIV. OMEGR SPECTFTCAMTONS

A. This study will be performed in compliance with the FDA Good Laboratory Practice Regulations for nonclinical laboratory studies (21 CFR 58) except where deviations are required by the NTP April, 1987 General Statement of Work and subsequent modifications.

B. This protocol will be the controlling document in case of discrepancies between the protocol and SOPs. If this occurs the principal Investigator is to be notified immediately for clarification.

C. A list of all relevant standard operating procedures (SOPs) for this study are present in Attachment I.

XV. BRATIRA AND SAETHY

PNI's Health and Safety Plan (EB-HS-3S1C) has been approved by NTP. In addition, a respiratory program is instituted. This is supplemented by using supplied-air respirators (6B-HS-3S19) which will be worn by personnel at all times when they are in exposure rooms and by having available selfcontained breathing apparatus (6B-HS-3SøW) for use when entering a room under emergency conditions following a leak. 
XVI. REVERENCES

Culik R., D.P. Kelly, J.J. Clary. 1978. Inhalation studies to evaluate the teratogenic and embryotoxic potential of $\beta$-chloroprene (2-chlorobutadiene-1,3). Toxicol. Appl. Pharamcol. 44:81-88.

Koeter, H.B.W.M., I.M. Appelman. 1980. Inhalation embryotoxicity/ teratogenicity studies with B-chloroprene in rats. Report No. R6387. Centraal Instituut voor Voedingstonderzoik, Utrechtseweg 48, zeist.

Salnikova, I.S. 1968. Embryotropic effect of volatile substances from nairit latexes. Toksikol. Nov. Prom. Khim. Veshchestv. 11:106-111.

Salnikova, L.S., V.N. Fomenko. 1973. Effect of chloroprene on embryogenesis. GIg. Tr. Prof. Zabol. 8:23-26.

von Dettingen, W.F., W.C. Hueper, G. Deichmann, F.M. Wiley. 1936. 2-Chloro-butadiene (chloroprene): Its toxicity and pathology and the mechanism of its action. J. Ind. Hyg. Tox. 18:240-270. 
XVII. APPROVAT RY PNT

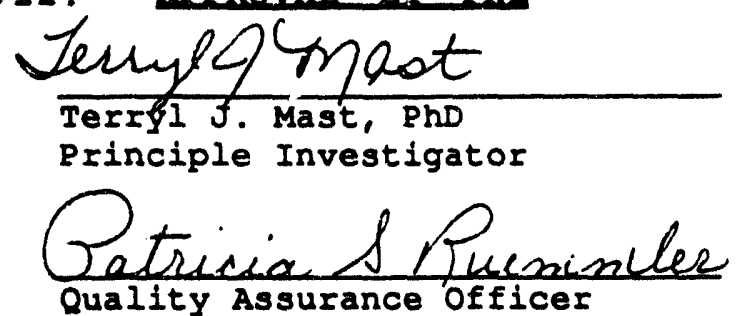

XVIII. APPROYAT BY NTS

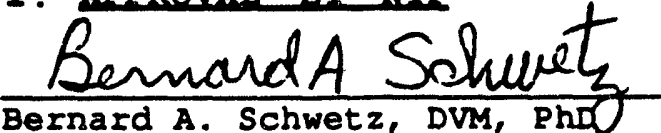
study officer

XIX . MAMENDMENES/REYTSTONS

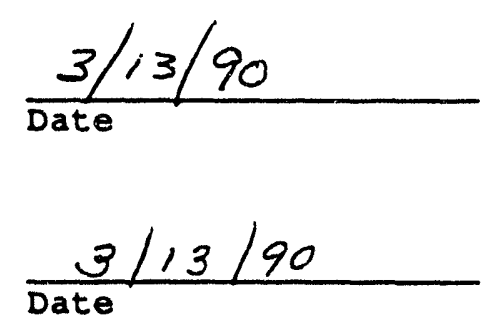

$\frac{20 \operatorname{Man} 90}{\text { Date }}$ 


\section{STANDARD ORERATING PROCEDURES \\ FOR DEVRLORKENTAI TOXICOLOGY STUDIES}

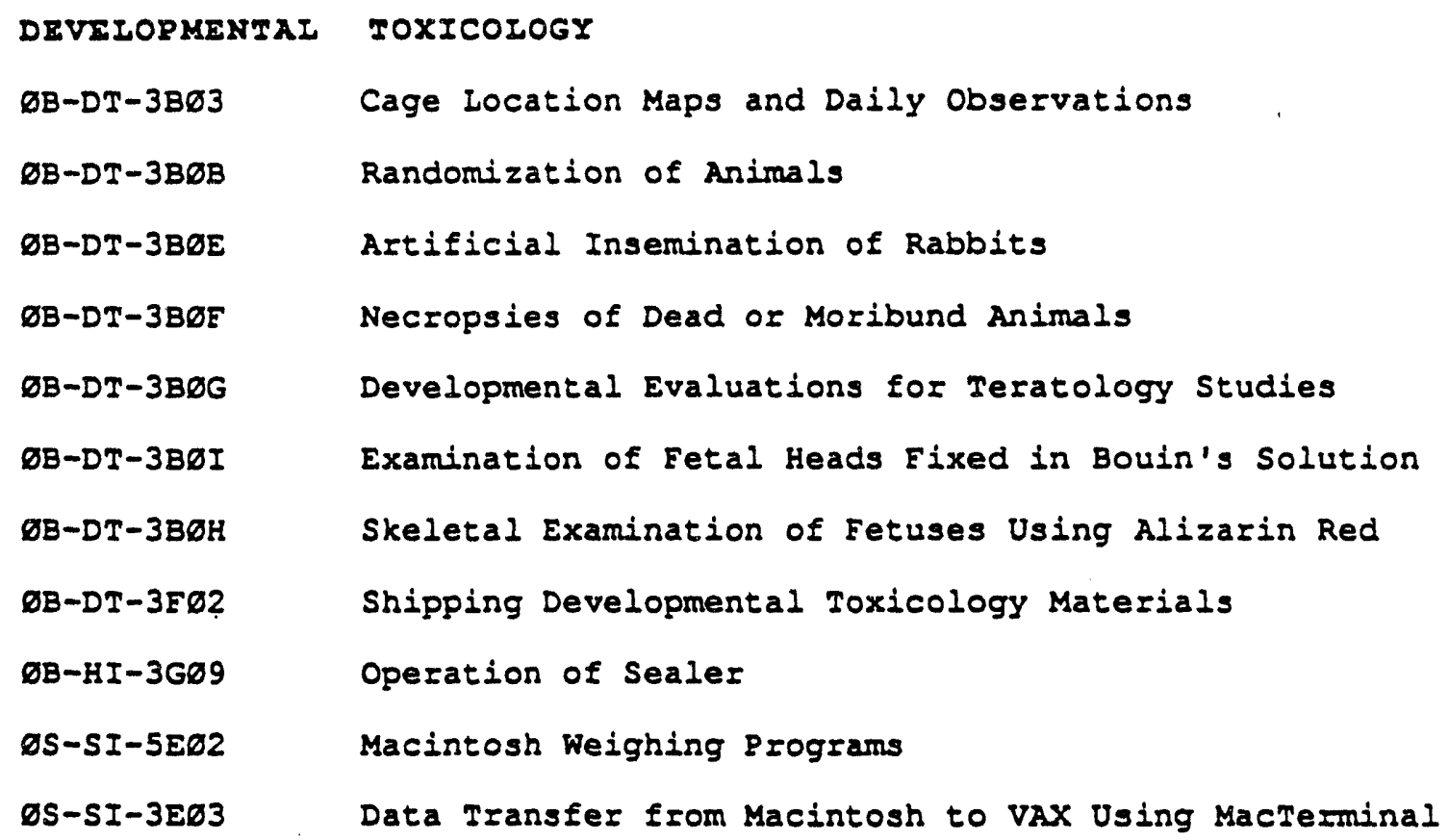




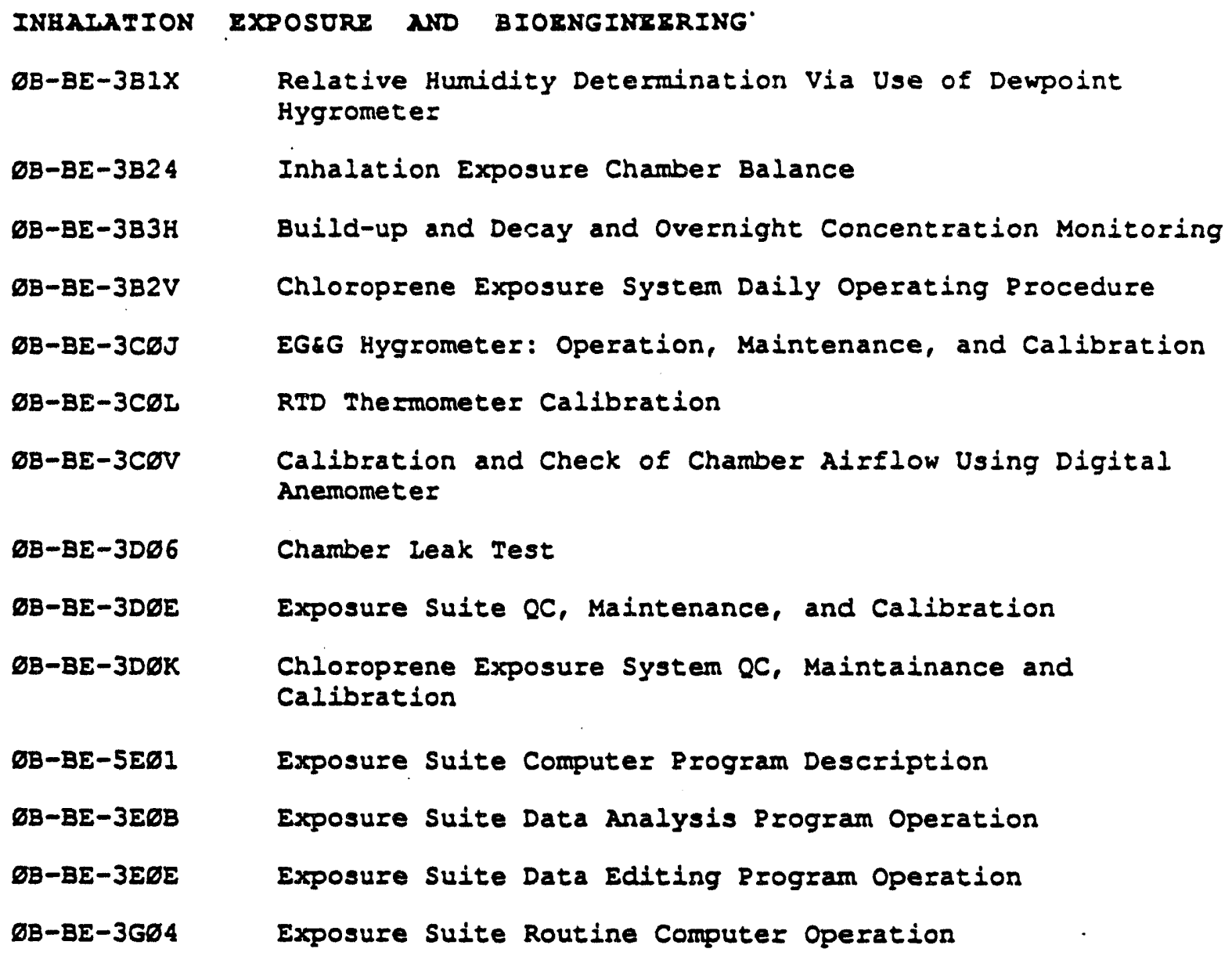




\section{$\operatorname{SATETY}$}

\begin{tabular}{|c|c|}
\hline$\varnothing B-H S-3 S 19$ & $\begin{array}{l}\text { The } 3 M \text { Brand } w-2860 \text { Hardcap, Continuous-Flow Air Line } \\
\text { Respirator }\end{array}$ \\
\hline DB-HS-3SIB & Respiratory Protection Program \\
\hline DB-HS-3SIC & Bioassay Studies: Health and Safety Plan \\
\hline DB-HS-3SIL & Biohazard Protocol - Chloroprene \\
\hline פB-HS-3SøW & Scott 4.5 Self-Contained Breathing Apparatus (SCBA) \\
\hline NTP PROJECT & OFFICR \\
\hline$D B-Q A-3 E D A$ & Filling out Data Sheets \\
\hline$\varnothing B-9 A-3 E \emptyset 6$ & $\begin{array}{l}\text { Data Handling and Storage of NTP Study Documents and } \\
\text { Materials }\end{array}$ \\
\hline
\end{tabular}




\section{INHALATION EXPOSURE SYSTEM DESCRIPTION}

I. ANIMAL EXPOSURE CHAMBER

II. EXPOSURE SUITE SYSTEM DESCRIPTION

III. TEST ARTICLE GENERATION AND MONITORING

A. Test Article Generation System

B. Test Article Monitoring System

IV. CHAMBER ENVIRONMENTAL CONTROL AND MONITORING
A. Temperature
II -5
B. Relative Humidity
C. Air Flow
D. Vacuum

V. ANIMAL FACIITYY AIR HANDLING SYSTEM

VI. EXPOSURE SUITE ALARM SYSTEM

VII. CHAMBBER EXHAUST WASTE TREATMENT

VIII. DATA HANDLING

IX. EQUIPMENT OR POWER FAIUURE PROTECTION SYSTEMS II-10 REFERENCES 
OB-DT-1F36-00-0270.

ATTACHMIENT II

Page II-2

\section{INHALATION EXPOSURE SYSTEM DESCRIPTION}

\section{ANIMAL EXPOSURE CHAMBER}

The animals will be exposed and maintained in inhalation exposure chambers developed at BNW (U.S. Patent No. 4,261,741, August 12, 1980; Moss, 1980; Brown and Moss, 1981; Moss et al. 1982) and now commercially produced by the Harford Division of Lab Products, Inc., Aberdeen, MD. The chamber (Figure 1) facilitates multiple-tier exposures of various laboratory animal species to aerosol- and vapor-laden atmospheres. The total volume of the chamber is $2.3 \mathrm{~m}^{3}$ with an active mixing volume of $1.7 \mathrm{~m}^{3}$, the remainder being the inlet and exhaust volumes where animals are not placed. For rabbits, there are two levels of caging, each level split into two tiers which are offset from each other and from the chamber walls. Drawer-like stainless steel cage units composed of two animal cages are suspended in the space above each tier. Stainless steel catch pans for the collection of urine and feces are suspended below each cage unit. Catch pans are left in position during each e::posure period. Cageboards are added to these catch pans during non-exposure periods to reduce ammonia concentrations.

The chamber was designed so that uniform aerosol or vapor concentrations can be maintained throughout the chamber when the catch pans are left in position. Incoming air containing a uniform mixture of test material is diverted so that it flows vertically along the inner surfaces of the chamber. Eddies are formed (Figure 1) at each tier as the aerosol or vapor flows past the catch pans. Stagnant zones that would normally exist above each pair of catch pans are cleared by exhaust flow through the space between the tiers. Aerosol or vapor reaching the lowest level is deflected across the bottom tiers by metal surips in the space between the catch pan and the wall. Tests have shown that aerosol or vapor concentration homogeneous to within $8 \%$ throughout the chamber can be obtained repeatedly provided the aerosol or vapor is uniformly mixed before passing through the chamber inlet (Griffis et al. 1981).

\section{EXPOSURE SUTTE SYSTEM DESCRIPTION}

The exposures will be conducted using an automated data acquisition and control system in an exposure suite (Figure 2) consisting of three exposure rooms and a Suite Control Center room (only one of the exposure rooms will be used for this study). A central computer monitors the basic chamber functions (i.e., test chemical concentration, air flow, vacuum, temperature, and relative humidity) in each of the three exposure rooms. The executive computer is a Hewlett-Packard (HP) Model 9816. All data acquisition and system control originates from this computer.

All experimental protocols related to the data acquisition and control system (such as data channel assignments, monitoring frequencies and alarm settings) reside in the execurive computer and are entered into tables accessed by menus.

Data input to the executive computer is accomplished through several interface instruments. All on-line chemical monitor data are collected and preconditioned by HP-85B computers, one for each of the exposure rooms. Conditioned data are transferred to the 
OB.DT-1F36-00-0270.

ATTACHMENT II

Page II-3

executive computer for analysis, concentration control, data storage, and printing. Data from all monitoring equipment other than chemical monitors are inputted through a Colorado Data Systems (CDS) Model 53A-[BX Intelligent Interface System (IIS).

System control is provided from the computer by means of control relays in the CDS IIS. These relays control such devices as valves, drive motors, audible alarms, indicator lamps, etc.

Data and comments from each exposure room are stored on separate magnetic diskettes by HP Model 9121 micro-floppy disk drives. Data and comments from each exposure room are printed on separate thermal dot matrix printers (HP Model 2671G). Data are printed and stored immediately upon completion of the measurement to the "Daily Log". At the end of the day (24-hour period), the daily data are analyzed and a summary is printed. This summary includes the mean, standard deviation, \% relative standard deviation, maximum, minimum, and number of measurements for each set of data for the 24-hour period. A second printout provides a table of outliers (i.e., all data points which are beyond the critical limits defined in the protocol). This outlier table allows rapid determination of problem areas in the data. A third printout provides a list of all comments generated by the computer and operators. This allows rapid inspection of generarion start and stop times and any problem areas.

A complete description of the software for this system is contained in BNW document $\varnothing \mathrm{B}-\mathrm{BE}-5 \mathrm{E} \emptyset 1$. Maintenance of this system is detailed in SOP \# ØB-BE-3DØE. Routine operation of the system software and hardware are detailed in SOP \# ØB-BE-3GØ4.

\section{TEST ARTICLE GENERATION AND MONTTORING}

\section{A. Test Article Generation Sustem}

The method used for the generation and delivery of chloroprene (CHIP) is shown in Figure 3. The generator is housed in a vented cabinet located in the Suite Control Center. The cabinet is vented to the building exhaust. The generator employs a rotary evaporation system (Büchi Rotavapor, Model EL-131S) to produce high purity chloroprene vapor. A 1-liter evaporating flask is filled (under a nitrogen blanket) once at the beginning of each day with chloroprene from one or more of the original chloroprene containers. The flask is immersed in a hot water bath at approximately $150^{\circ} \mathrm{F}$. A calibrated nitrogen stream is metered into the rotating flask and through the generator from the flask to the condenser. The resulting vapor is forced out of the mouth of the flask into the condenser. The condenser temperature is maintained by a temperature-regulated water bath. The condenser brings the vapor to the desired temperature and condenses part of the total vapor. The condensation controls the chloroprene vapor concentration produced by the generator. Condensate is renumed to the rotating flask.

The nitrogen flow and temperature of the circulating water and other parts of the vaporization system can be adjusted unil a sufficient ourput of vapor is reached. The total chloroprene output of the generator can be calculated from the metered nitrogen flow and an estimate of the chloroprene vapor pressure at the minimum temperanure reached within the condenser. For example, at a circulating water ternperanure of $28^{\circ} \mathrm{F}$, the concentration of the vapor is estimated at $89,000 \mathrm{ppm}$. The generator output is set to meet the demands of achieving the target concentrations in the exposure chambers plus a 20\% surplus delivery line flow. The excess delivery flow allows for adjustments to the vapor delivery system's operating parameters without affecting other flow rates. Unused delivery line flow is diluted with compressed air and then sampled by a second GC before being vented to waste. 
OB-DT-1F36-00-0270

ATTACHMENT II

Page II-4

From the condensing column, the vapor enters a short distribution manifold from which individual delivery lines carty a metered amount of vapor to each exposure chamber. Each delivery line is connected to the distribution manifold through a fine metering valve and flowmeter. At the chamber end of each delivery line, an AirVac(B) pump withdraws the appropriate amount of chemical vapor from the manifold to reach the target concentration. Chamber concentrations are adjusted by the metering valves and/or by adjustment of the compressed air pressure to the vacuum pumps. At the end of the delivery line, the vapor enters a pneumatic 3-way valve where it is directed to the exposure chamber or the chamber exhaust system as appropriate. These valves allow for a faster buildup of vapor concentration at seart-up as well as more rapid diversion of chemical flow from chambers in the event rapid shutdown is necessary. At the start of a generation period, these valves are positioned to route the vapors to the chamber exhaust until the concentrations in the distribution system have stabilized and volatile trace contaminants in the evaporation flask are purged. When the system is stable and exposures are ready to proceed, computer-controlled start-up of the exposure is initiated by rotation of the 3-way valves to the exposure position. Dilution of the nitrogen/ chloroprene vapor mix with air to the target chamber concentrations occurs immediately before entry to the chambers.

Generation proceeds in stages: warm-up, generation and shutdown. During warm-up, the pneumatic 3-way valves are in the exhaust position and heating of chemical in the evaporacing flask and water in the bath proceed together. After operating temperatures are reached, at the direction of the operator, computer-controlled start-up is initiated and the pneumatic valves are set to the exposure position. After stabilization of the chamber concentrations and possible fine adjustments of the vapor delivery and nitrogen flow rates, the generator is in its normal operating stage. During this stage, the generator operates under computer and exposureoperator supervision. The exposure operator monitors the various vaporization temperanures as well as other operating parameters. The computer can iniciate an interruption of chemical delivery to any chamber under cerrain conditions by rotating the appropriate 3-way valve.

Shutdown at the end of the generarion stage is similar to a computer-initiated shutdown. After the 3-way valves are rotated to the exhaust position, stopping exposures, the operator stops the evaporator flask rotntion, turns off the bath heater and floods the bath with cold water. After the evaporating flask cools, it is removed from the generator and replaced with a cleaned flask. Nitrogen continuously purges the vaporization system until preparation for the next day's generation.

Routine operation of the generation system is detailed in SOP\# $\emptyset \mathrm{B}-\mathrm{BE}-3 \mathrm{~B} 2 \mathrm{~V}$. Maintenance and QC procedures are detailed in SOP\# ØB-BE-3D $\varnothing \mathrm{K}$.

Measurement of vapor concentration versus time (buildup and decays) will be obtained for all chambers before the start of the study and during the study. (SOP\# OB-BE-3B3H)

\section{B. Test Article Concentration Monitoring}

An on-line Hewlen-Packard Model 5890 gas chromatograph equipped with an flame detector (FID) will be used to monitor the exposure chambers, the control chambers, the exposure room, and the output of a standard gas cylinder. Sampling from multiple positions will be accomplished by means of an oven-mounted, 12-port stream select valve. The sampling system (Figure 4) is incorporated into the relative humidity (RH) sampling system. Samples of the amosphere from each sample location are continuously drawn by a vacuum pump through teflon sample lines to a location near the input to the 12-por sample valve. This assures fresh samples at the monitor. The sample lines, which continue from the point where they tee-off to the 12-por valve to the dewpoint monitor, are 1/16" teflon. 
Sample values are accumulated and printed by an HP Model 85B computer until samples from all twelve ports of the stream select valve have been measured. These values are then sent to the executive computer for printing and storage. Each value accumulated by the HP85B is compared with limit values for that particular location. If the value is beyond the control limits, the HP85B will immediately send the information to the executive computer which will take the appropriate action as follows:

- Concentration $\geq$ non-critical low limit and $\leq$ non-critical high limit: No action

- Concentration < non-critical low limit but $\geq$ critical low limit: Indicate on daily printout

- Concentration < critical low limit: Indicate on daily printout and activate audible alarm

- Concentration > non-critical high limit but $\leq$ critical high limit: Indicate on daily printout

- Concentration > critical high limit: Indicate on daily printout, activate audible alarm, terminate generation of test material

The on-line gas chromatograph will be calibrated against quantitatively analyzed bubbler grab samples collected from the exposure chambers. Standards will be prepared gravimetrically. The on-line monitor calibration will be confirmed at least once per month by grab sampling. The calibration check will be performed according to SOP \#ØB-AC-3CØV. Instrument drift will be checked daily against an on-line standard.

A constant concentration stream of chloroprene vapor, used only to detect instrument drift, is provided by compressed nitrogen/CHLP bottled gas. The chloroprene standard is monitored every 12 th sample throughout the exposure period. The standard is also checked before the start of each exposure day. The measured concentration for the standard is required to be within $\pm 10 \%$ of the assigned target value before any exposure begins without consultation with the exposure control task leader. During the course of the exposure, if the on-line standard is within $\pm 5 \%$ of the target value, no change in calibration is required. If the on-line standard is beyond $\pm 5 \%$ of its assigned target, the lead chemist is informed immediately by an exposure specialist. Additional grab sampling is initiated by the chemist on a case by case basis when drift in the on-line standard is between $\pm 5-10 \%$. A cumulative drift of $10 \%$ or greater requires immediate recalibration of the on-line monitor by grab sampling.

Daily operating procedures for the concentration monitoring system are contained in SOP $\# \varnothing B-A C-3 B 1 N$. Rourine maintenance of the GC is covered in SOP \#ØB-AC-3D $\varnothing 9$.

The uniformity of the distribution of the test chemical in the chamber will be checked before the start of the study and during the first week of exposure. (SOP \#ØB-BE-3B24)

\section{CHAMBER ENVIRONMENTAL CONTROL AND MONITORING}

\section{A. Temperature}

Nearty all of the heat load contributed to the exposure chamber by the animals is dissipated from the chamber by radiation through the chamber wall (Bernstein and Drew, 1980). The temperaurre of the air supplied to the chamber has little effect on the temperamure of the chamber. On the other hand, the temperature of the room housing the chamber has a great deal 
of effect. Consequently, chamber temperature is maintained in the proper range primarily by controlling the room temperature.

Temperatures of the exposure chambers and exposure room are measured by Resistance Temperature Devices (RTDs). The RTDs are placed in a represientative location in each chamber. Each RTD is connected to an Omega Model 412B Digital Thermometer by either a manual select switch or by computer controlled scanner relays. This allows the temperaure to be read manually or to be recorded automatically by the exposure system executive computer. Temperatures are automatically recorded at regular intervals during each 24-hour day. All temperanure measurement equipment except the RTDs is located in the Exposure Suite Control Center. RTDs are calibrated to within $0.5^{\circ} \mathrm{F}$ of a certified mercury thermometer (SOP \# ØB$\mathrm{BE}-3 \mathrm{C} \emptyset \mathrm{L})$ before the start of the study and at least every two months thereafter.

\section{B. Relative Humidity}

Relative humidity $(\mathrm{RH})$ in the exposure chambers is controlled by the system depicted in Figure 5. Equipment located in the RH Control Equipment Room (Room 335 of the LSL-II basement) provides separate ducts of dry and moist air to each exposure chamber. Filtered air with a maximum dewpoint of about $53^{\circ} \mathrm{F}$ is supplied to the RH Control Equipment by the building HVAC system. This air is evenly delivered to two ducts. Air from the first duct passes into a plenum where steam, generated from city tap water with no additional additives, is injected to bring the air to a dewpoint of about $60^{\circ} \mathrm{F}$. This provides the moist air source for the chambers. The air from the second duct is passed through a refrigeraion coil which reduces the moisture content of the air to a dewpoint of about $40^{\circ} \mathrm{F}$. This provides the source of "dry" air for the chambers. A manually controlled mixing valve for each chamber mixes the proper proportions of the moist and dry air to maintain the proper RH in each chamber.

Relative humidity is measured using an EG\&G Model 910 dewpoint hygrometer located in the Exposure Suite Control Center. Air from the exposure chambers is sampled from a representative location. A teflon filter is placed at the chamber end of the sample line if the test article is an aerosol. Samples of the air from each measurement location are continuously pulled through polytetrafluoroethylene (PTFE) tubing to a central location in the Exposure Suite Control Center. This assures a fresh sample at the dewpoint hygrometer. Sample air from a particular locarion is routed by a multiplexed valve system to either the exposure system exhaust or the dewpoint hygrometer for RH determination. The valves are controlled by either a manual switch or by a computer controlled relay, allowing $\mathrm{RH}$ to be measured manually or automatically by the exposure system executive computer. $\mathrm{RH}$ is automatically recorded at regular intervals during the 24-hour day.

Once the dewpoint has been determined by the hygrometer, the $\mathrm{RH}$ is automanically calculated by the exposure system executive computer using the dewpoint value and the temperature measured simultaneously at the same location by the RTD system. The following equation is used for this calculation:

$$
\% \mathrm{RH}=\frac{10\left[9.91-\frac{2714.55}{(5 / 9)\left(\mathrm{T}_{1}-32\right)+293.3}\right]}{10\left[9.91-\frac{2714.55}{(5 / 9)\left(\mathrm{T}_{2}-32\right)+293.3}\right]} \times 100
$$


OB-DT-1F36-00-0270.

ATTACHMIENT II

Page II-7

- Where: $\quad T_{1}=$ dewpoint temperature $\left({ }^{\circ} \mathrm{F}\right)$

$\mathrm{T}_{2}=$ drybulb temperature $\left({ }^{\circ} \mathrm{F}\right)$

Calibration of the dewpoint hygrometer is established prior to the stirt of the study and checked at least every two months following SOP \# $\varnothing \mathrm{B}-\mathrm{BE}-3 \mathrm{~B} 1 \mathrm{X}$. Initial calibration requires comparison at three $\mathrm{RH}$ levels $(-30 \%, 50 \%$ and $70 \%)$ of the $\mathrm{RH}$ calculated by the monitor to measurements made by a calibrated portable hygrometer and RTD located near the chamber.

\section{Airflow}

Air flow in the chambers is maintained by the vacuum in the central chamber exhaust duct. This vacuum is created by the chamber exhaust flow fans located in the Souih Equipment Room of the LSL-II Building. There are two parallel exhaust fans, one operating with the other providing backup. Both fans operate from emergency power.

Chamber air flow rate is controlled by a gate valve in each individual chamber exhaust duct. A drive motor attached to the stem of this valve allows the control of chamber flow either by computer or manually from the Exposure Control Center.

Fine control of exposure concentration can be accomplished by automatically or manually adjusting the valve position to control chamber dilution air flow within the allowable limits. Gross adjustment of concentration must be done manually by adjusting the generation system.

Chamber air flow is measured by a multiplexed orifice-meter system consisting of a calibrated orifice located in each chamber exhaust, a Validyne Model DP-45 pressure transducer, a Validyne Model CD-18 carrier demodulator, and a Validyne Model PM-12 digital volmeter. The pressure transducer is muluiplexed to each chamber's flow orifice by valves remotely controlled either manually or by means of the executive computer. This allows flow to be measured either manually or automarically. Flow is automatically recorded at regular intervals during the 24-hour day.

Calibrated flow orifice meters are located at both the inlet and exhaust to each chamber. By comparing the measured flow as the inlet and exhaust, leaks in the chamber can be detected. A leak check is automatically performed by the executive computer when each chamber is closed. If a leak is detected, the executive computer will notify the operator and will not allow exposures to proceed until the leak is repaired. This system is sensitive to very small leaks which may cause an imbalance of test article concentration within the chamber.

Calibration of the flow orifices will be done before the start of the study and at least every two months thereafter following SOP \# ØB-BE-3CØV. Each flow orifice is calibrated to within \pm 0.5 CFM by comparison to a calibrated digital vane anemometer temporarily inserted in the chamber duct during non-exposure periods.

\section{Vacuum}

The chambers are maintained at a slight negative pressure compared to the room in order to reduce the possibility of escape of test articie. This negative pressure is created by the pressure drop across the HEPA and charcoal filters at the iniet to each chamber.

The same Validyne pressure transducer system used to measure chamber flows is used to measure chamber vacuum. Vacuum in the chamber is measured relative to aumospheric 
pressure in the Suite Control Room. Vacuum is automatically recorded at regular intervals during the 24-hour day.

Vacuum is also continuously monitored by a mechanical pressure switch attached to each chamber. In the event of leak in the chamber, the pressure switch will immediately shut off the flow of test article to the chamber and activate an audible alarm.

\section{ANIMAL FACILITY AIR HANDLING SYSTEM}

Supply air enters the building through two identical parallel air handling systems (Figure 6). Each system consists of a pre-heat coil, a filter system, a heating coil, a chilling coil, and a supply fan. The pre-heat coil heats the air to a minimum of $45^{\circ} \mathrm{F}$. The filter system, comprising a roll filter, pre-filter, and a bag filter, rids the air of most particles. The heating and chilling coils maintain the temperature of the air exiting the air conditioning system at about $53^{\circ} \mathrm{F}$. The chilling coils also dry the air to a dewpoint not greater than $53^{\circ} \mathrm{F}$.

Although simultaneous operation of both of the parallel air supply systems is necessary to provide the 20 air changes per hour typically supplied to each animal room, only one of these systems, which can be operated from the emergency power system, is required to maintain the rooms within the temperature and flow specifications required by the protocol. Exposure of the animals to the test article can continue in the event of the failure of one of the air supply systems. However, exposuri: generally do not continie unless all building systems are functioning normally.

The air from the two parallel building air supply systems is mixed together by an air mixing unit and is divided into two ducts which feed the rooms on the East and West sides of the animal quarters. If necessary, steam is injected into the air in these ducts to maintain the relative humidity of all rooms in the basement at a minimum of $35 \%$. In rooms where further room RH control is necessary, it is provided by individual steam generators located in the room. Prior to entering the animal room, the air is filtered through a HEPA filter.

Air for exposure chambers is supplied to a chamber relative humidity conditioning system from the building air supply systems. A single supply system is sufficient to supply air to the RH conditioning systems for all exposure chambers in the facility.

Exhaust from the animal room is filtered by a room HEPA filter and again through a bank of building exhaust HEPA filters assuring no escape of aerosol particles from the facility. Three parallel exhaust fans provide exhaust from the rooms. Two of these fans are in operation with the third as a backup unit. One fan can be operated from the emergency power system in case of power failure.

A separate exhaust duct system for the chambers allows for the addition of scrubbers to remove particles or vapors before exhausting from the building. Because the chamber exhaust system has a separate fan, failure of one of the building exhaust fans will not prevent the continuation of exposures. However, exposures generally do not continue unless all building systems are functioning normally.

\section{EXPOSURE SUTTE ALARM SYSTEM}

An extensive system of alarms has been incorporated into the exposure suite automated data acquisition and control system to provide safety for the system operators, protect the health of the animals and ensure the integrity of the study. There are actually two separate 
alarm systems; one provided by the computer and a separate "physical" alarm system which provides redundancy for some of the computer alarm functions.

Following each function measured by the computer, the value is compared to the alarm limit values (stored in the computer memory) for that function. There are four limit values for each function and location monitored by the computer, high and low non-critical and high and low critical. For example, chamber flows may have the following limits:

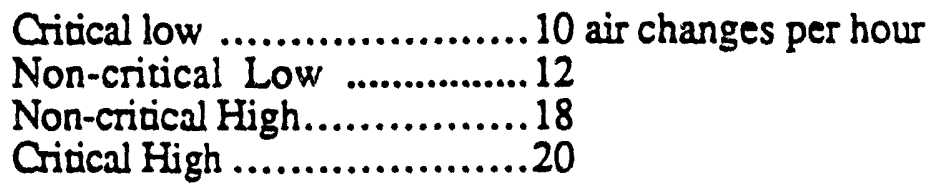

The result of an alarm condition depends on the function measured and the measurement location. Each function and location has an alarm response assignment in the computer. Again using chamber flow as an example, flows exceeding the non-critical limits but remaining within the critical limits will cause the computer to print a "beyond-non-critical-limits" symbol, "(" if low and ")" if high, next to the data on the daily log printed by the computer. A chamber flow which exceeds the critical limits will cause the computer to print a "beyond-critical-limits" symbol, " $>$ " if high and " $<$ " if low, on the daily log and to turn on the critical alarm audio aler. A critical low flow alarm will also shut off the flow of test article to the chamber. Although it is possible for the computer to make automatic corrections to air flow in the chamber, this is not done because to do so would affect concentration of the test article in the chamber. A critical low negarive pressure in a chamber (which may be the result of a leak in the chamber) will also cause the computer to shut off the flow of test article to the chamber. Similar responses result from alarms arising from temperature and relative humidity measurements in the chambers, however these alarms have no affect on the operation of the test article generator.

The physiral alarm system includes the following continuously monitoring devices:

- Chamber pressure (also detects critically low flow if it is the result of pump failure and not a clogged chamber inlet duct)

- Generator cabinet exhaust flow

- Chamber exhaust system flow

- Building exhaust system flow

In all cases an alarm condition from any one of these monitors is considered critical and results in the test article generator being shut off.

\section{CHAMBER EXHAUST WASTE TREATMMENT}

The air from the central chamber exhaust duct is mixed with the air from the entire animal facility $(-75,000 \mathrm{cfm})$ prior to being exhausted from the building stack. Dilution of the chamber exhaust with the building exhaust results in an acceptable stack concentration usually on the order of one-tenth the Threshold Limit Value for the test article.

\section{DATAHANDLING}

Data from each exposure room are stored in the Exposure Suite Control Center on separate magnetic disks by Hewlett-Packard (HP) Model 9121 micro-floppy disc drives. Data and comments from each exposure room are printed by separate thermal dot matrix printers (HP Model 2171G) or by ink jet printers (HP Model 2225A). Data are printed and stored 
immediately upon completion of the measurement to a Daily Log (example, Figure 7). Both the Daily $\log$ and the disks will be maintained in the study files. The Daily Log will be considered the raw data. The Daily Log includes the time of measurement, the measurement location (such as chamber), the measurement function (such as temperature), the value of the measurement, the percent of target, an alarm code, and a status code. See Figure 7 for an explanation of the alarm and status codes.

At the end of the day (24-hour period), the daily data are analyzed and three summaries are printed. The first (example, Figure 8 ) includes the mean, $\%$ of target, standard deviation, \% relative standard deviation, maximum, minimum, and number of measurements for each function (such as temperature) and location (such as chamber) monitored over the 24-hour period. The second (example, Figure 9) provides a list of outliers; that is, all data points which were beyond the defined critical operating limits. This printout allows for quick review of data which are outside the operating limits. The final summary (example, Figure 10) is a printout of all comments made by the computer, exposure specialist and exposure operator during the $24-$ hour period. This includes comments on startup time, exposure termination, new calibration factors entered, and other information. This summary allows a quick review of events that occurred during the day. In addition, once each week, a chamber exposure time summary is printed (Figure 11). This summary includes total accumulated exposure time during the week for each chamber and also the mean daily length of exposure, standard deviation, maximum and minimum daily exposure time and the number of days on exposure.

Data handling and analysis procedures are described in SOPs $\emptyset \mathrm{B}-\mathrm{BE}-3 \mathrm{E} \varnothing \mathrm{B}$ and $\varnothing \mathrm{B}-\mathrm{BE}-3 \mathrm{E} \varnothing \mathrm{E}$.

\section{EOUIPMENT OR POWER FAILURE PROTECTION SYSTEMS}

Power is provided to the Battelle complex from two separate city substations through an automatic switching device. This significantly reduces the possibility of losing city power. Power from the city is routed to equipment in the LSL-II building through two types of motor control centers. One type can switch power from the ISL-II diesel generator. The other has access only to city power. The emergency-power-type motor control center has a low voltage detector on each leg of the three-phase input power. If the city supplied power should fail or "brown out", these detectors automatically start the emergency power diesel generator and route the emergency power to the equipment connected to the emergency-power-type motor control center.

All equipment critical to the well-being of the animals is connected to the emergencypower-type motor control center. This equipment includes:

- Emergency lighting and electrical outlets

- Building air condicioning chillers \#1 and \#2

- Building heating boilers and feedwater pump systems \#1 and \#2

- Air compressors \#1 and \#2

- Air supply fans \#1 and \#2

- Air exhaust fans \#1 and \#2

Note that there are two identical units of all equipment that is vital to the well-being of the animals (heating, cooling, supply air, exhaust air, and compressed air). Either of the two units has sufficient capacity to maintain the animal environment within a safe range. In all cases, the emergency power system will operate one of the two identical systems. 
All building or chamber systems which are essential to the survival of the animals are alarmed. If a system malfunctions, an alarm is tripped in the Power Operator's office. A Power Operator is on duty 24 hours'day, 7 days/week. If the Power Operator is not authorized to correct the problem that caused the alarm, he immediately calls the appropriate personnel of the programs affected.

\section{REFERENCES}

Bernstein, D.M. and Drew, R.T. (1980). "The major parameters affecting temperature inside inhalation chambers", Am. Ind. Hvg Assos. J., 41, pp. 420-426.

Brown, M.G. and Moss, O.R. (1981). "An Inhalation Exposure Chamber Designed for Animal Handling", Lab. Anim. Sci, 31, pp. 717-720.

Decker, J.R., Moss, O.R., and Kay, B.L. (1982). "Controlled-delivery vapor generator for animal exposures", Am. Ind. Hvg. Assoc. J. 43, pp. 400-402.

Griffis, L.C., Wolff, R.K., Beethe, R.L. et al. (198i). "Evaluation of a Multi-Tiered Inhalation Chamber", Fundam. Appl. Toxicol, 1, pp. 8-12.

Moss, O. R. (1980). "A chamber providing uniform concentration of particulates for exposure of animals on tiers separated by catch pans". In Workshop on Inhalarion Chamber

Technology BNL 51318, Drew, R.T., editor. Brookhaven National Laboratory, Associated Universities, Inc., Upton, NY.

Moss, O.R., Decker, J.R. and Cannon, W.C. (1982). "Aerosol Mixing in an Animal Exposure Chamber Having Three Levels of Caging with Excreta Pans", Am. Ind. Hyg. Assoc. J. 43 pp. 244-249. 
OB-DT-1F36-00-0270.

ATTACHIMENT II

Page II-12

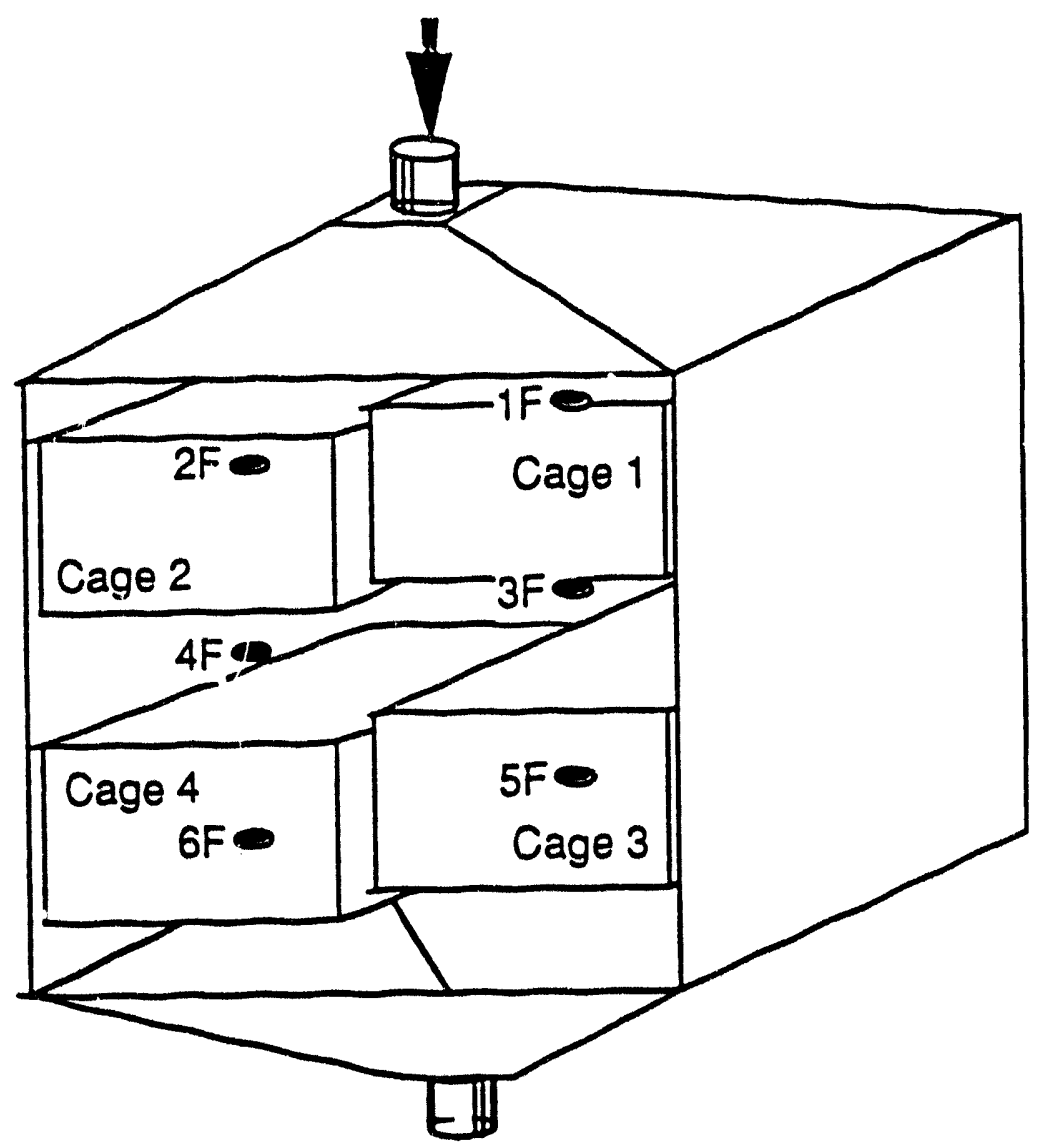

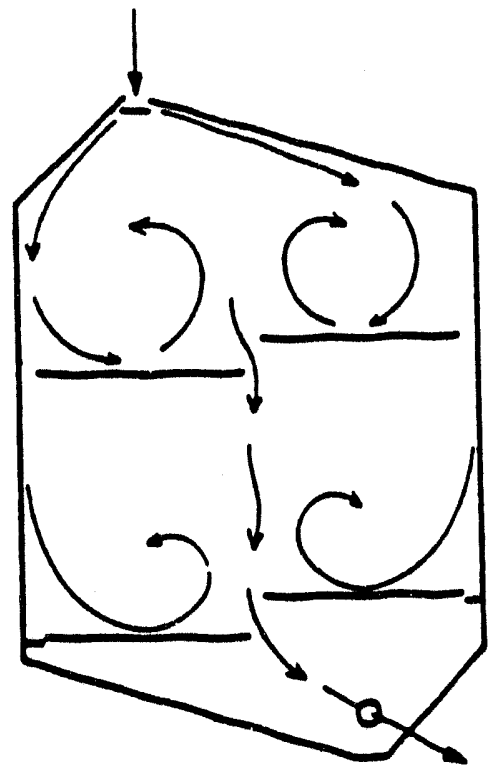

FRONT VIEW

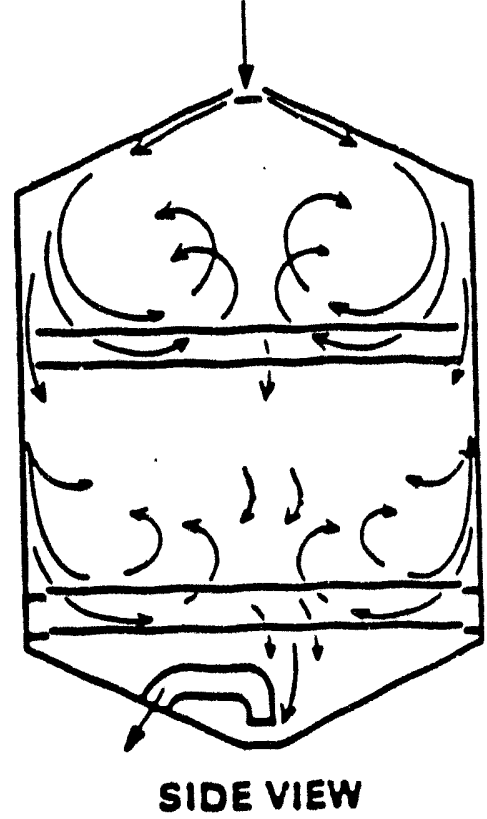

Figure 1. Inhalation Exposure Chamber Designed at BNW. Top: Oblique View of the Chamber, Bottom: Airflow Patterns). 


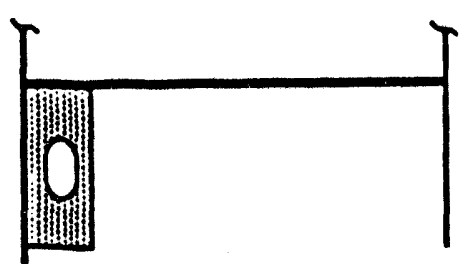

ROOM 327

NOT USED

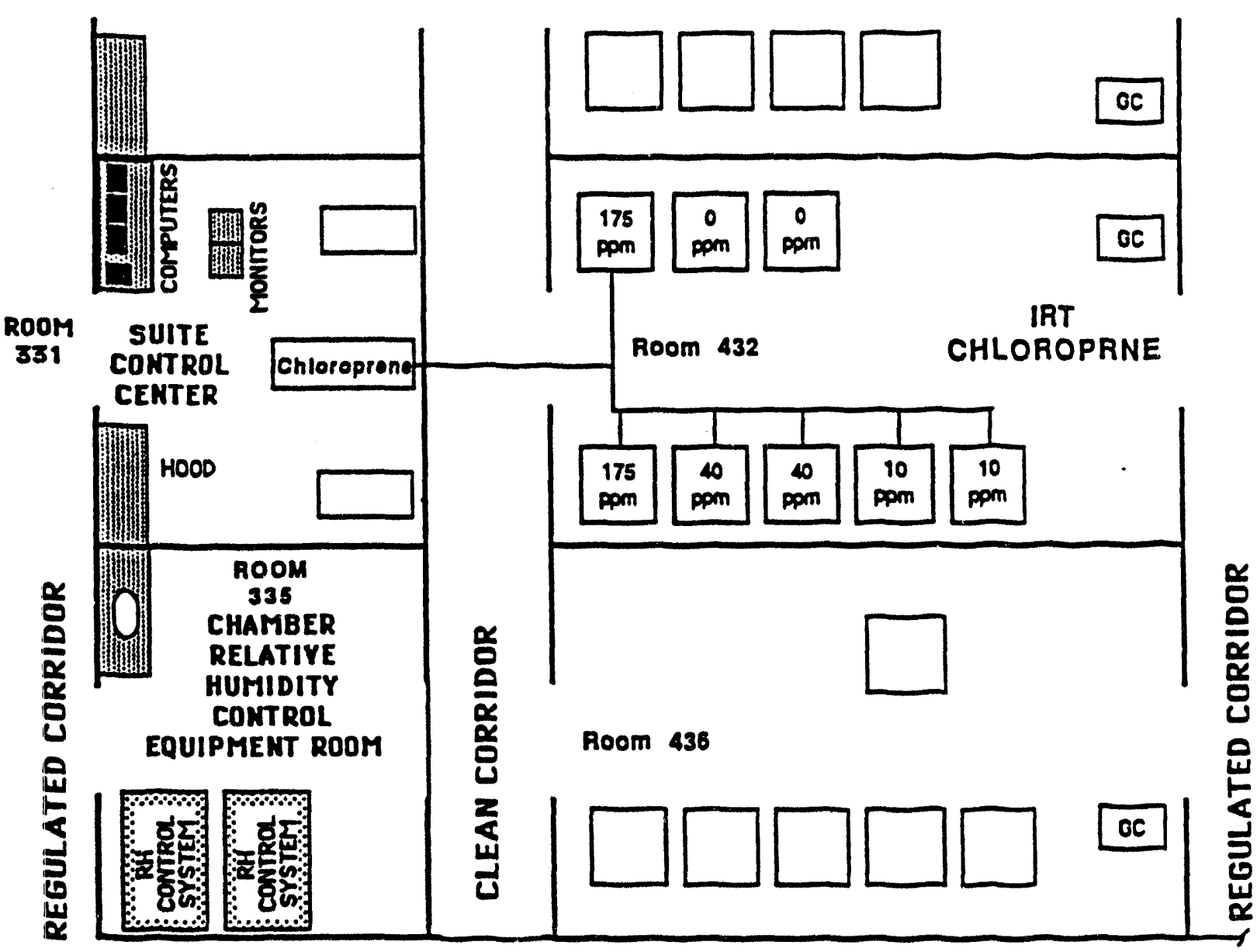

Figure 2. Schematic of the Chloroprene Exposure Suite. 
OB-DT-1F36-00-0270.

ATIACHMENT II

Page D-14

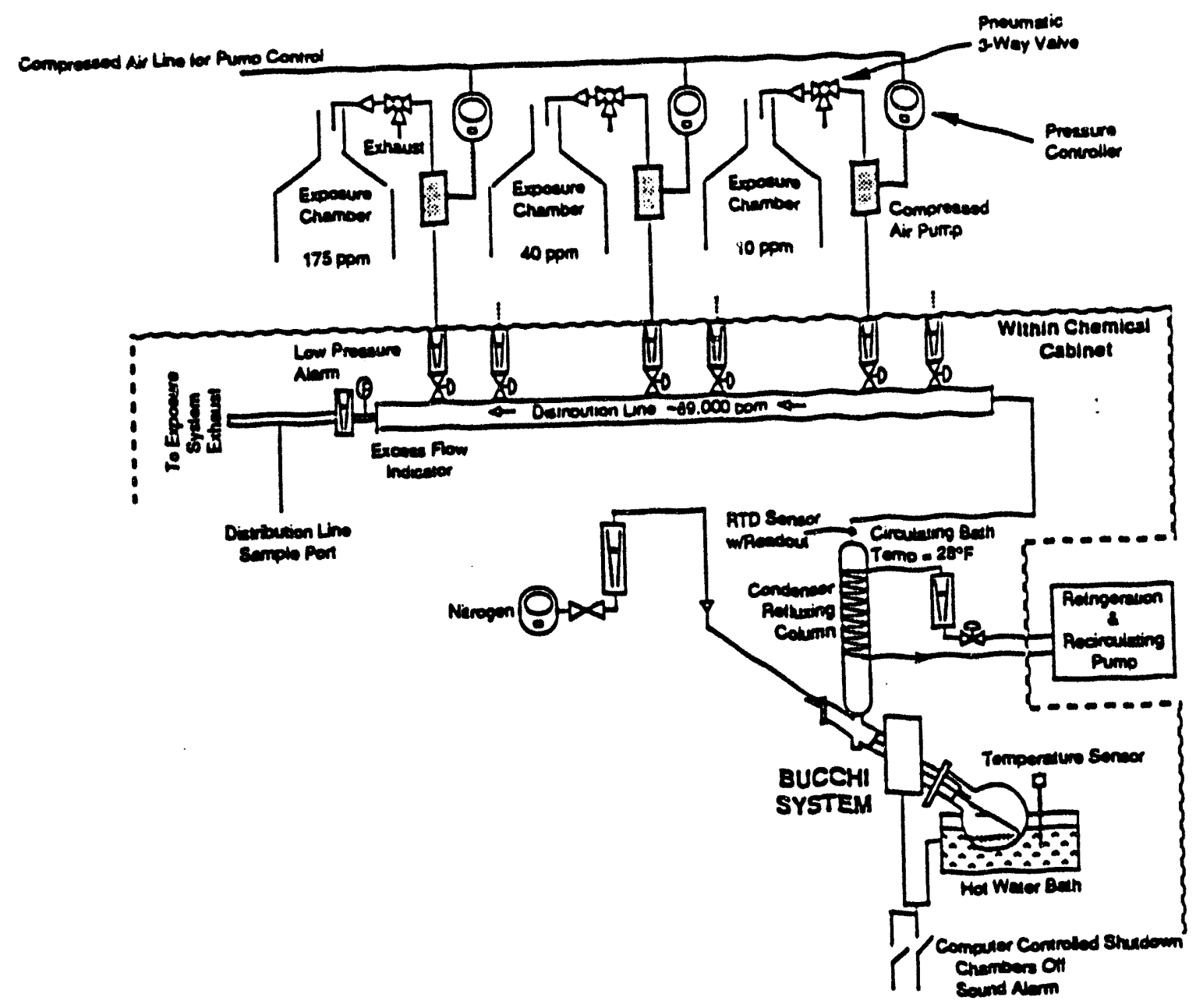

Figure 3. Schematic of Chloroprene Vapor Generation and Distribution System.

$D \cdot 42$ 
ØB-DT-1F36- $00-0270$.

ATTACHMIENT II

Page II-15

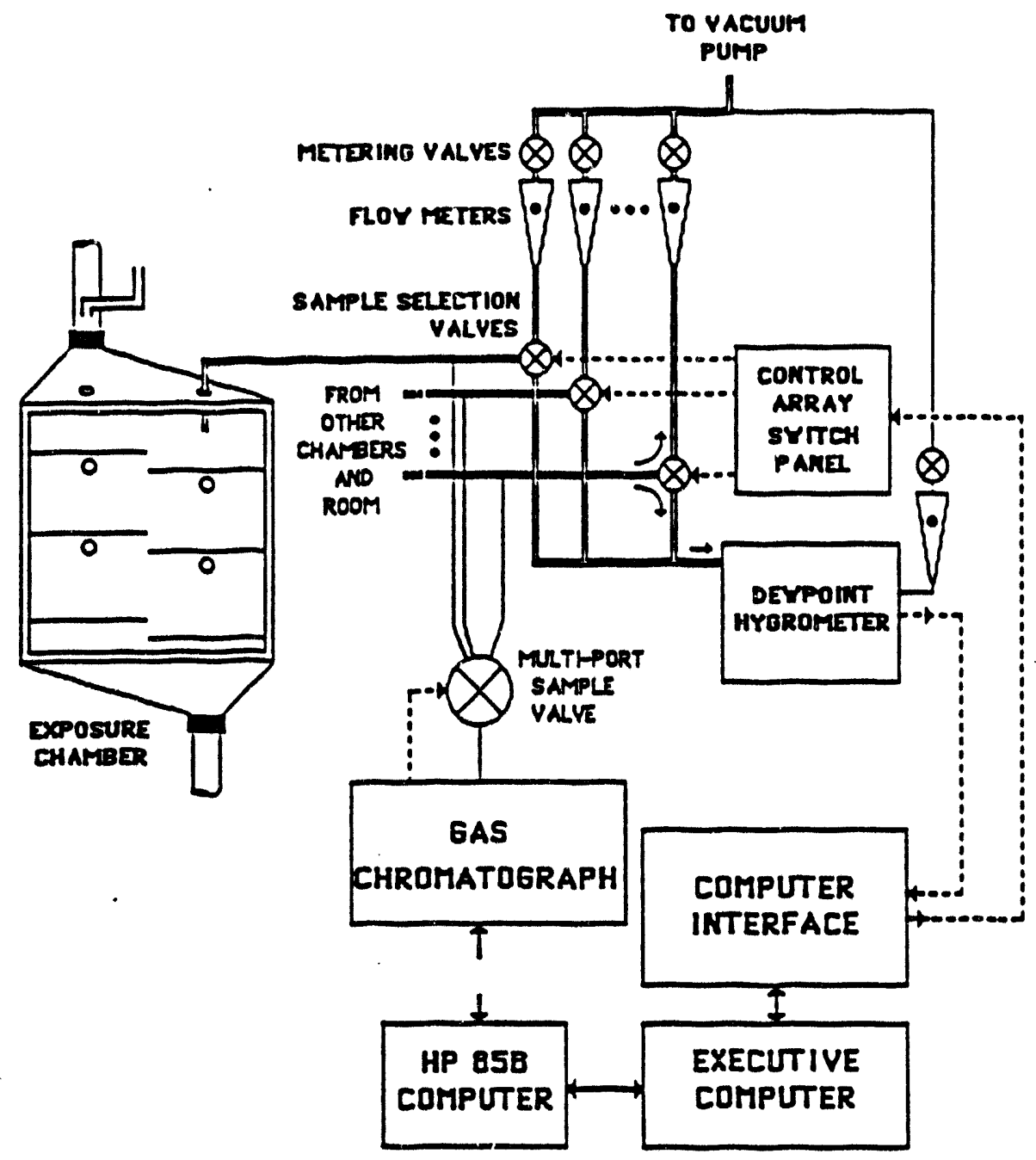

Figure 4. Schematic of the Dewpoint and Chemical Monitoring System. 
OB.DT-1F36-00-0270.

ATTACHMENT II

Page II-16

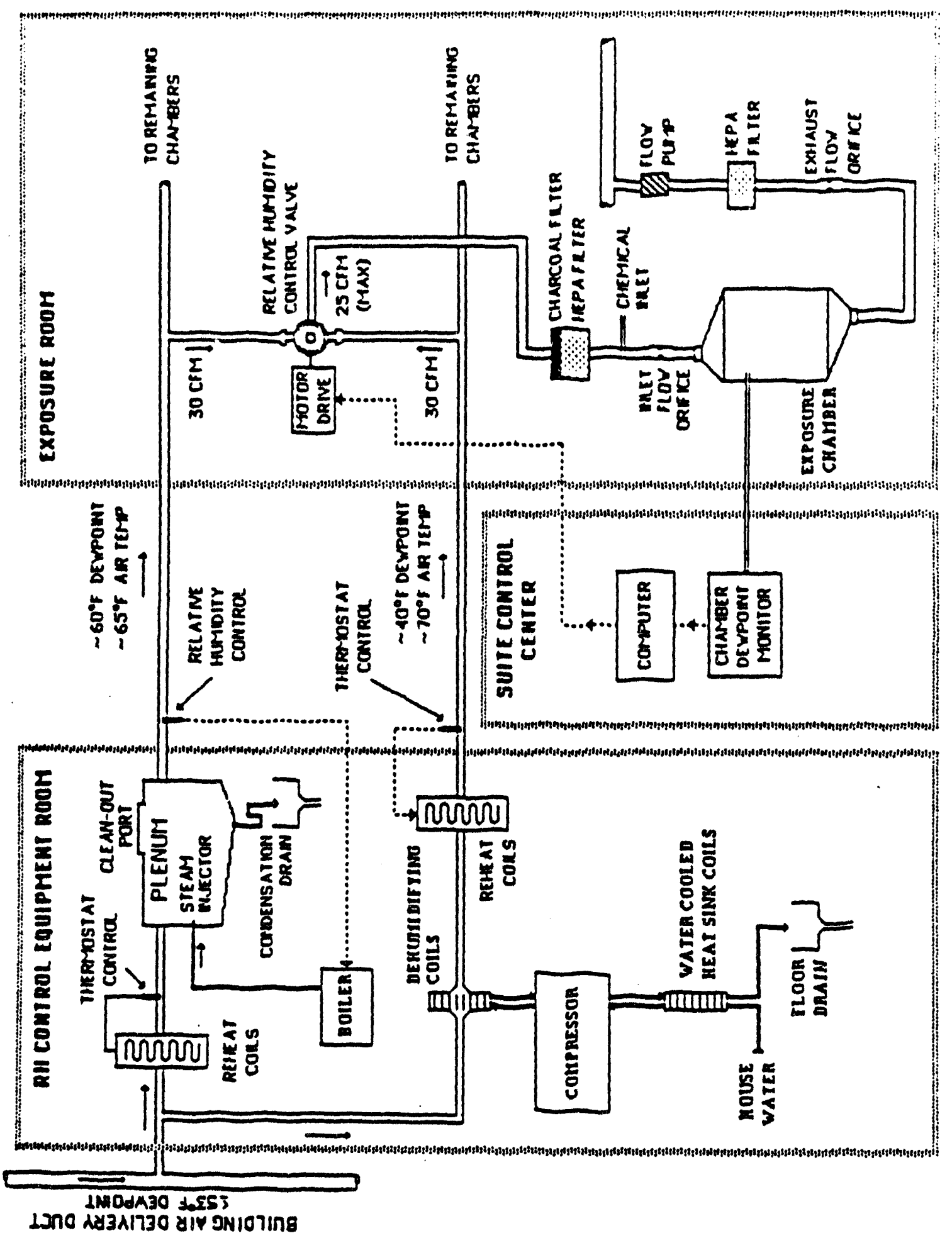

Figure 5. Schemaric of Chamber Relative Humidity Control System. 


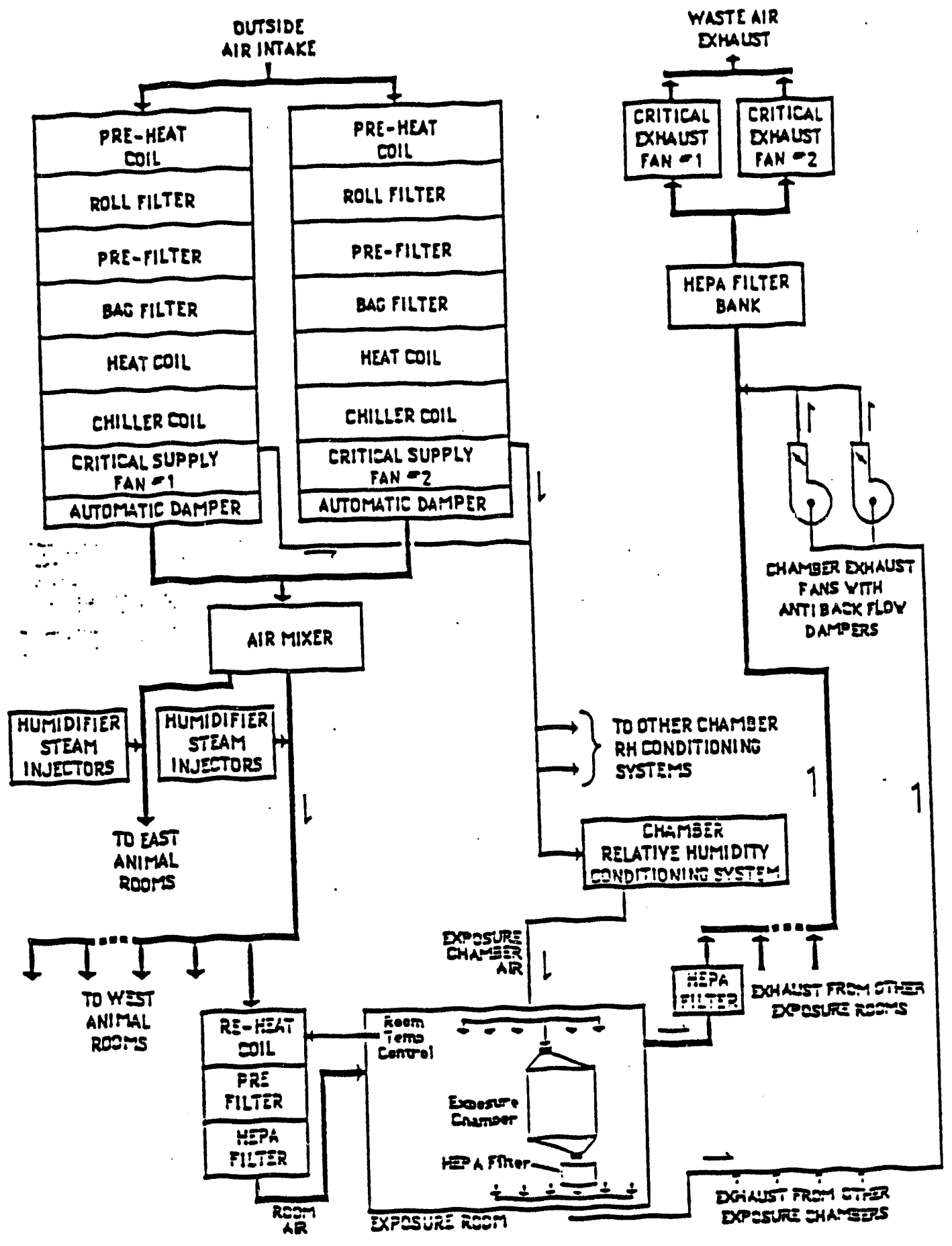

Figure 6. Air Handling System for Animal Rooms of Life Sciences II Building. 


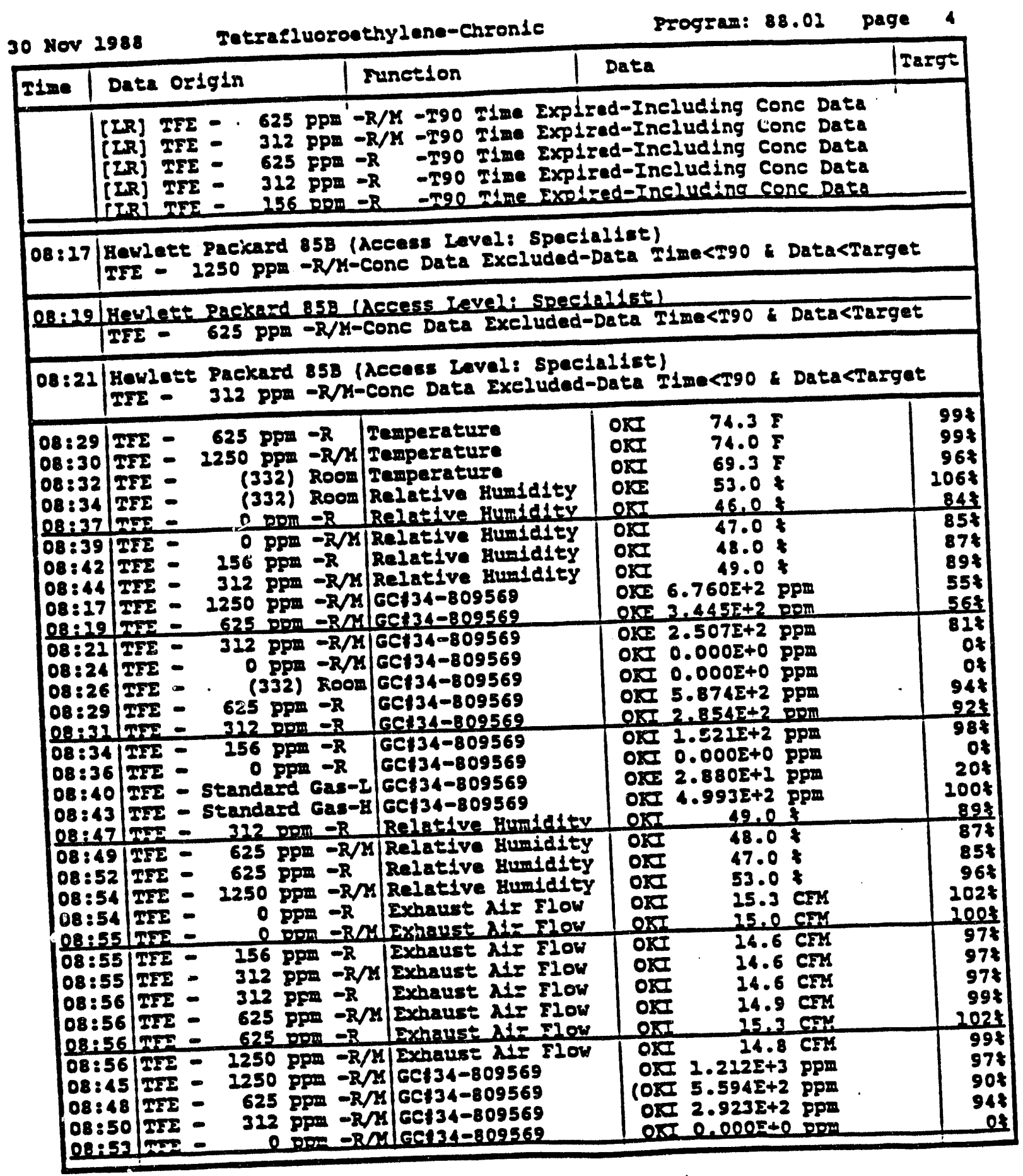

Figure 7. Example of 24-Hour "Daily Log" Printout from Data Acquisition and Control Computer. See Following Page for Explanation of Columns. 
ØB-DT-1F36-00-0270.

ATTACHDIENT II

Page II-19

Figure 7. (continued)

\section{DESCRIPTION OF COMPUTER "DAIIY LOG" OUTPUT}

The date, exposure name, program version and page number will be printed at the top of each page of the daily $\log$

Column 1: Time - time that measurement was taken

Column 2: Location - location of measurement (for example, chamber)

Column 3: Function -- measurement function (for example, temperature)

Column 4: Data -

Alarm Code - "(" Indicates data < non-critical low but $\geq$ critical low alarm value

")" Indicates data > non-crivical high but $\leq$ critical high alarm value

"<" Indicates data < critical low alarm value

">" Indicates data > critical high alarm value

"[" Indicates data < supercritical low alarm value

"]" Indicates data > supercritical high alarm value

Status Code -- "OK" Indicates monitoring instrument is functioning properly and is calibrated

"BS" Indicates service time of monitoring instrument has expired. (Usually indicates that instrument calibration should be

checked. Does not necessarily mean that data is not valid)

"I" Indicates data will be included in summary

"E" Indicates data will be excluded from summary

"MDM" Indicates manual data measurement

"OED" Indicates off exposure data

Data Value - Data may be expressed in scientific notation ( $x . x x x$ Eyy)

Units Label - Units of measurement (e.g., ppm, ${ }^{\circ} \mathrm{F}, \mathrm{mg} / \mathrm{m}^{3}$ )

Column 5: Target $-9 \%$ of target concentration for the measurement 
ØB-DT-1F36-00-0270.

ATTACHMIENT II

Page II-20

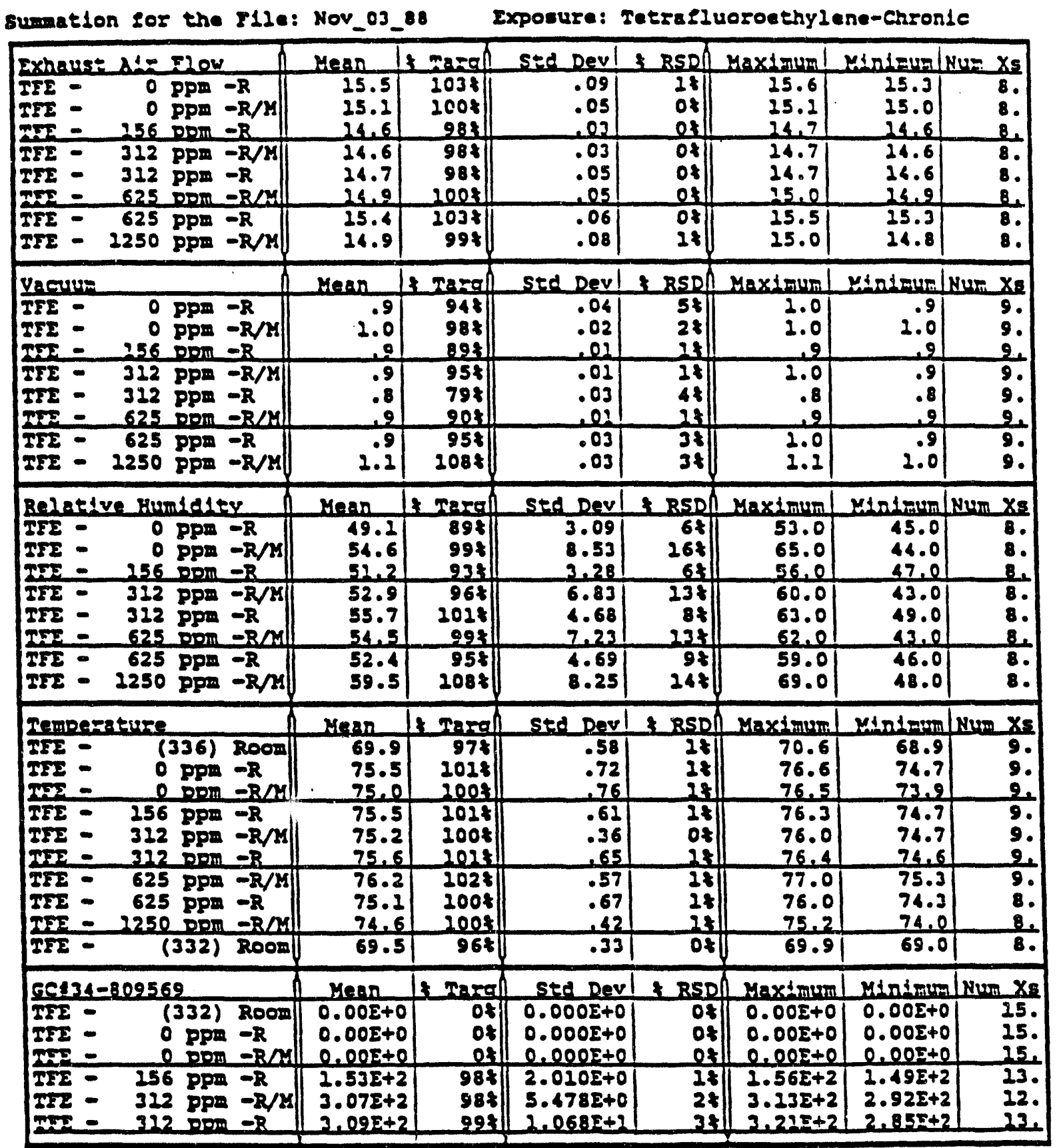

Figure 8. Example of 24-Hour "Data Summation" Printout from Data Acquisition and Control Computer. 
DB-DT-1F36-00-0270.

ATTACHMENT II

Page D-21

Outller Table Lor the F1le: Nov_2l_88 Exposure: Acetonftrile

\begin{tabular}{|c|c|c|c|c|c|c|c|}
\hline $0=1010$ & & Insframent & Intme & nece & Iowe: & marat: & Hiaher \\
\hline Aceto - & 0 pp=-Y & Relaelve HumldIEY & $10: 24$ & 33.0 & 35.0 & 55.0 & 75.0 \\
\hline
\end{tabular}

Figure 9. Example of 24-Hour "Data Outlier Table" Printout from Data Acquisition and Control Computer. Table shows data which were beyond the defined Crivical Limits. 


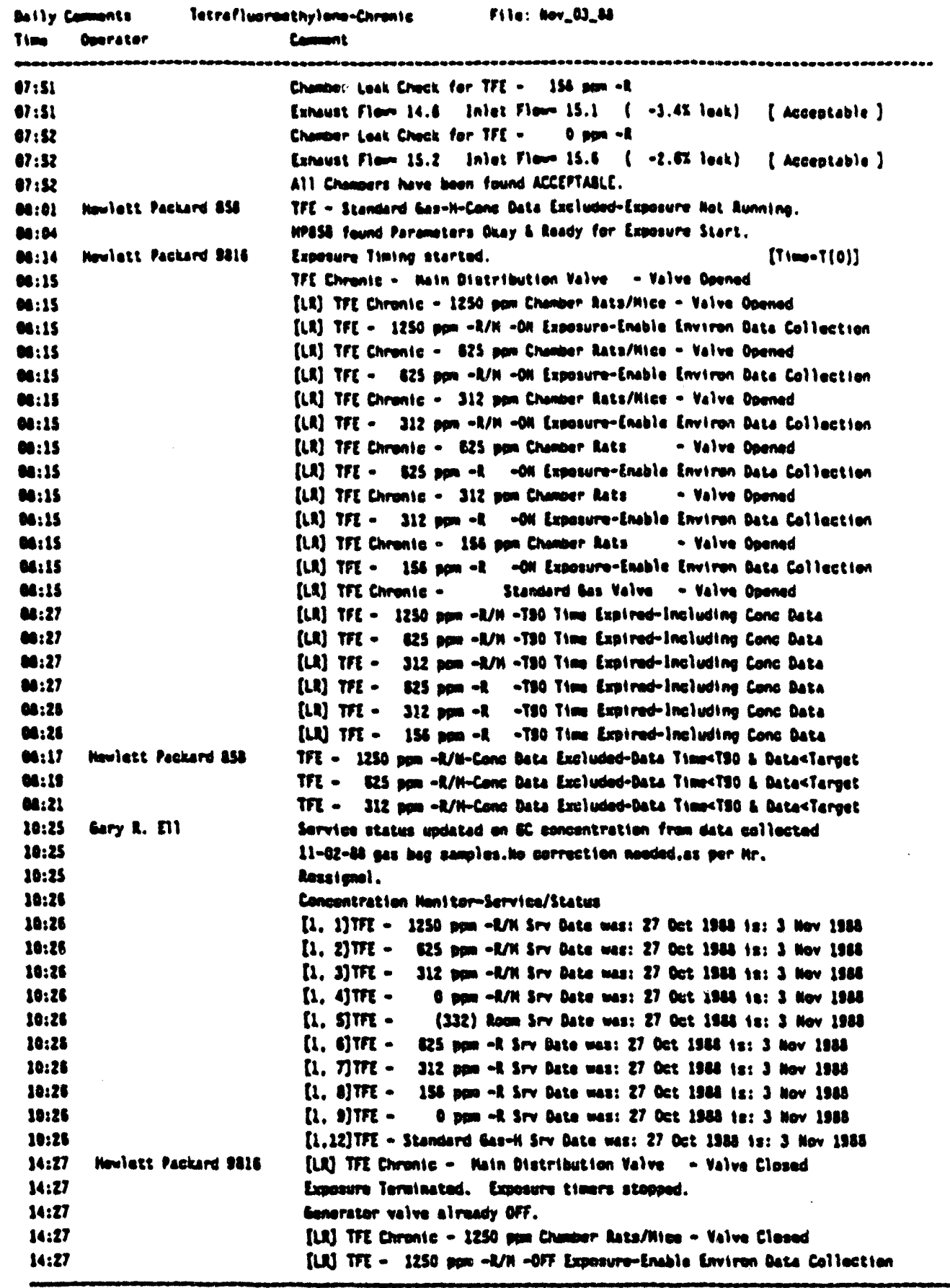

Figure 10. Example of 24-Hour "Comment Summary" Printout from Data Acquisicion and Control Computer. Table shows a summary of all comments recorded on "Daily Log" printout. 
OB-DT-1F36-00-0270.

ATTACHMIENT II

Page II-23

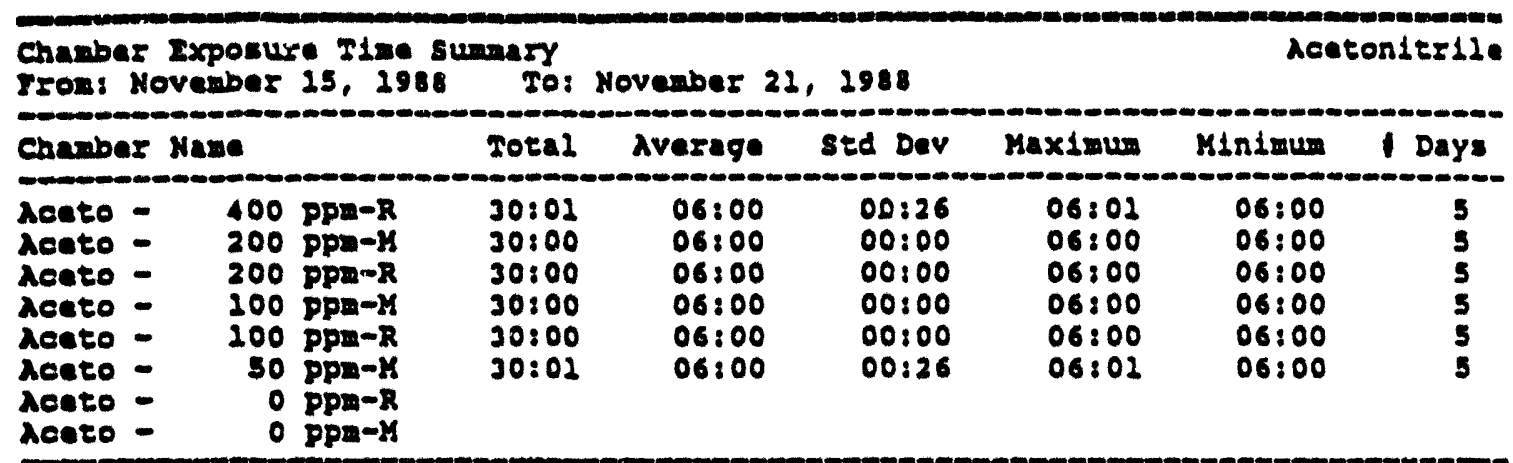

standard Deviation is in Minutes seconds. All others aze in Hours a Minutes Exposure Times DO NOT Inelude T90 time.

Figure 11. Example of Weekly Chamber Exposure Time Summary. 
STANDARD OPERATING PROCEDURE:

ARTIEICIAI INSEMINATION OF RABBITS 


\section{Page 1}

\section{Title: Artificial Insemination of Rabbits}

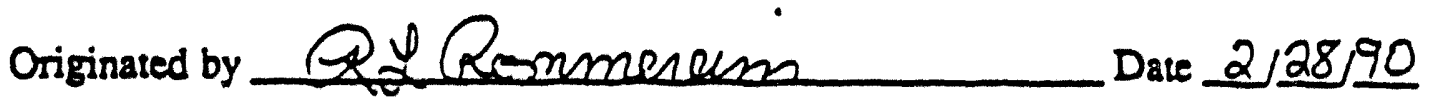
Approved by JumlQ4/ast Date 31690 Approved by Bat J. Cho Date $3 / 6,93$ Approved by (Tive : Date _ـ_ _

\section{Circulation List:}

Taskleader (2)

QAU

Record of Revisions, Changes, and Reviews:

\begin{tabular}{|c|c|c|c|c|}
\hline $\begin{array}{l}\text { Rev } \\
\text { Lener }\end{array}$ & $\begin{array}{c}\text { Dare } \\
\text { Implemented }\end{array}$ & Comment & $\begin{array}{c}\text { Signa } \\
\text { Task Leader } \\
\end{array}$ & $\begin{array}{l}\text { re/Dave } \\
\text { Tech Gro. Mgr. }\end{array}$ \\
\hline & & & & \\
\hline & & & & \\
\hline & & & & \\
\hline & & & & \\
\hline & & & & \\
\hline & & & & \\
\hline & & & & \\
\hline & & & & \\
\hline & & & & \\
\hline & & & & \\
\hline & & & & \\
\hline
\end{tabular}


A. Assemble materials for artificial insemination.

1. Semen Collection
a. Artificial vaginas (AVs); see Section B for assembly instructions.
b. K-Y jelly
c. Thermometers - calibrated
d. Sink with hot running water
e. Heavy rubber glove with long (elbow length) arm and cut-off fingers

2. Soerm Evaluation
a. Microscope
b. Calculator
c. Slides and cover slips
d. Pasteur pipettes and bulbs
e. RBC diluting pipettes
f. Disposable pipettes 1,5 , and $10 \mathrm{ml}$
g. Saline (0.9\%)
$\mathrm{h}$. If formal saline ( $1 \mathrm{ml}$ formalin in $100 \mathrm{ml}$ saline)
j. Hemacytometer
k. Beakers and Haemo-sol (for cleaning hemacytometer)
1. Hand counter

3. Chorionic Gonadotropin Injection
a. Gauze squares
b. Sterile saline
c. Chorionic gonadotropin, 500 USP units $/ \mathrm{ml}$ in saline (use $0.2 \mathrm{ml} /$ dose--100 units/doe) obtained at a local pharmacy by prescription from our staff veterinarian.
d. 1 or $2 \mathrm{ml}$ syringes with 22-6 needles

4. Insemination
a. Semen extender; see section $E$
b. Insemination pipettes (plastic or glass tubing, 3-7 $\mathrm{mm}$
c. diameter with a smooth rounded end attached to a syringe
c. $50 \mathrm{ml}$ Plastic centrifuge tube with cap for inseminant




\section{Preparation of AVs (See Figure 1.)}

\section{Materials for AV}

a. Smooth, flexible radiator hose (4 $\mathrm{cm}$ diameter $\times 8 \mathrm{~cm}$ long)

b. Latex AV collection funnel (Nasco; Modesto, California), shortened to $\sim 15 \mathrm{~cm}$

c. Wide rubber band (can be cut from top of the AV liner)

d. Rubber stopper, size 9, with 2 holes

(1) $1.5 \mathrm{~cm}$ hole to hold semen collection tube

(2) $0.5 \mathrm{~cm}$ hole for glass tube

e. Glass tube $(0.5 \mathrm{~cm}$ diameter $\times 6 \mathrm{~cm}$ long) with fire-polished ends

f. Tygon tubing $(0.4 \mathrm{~cm}$ diameter $\times 5$ to $6 \mathrm{~cm}$ long)

g. Pinch clamp for tubing

h. Semen collection tube; graduated centrifuge tube (plastic, $15-20 \mathrm{ml}$ volume cut down to $5 \mathrm{ml}$ volume, $1.5 \mathrm{~cm}$ diameter with pol ished edges)

\section{Assembly of AV}

a. Insert glass tubing into the small hole of the rubber stopper until flush with the bottom of the stopper.

b. Fit tygon tubing over end of exposed glass tubing.

c. Insert the AV liner into radiator hose, leaving approximately $4 \mathrm{~cm}$ of the top of the liner exposed.

d. Fold top of the liner over radiator hose and secure with the wide rubber band.

e. Insert narrow end of the AV liner through the large hole of the rubber stopper, making sure the stopper will plug into the radiator hose.

f. Insert the semen collection tube into the narrow end of the AV liner, covering the open end of the tube enough to create a good seal. Push the tube up into the stopper securely.

g. Place clamp on Tygon tubing.

$$
\text { D. } 55
$$




$$
\begin{aligned}
& Q B-D T-3 B Q E-O 3 \\
& \text { Page } 4 \text { of } 11
\end{aligned}
$$

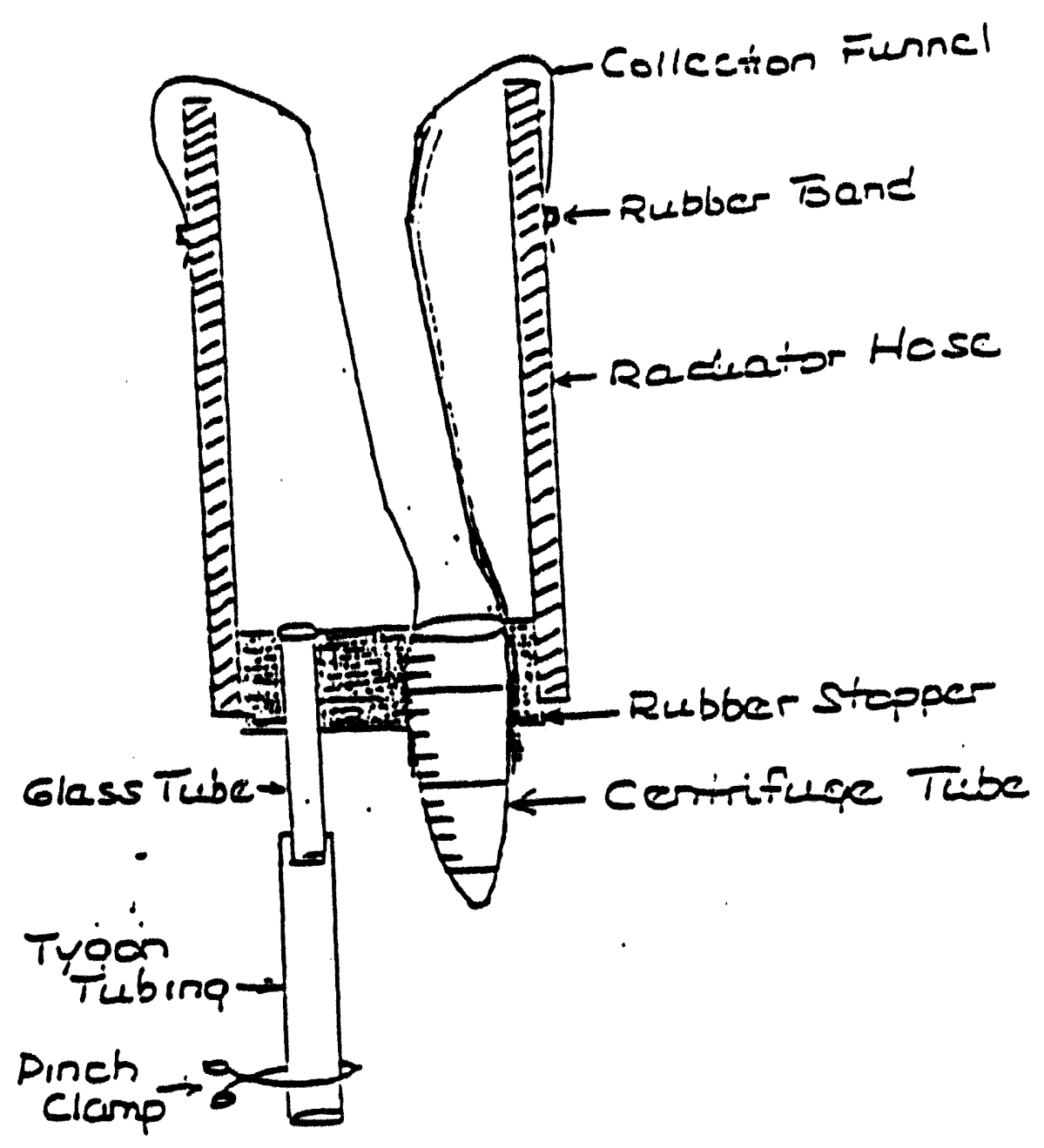

FIGURE 1. Materials and Preparation of Artificial Vagina for Rabbit Semen Collection

D. 56

GFIGIA U SF 
$\emptyset B-D T-3 B \emptyset E-\emptyset 3$

Page 5 of 11

3. Preparation of AV for Semen Collection

a. Remove the stopper and fill assembled AV with hot tap water. Stopper the radiator hose tightly to create a closed-system. NOTE: Avoid introduction of water into AV lining or collection tube as water will kill sperm.

b. Hold the AV upside down with the Tygon tubing toward your mouth. Open the clamp and blow into the tubing to inflate the AV. Reclamp while inflating.

c. Insert the thermometer $\sim 3 \mathrm{~cm}$ into the end of the AV to check the temperature, $42-45^{\circ} \mathrm{C}$. If the temperature is too high, the male will urinate. If it is too low, the male will not ejaculate.

d. Form the folds of the liner into a "T" shape if possible. Smear the inflated end of the AV liner with K-Y jelly.

e. Prepare a sufficient number of AVs to attempt semen collection from all of the bucks.

4. Cleaning of the AV

a. The AV must be cleaned after each ejaculate. Clean the AVs after all collections are made.

b. Detach the narrow end of the liner from the stopper and invert the liner. Wash all parts thoroughly with a detergent solution (Haemo-sol), rinse with water, then with $70 \%$ alcohol, and allow to air dry.

C. Semen Collection

The bucks must be trained during the quarantine period ( 4 weeks) to serve an AV with the assistance of a teaser doe. This training period also tends to improve semen quality. Semen collection may be attempted daily; obtain approximately 2-3 samples per buck per week.

1. Put on the heavy, elbow length rubber glove to protect your arm from the rabbit's claws.

2. Carry the teaser doe and the prepared AV to the buck's cage. Do not place the buck in the female's cage as this is not his territory.

3. Hold the teaser doe securely behind her head with one hand, position her over your other arm with her hind legs straddiing your hand and the AV. Hold the doe's tail down over the vaginal area to help protect her from the male.

$$
\text { D. } 57
$$


4. Position the opening of the AV just under the teaser doe's tail. Allow the male to mount the teaser doe and, if necessary, slowly move the AV towards the penis. Caution should be used to avoid allowing the male to inseminate the teaser doe.

5. After ejaculation into the AV, return the doe to her cage and visually check the contents of the collection tube. Discard the sample if any urine (yellow sediment) or blood is observed. A clear, gelatinous material may be seen. This is the copulation plug and does not interfere with the purity of the sample. Healthy semen is a chalky white color.

6. To remove the collection tube with the pure semen sample, carefully empty the water out of the liner jacket and pull the tube gently from the stopper, making sure the liner is still securely attached. Dry the tube and liner with a Teri towel and gently roll the liner away from the top of the tube with your thumb while holding the tube in the same hand. DO NOT allow any moisture to come into contact with the collection tube contents as water will kill the sperm. Cover the collection tube with parafilm and place in numbered slot in the holding tray. Record the buck number corresponding to the sample number.

\section{Semen Evaluation (see form on page 11)}

\section{Motilitv Estimation}

a. Remove the copulation plug (if present) with forceps. Place a drop of seminal fluid and a drop of saline on a slide and cover with cover slip.

b. Examine sperm for active wave motion and a large number of active sperm. Record the following:
(1) date
(2) buck number
(3) volume of ejaculate minus the copulation plug
(4) : motility and motility score 0 to 4 ( 4 is best)
(5) technician ID

2. Poolino Samples

Pool a minimum of 3 acceptable samples into a graduated plastic centrifuge tube $(50 \mathrm{ml})$. Use samples with $\geq 70 \%$ motility and a score of $\geq 3$. 


\section{Sperm Count}

a. Mix the pooled sample by gentle swirling.

b. Fill the RBC pipette to the 0.5 mark with semen.

c. Wipe the pipette clean and immediately fill to the 101 mark with if formal saline (This is a 1:200 dilution.). Place one finger over the tip of pipette and remove the suction apparatus from the opposite end. Place your thumb and forefinger over each end. Shake the pipette vigorously to mix semen and formal saline ( 30 seconds).

d. Discharge and discard fluid from the pipette stem and part of the bulb (approximately one-third of the bulb contents).

e. Charge both chambers of the hemacytometer with the fluid remaining in the RBC pipette and let it stand briefly.

f. Use a 10X eyepiece to read the hemacytometer. Count the . number of sperm in the 1-mim squares (large center square and four corners) until the count is greater than 200 sperm. Count up to five 1-mm squares. Sperm lying on the lines on the bottom and right sides of the large squares are included in the count, but not those on the top or left lines. Make two counts, one from each chamber. Record the average.

g. Clean the hemacytometer by immersing in hot Haemo-s0l solution. Gently rub the hemacytometer and cover slip with fingers and rinse both in hot water then $70 \%$ ethanol. Wipe dry with a gauze pad; DO NOT drain dry. Flush RBC pipettes following the same procedure, then air dry. A drying oven may be used.

4. Calculation of Soerm Count

a. The sperm count equation is:

Sperm/ml = number sperm counted $\times$ Dilution Factor

ilution Factor $=\frac{200^{*}}{\text { [Number of } 1-\operatorname{mm} \text { Squares Counted }\left[1 \times 10^{-4} \text { m1/square]"* }\right.}$

* 200 = dilution from RBC pipette.

volume of a 1-nm square. 
Calculated Dilution Factors are listed below:

Number of 1-mm

Squares Counted

\section{Dilution Factor}

1
2
3
4
5

$2 \times 10^{6}$
$1 \times 10^{6}$
$0.66 \times 10^{8}$
$0.5 \times 10^{8}$
$0.4 \times 10^{6}$

b. Example:

If 2 1-mm squares had a count of 284 sperm

Sperm/ml $=(284)\left(1 \times 10^{8}\right)=284 \times 10^{8} \mathrm{sperm} / \mathrm{ml}$

\section{Calculation for Semen Extension}

a. Required: $0.5 \mathrm{ml}$ inseminant/doe for $\mathrm{AI}, 20-30 \times 10^{8} \mathrm{sperm} / \mathrm{ml}$

The term inseminant is used for the mixture of semen plus extender.

b. Total number of sperm in the pooled sample is calculated as follows:

Total sperm $=($ sperm/mi pooled semen $) \times(\mathrm{ml}$ pooled semen $)$

c. Calculate the dilution necessary to yield $20-30 \times 10^{6} \mathrm{sperm} / \mathrm{ml}$ in the final volume of inseminant. Allow at least $1-2 \mathrm{ml}$ extra volume for losses during insemination.

$$
m] \text { inseminant }=\frac{\text { total sperm }}{20-30 \times 10^{6} \mathrm{sperm} / \mathrm{ml}}
$$

Example:

Given $284 \times 10^{6}$ sperm/ml and $1.8 \mathrm{ml}$ pooled semen

Total sperm $=\left(284 \times 10^{8}\right.$ sperm $\left./ \mathrm{mI}\right)(1.8 \mathrm{ml}$ pooled semem $)=511$ $\times 10^{6}$ total sperm

ml inseminant $=\frac{511 \times 10^{8} \text { Sperm }}{25 \times 10^{6} \text { sperm/m } / l^{*}}=20.4 \mathrm{ml}$ Inseminant

${ }^{\star} 25 \times 10^{8} \mathrm{sperm} / \mathrm{ml}$ inseminant is within the range of $20-30 \times 10^{6}$ required. 
$20 \mathrm{ml}$ of inseminant is sufficient to breed 36 does plus have approximately $2 \mathrm{ml}$ for volume loss and post-insemination examination.

d. Perform dilution using extender at room temperature. Cap the tube and mix contents by gentle inversion.

e. Store the tube containing the extended semen at approximately $35^{\circ} \mathrm{C}$ throughout the insemination procedures.

\section{E. Preparation of Semen Extender}

One of the following extenders may be used.

1. Oviduct Stimulating Medium (OSM)

This semen extender can be prepared up to one week prior to use and refrigerated until used. The following chemicals are added per liter of boiled, cooled distilled water:
$\mathrm{NaCl}$
$\mathrm{KCl}$
$\mathrm{MgCl}_{2}$
$\mathrm{CaCl}_{2}$
$\mathrm{NaHCO}_{3}$
$\mathrm{NaHPO}_{4}$
Glucose
EDTA (sodium)
$6.30 \mathrm{~g}$
$.75 \mathrm{~g}$
.109
$.37 \mathrm{~g}$
$3.36 \mathrm{~g}$
$.069 \mathrm{~g}$
$.270 \mathrm{~g}$
Penicillin/streptomycin $(10,000 \mathrm{IU} / 10 \mathrm{mg})$
.159

Adjust the $\mathrm{pH}$ to 7.4 each day the OSM is to be used.

2. Buffered egg yolk extender may be prepared, one to two days prior to AI:

a. Clean and check all supplies.

b. Obtain a supply of fresh eggs.

c. Prepare TRIS-citrate buffer for extender.

(1) Weigh the following:

- $\quad 3.028 \mathrm{~g}$ TRIS (hydroxymethyl aminomethane)

- $\quad 1.675 \mathrm{~g}$ citric acid

- $\quad 1.250 \mathrm{~g}$ glucose

(2) Place chemicals in a $100-\mathrm{ml}$ volumetric flask, dissolve, and make up to volume with boiled and cooled distilled water. 


\section{(3) Label flask and store at room temperature.}

e. On each day of AI prepare semen extender. Mix $6 \mathrm{ml}$ egg yolk and $30 \mathrm{ml}$ TRIS-citrate buffer. Adjust $\mathrm{PH}$ to 6.8 to 6.9 with $2.5 \mathrm{~N} \mathrm{NaOH}$ or dry citric acid.

\section{F. Preparation of Chorionic Gonadotropin for Injection}

1. Dilute the contents of the vial with sterile saline according to package instructions. Do not use the diluent that comes with the chorionic gonadotropin.

2. Shave both ears of all breeding does 1 to 2 days before insemination. See Section 6.7 for injection procedures.

G. Artificial Insemination (AI)

1. Begin insemination within 2 hours of semen collection.

2. Mix the inseminant by gentle swirling of the tube. Draw $0.5 \mathrm{ml}$ into the insemination pipette. Draw air into syringe prior to drawing up fluid to allow space for delivery of the total volume. A new pipette is used for each doe.

3. Coat the end of pipette with K-Y jelly.

4. An assistant will position the doe for insemination as follows: The assistant will be seated. Place the doe on the floor, facing the assistant between his/her feet, and lift the doe's rear quarters between the assistant's knee so that the doe's head is near the floor and her back is toward the assistant. Hold the doe's hind feet and legs securely. Lateral support is provided by the assistants knees and legs.

5. Remove any fecal material present with a gauze pad. Insert the end of the pipette into the vagina and rotate with gentle pressure until it slides under the pubic bone and up to the cervix.

6. Discharge the pipette and withdraw it from the vagina.

7. After insemination, inject the doe in a marginal ear vein with $0.2 \mathrm{ml}$ of the chorionic gonadotropin. This causes the ovaries to ovulate.

8. Patting the doe on tive bottom as she is returned to her cage may improve ovulation and pregnancy rate.

9. If sufficient inseminant is left after the insemination procedure, evaluate sperm motility and $i$ motile. 
PROJECT: NTP-IRT

STUDY: RABBIT TERATOLOGY TECH ID:
CHEMICAL: CHLOROPRENE INVESTIGATOR: TJ MAST DATE:

A. Semen Collection: Time

Buck \# Samole\# Motility (0-4)

\%Motility Volume (ml) Comments
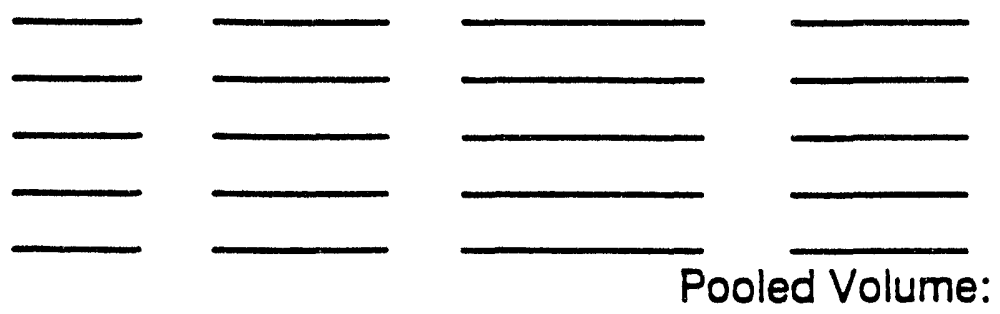

B. Sperm Count: Time

$\begin{array}{ccc}\begin{array}{cc}\text { \#1-mm } \\ \text { Squares }\end{array} & \begin{array}{c}\text { Dilution } \\ \text { Eactor } \times 10^{6}\end{array} & \begin{array}{c}\text { Sperm } \\ \text { Count }\end{array} \\ 1 & 2 & \times \\ 2 & 1 & \times \\ 3 & 0.66 & \times \\ 4 & 0.50 & \times \\ 5 & 0.40 & \times\end{array}$

Note: Total sperm must be at least does and $20 \times 10^{6} \mathrm{sperm} / \mathrm{ml}(\mathrm{minimum})$ and does $\times 0.5 \mathrm{ml}$ inseminant/doe = ml inseminant needed. Pooled

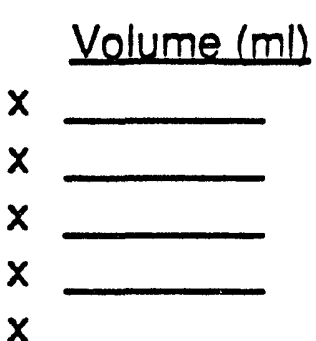
Addition of $\mathrm{ml}$ extra makes the total volume prepared today =

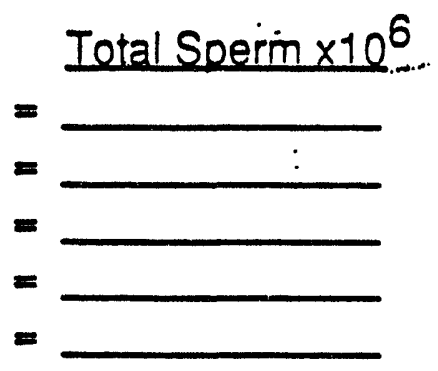

$=$ $\times 10^{6}$ for today's insemination based on $\mathrm{ml}$ inseminant. $\mathrm{ml}$ inseminant

C. Semen Extension $\mathrm{ml}$ inseminant $=$ $\times 10^{6}$ total sperm + Note: Sperm/ml of inseminant must be $20.30 \times 10^{6}$ $\times 10^{6} \mathrm{sperm} / \mathrm{ml}$ $\mathrm{ml}$ pooled semen + $\mathrm{ml}$ extender $=$ $\mathrm{ml}$ inseminant

D. Chorionic Gonadotropin: 5000 units $/ 10 \mathrm{~m} /$ sterile saline Lot \# Expiration date

Dosage: $0.2 \mathrm{ml} / \mathrm{doe}$ (100 units/doe)

Note: Up to 50 does can be injected from one $10 \mathrm{ml}$ bottle.

E. Insemination: Start Time Completion Time

F. Post-insemination Sperm Examination: Time Sperm motility $(0-4)$ $\%$ Motility 
Cage Maps

D - 65 
PROJECT: NTP-IRT

STUDY: RABBIT TERATOLOGY

ROOM: 432

Acclimation GepA only
CHEMICAL: CHLOROPRENE

INVESTIGATOR: T. MAST

DATE: 3/23/90 - 3/25/90

FrIOAY - SUNOAY

CHAMBERS: CONTROL

\# 7

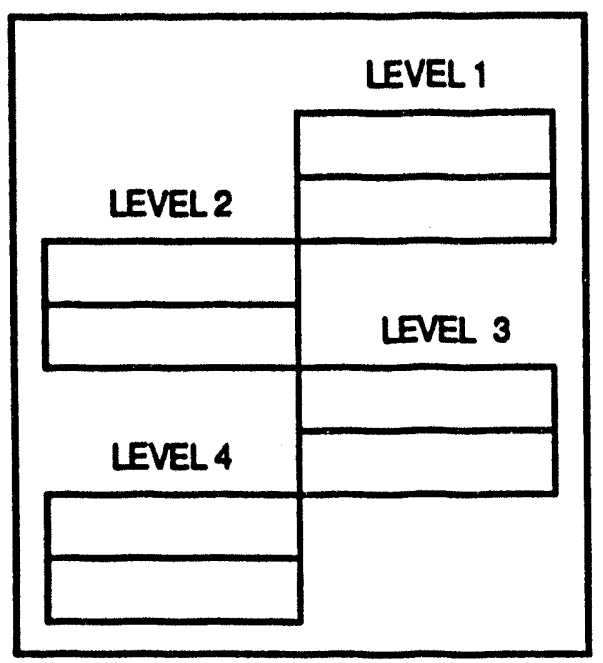

\# 8

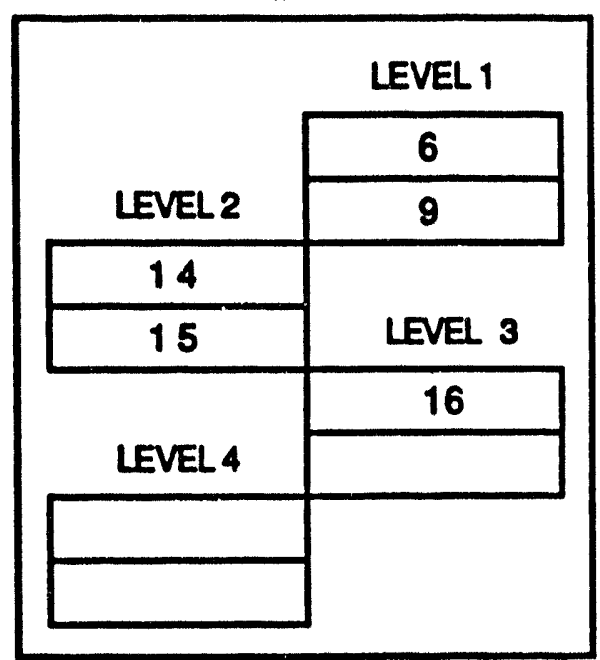

COMMENTS:

CHAMBERS: 10 PPM

$\# 1$

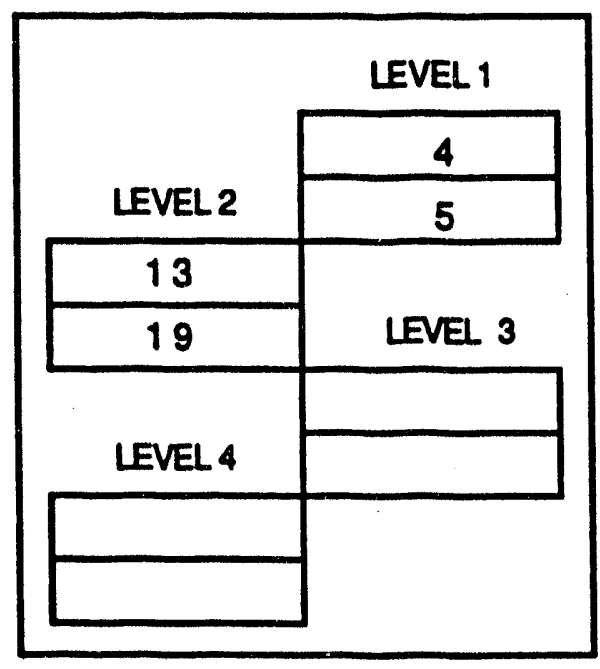

\#2

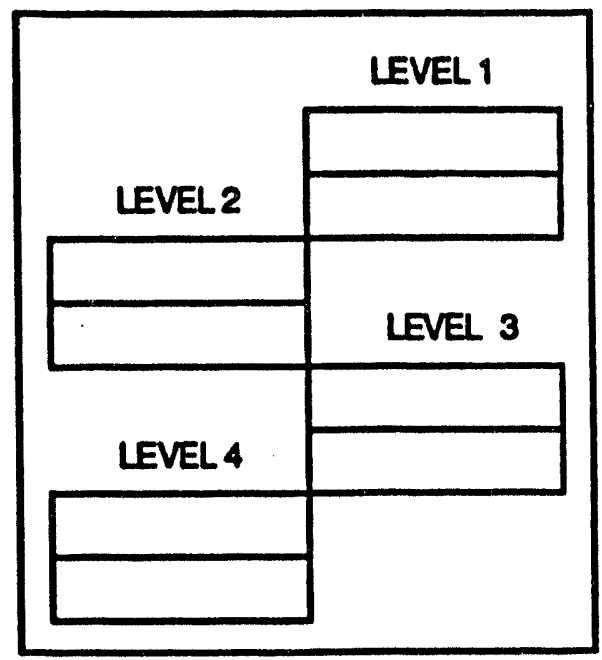

COMMENTS:

VERIFIED BY:
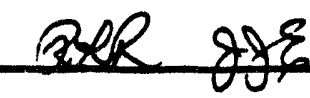
PROJECT: NTP.IRT

STUDY: RABBIT TERATOLOGY

ROOM: 432

Acelimation Gept only
CHEMICAL: CHLOROPRENE

INVESTIGATOR: T. MAST

DATE: $3 / 23 / 90$ - 3/25/90

CHAMBERS: 40 PPM

\#3

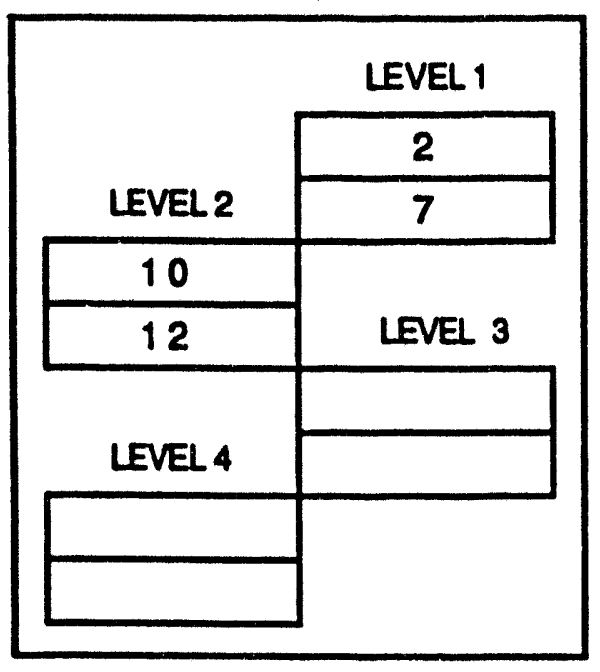

\# 4

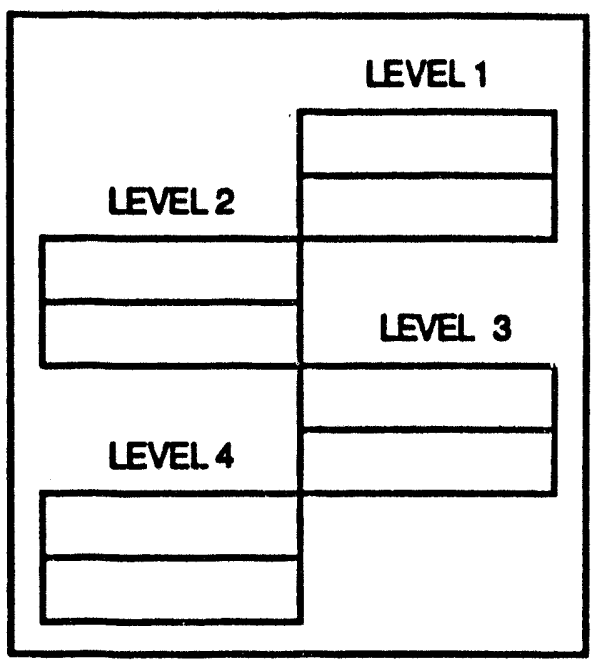

COMMENTS:

CHAMBERS: 175 PPM

\# 5

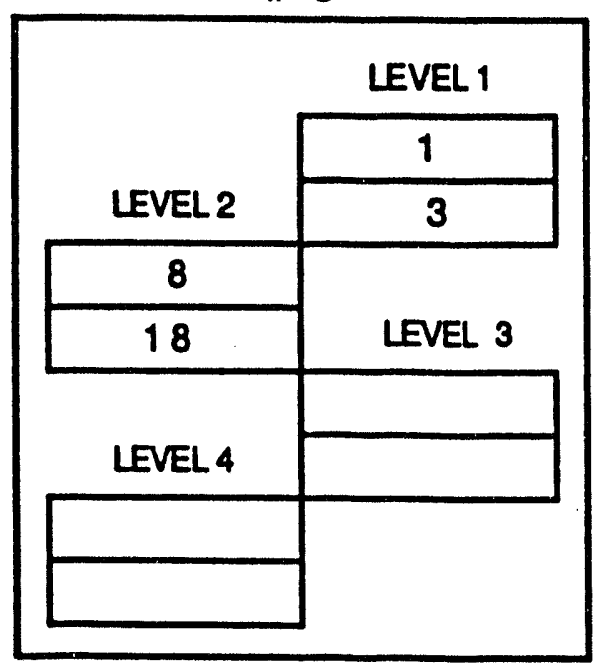

\#6

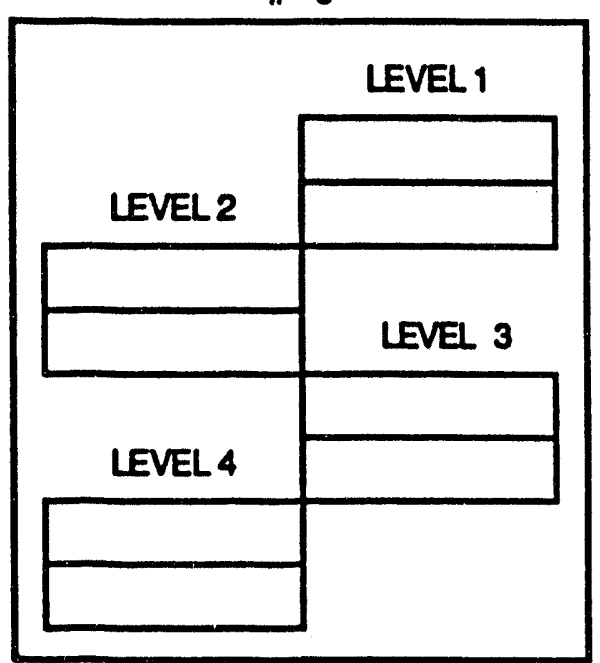

COMMENTS:

VERIFIED BY: RQR 
APPENDIX E

QUALITY ASSURANCE

Quality Assurance Statement

E. 1 


\section{INHALATION DEVELOPMENTAL TOXICITY STUDY OF \\ CHLOROPRENE IN RABBITS}

\section{Quality Aseurance Statement}

Lleted below are the phases and/or procecures included in the study described in this report which were reviewed by the Qually Aseurance Unll curing the period 1/1/80 - 4/30/80, or speciflcally for this atudy. Included are the dates the reviews were performed and findings reported to management. (Any findings llkely to affect the outcome of the study were reported to the study director or his destonee at the time of the review.)

Phase/Procedure Reviewed

Animal Recoipt

Bocy Wolghts

Clinical Observations

Dosing

Necropey

Teratological Examinations

Data

Draft Report

Final Report
Review Date

$1 / 11 / 90$

$2 / 13 / 90$

$3 / 5 / 90$

$4 / 3 / 90^{\circ}$

$4 / 19 / 90^{\circ}$

$4 / 19 / 90^{\circ}$

7/9-10/90

$8 / 3,6,9,10,13,14 / 90$

$4 / 21,25,26 / 94$
Date Findinge

Submitted in Writing to Study Director/Management

$1 / 18 / 90$

2/20/90

$3 / 5 / 90$

$4 / 13 / 90$

$5 / 11 / 90$

$5 / 11 / 90$

$8 / 8 / 90$

$8 / 15 / 90$

$4 / 26 / 94$

-Roviowed specilically for this study

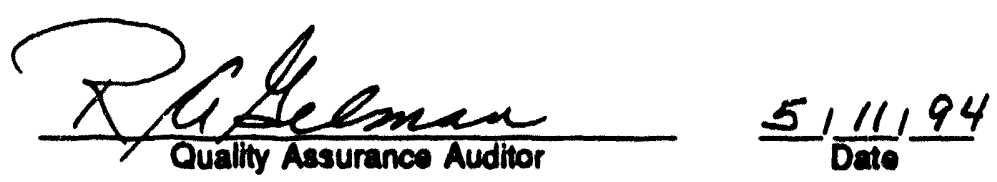




\section{DISTRIBITION}

No. of

Coples

\section{OFESITE}

2 DOE/Office of Scientific and Technical Information

10 Dr John Bucher

NIEHS, NTP, DTRT

P.O. Box 12233

Research Triangle Park, NC 27709

Elizaboth Ford

NIEHS, CPMB

P.O. Box 12874

Research Triangle Park, NC 27709

\section{ONSITE}

DOE Bichland Oonarations Otfice

D.K. Jones

\section{Pacific Northwest Laboraton}

14 T.J. Mast (5)

R.A. Golman

Program Office (2)

Publishing Coordination

Technical Report Files (5) 

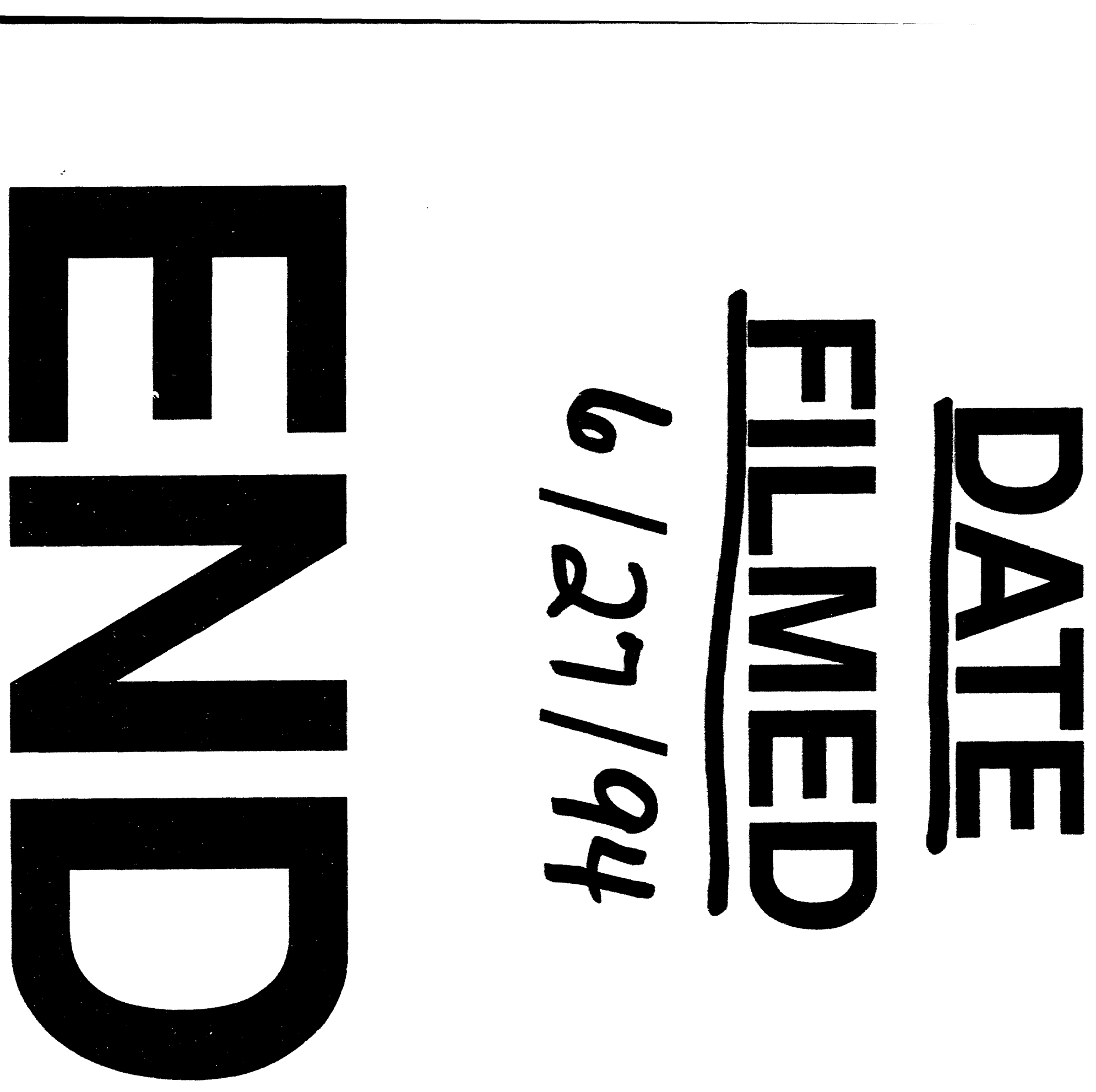
